\title{
Disclosing Horizons
}

Architecture, perspective and redemptive space

Nicholas Temple

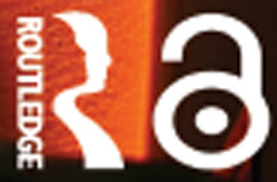




\section{Disclosing Horizons}

Disclosing Horizons examines the influence of perspective on architecture, highlighting how critical historical changes in the representation and perception of space continue to inform the way architects design.

Since its earliest developments, perspective was conceived as an exemplary form of representation that served as an ideal model of how everyday existence could be measured and ultimately judged. Temple argues that underlying the symbolic and epistemological meanings of perspective there prevails a deeply embedded redemptive view of the world that is deemed perfectible.

Temple explores this idea through a genealogical investigation of the cultural and philosophical contexts of perspective throughout history, highlighting how these developments influenced architectural thought. This broad historical enquiry is accompanied by a series of case-studies of modern or contemporary buildings, each demonstrating a particular affinity with the accompanying historical model of perspective.

Nicholas Temple is Professor of Architectural Design at the School of Architecture of the University of Lincoln, having previously taught at the University of Liverpool, Leeds Metropolitan University, the University of Nottingham and the University of Pennsylvania. 


\section{Disclosing Horizons}

Architecture, perspective and redemptive space

Nicholas Temple 
First published 2007

by Routledge

Published 2017 by Routledge

2 Park Square, Milton Park, Abingdon, Oxon OX14 4RN

711 Third Avenue, New York, NY 10017, USA

Routledge is an imprint of the Taylor \& Francis Group, an informa business

Copyright (C) 2007 Nicholas Temple

Typeset in Univers Light by Wearset Ltd, Boldon, Tyne and Wear

The Open Access version of this book, available at www.tandfebooks.com, has been made available under a Creative Commons Attribution-Non Commercial-No Derivatives 4.0 license.

\section{British Library Cataloguing in Publication Data}

A catalogue record for this book is available from the British Library

Library of Congress Cataloging in Publication Data

A catalog record for this book has been requested

ISBN13: 978-0-415-41653-5 (hbk)

ISBN13: 978-0-415-28357-1 (pbk) 
To my grandmother, Rene Isabel Temple (1907-2005), for whom everything in life was "very interesting". 


\section{Contents}

Illustration credits $\quad$ ix

Acknowledgements $\quad$ xi

Introduction 1

1 Order and chaos, or "What to leave out?" 4

Taking measures 4

$\begin{array}{ll}\text { Nietzsche's perspectivism } & 12\end{array}$

$\begin{array}{lr}\text { Being-in-the-world } & 14\end{array}$

Alterity and infinity $\quad 20$

$\begin{array}{ll}\text { Visible and invisible } & 21\end{array}$

$\begin{array}{ll}\text { What to leave out? } & 23\end{array}$

2 Number, geometry and dialectic $\quad 24$

$\begin{array}{ll}\text { The origin of geometry } & 24\end{array}$

$\begin{array}{ll}\text { Pythagoras and the unutterable } & 27\end{array}$

$\begin{array}{ll}\text { The Meno } & 34\end{array}$

$\begin{array}{ll}\text { The Timaeus } & 38\end{array}$

Ad triangulum versus ad quadratum $\quad 42$

Triangulating perspective $\quad 44$

The School of Athens $\quad 50$

Louis Kahn's Yale Art Gallery $\quad 65$

$3 \quad$ Light, memory and colour $\quad 76$

$\begin{array}{ll}\text { Medieval transformations } & 76\end{array}$

$\begin{array}{ll}\text { From memory to recorded document } & 78\end{array}$

Light metaphysics $\quad 81$

$\begin{array}{ll}\text { Optical science } & 84\end{array}$

Grosseteste's light $\quad 86$

$\begin{array}{ll}\text { The Bishop's Eye } & 88\end{array}$

Light and perspective $\quad 96$

Light and the colour of experience 101

Steven Holl's Chapel of St Ignatius 102

4 Topography, rhetoric and the vanishing point 112

Horizontal and vertical worlds 112

$\begin{array}{ll}\text { Convivial settings } & 113\end{array}$

$\begin{array}{ll}\text { Alberti's eye } & 122\end{array}$

Nicholas Cusanus 140

The Papal Window 143

Álvaro Siza's Galician Centre for Contemporary Art 150 
5 Unity in multiplicity $\quad \mathbf{1 6 0}$

$\begin{array}{ll}\text { Baroque and universality } & 160\end{array}$

$\begin{array}{ll}\text { Distentio animi and the dome } & 162\end{array}$

$\begin{array}{ll}\text { Athanasius Kircher } & 166\end{array}$

$\begin{array}{ll}\text { Leibniz and the monad } & 173\end{array}$

$\begin{array}{lr}\text { J. B. Fischer von Erlach } & 178\end{array}$

$\begin{array}{ll}\text { Hofbibliothek } & 184\end{array}$

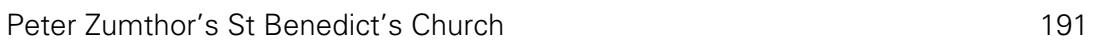

$6 \quad$ Nature and immensity 199

$\begin{array}{ll}\text { Transgressing boundaries } & 199\end{array}$

$\begin{array}{ll}\text { The picturesque and the sublime } & 203\end{array}$

$\begin{array}{ll}\text { Chambers and oikoumene } & 209\end{array}$

Boullée's visionary perspectives 213

$\begin{array}{ll}\text { Casper David Friedrich's studio } & 216\end{array}$

Rem Koolhaas' EuraLille and "I'Espace Piranesien" 221

7 Disjointed views $\quad 230$

$\begin{array}{ll}\text { Attention and perspective } & 230\end{array}$

$\begin{array}{ll}\text { Attention and distraction } & 233\end{array}$

Illusion of a "mastering totalisation" 237

$\begin{array}{ll}\text { Magnification and distortion } & 241\end{array}$

$\begin{array}{ll}\text { Gustave Moreau's house } & 245\end{array}$

Eric Parry's artists' studios, London $\quad 250$

Conclusion: architecture that looks back at us 262

$\begin{array}{lr}\text { Notes } & 270\end{array}$

$\begin{array}{ll}\text { Index } & 300\end{array}$ 


\section{Illustration credits}

We are indebted to the people and archives below for permission to reproduce images. Every effort has been made to trace copyright holders, but in a few cases this has not been possible. Any omissions brought to our attention will be remedied in future editions.

akg-images 4.29

The Beinecke Rare Book and Manuscript Library, Yale University Library 5.5

The Bibliothèque nationale de France 6.4, 6.5

Hélène Binet 5.16, 5.17, 5.20, 5.21

The British Library, London 3.1

Matthew P. Bunza 3.14, 3.15, 3.16, 3.17, 3.18, 3.19

Eamonn Canniffe 4.16

Martin Charles 7.7, 7.8, 7.9, 7.10, 7.11, 7.12, 7.13

The Anne and Jerome Fisher Fine Arts Library, University of Pennsylvania

Library 2.1, 2.4, 2.6, 2.7, 2.13, 4.11, 4.13, 4.19, 4.23, 4.24, 4.25, 5.7, 5.8, 5.9,

$5.10,7.2$

The Gustave Moreau Museum, Paris 7.4, 7.5

Roland Halbe Fotografie 4.33, 4.34, 4.35, 4.36, 4.38

Jonathan Hale 2.26, 2.28

Mike Hammock 6.1

Louis I. Kahn Collection, University of Pennsylvania and Pennsylvania Historical and Museum Commission 2.27, 2.29, 2.30, 2.31

Claudia Lynch 4.37, 4.39

MIT Press C.2

Eleanor Murkett 5.2

Museo di San Marco, Florence (C) akg-images/Rabatti-Domingie 4.6

The Nationalbibliothek Bildarchiv, Vienna 5.6, 5.11, 5.12, 5.13, 5.14, 5.15

The National Gallery, London 3.9

Board of Trustees, National Gallery of Art, Washington 4.9

Office for Metropolitan Architecture 6.9, 6.10, 6.11

Fran Osborne 6.3

The Österreichische Galerie Belverdere, Vienna 6.6, 6.7

Eric Parry 7.14

Photo SCALA, Florence 2.15, 2.18, 3.8

Photo SCALA, Florence. Courtesy of the Ministero Beni e Att. Culturali 2.9

Photo SCALA, Florence. The Museum of Modern Art, New York (MoMA).

Charcoal on paper. Gift of Larry Aldrich 7.3

Private Collection 2.24, 2.25, 7.1 
The RIBA Books and Periodicals Collection 6.2

Mark Soasey 3.10, 3.13

Special Collections Research Center, University of Chicago Library 5.3, 5.4

Stiftung Bibliothek Werner Oechslin 4.20

D. Vagnetti 4.12

All other images are copyright of the current author. 


\section{Acknowledgements}

I began researching and writing this book while I was an Assistant Professor of architecture at the University of Pennsylvania (2000-2002). It was during the many enjoyable and stimulating PhD seminars at PENN that the theme for this book first took shape. I am indebted to the PhD students for posing difficult questions and for challenging my preconceptions; in particular, Manuel Heredia, Alexander Eisenschmidt, Raffaella Fabiani Giannetto, Hayub Song, Kenneth Jacobs and Esra Sahin. I wish to thank Prof. David Leatherbarrow for supporting the project at its inception and for his generosity in sharing with me his knowledge of, and insight into, the history and philosophy of architecture and landscape. Discussions with other colleagues at PENN, notably Prof. John Dixon Hunt and Franca Trubiano, helped give further direction to my research during this period. I am further indebted to Prof. Dalibor Vesely who, during a visit to the Philadelphia Museum of Art in 2001, revealed to me the significance of eighteenth-century landscape painting in Western culture, and who generously allowed me to read parts of his unpublished manuscript on architectural representation.

Inspiration for the book was also drawn from my teaching in design studio at Leeds Metropolitan University and Nottingham University. In particular I wish to thank my former students, Jaskran Kalirai, Mark Cannata, Krishan Pattni, Mike Hammock and Robert Scott. Friends and colleagues have provided much moral and intellectual support during difficult periods of the research; Adam Sharr and Eamonn Canniffe for reading - and commenting on - drafts of some of the chapters; Prof. Donald Kunze, Manwinder Lall, Jonathan Hale, Raymond Quek, Renée Tobe, Matthew Higgins, Daniel Rosbottom and Patrick Lynch for insightful comments and sympathetic observations. Also, many thanks to Prof. Clive Knights for providing a large number of images for the book. A close friend and intellectual companion, Soumyen Bandyopadhyay was a great support and inspiration during the later stages of the project. Chris Belledonne undertook the painstaking process of compiling and formatting images, for which I am eternally grateful. For patience and commitment to the project I would like to thank Caroline Mallinder, Georgina Johnson and Kate Reeves at Routledge.

Financial support from an RIBA Research Trust Award and a Stroud Bursary, from the Society of Architectural Historians of Great Britain, allowed me to successfully complete the project. I would also like to thank Anna Rubbo, editor of the Architectural Theory Review, for granting me permission to use parts of an article I published in the journal for Chapter 3 of this book.

Most importantly, I wish to express my deepest gratitude to a former teacher, Peter Carl, who first inspired me as an undergraduate (and later as a PhD student) to look deeper into the mysteries of architecture. His openness to 
intellectual enquiry, and insatiable curiosity about anything related to architecture, continues to guide me in my teaching and research.

Finally, it would be remiss of me not to mention my family - my wife, Barbara, and three children, Rosie, Theo and Jules - who over the past five years have graciously accepted my periodic absence from weekend outings when the demands of research got the better of me. 


\section{Introduction}

This book examines the role of perspective in architecture, not however in terms of the methods and techniques of representation, but rather in relation to changing notions of order in history. Building upon - and challenging - recent scholarship in the field, notably in the work of Hubert Damisch, Alberto Pérez-Gómez, Karsten Harries and Dalibor Vesely, the study argues that from its earliest developments perspective was understood as a redemptive view of order whose origins can be traced back to a deeper philosophical tradition, well before the advent of perspectiva artificialis. This tradition provided the foundation of what was later to emerge - as a theoretical possibility - an ideal constructed perspectival world. Such a world was deemed potentially perfectible in the eyes of humanity land of God) and could therefore be distinguished from the equivocations and uncertainties of everyday circumstance.

Broadly, the study examines this changing world-view at two levels: first by highlighting how major thinkers of the past grappled with the concept of perspective, and second by considering how theological, philosophical, aesthetic and scientific views of perspective influenced developments in architecture.

Taking Nietzsche's assertion of truth as essentially perspectival as a critical point of departure, the work considers Pre-Socratic, Platonic, Augustinian and Medieval cosmologies as "antecedents" to perspective. By this I am suggesting that certain critical historical changes in the nature and meaning of number, geometry, light and language contributed to the emergence of a perspective outlook. With the establishment, however, of a thoroughly instrumental perspectivism in the modern age, the traditional belief in an embodied transcendent/divine world is superseded by an understanding of space defined in largely quantitative or abstract terms. One of the consequences of this transformation is the new emphasis given to the epistemological "rightness" of perspective. This is based on the illusion, prevalent in the nineteenth century, of a corresponding relationship between perceptual experience and perspectivally ordered space.

Chapter 1 outlines the philosophical background to perspective in the nineteenth and twentieth centuries, highlighting the debates about perceptual/ psychological views of reality. Underlying these debates, as will become clearer later, was a cultural crisis that centred on the absence of a shared understanding of "measure"; a sustained and communicative relationship with the world that once existed in earlier times. The chapter will outline how this crisis provided the impetus for a new philosophical initiative; to communicate a form of measure that transcends the solipsism of the modern age and its drive for a calculated instrumental order.

It is in the context of this modern crisis that Chapter 1 introduces the principles of Nietzsche's perspectivism followed by brief investigations of the 
different phenomenological approaches to perspective in the ideas of Martin Heidegger, Maurice Merleau-Ponty and Emmanuel Levinas. The study outlines the main areas of dispute, concerning the nature and meaning of "the other" in perspective (its directionality and focus), and concludes with a study of Levinas' concept of "alterity". Chapter 1 aims therefore to articulate the broader philosophical context of perspective. At the same time, however, the chapter seeks to establish the theoretical ground on which a deeper understanding of the historical and cultural backgrounds of perspective can be gained. Only by establishing such a relationship can we engage constructively in contemporary debates about the role of perspective in architecture.

The decision to adopt a broadly phenomenological approach to the subject was influenced in part by Karsten Harries' assertion that:

the theory of perspective teaches us about the logic of appearance, of phenomena. In this sense the theory of perspective is phenomenology. So understood, phenomenology lets us understand why things present themselves to us as they do. This is indeed how Kant's contemporary, Johann Heinrich Lambert, to whom we owe the term, understood it. Phenomenology meant to him a "transcendent optics," the theory of perspective in the widest sense. ${ }^{1}$

This initial philosophical outline in Chapter 1 is followed by a series of essays that trace the historical developments in perspective. Whilst this essentially historical survey could be read as a single work it is also possible to treat each essay independently, given that each chapter focuses on a particular perspective outlook developed during a specific historical period. In view of this arrangement, I have taken the liberty to omit detailed summaries here and instead provide more in-depth introductions at the beginning of the chapters. I should point out however that these chapters follow a common thematic structure that is divided into two parts.

The first aims to establish - through a broadly genealogical investigation of perspective - the way different modes of thought (symbolic/analogic, aesthetic, scientific, etc.) have influenced perspective. This begins in Chapter 2 with an examination of Pythagorean/Platonic cosmology and concludes in Chapter 7 with a study of modern concepts of the panorama and simulation. To take Chapter 6 as an example, which is entitled "Nature and Immensity", I examine eighteenthcentury views of perspective through an exploration of the idea of divinised nature, a notion that conceived the world as a vast subliminal landscape. In the representations of this period, of which the visionary drawings of Etienne-Louis Boullée will serve as examples, the continuity between real and illusory space (earlier characterised in Renaissance perspective) gives way to an encroaching fear of emptiness and a sense of awe and incomprehension towards nature's immensity. One of the consequences of this demise of an assured place in the cosmos is the progressive disengagement of the subject from an increasingly objectified world-view. Reflecting this detachment from a limitless - enveloping space is a new emphasis given to the inner (fathomless) depths of the self, a point 
I will examine in the context of a diptych painting by the German Romantic painter Casper David Friedrich.

The second part of each chapter consists of a short case-study of a modern or contemporary building. These case-studies are intended, in one sense, to be reflective of past traditions in the way a particular historical outlook of perspective serves as a "subtext" to a modern architectural concept. The decision to include these case-studies in the larger historical work was not prompted by a conviction in the existence of straightforward correlations between historically distant world-views and our own. Nor should it be seen as a deliberately polemical move - to challenge or undermine commonplace views about the uniqueness of the contemporary situation. Rather, the juxtaposition seeks to establish, through hermeneutical enquiry, a theoretical ground on which to question issues of continuity and difference in perspective between our own time and a given historical period. Accordingly, the buildings have been chosen specifically to demonstrate a certain affinity with the accompanying perspective outlook.

Taking Chapter 6 again as an example, I examine the large urban project of EuraLille by Rem Koolhaas and OMA and consider the design, and its supporting polemics, in the light of Enlightenment views of space. In particular, Koolhaas' proselytising of the "temporalisation" of space in Late Capitalism, and its implications for a placeless architecture, will be explored in the context of eighteenth-century notions of an all-encompassing immensity. This is followed by a brief investigation of the so-called "Espace Piranesien" and its contested associations with the "anti-space" of Piranesi's prisons (Carceri) series.

The aim of this twofold structure in each chapter is first to argue that perspective was, from its very inception, rooted in a cosmological tradition and that its subjection to the forces of instrumental thinking was accompanied by gradual changes in our perceptual relationship to the world. Second, the study seeks to demonstrate how critical cultural transformations, that have shaped perspective throughout history, continue to inform our understanding of space. Perpetuating this influence, as I will seek to argue, is the abiding - yet largely unrecognised - role of perspective as a redemptive view of order, whose appropriation of reality (into paradigmatic forms of representation) continues to influence the way architects perceive and define space. 


\section{Chapter 1}

\section{Order and chaos, or}

\section{"What to leave out?"}

\section{Taking measures}

In his poem, "In lovely blueness ...", the German poet Friedrich Hölderlin (1770-1843) asks "Is there a measure on earth?" The question is posed, it seems, in response to a terrible loss felt by Hölderlin - a loss that "no mourning can measure". ${ }^{1}$ This concerns the demise of an embodied view of the world where all human experience was mediated through a divine Being. This mediation moreover allowed the possibility of a dialogue between the temporal and the eternal, the utterable and the ineffable. Denied such a relationship, and confronted by a new spirit of freedom brought about by triumphs of science and technology, Hölderlin holds out the hope for a poetic measure "on earth" that can restore an embodied world.

This form of measure finds expression in our gestures, whose physiognomies reveal ethical meanings about our place in the world. ${ }^{2}$ Critically, as this study aims to highlight, perspective constituted an ideal framework in which such ethical gestures could be articulated and given paradigmatic significance. Indeed, it is through perspective that we find this ethical dimension of gesture rendered phenomenologically as the spatial depth of human experience.

We get a sense of this ethical meaning of perspective in Hölderlin's poetry where, like Romantic painting, the representation of landscape invokes a poetic revery of creation that speaks of God "dwelling" immanently on earth:

[Hölderlin] imagines no extra-terrestrial setting for [God's] activities but makes them manifest on earth, in the Alps or the Greek islands, and in earthly phenomena, such as day, night, storms, and warfare. Dante describes Hell, Purgatory, and Paradise with the clear precision of the topographer, so creating a visionary world distinct from the real one. Hölderlin keeps within earthly limits, but his act of creation is akin to Dante's. ${ }^{3}$ 
At the heart of Hölderlin's world-view is a firm belief in a special alliance between ancient Greek civilisation and German culture, whereby the histories and traditions of both are providentially entwined. The poet's understanding of geography, as a domain for revealing a latent continuity between a mythical past and a transient present, highlights something critical about the emerging modern perspective of the world. In this perspective notions of "otherness" are conceived in intersubjective terms as personal poetic encounter.

Whilst reflecting upon earlier traditions of a redemptive view of topography - redolent of Dante - Hölderlin nevertheless saw his own world as being in an interim or transitional state where the gods have fled. This absence leads Hölderlin, in his poem "The Only One", to question the very possibility of "right" measure:

Never, much though I wish to, can I find

The right measure. But a god,

If he comes, knows what I wish, the best. ${ }^{4}$

In spite of Hölderlin's sense of futility of finding the right measure, he nevertheless leaves open the possibility of a return of the gods. This takes on particular significance in Hölderlin's lifelong poetic journey where he seeks to restore a mythic tradition. In this journey he retraces imagined or obscure places where divine presence once held sway. Significantly, Hölderlin's restorative vision was conceived around the principle of the "poetic task as the abbreviation of the world", an encompassing vision that was partly influenced by developments in aesthetics in the eighteenth century. ${ }^{5}$ Introduced in the metaphysics of Gottfried Wilhelm Leibniz and the philosophy of Alexander Baumgarten, the idea of an aesthetic outlook emerged in part as a result of a new emphasis on individualising experiences. In these, the origins and meanings of things cannot be accountable through reason alone, given that they are hidden or recondite. ${ }^{6}$ This obscurity, as we shall see later in Chapter 5, served as the basis of Leibniz's idea of the monad where every mind presents itself as a world unto itself - or as Leibniz describes it, "a little divinity" without finite boundaries. ${ }^{7}$ Considered in terms of Hölderlin's poetry, this emphasis on the self-sufficiency of ontological entities leads to a certain distancing of the poet from things and events. ${ }^{8}$ Immediate experience merely presages a deeper mytho-historic reality that Hölderlin conveys through his poetic vision of an idealised landscape.

This understanding of the world was inspired, among other things, by Immanuel Kant's assertion that the mind is not merely a passive recipient in perception but an active originator of experience. ${ }^{9}$ Hölderlin's perception of reality requires a form of measure that is not an abstract calibration of an already rationally conceived world. Rather it assumes a correlation between an inner tempo - or rhythm - of being (redolent of St Augustine's idea of threefold time), and a background - pre-ordained - natural order. ${ }^{10}$ Significantly, Peter Fenves deploys the term "lawful calculus" to convey this particular notion of measure in Hölderlin's poetry, a term that strangely obscures the modern distinction between scientific 
and poetic thinking: "To ensure that the incalculable does not escape calculation after all, the calculus Hölderlin proposes, like the one Leibniz coinvented, must be infinitesimal: its range is 'the infinite and continuously determined relation.' "11

The binding of this incalculable infinite to our "calculated" earthly existence is expressed in the rhythms of poetic meter; the pauses - or "caesurae" - of Hölderlin's poetry become analogous to the locations or settings of his mytho-historic landscape. Here, the spatiality of Hölderlin's poetry invokes a perspective of the world, but one that is by definition ill-defined or "awkward": "Sophocles is right... The infinite, like the spirit of states and of the world, cannot be grasped other than from an awkward perspective [aus linkischen Gesichtspunkt]."12

The implication here of obliquity - of an "eccentric" perspective of the world - is what Fenves sees as the basis of Hölderlin's idea of "arresting language" $;{ }^{13}$ a language (and a landscape) whose narrative is periodically suspended by the "monadic" singularity of the word (and the place). We could be forgiven for comparing this idea of an eccentric point of view with anamorphic projection that developed in the seventeenth century. This technique, as we shall discuss in Chapter 5, advanced the principle of an itinerant observer searching out an optimum point in space that in the end is projected to infinity. The emphasis, however, on the "punctum" in anamorphic projection, around which the world is deemed incomprehensible and therefore meaningless, could be seen as prophetic of the world that Hölderlin was seeking to remedy, a world that was conceived in the geometric terms of René Descartes who assumed the complete selfsufficiency of the observer.

It is worth comparing the world of Hölderlin with that of the Renaissance when perspective was first "codified". In this age, as I will highlight in Chapters 2 and 4, we see perspective being articulated as part of a broader analogical understanding of the world, where corresponding relationships between painting, sermon, architecture, urban design, humanist text and so on were supported by a prevailing onto-theological order. By the late eighteenth century, however, this mediated world was all but shattered and replaced by an intensely private poetic vision where individual experience becomes the sole means of redeeming the world.

Problematic in Hölderlin's quest for poetic measure is the dearth of poetic existence in the modern age. Martin Heidegger considers this problem in the light of Hölderlin's meditation on the "measure of all measuring", where he states that: "it might be that our unpoetic dwelling, its capacity to take measure, derives from a curious excess of frantic measuring and calculating". ${ }^{14}$ For Heidegger, the modern proclivity towards instrumental modes of measuring and calculating - whereby the world is reduced to mere abstract quantitative data - becomes an obstacle to the only truly authentic measure. In Hölderlin's poetry this measure, as we have seen, requires a distancing from familiar things and places. Periodically exiled from his beloved homeland in Swabia, Hölderlin goes in search of a world in which one can speak of landscape in analogous terms as a poetic narrative of revealed truths. Only by being a wanderer can a meaningful dialogue between 
everyday experience and a mythic/historic past be maintained. ${ }^{15}$ Such a task however was precarious since the "interim age" was characterised by disunity and separateness. ${ }^{16}$

In his homelessness, Hölderlin transforms actual geographical features (rivers, mountains, islands, coastlines, etc.) into idealised places for spiritual respite. Of particular significance in this poetic journey is the river as a metaphor of Hölderlin's encompassing vision; its source in the mountains affirms the divine origins of all being, whilst its passage through countryside and city ensures replenishment of the manmade order. ${ }^{17}$ In this relationship the river is portrayed as an "umbilical link" between the mythic landscape of the gods and the working/cultivated landscape of mortals. Hölderlin's particular interest in the Danube River, for example, clearly alludes to this association. Originating in the mountains in Southern Germany the river "abruptly changes course and veers off sideways, winding its way eastwards to the Black Sea". ${ }^{18}$ Implicit in the course of the Danube, in its sudden reorientation towards the east, is the destiny of all humanity, embodied in the recovery of a mythic world. This is given geographical definition in the relation between "Hesperia" (the west) and Greece in the east; the latter signals the mytho-poetic landscape of ancient Greek civilisation whilst the former embodies the restored Golden Age in Swabia. Both regions become metaphorical poles in Hölderlin's poetic landscape; the Greek past is an "inspiration" whilst the Hesperian future is a "responsibility". ${ }^{19}$

This redemptive view of topography was not, however, unique to Romantic thinking but relates to a deeper tradition. In particular, we are reminded of Francesco Petrarch's famous ascent of Mont Ventoux in the fourteenth century, in which he records his view of the Alps and his longing to return to his homeland in Italy. The experience was intended to be seen as an allegory of man's spiritual ascent. At the same time, Petrarch's account could be regarded as an important precedent to the emergence of a perspective understanding of landscape in the early Renaissance, a topic to be discussed in Chapter 4. What makes, however, Hölderlin's providential reading of landscape different from earlier examples is the intensity - and indeed urgency - of the poetic vision, and the manner in which the solitary poet is conceived as the bearer of human destiny.

Hölderlin often deploys in his poetry the metaphors of light and darkness - and their intermediate coloured hues - to evoke the distance separating humanity from divinity:

The conditions that justify the journey impinge on the landscape: the spiritual darkness and the restlessness of the age are expressed in woods and streams. Similarly, in "Germanien" the streams and the heavy sky are expressions of the longing and oppression that characterise the times. In "Patmos" as in "Brod und Wein" the journey begun in darkness ends in Greek daylight ... [Hölderlin] turns from an entirely Greek landscape, all colour and light, to the dark cave of Patmos, an island with only Christian associations, to something more like the darkness of home. ${ }^{20}$ 
Like a theologian meditating on original sin, Hölderlin sees this luminary evocation of past worlds as a way of shedding light on his own predicament. But such a perspective, with its hope for some future salvation, begins to disintegrate from 1802 onwards. Hölderlin's return to his homeland across the Alps marked the end of his wanderings, and hence the unity between everyday life and the world of art that this itinerant existence helped sustain. After his return, which was to result in Hölderin becoming insane during his final years in Tübingen, the poet's ambulatory perspective of the world is replaced by the fixed view from the poet's window. In this transformation, the window takes on the role of a "world picture" that in some ways anticipates Heidegger's notion of "enframing": the "dominant mode of unconcealment, i.e., of representing the world". ${ }^{21}$ As we shall examine in Chapter 7, the pre-eminence of the view in Hölderlin's last years could be compared to a diptych painted by Casper David Friedrich of his studio in Dresden and overlooking the river Elbe. Painted in 1806, around the same period as Hölderlin's mental breakdown in Tübingen, the diptych evokes a feeling of deep introspection. This is indicated in the way the dark and foreboding interior of the artist's studio appears largely disconnected from the light and ethereal landscape beyond as seen through two large windows.

Prior to his last years in Tübingen, Hölderlin's itinerant life served as a rich reservoir of poetic experiences that sought a dialogue with a latent mythic world. The poet's later "confinement" to the framed view, on the other hand, could be seen as signalling a condition more prevalent of modernity, in the way the detached view constitutes an abiding reference in the poet's experiences of a world "out there". Modern detachment is one of the prerequisites for control and mastery, as I will explain later in Chapter 7, and was therefore essential to the advances in modern science and technology.

For Heidegger, enframing of our lived experiences reflects a particular world-view that assumes the almost invincibility of humanity:

Man can never put himself in the place of God, because the essence of man never reaches the domain of the essence of God. On the contrary, compared to this impossibility, something much more disquieting can come about - something whose essence we have hardly begun to think. ${ }^{22}$

In this "disquieting" situation that Heidegger describes we are being alerted to the dangers of a progressive closure to an existentially conceived world that is the result of the modern self seeking autonomy. Anticipated in the emerging aesthetic view in the eighteenth century, discussed earlier, the priority given to a selfreferential point of view leads ultimately to a state of closure with respect to poetic experience. Such a tendency renders the hope for a communicative domain on earth as, at best, problematic and, at worst, simply beyond reach.

Quite how we can begin to address this modern situation would seem to depend initially upon our capacity to realise, as Heidegger argued, that our instrumental world-view is not a uniquely modern condition but rather part of a 
complex historical and cultural development that can be traced back to the dawn of philosophical thought. This begins with ancient Greek philosophy when the emergence of self-consciousness saw religious thinking being overshadowed by pure - free - thought. ${ }^{23}$ Significantly, as I will argue in Chapter 2, it is in the light of this continuity with Greek philosophical thought that the question of the emergence of perspective should initially be considered, rather than the Renaissance or even the Middle Ages.

The demands for circumspection and clarity in modern science generally take precedence over the ambiguity of dream and creative thought. According to Georg Simmel, this priority leads to an internal conflict - or schism - in the modern self that can be characterised by the condition of alienation. ${ }^{24}$ In this schism, the emphasis on objective certainty results in an equally prevalent condition of intense subjectivity. ${ }^{25}$ One consequence of this dichotomy is that the modern self construes the world in largely dualistic terms: as a site of universal and quantifiable attributes and as a reservoir of private - and emotionally charged - experiential moments. The duality could be summed up as a dichotomy between natural and human phenomena.

Whilst most acute in modern consciousness, this dualistic outlook has long existed as a potential problem in human history, as Alexandre Koyré notes:

it is the splitting of our world in two ... by substituting for our world of quality and sense perception, the world in which we live and love and die, another world - the world of quantity, of reified geometry, a world in which though there is a place for everything, there is no place for man. This, the world of science - the real world - became estranged and utterly divorced from the world of life which science has been unable to explain - not even to explain away by calling it subjective... Two worlds, this means two truths. Or no truth at all. This is a tragedy of modern life which solved the riddle of the universe but only to replace it by another riddle, the riddle of itself. ${ }^{26}$

In modern terms, outward measure is characterised, for example, in the practice of land-surveying, where one's relationship to the world is reduced to numerical data and the calibrating and mapping of terrain. Inward measure, on the other hand, is typically (but rather narrowly) defined by the quasi-scientific methods deployed in modern psychology. In attempting to overcome uncertainty and ambiguity in the complex and multivalent experiences of humankind early developments in psychology sought to reduce human consciousness to a series of predictable mental states that can be diagnosed and analysed in isolation. ${ }^{27}$ This specifically analytical emphasis on modern views of inward measure obscured the poetic view of measure that is the legacy of Hölderlin and the Romantic movement.

The relation between introspective and outward measure reveals what Edward Casey calls a genealogy of space. 


\begin{abstract}
Begin with the thematizing of the circumspective spatiality at stake in concrete activities such as surveying and building, [then] proceed to the disinterested looking that corresponds to the present-at-hand ... and end in the construction and contemplation of a sheerly homogeneous space (including its geometrical representation . . .). ${ }^{28}$
\end{abstract}

By the seventeenth century the distinction between an "indeterminate beyond" and "introverted experience" became a source of deep anxiety. ${ }^{29}$ It was this dislocation that Hölderlin was seeking to overcome in his quest for a measure on earth. In the eighteenth and nineteenth centuries concern for this ever-widening gap was given a new urgency in artistic attempts to restore the inter-relationship between objects and their settings; the notion of Gesamtkunstwerk (or total work of art) is indicative of this. ${ }^{30}$ But such intentions were limited in scope given that they were more about issues of abstract synthesis than content. Taking Hölderlin's visionary ideas as an example, it is clear that the question of measure requires not just poetic insight but also hermeneutic understanding. This understanding, as Werner Marx infers, initially draws meaning from an already established tradition:

we can first ask about measure in the traditional, metaphysical sense ... i.e., as an absolute normative standard given prior to and transcendent of all measuring, but that nonetheless is at the same time "immanent" and has the binding force of an obligation, a standard that is furthermore "univocal" and "manifest". ${ }^{31}$

Considered in the context of modernity, this traditional "standard" operates at the level of an enigmatic understanding of the divine, in which Being is neither present nor absent. Jean-Luc Marion alludes to this point in his interpretation of Hölderlin's thought:

man loses measure as soon as he wants to measure himself against divinity and its standard ... forgetting that measure, which ensures his essence, imitates only a withdrawal of the divinity whose image that essence is. Precisely because the divinity gives itself in that withdrawal. ${ }^{32}$

Echoing Heidegger's warning, referred to earlier, Marion sees phenomenological understanding of being-in-the-world as reflecting upon a deeper onto-theological tradition of measure, constituted in the mystical withdrawal of God: "For no visibility gives itself to be seen in a figure without a withdrawal preceding it in order to receive it." 33 Marion makes the point that the withdrawal in one's encounter with God is a continual movement. Accordingly: "The unavoidable and mutely urgent task then becomes to learn that only separation can define approach, and withdrawal advent. What we here name distance attempts to apply itself to this." ${ }^{34}$ 
Distance therefore assumes the potential for both proximity (intimacy) and remoteness (estrangement). Only by responsible action can this tension between both conditions be reconciled. ${ }^{35}$ This understanding of measure reflects Hölderlin's perspective; divine absence is not absolute but is rather measured as withdrawal. Hölderlin attempts to convey this process poetically through the experience of "taking-in" a view, in its capacity to conserve what is otherwise hidden:

"saving" registers the step back that opens up perspective, as the altitude of an aerial view allows figures and contours to appear that are missed by the overly terrestrial gaze, in short, preserves the advent of the invisible image. ${ }^{36}$

The allusion here to an aerial view in Hölderlin's poetry is especially revealing when we consider that the panorama was perhaps the most widely used form of representation of the city in the nineteenth century, an issue I discuss further in Chapter 7. For Hölderlin, however, the elevated view was clearly not intended to convey a "mastering totalization", characteristic of modern instrumental/scientific thinking. ${ }^{37}$ Rather, it expresses a poetic vision where the unseen mythic world lies embedded in the visible world. Hölderlin is reflecting here upon a much deeper tradition of revealed truth in which idea, desire and vision are intimately entwined. ${ }^{38}$

Implicit in the aerial view is the opening up of new horizons, which in early modern thought were deemed equivalent to a pre-existing infinitesimal realm. Quite how this realm can be comprehended in one's perspective reveals one of the most critical aspects of nineteenth-century culture, as I will discuss in Chapter 7. We are given a sense of this problem in Fenves' interpretation of Hölderlin's thinking:

there is no perspective on the infinite, other than that of an infinite being, who, however, cannot be ascribed any perspective at all. Since every perspective is correlated with a particular horizon, every one is finite. The "right" perspective from which to grasp the infinite cannot be, moreover, the nonperspective of an infinite being, for the infinite, according to Hölderlin, cannot be grasped as a being in the first place: it is not one thing among others, much less the highest from whose vantage point all things are revealed as they truly are. Grasping the infinite is therefore a particularly precarious operation - or balancing act. ${ }^{39}$

As I have already noted, the unavoidable consequence of this "precarious operation" - in which it is impossible to establish a definitive point of view of the world - is the "awkward" perspective referred to earlier. Implicit in this obliquity is the conception of a latent mytho-poetic world that is not open to direct encounter - as a complete and unified whole - but is rather revealed as fragmentary experiences: intense poetic moments in the itinerant's ambulatory perspective. ${ }^{40}$ 


\section{Nietzsche's perspectivism}

Hölderlin's search for a redemptive perspective, with his yearning for a return to a mythic world, takes on a radically different emphasis in Frederick Nietzsche's perspectivism. In this perspectivism, understanding of the world is conveyed in panoramic terms as personal mastery over one's ever widening field of vision. Hence, perspective constitutes not an earthly measure of humanity's relationship to a hidden divine order but rather a regulative ideal - and a unifying abstract structure - that draws authority from humanity's relationship to itself. ${ }^{41}$ In contrast, therefore, to Hölderlin's idea of measure being endowed with care and guided by a "pure heart", Nietzsche sees measure as a dimension of power. Accordingly, the only reliable truth accessible to human comprehension is perspectival truth, but one that is no longer informed by some larger redeeming purpose or divine authority. Indeed, Nietzsche dismisses all forms of absolutism as a "camouflage" to perspectivism, claiming that there are no such things as metaphysically true elements. ${ }^{42}$ Instead, all subjects and objects are fabricated. Given this absence of an eternal order, Nietzsche summons each of us to invent our own virtue - and ultimately our world - by "sampling" different perspectives. ${ }^{43}$

Pervading Nietzsche's perspectivism is his concept of the will-topower. As the locus of individual will, perspective constitutes a constellation - or "bundle" - of individual "drives", impulses and actions that make up quanta of power: "every center of force adopts a perspective toward the entire remainder, i.e. its own particular valuation, mode of action, and mode of resistance" ${ }^{44} \mathrm{~A}$ motivating force behind this form of perspectivism is the preservation of "the individual, a community, a race, a state, a church, a faith, a culture". ${ }^{45}$

From these quanta are indexed perceived truths, whose terms of reference are determined by external forces. These quanta moreover could be seen as "increments" of Nietzsche's modality of measure not communicated by rational deduction but experienced as flashes of revealed truth. As Heidegger points out:

What lives [in Nietzsche's perspectivism] is exposed to other forces, but in such a way that striving against them, it deals with them according to their form and rhythm, in order to estimate them in relation to possible incorporation or elimination. The angle of vision, and the realm it opens to view, themselves draw the borderlines around what it is that creatures can or cannot encounter. ${ }^{46}$

For Nietzsche, the question of truth in one's perspective is not simply determined by what to include or eliminate in one's visual frame. As Heidegger argues, Nietzsche's perspectivism is a revealing process of "bringing forward into appearance, a letting radiate". This in turn leads to a "semblance" of the world which is "the actual and sole reality of things". ${ }^{47}$ Significantly, Heidegger was later to question the veracity of semblance in his own philosophy, given that it conflicted with his notion of an authentically situated world. ${ }^{48}$ Notwithstanding this difference, Heidegger concludes in his study of Nietzsche that "what becomes manifest in one perspective petrifies and is taken to be the sole definitive appearance, to the disregard of other perspectives". ${ }^{49}$ 
The priority of one perspective over another in Nietzsche's philosophy presupposes the notion of a constituting "world picture" that dominated nineteenth-century culture. In this idea, the thing represented is treated as if it were a world, which elicits truth from its own terms of reference rather than seeking dialogue with a larger constituting horizon. One consequence of this emancipation of the object is that architecture becomes increasingly construed as autonomous work; as a "picture" in itself that is awaiting realisation. Dalibor Vesely traces the background to this phenomenon:

In the eighteenth century, and particularly due to the development of perspective, there is an apparent shift toward delusion in which one participates for the sake of representation rather than reality. In the end there is nothing to participate in but representation itself. This culminates in the spectacle, the panorama, the international exhibition, and finally in film and television. It is representation for the sake of the fantastic, without knowing or caring where it comes from, without a concern for its dialogue with reality. ${ }^{50}$

The notion of a world picture serves as a pervading theme in Nietzsche's principle of will-to-power in perspective. This principle, however, does not assume the possibility of a collective, or overarching, perspective field as Hölderlin sought. On the contrary, Nietzsche asserted that human thought and creativity are constantly confronted by two conflicting terms of reference, art and truth, each claiming authority over the other:

Art is the most genuine and profound will to semblance, namely to the scintillation of what transfigures ... In contrast, truth is any given fixed apparition that allows life to rest firmly on a particular perspective and to preserve itself. As such fixation, "truth" is an immobilizing of life, and hence its inhibition and dissolution. ${ }^{51}$

It would seem, therefore, that Nietzsche had conceived two largely opposing forms of perspectivism: one based on fixation (truth) and the other based on transfiguration (art). Their opposition highlights the epistemological consequences of perspectivism in modernity; the creation of emancipated knowledge resulting from the separation between technē and poiēsis. ${ }^{52}$ In this emancipation, truth is conceived perspectivally as a form of codified knowledge that can be deployed outside any given situation. This instrumental form of perspective however is radically different from the situated world underlying Renaissance perspectiva artificialis as I will highlight in Chapter 4.

To some extent, Nietzsche's twofold perspective reflects the two conditions of measure discussed earlier: the first based on abstract principles whilst the second is motivated by a desire to re-evaluate humanity's relationship to the world through the spontaneity of immediate experience. Marx suggests that the latter forms the basis of an "other thinking", a form of "nonmetaphysical ethics" 
that seeks to overcome the hegemony of positivistic sciences in the modern age. ${ }^{53}$ In spite of this aspect of Nietzsche's thought, however, George Pattison makes the case that "Nietzsche is the voice of modern metaphysics, whilst Hölderlin presages the overcoming of metaphysics." ${ }^{54}$

Taking Nietzsche's philosophy as a critical point of departure, this "other thinking" contributed to the phenomenological project to restore perspective to its proper ontological status as a measure of human "situatedness" in the world. The notion of situation - the German "Lage" is perhaps the closest equivalent - forms a central theme in this enterprise. ${ }^{55}$ It refers to a context in which we are always already involved, and of which no complete objective knowledge is possible. ${ }^{56}$ Accordingly, situations are by definition hermeneutical, meaning they are rooted in a pre-existing historical context. As such they are substantiated by what Heidegger calls a "fore-having", a "fore-sight" and a "fore-conception" ${ }^{57}$ This means that the very nature of human enquiry ("ontological interpretation") is always informed by a pre-given historical condition that ensures unity with the totality of Being. ${ }^{58}$

Considered in more general terms, situation could be said to denote the context in which our existence in the world carries ethical meaning, as Peter Carl suggests: "If whatever is held to be universal is inevitably ethical in content (because it speaks of what is common to all), and if metaphor is the most direct avenue of interpretation, the situation gives the 'world' in which this interpretation has continuity, or meaning." ${ }^{59}$ This continuity is sustained by what Vesely argues is the capacity of situations to "structure our experience" and therefore to serve as "receptacles of experience". ${ }^{60}$ In this twofold function, situation thus brings into dialogue multiple conditions of experience, from practical life to the exemplary gestures of ritual and drama. ${ }^{61}$

It is important to point out that this notion of situation provided the basis of a symbolic understanding of perspective in the Renaissance. In this symbolism, as I shall argue in Chapter 4, both real and ideal were believed to form part of the same unified redemptive order that could be brought to a level of human participation through a perspective articulation of space. ${ }^{62}$ By the eighteenth century, however, the relation between situation and perspective breaks down, resulting in perspective becoming little more than an instrumental construct emptied of metaphorical content. This shift led to the effective emancipation of perspective from an embodied world, becoming an autonomous construct for the purpose of pictorial effect. It was only as a result of the brief - but significant - interlude of Romanticism that perspective was rescued from the abyss of mere technique. ${ }^{63}$ What we see in Nietzsche's "empowered" perspectivism is, in one sense, symptomatic of the abandonment of the situated realm as such, and its assumptions of some higher constituting (divine) order. In its place Nietzsche advances a perspectivism that gives priority to the human agent as revealer of the world.

\section{Being-in-the-world}

The demise of a common communicative domain becomes most apparent in the nineteenth century where the proliferation of architectural styles and the artificial 
settings of international expositions reflect a world in search of some larger organising system. Each construct was paraded as a world-picture, whose terms of reference lay claim to a broader historical spectrum. In reality, however, each only contributed to the plethora of formal attributes and the confusion about what constitutes cultural order.

The crisis was to lead philosophers, from the late nineteenth century, to radically rethink the nature and meaning of measure through a phenomenological approach to the world. This was initially developed in the philosophy of Edmund Husserl who argued that the togetherness of the "I" and the world can be validated in a transcendental-eidetic way. ${ }^{64}$ Husserl's philosophy takes Immanuel Kant's idea of a transcendental dialectic as a point of departure, from which he develops the notion of "experiential and theoretical self-evidence" ${ }^{65}$ In this principle, Husserl believed that consciousness is a universal transcendental condition that can be understood by rational argument. The universal status was underpinned by the Kantian notion that knowledge is not so much informed by direct experience as by the structures of the mind. This led many to accuse Kant and his followers of solipsism, an accusation that Kant himself sought to overcome by asserting that the rational structures of the world actually echo the rational modalities of thought. However, Kantianism could never shake off associations with psychologism in which knowledge of "things-in-themselves" is deemed impossible.

The problem of psychologism was to persist in Husserl's phenomenological interpretation of Kantian transcendentalism. This is in spite of the fact that Husserl was to play a critical role in the development of twentieth-century phenomenology that sought to replace the dominance of a limited perceptual understanding of experience with one guided by a deeper sense of belonging to a world order. Central to this role were Husserl's ideas of intentionality and categorical intuition, both of which he explores in the sixth book of his celebrated Logical Investigations. Starting with Kant's assertion of consciousness as directing agent, Husserl conceives the notion of intentional comportment towards the world, or what Theodore Kisiel describes as intentionality's "self-directness-toward" consciousness. ${ }^{66}$ In this directedness, intentionality is defined by the processes of reason, by which the world can be understood perceptually through the filter of a discerning subject (or ego-cogito). This evidently Cartesian predilection was criticised by Heidegger, who believed that experience of the world (praxis) actually precedes - rather than follows - perception. ${ }^{67}$ Consequently, Heidegger asserts that Husserl's psychological reading of intentionality formed only a very limited part of a much larger sphere of intentionality revealed through "life's facticity" . 68 Hence, going beyond Husserl scientific approach, Heidegger probes the inner depths of intuition itself by revealing its "pre-intuitional" substance.

The means by which intentionality manifests itself in perceptual experience takes the form of "categorical intuition", the second important aspect of Husserl's sixth book, which Heidegger considered to be the "focal point of Husserlian thought". ${ }^{69}$ In this idea Husserl implies that intuition is informed not merely by the senses but by an already pre-given ontological dimension of 
existence, a principle that Heidegger was to develop further in his later seminal work Being and Time. Husserl's principle, however, fell short of a clear and explicit exposition of the full scope of the "truth of being (e.g., the disclosedness of context)" in one's experience of the world, relying instead on scientific methods to reveal the modus operandi of sense perception. ${ }^{70}$ As a consequence:

Heidegger warns of the danger of objectification or "reification", and so of "unliving", that comes from exemplifying intuition through sense perception, as Husserl does. He suggests instead that the very first level of phenomenological intuition is in the sheer understanding of the meaningful contexts developed by life-situations, since these "pregivens" in which the totality of life tends to be expressed can never in any way be objectified..$^{71}$

Departing therefore from Husserl's lifeless reading of experience, where the relationship between entities takes priority over their being as such, Heidegger conceives a new phenomenological perspective that centres on the idea of being-in-the-world (Dasein), or humankind's "situatedness" in the world. In this philosophy, Heidegger turns away from subjectivity by restoring "things to a place of centrality". ${ }^{72}$ This centrality opens the way to the possibility of understanding things as they are rather than construing the world from a purely rational position, a point that has important implications to a modern perspective view, as we shall see later.

Heidegger's quest to "restore" embodied meanings to human experience entailed questioning Nietzsche's relativistic perspectivism, and the metaphysical principles it assumes. In particular, Nietzsche's emphasis on preservation and mastery is overturned by Heidegger and replaced by a particular interpretation of Hölderlin's idea of care (Sorge) in one's being-in-the-world. ${ }^{73}$ In this existential outlook, assumptions of a perspectivally ordered world are radicalised - and ultimately put in jeopardy - by the emphasis given to a pre-existing relationship to the world (Dasein), prior to the implementation of relational constructs.

This leads us to the specific issue of Heidegger's thinking on perspective. In order to understand this thinking we need first to examine Heidegger's criticism of René Descartes' philosophy. ${ }^{74}$ In his Being and Time, Heidegger highlights Descartes' distinction between ego cogito and res corporea, arguing that their separation constitutes an opposition between nature and spirit. The question of what defines the essence of res corporea, or rather its "substantiality", leads Descartes to the notion of res extensa. Extension constitutes "the real Being of that corporeal substance which we call the 'world' ". ${ }^{75}$ Moreover, "a corporeal Thing that maintains its total extension can still undergo many changes in the ways in which that extension is distributed in the various dimensions, and can present itself in manifold shapes as one and the same Thing". ${ }^{76}$ This "one and the same Thing" affirms the universal status of "substantiality" which in Descartes' philosophy constitutes the central "idea of Being". ${ }^{77}$ 
As Casey points out, one consequence of Descartes' notion of extension is that "every instance of extension is a material body. Not only does matter occupy space, but space is matter." 78 This coincidence led, in the seventeenth and eighteenth centuries, to a protracted debate about the nature of the universe and our perception of it. At issue here was the question of whether the universe could be understood in relative or absolute terms, the former exemplified in the theories of Descartes and Leibniz and the latter in those of Newton. In the case of Descartes, who advocated extension as the only true "measure" of the universe (and one which is by definition objective and universal), we are left wondering how such measure can inform the richness of human experience. As Jean-Luc Marion points out, "Cartesian philosophy is deployed as an explicit and avowed non-ontology", given that Descartes leaves undetermined the nature and meaning of Being..$^{79}$ Instead, all expression is reduced to thought, which only circumspectly relates to the world. Thought is constituted in the notion of the ego, whose characteristics of autonomy and self-sufficiency are equated with the supreme Being; the divine creator. Indeed, Descartes' solipsism is an attempt to reduce God to pure thought. ${ }^{80}$

Heidegger's criticism of Descartes' philosophy centres on the specific issue of the inaccessibility of Being. This is due to Descartes' reduction of Being to intellectual/mathematical enquiry and its expression in the abstract terms of extension. In place, therefore, of the Cartesian notion of measure, as infinitely extended, Heidegger develops a modality of measure that is constituted around the idea of the "concealedness" of the world, drawn from Hölderlin's poetic vision of earthly measure. This is succinctly highlighted in the following:

What is the measure for human measuring? God? No. The sky? No. The manifestness of the sky? No. The measure consists in the way in which the god who remains unknown, is revealed as such by the sky. God's appearance through the sky consists in a disclosing that lets us see what conceals itself, but lets us see it not by seeking to wrest what is concealed out of its concealedness, but only by guarding the concealed in its self-concealment. Thus the unknown god appears as the unknown by way of the sky's manifestness. This appearance is the measure against which man measures himself. ${ }^{81}$

By conceiving the world as a domain in which appearance is always prefixed by ontological meanings Heidegger is seeking to restore humanity's situatedness in the world. This existential outlook marked a critical turning point from the stilldominant Cartesian view. As we saw earlier in the context of Husserl's phenomenology, Descartes' elevation of the thinking self - and its accompanying abstraction and homogenisation of space - was to continue to influence philosophical thought in the late nineteenth and early twentieth centuries. Its impact, moreover, on perspective was profound and long lasting. It set in place a gradual but decisive transformation of perspective from an essentially situated understanding, evident, as we have seen, in the Renaissance (when the eternity of the 
ideal/sacred and the temporal were ontologically bound), to a pure eidetic scaffold: "For the very methodology of Descartes is to narrow one's view of the world to the mode of seeing it merely as present-at-hand. With so narrow a view, the perspective necessary for seeing the world is ontologically lost." 82

For Heidegger, the idea of the world as an assortment of objects or things, that are independent of their use (and therefore merely "present-at-hand") assumes our effective disengagement from the lived world. Such detachment is directed by perception alone, or more specifically by what Husserl calls the "perceivedness of bodily presence". But, as Kisiel points out: "Isolated perception in its directedness-toward is still an intentionality derivative from the more encompassing 'already involved with' of the structures of care." ${ }^{83}$

In this notion of care, borrowed from Hölderlin, being-in-the-world is always conditioned by a "concernedness" for everything that is present. This concernedness, moreover, takes the form of responsible action with respect to a "worldhood" of life-situations. Hence, perceptual understanding is always presaged by "the more immediate presence of the handy within reach and grasp" ${ }^{84}$ For Heidegger, "The Objective distances of Things present-at-hand do not coincide with the remoteness and closeness of what is ready-to-hand within-theworld." 85

It is interesting to note that Heidegger's idea of the "ready to hand", in which the world is deemed "within reach and grasp", underlies many Renaissance representations. In particular, the way in which perspective appears to guide human gestures, from the ambit of local situations - typically represented by gesticulating figures in dialogue - to some culminating event or focus assumes a divine world that is potentially accessible and therefore receptive to our gestures. We will examine this aspect of Renaissance iconography in Chapter 2 in the context of Leonardo da Vinci's Last Supper and Raphael's School of Athens.

The shift from the more technical notion of "present at hand", that considers a perceptual relationship to the world, to the idea of "ready to hand", that affirms a living/working being (and therefore embodied world), heralds a critical change in twentieth-century philosophical thought. It set in place a radical rethink about the nature and meaning of a perspectivally oriented world. A guiding principle in this regard is Heidegger's notion of "region" (Gegend) that informs his situational philosophy. ${ }^{86}$ Rather than denoting a field of vision - or horizon where objects are represented - the region is "that which lets the horizon be what it is". ${ }^{87}$ It conveys "what the open [das offene] around us is in itself". ${ }^{88}$ "The open" could be described as the "background" from which the region emerges as a situated realm, or what Marx describes as the region's "gathering movement" ${ }^{89}$ Here, things are not characterised as mere objects since they no longer stand before us. Instead, "they rest" in the gathering movement of the region, and in so doing return "in the abiding of the expanse". ${ }^{90}$

An indication of how we interpret the notion of region in perspectival terms is implied in Gottfried Boehm's examination of perspective in Heidegger's thinking: 
Spatial perspective, or better the perspectivism of consciousness has disappeared. Now we have to argue the meaning of existence, which appears in relation to time. We are now interested in how we can think of Being. How thinking is possible, if it is defined not by the person's perspectival relation/truth but rather based on the other side of perspectivism. ${ }^{91}$

Boehm's assertion of the disappearance of perspectival consciousness, by the prioritising of the "other side of perspectivism", highlights a crisis in perspective in modernity. But such a crisis should not assume that perspective, in its broader philosophical sense, no longer carries meaning in the modern age. On the contrary, something more ambiguous is implied here that is underlined by developments in the modern concept of "enframing" - or world-picture - discussed earlier. Boehm's reference to "the other side of perspectivism" could be said to condition hermeneutic insight in our "situatedness" in a historical world. It refers to the locale of perspectival depth that lies inside human situations. The inference here of a reciprocity of perspective thinking, by which my being is already present - and indeed "acknowledged" - in the world relates to a deeper ontological tradition that can be found for example in Nicholas Cusanus' writings examined in Chapter 4.

In this inversion of the perspectival frame Boehm is highlighting the central hermeneutical task; to overcome the notion of an outside point of view that is the illusion of rational/instrumental thought: "The being with existence and the Being-in-the-world permit no 'space in-between' in which it would be possible for the self to concentrate on its perspectival point of view, in order to position the things as a vanishing structure". ${ }^{92}$

Being-in-the-world for Heidegger means that the Cartesian idea of "perspectival selfness" becomes largely irrelevant. ${ }^{93}$ It ensures an openness of being with respect to a region, and in so doing radically re-evaluates the conventional notions of a perspective view of the world. In this project human existence is conceived as always already in possession of the world, by which "beingtogether can explain a pure view in perspectivity". ${ }^{44}$ This idea of a "pure view" could be misinterpreted as alluding to some ideological intention. Such an assumption, however, is clearly not the case given that the particular notion of view conveys an existential process of "being there" that exists "prior to all psychology of moods". ${ }^{95}$ Accordingly:

Dasein is the place of openness, the there ... Hence we say that Dasein's being is in the strict sense of the word "being there" (Dasein). The perspective for the opening of Being must be grounded originally in the essence of being-there as such a place for the disclosure of Being. ${ }^{96}$

In this existential understanding Heidegger believes that one's encounter with phenomena requires "no mediation in terms of perspectival seeing and a transcendental 
aesthetic". ${ }^{97}$ Instead a phenomenon "explains the dimension in which first the self is perspectivally confronted with its appearance".${ }^{98}$ In other words, a phenomenon already assumes in its appearance the presence of the witness.

The issue of Being-in-the-world in Heideggerian thought profoundly influenced a number of key thinkers in the twentieth century, each of whom sought in various ways to redefine the nature and meaning of perspective in modernity. For the sake of brevity, I will examine the work of only two philosophers, Emmanuel Levinas and Maurice Merleau-Ponty.

\section{Alterity and infinity}

Unlike Heidegger, Levinas considered human inter-relationships as fundamental to Being-in-the-world that would also provide the context for a religiously (and ethically) oriented perspective. Two works will serve as the main references here; Alterity and Transcendence and Totality and Infinity. Challenging the established philosophical assumption of a radical "immanentisation" of modernity, Levinas claims that transcendence is "alive in the relation to the other man". $99 \mathrm{He}$ develops a philosophy that centres around one's encounter with the face of the other. This is an inter-subjective relationship that is not reciprocal but rather "asymmetrical". Accordingly, rather than pertaining to a common space, this relationship exists "across the écart separating the / from the other". ${ }^{100}$ The status, however, of the "I" in this dialogue highlights a crisis which concerns

the being of a being [l'être de l'étant] in the human. A crisis of being, not because the meaning of this verb ... remains to be understood ... but because, being myself, I already ask myself whether my being is justified, whether the Da of my Dasein is not already the usurpation of someone's place. ${ }^{101}$

The nature of this crisis lies at the very heart of the crisis of perspective that Boehm describes. By surrendering the dominion of vision, Levinas is undoing perspective's hegemony. Accordingly, Heidegger's quest to overcome the privileging of the point of view, in one's relationship to the world, becomes for Levinas the basis of a concern for one's fellow humans. This concern is registered as an "unlimited responsibility", from which we are never discharged. ${ }^{102}$ Such responsibility means that there can never be an immanence since my very identity has meaning only in the light of the other. ${ }^{103}$

Unlimited responsibility is founded on the principle of what Levinas identifies as the infinitude of alterity; the "infinitely other in the other person". ${ }^{104}$ The principle of alterity is rooted in a philosophical tradition that can be traced back to Christian/Platonic thought. At the centre of this tradition is the idea of the soul as the seat or receptacle of God, from which human salvation can be sought. From this tradition developed many of the principles that underpin Western metaphysics. Of particular interest here is the idea of a correlation between 1) the infinity and absoluteness of God's power, 2) the infinitude of space and 3) the eternal nature of the soul. The inter-connection between these three levels of 
reality did not suddenly emerge but rather developed gradually as part of a changing world-view.

A key figure in this development was the late sixteenth-century heretic Giordano Bruno who made a case for equating God's absolute authority with the idea of an infinite universe. ${ }^{105}$ Given the more recent historical background to this relationship, as we discussed earlier, it is significant that Levinas deploys a particular understanding of the infinite to convey one's responsibilities to the "other". ${ }^{106}$ In his defence of a caring - rather than "egoistical" - outlook Levinas seeks to substitute Descartes' notion of extension, as a mere qualification of infinitude, with the notion of ethical concern in the exteriority of the other: ${ }^{107}$ "The idea of infinity ... does not proceed from the I, nor from the need in the I gauging exactly its own voids; here the movement proceeds from what is thought and not from the thinker." 108 Consequently, for Levinas the infinite is considered in relational and ontological terms, redolent of Hölderlin, rather than constituting an affirmation of an abstract and universal state. It is from this ethical standpoint that Levinas develops his modality of measure:

Infinity is not the "object" of a cognition (which would be to reduce it to the measure of the gaze that contemplates) ... [nor is it] an immense object, exceeding the horizons of the look. It is Desire that measures the infinity of the infinite, for it is a measure through the very impossibility of measure. The inordinateness ... measured by Desire is the face. ${ }^{109}$

In this religiously oriented perspective, in which neighbourly love transforms vision into an epiphany, Levinas conceives the idea of an "ethical optics". Challenging many aspects of Heidegger's hermeneutic philosophy, in particular the absence of a clearly stated ethical dimension in Being-in-the-world, Levinas' phenomenological perspective takes the face of the other as the vehicle for a transcendent otherness. The epiphany of the face becomes therefore the means of revealing and affirming - God.

\section{Visible and invisible}

Levinas' idea of an ethical optics finds parallels in Maurice Merleau-Ponty's phenomenology of perception. For Merleau-Ponty "To see is as a matter of principle to see further than one sees, to reach a being in latency." 110 In this way of seeing we are led to an "invisible substructure of the visible" that exists prior to any bifurcation of objective and subjective realms. This idea forms the central theme of Merleau-Ponty's seminal - but unfinished - work The Visible and the Invisible. In this study Merleau-Ponty develops his thesis of the primacy of bodily perception "that provides the basis for grasping the experience of time, for perception is ... a leaping out of oneself toward the world". ${ }^{111}$ This leaping is what Merleau-Ponty calls "dehiscence", "a splitting open of the body as touching and touched, as seer and seen that allows the body to experience things, that puts the body in contact with things where they rest, yet that separates it from them at the 
same time."112 The notion of dehiscence is deployed in Merlaeu-Ponty's Visible and Invisible in an attempt to make sense of the expression "there exists". To perceive an existent thing is to project oneself to its very core. Accordingly, our body forms an integral part of this perceptual process:

No doubt, it is not entirely my body that perceives, that I cannot perceive without its permission; the moment perception comes my body effaces itself before it and never does the perception grasp the body in the act of perceiving ... it is as if [my body] were built around the perception that dawns through it. ${ }^{113}$

From this idea Merleau-Ponty concludes that perception "emerges in the recess of my body", a point that is underlined by the expression "the flesh of the world". ${ }^{114}$ The expression underlines the corporeal nature of perception: "my body is made of the same flesh as the world (it is a perceived), and moreover ... this flesh of my body is shared by the world, the world reflects it."115 This is explored in a speculative manner in the final, unfinished, chapter of Visible and Invisible, entitled "The Intertwining - the Chiasm". The chiasm denotes the intersection "between the human body and the world that produces perceptual meaning, i.e., the visible or sensible". ${ }^{116}$ The term seeks to affirm a kinship between the lived world and the lived body that can overcome the notion of a point of view of a detached observer. Against the background of an objective/subjective dichotomy, in which everything is treated in atomistic or mechanistic terms, Merleau-Ponty asserts that Being excludes all mere appearance since the perceiver is always enveloped in his or her own perception, a notion that is echoed in Boehm's reference to the "other side of perspectivism" referred to earlier. This runs counter to the notion of an "unsituated gaze" as Merleau-Ponty explains:

Take up again the analysis of the cube. It is true that the cube itself, with six equal faces, is only for an unsituated gaze, for an operation or inspection of the mind seating itself at the centre of the cube, for a field of Being ... And everything one can say about the perspectives upon the cube do not concern it. ${ }^{117}$

Hence, Merleau-Ponty considers the geometry of vision in optics as antithetical to perceptual experience, given that "what is given to me phenomenally is not a set of displacements or non-displacements of this kind". Rather, "it is the difference between what takes place at one distance and another distance, it is the integral of these differences". ${ }^{118}$ The clear difference, promulgated by Merleau-Ponty, between geometry of vision and embodied perceptual experience was not, however, always the case, as we shall see in Chapter 2 in the context of Leonardo da Vinci's Last Supper.

Unlike Levinas' phenomenology, which advocates the asymmetrical relationship between the witness and his fellow men, Merleau-Ponty espouses a more encompassing mode of perception as a continual interaction with the world 
of phenomena. A guiding influence of both phenomenological perspectives is Heidegger's notion of Being-in-the-world, discussed earlier, in which one's presence "lets appear" the ready-to-hand, or handiness of the world. In the case of Levinas, as we have seen, this idea of letting appear takes on an obligatory role on the part of the witness, whilst Merleau-Ponty's phenomenology is conceived in terms of a complete and abiding reciprocity.

\section{What to leave out?}

From what I have outlined in this chapter, it seems apparent that the emergence and development of Phenomenology in the late nineteenth and early twentieth centuries coincided with - and drew influence from - a crisis in perspective. From the grip of Cartesian principles in Kantian and Neo-Kantian thought to the phenomenology of perception of Merleau-Ponty, the crisis provided a critical context in which fundamental questions about our relationship to - and understanding of the world were raised. In the resulting shift from an essentially psychological to an ontological/historical perspective, the notion of Being-in-the-world emerges as a central hermeneutic issue.

It is in the context of this shift that we should recognise that the challenges facing contemporary architecture have less to do with unwanted "obtrusions" - about what to include or leave out in our choice-ridden culture - and more about grasping in a hermeneutic sense various "ways of seeing" and representing the world: each different in their respective terms of reference but all ultimately rooted in the same historical/phenomenal world. In our quest for clarity of thought, and wished-for mastery of the visual field, we leave unquestioned the issue of our relatedness to the world, of which perspective is traditionally one of its principal constituting realms. 


\section{Chapter 2}

\section{Number, geometry and dialectic}

\section{The origin of geometry}

In his essay, "The Origin of Geometry", Edmund Husserl examines geometry as a heritage that is both handed down and rediscovered. ${ }^{1}$ He argues that the field of geometric enquiry entails ideal objects - ready-made and unalterable configurations - whose meanings are revealed by a twofold process: by "regressive enquiry" into the history of geometry, and by a "continual forward development" that imparts a sense of discovering geometric truths as if for the first time. ${ }^{2}$ This conflation of reflective and anticipatory realms could be said to constitute the essence of geometry as a tradition. ${ }^{3}$

In this chapter I will examine the inter-relationship between perspective and geometry by taking Husserl's principle of the origin of geometry as a point of reference. The principal aim of the study is to highlight the way in which classical geometry was transmitted to perspective and how this development was put to the service of a new spatial-temporal understanding of order. The study will begin with an examination of the "genealogy" of geometry as it relates to a number of key philosophical works, especially Plato's Meno and Timaeus. The aim of this part of the study is to ascertain how geometry was deployed to re-affirm an existing world-view that saw number and language as dialectically related aspects of the same cosmological order.

The second part of the chapter will focus on the role of geometry in Renaissance iconography, in particular how discourses on geometry gave support to a pre-ordained onto-theological order. This will be examined in the context of fresco painting, rather than building, since it is in this medium that the relation between geometry, language and perspective was most explicitly articulated in Renaissance culture. A key area of focus in this part of the study will be Raphael's famous fresco the School of Athens.

The concordance invoked in the fresco between Greek philosophy and Renaissance humanism, and between Greek scientific thought and Renaissance 
concepts of space, was sustained by an all-pervasive belief in correlative thinking. Through analogy, classical cosmology was presented as an inherited tradition that could be conveyed perspectivally. Precisely how this legacy was understood and represented - as a "handing down" of a received tradition - will be explored here.

Finally, in the concluding case-study to this chapter I will examine the role of geometry and perspective in the Yale Art Gallery by Louis Kahn. I will argue that Kahn's use of geometry in his architecture was inspired by a deeply felt belief in a dialogue between instrumental and symbolic meanings, a belief that could be said to echo Husserl's search for continuity in geometric thought.

Before beginning this investigation, however, it would be useful to begin with a brief outline of some key issues about geometry and its relationship to perspective. Traditionally, geometry has provided a symbolic framework for revealing the otherwise hidden cosmological meanings of the world. This function was made possible by a particular - indeed unique - feature of geometry, as Robin Evans explains:

In a universe construed after the fashion of Western metaphysics, with matter and spirit opposed, geometric forms move easily across the border between the visible and the invisible, the corporeal and incorporeal, the absolute and the contingent, the ideal and the real. ${ }^{4}$

From our modern standpoint, the mediating function of geometry would seem to be most evident during the period that witnessed the "rediscovery" of perspective. It was during the Renaissance that the relation between the ideal and the real was brought to a level of visual clarity and cultivated through intellectual and artistic initiatives. But this cultivation was not without its complications and contradictions, particularly in respect of the generally held belief in the numerical foundations of geometry that served as one of the guiding principles of humanist thought.

Implicit in this relationship was a twofold meaning: 1) a qualitative value that was underpinned by Pythagorean number mysticism and Platonic ideal forms; and 2) a quantitative value that was informed by an encroaching epistemological understanding of the universe. As will become clearer later, Husserl's enquiry into the historicity of geometry provides a useful philosophical context in which to explore this relationship.

Whilst there existed a fervent belief in historical continuity in the Renaissance, whereby the present was seen as providentially related to a mythohistoric past, it is also the case that the late fifteenth and sixteenth centuries witnessed an impending crisis about the nature and meaning of order. James Hankins attributes to this crisis a questioning of faith in the Christian tradition that was brought about by a new freedom of enquiry in humanist thought. ${ }^{5}$ For Husserl, moreover, this crisis was characterised by a loss of understanding of geometry's origins that once drew meaning from an onto-theological world-view: 
without the actually developed capacity for re-activating the original activities contained within its fundamental concepts, i.e. without the "what" and the "how" of its pre-scientific materials, geometry would be a tradition empty of meaning; and if we ourselves did not have this capacity, we could never even know whether geometry had or ever did have a genuine meaning, one that could be "cashed-in". ${ }^{6}$

The capacity of modernity to understand the pre-scientific view of geometry as a tradition is precisely what Husserl seeks to illuminate in his phenomenological enquiry. The critical turning point in the change from an inherited to a pure autonomous - geometry takes place in the ideas of Galileo, as Jacques Derrida notes:

What Galileo inaugurated, opening the way for objectivism by making mathematicized Nature an "in itself", marks the birth of a crisis in sciences and philosophy ... For Galileo, the sense of the geometrical tradition's origin was already lost: Galileo was himself an heir in respect to pure geometry. The inherited geometry, the inherited manner of "intuitive" conceptualizing, proving, constructing, was no longer original geometry: in this sort of "intuitiveness" it was already empty of its sense. ${ }^{7}$

Seen in the historical context of perspective, Derrida's interpretation raises an important question: was perspectiva artificialis understood as part of a stillestablished inherited geometrical tradition, whose loss can be traced in postRenaissance developments? Alternatively, is pure geometry somehow implicit in Renaissance perspective? If the latter is the case then can we therefore assume that any symbolic associations in perspective during this period were already at risk of being "empty of sense"? In other words, was Renaissance perspective part of an already-established instrumental world, indeed one of its principal agents?

This idea is implied by Hubert Damisch who asserts that the critical transition that Husserl describes extended "under the standard of perspective". ${ }^{8}$ Indeed, Damisch argues that the transition continued "well beyond the crisis of the representational system inherited from the Renaissance, evidence for which can supposedly be found in painting since the époque of Cezanne and the beginnings of cubism". ${ }^{9}$ Hence, Damisch sides with the premise that modern (pure) geometry - with its loss of sense - actually emerged from "perspectival endeavours". ${ }^{10}$

In this chapter, I will challenge Damisch's assertion by arguing that the relationship between geometry and perspective was not so emphatically determined by encroaching abstract/instrumental thinking. As the following will seek to demonstrate, the changes wrought by new modes of philosophical and scientific thinking were, until the Renaissance, circumscribed by a still-prevailing continuity of traditions whose terms of reference are most clearly expressed in the relation between number, geometry and perspectiva artificialis. 


\section{Pythagoras and the unutterable}

At the heart of Pythagorean cosmology is the role of number (or more specifically whole numbers) in the composition of the universe. By attributing not only a sacred character, but also a substantial (even physical) reality, to numbers Pythagoras was seeking to equate all numerical relationships with the elements of things. In other words, "the world, in its purest and most abstract form ... was built on commensurate, or rational, numbers." 11

Pythagoras made no distinction between abstract and concrete notions of reality. Instead, space is conceived as a domain of discrete units, whose interrelationships are defined in terms of numerical proportions. It is from these relationships that form emerges. The order of the cosmos is therefore intrinsically countable, whereby numbers serve as entities of constellations and hence as heavenly shapes of things. Typically, these shapes are formed by triangular relationships that were later to provide the foundations of Platonic cosmology. Pythagoras believed that the distances separating heavenly bodies possess the same proportional relationships as those that produce harmonious sounds from a plucked string. The idea of universal consonance was later given a distinctly anthropomorphic

2.1

Map of the constellations following Vitruvius (bk 9). Giovanni Antonio Rusconi, Della architettura di Gio. Antonio Rusconi, con centosessanta figure dissegnate dal medesimo . . (Venice, 1590), p. 124. Echoing Pythagoras, Vitruvius saw the constellations as the creation of triangulated relationships between the lights emitted by the stars.

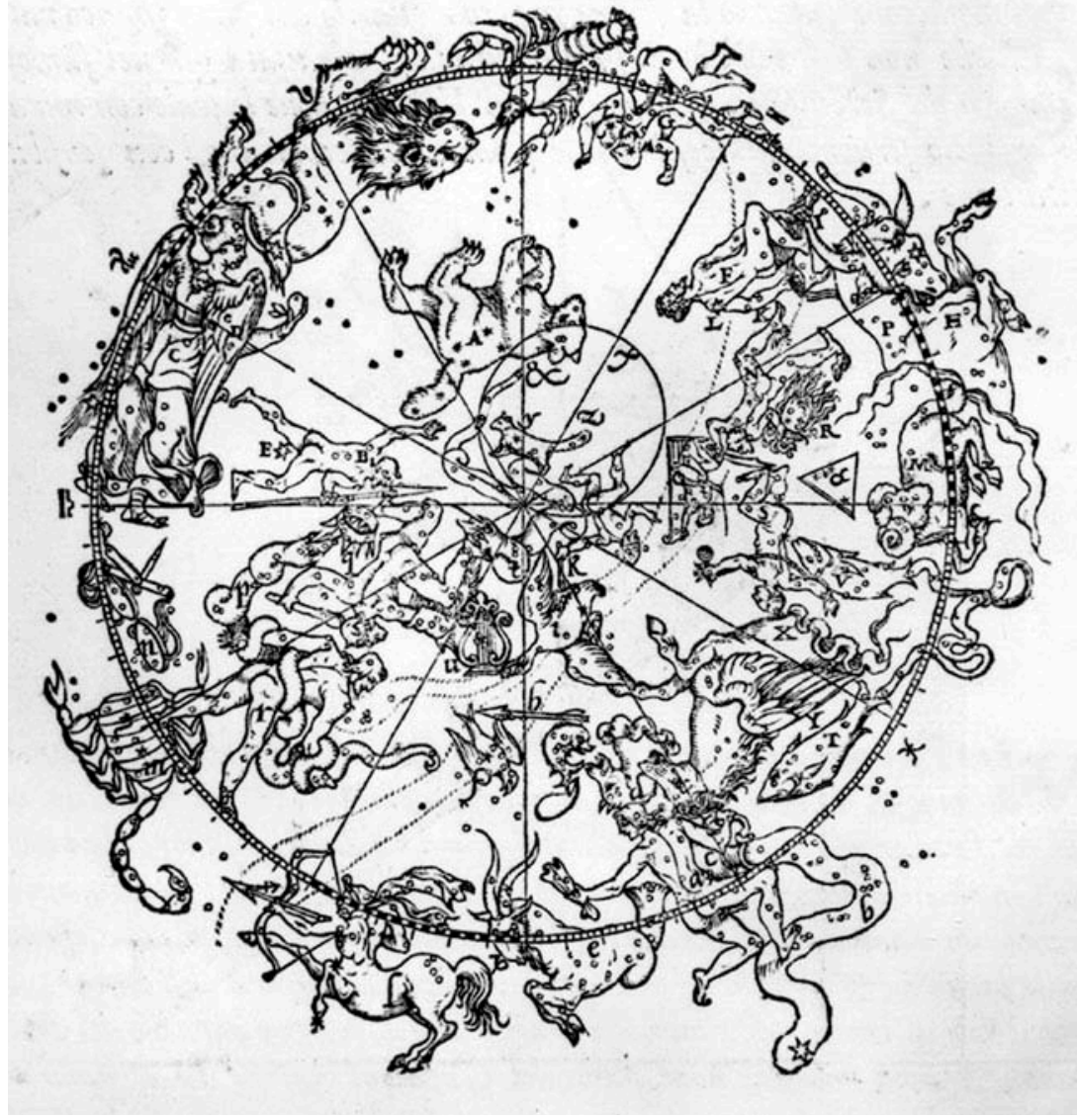


emphasis when the Pythagoreans claimed a direct correlation between a numerically ordered cosmology and the proportions of the human body. ${ }^{12}$

The principle of an interdependent world, one that is shaped by number, was communicated at the level of human dialogue by the use of pebbles or tokens, each representing the constituent numerical entities. Such simple devices for calculating and representing proportional relationships continued to resonate meanings during the Middle Ages, as Hugh of St Victor describes in his De Studio Legendi:

I laid out pebbles for numbers, and I marked the pavement with black coals and, by a model placed right before my eyes, I plainly showed what difference there is between an obtuse-angled, a right-angled, and an acute angled triangle. Whether or not an equilateral parallelogram would yield the same area as a square when two of its sides were multiplied together, I learned by walking both figures and measuring them with my feet. Often I kept watch outdoors through the winter nights like one of the fixed stars, by which we measure time. Often I used to bring out my strings, stretched to their number on the wooden frame, both that I might note with my ear the difference among the tones and that I might at the same time delight my soul with the sweetness of the sound. ${ }^{13}$

The use of pebbles as mimetic devices underlies an important aspect of numerical understanding in ancient Greece. This concerns the absence of a numerological notation and a symbol for zero. For the former, the ancient Greeks relied upon the letters of their alphabet to serve as symbols of numerical quantities. This meant that numbers could be read as words and - conversely - words could be construed as groups of rational numbers. The use of Greek letters as a computational language was a cumbersome process that resulted in the development of alternative methods, such as tokens for counter-casting. What was in fact an early form of abacus goes some way to explain the Latin term "calculus", meaning pebble. ${ }^{14}$ As David Furley states, the pebble is not a building block of a structure, "not parts into which the thing [the human body] can be divided". Rather, it represents "certain proportions characteristic of a thing". ${ }^{15}$

The belief in a continuum of rational numbers, that are defined in terms of ratios of two integers, was "the perfect metaphor for the similarly gapless geometric figure represented by the line" ${ }^{16}$ This continuum served as the basis for the generative principle of the gnomon that moves from unity (monad) to multiplicity. The gnomon is commonly used to denote the end term of a summation of odd or even numbers as below:

$1, \quad 1+2=3, \quad 1+2+3=6, \quad 1+2+3+4=10, \quad$ etc.

$1, \quad 1+3=4, \quad 1+3+5=9, \quad 1+3+5+7=16$, etc.

Derived from the Greek meaning "indicator", gnömōn is more correctly translated as "that which allows one to know". ${ }^{17}$ Typically configured as dots or tokens, the 
gnomon when repeated results in a new figure similar to the original but different in magnitude. In this process of self-repeating figures, gnomens constitute entities that lead to shape.

The translation from formless unity to formed multiplicity is intimately bound to the ancient Egyptian practice of time-keeping. The solar clock, or merkhet, comprised an " $L$-shaped object with a short vertical arm and a long graduated horizontal arm that was rotated in such a manner that the shadow of the vertical arm fell on the graduations of the horizontal arm". ${ }^{18}$ Significantly, as Midhart Gazalé points out, the gnomon is a literal translation of merkhat, thereby suggesting that the numerical configuration of shape - that emerges from an abstract point in space - is analogous to the extension of a shadow formed by the L-shaped armature of the sun-dial. ${ }^{19}$ Whilst the former is communicated by a process of logical argument, the latter is drawn from direct visual experience. Both, however, could be said to constitute aspects of the same homologous cosmology in pre-philosophical times when idea and reality were effectively synonymous. But such an inter-related world was later to be challenged by Plato who construed number and geometry not as extensions of the physical world but rather as metaphysical models of eternal Ideas, of which reality is but a pale imitation.

Unlike the theoretical/discursive role of number and geometry in Greek philosophy, the ancient Egyptians understood measure in more practical terms, such as the act of parcelling up land for agricultural and religious purposes. The practice was undertaken for example by deploying the Pythagorean 3-4-5 rightangled triangle to form a simple device. It consisted of a looped piece of string, along whose length were formed twelve knots each placed equidistantly. This simple device provided a flexible means of pegging out the corners of plots.

The arrangement, however, of knots in the surveying tool of the triangle evidently derives from the same tradition of a numerically conceived cosmos defined by gnomonic sequences. This is given by the fact that the gnomic sequence extends as an ever-expanding series of angles, each comprising odd or even units. From these are generated polygons (triangles, squares, pentagons), as well as solids such as pyramids. ${ }^{20}$ The stacking - or generating - of these shapes follows the rules of gnomic difference that lead to the same continuous analogical relationship. In more sophisticated cultures, these sequences were used to create highly complex geometries, as we see for example in the dome of Guarino Guarini's SS. Sindone in Turin. ${ }^{21}$ More recently they have formed the basis of fractals. ${ }^{22}$
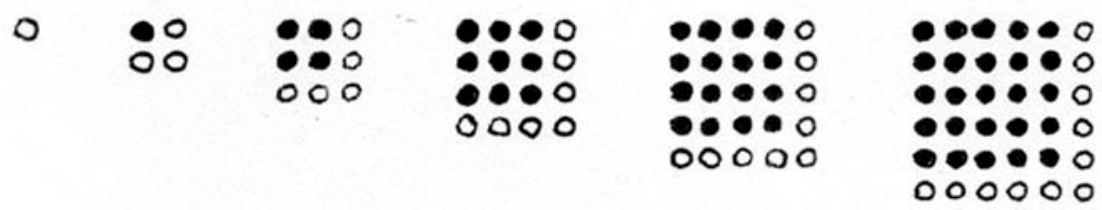

2.2

Example of gnomonic sequence. Creation of tetragonal numbers by means of successive addition of odd numbers. The gnomons are shown as white circles. 
From the fourth century BC onwards, gnomic sequences were deployed as memory devices for ordering and storing knowledge; a practice that continued in the Middle Ages as we see in the writings of Hugh of St Victor. ${ }^{23}$ In asking his pupils to acquire a "mental" space, Hugh of St Victor requests that they imagine

a sequence of whole numbers, to step on the originating point of their run [monad] and let the row reach the horizon [extension] ... the exercise consists in mentally "visiting" these numbers at random. In his imagination the student is to dart back and forth to each of the spots he has marked by a roman numeral. After doing this often enough, these visits will become as habitual as the movements of the moneychanger's hand. ${ }^{24}$

Of these sequences of figurate numbers, those that comprise the Tetractys were deemed the most venerated in Pythagorean cosmology. The number 10 carried a particular significance that was based in part on an important relationship, namely that the sequence of four integers that add up to $10(1,2,3,4)$ also define the principal proportional relationships that make up the musical scale: 1:2 (octave), 2:3 (fifth) and 3:4 (quarter). As we shall examine later, these "magical" ratios provided the impetus for the application of musical harmony to perspective during the Renaissance. The idea of completeness in the number 10 (or decad), that imparts shape to the "perfect triangle", is echoed in the cosmic sphere since a tenth celestial body (the so-called "counter-earth") was believed to complete the nine already known. The symbolism of the tetractys was later made a cornerstone of Neo-platonism as we see in Boethius' treatise De institutione musica and the Theologumena arithmeticae attributed to lamblichus. ${ }^{25}$

The sanctity attributed to 10 was doubtless an influencing factor in Vitruvius' decision to divide his De architectura into ten books. However, as Indra McEwen points out, "The ten-book division is far from inherent in the thematic organisation of De architectura ... and indeed bears a rather strained relation to it" ${ }^{26}$ The inherent awkwardness of the subdivision of topics in Vitruvius' treatise was evidently considered to be more than compensated for by their "completion" in the sacred decad, which the Greeks called the teleon. ${ }^{27}$ Interestingly, the arrangement of these books - which were originally written on papyrus scrolls suggests a more specific relationship to the tetractys. Like ten pebbles arranged in triangular formation, the ten scrolls that comprise Vitruvius' De architectura could similarly be assembled in the form of the tetractys; stacked in diminishing order from four to one. McEwen provides a physical reconstruction, in the form of a plaster, wood and surgical gauze model, to prove the point ${ }^{28}$ It would be misleading, however, to construe this configuration as merely coincidental, resulting from the utility of the scroll's shape for such assembly, or as a theoretical idea divorced from the ancient practices of storing and disseminating knowledge. On the contrary, as McEwen has eloquently argued, the significance of this affinity between Vitruvius' De architectura and the tetractys stems from a deep tradition of correlative thought that was communicated through language. 
2.4

Explanation of the Theorem of Pythagoras.

Giovanni Antonio Rusconi, Della architettura di Gio. Antonio Rusconi, con centosessanta figure dissegnate dal medesimo ... (Venice, 1590), p. 122
I.2:
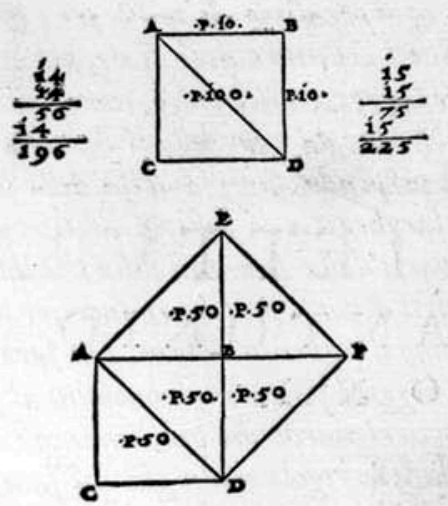

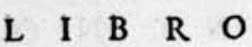

I A feguente mifura, fecondo il teL sto di Vitrunio nel Secondo Capitolo del Nono Libro, cimostra l'inuentione, E la regola della fquadra, che fu trouata daPttagora con molta facilità: Er baftarì di registrar qui il tefto di efo Vitrunio per fodisfattione, E inselligenza del Lettore. Se fi pigliarà tre regole, delle quali una fia piedi tre, l'altra quattro, la ter Za cin que, et queste regole fi compongano infieme con le tefte, fi che facciano una figura triangolare, condur anno la fquadra giusta: E' fe faranno le lunghezTe loro di pari lati fe ne formarà un quadrato perfetto, dico che del lato di tre piedi $f i$ fara un quadrato di noue piedi quadri: di quella di quattro piedi un quadrato di fedici piedi quadri, E' di quello di cinque un' altro di venticinque, E' cofi quanto spatio farà occupato da due quadri, l'uno di tre, l'altro di quattro piedi per lato, tanto numero di piedi quadri verrà dal quadro tirato fecondo il lato di cinque piedi.

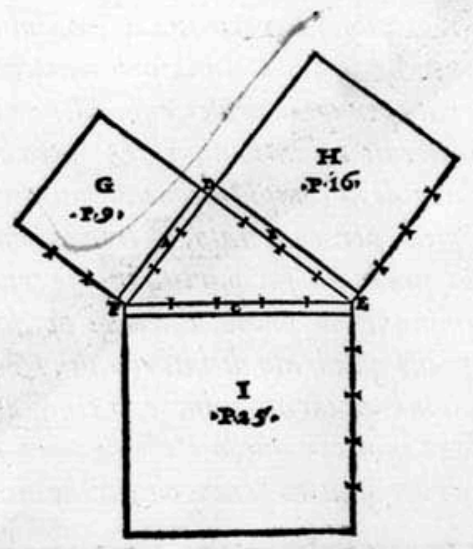

An important feature of correlative thinking is the role of ratio. The term denotes not just numerical calculation but also extends to other corresponding fields. Considered in terms of language, ratio "is understood as the privileged channel of communication with the order of the cosmos". ${ }^{29}$ In such a communicative domain, "The learned men who held nearly all things in common 'for the purposes of discussion' were men whose ratiocination took linguistic form." 30 Rooted in Platonic tradition, the idea of ratio-as-language defined the central 
Stoical principle of internal speech, or "articulate thought". ${ }^{31}$ This principle lies at the heart of Vitruvius' attempt to write the body of architecture, in which Pythagorean/Platonic cosmology lies embedded in language and its concretisation as a physical ordering of texts. Each text is presented as distinct, yet at the same time indelibly connected to a larger cosmic order. As we shall see later in this chapter, the relation between number and "internal speech" provided an important precedent in the emergence of a correlative relationship between written testimony and geometry.

What is important to emphasise here is that pervading Vitruvius' De architectura is the Pythagorean notion of the cosmos as an essentially closed system of whole number relationships that are deemed universally applicable and therefore divinely true. The discovery, however, of the so-called "unutterable" (the irrational number) led to a crisis in Greek thought and of Pythagoras' tactile numerology. This crisis did not lead to the abandonment of Pythagorean cosmology but rather provided the catalyst for an important and decisive revision of its underlying principles. The nature of this change could be described as a shift from an arithmetical understanding of order - determined by units of whole numbers to one guided by extension through geometry. The triangle provided the principal analogical device in this transformation, revealing the way number and geometry can co-exist as two facets of the same unified cosmology. ${ }^{32}$

The theorem attributed to Pythagoras heralded a decisive moment in Greek science, since the discovery of the incommensurable (defined by the diagonal of a square in relation to its side) meant that counting and measuring number and geometry - seemed irreconcilable. However, as I will explain later, Plato sought to overcome this potential schism by identifying in both modes of order a single principle embodied in the idea of the "Receptacle" of creation. Notwithstanding this unifying cosmic order, the irrational numbers $\sqrt{2}$ lad quadratum) and $\sqrt{3}$ (ad triangulum) have become almost emblematic of the crisis that Pythagoras is said to have inadvertently created.

One important consequence of Pythagoras' "discovery" is a change in the qualitative understanding of number. Like the Greek $\pi$, irrational numbers possess an indeterminate value. If we apply, therefore, Pythagoras' belief in the numerical nature of things to irrational numbers then it becomes apparent that the world can no longer be construed as a closed system - of discrete arithmetical proportions - but rather as continually extensive and therefore infinite. The Greeks, however, long resisted the idea of infinity since it contradicted their predisposition towards a closed and ordered universe. Aristotle was most emphatic in resisting such a possibility. He sought to distinguish between the reality of a finite world and what he regarded as essentially abstract models of infinitude. ${ }^{33}$

In spite of the conflicts that existed in Greek science about the nature of the universe, as we see for example in the disputes between the Atomists and the Aristotelians, the principle of a closed universe largely dominated Greek thought and indeed persisted until the Renaissance. ${ }^{34}$ Notwithstanding this dominance, the idea of the infinite was never off the agenda, as Furley highlights in the following "mental picture" of the cosmos in ancient Greece: "the stars were part 
of our world: they are the boundary beyond which the infinite universe (if it is infinite) begins." 35

Significantly, the Aristotelian distinction between finitude as an actuality and infinitude as a hypothesis was to be decisive in Greek cosmology since it broke the bond that once made arithmetic models and physical reality commensurate. Accordingly, number takes on a meaning that can safely be "measured" in analogous terms, rather than deemed coterminous with the physical essence of things as Pythagoras believed.

Closely allied to this departure from the Pythagorean world is the contentious issue of zero. The absence of a symbol to denote zero in Greek numerology meant that arithmetic reckoning necessitated leaving gaps in the matrix of tokens or pebbles. Such demonstrable absence, in an otherwise occupied and inter-related world (as Aristotle believed) leads us to speculate whether the idea of the void acquired a degree of acceptance in everyday human actions. It would seem nevertheless that the principle of an inter-related universe, which imposes a limit on the cosmos, would have made such a notion inconceivable, a point that is succinctly conveyed in the following:

The infinite variety of quality in sound is reduced to order by the exact and simple law of ratio in quantity. The system so defined still contains the unlimited elements in the blank intervals between the notes; but the unlimited is no longer an orderless continuum; it is confined with an order, a cosmos, by the imposition of Limit and Measure. ${ }^{36}$

The "safety net" provided by a closed universe was later to be undermined in the Renaissance by a new understanding of measure that revised the ancient notion of ratio and its underlying principle of a limit. This understanding, which we see expressed in both the marketplace and in philosophical/humanist ideas, gave support to the possibilities of infinity and zero. Significantly, the "rediscovery" of perspectiva artificialis must be seen in the light of this transformation, as Brian Rotman suggests:

the introduction of zero in the practice of arithmetic [in the form of Hindu numerals introduced to the West by the Arabs], the vanishing point in perspective art, and imaginary money in economic exchange are three isomorphic manifestations, different, but in some formal semiotic sense equivalent models, of the same signifying configuration. ${ }^{37}$

Whilst Christianity largely adhered to the classical Greek denial of the void or nothingness, the new climate of humanistic enquiry in the fifteenth and sixteenth centuries helped fuel speculation about the possibility of a universe without end. What prevailed therefore in classical Greek thought as a resistance to the idea of limitless space, and its mathematical correlation of zero in arithmetic reckoning, emerges in the Renaissance as legitimate terms of reference for a world in which "the centre is everywhere, and the circumference nowhere". ${ }^{38}$ 


\section{The Meno}

The discovery of the "unutterable" in ancient Greek thought contributed to the development of Plato's cosmology, as Karl Popper suggests:

Plato's central philosophical doctrine, the so-called Theory of Forms or Ideas, cannot be properly understood except in an extra-philosophical context - especially in context of the theory of matter which developed as a result of the discovery of the irrationality of the square root of two. ${ }^{39}$

An indication of this can be found in the little dialogue, the Meno, which will serve as an initial reference in this enquiry. The work reveals the progression in Platonic thought from a strictly numerical (arithmetic) order to a geometric one. The dialogue of the Meno is primarily between Socrates and a young Thessalian, called Meno, who is being attended by a slave boy. Meno asks Socrates if goodness can be taught or whether it can be acquired by practice. Socrates however poses a third possibility which serves as the general theme of the dialogue; namely that goodness is naturally "inborn". The principle underlies Plato's theory of Ideas and provided the basis on which exemplary ideas, such as justice, were deemed eternal objects of thought with "universal and unconditional validity". ${ }^{40}$

In response to Meno's question Socrates seeks to argue a more general proof that knowledge is not simply handed on from one person to another. Rather, we possess an inner knowledge that resides eternally in our soul and therefore exists before we are born. At the same time as responding to Meno's enquiry Socrates is also addressing a well-known Sophist dilemma: namely that we either know a thing, and therefore have no need to look for it, or we do not know it, in which case we cannot know what we are looking for. In other words, we either possess complete knowledge, and therefore worldly experience plays no part in its acquisition, or we are born into this world with blank ignorance, in which case experience is everything. For Socrates, learning is a process of recollection, or anamnesis, that provides, as F. M. Cornford describes: "degrees of knowledge between these two extremes". ${ }^{41}$ Socrates argues that it is possible to possess in one's mind true opinions about the world of which we have no knowledge.

The task of proving the existence of prior knowledge in the soul prompts Socrates, in the second part of the dialogue, to pose a series of questions to the attending slave boy. These relate to a simple geometrical problem: to construct a square whose area is double that of a given square. In the dialogue, the method of discovery and the method of proof become ostensibly the same, since true beliefs become knowledge only when, in the words of Gregory Vlastos, they are "bound fast by the calculation of reason". ${ }^{42}$

According to Karl Popper, implicit in Plato's proof is an attempt to demonstrate difference between arithmetical and geometrical methods. In prompting the slave boy to "discover" the solution, Socrates draws his attention to the diagonal of the unit square, whose magnitude is the irrational number $\sqrt{2}$ referred to earlier. By asking the slave boy to calculate its length, Socrates 
2.5

The geometric problem described in the Meno:

Formation of new square from diagonal of the original (A); Rotational effect of the two squares (B); Gnomic effect of the two squares (C)

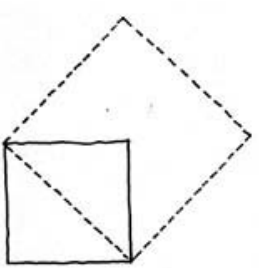

A

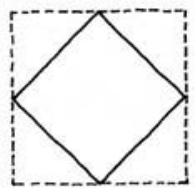

B

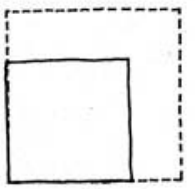

C

suggests a different method from mere counting: "If you do not want to work out a number for it, trace it." ${ }^{43}$ The proof entails drawing a new square using the diagonal as a side, "but the transition from the first to the second of these figures cannot possibly be shown to be valid by the arithmetic of dots, and not even by the method of ratios". ${ }^{44}$

What the Meno reveals through dialogue could be said to foreshadow a new geometric view of the world. Given Plato's belief that "true understanding of the cosmos comes from knowledge perceived by the intellect rather than the senses", the dialogue between Socrates and the slave boy could be seen to affirm that geometric forms constitute "imperfect realizations of mathematical proportions". ${ }^{45}$ As we shall see later in the context of the Timaeus, Plato sought to reconcile both modes of understanding the cosmos.

The deployment of the diagonal of the original square (with its "irrational" magnitude) to form the new square clearly undermines the Pythagorean principle of the universality of whole number ratios. It "destroyed the hope of deriving cosmology, or even geometry, from the arithmetic of natural numbers". ${ }^{46}$ In recognising this problem Plato replaced arithmetical theory with a new mathematical approach, what Popper calls "an autonomous geometrical method". ${ }^{47}$ Central to Plato's transformation of the Pythagorean order is the assertion that incommensurability need not assume "incomparability by geometrical methods, or by measurement, but incomparability by arithmetic methods of counting" ${ }^{48}$ By shifting emphasis from the practice of counting to one of measuring, Socrates' "proof" of anamnesis reveals a critical transition in the understanding of order that was to have significant implications in Greek science:

Ever since Plato and Euclid, but not before, geometry (rather than arithmetic) appears as the fundamental instrument of all physical explanations and descriptions, in the theory of matter as well as cosmology. ${ }^{49}$

The nature of this transformation becomes all the more important when we examine the Meno in the context of Husserl's enquiry into the origin of geometry. At the heart of Plato's dialogue is the question of the relation between reasoning and looking, inference and observation, in the identification of the solution. This touches on the point raised earlier, and alluded to by Vlastos, that the method of discovery and the method of proof are in principle coterminous. But denied such "logically primitive propositions, whose "binding' could no longer be derived by 
entailment from yet others", 50 it is likely that the slave boy would never have arrived at the solution. Precisely what these primitive propositions are, and how their disclosure is made possible through the transformation from an arithmetic to a geometric understanding of order, are issues that are fundamental to the development of scientific thought, a point that requires more detailed discussion than can be given here.

Critically, Plato's theory of Forms or Ideas, and the role of anamnesis in their disclosure, could be said to form a point of departure for Husserl's principle of geometry as heritage. What are construed by Plato as eternally valid truths, by virtue of our innate knowledge, becomes for Husserl a historical problem of language. Husserl asks how the "intra-subjective" structure of linguistics, as we see in the dialogue between Socrates and the slave boy (what Husserl calls "geometrical speech") is transformed into an objective structure that can be understood by all. In alluding to Plato's principle of recollection Husserl states:

To the passivity of what is at first obscurely awakened and what perhaps emerges with greater and greater clarity there belongs the possible activity of a recollection in which the past experiencing (Erleben) is lived through in a quasi-new and quasi-active way. ${ }^{51}$

Accordingly, the eternity of the Platonic Idea is, for Husserl, the product of historical repetition: "In the unity of the community of communication among several persons the repeatedly produced structure becomes an object of consciousness, not as a likeness, but as the one structure common to all." ${ }^{52}$ Therefore, the "logically primitive propositions" revealed by Platonic anamnesis are re-constituted in Husserl's argument as ideal structures that exist as historical entities.

This complex interplay between number, geometry and language relates back to the earliest traditions of Greek thought. For Ivan Ilich this tradition is rooted in a pre-literate culture in which "the ear was continuously seduced into collaboration with the eye". ${ }^{53}$ The advent of writing, however, led to letters being "considered as the elements of speech". This led some Greeks to turn "this symbolic alphabetization of utterance into a paradigm of the metaphysical constitution of the universe". ${ }^{54}$ It is for this reason that the "alphabetic analysis of speech" became analogous to the "philosophical analysis of being which came into existence hand-in-hand". ${ }^{55}$

When understood in the historical context of the Meno, Husserl's interpretation of geometry raises an interesting issue. Unlike most of the other works by Plato, the dialogue is dated at a time when it would seem likely that Plato was actually present at the conversation whose content he reconstructs from his own recollections. ${ }^{56}$ Moreover, as $\mathrm{A}$. E. Taylor points out, "the dialogue opens with an abruptness hardly to be paralleled elsewhere in the genuine work of Plato by the direct propounding of a theme for discussion; there are not even the ordinary formalities of salutation. " ${ }^{57}$ This suggests that Plato's account was not intended as a polished "reconstruction" of the event, appropriated by the formalities and protocols of the written dialogue. Rather, it would seem that Plato sought to 
convey as far as possible what actually took place - to reveal the essences of the utterances and actions of the dialogue as if they were happening for the first time. Husserl's argument of correlative thinking between geometry and language could provide a clue to understanding this aspect of the text. An important function of "written, documenting linguistic expression is that it makes communications possible without immediate or mediate personal address; it is, so to speak, communication become virtual". ${ }^{58}$ The shift from number (arithmetic) reckoning to geometric (mathematical) reasoning in the Meno, from an essentially oral mode of communication - in the Socratic tradition - to an inscriptive one, could be said to correlate with Plato's twofold role as passive witness and active recorder:

the writing down effects a transformation of the original mode of being of the meaning-structure ... within the geometrical sphere of selfevidence, of the geometrical structure which is put into words. It becomes sedimented, so to speak. But the reader can make it selfevident again, can reactivate the self-evidence. ${ }^{59}$

What is implied here is a correspondence between geometry and philosophical discourse, by which geometry constitutes the basis of an enquiry into the nature of things, and therefore philosophy. As an early work by Plato, the Meno highlights, therefore, a critical transition in philosophical thought that coincides with the emergence of a geometrical understanding of the cosmos.

We know that the Meno was known in the Renaissance. An almost unintelligible twelfth-century translation, by Henricus Aristippus of Sicily, came to the attention of Nicholas Cusanus in the fifteenth century. ${ }^{60}$ It was largely through his perseverance and scholarship that the work came into the public domain and provided the main source for later Neo-Platonists and humanists. It is conceivable, as I will explain later, that Cusanus' version of the Meno influenced the composition of Leonardo da Vinci's famous fresco, The Last Supper (Cenacolo).

The complex inter-play between written and spoken language, number and geometry in Greek thought allowed ideas and beliefs to be transmitted freely without the divisions that dominate modern thought. The shift, however, from number-reckoning to geometric reasoning, and their respective oral and written correlatives, contributed to a way of thinking that set in place the foundations for an epistemological understanding of the world, as exemplified in the philosophy of René Descartes. Critical to this transition is the role of writing as a memory device which we shall examine in more detail in Chapter 3. Socrates distrusted the act of writing, as we see in Plato's Phaedrus, since it undermines the "inner writing" that constitutes oral memory:

For this invention will produce forgetfulness in the minds of those who learn to use it, because they will not practise their memory. Their trust in writing, produced by external characters which are not part of themselves will discourage the use of their own memory within them. You have invented an elixir not of memory but of reminding. ${ }^{61}$ 
Hence, as both an "impromptu" written account of a dialogue and an explication of anamnesis through geometry, the Meno serves as a testimony to the internal conflicts that underlie philosophical discourse.

\section{The Timaeus}

As one of the most studied of Plato's works, the Timaeus is also the most complete formulation of cosmology from the classical world. The work, however, is not a treatise on astronomy, as some have argued, but rather a myth of creation. As such it is a theological meditation on an unchanging and eternal world, a world that emanates from what Plato believed to be a World-Soul that is made as "a likeness (eikōn) of what is accessible to reason". ${ }^{62}$ As embodiments of the Cosmic order, number and geometry provide the principal mechanisms for making this harmonic system intelligible and meaningful.

Plato introduces for the first time in Greek philosophy the idea of a single creative being, the Demiurge. In spite, however, of claims by some NeoPlatonists and theologians, the Timaeus is clearly not the work of a monotheist. ${ }^{63}$ Instead, implicit in Plato's model of an inter-related world of Being and Becoming - the World-Soul and the Cosmos - there emerge two distinct (yet not irreconcilable) orders of existence: the intelligible/permanent and its changing visible copy ${ }^{64}$ By bringing these modes of order into a single cosmological system, Plato has effectively reconciled two traditionally opposed views of Greek thought: the Parmenidean notion of the ungenerated and indestructible order of Being and the Heraclitan principle of universal flux. ${ }^{65}$ The former identifies an unbridgeable gap between being and seeming whilst the latter asserts that change permeates the cosmos.

Creation in Platonic cosmology does not occur in a vacuum, in empty space, but rather in the Receptacle (eidola), or place, of permanent being. John Sallis argues that in the transformation from the intelligible to the visible, "something like place came into play, letting things be set apart as they are gathered into the comprehensive visible cosmos". ${ }^{66}$ This process leads to an important conclusion: "what distinguishes the kind of inclusion characteristic of the visible cosmos is that, unlike intelligible inclusion, it holds together in an extended place beings that, with respect to one another, are in different places within this comprehensive place." 67

The Receptacle is not a metaphysical container or "womb", out of which things are conceived. Rather it constitutes what Plato strangely describes as a "nurse" of Becoming, where "qualities appear, as fleeting images are seen in a mirror" ${ }^{68}$ This raises an important question that has preoccupied scholars: Did Plato construe form and space as synonymous? If this were the case then it could be argued that "the same thing will be container and content, and Being will become two things; place and body; for the container is place and the contained, body". ${ }^{69}$ Plato, however, would have considered such an argument absurd since the result would leave Being as unlimited and therefore nowhere. Nevertheless, the Timaeus leaves the distinction somewhat open, stating in ambivalent terms that, "The Form is contrasted with Space in that the Form 'never receives 
anything else, into itself from elsewhere', and with the copy in that 'it never itself enters into anything else anywhere' ". ${ }^{70}$

In attempting to overcome the problem of mere coincidence of both, with the result of nothingness, Plato puts forward the following explanation: "Space [the Receptacle], as eternally self-existent, provides the copy with a 'room' or situation where it can 'somehow cling to existence ... and escape being nothing at all' ". ${ }^{71}$ As we shall see later, this idea of the self-existent Receptacle, conceiving a "room" or situation through its copy, was to underlie Renaissance perspectival views of space.

The shift from chaos to order in the Platonic Receptacle requires an appropriate proportioning of the four characters that make up the spatial ether - of fire, air, water and earth - whose fleeting qualities (hot, cold, moist and dry) give measure to the nascent cosmos. Through the binding of these qualities, which Plato understood in terms of "bonds" that are formed by geometrical proportions, the Demiurge constructs the body of the cosmos. ${ }^{72}$ Plato identifies in this process three states or conditions: Being, Sameness and Difference. These delimit the particular "blendings" of the qualities. ${ }^{73}$ In one sense, these three states draw upon the Pythagorean understanding of numbers as constituents of the physical universe. Indeed, one of the connotations of the tetractys $(1+2+3+4=10)$ is its correspondence with the development from a point (1), to a line (defined by two

2.6

Demonstration of how polyhedra are generated from triangles.

Christian Schessler,

Demonstrationes mathematicae oder Untersuchung derer mathematischen warheit (Dresden, 1698), p. 28

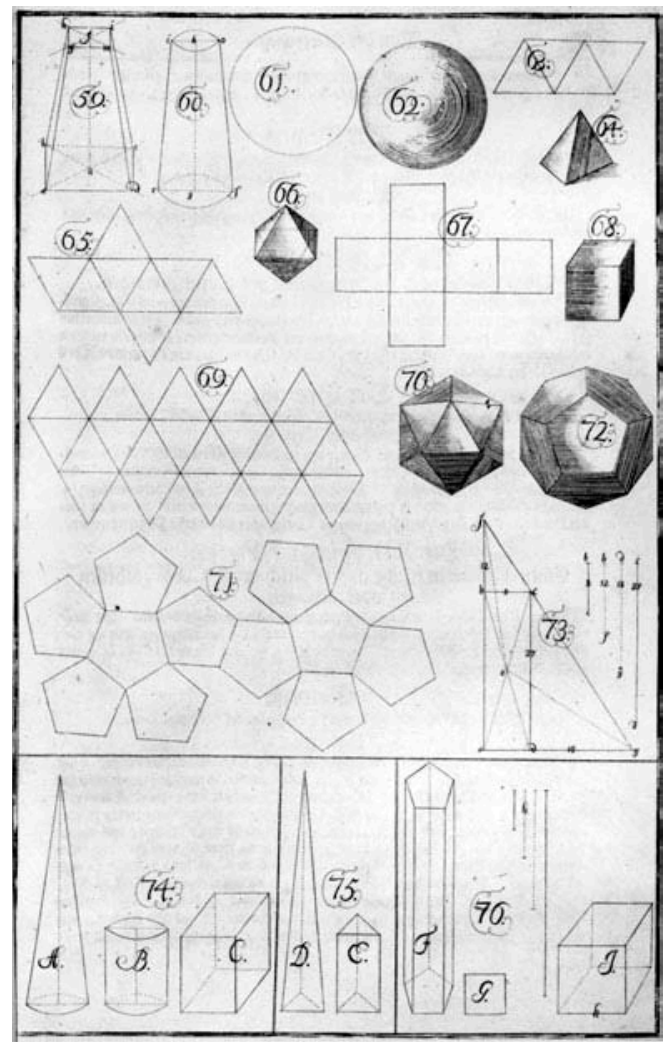




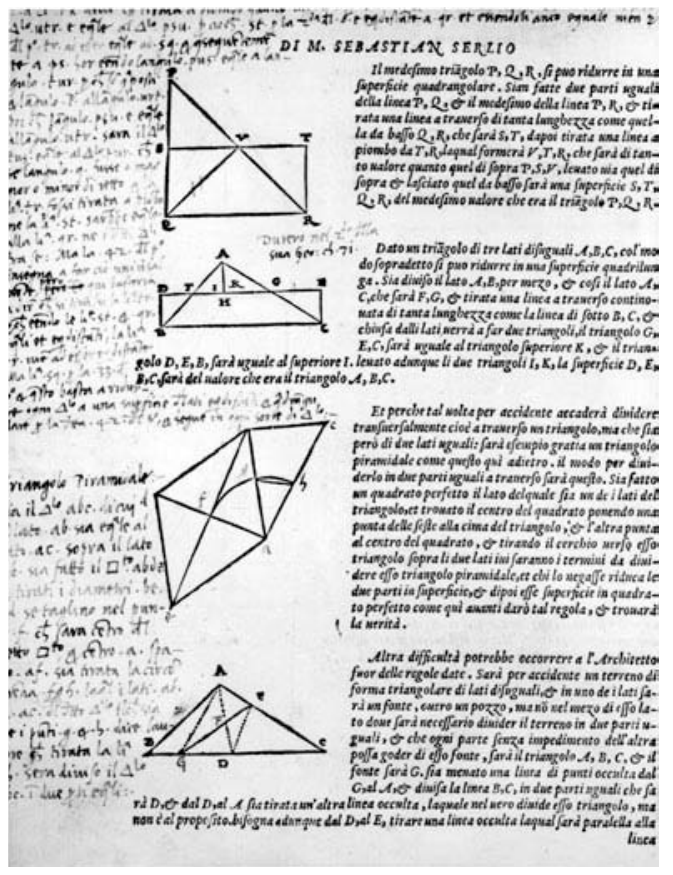

Theory of triangles and pyramids, with supporting marginalia. Sebastiano Serlio (1475-1554), Tutte l'opere s'architettura ... (Venice, 1566), bk 1, p. 6v

points) to a plane (defined by three points). This correspondence, however, departs from Pythagoras' principle of the substantial and physical nature of whole numbers.

Plato's idea of the Demiurge composing the soul, through the gathering of the three elements into unity, was enthusiastically endorsed by Christian commentators who equated the triune principle of the mean with the Trinity. This gave support to the idea, advanced by theologians and Neo-Platonists, of the prophetic nature of the Timaeus. Elevated to the status of an "Attic Moses", Plato was seen, by many Christian thinkers, as one of the key figures in the establishment of a prisca theologia (ancient theology) that foreshadowed Christian theology. ${ }^{74}$

The significance of 3 in Platonic cosmology is highlighted by the way the four primary bodies of the cosmos, the pyramid (tetrahedron), the octahedron, the icosahedron and the cube, come into being. Each are composed of triangles, the cube from the 45 degree isosceles $(\sqrt{2})$, and the other three solids from the equilateral triangle $(\sqrt{3})$. These triangles, as Cornford points out, "are taken as the two irreducible 'elements' for the construction of all the four solids": ${ }^{75}$

Depth ... must be bounded by surface; and every surface that is rectilinear is composed of triangles.... If planes can be constructed of triangles, triangles ... can be constructed of lines, and lines can be expressed as numbers. ${ }^{76}$

In the Timaeus we see Plato's cosmology emerging through a series of geometric transformations in which the equilateral triangle constitutes the universal element of fire, water and air whilst the square is the element of earth. ${ }^{77}$ 
The primacy of the triangle in Platonic cosmology can clearly be traced back to the Pythagorean tetractys. Whilst 3 in Platonic cosmology delineates the number of "bonds" or "blendings" of cosmic elements, 4 affirms completion of the cosmic order as expressed in the four seasons, the four elements, the four cardinal points and the four Empedoclean "roots". ${ }^{78}$ Plato uses the mystical numbers of the tetractys to develop the so-called "double tetractys", or lambda. This is based on two numerical progressions, the first even and starting with 2 and the second odd and commencing with $3 .^{79}$ Both number series, moreover, conclude with the third power since the "cube" symbolises the third dimension of all bodies. Finally, the numerically greatest of the numbers in this combined sequence, 27 , is equal to the sum of all the numbers $(27=1+2+3+4+8+9)$ in the lambda, reinforcing the Pythagorean reverence for closed arithmetic systems.

A point of contention in the relation between Pythagorean numerology and Platonic cosmology concerns the issue of whether musical harmony - as it pertains to the numerical ratios of the tetractys - continued to inform Plato's new geometric order. For Cornford, the interpretation of number in the Timaeus, "with the functions of the soul as a bond holding the world's body together", departs from Pythagoras' limited system of arithmetic ratios made audible by the plucked string. ${ }^{80}$ Instead of constructing a scale that can be sung, Plato was seeking to compose what Cornford describes as an "unheard melody". ${ }^{81}$ Sallis, however, challenges this view by arguing that musical harmony, whilst not made explicit in the Timaeus, pervades Platonic cosmology and underpins the configuration of the lambda. ${ }^{82}$ At the risk of oversimplifying the issue I would argue that implicit in Plato's Timaeus is the idea of the cosmos of geometrical relationships as "registering" the eternity of the music of the spheres. This metaphysical recording, moreover, is the result of an always pre-existing knowledge that is recollected and therefore does not require human audibility for its communication.

In moving between the realms of the visible and the invisible, the corporeal and incorporeal, geometric forms functioned in Platonic thought as objects of contemplation that disclose a pre-ordained metaphysical order. This

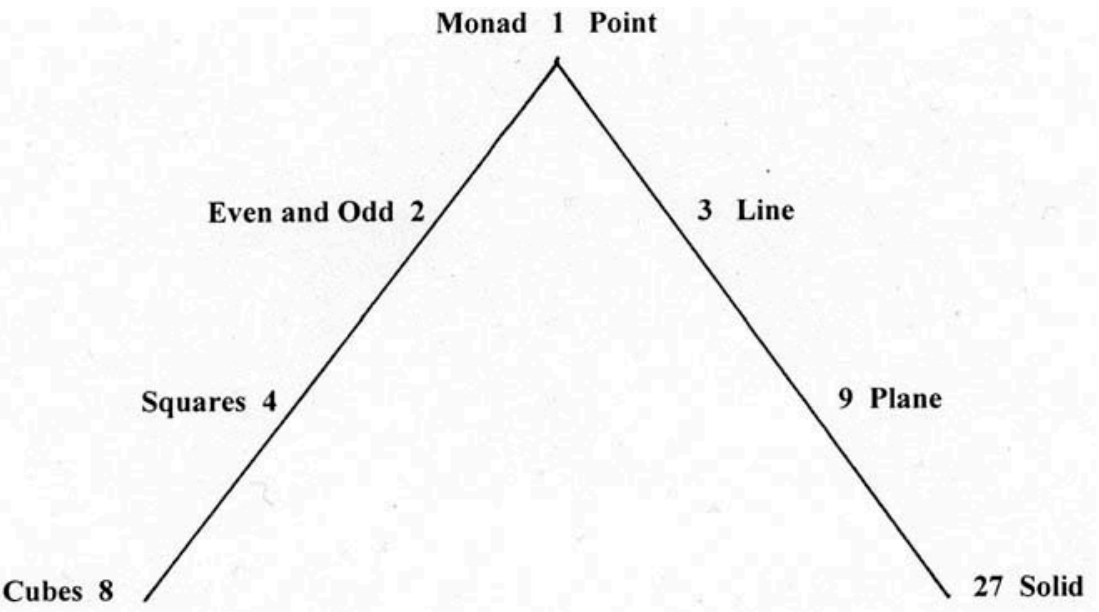


understanding of geometry was to have a particular bearing on Renaissance views of order, particularly as they pertain to perspectiva artificialis. On the one hand geometry re-affirmed a heritage of revealed truth that disseminated from earliest times, and on the other constituted a body of eternal Forms that could be recollected. This twofold meaning, as we will see in the context of Raphael's School of Athens, was made possible by a combination of a revived interest in NeoPlatonism and by a new historical view of the past.

The Timaeus provided one of the keys to this continuity. The text was widely read and studied in the fifteenth and sixteenth centuries, thanks to the availability of Cicero's part translation and the famous commentary by lamblichus. ${ }^{83}$ It was, however, Leonardo Bruni's modern translation of the Timaeus, dated 1440, that provided the standard reference in humanist circles. ${ }^{84}$

\section{Ad triangulum versus ad quadratum}

The emergence of a theory of architecture in the Renaissance was informed by a less than clear relationship between Pythagorean number and Euclidean geometry. Michele Sbacchi argues for a polarity between both since their respective standpoints derive from two ostensibly irreconcilable texts: Plato's Timaeus and Euclid's Elements. ${ }^{85}$ Sbacchi argues that this dichotomy can be traced back to the "epistemological difference between number and geometry" revealed in the Meno. ${ }^{86}$ Whilst Leon Battista Alberti dealt with geometry in his minor work, the Ludi Mathematici, the absence of any direct reference to Euclidean methods in his De Re Aedificatoria suggests, according to Sbacchi, the primacy of numerical ratios over geometrical relationships in architectural theory and practice during the Quattrocento. ${ }^{87}$

This interpretation would seem to be borne out in Vitruvius' application of Pythagorean principles to architecture in Book IX. Indeed, Vitruvius provides, in his examination of architectural proportions, a summary of the Meno dialogue between Socrates and the slave boy. Whilst, however, his reference to Socrates' "geometrical demonstration" could be construed as an attempt to overcome the problem of incommensurables, Vitruvius adheres to the principle of whole number ratios in the definition of architectural order. His account, moreover, in Book IX became a standard reference in Renaissance treatises, serving as a reminder of the absolute and unquestioned authority of Pythagorean/Platonic cosmology in the understanding of architecture in the fifteenth and sixteenth centuries.

Rudolf Wittkower underlines this emphasis on Pythagorean/Platonic tradition by asserting that whilst the Middle Ages largely favoured Euclidean geometry, the Renaissance had a closer affinity to the "arithmetic side of the tradition". ${ }^{88}$ Wittkower's argument, however, is criticised by Richard Padovan who considers it as too biased towards the proportional systems of whole number ratios. ${ }^{89}$ This is in view of the fact that both Alberti and Palladio used irrational numbers in their work. In discussing, in his De Re Aedificatoria, musical ratios Alberti openly acknowledges the usefulness of "certain natural relationships that cannot be defined by numbers, but that may be obtained through roots and powers". ${ }^{90}$ The issue, moreover, is further complicated by Sbacchi's suggestion 
that "[Alberti's] emphasis on lineamenta (lineaments) and lines, never fully understood, could be an acknowledgement of a building practice leaning more toward geometry than toward numerology." 91

This last point clearly casts doubt on Sbacchi's earlier assertion of an irreconcilable relationship between discrete units of measure in numerical proportions and geometrical extension in the Renaissance. Indeed, the role of lineaments in Alberti's theory of architecture raises questions about the relationship between both traditions. This relationship, as I will seek to demonstrate, was informed by a more general proclivity towards synthesis in the Renaissance, by which ad quadratum and ad triangulum operate at the level of "double-functioning". Leo Steinberg calls this process "duplexity" which he applies to the perspective construct of Leonardo da Vinci's Last Supper, a topic for later discussion. ${ }^{92}$ In this idea, geometry and number are conceived not as competing systems but rather as expressions of the same unified cosmological order, albeit revealed through different modes of understanding. The connection between both, moreover, is based less on rational argument and more on a faith in an inter-related world in which both number and geometry are divine in nature.

The idea of "duplexity" could also be said to underlie Lionel March's interpretation of incommensurables in Alberti's architecture, and their relationship to lineaments. March explores this in the context of the plan of the church of San Sebastiano in Mantua. Challenging the idea that lineaments merely define the physical layout of buildings, March constructs through "mental" lines what he calls the "eidetic mesh". ${ }^{93}$ These lines are laid out in accordance with certain proportional relationships that he argues are based on the Pythagorean 20-21-29 right triangle. In this configuration March believes that Alberti was seeking to fuse the irrationals of the ad triangulum with the whole number ratios of ad quadratum, arguing that "Worldmaking requires more than the geometry of the square." 94 Accordingly:

The éíos [eidetic image] is impregnated with ad triangulum relationships. Alberti has achieved one of the classic unions: the contrary traits of square and triangle brought into harmony: in his terms the diagonals of the God-evoking cube. ${ }^{95}$

The search for a method of ordering space, by which number and geometry can be brought into harmonious dialogue, also informed developments in perspective during the Renaissance. This can be seen for example in Leonardo's application of harmonic proportions to the perspective field. In this approach Leonardo sought to reconcile the ideal "objective" model of the cosmos, as it is configured in numerical terms, with the notion of a place of divine "otherness" in perspective. This is partly reiterated in Brunelleschi's experiments in perspective which "saw no contradiction between objective proportions and subjective [optical] impressions of a building". ${ }^{96}$ From this inference of continuity between subjective and objective fields, Padovan draws the conclusion that "the key to the Renaissance discovery of systematic laws of perspective was that these laws are themselves 
ruled by proportion. The proportions that Renaissance architects applied to the measures of their buildings were seen in perspective." 97

But such an argument should not allow us to assume that the understanding of the proportional relationships in the spaces of actual buildings were considered in the Renaissance to be directly commensurate with those of a perspective representation of a sacred event. The illusory space of the fresco was often conceived as a means of symbolically transforming the physical surroundings rather than merely visually replicating them. This appropriation, moreover, may explain why representations of architectural ensembles in many Renaissance paintings have been found to be unrealisable as actual buildings. ${ }^{98}$

It would be easy to explain this difference between pictorial perspective and the perspective "effect" of actual buildings on the basis of the necessary adjustments in the former to achieve the most desired optical effect. But such technical considerations were never made in isolation since they were always informed by symbolic concerns. Indeed, implicit in the symbolism of perspective is the "presence" of an ideal (or sacred) domain, a domain, however, that is not directly accessible to the observer but one which can nevertheless be open to dialogue and veneration. To this extent, Renaissance perspective, by virtue of its removal from everyday praxis, could be understood as informing by example the way the "lesser" situations of actual human events can achieve degrees of proximity to sacred space. This essentially ontological dimension of perspective, that derives in part from the cosmological meanings of geometry and number, effectively puts in parenthesis the argument of an exclusively epistemological function to Renaissance perspective. It is my contention that such a symbolic understanding lies at the heart of Leonardo's thinking of perspectiva artificialis and served as the basis for the iconography of both his Last Supper and later Raphael's School of Athens.

\section{Triangulating perspective}

Internal to the perspective field - and implicit in its symbolic meaning - is the heritage of geometry as a mediating device between physical and metaphysical realms. It is within this symbolic realm that questions of continuity between Greek cosmology and Christian theology find their most fertile ground. This finds expression as a symbolic transmission from Pythagorean/Platonic cosmology, through Euclidean geometry, and finally to perspectiva artificialis; from a realm of cosmological entities - revealed in the constellation of heavenly bodies - to a geometrically ordered point of view.

I would like to explore this idea by first examining Leonardo's Last Supper in Santa Maria delle Grazie in Milan. In his recent study of the fresco, Leo Steinberg explores the relation between surface and depth in the fresco's iconography:

Begin by asking whether a Renaissance painting is read as an arrangement mapped on the picture plane or, following its illusionistic directions, in depth. If we let both readings stand, we may find Christ's right hand doubly transitive, claiming both the dish and the glass. ${ }^{99}$ 
2.9

\section{Last Supper, Leonardo da Vinci (1452-1519).}

Milan, Church of Santa Maria delle Grazie
The ambiguity of this gesture relates to a much debated issue in art-historical scholarship: was the Last Supper intended to represent Christ announcing to the apostles the imminent betrayal by one of the assembled - thereby foreshadowing his crucifixion - or does the work show the Saviour in the act of disclosing the numinous (other-worldly) properties of the wine and bread as his blood and body respectively? Steinberg makes a strong case for a compound gesture, by which the dramatic (betrayal) and the sacramental (Eucharistic) converge on Christ's right hand which is situated at the intersection between "orthogonal and traversal directives". ${ }^{100}$ At this junction the traversal reveals imminent betrayal by the hand's "leftward motion, collineate with the table, [that] runs past John's hyphening clasp - to the sinistra of Judas". ${ }^{101}$ Hence, Christ's right-hand traversal is balanced by Judas' left-hand gesture, both extending out towards the "treason dish" that anticipates Pontius Pilate's renunciatory ablution. This traversal in turn intersects the "orthogonal that descends from the centric point of the picture (at Christ's right temple) through the shoulder and arm down to the wine". ${ }^{102}$ Hence, "Surcharged by the context, [Christ's right hand] forms the pivot wherein the twofold event of this supper coincides with the given duplexity of perspective". ${ }^{103}$

Steinberg's penetrating analysis of the fresco has a special significance in this study since it reveals a particular understanding of the relationship between

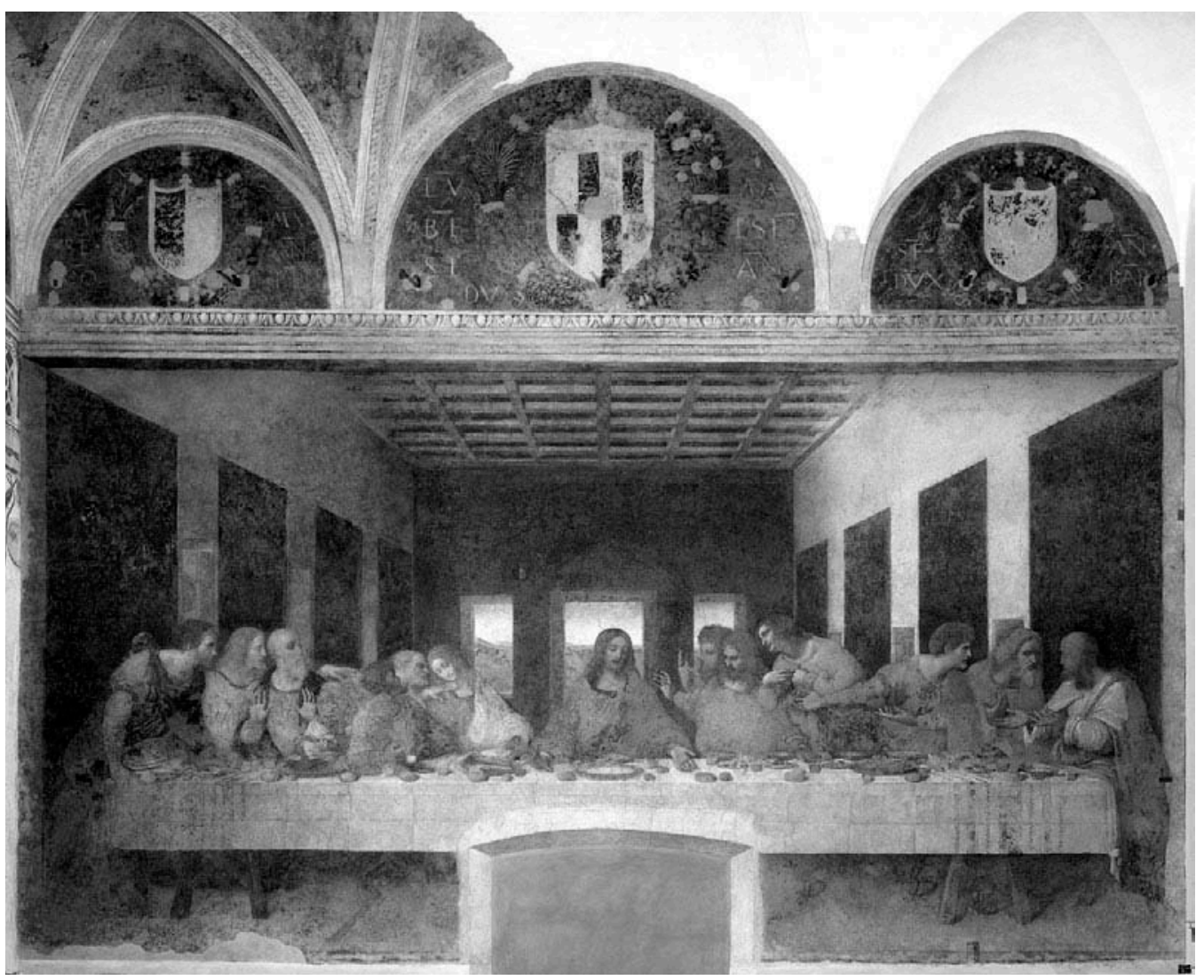


Platonic geometry and perspective in the late Quattrocento. It suggests the existence of correlative thinking between the notion of surface (traversal) - constitutive of Christ's humanity (Betrayal/Passion) - and of depth (orthogonality) that is revelatory of the Saviour's immortality (Eucharist). This is made legible by the outline configuration of Christ in the Cenacolo that "generates" the whole perspective construct. Christ's extended and splayed arms, that hover above the horizontal plain of the table, delineate two sides of an equilateral triangle or, when construed three-dimensionally, delimit the volume of a tetrahedron. Christ's head crowns the apex of this pyramid, whose location is coterminous with the vanishing point of the fresco. This configuration also informs what transpires as a trapezoidal, rather than orthogonal, layout of the painted chamber of the Last Supper. Steinberg describes this illusory effect as "a perfect rectangular construct driven toward triangularity, but driven to it as to another perfection". ${ }^{104}$ Hence, the equilateral triangle defined by Christ's body, that also constitutes the elemental generator of Platonic solids, is appropriated in da Vinci's Last Supper by the triune symbolism of Christ's incarnation. The metamorphic effect created by the transformation from two-dimensional geometry to three-dimensional projective geometry invokes the idea of the Timaean Receptacle as "bearer" of an emergent or nascent space.

Implicit in the matrix of subdivided walls, ceiling and floor in the perspective construct of the Last Supper, along with the subdivisions of the retinue of Apostles into distinct groups of three, is an acknowledgement of Pythagorean ratios within the then prevailing tradition of Medieval numerology. Quite how this handling of numbers informs the perspective is suggested by Leonardo's application of harmonic proportions to the checkerboard floor of Alberti's perspectiva artificialis referred to earlier. This application formed part of a larger theory of reality as Martin Kemp describes:

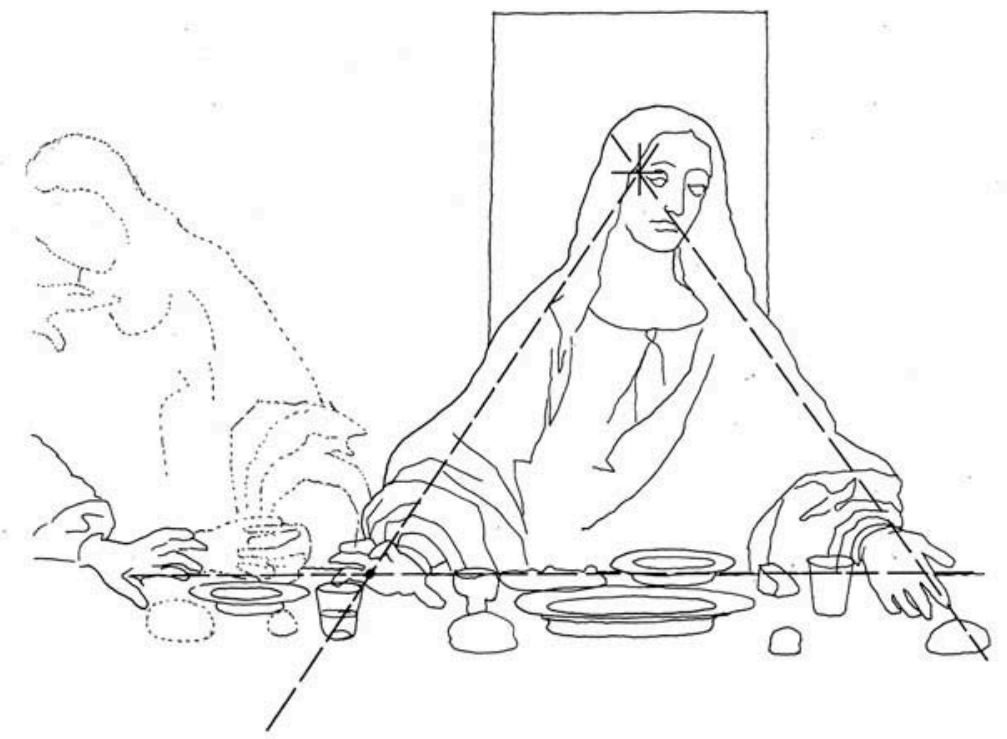

2.10

Christ inscribed in the equilateral triangle. Taken from Leonardo da Vinci's Last Supper. Drawn by the author after Steinberg 
the apparent diversities of nature are symptoms of an inner unity, a unity dependent on something like a "unified field theory" that reaches out to explain the functioning of everything in the observable world. For Leonardo, this unified theory relied upon the proportional (geometric) action of every power in the world and explained the design of everything.... Proportional theory explains why things look smaller as they become more distant; why the twigs of a tree are narrower than the branches (and in what ratio); why shadow becomes weaker the further it is from the object casting it. ${ }^{105}$

Like the concentric ripples of water emanating from a pebble thrown into a pond, the pyramid of vision similarly imparts proportional - gnomic - enlargement from unity to multiplicity. Leonardo argued that "the power of the emanations from the object - he called them 'species', in line with the medieval tradition of optical science - diminished proportionately the further they are detached from the object." 106

In the case of the Last Supper the calibration of depth takes on a more complex system of numerical ratios. These oscillate between the background perspective armature (chamber) and the inhabited space (disposition of apostles). As Steinberg states: "The task, never before attempted, was to collect in 'conjoint presence' a superdozen male sitters ... to convert the drag of enumeration into what [Leonardo] called a 'harmonic total effect' ". ${ }^{107}$ To this end, number and perspective conflate within this distended space.

The "harmonic total effect" is not conveyed, as one might expect, as a seamless extension of the actual space of the refectory but rather deviates in a fashion that can only reinforce the idea of alterity. ${ }^{108}$ Described by Steinberg as a

2.11

Perspective view of the Last Supper in relation to Refectory. Drawn by the author after Steinberg

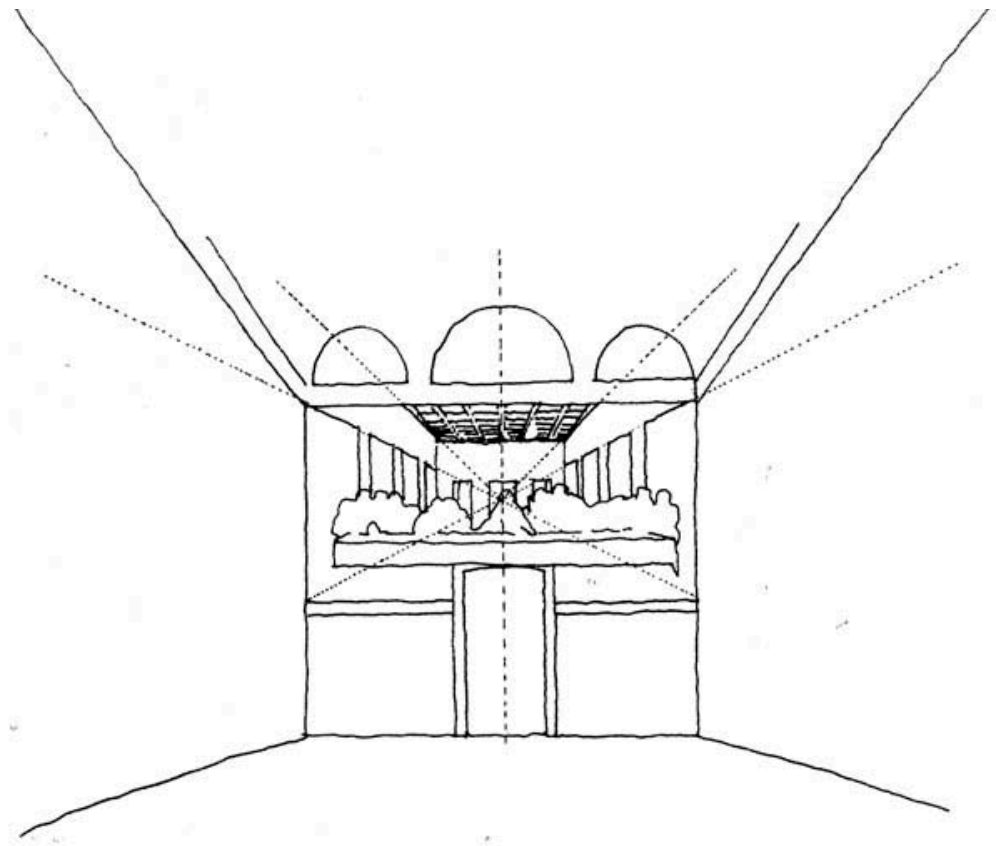


warping into otherness, this transformation is made explicit by the fact that the fresco is located in an elevated position in relation to the refectory, thereby creating the effect of aloofness from the everyday rituals and activities of the actual space below. Steinberg believes that Leonardo sought to register pictorially the discrepancy between "the form as perspectival projection and the same form in visual experience". ${ }^{109}$ In identifying the discrepency between the perspectival diminution of the painted tapestries in the fresco and the frieze decoration of the refectory, that runs along the side walls under the lateral vaulting, Steinberg provocatively states that the two systems "refract like a stick dunked in water, so that the perspectives of the real and the depicted walls disagree". ${ }^{110}$

When understood in the larger setting of the Last Supper this effect of refraction, at the interface between illusory chamber and actual refectory, takes on a surprising topographical significance:

Begin at the Last Supper wall of the refectory. A line sprung from its midpoint - produced at the angle of Christ's left arm crossing the table - reveals a surprising connection: clearing the porta antica and traversing the Chiostro dei Morti, this rectilinear course, running south-east at 45 degrees, homes in on the midpoint of Bramante's tribuna, the church's domed crossing. Or reversing the sequence, the centerpoint of the dome is located to lie on one straight diagonal with the refectory entrance and the midpoint of the Last Supper wall - the point whence Leonardo's Christ initiates that commanding axis by the fiat of his left hand. In other words, the direction of Christ's life-giving motion defines the dome's radius. ${ }^{111}$

In Steinberg's analysis of this topographical relationship we become aware of the "refraction" taking place between the 30 degree line that is defined by the left arm of Christ, and subtending from the vertical axis of the equilateral triangle framing the Saviour's body, and the 45 degree topographical line that terminates at the tribuna of the church. Observing this latter diagonal line between mural and dome, whose passage is pre-defined by the porta antica, the square cloister and the tribuna, one is struck by the way in which it reaffirms the larger square configuration of the monastery. As if echoing the geometric problem posed by Socrates in the Meno, in which the philosopher brings the diagonal (unutterable) to the attention of the slave boy, the diagonal that traverses the plan of the monastery could be said to embody the whole symbolic order of the complex. What can be understood in terms of whole numbers - as the dimensions of the other two sides of the 45 degree triangle (that delineate the actual ceremonial axes between basilica and refectory) - delimit the invisible and irrational magnitude of the diagonal that defines the sacred axis between the human Christ (Last Supper) and his divinity (Tribuna). The symbolic significance of the square in this instance has a certain Cusanian connotation - the infinite (irrational) inscribed in the finite (whole numbers of the four sides) - a point that may conceivably have been the result of an influence of Cusanus' interpretation of the Meno on Leonardo's fresco, referred to earlier. ${ }^{112}$ 
2.12

Plan of the fifteenth century complex of Sta. Maria delle Grazie, Milan, showing diagonal relationship between Leonardo da Vinci's Last Supper in the Refectory and the Tribuna of the Basilica by Donato Bramante. Drawn by the author after Steinberg

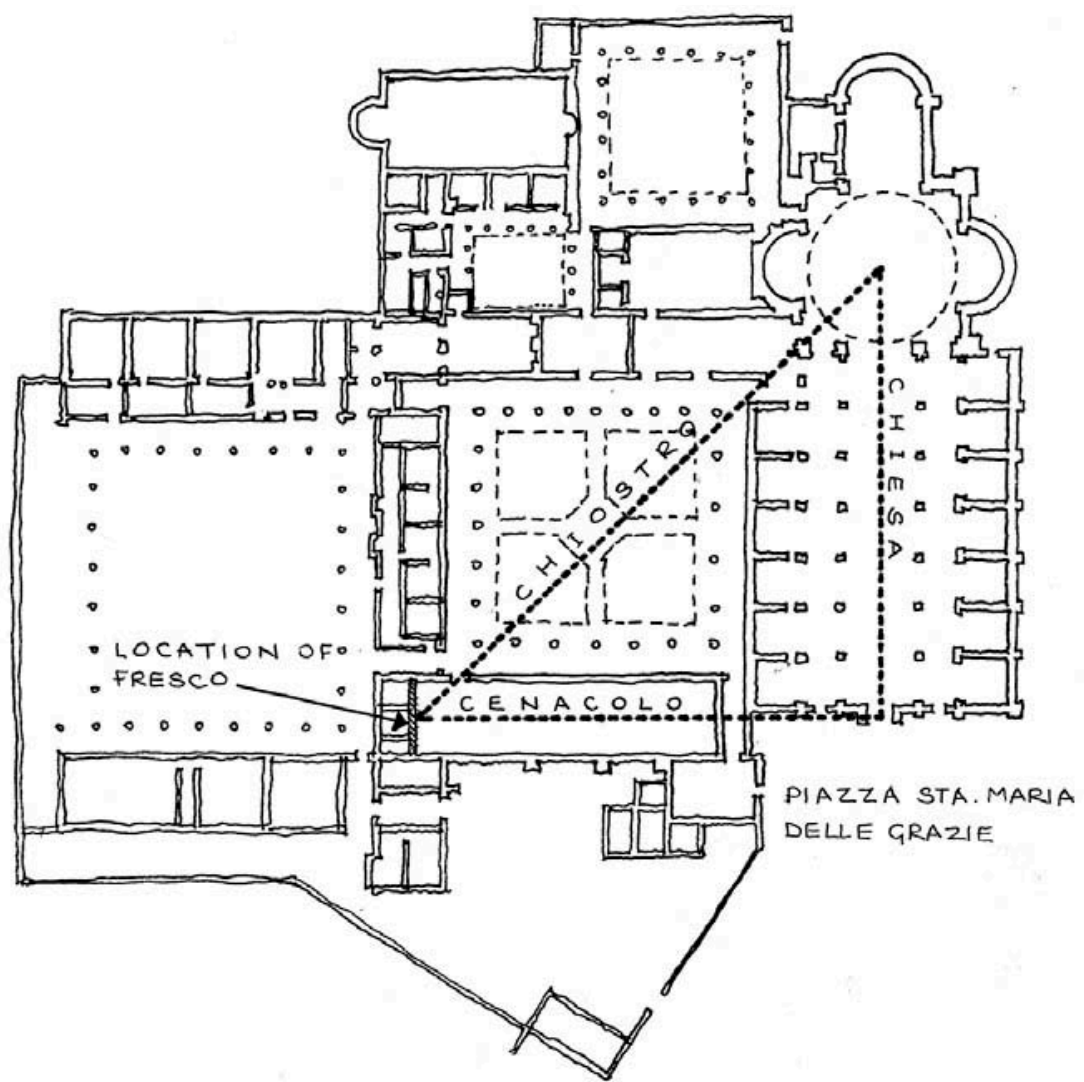

Clearly, Leonardo identified in the timeless setting of the Last Supperpoised at the intersection between traversal and orthogonal, the sacramental and the dramatic - a paradigm in which the liturgical and symbolic axes of the actual spaces of the monastery could be situated. This reinforces Steinberg's argument, outlined earlier, of a "warping to nothingness", in the dialogue between the perspective lines of the fresco and the perspective effect of the refectory. This deviating relationship between actual and illusory space was almost certainly informed by Christian/Neo-Platonic notions of emanation. Of particular interest here is Alberti's "visual geometry" in which he states (in his "Ludi matematici") that in the act of seeing the painter like the surveyor "makes triangles". ${ }^{113}$ This ocular process of triangulation underlies Alberti's perspectiva artificialis which strictly adheres to the Euclidean principle that all lines of sight are conceived either as parallel or at right angles to one another. As Alberti states in his della Pittura:

The parts of the visual triangle are the angles and the rays, which in proportional quantities will be equal, and in non-proportional quantities unequal ... You have seen how any lesser triangle may be proportional to a greater, and remember that the visual pyramid is made up of triangles. So all we have said about triangles may be transferred to the pyramid. ${ }^{114}$ 
The primacy of the triangle in Alberti's perspective has obvious Platonic connotations. In particular his reference to the idea of triangles as constituent parts of the visual pyramid was clearly an allusion to the Timaean principle of the triangle as an element of the cosmic order. Alberti's adherence to these geometries in his della Pittura - even when they seem questionable or unnecessary - is observed by Kemp:

It is this human mean or measure that [Alberti] uses when he begins to provide directions for the construction of perspectival space, though he nowhere explains why the properties of the pyramid result in the reciprocal geometry of his pictorial construction. ${ }^{115}$

This "reciprocal geometry" assumes a sustained dialogue between (ideal) pictorial and real space. By making such a relationship, however, Alberti was instigating an important transformation in which the metaphysical realm of the cosmic order is brought down to the level of human agency through perspective. Hence, what constitute eternal Ideas in Platonic cosmology are translated into a spatialtemporal matrix in Alberti's perspective.

By the seventeenth century, however, the connection between pyramids and vision loses much of the Platonic connotations and becomes more overtly instrumental and delusory. The anamorphic constructions, for example, in Jean Dubreuil's seventeenth-century treatise, La perspectiva practique - in which the pyramid is deployed as a mobile frame of reference - clearly demonstrate the reduction of Platonic geometry to the techniques of visual distortion. ${ }^{116}$

The equilateral and 45 degree isosceles triangles, that serve as the elemental constituents of the cosmos in Plato's Timaeus, acquire a special redemptive meaning in Leonardo's fresco. Intrinsic to this meaning, as I have already stressed, was a belief in the possibility of situating the eternal forms of Platonic geometry within the spatial-temporal realm of perspective. Leonardo evidently recognised the ease with which geometry can cross the boundaries between the "visible and the invisible, the corporeal and the incorporeal, the absolute and the contingent, the ideal and the real". ${ }^{117}$ However, the initiative was not straightforward but rather relied upon subtle, and sometimes complex, "corrections" to perspective conventions. In the Last Supper, the effect of refraction in the relation between fresco and refectory gives visual and spatial coherence to the duplexity of divinity and humanity in Christ. This double meaning could be said to provide a visual counterpart to Nicholas Cusanus' philosophical concept of the "coincident of opposites" to be discussed in Chapter 4. ${ }^{118}$ Indeed, Steinberg argues that these "abound in the [Last Supper]". ${ }^{119}$

\section{The School of Athens}

As we have already observed, to construe "measure" not from a qualitative point of view - of a largely finite and closed cosmology exemplified in classical ratio but rather as a quantitative calibration of an infinite perceptual field, was already anticipated in Renaissance perspective. Allied to this was the idea of an analogous 
2.13

The deployment of pyramids and cones in anamorphic projection Jean Dubreuil (1602-70), La perspectiva practique: necessaire a tons peintres, graveurs ... (Paris, 1647-51) (p. 122)

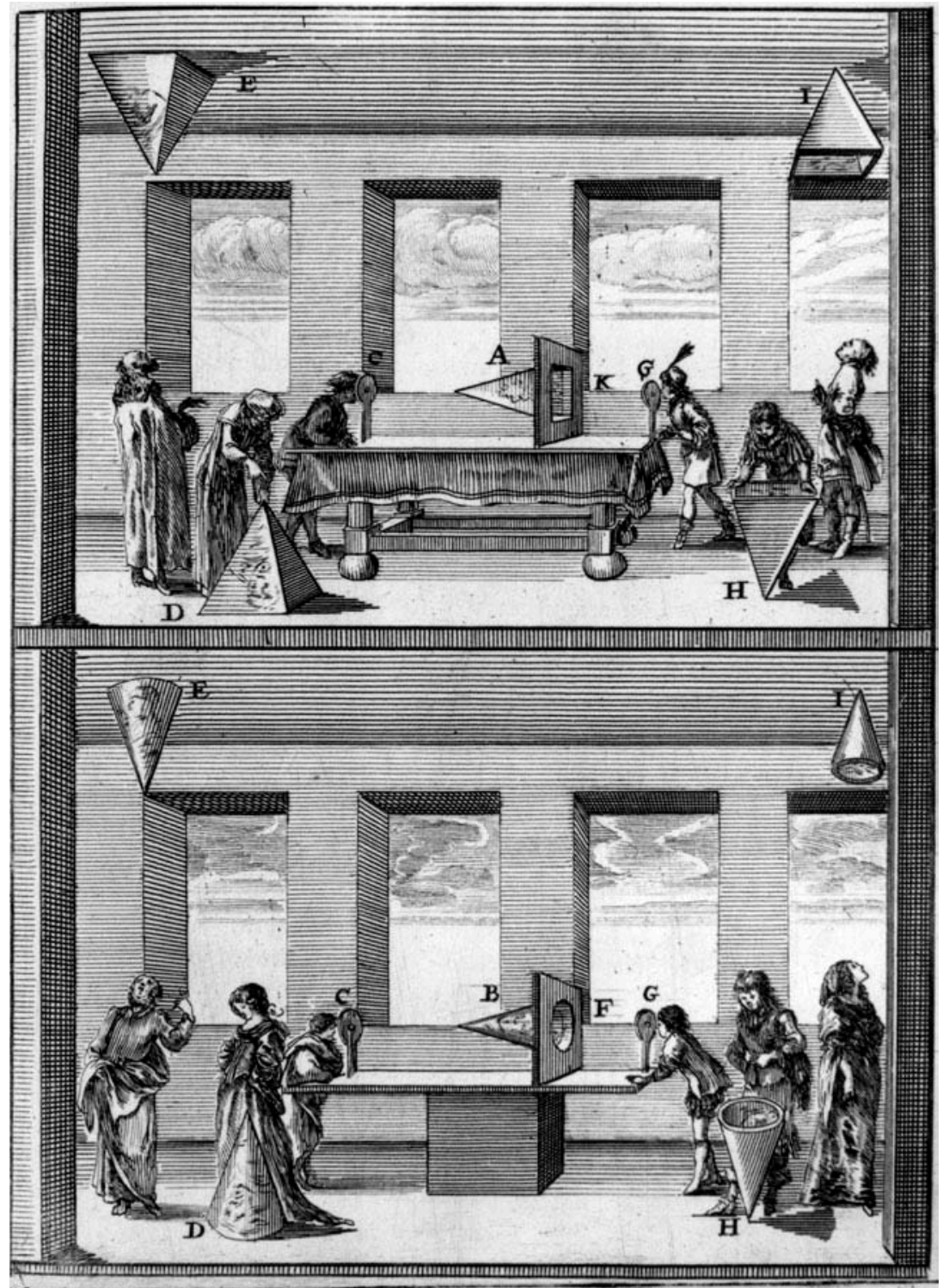

relationship between the new historical world-view of humanist and antiquarian thought and the implication of duration in the pictorial depth of perspectiva artificialis. ${ }^{120}$ Quite how this correlation was deployed in iconographic terms will be examined here in the context of Raphael's fresco, the School of Athens.

There are important differences between Leonardo's Last Supper and Raphael's School of Athens that should be noted. The former, as I have indicated, evokes the idea of a "transfiguration" of the ideal forms of Euclidean/Platonic geometry into the triune symbolism of the triangle that is situated within the spatial-temporal realm of perspective. With a different emphasis, the School of 
Athens conveys the principle of unity, not however through the metaphorical and symbolic nature of geometry as highlighted in the Last Supper, but rather in narrative terms as a process of "handing down" geometry as historical objects. This idea of an inherited tradition was underpinned by a particular historical perspective: the past, as it pertains to the three wisdom traditions of the Old Testament, GraecoRoman antiquity and the so-called prisca theologia, was believed to be youthful and therefore innocent. ${ }^{121}$ Contemporary existence on the other hand, by virtue of its historical remoteness from the harmonious and sinless aurea aetas, was presented by leading orators of the Renaissance (such as Girolamo Savonarola and Giles of Viterbo) as wretched and therefore in need of redemption. ${ }^{122}$ Hence, temporality becomes a "gauge" of human piety, whose paradigms of past deeds could be revived through the humanist rebirth of antiquity. Following, however, the Augustinian model of the twofold city, of civitas sanctas and civitas terenas, Renaissance views of redemption recognised the potential of humankind to rise above this historical decline by following a path to salvation.

The cycle of frescoes by Raphael in the Stanza della Segnatura was conceived with this redemptive view of history in mind. Located in the Papal Apartments in the Vatican - and executed during the Pontificate of Julius II - the room functioned as the private library of the Pope, hence the abundance of books represented in the frescoes. The School of Athens is located on the east wall of the stanza. Painted as part of an integrated iconographic programme, the fresco reveals to the observer a complex narrative of Greek philosophy and science that is represented in the form of an assembly of figures set in a monumental architectural context.

In a similar manner to the duplexity of Leonardo's earlier Last Supper, with its simultaneous evocation of Christ's passion and betrayal, the iconography

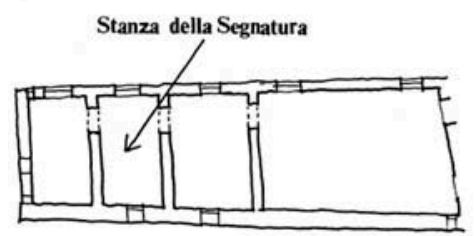

PAPAL APARTMENTS

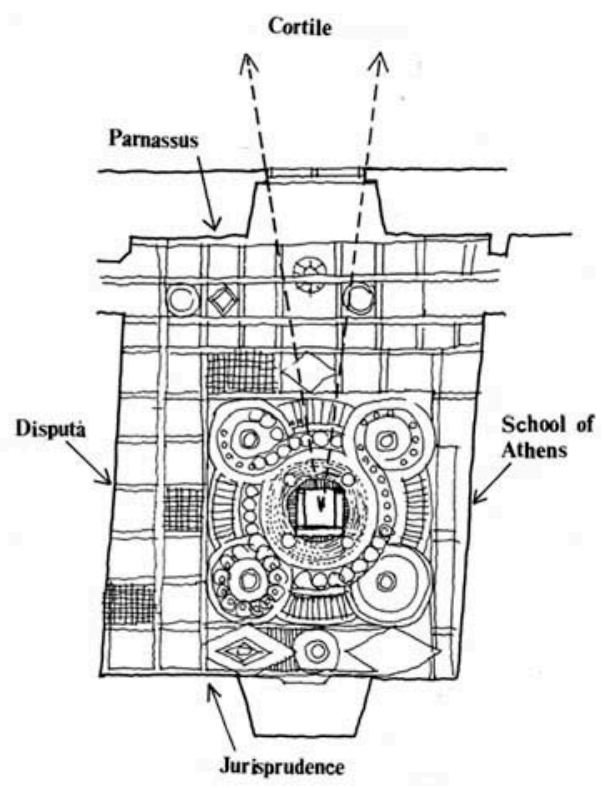

2.14

Plan layout of Julius II's Papal Apartments indicating location of the Stanza della Segnatura in the Papal Apartments, the locations of frescoes in the Stanza and the possible position of the papal seat on the Cosmatesque paving. Drawn by author after a reconstruction of the floor pattern by John Talman (1710-15) 
2.15

School of Athens,

Raphael

(1483-1520).

Vatican, Stanza

della Segnatura of Raphael's School of Athens also conveys a twofold message. This centres around the pairing of Aristotle and Plato, both occupying centre-stage of the fresco. From their respective philosophical positions - of sensus and spiritus - disseminate the retinue of philosophers who populate the surrounding space. The portrayal of an irreconcilable relationship between Aristotelian and Platonic thought would have been alien to Renaissance sensibilities. Humanists and NeoPlatonists of the fifteenth and sixteenth centuries generally believed in some shared order that could be communicated by textual and visual means. This idea was recently taken up by Christiane Joost-Gaugier in the context of the School of Athens. ${ }^{123} \mathrm{He}$ asserts that Raphael had intended to convey a "balancing of opposites" between Plato and Aristotle, given that the philosophers "share an absolutely equal status in the composition". ${ }^{124}$ Such an argument would seem to be supported by Cusanus, who believed in a synthesis between both "princes of philosophy", and Pico della Mirandola who claimed in his De ente et uno that the unity of both philosophers could be compared to the unity of God. ${ }^{125}$

Like other great Renaissance frescoes the School of Athens can be interpreted at many levels, whose meanings depend upon one's conversancy with - and understanding of - the iconographic material. For the sake of brevity, I will examine only those aspects of the fresco that are directly relevant to the theme of this investigation, namely the symbolic relationship between number, geometry

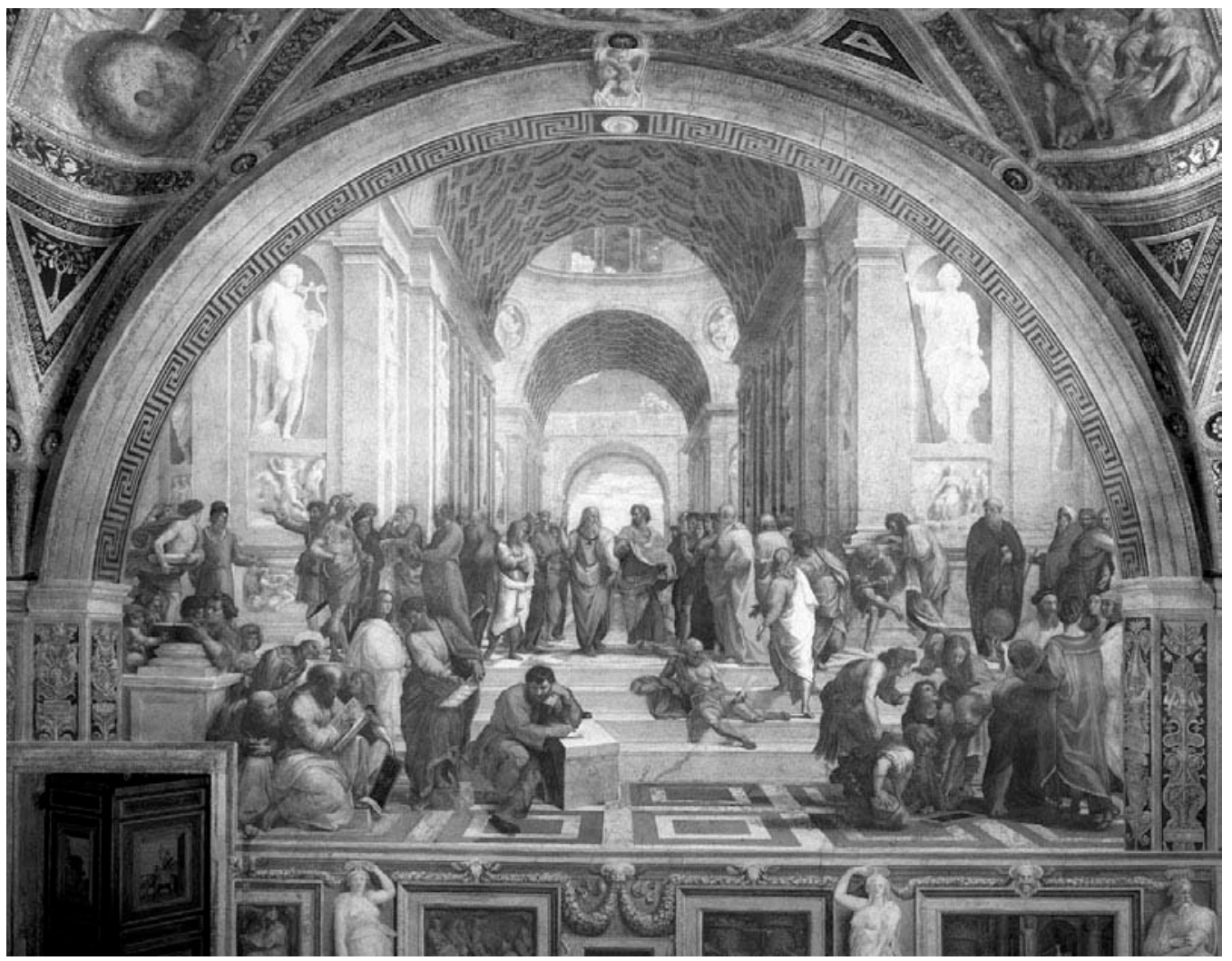


and perspective. Whilst Joost-Gaugier's study provides a convincing interpretation of the School of Athens, it overlooks an important aspect of the iconography. This concerns the significance of Platonic thought - and specifically the Timaeus - in Renaissance views of order, in particular on the symbolic understanding of perspective. The apparent harmony evoked in the compositional balance between Plato and Aristotle conceals, I would argue, a latent dialogue that echoes Husserl's principle of the origin of geometry. At the heart of this idea is the relation between the representations of Plato and Pythagoras which André Chastel saw as key to understanding the whole iconography of the fresco. ${ }^{126}$ Chastel claims that Raphael relied on Neo-Platonic material, particularly that of Marsilio Ficino, in the conception of the iconography. Taking as a point of reference Anton Springer's argument that the fresco is an allegory of the Liberal Arts, Chastel explores the spatial layering of the fresco: the left foreground embodies Grammar, Arithmetic and Music, as represented in the figure of Pythagoras; the right foreground, moreover, embodies Geometry and Astronomy, represented by Euclid, Ptolemy and Zoroaster; the middle ground finally, that is defined by the threshold of the top step, constitutes the zone of Rhetoric and Dialectic. ${ }^{127}$

An important, but not easily discernible, feature of the fresco's composition is the manner in which the disposition and setting of texts and tablets contribute to the overall order and decorum of the perspective. This reveals the episodic nature of the pictorial narrative that finds expression in the spatial arrangement of subjects that constitute the Liberal Arts. Forming integral elements in the composition of grouped figures that populate the scene, the texts and tablets interlock with the pictorial construction and serve as "anchor-points" in the fresco's narrative. Whilst not made explicit in the fresco, the spatial and symbolic correspondence between reading matter and perspective could be said to "originate" at the vanishing point of the fresco that coincides with the left hand of Plato. The philosopher is shown holding a large book whose binding is marked

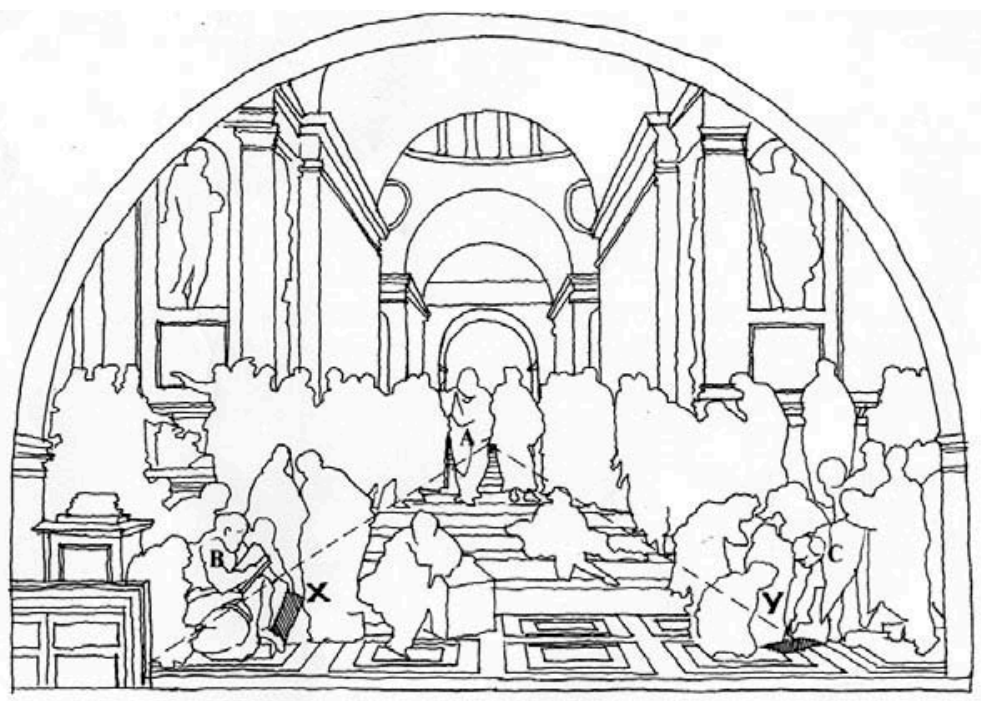

2.16

Outline of the
figures in the
School of Athens,
identifying some
of the principal
characters: Plato
(A); Pythagoras
(B); and Euclid (C);
and the tablets
(X \& Y)


with the title "Timeo" (Timaeus). When considered in the larger context of the fresco's iconography it is clear that the Timaeus constitutes the principal symbolic focus, indeed the fons et origo of the whole iconography. Whilst it can be argued that vanishing points in Renaissance paintings were generally not the location of important symbolic elements, the perspective constructs of the School of Athens and Disputa opposite appear to challenge this assumption, given that they reveal collectively a graduating and ascending movement towards synthesis. ${ }^{128}$ From the largely concealed vanishing point of the School of Athens - registered indirectly by the closed text of the Timaeus, to the explicitly celebrated vanishing point of the radiating monstrance in the Disputa - we are led on a visual journey from the limits of human knowledge (philosophy) to the infinitude of divine knowledge (theology). Leonardo's Last Supper no doubt served as a useful precedent in this regard, given that the pyramidal apex and vanishing point are coterminous with Christ's right temple.

Held upright, with binding oriented to the picture plain, the book of the Timaeus finds a correlative perspectival treatment in Plato's right hand. Here the index finger is shown pointing vertically. As if complementing this reciprocated gesture, Aristotle is represented holding a volume of his "Etica" (Ethics) that spans in a slightly inclined position between the philosopher's left hand and his thigh. This articulation of the Ethics is further echoed in the poised gesture of Aristotle's right hand that extends outwards towards the picture plain. In reference to Steinberg's argument of duplexity in the right hand gesture of Christ in the Last Supper, it could be argued that the manual gestures of Plato and Aristotle in the School of Athens invoke complementary modes of dimensionality, of the orthogonal and the traversal

2.17

Outline of the central figures of Plato and Aristotle highlighting the volumes of the "Timeo" (Timaeus) and "Etica" (Ethics)

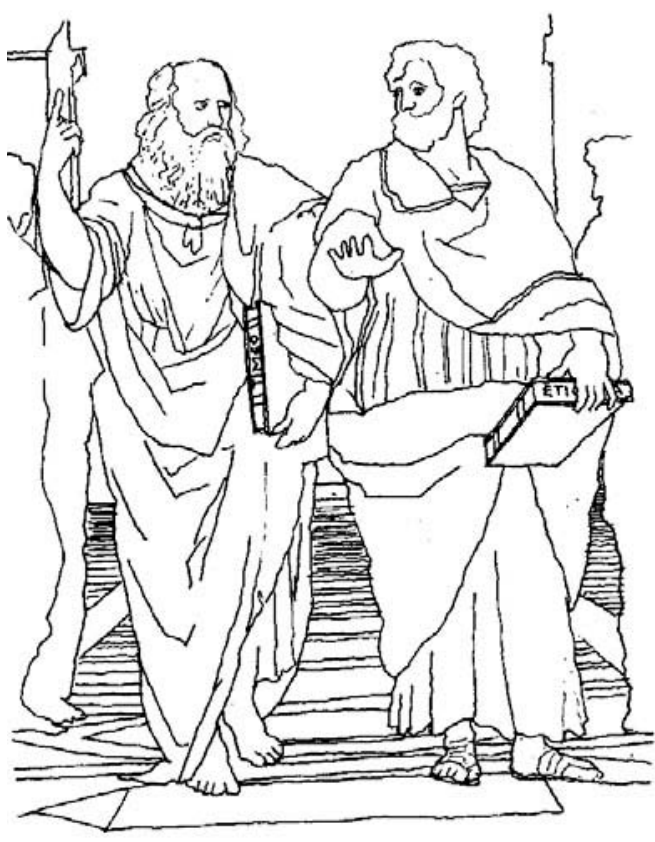


respectively. Unlike, however, the conflated meanings of the Saviour's hand, the traversal and orthogonal gestures in the School of Athens are conveyed separately. This separation re-affirms, in the distinct positions of Platonic in divinus and Aristotelian in naturalibus, the idea of philosophy as a foreshadowing of ultimate unity in theology celebrated in the monstrance of the Disputa opposite. ${ }^{129}$

Moving from the realms of the multitude of philosophers, engrossed in lively debate in the School of Athens, to the relatively silent and orderly arrangement of pious theologians and saintly figures in the Disputa opposite, we witness the pictorial embodiment of St Augustine's idea of the peregrinatio, or spiritual pilgrimage. ${ }^{130}$ The anticipatory union of world and divine knowledge (logos) was experienced as if by a process of "immersion" rather than one of "extrapolation". This is communicated through what Timothy Verdon aptly describes as an "insider dialogue". ${ }^{131}$

The notion of philosophy as a foreshadowing of theology is underpinned by the idea of the Timaeus as a prefigurement of the Bible. In considering Joost-Gaugier's claim that Aristotle was intended to be juxtaposed on equal terms with Plato, it seems the case that the fresco was conceived as a historiographical representation of the "handing down" of philosophical wisdom. In this process Plato constitutes the principal temporal reference. Such an interpretation, however, is not based on a straightforward sequential or chronological reading of the past, as we would perhaps assume, but is rather considered as a redemptive
2.18

Disputa

(Disputation over

the Blessed

Sacrament),

Raphael

(1483-1520).

Vatican, Stanza

della Segnatura

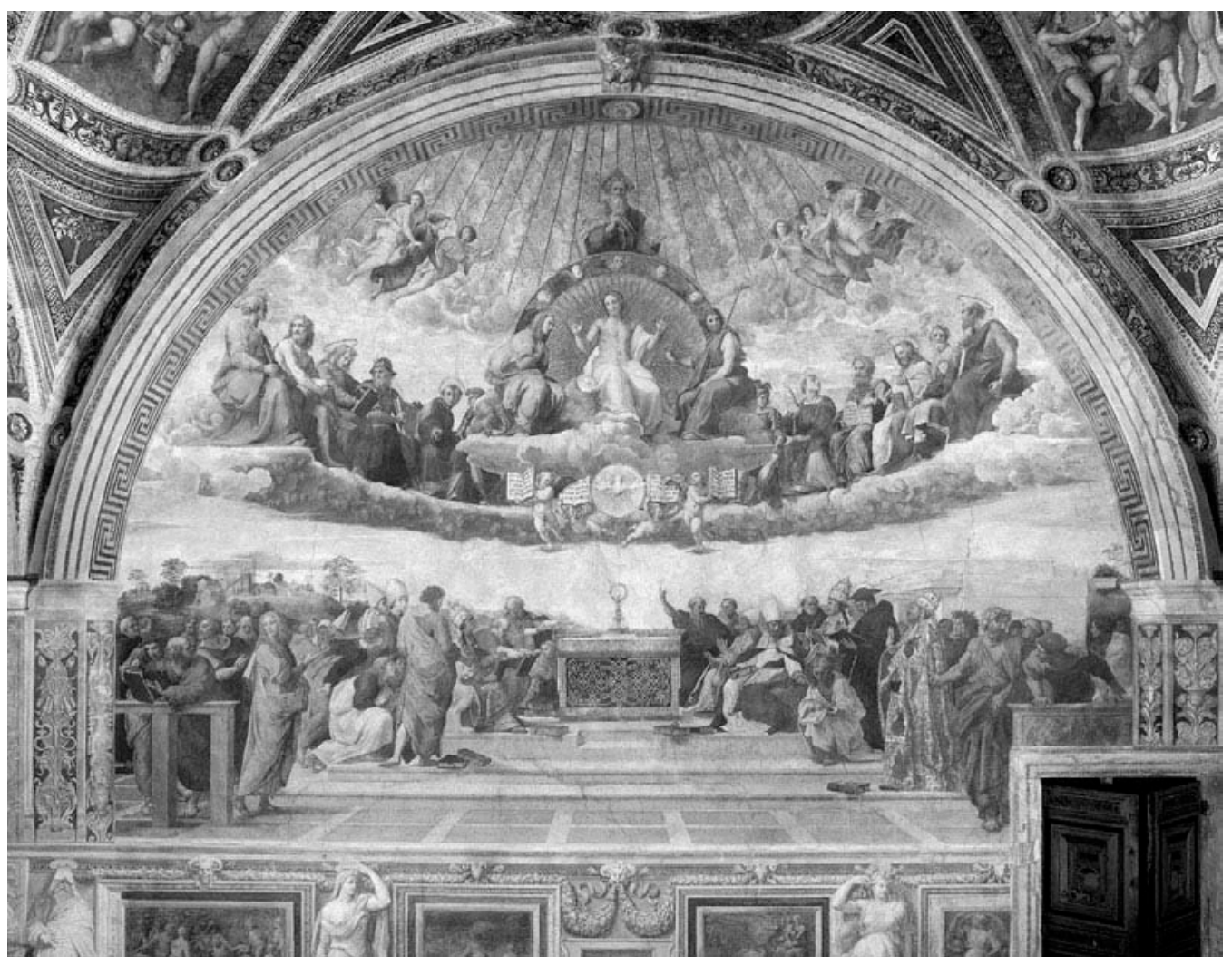


view of history that unfolds as a series of critical moments or dramas. As the "Attic Moses", Plato exemplifies the golden age of philosophy that, it was believed, prophesied the coming of Christ. It is from Platonic cosmology that the philosophical ideas of both predecessors and successors ultimately stem and are synthesised. Hence, in the Renaissance the Platonic world-view embodied the limits of human knowledge that both reflected upon an earlier primordial tradition and prepared the way for divine knowledge. The notion of the past as a series of dramas (or paradigmatic events) - from which all subsequent human endeavours draw meaning - is based on the principle that Plato and his immediate retinue embodied a philosophy that "sent human minds in search of God". ${ }^{132}$

At the heart of Renaissance views of the heritage of geometry is the mystery of the Trinity, whose numerological and geometric representations reveal the progression from philosophy to theology. Precisely how this process of inheritance of philosophical wisdom informs the larger composition of the School of Athens is illuminated by observing the perspective lines that radiate out from the vanishing point and extend to the lower corners of the fresco. Unlike the Last Supper, where Christ singly mediates geometry and perspective through his body, the figures in the School of Athens collectively participate in making legible and meaningful the surrounding perspective. This different emphasis is echoed by the treatment of the lower zone of both frescoes. Whilst the floor of the Last Supper is largely masked by the traversal expanse of the supper table, forming a kind of internal horizon above which emerges the mystical figure of Christ, the exposed paved floor and steps of the School of Athens provide a more explicitly calibrated measure of depth. It is within this latter perspective scaffold that the more balanced classical poses of standing, walking, kneeling and bending figures are choreographed.

Inherent therefore in the structure of the School of Athens is a concurrence between: 1) verbal dialogue/corporeal gesture (represented in the animated groups of discoursing figures), 2) written text in the disposition and arrangement of closed or open volumes and tablets, and 3) the underlying perspective/geometric order. Much as a classical rhetor or philosopher, immersed in dialogue or debate, the acts of reading and discussion are expressed in the fresco as an engagement of the whole body with the surrounding space. This is conveyed as if the body "reverberates" in the supporting perspective mesh. We are reminded here of the analogy between the proportional relationships of perspective and musical harmony as Leonardo sought to articulate. In the particular case of the School of Athens, the "resonating box" of the perspective frame could be said to register both the audible and inaudible sonorities - of speech and thought - that permeate the scene.

This interpretation reinforces Husserl's argument of correlative thinking between language and geometry. Whilst the majority of texts and tablets in the School of Athens sustain the symbolic and spatial order of the perspective, the Timaeus is itself the fons et origo of that geometric order. The principle of duplexity between geometry and text - and more specifically between the vanishing point and the Timaeus - gives substance to the idea of perspective as an embodiment of the Timaean Receptacle. The association is given a further dimension of 
meaning by Cusanus' idea that the "boundlessness of space and the infinite depth of the individual" is "experienced as epiphanies of God". ${ }^{133}$ However, given the philosophical and theological speculations about the meaning of infinitude in the Renaissance, the role of Platonic/Pythagorean ratios in the conception of the ideal or sacred reveals a potential problem: that infinity denies proportionality by the very fact of the absence of a limit. This, of course, is one of the great conundrums of Renaissance views of order that Leonardo sought to overcome by suggesting that the calibration of the Albertian floor grid can be delimited by finite and closed Pythagorean ratios of musical harmonies.

The idea of a fixed depth in the calibrated floor is in some ways alluded to in the School of Athens where we see the closing of the perspective by the figures of Plato and Aristotle, and by the proportional diminution of traversal lines created by the combination of changing floor levels and the surrounding vaulted architecture. This enclosed setting would seem to be a fitting prelude to divine infinitude that is conveyed in the coterminous relationship between vanishing point and monstrance in the Disputa.

The unobstructed area of the central paved floor and steps in the School of Athens loosely defines a zone that is visibly bounded by the principal characters of the iconography. Through body gestures and supporting texts, these figures "guide" the perspective lines from the vanishing point - coterminous with the volume of the Timaeus - to the lower left and lower right hand corners of the fresco. The "destinations" of these perspective lines are two slate tablets that are sited in the foreground of the fresco, at each corner. Each forms a focus of attention, around which are gathered curious onlookers. The slate on the left hand side is shown resting on the ground, in a tilting position, and held by an admiring youth. The one on the right is shown laid flat on the pavement.

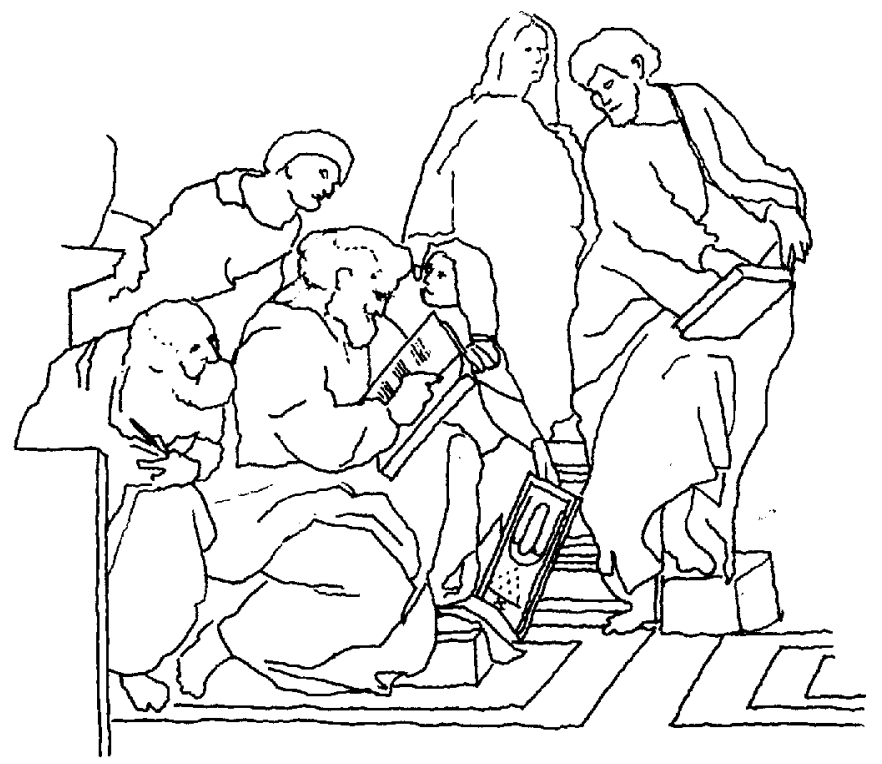

2.19

Outline drawing of lower left hand side of School of Athens showing figure of Pythagoras 
2.20

Outline drawing of lower right hand side of School of Athens showing figure of Euclid

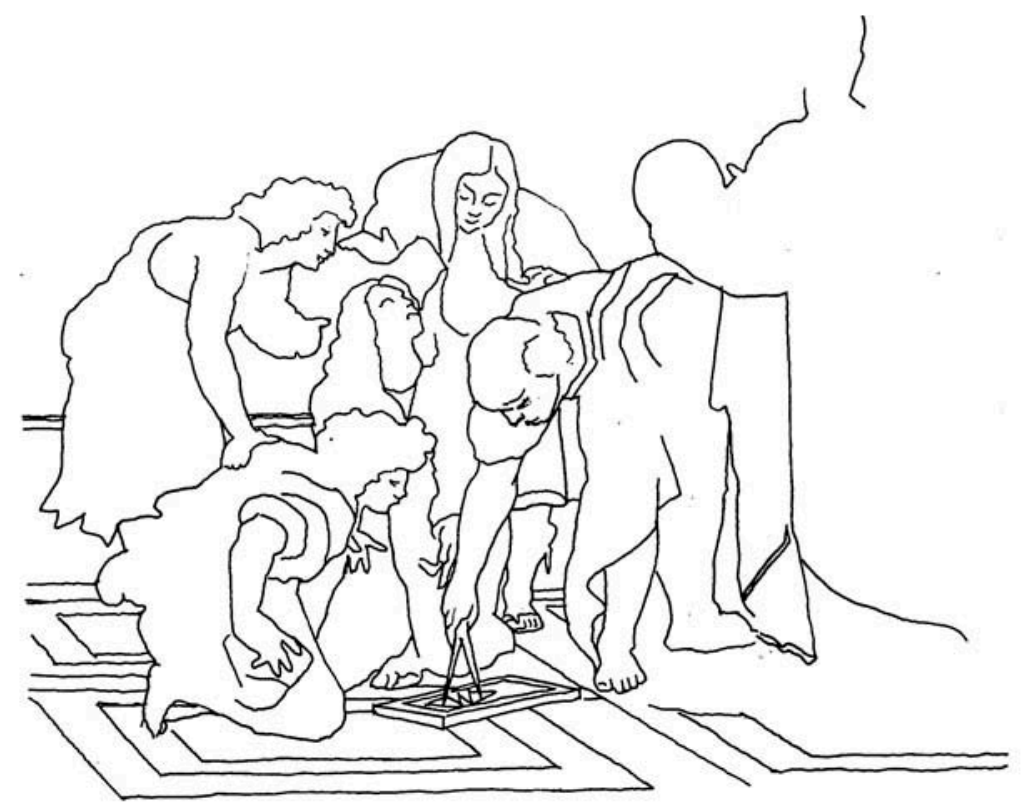

It is my contention that the content of the inscriptions on both slate tablets provides a clue to the symbolism of the whole fresco. The almost symmetrical relationship of the two slates is underpinned by the prominence given to two figures, each of whom is shown recording or measuring the contents of the tablets. On the left we see a bearded scribe kneeling with an open book and pen in hand. This figure is generally considered to be a representation of Pythagoras, given that the tablet nearby contains representations of the tetractys (in Roman numerals) and the musical harmonies of the tetracord highlighted (in Greek letters). On the right side, on the other hand, is a muscular and bald-headed figure shown bending over with dividers in hand and measuring a detail of the geometric configuration on the slate. He is generally believed to be Euclid for reasons that will be made clearer later.

In the perspective of the fresco we can clearly recognise a triangular relationship between the two lower figures (Pythagoras and Euclid) and the higher central figure of Plato (fig. 2.16). This relationship could be seen to represent in pictorial terms what Husserl understood as a transmission of the tradition of geometry. As predecessor and successor respectively to Plato, Pythagoras (the first philosopher) and Euclid (the first geometrician) are presented as two critical "anchors" to the larger arena of philosophical and scientific discourse. Moreover, we are able to identify important connections between the content of the Timaeus and the inscriptions on both slate tablets. This relationship centres on the principle of the historical transmission of arithmetic and geometric ideas. The Timaeus, as we have observed, transforms the closed and static world of Pythagorean number into a new creative order. It embodies a cosmos in which number and geometry form part of a common communicative domain that is governed by the Demiurge. 
Euclid, however, abstracts this cosmological and mythic realm by reducing geometry to a series of universal canons. Critical to this transmission is Euclid's Optics, which paved the way to the development of perspectiva artificialis. Raphael almost certainly identified in the three figures of Plato, Pythagoras and Euclid three critical stages in the understanding of the cosmos that could be put to the service of a new perspectival understanding of space.

In attempting to situate this pictorial narrative of Greek philosophy within the culture of early sixteenth-century Rome, Raphael devises a clever method of "double-identity". In this method contemporary figures, including some well-known personalities in the court of Julius II, are portrayed in the guise of the ancient philosophers. This strange conflation of present and past pervades the fresco in such a way that the retinue of ancient venerated figures can also be construed in part as an assembly of illustrious philosophers, humanists and artists/ architects of the Renaissance.

Plato is represented as Leonardo da Vinci, based on a well-known self portrait sketch by the artist. In the eyes of some historians this might seem a curious association given that Leonardo's scientific outlook erred, it seems, more towards Aristotelian thought. ${ }^{134}$ However, Steinberg's examination of the Last Supper clearly challenges this view. Moreover, Leonardo's ingenious "transfiguration" of Platonic geometry into a perspective rendering of Christian triune symbolism was doubtlessly an approach that Raphael sought to emulate in the iconography of the School of Athens and Disputa.

Beyond the circumstantial connections between the School of Athens and the Last Supper, there is evidence to suggest a more specific relationship. These concern the idea of historical "re-enactment". To begin with, the suggestion that Euclid is actually a portrait of Bramante is based, according to Ingrid Rowland, on a little-known pamphlet on perspective. ${ }^{135}$ Dedicated appropriately to Leonardo da Vinci - and entitled Roman Antiquities in Perspective ("Le Antiquarie prospettiche romane") - this four-page booklet is a vernacular poem published in Rome sometime between 1499 and 1500. Rowland argues that the anonymous author, "Prospettico melanese depictore" (Mr Perspective, a painter from Milan) is none other than Bramante himself. ${ }^{136}$ She supports her argument by directing our attention to the woodcut frontispiece which shows a male nude figure. Represented in a kneeling position, the figure's left hand is shown holding dividers which he is using to measure the side of a triangle inscribed on the floor. ${ }^{137}$ The similarity between this figure and the more sophisticated rendering in the School of Athens is hard to deny. It is arguable that Bramante's comical self-portrait, with familiar bald head and muscular body, became the basis of Raphael's representation of Euclid as an "ancient prospectivo". ${ }^{138}$ Given this direct influence one has to pose the question of the appropriateness of this association of Bramante with Euclid in the wider historiographical reading of the fresco.

The connection, I would argue, relates to Bramante's work in Milan at the end of the fifteenth century which was the same time that Leonardo was in the court of the Sforzas. We know that Leonardo was appointed, alongside Bramante, as one of the four main ducal engineers in Ludovico Sforza's court. ${ }^{139}$ 
Leonardo was by this time an established, indeed venerated, polymath. The activities of Leonardo and Bramante at Sta. Maria delle Grazie in the 1490s, both probable commissions of the ducal court, raise the possibility of some informal collaboration. This, as I have inferred earlier, relates to the geometric and symbolic relationships between the Last Supper and the tribuna of the Basilica, the former painted by Leonardo and the latter designed by Bramante. It is conceivable that Raphael recognised in this artistic and intellectual partnership an appropriate precedent in which to develop the iconography of the School of Athens.

The connection between ancient and contemporary histories was closely allied to textual sources. The first printed text of Euclid appeared in 1482, which spawned numerous humanist studies on number and geometry. ${ }^{140}$ Most notable were those of Luca Pacioli, in particular his Divina proportione published in 1509 during the execution of the frescoes in the Stanza della Segnatura. A close friend of Pacioli, Leonardo drew the geometric figures for this work soon after his execution of the Last Supper in Milan. ${ }^{141}$ It is conceivable therefore that the "handing down" of Platonic cosmology to Euclidean geometry was consciously "re-enacted" in the more recent understanding of the relation between perspective and geometry in the work of Leonardo and Bramante. The connection is further underscored by the likelihood, advanced by Vasari, that Bramante was himself involved - in some capacity in the perspective construction of the School of Athens. ${ }^{142}$

Besides being a close friend of the younger Raphael, having introduced his fellow Urbinese to the court of Julius II, Bramante was widely regarded as the expert in perspective at the time, hence the pseudonym "Mr Perspective" in the attributed pamphlet. Some commentators have taken this hypothesis a step further by claiming that the geometric configuration on Euclid's/Bramante's slate forms a clue to the underlying geometry of the surrounding architecture. ${ }^{143}$

Raphael's attempt to emulate the classical philosophers by constructing parallel histories, even at the level of contriving inter-relationships between ancient and recent events, raises the further question of the identity of the figure portrayed as Pythagoras. The identification, I would argue, requires an understanding of the significance of the abacus as both a memory of ancient Pythagorean practice of cosmic "tabulation" and as a symbol of Renaissance proclivities towards computation. ${ }^{144}$ The relation between ancient, Medieval and Renaissance views of number is nowhere more evident than in the changing understanding of the abacus. This centres on what Alfred Crosby describes as a shift from a qualitative to a quantitative understanding of measure. ${ }^{145}$ Counting boards became increasingly popular from the fourteenth century onwards, as a result of the demands for efficient means of calculating large numbers in commerce and trade. However, the reduction of number to mere quantity was not accompanied by the incipient decline in symbolic meaning. Martin Luther's comparison of the placement of counters on an abacus with the relationship between man and God goes some way to reinforcing the persistence of analogy in Renaissance numerology. ${ }^{146}$

The slate, represented on the left hand side in the School of Athens, has been called an abacus, due no doubt to the representation of the tetractys as an assembly of repeated Latin numerals that could be likened to tokens on a 
counting board. Among the many humanists who took a special interest in abbaco, Giles of Viterbo is especially important. This is due to his particular obsession with the relation between tabulation and number symbolism. Giles was influential in a project undertaken, but not completed, by Angelo Colocci, a fellow humanist in the court of Julius II. This entailed the study of God's creation through an examination of weights and measures, probably inspired by a passage in the apocryphal Wisdom of Solomon (11:21). It states that God sets "out everything in terms of measure and number and weight". In Giles' vast body of writing, which comprised sermons and commentaries, the mystery of the Trinity was a central theme. This is further borne out by the design of the coat of arms of the Augustinian friar. Comprising three hills, it was almost certainly intended to evoke the triune meanings of the Saviour's progression from death to ascension. ${ }^{147}$ As the most learned Neo-Platonist of his day, having come under the influence of Marsilio Ficino, Giles believed in the prophetic nature of Greek philosophy and the Jewish Cabala. This explains his belief that Pythagoras was the first to recognise the "glimmerings" of Trinitarian thought, of which the configuration of the tetractys was key. ${ }^{148}$ Giles probably recognised in the relation between number and geometry, and more specifically between an arithmetic and a geometric understanding of the Platonic triangle, the central mystery of the Trinity. Hence, the auxiliary identity of Pythagoras as Giles of Viterbo seems plausible and is supported by similarities between contemporary accounts of the Augustinian friar - with his dishevelled and bearded appearance - and the figure portrayed in the fresco.

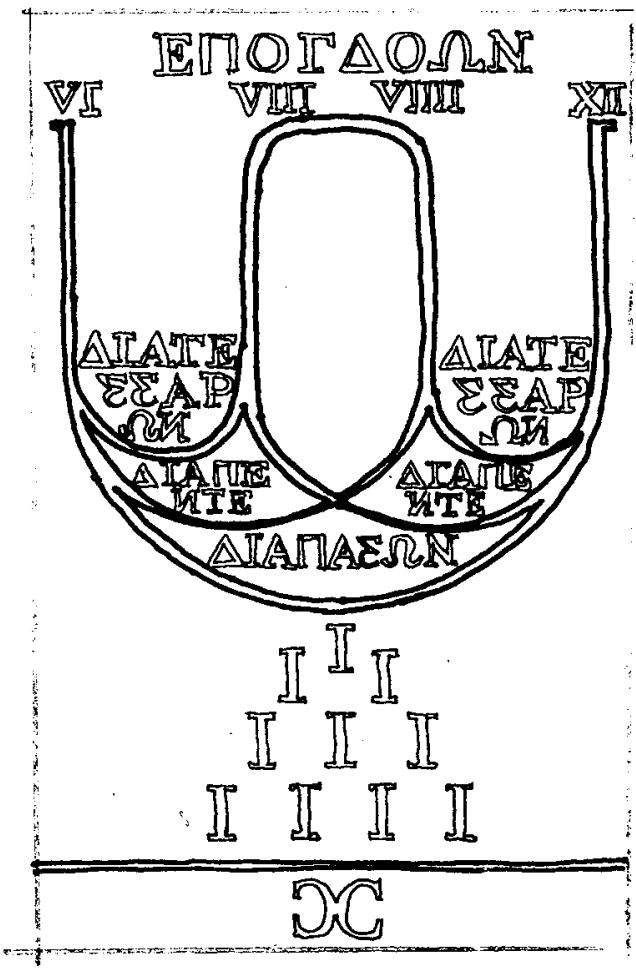

2.21

Reconstruction of image on left hand tablet of Pythagoras. Drawn by author after Giovanni Pietro Bellori's Descrizzione (1751) 
The portrayal, however, of a Renaissance Neo-Platonist, in the guise of the "first" philosopher, is somewhat complicated by Giorgio Vasari's assertion that the figure portrayed in the fresco is St Matthew. ${ }^{149}$ Such an identity was, no doubt, informed by the pose of the figure that is typical of representations of Evangelists, as well as by the nearby figure holding the slate which could be mistaken for an angel (Matthew's symbol). It would be easy to dismiss Vasari's claim on the grounds of the biographer's second-hand sources. Such, however, would only overlook a more conscious evocation of the Trinity in the symbolism of the fresco. This association is supported by the belief in the Renaissance of the prophetic nature of Greek philosophy - and Plato in particular - in the advent of Christ. As if to press home this point the combination of elements on the slate (the triangular configuration of the tetractys below the curved articulation of the tetrachord of musical harmonies) could be interpreted pictorially as a chalice evocative of the Eucharist, an interpretation which, however literal, should be carefully considered in the light of the interest in pictograms and hieroglyphics during this period. ${ }^{150}$ This leads us to construe Pythagorean number and musical harmony as "prefigurements" of the mystery of the Eucharist (and therefore the Trinity), serving therefore as a praeparatio evangelii - or preface - to the Gospel. ${ }^{151}$

It is open to speculation whether the right-hand figure of Euclid in the fresco was similarly intended to be interpreted Biblically, considering the allusions to Trinitarian symbolism in the geometry of his slate. Of particular interest here is the posture of Bramante which derives from a fairly standard Medieval representation of God as universal geometer with dividers in hand. Added to this is the allusion to the six pointed star of the Magan David in the interlocking triangles on the slate. Whilst the origins of the motif can be traced back as far as the Bronze Age, its specifically Judaic meanings became a source of much interest in the hermetic studies of Kabala in the sixteenth century. ${ }^{152}$ The approximation, however, of the motif to the geometry of the Magan David (given the displacement of the two interlocking triangles and their non-equilateral configuration), suggests not so much a direct replication of the symbol but rather its partial translation. This may partly be informed by the secondary function, alluded to earlier, of the geometry as a "summary" of the architectural background. However we attempt to decipher these multiple levels of significance it seems plausible that a duplexity of meaning was intended in which both Classical and Old Testament traditions become prophetic of the mystery of the Trinity. Given the location of the figures of Pythagoras and Euclid and their slates, in the foreground of the fresco, it is conceivable that allusions to Trinitarian symbolism were underlined by the "spatial" proximity of these figures to the Disputa opposite that celebrates theology.

The auxiliary identities of the three giants of Greek philosophy - of Giles of Viterbo (Pythagoras), Leonardo da Vinci (Plato) and Donato Bramante (Euclid) - supports the idea of a "handing down" of number and geometry to Renaissance perspective. At the heart of this tradition, as we also see in the Last Supper, is the symbolism of the triangle. The numerically generated triangle of the tetractys on Pythagoras' slate may have been interpreted by the author of the 


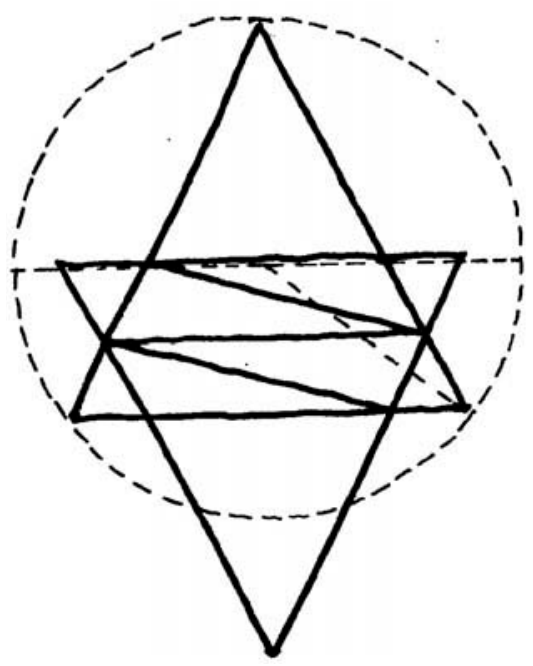

2.22

Reconstruction of image on right hand tablet of Euclid

fresco as foreshadowing Platonic geometry, and at the same time prophetic of the mystery of the Trinity.

The transformation from Pythagorean number to Platonic cosmology takes on a new rational order in Euclidean geometry. The intersection of the two isosceles triangles on Euclid's slate, that incidentally approximate to equilateral triangles, leads to the creation of the hexagon. Within this "emerging" configuration are shown two parallel lines connecting the internal corners of the hexagon and a diagonal formed between these lines. The significance of this geometry is not hard to recognise when we examine Euclid's demonstration of the so-called Theorem of Pythagoras in Book 1 (Proposition 47) of the Elements. The "proof" of $\sqrt{3}$ can be demonstrated in a hexagon since one or other of the internal parallel lines - and its diagonal - define two sides of a half equilateral triangle. ${ }^{153}$ Hence, implicit in the geometry of the hexagon are the very ratios that constitute Platonic cosmology.

This essentially "arithmetised" geometry that assigns a unit length of a line within a figure, from which the magnitude of other lines can be calculated, provides the basis of what David Fowler calls "anthyphairetic" geometry. ${ }^{154}$ Derived from the Greek verb anthuphairein - which Euclid uses to describe the operation of reciprocal subtraction in determining incommensurables - Fowler provides demonstrations of its application which include the diagonals of a hexagon. ${ }^{155}$

What emerges in this study of the School of Athens is a conscious attempt to convey within the framework of perspectiva artificialis a continuity between Pythagorean number, Timaean/Platonic cosmology and Euclidian geometry. This transmission, however, conceals within its own drama a series of historical crises that threaten discord: beneath the order and decorum presented in the fresco, between the traditions of Pythagoras, Plato and Euclid and their contemporary impersonators, one can identify the seeds of geometry's undoing as heritage. Husserl's examination of geometry in the work of Galileo, in which 
the autonomy of geometry forsakes its traditionally inherited role, is the ultimate consequence of this historical process.

It is from perspective that "reconciliation" is sought between these potentially conflicting positions, since it is perspective that provides the pictorial means of making the historicity of geometry legible and ultimately convincing. In a highly visual culture such as the Renaissance, dominated by humanist and antiquarian thought, perspective functioned as the principal mechanism for bringing the Pythagorean, Platonic and Euclidean traditions into a unified and harmonious whole, that in turn foreshadows the Christian Trinity. The transmission underlines the idea of representation as part of a larger cultural project: to ensure the restoration of the Golden Age through a redemptive understanding of history. It is in this context that John Sallis' succinct summary of the Timaeus could just as easily be applied to Renaissance views of order: "proportion is to generation what truth is to belief". ${ }^{156}$

\section{Louis Kahn's Yale Art Gallery}

In David Farrell Krell's recent essay, "A Malady of Chains", the author questions the underlying premise of Husserl's study of the origin of geometry: the assertion that geometry grants a certain continuity to the philosophical tradition, that can be sustained in spite of the closed logical systems that dominate modern thought, is disputed. ${ }^{157}$ Whilst the presence of the architectural metaphor in Husserl's work re-affirms a "seemingly ineluctable interlacing of architecture, philosophy, and geometry", the question of historical continuity between these three disciplines and their alignment to some larger order - can no longer be sustained. ${ }^{158}$ Husserl's use of the term "chain" to convey the tradition of geometric ideas, in which "each link interpenetrates the link before and after it", becomes the focus of Krell's dismissal of historical continuity.

In questioning Husserl's idea of "retracing" the origin of geometry, by a process of repetition and sedimentation, Krell asserts that "philosophy and architecture alike are facing the question as to how life goes on after geometry". ${ }^{159}$ This "post-mortem" of geometry - or more specifically of inherited geometry has significant implications for architectural thought given the traditional role of geometry in affirming the cosmological meanings of architecture. Krell asserts that the origins of geometry are not a "foundationalist" issue, meaning they are not a historically traceable and inter-connected problem. Rather, the process is an internalised affair informed by a "'culture enchained by its own equivocations', an ideality and a culture that Derrida finds in James Joyce rather than in Husserl". ${ }^{160}$

This denial of the historicity of geometry has become a familiar assertion in Deconstructivist writings that claim an essentially idealised metaphysics of presence. By examining the works and ideas of Louis Kahn, in particular his Yale University Art Gallery, I propose to question the assumptions of Krell's argument, and thereby open the way to a reinterpretation of Husserl's principle of continuity in geometry in the context of architectural thought.

Unlike the Renaissance, the use of geometry in the architecture of modernity is not supported by a self-evident tradition. Instead it is guided by 
competing and sometimes conflicting parameters, particularly relating to technological and symbolic issues. Kahn constantly sought to reconcile these views through architecture. His work was guided by a largely paradigmatic understanding of space, albeit one that was firmly embedded in the context of everyday experience. In challenging the assertion made by David De Long and David Brownlee that Kahn's architecture is essentially idealist, "informed by the fundamental Platonic distinction between 'form' and 'design'",'161 I propose to take Sarah Goldhagen's rather different position as a point of reference:

Kahn's civic and religious buildings ... are not texts but intertexts situated, as [Pierre] Bourdieu would have it, "within the space" of other contemporary works. Kahn - sometimes consciously, sometimes unconsciously - "oriented" his work toward the perceived demands of his audiences: his buildings were powerful aesthetic propositions to debates that preoccupied many. ${ }^{162}$

At the heart of Kahn's work was a belief that a certain understanding of the monumental - that is neither historically derivative nor technologically driven - can enhance social or communal cohesion. This conviction was underpinned by criticism of the excessive relativism pervading modern society: "Some argue that we are living in an unbalanced state of relativity which cannot be expressed with a single intensity of purpose." 163 Kahn counters this argument by asserting that architecture can provide the context for a new reforming spirit. In confronting relativism Kahn marshals geometry, not, however, as an assortment of available elements in and of themselves, but rather as an embodiment of a shared tradition.

The period of the late 1940s and early 1950s was critical to Kahn's creative development. It was during this time that Kahn was teaching at the Yale School of Fine Arts, where he met Josef Albers, former Bauhaus teacher. Albers was to have an important influence on Kahn's understanding of geometry. In his early years at Yale, Albers produced a series of paintings that comprised geometric figures etched in white on a black background. Pre-occupied with Gestalt notions of order, Albers' interest in certain geometric configurations was informed by what Goldhagen describes as "ambiguous perspectival relationships". ${ }^{164}$ Of particular interest here is his Constellation: Transformation of Scheme No.12 which shows a square with another square superimposed, of the same area, rotated 45 degrees. From the intersections of these two figures are drawn two sets of parallel lines, from whose intersections are generated certain spatial relationships. What is initially conveyed as a two-dimensional rotation of a square "unfolds" as a three-dimensional relationship between two interlocking rightangled planes set in the depth of the geometric frame. The resulting geometry could be seen as a modern counterpart to the "Euclidean" slate in the School of Athens referred to earlier. In both cases a geometric form - an isosceles triangle in the case of Raphael's fresco and a square in Albers' painting - is rotated to generate a second polygonal form (a hexagon in the former and an octagon in the latter). Within this second figure are inscribed parallel lines that connect the points 
Outline reconstruction of Josef Albers' ambiguous perspective entitled Structural Constellation: Transformation of Scheme No. 12 (1950). The original painting consists of a black background with geometric figures etched in white lines

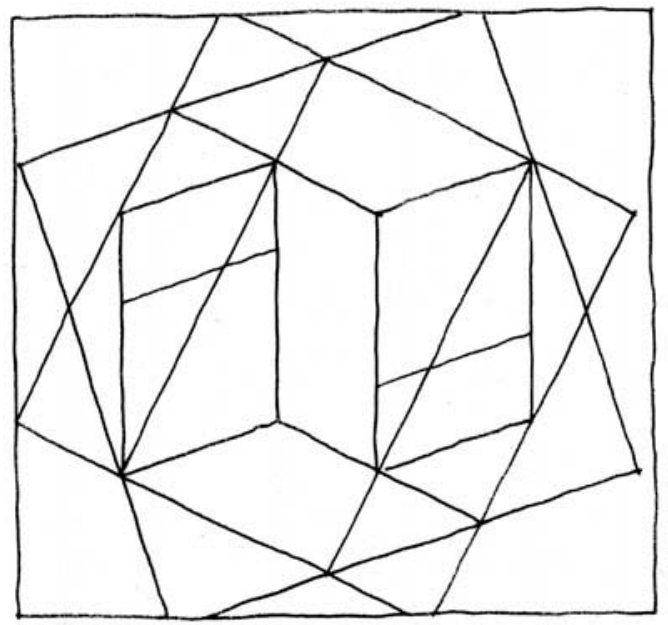

of intersection of the rotated figure. In each case a series of proportional relationships between lines lead to a transformation. In so doing, two-dimensional geometry propagates a third dimension of depth. In the case of the Euclidean slate, as previously discussed, some scholars argue that the diagonal lines within the interlocking triangles form a key to the centralised perspective of the painted architecture of the fresco. ${ }^{165}$ Albers' transformation, on the other hand, connotes a different perspectival arrangement. This entails a lateral displacement in the plain of the painting generated by the interlocking geometries. In comparing these two configurations, both of which take Platonic forms as initial generators to create perspectival relationships, one could say that the balanced articulation of sacred/ideal space - characteristic of Renaissance space - gives way to the multiple and eccentric perspectives of a new depth of field.

It would be easy to construe from this difference a fundamental and irreconcilable change from an essentially revelatory understanding of geometry to one of pure abstraction. But Albers' attempt to "perspectivise" Euclidean geometry suggests something less differentiated and more oriented towards a transformational reading redolent of Leonardo's Last Supper. It implies not so much a non-representational space as one conceived in phenomenological terms. ${ }^{166}$ Central to this concept is the traditional eschatological notion of light as the "primogenitor of form", which in Albers' inscriptive black and white studies provokes a contemplative response. ${ }^{167}$

This revelatory understanding of geometry lies at the heart of Kahn's work. In a series of drawings executed between 1948 and 1950 Kahn explored the ambiguous relationships between solid and void, light and dark, surface and depth. These are articulated using similar folded plains as those found in Albers' paintings. However, unlike Albers' ambiguous perspectives, which are framed within clearly defined geometric figures, Kahn's studies are "situated" in an implied topography or terrain. His interest in the relation between architectonic (geometric) form and horizon was to inform a number of drawings and paintings he executed during a three-month residency at the American Academy in Rome in 1951. Of special 


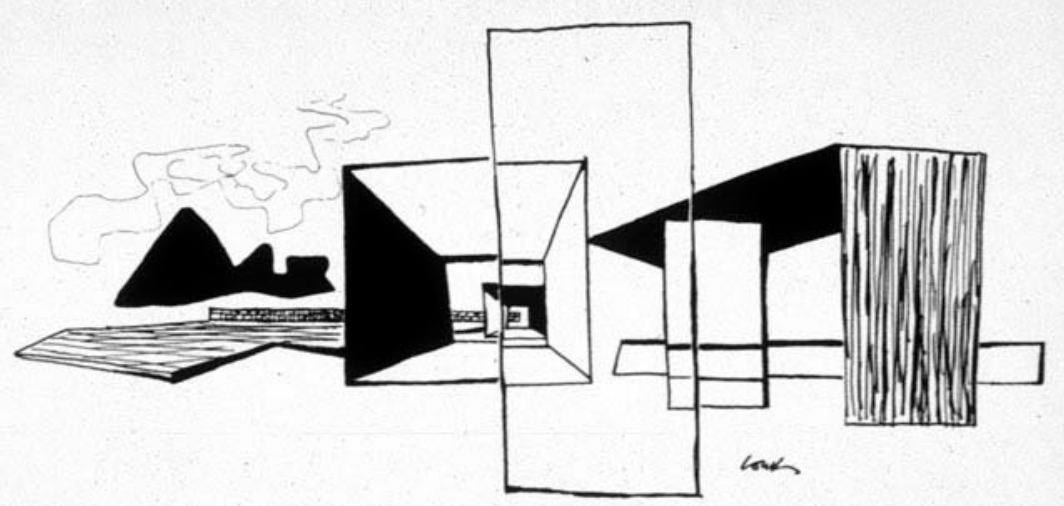

interest here is a series of drawings of the pyramids at Giza which he undertook during a brief visit to Egypt. As Goldhagen describes, Kahn explored "how the triangular shadow coming off one side of a pyramid distorted one's perception of its regularity, an idea he had broached in his abstract line drawings for several years". ${ }^{168}$ It is evident from these that Kahn was fascinated both by the perspectival effect that is created by the sequential relationship of the three pyramids, and also by their materiality and larger topographical setting. This finds expression in Kahn's emphasis on sharp shadows, textures and earthy colours.

One drawing is particularly revealing in this regard. Shaped in the form of a square divided into quadrants, the drawing comprises in each quadrant separate studies of the pyramids. The square format of the study - with its subdivisions

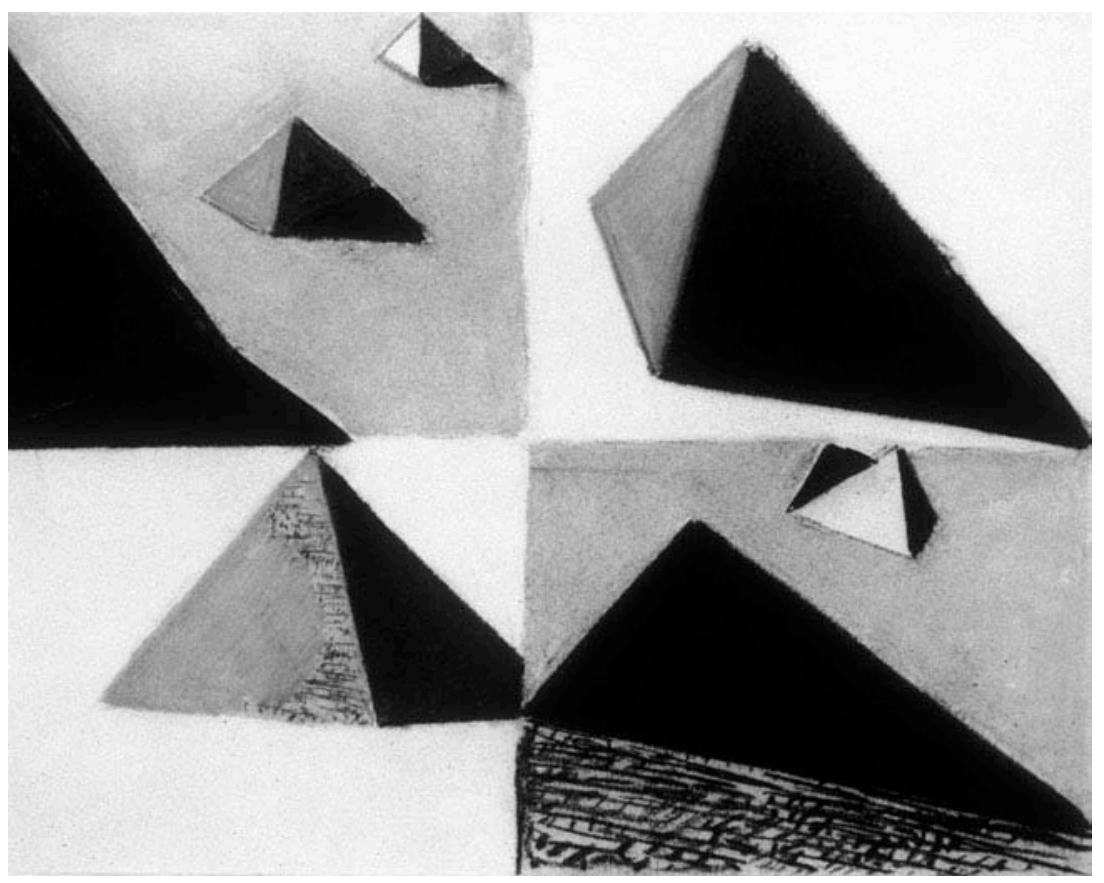

2.24

Louis Kahn,

Transparency \#1 (1948-50)

2.25

Pastel study in the form of quadrants of a square showing different perspective views of the Pyramids of Giza, Louis Kahn (1951) 
- reiterates the fourfold cosmological geometry of the pyramid. In each quadrant Kahn represents the pyramids from various elevated vantage points, suggesting that the drawings were constructed largely from imaginary points of view rather than recorded directly from actual locations.

The arrangement and configuration of these representations suggest that they could be interpreted sequentially, like film clips. Beginning from the top left, an elevated "panoramic" perspectival view of the three pyramids is shown, followed by a view in the right quadrant of an isolated pyramid also viewed from an elevated position. Then in the lower left hand quadrant is a representation of a single pyramid in an almost oblique projection, and finally on the bottom right quadrant is a view taken from the top of one of the pyramids looking down towards the ground, with a distant view of its neighbour. Combined, the shifting angles of the shadows cast by the pyramids could be construed as a pictorial device for "tracking" the movement of the sun. ${ }^{169}$ This is underlined by the shifting perspectives that "jump" from distant horizon to focused downward view.

The ambiguity, evident in Kahn's sketches, between solid and void, surface and shadow, proximity and depth, underlines the inter-relationship between the acts of drawing and building. The "searching for analogues to ideas he had seen in another medium" was indicative of Kahn's firm belief in the mediating role of geometry in communicating a dialogue between idea and physical expression. ${ }^{170}$

It was during his residency at the American Academy that Kahn received the commission to design the Yale Art Gallery. Kahn's evident interest in the triangle as generator of elemental solids was to play a pivotal role in the design. Besides the possible influence of his experiences in Egypt, as well as the impact of Albers' geometric transformations, Kahn's design was probably also inspired by Buckminster Fuller's work on space frames. In particular, Fuller's work on three-dimensional triangulation, using light skeletal structures, almost certainly inspired Kahn's design for the ceiling of the Gallery. Kahn would undoubtedly have been sympathetic to Fuller's treatment of geometry as a generator for radically transforming inhabited space at a time when society had become disillusioned with mainstream Modernism. Whilst Fuller's innovation in space frames was largely driven by technological concerns, the "celestial" impliciations of its geometry, especially in the geodesic dome, were probably recognised by Kahn.

For many commentators and architects, the Yale Art Gallery heralded a new vision of modernism that drew much from historical precedent. To this end, the work departs from the still-dominant International Style which was largely indifferent towards the past. The quiet simplicity and restraint of the exterior of the building, with its contrasting brick and glazed envelope - subdivided by continuous concrete drip courses - partly conceals the horizontal stratification of interior space. The combination of the deep tetrahedral ceiling, cast in a three foot thick in-situ concrete slab at each floor level, and a largely blank concrete stair "silo", that punctuates the four floors and extends the full height of the building, gives the interior a poetic monumentality unique to American architecture of this period. Both Goldhagen and Brownlee/De Long emphasise the significance of this 


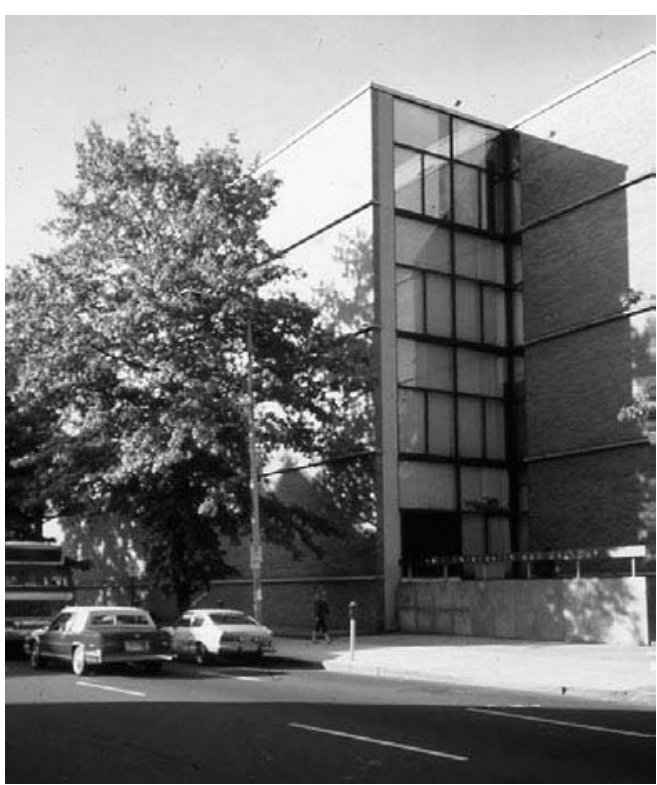

2.26

View of entrance, Yale University Art Gallery, New Haven, Conn., Louis Kahn (1951-53)

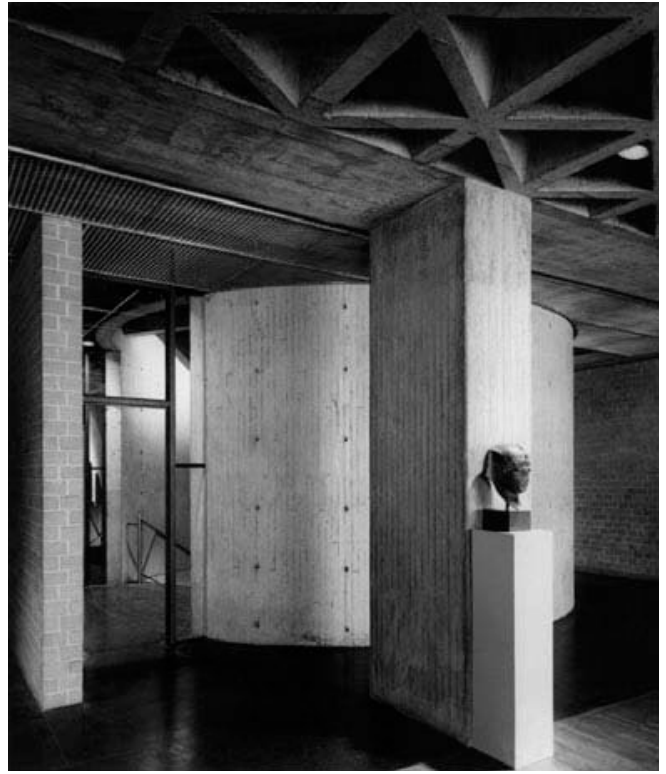

2.27

View of interior looking towards the "silo" drum of the staircase showing the trapezoidal ceiling, Yale University Art Gallery, New Haven, Conn., Louis Kahn (1951-53)

\subsection{8}

Detail view of trapezoidal ceiling, Yale University Art Gallery, New Haven, Conn., Louis Kahn (1951-53)

building in its departure from the modernist principles of the straightforward open plan. Instead, as Goldhagen observes somewhat paradoxically, the "Volumes are simply there", meaning they are explicitly stated rather than conveyed as transitional space without clear definition. ${ }^{171}$ The dominance of the in-situ concrete ceiling, with its deep coffering and textured surfaces, reinforces the visual containment of the spaces.

Upon entering the building, you are immediately struck by the contrast between the light glazed entrance-way and the mass of the tetrahedral concrete 
ceiling that "weighs" heavily upon you like the soffit of a cave. On axis with the entrance is the "silo" stair-well, that forms part of a zone of vertical circulation delineated by the contrasting black polished slate floor. Situated at right-angles to the axis of the entrance - and extending the full width of the building - this intermediary area interrupts the main area of the gallery, dividing it into two equal parts. The orientation of the entrance to the drum of the staircase provides the only clear visual clue to the direction of movement within the building.

For Brownlee and De Long, the influences on the design reflect a particular alliance: "Kahn's approach seems characterized not so much by a pairing of history with advanced technique as by the pairing of history with a superimposed geometric order that gave the impression of advanced technique."172 The connection between history and geometric order was clearly a primary concern for Kahn who incorporated within the design aspects of the ideas of Albers and Fuller, as well as references from his trip to Egypt. Quite how these influences were brought into play entailed a complex negotiation. In publications of his work, Kahn made known his preference for the ceiling plan of the Yale Art Gallery, implying that the ceiling served as a kind of topographical matrix of the building that gave geometric cohesion to the otherwise neutral volumes of the spaces.

Vincent Scully suggests that the pyramidal coffers of the ceiling relate directly to Kahn's experiences of the pyramids of Giza. ${ }^{173}$ It would be easy, however, to dismiss this direct comparison, given that it overlooks the obvious difference between the square-based pyramids of Egypt and tetrahedron voids in Kahn's design. But such a dismissal, relevant as it may be from a purely formal perspective, ignores the more general symbolic intention underlying Kahn's work. The contrast between the complex - and indeed precise - geometry of the ceiling, and its rough execution as an uneven concrete finish, is evocative of Plato's distinction between Being and Becoming in the Timaeus. This is expressed in the manual process of pouring and setting concrete into pure geometric volumes that express the transformative effect of ideal Platonic forms into their physical (proximate) manifestations. Kahn was evidently fascinated by the way architecture

\subsection{9 \\ Ceiling plan, Yale University Art Gallery, New Haven, Conn., Louis Kahn (1951-53)}

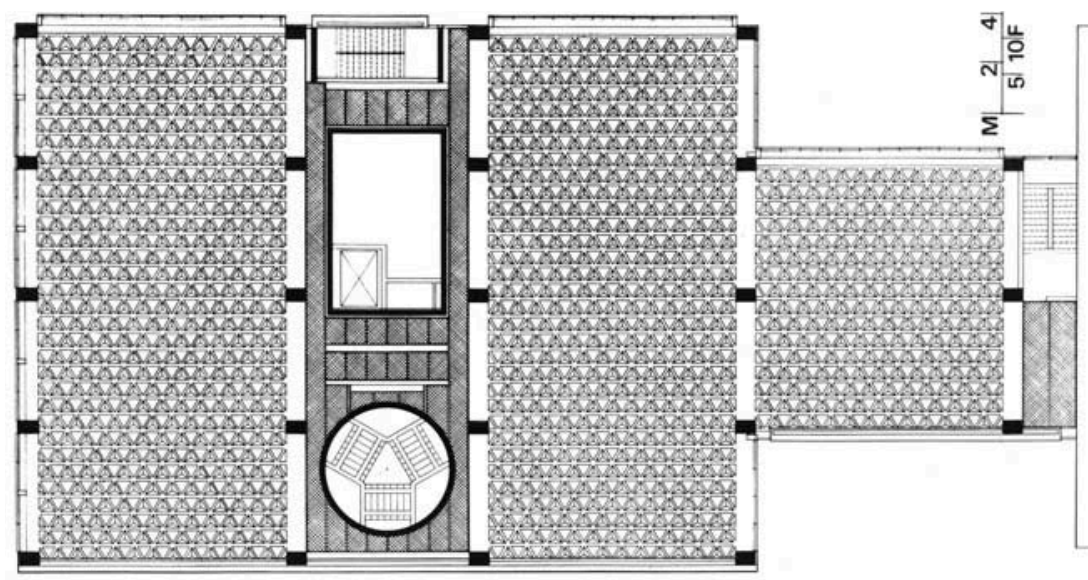




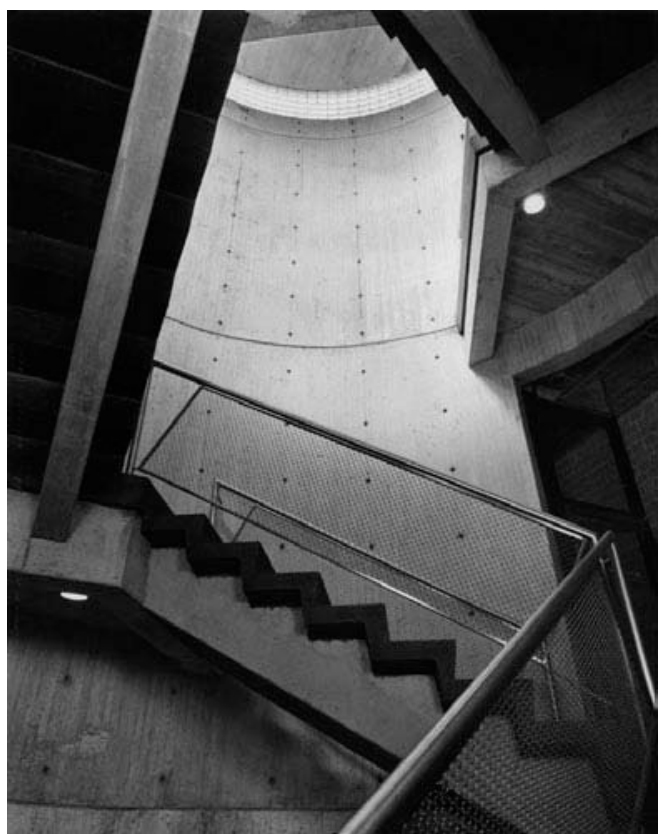

2.30

View of stairwell looking up towards triangular roof-light, Yale University Art Gallery, New Haven, Conn., Louis Kahn (1951-53)

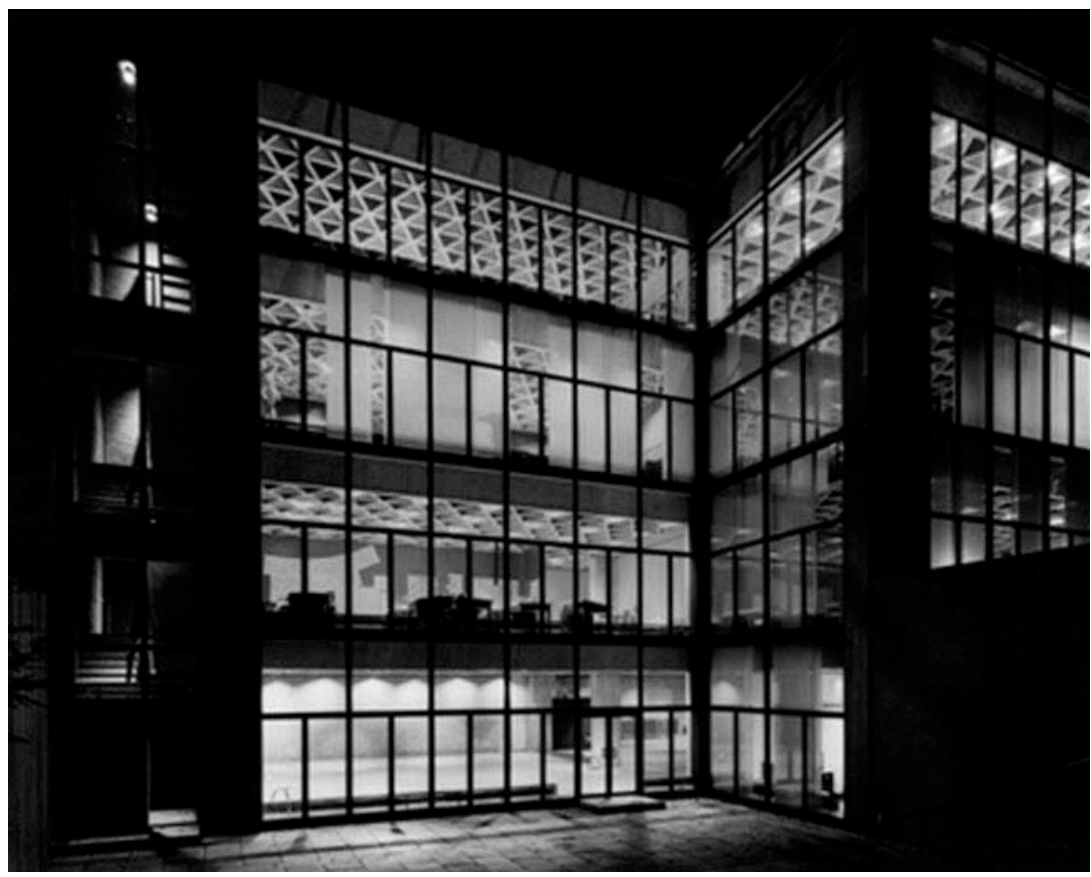

2.31

Exterior view of building during evening with trapezoidal ceilings illuminated, Yale University Art Gallery, New Haven, Conn., Louis Kahn (1951-53) 
could invoke an inter-relationship between the ideal and the actual, between unalterable perfection and its imperfect shadow. Beyond its own self-generating rationale, the use of this geometry to generate a spatial matrix evidently carried a deeper symbolic meaning in Kahn's work. We get a sense of this in an interview with Kahn regarding his later design for the Universal Atlas Cement Company Building. He states:

The acceptance of the tetrahedron also reveals spatial opportunities. The structure teaches. This is the natural shape which a tetrahedral system will make without interference... The building makes itself strong by reason of its triangulation. ${ }^{174}$

Kahn's belief in the pedagogical function of geometry, in which the tetrahedral system forms shapes "without interference" could be likened to the generative role of geometry revealed in Plato's Meno, discussed earlier. Rather than suggesting the idea of an internal, self-referential logic, Kahn is implying that triangulation affirms an eternal order, redolent of a cosmology.

Understood in these terms, the structure of the ceiling at the Yale Art Gallery could be interpreted metaphorically as a celestial matrix of geometric relationships. In one sense this could be read as a constellation of inter-dependent triangular relationships that invoke Plato's cosmology. Such an interpretation could be considered further in the context of Kahn's drawings of the Giza pyramids. As we have seen, these represent the pyramids at various elevated positions, from where the solidity of the monuments can be most clearly conveyed against the background of the vast and flat desert landscape. In the case of the Yale Art Gallery ceiling, Kahn has effectively translated the solid - earth-bound - squarebased pyramids of the desert into the "sky-bound" negative triangular-based tetrahedrons. In this translation, it could be argued that Kahn was reflecting upon the generally held view of the celestial significance of the pyramids of Giza, which more recently have been found to "mirror" the belt of Orion. ${ }^{175}$

Combined with this association are allusions to Albers' geometric "transformations". In one's perception of the constantly shifting alignment of volumes of the tetrahedrons we are reminded of the oblique perspective in Albers' Constellation: Transformation of Scheme No.12. This connection is reemphasised by the visual effect of the projecting edges of the concrete ribs of the pyramidal coffers that protrude in relief against the darker voids above. The effect could be likened to the white lines etched on the black backgrounds in Albers' geometric "experiments".

The heavy mass of the ceilings are only relieved by the mass of the silo staircase that punctures through the floors. This extruded cylindrical volume terminates at high level with a triangular canopy that spans the opening of the drum and partly conceals a roof-light above. Hence, the canopy is set in sharp relief against the light flooding in through the side openings. What is experienced in the main exhibition spaces as a matrix of volumetric tetrahedrons is reduced in the stairwell to the constituent geometric form of the triangle. This geometry 
is further echoed in the triangular arrangement of the stairs in the drum below. The shift from the continuum of the triangular coffered ceiling in the gallery spaces to the isolated triangular canopy in the stairwell (the latter telescopically extended through the building) was doubtless informed by Kahn's understanding of the cosmological meanings of geometry. This symbolism could be interpreted as a generative process that moves from the singular equilateral triangle - evocative of the element of "Demiurgic" creation - to the multiplicity of coffered tetrahedrons that extend across the expanse of the ceilings beyond.

We are reminded, in the shift from the horizontality of the exhibition spaces to the verticality of the stair drum, of a story retold by Socrates in Plato's Theaetetus. It tells of a

Thracian maid-servant who exercised her wit at the expense of Thales, when he was looking up to study the stars and tumbled down a well. She scoffed at him for being so eager to know what was happening in the sky that he could not see what lay at his feet. Anyone who gives his life to philosophy is open to such mockery. ${ }^{176}$

One advantage, however, of Thales' misfortune was his "discovery" that the well provided an instrument of sorts for isolating - and thereby individuating - the elemental triangle of creation from the profusion of triangles that make up the heavenly constellations. The shift from one to the other could be construed in perspectival terms as a transformation from a primordial state of reverie and wonder of the celestial realm to the "point of view" of an observer defined by the telescopic apparatus of the stair drum.

In attempting to overcome the pitfalls of instrumentality, that we see for example in aspects of Fuller's structural constellations, the Yale Art Gallery reveals a more ambiguous - and ultimately more rewarding - dialogue between geometry and architecture. This dialogue is underpinned by what Goldhagen considers as an existentialist aspect to Kahn's thinking. ${ }^{177}$ Of particular relevance to the Yale Art Gallery is the existentialist notion of authenticity, first introduced by Martin Heidegger in twentieth-century philosophy and popularised in the writings of Jean-Paul Sartre. ${ }^{178}$ By seeking to overcome the modern proclivity to "construct" identities, that gives undue emphasis to an aesthetic of the present, the question of authenticity - when considered as a phenomenological/existentialist concern - allows for a more situated relationship to temporal existence. We see this in Kahn's use of geometry in the way it reflects upon a deeper tradition and at the same time anticipates future possibilities for architecture. Accordingly, Kahn believed that the historical world is always already present in our experiences and thereby open to creative reinterpretation. As Kahn himself said: "What is has always been. A validity true to man presents itself to a man in circumstances. A man can be a catalyst to a validity. Yet it has to await its realization, it has to be given presence." 179

We are reminded here of Heidegger's differentiation between the innate historicity of the world and its historiographical representation: 
The transcendence of the world has a temporal foundation; and by reason of this, the world-historical is, in every case, already "Objectively" there in the historicizing of existing Being-in-the-world, without being grasped historiographically. ${ }^{180}$

In Kahn's search for authenticity the background historical world - that exists as part of our situated experience - provides a communicative domain that can be shared. It is from this pre-existing historical world that Kahn drew upon architectural ideas:

Kahn's buildings become receptacles for communal identification partly by provoking viewers' associative memories - embodied history, internalized as second nature and so forgotten as history.... Viewers appropriate these vast new constructions as a modern continuation of a pre-existing communal heritage. ${ }^{181}$

Communal heritage in this instance could be likened to the Husserlian idea of geometry as tradition, discussed earlier, only in the case of Kahn geometry is experienced phenomenologically through built form rather than "handed down" through discourse. It is in the context of this understanding that Krell's argument against a historical view of geometry must be challenged. Rather than considered in terms of an "atemporal" present, as Krell seems to allude, geometry serves in Kahn's work as a communicative tool that can sustain, by metaphorical means, a dialogue between the materiality of architecture and the metaphysical ground of its origin. 


\section{Chapter 3}

\section{Light, memory and colour}

\section{Medieval transformations}

Medieval Europe witnessed the beginnings of a scientific outlook that saw light as a phenomenon requiring rational explanation. This new outlook, however, was informed by a prevailing onto-theological world-view that assumed all knowledge as revealed truth.

Coinciding with this nascent scientific view were important changes in the understanding and perception of space. Whilst the "perspectivisation" of space was not in full swing until the early Renaissance, the cultural conditions necessary for such a transformation were already in place by the end of the thirteenth century. ${ }^{1}$ Indeed, a number of key developments occurred during this period that lay the foundations for a new perspective outlook. Among these, as Dalibor Vesely notes, were the "growing individualism of cities, the first signs of a new humanism, and the change in the nature of knowledge... which includes the return to Aristotelianism and the formation of a new philosophy of light and optics". ${ }^{2}$ Related to these developments, as this chapter will highlight, was an important shift in the understanding of the relation between visual experience, spoken language and textual narrative.

A unifying factor in the movement towards perspective is the way representation, and the ordering of space generally, begin to take into account the position of the spectator. This is most apparent in religious events:

The role of the spectator was further cultivated in the religious plays performed first in churches and then, during the fourteenth century, mostly in the open spaces of the city. The performances in the open were staged in a setting oriented precisely east to west, in an idealised representation that eventually transformed the whole city temporally into an ideal city. ${ }^{3}$ 
The example of the Medieval Passion Plays highlights the way in which both performer and spectator experience the city as a series of dramatic episodes within the larger procession. These settings periodically appropriate existing public space by orienting movement perspectivally, into the "depth" of the city. Such religious performances were deemed in one sense as re-enactments of Biblical events that elevated the city as a "mirror" of heavenly Jerusalem. ${ }^{4}$ By the Renaissance, as we shall examine in Chapter 4, these periodic transformations took on new paradigmatic status, when questions of authenticity and meaning increasingly drew example from theoretical (humanistic) rather than theological models of the ideal city.

It was, however, in the study of light and optics that this shift to a "perspectival" view of the world was most apparent during the Middle Ages. The Medieval experience of filtered light, as we see for example in stained glass windows, was understood in analogical terms as a mediating realm between earthly matters and heaven. ${ }^{5}$ This mediating function meant that light - in particular coloured light - served as a symbolic "bridge" between the eternal and ineffable realm of the divine spirit and the temporal world of human perceptual experience.

An important factor in the development of Medieval light symbolism was the revival in classical optics. Drawing influences from Arab translations and commentaries of the works of Aristotle, Euclid and others, this revival was motivated by a desire to bring optical theory into line with theological thought. The success of the enterprise, as will become clearer later, depended in part on the degree to which the beholder was "attuned" to a redemptive notion of vision. Critically, the Gothic cathedral constituted the principal means of imparting this insight.

The present chapter examines the role of light and optics in the development of perspective by taking the notion of attunement as its guiding theme. The term "attunement" (Gestimmtheit in German) is more familiar in phenomenological enquiry where it conveys the receptiveness of the "state-of-mind" to the "disclosedness" of the world. ${ }^{6}$ In this chapter I use the word to denote the necessary adjustment of perception (and by implication of the soul) to fully experience the other-worldly - transcendent - qualities of light underlying the Medieval worldview. This adjustment could be likened to the tuning of a musical instrument so that it is in harmony with what is already latently present, namely heavenly music (or "music of the spheres"). Considered in theological terms, "attunement" evokes the Augustinian idea of the soul turning - or orienting - towards the divine light (logos) of the merciful God. ${ }^{7}$ The desire of the repentant soul for redemption was intimately bound to Medieval beliefs in a pre-existent divine order, of which light was its most visible manifestation.

The study begins with an examination of important changes in the nature and meaning of text in the thirteenth century, given that these played a key role in the emergence of a luminary understanding of perspectival space. This will be followed by a brief overview of the historical background of optical theory and of the light symbolism of Dionysius the Pseudo-Areopagite. I will then examine 
the ideas of the thirteenth century Bishop of Lincoln, Robert Grosseteste, who has been described as the "father" of Medieval optics. This part of the study will focus primarily on the influence of Grosseteste's studies of light on the design and symbolism of Lincoln Cathedral during his episcopate. My attempt to draw correlations between built form and theological/scientific views of light is based on the premise that Grosseteste saw the Cathedral as a setting where attunement to a transcendent realm could be directly experienced.

Closely allied to developments in optics and light symbolism in the thirteenth century were other factors that contributed to the gradual perspectivisation of space. Of special interest here is the shift - prevalent in Cathedral schools from a tradition of oral communication to one of silent reading. In this shift, vision takes precedence over utterance, a point I will examine further in the context of Grosseteste's contributions to systems of indexing.

Quite how the transition from Medieval optical theory to pictorial perspective occurred will form the subject of the next part of this chapter. We will explore this in the context of the writings of Lorenzo Ghiberti and the so-called London Annunciation, one of a number of representations of the theme by Filippo Lippi. By referring to the investigations of Dalibor Vesely, Leo Steinberg and Samuel Edgerton, I will argue that the transition was not as decisive as some have suggested but rather entailed a brief period (in the early fifteenth century) when pictorial perspective and optics co-existed as inter-dependent elements of the same revealed truth.

In the concluding part of this chapter I will examine the nature and meaning of colour in the modern world, focusing on the ideas of Walter Benjamin. Here I will argue that Benjamin's phenomenological perspective of colour, in which understanding is conveyed as pure experience, was derived in part from a deeper messianic tradition relating back to the apocryphal texts of the Pseudo-Dionysius. Benjamin however saw this Judeo-Christian tradition as a point of departure from which to transform the earlier transcendent understanding of colour into a radically immanent one. This emphasis will serve as a theoretical context for an examination of the Chapel of St Ignatius in Seattle by Steven Holl. In this seminal architectural work the articulation and ordering of space is defined chromatically by the interplay between colour fields and filters. To what extent Holl's design drew upon a latent tradition of colour symbolism will be considered in this case-study.

\section{From memory to recorded document}

In Chapter 2 we saw, in the context of Plato's Meno, how the change from number reckoning to geometry coincided with the new practice of recording and formalising philosophical dialogues. This change, however, did not signal the end of an oral tradition, which was to persist into the Middle Ages and beyond, but rather set in motion the conditions necessary for the eventual dominance of written testament. This begins to happen in earnest in the late twelfth and early thirteenth centuries when we witness a significant increase in record making. The development suggests a shift from the practice of habitually memorising things to the act of writing. As M. T. Clanchy notes, the transition was as profound "a 
change in its effects on the individual intellect and on society" as the later transformation from script to print. ${ }^{8}$

The increasing demands for documented records in the affairs of State and Church led to the emergence of a new style of script in the twelfth century, the cursive, that enabled scribes to write faster. ${ }^{9}$ This was accompanied by new manuscript formats to ensure greater clarity, such as the glossed scholastic text and the more revolutionary pocket-sized Bible. ${ }^{10}$ Coinciding with these changes was an increasing prevalence of silent reading. In the oral traditions of the ancient and early Medieval worlds, the act of reading aloud assumed the primacy of text as a complete and indivisible body of revealed truth. The lack of paragraphs and punctuation marks in Medieval manuscripts, that would later provide the necessary cues for pausing and reflecting in silent reading, meant that writing was "no more than speech on a page". ${ }^{11}$

Moreover, "Not only did oral activities predominate in the act of reading, they also determined the task of the eyes." 12 In other words, the process of reading a text aloud - as opposed to reading silently - led to the flow and rhythm of words in utterance taking precedence over merely recognising individual letters.

Hence, before the twelfth century reading was by all accounts a very vocal affair that gave public recognition to an individual's devotion to God. The occasions for reading were determined by the strict order of canonical prayer, typically announced by the sounding of a bell. However, with the growing prevalence of silent reading, from the beginning of the thirteenth century, the analogy between reading and bell ringing was lost. In its place emerges the more private scholastic activities in monastic libraries. ${ }^{13}$ One consequence of this change is that reading becomes an "intercourse between a self and a page". ${ }^{14}$

Accompanying the increasing volume of written matter in the twelfth century was a practice of indexing texts. Early Medieval manuscripts were generally produced without indexes or contents pages. This meant that the reader could not easily dip in and out of a manuscript. However, by the late twelfth and early thirteenth centuries a new practice emerges of incorporating notes on pieces of parchment (cedulas) that served as memoranda to an accompanying text. Grosseteste was, it seems, one of the first to introduce this method for jogging his memory on important aspects of a manuscript. ${ }^{15}$ It would be misleading, however, to assume in this early form of indexing a direct correlation with modern indexing systems. The meaning of the Latin term "index" reveals much in this regard:

The word "index" is a shortened form of index locorum. The loci (places) in such an index were the "commonplaces" or headings, under which a thinker organised various subjects for recall. These "places" were located in the mind's eye and not in the book being read. ${ }^{16}$

Hence, whilst the signs for jogging the memory were located in the margins of the text, the place where this material was ordered occurred in the reader's mind. 
Mental indexing was a common feature of ancient rhetoric, as we see for example in the anonymous Ad Herennium. ${ }^{17}$ The text, which was mistakenly attributed to "Tullius" (Cicero), deploys mnemonic images to assist the orator in delivering his speech without the aid of a text. Its precepts for developing an artificial memory had a significant impact on Medieval scholastic thinking. ${ }^{18}$ We can see this most clearly in the introduction of pictographic indexing (or signa) in the late twelfth century that was first used in a systematic way by the Dean of St Paul's, Ralf de Diceto. ${ }^{19} \mathrm{He}$ describes how the making of a chronicle "always runs on infinitely", in which case the reader needs markers to prompt his memory at critical points. ${ }^{20}$ The idea of forging a "trail of thought", through a seemingly endless document, could be likened to the experience of navigating an unfamiliar territory in which the explorer is seeking out landmarks to delimit a route.

The analogy between place and mental indexing was to take on added significance in the emergence of perspective in the Middle Ages. This is initially indicated in the primacy given to the eye in the search for wisdom. Ivan Illich argues, in his investigations of the ideas of Hugh of St Victor, that the twelfth century witnesses "a special correspondence between the emergence of selfhood understood as a person and the emergence of 'the' text from the page". ${ }^{21}$ The distinction between text and page, whereby the message emerges out of the text as divine illumination, reflects a new visual perspective. This form of perspective, however, is different in kind from that relating to the printed page in the Renaissance. In the latter, the page takes on an analogous relationship to the picture plane of pictorial perspective (perspectiva artificialis), a point for further discussion in Chapter 4.

By the end of the thirteenth century the individual cataloguing methods of bishops and deans were supplemented, and eventually superseded, by the introduction by English Franciscans of shared catalogue systems. Significantly, these were used by more than one hundred and eighty ecclesiastical libraries. ${ }^{22}$ The contrast between the traditional Benedictine practice of poring over single books and the friars' demands for more efficient means of accessing information from different sources could not be more apparent in this development.

The creation of systematic indexing and cataloguing methods contributed to a new understanding of the manuscript. ${ }^{23}$ Traditionally, the religious text is understood as "revelatory" in nature, whereby the single work constitutes a complete and unitary divine message: "Reading is for the early Christian primarily the interpretation of one book", whereby "the pious reader desires to be possessed by the word, not to manipulate it". ${ }^{24}$ By the thirteenth century, this understanding of text is transformed by the introduction of a series of distinguishable parts awaiting intellectual scrutiny and interpretation. Illich argues that the period of the thirteenth century saw the emergence of an important distinction between the "light of reason" and the "light of faith", both of which lead to two kinds of reading; philosophy (/umen rationis) and theology (lumen fidel). ${ }^{25}$ Grosseteste, among others, recognised the problem posed by the separation between faith and reason which he sought to bridge through the unifying agent of light.

Besides the use of pictographic signa as indexing tools during this period, a more abstract method was developed by Grosseteste whilst at Oxford: 
Grosseteste devised a system of about 400 symbols, which he placed in the margins of texts to indicate different subject matter. An upturned "V", for example, indicated references to "God's wisdom" and a crescent moon pointing to the left indicates "the dignity of man." ... Grosseteste's signa are abstract in form: intersecting lines, patterns of dots, and the like. ${ }^{26}$

Grosseteste's use of intersecting lines and dots in his indexing system is, in one sense, redolent of the elements that constitute Pythagorean/Platonic cosmology, discussed in Chapter 2. The combination of these elements as memory devices evokes the role of number and geometry in Platonic notions of recollection (anamnesis); in particular as they pertain to gnomonic relationships (from formless unity to formed multiplicity). Grosseteste's system of motifs could even be likened to the marks used by masons to indicate the order of assembly of stone components in a church. ${ }^{27}$ Considered in this sense, one could speculate that Grosseteste was seeking to develop a symbolic system that conveys, in analogous terms, the relation between the temporal acts of reading and building, the latter conveyed symbolically through the spatial progression in sacred architecture. This relationship is indicated by the way in which the motifs that Grosseteste deploys seem to convey a hierarchical - or graduating - relationship to God. As we shall see below, the implied connection between text, geometry and building was not simply of scholastic interest but also served a more practical purpose during Grosseteste's role as the Bishop of Lincoln.

\section{Light metaphysics}

During the Middle Ages questions concerning the nature and meaning of light drew ideas from two inter-related influences, both derived from ancient traditions. For convenience we will call these influences the cosmological and the optical, both of which will be explored in some detail in this enquiry. The first outlook conceives the medium of light as constituting the "gaze" of God. At the heart of this outlook is the notion of light as fons et origo (source and origin) of all created things - an idea that can be traced back to the earliest creation myths. ${ }^{28}$ It provided the basis of Neo-Platonic and Early Christian meditations about the Creator and inspired the light worship of the Manicheans.

At the heart of this tradition is the principle of an ontology of light. Considered in specifically Christological terms, the principle assumes the illumination of the world as embodying the redeeming power of God's grace. What was once construed in mythic traditions as affirming the presence and authority of cosmic deities, takes on a more complex metaphysical dimension in Neo-Platonic and Christian symbolism. In this dimension, the meaning of light is understood in relation to its opposite, darkness. Expressed in the story of Creation in Genesis, the duality provided the basis of a rich symbolism in Christian iconography, as we see for example in representations of the Last Judgement. ${ }^{29}$

This symbolism could be compared to Plato's famous "simile of the cave", described in the Republic. The philosopher uses the duality between light 
and darkness as a metaphor to convey the passage from ignorance to enlightened thought. ${ }^{30}$ This principle underlies Early Christian views of light, as we see for example in the writings of St Augustine and Dionysius the Pseudo-Areopagite.

In the particular case of Dionysius, the simple duality between light and darkness - indicating the states of salvation and sin respectively - takes on a mystical significance in his principle of "negative theology". ${ }^{31}$ At the heart of Dionysian theology is the notion that divine light is numinous, meaning that it is not of this world and therefore cannot be directly related to the everyday experience of natural light. Accordingly, our understanding of divine light is explained in analogical terms as a state of blindness, whereby the infinitesimal power of God is registered in the infinitesimal brightness of his presence. Darkness, therefore, is understood not in terms of deprivation but rather in terms of transcendence. In such a transcendent darkness light is so bright that it prevents one from seeing, forcing the worshipper therefore to look inwardly. It is for those "who pass beyond the summit of every holy ascent, who leave behind them every divine light, every voice, every word from heaven, and who plunge into darkness where as scripture proclaims, there dwells the One who is beyond all things". ${ }^{32}$

Blinding brightness defines a condition of being where the presence of the unknowable God can be experienced only in the negative (absolute darkness) rather than in the affirmative (light). Dionysius' symbolism transforms the simple duality of light and darkness by communicating the idea of a "coincidence of opposites". In this paradoxical idea, which I discussed briefly in Chapter 2, the obstacle of an unbridgeable divide between the finitude of human experience and divine infinitude is transformed into a mystical dialogue. ${ }^{33}$ Consequently, the coincidence of opposites overcomes the conflict between an understanding of darkness and of light as different by degree and as part of a process.

Closely allied to Dionysius' theology of light is his notion of hierarchy. ${ }^{34}$ The term, which was supposedly invented by the Greek mystic, denotes the progressive relationship between earthly and heavenly realms. The gulf separating humanity from divinity is filled by tiers of angelic intermediaries whose task is to disseminate the message of divine Logos. In so doing, hierarchy could be said to provide a symbolic framework for Dionysius' concept of negative theology; the position of intermediaries in the larger hierarchy is registered symbolically by the degree of intensity of heavenly light. Acting as a mystical "ladder" to God, Dionysian hierarchy reveals simultaneously ascending and descending relationships between perceptible (corporeal) and imperceptible (divine) light.

The impact of the ideas of Dionysius on Medieval thought was only fragmentary at first. In the early part of the twelfth century, extracts from the Dionysian corpus could be found in the writings of Peter Lombard and others. ${ }^{35}$ By the mid-twelfth century, however, the Dionysian corpus began to acquire an almost venerated status. This was partly due to a mistaken identity concerning the authorship of the texts. Latin commentaries on the corpus identified the writer as Dionysius the "Areopagite", believed to be the same Dionysius "the convert", mentioned in the Acts of the Apostles. He was also identified with the same Saint Denis, the martyred first bishop of Paris. ${ }^{36}$ The confusion over the identity of this 
figure further enhanced the mystery surrounding the apocryphal writings. A corrupted Greek manuscript of Dionysius' corpus was donated, as a precious relic, to the Abbey Church of Saint Denis by Louis the Pious. It was in this Abbey, coincidentally, that the first bishop of Paris was buried. The text, which was translated into Latin by the Irish theologian John Scotus Eriugena in the early ninth century, inspired Abbot Suger's later building work at the Abbey in the twelfth century. ${ }^{37}$

The influence of the corpus on architecture was drawn mainly from Dionysius' use of the analogical method for interpreting light, or what Abbot Suger construes as "upward-leading" (anagogicus mos). ${ }^{38}$ In this method the experience of light is expressed as a two-stage process. This is explored by Erwin Panofsky in the context of an account by Suger of some "resplendent doors" in the Abbey:

[Suger] describes the resplendent doors ... as "being bright" (clarere), and even calls them "lights" (/umina), in a purely perceptual sense. But he goes on to say that this physical "brightness" will "brighten" (clarificare) the mind of the spectator by the spiritual illumination so that it may travel through those terrestrial or visible "lights" to the "True Light" of heaven. ${ }^{39}$

Suger's allusion to light as a metaphoric journey, that moves from sensual experience to spiritual fulfilment, is a thoroughly Dionysian idea. It derives from the Platonic principle of intellectual Forms, only here light (rather than number and geometry) constitutes the principal mode of transmitting the eternal and ineffable realm of the divine to the human soul. The reliance on luminous objects to "trigger" a mystical experience of light formed a central theme in Medieval analogical thought.

Grosseteste had intimate knowledge of the precious manuscript at St Denis. Indeed, he was the first to bring out a translation and commentary of the Dionysian corpus in the thirteenth century, following its earlier reception in the French Cathedral schools of the twelfth century. ${ }^{40}$ Two aspects of Dionysius' work exerted the most influence on Grosseteste's thinking. The first, closely related to his translations of the Celestial Hierarchy and Ecclesiastical Hierarchy, concerns Grosseteste's conviction about the need for a clearer hierarchical structure in the Church that can mirror the celestial hierarchy. This analogy is highlighted in a dispute that took place at Lincoln Cathedral between Grossesteste and the Chapter and Deacon. The dispute centred on the issue of visitations and the Bishop's jurisdiction over the running of the Cathedral. Coinciding with the Bishop's work on the Dionysian corpus in the late 1230s, the dispute sharpened Grosseteste's resolve to redefine the role of the bishop in the pyramid of authority, from Pope down to the parish priests. Grosseteste's interpretation of Church hierarchy was also to inform his understanding of the iconography of Lincoln Cathedral, a point which we will return to later.

One aspect of Dionysian hierarchy that is generally overlooked concerns its influence on the symbolism of colour. John Gage identifies parallels between this and a Byzantine mosaic of the Transfiguration of Christ from Sinai: 
In the Transfiguration the "light" emanating from Christ's mandorla becomes whiter as it recedes from its source, and here at Sinai it even turns the Apostles' garments blue. This unusual characteristic ... may be a reflection of the view propagated by the sixth-century theologian the Pseudo-Dionysius, that at this moment in Christ's life, "a cloud and darkness were about him". ${ }^{41}$

The idea seems to echo Grosseteste's understanding of hues as constituting "grades" of light and darkness, whose sequence serves as a "perceptual bridge" to the ultimately imperceptible divine light revealed in the Saviour's Transfiguration. Grosseteste constructed a network of colours, comprising two interconnected sequences of seven ascending and seven descending hues. ${ }^{42}$ Probably intended to serve as the basis of a three-dimensional model of light, this remarkable construct of inter-connected sequences of hues is indicative of the influence of Dionysian theology on Medieval colour theory.

The second influence that we can trace in Grosseteste's work is drawn, among other sources, from the Bishop's study of Dionysius' Mystical Theology. In this influence, which we will explore in more detail later, Grosseteste's investigations are underpinned by a belief in the transcendent nature of light (its self-multiplication and diffusion), whose meanings are ultimately beyond every limitation and explanation.

\section{Optical science}

In antiquity we witness the first tentative shift away from the idea of a transcendent God lighting up the cosmos to the idea of man lighting up his own personal world. This shift highlights the second influence on the nature and meaning of light, namely the optical. Inference of this shift can already be seen in Plato's notion of the "fire in the eye": the belief that the act of seeing contributes to the illumination of the world. One consequence of this gradual transition, from an essentially emanatory/transcendent understanding of light to what would ultimately become an immanent one, is the growing dominance of optical theory in philosophical and scientific discourse. Concerned with matters relating to the nature and propagation of light, including the study of colour, the eye and the visual properties of mirrors and refracted surfaces, optics was understood in the Middle Ages as perspectiva naturalis. ${ }^{43}$

The term was subsequently appropriated in the Renaissance to denote the techniques of pictorial representation in perspectiva artificialis. Underlying this appropriation of traditional optics to pictorial space was an important development, as Hubert Damisch explains:

Whereas perspectiva naturalis demonstrates the how and the why of the apparent diminution of objects in proportion to distance, perspectiva artificialis would seem to have been a development of it - an unforeseeable one? - intended to subject representation to the laws of optics, or again, in the ancient sense of the word, to those of vision, 
the clear, distinct kind of vision that is understood in ancient discourse on geometry. The problem facing us is that of determining whether, in so passing from one register to another, one renounces traditional optics, appealing instead to a new idea of science, and of representation. ${ }^{44}$

The nature and extent of the transition, which I referred to earlier in Chapter 2 in the more general context of geometric thought, gives some measure of the gradual "perspectivisation" of the world. The shift from a Scholastic to a Humanistic world-view contributed to the demise of the traditional idea of an embodied transcendent Being. ${ }^{45}$ As Cecil Grayson notes in the context of Leon Battista Alberti's famous treatise della Pittura:

[Alberti's] view, typical of the religious sense of humanists, looks from Man outward toward God, and not, as broadly speaking characteristic of medieval thought, from God and eternity to Man. This fundamental shift of perspective is seen in the fifteenth-century celebrations of the dignity of Man that reach their climax in the work of Pico della Mirandola. ${ }^{46}$

Whilst firmly rooted in the Scholastic tradition of the Middle Ages, Robert Grosseteste's work as a theologian and natural philosopher should nevertheless be seen as occupying a critical position in the transformation Grayson describes. Within this transformation Grosseteste attempts to define a perceptual field that allows a balance between an optical and a mystical (cosmological) reading of light. His many writings attest to a vision of light that was both influenced by the Dionysian corpus and at the same time lays the foundations for a physical theory of light.

During the thirteenth century Aristotelian philosophy had a significant influence on the Scholastic understanding of optics. ${ }^{47}$ One of the underlying tenets of Aristotle's philosophy is the opposition to the Platonic view "that natural things are based on mathematical things; and mathematical things on divine things". ${ }^{48}$ The Aristotelian distinction between the physical world and the abstract realm of mathematics was challenged by Grosseteste and his pupil Roger Bacon. Both applied a Platonic view to optics that sought to bridge the divide separating sensus from spiritus. In so doing Grosseteste gave legitimacy to the notion of the cosmos as a mediating realm between divine intellect and human perception.

Grosseteste worked during a period that saw a growing interest in the classical debates about the nature and meaning of vision. The dominance of optical theory in the Franciscan schools in the thirteenth century could be said to represent a small shift away from the understanding of light that prevailed in the French cathedral schools during the twelfth century. In the case of the latter, as we have seen, light was considered in every sense as a mystical medium that required analogical understanding. The re-emergence of optical thought in the thirteenth century led to a revision of this mystical view. It is in the context of this shift that Grosseteste's work as natural philosopher and theologian was so critical. 
At the heart of the classical debates about vision was the philosophical dispute between the physical (Aristotelian) view - that construes vision as essentially a process of intromission - and the mathematical (Euclidian) view - that argues for an extramission theory. ${ }^{49}$ Compared to "Plato's somewhat elusive, immaterial bridge of light between object and eye", Euclid's Optics effectively reduces the visual field to a cluster of rays, cones and angular measurement. ${ }^{50}$ Whilst Euclidian geometry has its roots in Platonic cosmology, the new emphasis on clarity - as opposed to ambiguity - signalled a new departure..$^{51}$

The interest in the geometry of vision in the Middle Ages, that we see in the work of the "perspectivists" (Witelo, Roger Bacon and John Peckham), was to bring new challenges to Scholastic thinking. In particular, to what extent is this way of explaining vision compatible with the principle of an embodied and transcendent light? In other words, how might the fixation with optical geometry and the retina be compatible with the notion of an all-pervasive divine light? Grosseteste's Platonic understanding of vision sought to address this potentially problematic relationship by reconciling perceptual and cosmological aspects of light.

\section{Grosseteste's light}

The contributions made by Grosseteste, and the later Medieval perspectivists, to optical theory were initially indebted to the Arab Aristotelians. ${ }^{52}$ Among the first Arab authorities in this field was the ninth-century natural philosopher, Al-Kindi (Alkindi), who resided in the Abbasid court in Baghdad. His De aspectibus, which was translated into Latin, was to have a major influence on Grosseteste. ${ }^{53} \mathrm{~A}$ central plank of the work is the notion that all objects and substances produce rays of light rather like stars. These rays are emitted in all directions, thereby binding the physical world into a web of abundant light. The idea of radiant light probably provided the inspiration for Grosseteste's famous theory of the "multiplication of species". Rooted in Neo-Platonic doctrine, the term "species" is partly derived from the Greek word eidola. It refers to thin films of atoms that emerge from the visible object. The meaning served as the basis of Aristotle's principle of light being a form - rather than a substance - that produces images of itself in our perception. The multiplication of species accounts for the idea that light does not move but disperses, "just as our shadow on the ground, as we walk along, is not really a moving thing but is continually being re-created in a new place". ${ }^{54}$ Grosseteste's development of this idea was prompted by a desire to classify visual experience as identifiable "moments" of judgement.

Underlying Grosseteste's idea of the multiplication of species is the principle of light as the prima corporeitas, or first corporeal substance. The Bishop of Lincoln "wished a total reduction of natural philosophy to the workings of light and of the workings of light to geometry". ${ }^{55}$ This mediating function of light - in the chain of connection between divine creation and geometry - was to serve as an underlying theme in two works by Grosseteste; De Luce and Hexaëmeron. The first text, which is a little meditation on the beginning of forms, explores the interrelationship between light and matter in Grosseteste's cosmology. ${ }^{56}$ Grosseteste talks of the "sphericity" of radiant light in this cosmology. Influenced by Alkindi, 
3.1

\section{Illuminated} manuscript (Royal 6.E.V f.6) showing image of Robert Grosseteste

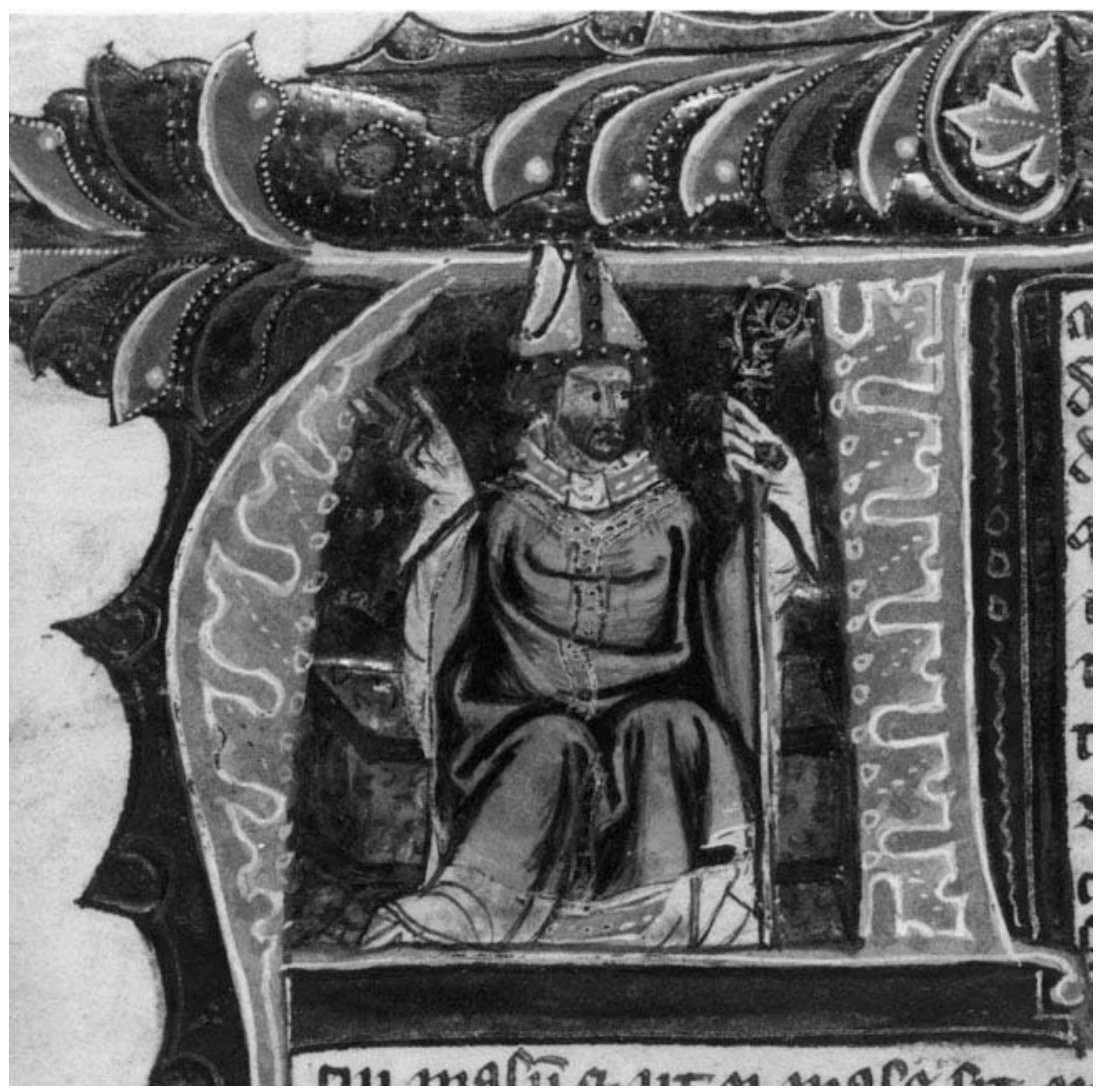

light (lux) diffuses itself spherically, "forming the outermost sphere, the firmament, at the farthest point of its diffusion.... From every part of the firmament light (lumen) is diffused towards the centre of the sphere, this light (the light of experience) being the corpus spirituale." ${ }^{57}$

At the heart of this process of diffusion is Grosseteste's idea of the corporeity of light:

Corporeity ... is either light itself or the agent which performs the aforementioned operation and introduces dimensions into matter in virtue of its participation in light... Therefore light is not a form subsequent to corporeity, but it is corporeity itself. ${ }^{58}$

Moreover, light, "which is itself simple, is multiplied an infinite number of times, [and] must extend matter, which is likewise simple, into finite dimensions".59 Hence, light could be said to extend its reach from the created world to divine eternity.

In the second text, the Hexaëmeron, which is Grosseteste's commentary on the creation narrative in Genesis, the Bishop refers to the relation between "aspectus" and "affectus": "In the same way as light is understood to mean the 
knowledge of the truth, with regard to the glance of the mind, in just that way it is understood as the love of the known truth in the desire of the mind."60 This reveals something curious about Grosseteste's interpretation of optics, namely that "The mind's range of vision cannot extend further than its range of love." Such an understanding, as Richard Southern asserts, formed a maxim in Grosseteste's interpretation of the physical world. ${ }^{61}$ It appeals to the observer to look beyond the world of circumstance, in space and time, by resorting to his mental affectus (desire/love). Through affectus the observer can be properly attuned to his mental aspectus (glance). In this "extension" of knowledge by illumination, the geometry of vision is not a mechanistic framework, as we later see in the optics of René Descartes, but rather embodies the emanating power of God that invites the beholder to seek salvation in transcendent otherness.

The binding of aspectus with affectus in Grosseteste's understanding of vision was informed by his cosmology of light. In this cosmology the Platonic idea of emanation, and its redefinition in corporeal form, offered "the possibility of envisaging the most universal aspect of material things - pure extension - in geometric terms". ${ }^{62}$

Significantly, Grosseteste's deployment of ocular geometry to the cosmology of light was to provide fertile ground for a symbolic understanding of sacred space, as we shall see in the context of Lincoln Cathedral.

\section{The Bishop's Eye}

Grosseteste's appointment as Bishop in 1235, to take charge of the largest diocese in England, was an auspicious moment in the Middle Ages given his reputation at the time as one of the leading theologians and scientists in Europe. The 1230s was an extremely productive period for Grosseteste, being a time when he was engaged in a number of studies on optics. The demands of his administrative and pastoral duties as Bishop of Lincoln were to have a fertile influence on his thought. Like Oxford, Lincoln had established schools of theology and canon law and it was Grosseteste who expanded the breadth of scholarly activity in the city. ${ }^{63}$ At the time of his appointment, Grosseteste was attempting to master Greek and Hebrew, which would later enable him to undertake important translations such as Aristotle's Nicomachian Ethics in the 1240s. To aid him in this task Grosseteste founded a translation school in Lincoln and engaged the duties of a number of Greek scholars. ${ }^{64}$

The period of Grosseteste's episcopate was also a time of much building activity at the Cathedral. This included the completion of the Cathedral nave, the rebuilding of the central tower, following the collapse of the original in 1237-39, and the construction of the Galilee Porch on the south transept. ${ }^{65}$ Much of this work was a continuation - or embellishment - of the first Gothic phase of the Cathedral undertaken by the venerated bishop of Lincoln, St Hugh of Avalon. The period of Grosseteste's episcopate was one of the most productive in the history of the Cathedral. Of the documents that have been preserved from the early thirteenth century one in particular sheds light on the symbolism of the Cathedral. This is the Metrical Life of St. Hugh, written by Henry of Avranches, a 
Lincoln Cathedral. Plan layout indicating locations of the Deanery, Bishop's Palace, Dean's Eye and Bishop's Eye

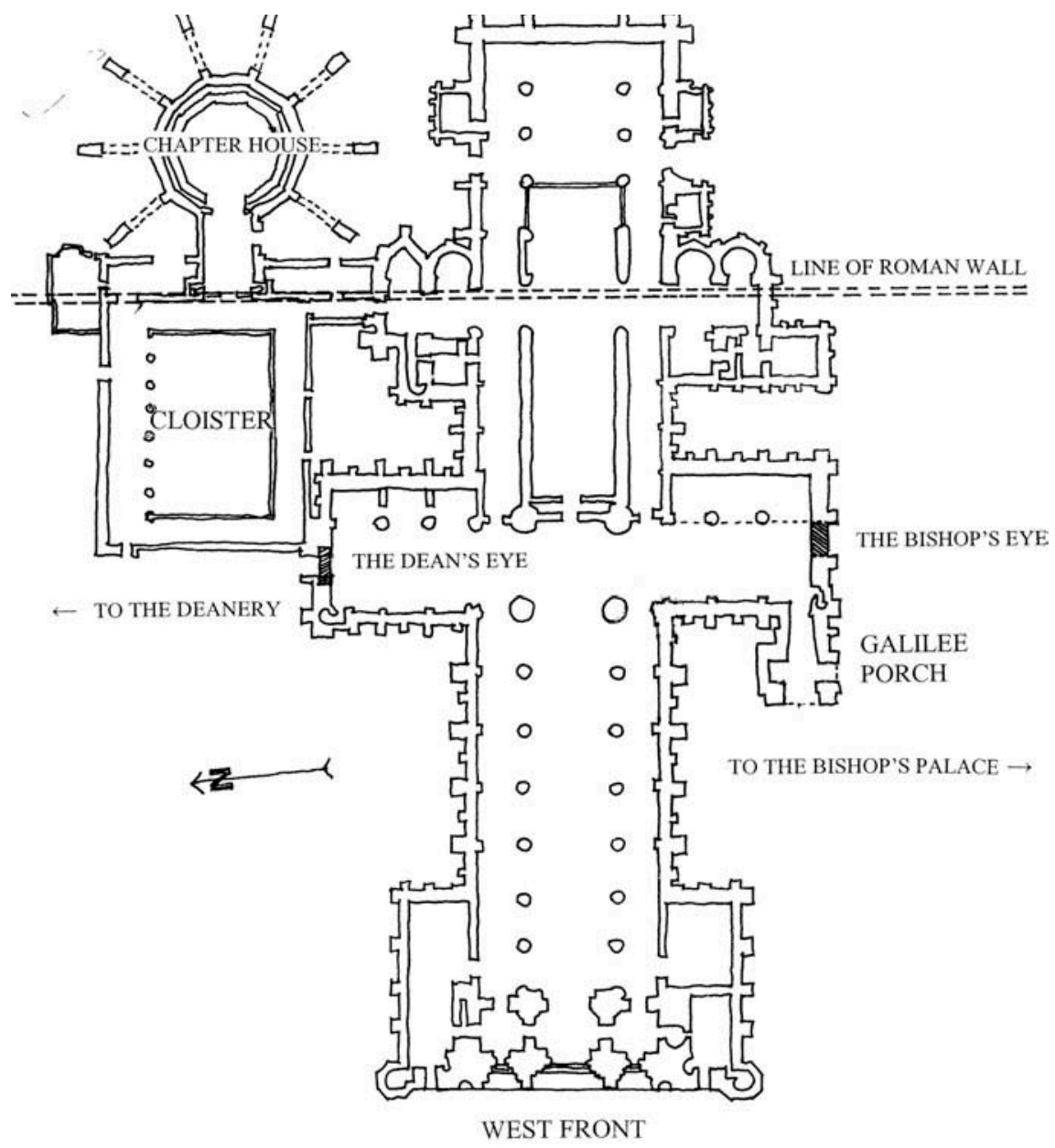

friend of Grosseteste, during the period 1220 to 1230 . At this time the transformation of the old Romanesque cathedral into a Gothic building had proceeded as far as the crossing between the nave and the choir. This is confirmed by the reference in the Metrical Life to two great rose windows in the main transepts, the so-called Bishop's Eye and Dean's Eye. The latter, which is located in the north transept, still retains to this day its original tracery and some of the glass, including a scene of St Hugh's funeral. However, it is conjectural whether much of the vaulting of the transepts survived the collapse of the central tower in 1237 and indeed whether Grosseteste took charge in restoring this to its original state. ${ }^{66}$

The description of the two rose windows in the Metrical Life is particularly germane to this study. Completed during the episcopate of Grosseteste, these monumental windows provide a fascinating testimony to the understanding of light, and its relationship to vision, in the Middle Ages. Henry of Avranches invokes powerful symbolic meanings to this relationship. These are reinforced by 


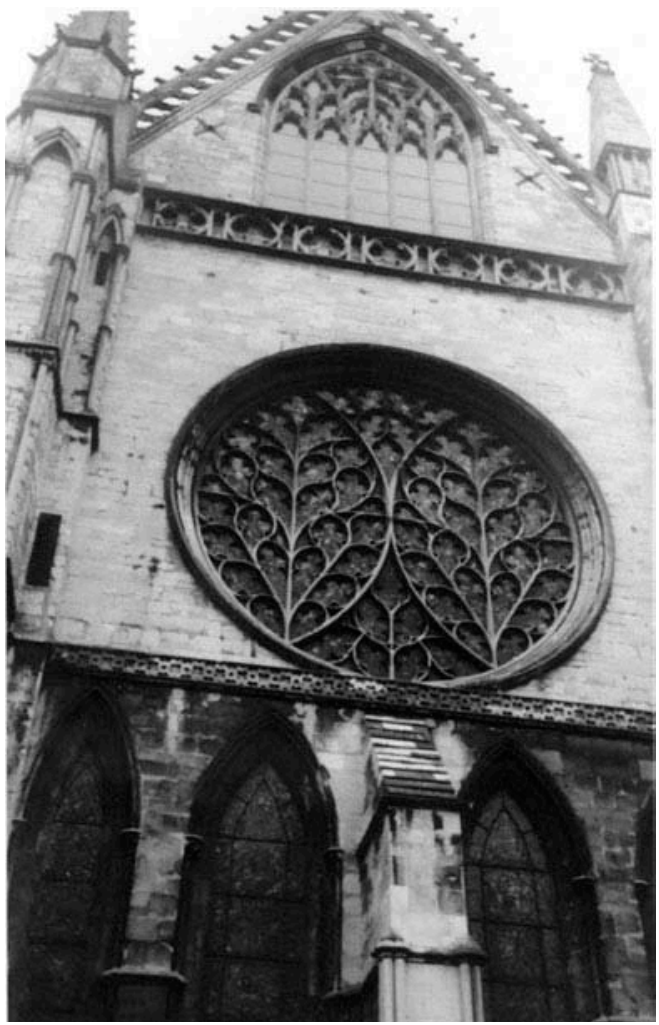

3.3

Lincoln Cathedral. Exterior view of the Bishop's Eye from the south transept

the locations of the two windows; on the dark north side and on the sunny south side of the Cathedral:

For north represents the devil, and

south the Holy Spirit and

it is in these directions that the two

Eyes look. The bishop

faces the south in order to invite in, and the dean the north

in order to shun; the one takes care to be saved, the other

takes care not to perish. With these

Eyes the cathedral's

face is on the watch for the

candelabra of heaven and the

darkness of Lethe (oblivion). ${ }^{67}$

The implied anthropomorphism of the windows, expressed in the symbolism of the two eyes "looking the one to the south to invite the Holy Spirit, the other to the north to guard against the influence of evil", seems to echo Grosseteste's 
3.4

Lincoln Cathedral. View of the remains of the Bishop's Palace to the south

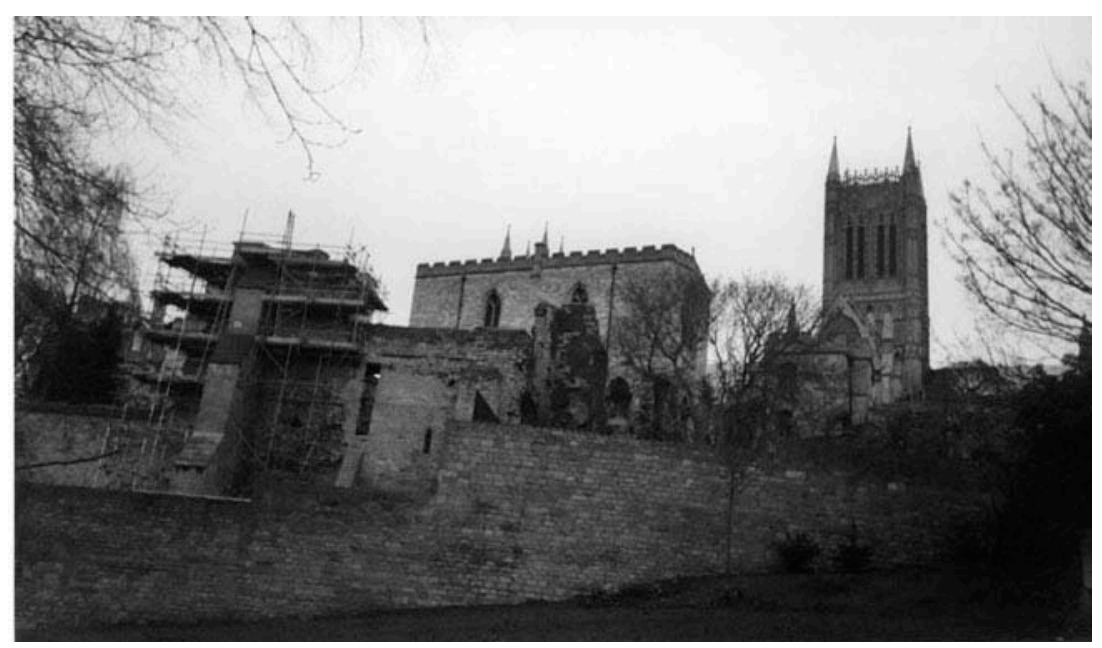

3.5

Lincoln Cathedral. View of the Galilee Porch from the west

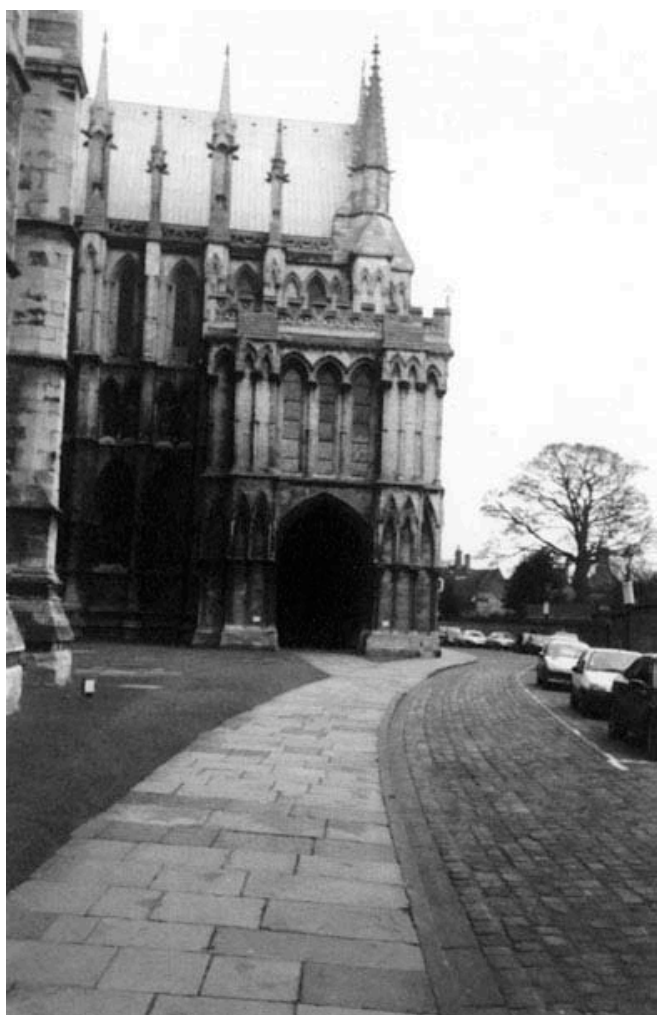

redemptive notion of vision. The names given to the rose windows at Lincoln suggest, moreover, some special alliance between their orientations and the ministries of the Dean and Bishop. This idea is further underlined by topographical connections and textual references. The "Bishop's Eye" faces the nearby Palace of the Bishop, located on the southern slopes adjacent to the "Minster yard". It 
was here that the bishop resided and took charge of his Diocese. ${ }^{68}$ During Grosseteste's episcopate the south transept of the Cathedral was adapted to include the addition of the monumental Galilee Porch that can still be seen today, albeit altered with later Perpendicular additions. Located on the west side of the transept, the porch was built as the main entrance to the Cathedral from the nearby Bishop's Palace.

The use, moreover, of the title "Galilee" in the name of the Cathedral porch may allude to the judicial function of the room located at first floor above the entrance: "where now the Chapter muniments are stored, and where formerly the Dean and Chapter took cognizance of offences committed in the precincts in their court of jurisdiction, 'curia vocata le Galilee' ". ${ }^{69}$ Laid out in the form of a cross, the porch can be entered on the south or west sides.

At about the same time as the construction of the Galilee Porch, Grosseteste also had built a two storey porch to the West Hall of his palace, which was of similar design and roughly on axis with the south transept of the Cathedral. The topographical relation between the Galilee Porch and the nearby Bishop's Palace is further suggested in a description dating from the time of Henry VIII. This states that the doorway of the Galilee Porch was in proximity to the "Byshop's Palace hangginge in declivio". ${ }^{70}$ The relation between the Bishop's Palace and the south transept is echoed on the north transept of the Cathedral which faces the Deanery. ${ }^{71}$ The Dean would enter the Cathedral through a more modest entrance in the gable wall of the north transept, directly beneath the monumental rose window, the "Dean's Eye".

The orientation of the ceremonial entrances on the north and south transepts, towards the Deanery and Bishop's Palace respectively, acquires a particular symbolic meaning when we consider the significance of the rose windows as "emblems" of the two eyes of the Church; of the Dean and Bishop. Facing the monumental Bishop's Eye, at the summit of the hill, the porch of the

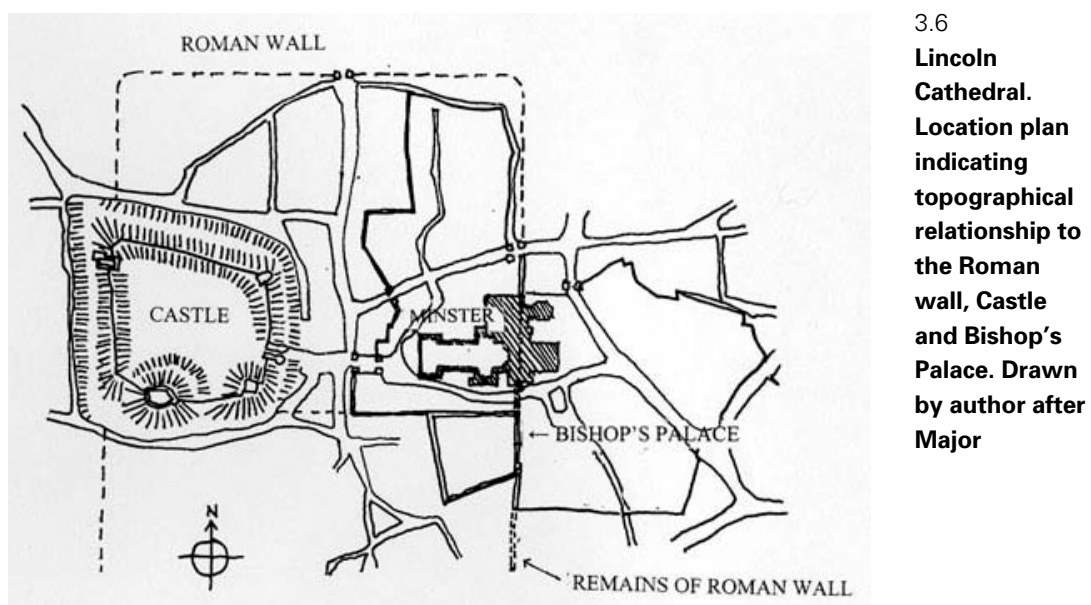


West Hall of the Bishop's Palace would have served as a ceremonial gateway in the processional route of the Visitation, mirrored at the other end by the Galilee Porch. ${ }^{72}$ Clearly, the ceremony of the Visitation acquired certain political connotations during the episcopate of Grosseteste, as we saw earlier, in respect of the Bishop's zeal for reform of the Church.

Grosseteste draws, in his use of optical metaphors, important analogies in the duality between the Dean's Eye and Bishop's Eye as highlighted in the Metrical Life of St. Hugh. This is clearly demonstrated in a pamphlet written by the Bishop in 1239 in response to the dispute, discussed earlier, between the Bishop and the Dean and Chapter. The dispute initially centred around the so-called "Feast of Fools" when the church was turned into a "house of joking, scurrility and trifling". ${ }^{73}$ Grosseteste's objections, however, extended beyond particular "immoral" feasts to more general issues of the role of the Bishop in the affairs of the Cathedral. At the heart of this dispute was the relation between the Bishop as Principale Caput and the Dean and Chapter as Caput Numerale. The question of how pastoral responsibility should be delegated from the Bishop to the clergy was a crucial concern for Grosseteste. He sought to give hierarchical order to the Church Militant in much the same way that the Pseudo-Dionysius articulated angelic roles in the Heavenly Church. ${ }^{74}$

In the pamphlet Grosseteste resorts to Biblical analogies and optical metaphors in an attempt to redefine the role of the bishop in the Church hierarchy:

From the advice of Jethro to Moses, we learn that there are different kinds of ecclesiastical powers, Moses being the type of Christian prelate. In appointing assistants to help him, he did not give up or diminish his power, but reserved to himself the more important cases. The same is true of the prelates, as appears by the example of a mirror reflecting the sun's rays. What the inferior power can do, the superior can, though not the contrary; for inferior judges have only individual cases committed to them, since, if a whole diocese or chapter goes wrong, only the prelate can judge it. To the prelates is therefore reserved the judgement and correction of all cases, individual and universal.... Unless ... the dean and chapter have special exemption from the Pope, they must be subject to the bishop's visitation, as he cannot diminish his own powers... The dean, who always resides in the cathedral, cannot be its visitor, nor, if he could, would that be any reason for excluding the bishop.... As the sun gives light to the moon and stars, so the Pope imparts power to the bishops, and the bishops to their inferiors in each diocese. They can no more hinder the bishops, than the moon and the stars the sun's shining. ... The bishops are also watchmen, and this involves disciplines as well as exhortation, as appears from various examples. Watchmen are placed in vineyards to protect the vines; and though the charge belongs to the head watchman, yet he is pleased if the inferiors anticipate him in the watch, and he must see that they do their duty. So also the bishop. ${ }^{75}$ 


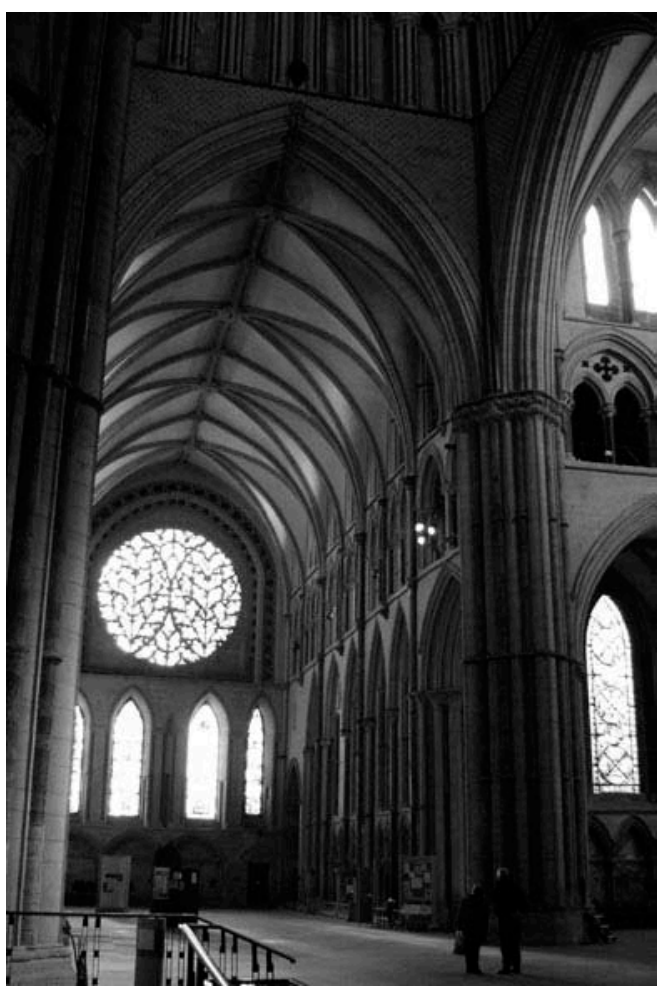

\section{7}

Lincoln Cathedral. Interior looking south towards the Bishop's Eye

Two important issues emerge from this pamphlet. The first relates to the use of luminary references, such as the reflection of light from a mirror or the moon, as metaphors for the transmission of responsibility from a higher order (the pope or bishop) to "inferiors". The second concerns the idea of prelates as watchmen, a notion that is strikingly similar to the description of the Bishop's Eye and Dean's Eye from The Metrical Life of St. Hugh:

The bishop faces the south in order to invite in, and the dean the north in order to shun; the one takes care to be saved, the other takes care not to perish. With these eyes the cathedral's face is on the watch for the candelabra of heaven and the darkness of Lethe (oblivion). ${ }^{76}$

It would seem plausible therefore that Grosseteste had in mind the two rose windows, and perhaps the reference to them in the Metrical Life, when he wrote this pamphlet to the Dean and Chapter. The eyes of the prelates embody the eyes of the Church that watch over the congregation, warding off sinful ways and inviting in penitent discipline. Here, the "father" of Medieval optics presents, through architecture, a "chain of command" that echoes the inter-relation between divine and human vision. The symbolic meanings of the rose windows embody simultaneously the watchful glances of earthly beings - of Dean and Bishop - and the ocular light of divine Being. We are reminded in this relationship of Grosseteste's 
play on the words "caelum" (heaven) and "caelatum" (engraved) in his description of the engraving of stars in the heavens. ${ }^{77}$ The carving of the newly completed tracery of the rose windows at Lincoln Cathedral, in which the starry heavens are embroidered in stone, serves as a powerful emblem of this celestial symbolism.

Related to the symbolism of the rose windows is Grosseteste's reference to the illumination of the sun on the moon as a metaphor of the "shadowing" of the Dean by the Bishop, and the Bishop by the Pope. This is further echoed in an anonymous account of the interior of Lincoln Cathedral, written probably around 1230 and summarised here by John Gage:

The poetic account begins in a rather conventional way by invoking the power of the luminous nave and choir windows to overcome the "Stygian tyrant", continuing: "And two are greater, like two lights, their circular blaze, looking upon the directions of the north and south, surpass through their double light all the other windows. The others can be compared to the common stars, but these two are one like the sun, the other like the moon." Then the author turns to the more immediate and exciting image of the rainbow: "In this manner these two candles lighten the head of the church, and they imitate the rainbow with vivid and various colours; not indeed imitate, but excel, for the sun makes a rainbow when it is reflected in the clouds: these two sparkle without sun, glitter without cloud." 78

The striking similarity between this description, the interior of Lincoln Cathedral and Grosseteste's solar and lunar references in his pamphlet leads one to speculate that they all reflect a common understanding of the analogical relationship between celestial symbolism and architecture.

In the particular case of Grosseteste's celestial references the analogy further demonstrates the Bishop's more practical interest in astronomy as a vital service to the Church. Grosseteste made effective use of his own astronomical observations and calculations in order to correct anomalies in the Julian Calendar. The fruits of his labour were recorded in his Computus correctorius, written around the same time as the anonymous description of 1230 . Critical to Grosseteste's task was the dating of Easter Sunday. Christ's resurrection is traditionally dated during the period of the Jewish Passover, in accordance with the phases of the moon. Hence, rather than being fixed in the Christian calendar, it "drifts against the solar calendar, changing year to year" ${ }^{79}$ Attempts to predict the relationship between the sun, moon and the other luminaries is invoked in the anonymous account of Lincoln Cathedral where the interior is conveyed as a microcosm of the universe. These celestial references could be said to anticipate later developments, from the late sixteenth century onwards, when cathedrals and churches were adapted as solar observatories. Such an association, however, should be treated with a degree of caution: what was understood in the Middle Ages as an embodiment of the heavenly realm symbolised in the "constellations" of stained glass windows - is transformed in 
the early modern age into an instrument for measuring the path of the meridian. ${ }^{80}$

Another aspect of the anonymous account of the interior of Lincoln Cathedral is of interest to this enquiry. This concerns its reference to the relation between the many hues of the rose windows and the experience of a rainbow. The relationship could be compared to Grosseteste's own studies of colour and the rainbow. In his De iride Grosseteste is the first to correctly explain the cause of the rainbow by refracted light, based on Alkindi's theory of burning glasses. An underlying assumption in this "discovery" is that colour is light incorporated into a material medium, and as such serves as a perceptual prefigurement to the blinding light of the divine. This principle finds expression in the brilliance of the two rose windows of the Cathedral. In these, the search for salvation, expressed in the ascendancy from the human perception of coloured light to the experience of the superabundant realm of divine light, is conveyed metaphorically in the physical movement from darkness to light.

The political dimensions of Grosseteste's work as Bishop of Lincoln, highlighted in his pamphlet to the Dean and Chapter and in the construction of the monumental Galilee Porch, were supported by an abiding belief in the sacred qualities of light. As this chapter has sought to argue, Grosseteste saw the redemptive nature of light as a means of guiding the beholder to transcend ignorance and sin. Accordingly, the entwined relationship between seeing and believing, invoked in Grosseteste's interpretation of aspectus and affectus, provided the key to understanding the beholder's attunement to divine grace. The idea further underlies Grosseteste's allusion to the symbolic and topographical relationships of the two "eyes" at Lincoln Cathedral. Through the metaphor of the watchmen, the two eyes invoke the journey of the repentant sinner in his or her search for atonement.

\section{Light and perspective}

The understanding of light and colour in the early Renaissance represented both a continuation of Medieval precepts and a new departure. During the fifteenth century, when perspective was being "re-discovered" and codified, the influence of Medieval optics and light symbolism would seem at first difficult to ascertain. Perhaps one indication of the shift from Scholastic to Humanistic thinking can be found in Renaissance stained glass. Generally, Medieval stained glass arrived late in Italy in the fifteenth century. This is highlighted for example in the embellishments of Santa Maria del Fiore, the Cathedral of Florence. Lorenzo Ghiberti, Paolo Uccello and others were commissioned to design some stained glass windows for the interior. At first, the design and execution of these would seem to be based on established Medieval practices. However, more detailed investigation reveals some important differences. To begin with, stained glass windows in the Renaissance were designed using cartoons, a technique that is more typical of fresco painting. The scenes represented are shown extending over the whole of the stained glass, thereby ignoring the positions of the window mullions that once delineated the narrative structure in Medieval stained glass. Hence, Renaissance stained glass is treated more as a "mural" of a single scene rather than as an embroidered tapestry 
3.8

\section{Nativity, Paolo}

Uccello

(1397-1475).

Florence Cathedral

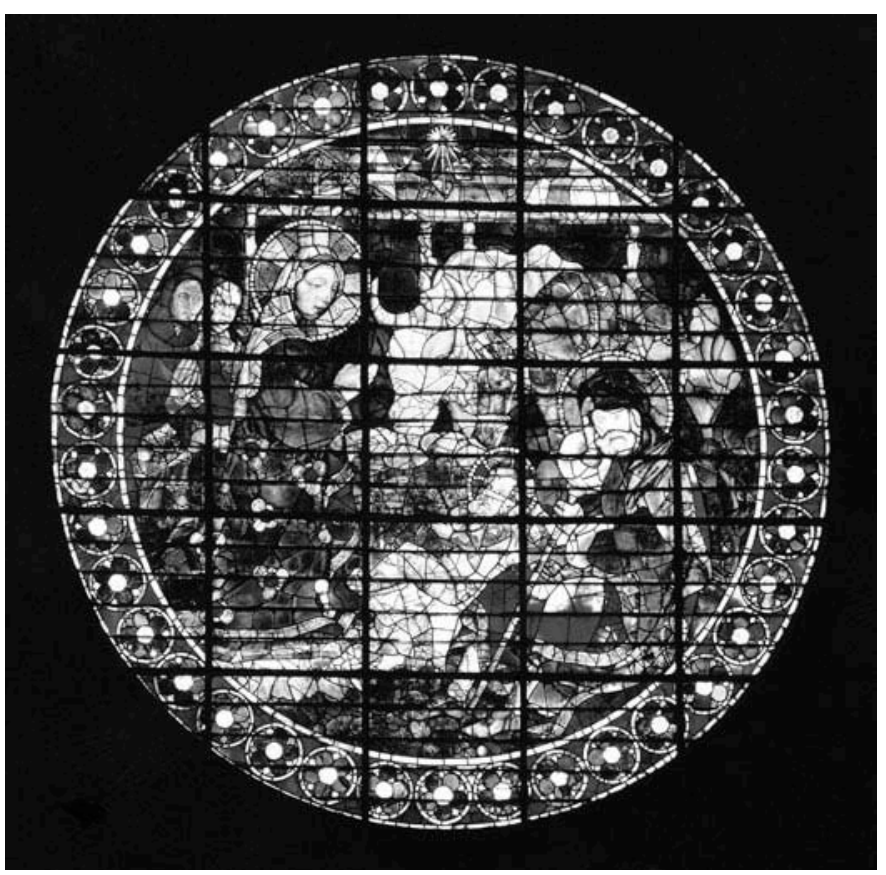

of interconnected scenes. Integrally related to these innovations was the attempt to provide "correct" perspectival representations. Unlike Medieval stained glass, where the tapestry of coloured glass creates an interplay between light and geometry, the Renaissance prioritises the overall pictorial effect of the scene being represented, over and above the shape and physical construction of the window. We can see this, for example, in a stained glass window by Paolo Uccello, of the Nativity, that forms one of the occuli of the drum of the dome of Santa Maria del Fiore. In contrast to the radiating geometry of the rose windows of Medieval cathedrals (as we saw at Lincoln for example), that celebrate the cosmic symbolism of light, the perspective scenes of Uccello's stained glass seem to transgress their encompassing geometric forms by becoming effectively painterly representations.

It would be a mistake, however, to conclude from these evident differences a decisive and irreconcilable shift away from Medieval light symbolism in fifteenth-century Florence. The period of the Early Renaissance, we should remember, was still fundamentally defined by a Medieval onto-theological outlook. This continuity, as Dalibor Vesely notes, "was obscured only because of the new mode of perspectival representation, which made the transcendent meaning of art more immanent and implicit, but not absent" ${ }^{81}$

We can see this continuity most clearly in the ideas of Lorenzo Ghiberti, whose "Commentaries" (Commentari) reveal much about the meaning of vision during this period. In these texts, Ghiberti is "almost exclusively concerned with relating visual experience to the judgment of sense (virtu distinctiva)" ${ }^{82}$ The relationship moreover is formulated in perspectival terms, whereby experiences of apparent size and distance "depend largely on the proportional distribution of light 
and shadows of a body". ${ }^{83}$ We are reminded here of Leonardo da Vinci's interest in proportional relations in perspective, discussed in Chapter 2. In the case of Ghiberti, however, light plays a more central role in perspective representation, over and above questions of a geometrical understanding of space. In this approach Ghiberti "treats the Medieval tradition of the divine origin and meaning of light as a problem of human knowledge and wisdom, as a new relationship between thinking and seeing, giving the visible phenomena a new importance" ${ }^{84}$ The main sources of Ghiberti's investigations in his third Commentary - from the Arab Aristotelians (Alhazen, Avicenna, etc.) to the Medieval "perspectivists" (Witelo, Bacon, etc.) - have led some to consider the work as retardataire. ${ }^{85}$ But this is only to overlook the underlying objectives of Ghiberti's investigations which should be seen to run parallel with - rather than counter to - the developments in pictorial representation by Brunelleschi and Alberti.

Between the realms of corpi luminosi (radiant bodies) and corpi umbrosi (opaque bodies) in Ghiberti's visual thinking are diaphanous bodies (corpi diafani) that serve a mediating function in one's understanding of the world. Diaphanous bodies (as we shall see in Chapter 4 in the context of Nicholas Cusanus' interest in the beryl stone) take on metaphorical meanings in the way that the refraction of light conveys a communicative domain between divine intellect and human understanding. This domain can be traced to the ideas of Grosseteste, as we saw earlier in the context of aspectus and affectus, only in the case of Ghiberti the task was driven more by a desire to reconcile the relation between perspective representation and visual experience. ${ }^{86}$

In attempting, at one level, to overcome the overtly structured matrix of perspectiva artificialis, Ghiberti saw light as a medium for defining the proportional relationships of bodies in space. Vesely argues that in this medium Ghiberti found a more fundamental depth to the one defined by geometrical construction, one that could be described as "situational". ${ }^{87}$ This point is, to some extent, demonstrated in his famous bronze reliefs for the Baptistery doors in Florence where the artist deploys various gradations of relief to the figures represented in an attempt to convey, by the effects of light and shadow, their relative positions and depth of field - within the illusory space.

Ghiberti's interest in Medieval light theory was not an isolated affair during this period. We know that Medieval optical texts were in circulation in Florence during this period, testified in part by Ghiberti's own references to them in his Commentarii. These probably exerted influence on current theological ideas as well as on artistic representation. One important figure in this regard is Antonino Pierozzi, Dominican priest, Prior of the Convent of San Marco and later Archbishop of Florence. He became an esteemed religious figure and was canonised in 1523. Towards the end of his life Pierozzi was especially interested in the mystical nature of light which he identified with the life of the Virgin Mary. ${ }^{88}$ It may have been through Ghiberti's translations and interpretations that Pierozzi became familiar with the writings of the English Franciscan and pupil of Grosseteste, Roger Bacon, one of the leading figures in Medieval optics. Bacon's De multiplicatione specierum drew influence from Grosseteste's principle of light as the source 
and origin of all being. The work promulgates the idea, first conceived by Alhazen and developed by Grosseteste, that all objects in the world (both physical and spiritual) emanate invisible forces. These forces, as we have already discussed, are referred to in Latin as species that multiply endlessly throughout the cosmos. What particularly interested Bacon was the manner in which species move through a medium in such a way that there is no change of place; "it is not produced by a flow from the luminous body, but by a drawing forth out of the potentiality of the matter of the air". ${ }^{89}$

A copy of De multiplicatione specierum can be found in San Marco Library, probably purchased either by Cosimo de'Medici or Antonino himself during his role as Prior of the convent. ${ }^{90}$ Other copies of works by Bacon were purchased for the Biblioteca Riccardiana and the Medicean Biblioteca Laurentiana. ${ }^{91}$ It seems clear from this evidence that there was much interest in Medieval optics during the period that also witnessed the "rediscovery" and codification of perspective.

Quite how Medieval notions of light and Renaissance perspective overlap is highlighted in a painting, the Annunciation, in the National Gallery in

3.9

Annunciation,

1450-53, Fra

Filippo Lippi

(1406-69). Detail

of right hand side

of painting

showing

relationship

between Dove and

the Virgin's

abdomen

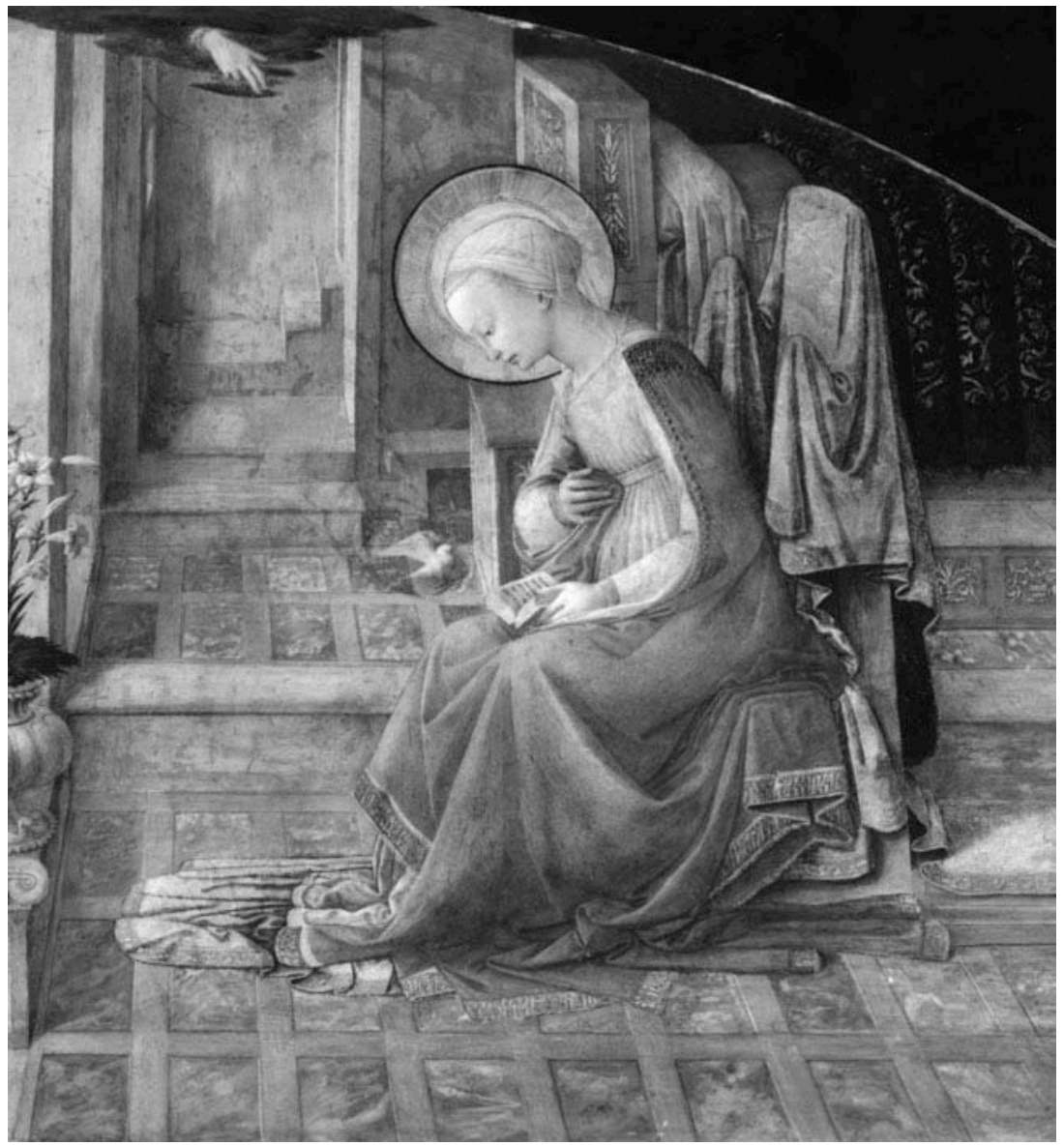


London by the Florentine artist Fra Filippo Lippi. Leo Steinberg provides a penetrating analysis of the work in relation to optical theory. The London Annunciation is one of a number of versions executed by Lippi, but is the most daring and innovative in its composition. The deployment of metaphors to convey the effect of God's work on the Virgin's womb were common in Medieval devotional texts. The event was typically likened to "an infusion of breath, to sound entering by the ear, and to the vivifying action of dew". ${ }^{92}$ On the first metaphor fertilisation by divine breath (or "divine exhalation") was, as Steinberg notes, probably influenced by the etymology of the term spiritus - meaning breath of air. ${ }^{93}$ This finds expression in many examples of the Annunciation that show a ray issuing from God's mouth and being guided by the Dove towards the kneeling Mary below.

In Filippo Lippi's London Annunciation, we clearly see that the breath metaphor was considered inappropriate to convey the central mystery of divine fertilisation. The primacy given to vision in the age of perspective, as the most noble of the senses, took precedence over "Christ enfleshed by way of breath or acoustics".$^{94}$ To this end, we witness a translation of the earlier metaphor through the medium of light:

Mary's womb is impregnated by light as the eye is by sights received. Lippi's symbol of a uterine radiance drawn forth by approaching light represents a precisely visualised mechanism: it reflects a theory, widely held in medieval and Renaissance speculation, concerning the nature of visual perception. ${ }^{95}$

This interpretation needs to be seen in the context of Roger Bacon's synthetic theory of light that seeks to reconcile intromission and extramission theories. The power issuing from the eye "alters and enobles the medium and renders it commensurate with sight, and thus it prepares for the approach of the species of the visible object" ${ }^{96}$

Vesely argues that the place of the "mixing" of species - in the pyramid of vision - "anticipated the pictorial plane in Renaissance perspectival construction". ${ }^{97}$ In Lippi's London Annunciation, the loss of altitude of the Dove, unique in Christian art, should be considered in the light of Vesely's argument. Consider, to begin with, the specks of gold dust that are shown emanating from the Dove's beak. These are reciprocated by similar motes emerging from the Virgin's abdomen exposed by a slit in her dress. Departing from scriptural text, in which the Holy Ghost is described as "overshadowing" Mary, Lippi instead brings the event firmly down to earth, so to speak, as a dialogue between recipient (Mary) and mediator (Dove). In so doing, the "Dove and womb are consubstantial, reciprocal, and about to commingle" ${ }^{98}$ As if to reinforce this horizontal - firmly terrestrial - encounter Lippi locates the pictorial exchange within the grid of the surrounding floor that converges perspectivally towards the hand of God, positioned aloft at the apex of the painting. The conflation of Baconian optics with Renaissance perspective makes this painting especially significant in the history of sacred art: it at once reflects a still meaningful luminary and transcendent outlook and anticipates, if only distantly, an encroaching immanent world. 


\section{Light and the colour of experience}

Against the historical background of light symbolism that I have outlined above, the question of the nature and meaning of light in the modern age is far less easy to ascertain, beyond scientific explanations. From the seventeenth century onwards, light played a pivotal role in the development of a mechanical view of the universe, as we see for example in the optical writings of Isaac Newton. Notwithstanding this established instrumental outlook, that continues unabated to this day, it has become increasingly evident in recent scientific scholarship that light possesses unfathomable mysteries that defy conventional scientific explanation. As Arthur Zajonc admits, even armed with all the sophisticated theories of laboratory research in quantum optics "I have no sense of closure regarding our knowledge of light". ${ }^{99}$

This has prompted Zajonc and others to consider that our understanding of light can only be deepened if we have a better knowledge of its historical and philosophical backgrounds. Central to this enquiry, as the present chapter has already alluded to, is the inseparable relation between the outer light of nature and the inner light of the mind. ${ }^{100}$ It is in the context of this relationship that we should consider Louis Kahn's assertion that "We are actually born out of light, you might say. I believe light is the maker of all material. Material is spent light." 101 Redolent, in one sense, of Grosseteste's cosmogony of light, Kahn's description of light should be seen as integrally related to his understanding of geometry in architecture. I argued in Chapter 2 how Kahn's fascination with triangulation was informed by Plato's idea of the inter-relation between Being and Becoming, by which the temporal realm of human circumstance is borne out of the eternal realm of the cosmic order. Accordingly, Kahn's deployment of primary geometric forms was motivated by a desire to communicate, through the surface effects of light and shadow, the inherently cosmic nature of all human situations as they are expressed in architecture.

What underlies Kahn's cosmogony, however, is a belief in the universality of light, as the fons et origo of all creation. This principle was also to serve as the basis of an early scientific view of light anticipated in the works of Grosseteste and Bacon. It was from this principle that the idea of a "universal luminiferous ether" was ultimately conceived, and from which modern analogical views of light developed, such as those of Newton, Descartes, Huygens, Young and Euler. ${ }^{102}$

The principle, which formed one of the planks of modern Western metaphysics, is in stark contrast to the rather different quest for reality transmitted through the sensations of colour. What is assumed in pure light as absolute and therefore objectively true - is relegated in the study of colour to the nuances of appearance, and therefore to subjective variation characteristic of modern psychology. The distinction seems to lead to the conclusion of an unbridgeable divide between the "unreality" of colour and the objective certainty of light. ${ }^{103}$ In the modern quest for clarity and generality - that draws upon universal principles - the issue of colour is considered largely irrelevant, given that it requires a human position or perspective. Hence, the physical and quantitative view of the world is by necessity free of references to colour. ${ }^{104}$ 
But such a clear modern distinction between "pure" invisible light and "impure" coloured light obscures a much deeper symbolic relationship, as we saw earlier in the colour theories of Grosseteste. At the heart of this relationship is the notion of sensual colour as precursor - or "bridge" - to metaphysical (divine) light. Colour possessed redemptive meanings in the Middle Ages that ensured a transition from the visible to the invisible. This idea was reinterpreted in the twentieth century in the ideas of Walter Benjamin. In an early work, entitled "The Rainbow: Dialogue on Fantasy" (Der Regenbogen: Gespräch über die Phantasie), Benjamin explores the notion of the multicoloured self. The work is in the form of a dialogue between two characters, Margarethe and Georg, in which the latter describes a dream; "I was not one who sees, I was only seeing. And what I saw were not things, Georg, only colour. And I myself was coloured into this landscape."105 In this dream, as Peter Fenves argues, colour takes on ontological meanings that transcend associations with objects - as mere properties of things: "Not only do the colours of Margarethe's dream 'look' beautiful, they also 'look out' and 'look at' ... each other. Only by being coloured into the colourful scene can Margarethe 'herself' see - and see 'herself'." 106

In this work we see Benjamin "recasting Kant's transcendental concept of experience into a speculative one". ${ }^{107}$ In other words, Benjamin seeks to overcome the notion of mastery over experience, by "allowing" colour to open up the possibilities of "discontinuous experience". But Benjamin's philosophy is not founded on experience alone but is also defined in messianic terms, whereby perception is gauged by an absolute and infinite realm. Howard Caygill questions this aspect of Benjamin's philosophy by stating that, "If the idea is redemptive, if it is meant to mend what is broken and to correct what is distorted, then it threatens to become dogmatic, bringing together past and future into an eternal present or apocatastasis." 108 For Benjamin, the notion of an "eternal present" can be experienced through an "immanent chromatic totality of space". ${ }^{109}$ Hence, space and colour are considered synonymous, whose experience does away with "both substance and a self-subsistent subject". ${ }^{110}$ Whilst in one sense Benjamin's philosophy of colour can be traced to an onto-theological tradition, it is also very much reflective of a modern inchoate world, whose sense can only be sought in immanent terms; through discontinuous experience. To this extent, Benjamin's philosophy is radically different from Grosseteste's chromatic model that assuredly defines an analogical bridge to divine light.

\section{Steven Holl's Chapel of St Ignatius}

In the design of some offices for an electronic trading company in New York, Steven Holl deploys various methods for bringing coloured light into the spaces. By installing coloured baffles in front of window openings the architect sought to create areas of concentrated coloured light, whose sources are concealed. These hidden surfaces, which Holl describes as being "folded behind the geometry of the spaces", allow bold colours to be nuanced into a subtle palette by the diluting effect of natural light. The result gives the impression not so much of directly illuminated surfaces but of a "viscosity" of colour fields that progressively 
3.10

St Ignatius Chapel, Seattle, 1991-97, Steven Holl Architects.

Exterior view along the processional route with reflective pond on the right

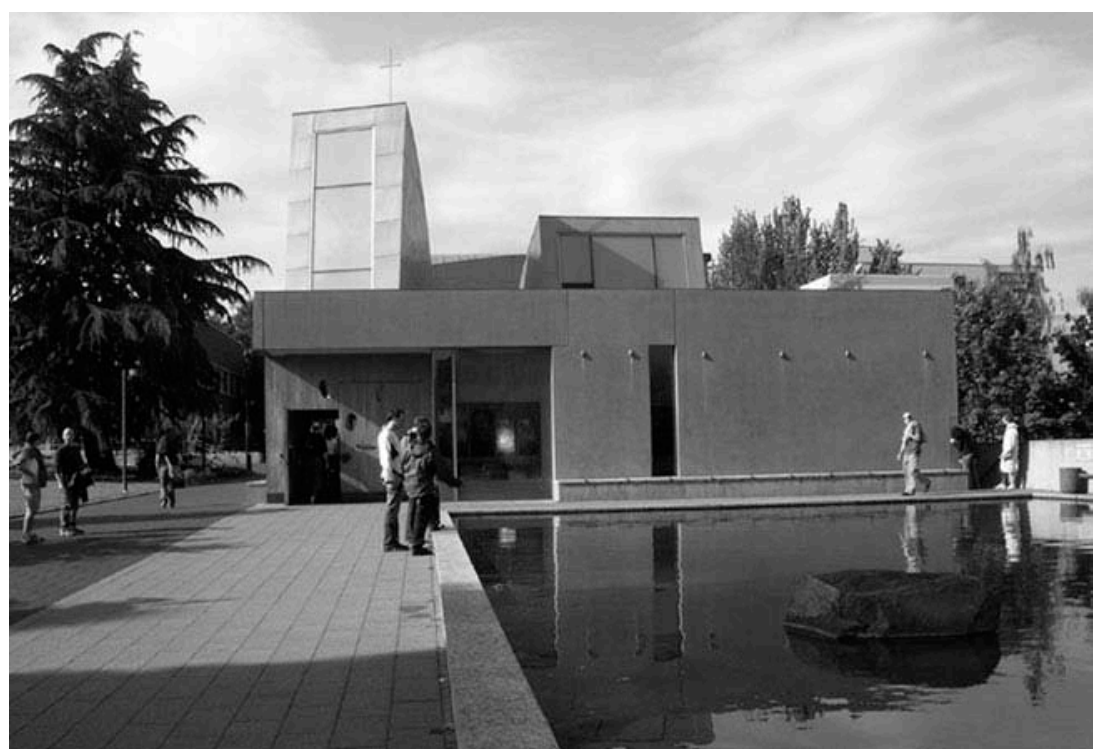

increases in density towards the originating interstitial openings. Holl talks of the effect of projected colour as analogous to the "intangible electronic trading" of the company, an analogy that reflects an intention to treat colour as a medium of exchange between human (technological) activity and an already present illuminated (cosmic) background. ${ }^{111}$ Implicit in this idea is the principle that colour allows a merging of object and field, thereby overcoming the entrenched opposition between subjective and objective realms that characterises a modern perspectival world.

Holl applied the technique to a more recent project, the Chapel of St Ignatius in Seattle. What was earlier limited in scope, to the largely undifferentiated activities of an office environment, is transformed into a more complex spatial exploration of colour in a modern religious building. But such an application was not instituted merely through a programme of functions or activities. Rather it emerged out of Holl's particular interest in the haptic realm. The relation between colour and the sense of touch may seem problematic in our culture. But Holl considers the notion of touch not in straightforward literal terms - as something distinct from the other senses - but in phenomenological terms redolent of Merleau-Ponty's notion of the "flesh" of vision outlined in Chapter 1. Through the haptic realm Holl is seeking to endow pure visualisation - that holds sway in our culture - with the tactile/corporeal nature of primordial experience. This is communicated through the visceral qualities of colour and texture.

The Chapel of St Ignatius exemplifies this understanding of the haptic realm. The dedication of the Chapel to St Ignatius Loyola, founder of the Society of Jesus (Jesuits), prompted Holl to explore the background of the sixteenthcentury saint. Of particular importance in this regard is St Ignatius' famous "instruction manual", the Spiritual Exercises, that continues to provide spiritual guidance in the Christian world. By "preparing and disposing the soul", the exercises strengthen the resolve of the repentant to seek salvation in the face of the 


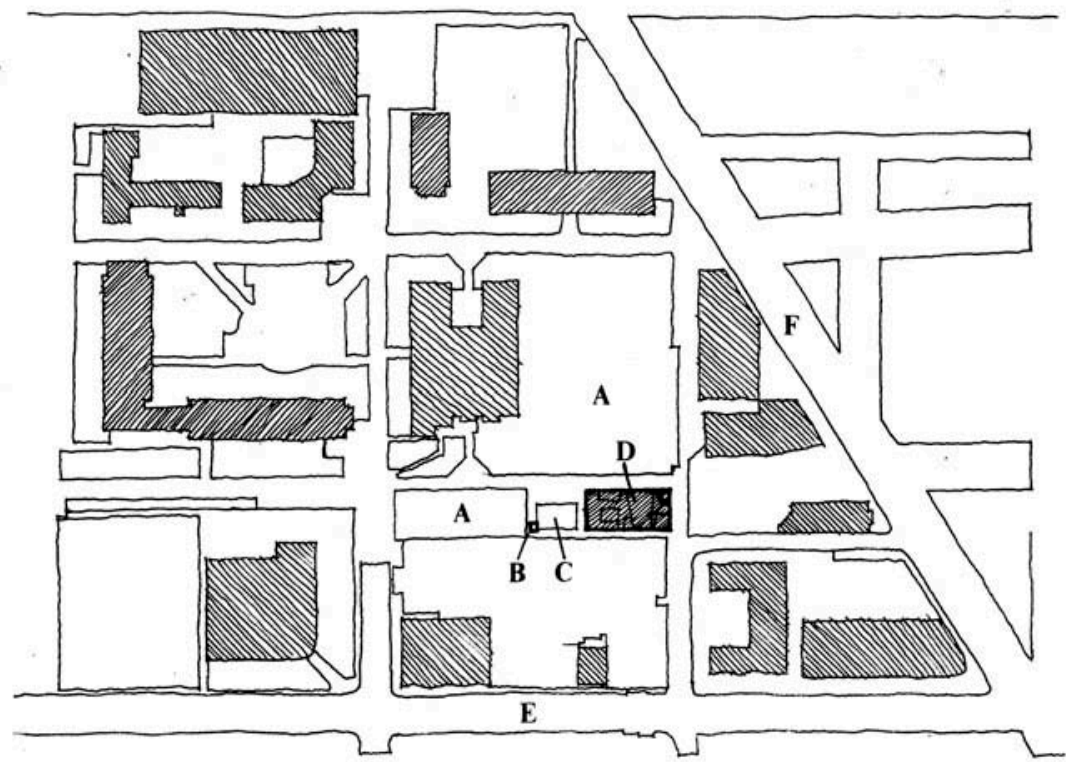

3.11

St Ignatius Chapel,

Seattle, 1991-97,

Steven Holl

Architects. Outline

site plan: New

Green Quadrangle

(A); Bell Tower (B);

"Thinking Field"

(reflecting pond)

(C); Chapel (D);

12th Avenue (E)

and East Madison

Street (F). Drawn

by author after

Holl

darker forces of the world. ${ }^{112}$ Accordingly, the exercises could be described as a redemptive journey, a ritual undertaking that extends over a period of approximately four weeks. Collectively, they constitute a spiritual battle between divine consolation and the desolation inflicted by sin; a battle that is consistent with Ignatius' own spiritual journey from soldier to saint. The progression from desolation to consolation, terms used by lgnatius, is expressed as a movement from darkness and light. The relation between both states, however, was not understood in terms of opposites but rather as degrees of spiritual growth. This became the primary inspiration for Holl's idea of a "gathering of different lights" in which movement through space is registered in chromatic terms as a search for atonement. ${ }^{113}$

The Chapel was conceived as the religious focus of the University of Seattle, a Jesuit institution founded in 1891, where both students and professors can worship. A key concern in the design of the building was the need to convey the global dimension of the Jesuits, an issue that was closely allied to seventeenth-century views of perspective, as I will explain in Chapter 5. In the context of Holl's design, this worldly authority of the Jesuits finds expression through the interplay between local elements of the design, defined by the siting and fabric of the building, and the "other-worldly" nature of colour. The latter transforms the physical characteristics of the building fabric by the changing effects from daytime to night-time light. This ritualised transformation - activated by the agency of light - brings into sharp focus the modern scientific assumption of the purely subjective, and therefore non-universal, nature of colour.

Located in an urban campus that was formed out of an existing urban block of the city, the building is sited in the centre of a former street with surrounding green spaces. The Chapel is shaped externally in the form of an elongated box 
3.12

St Ignatius Chapel, Seattle, 1991-97,

Steven Holl

Architects. Plan

indicating

Entrance (A);

Narthex (B); Ramp

(C); Font (D); Altar

(E); Chapel of the

Blessed

Sacrament (F); and

Choir (G). Drawn

by author after

Holl

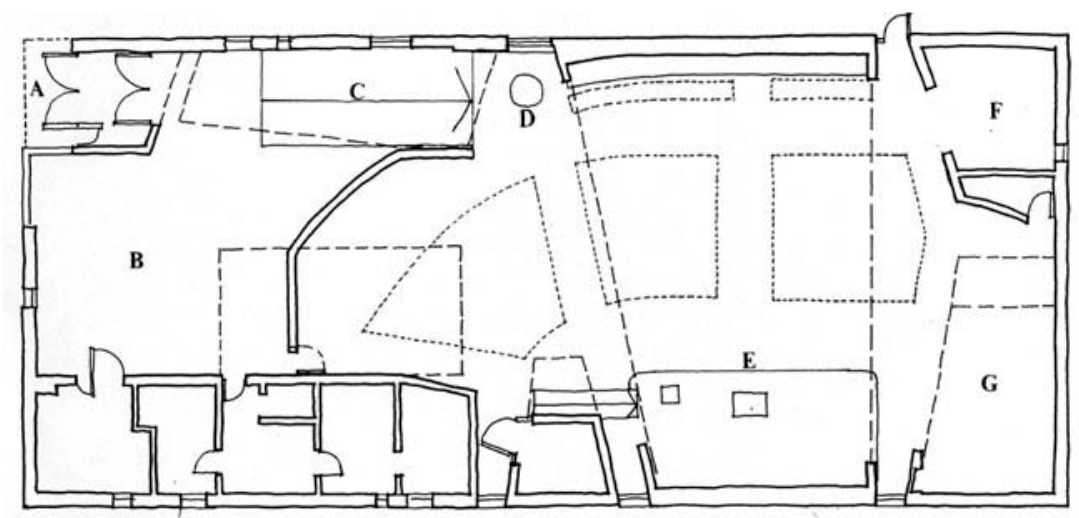

whose primary axis is oriented north-south. Extending beyond the south entrance of the building is a rectangular pond, the south-east corner of which is punctuated by a tall bell tower that announces to the university congregation the times of prayer and religious celebration. Approaching the building from the south, the Chapel appears to float in the water whilst the main entrance is demarcated by a path that extends along the western fringe of the pond. This processional route continues into the building, beyond the narthex (via a ramp), to the main body of the chapel. Rather than following the extended north-south processional route, the Chapel proper, in response to the Second Vatican Council, is shaped "in the round" with altar oriented due east in liturgical fashion. ${ }^{114}$ Combined, these two principal organising elements of the Chapel are brought into dialogue through a complex series of volumetric spaces that form the vaulted ceiling of the building.

It is through these volumetric spaces that Holl brings into play the idea of a "gathering" of different lights. Drawing upon the Jesuit principle of education as a process requiring a careful dialogue between the lights of reason and of faith, Holl develops the concept of seven bottles of light that emerge from the enclosing stone box, each corresponding to "a program element". ${ }^{115}$ These include the narthex, the procession hall, the main gathering space, the reconciliation chapel, the choir and the chapel of the Blessed Sacrament. The use of this metaphor indicates Holl's intention to create an aqueous quality of light in the interior, an idea that was conceived at an early stage in the design, as indicated in Holl's water-colour studies. The effect is achieved by the combination of colour fields (in the form of painted surfaces on suspended baffles) and coloured lenses. The tactile nature of the colour is achieved in part by the textured finishes on the walls and vaults (in the form of square/rectangular imprints), creating a layered chromatic effect.

The choice of colours, and their juxtaposition, was informed by a combination of perceptual criteria and symbolic intentions as Holl notes:

Moving deeper into the chapel, the light glows mysteriously from the reflected fields. Each "bottle of light" contains a unique reflected colour with a coloured lens of a complementary colour. When people stare at a blue rectangle and then a white surface, they will see a 
yellow rectangle. The twofold merging of concept and phenomena in the chapel is communicated in the visual phenomenon of complementary colours. ${ }^{116}$

The relation between colours and spaces in the Chapel was also partly informed by numerological concerns. In the context of the seven bottles, the seventh day is the day of accomplishment, according to St John: "While several miracles took place on a seventh day (Cana), at the seventh hour ... or on the sabbath day ...., Christ's solemn work was accomplished in the setting of a solemn seventh day, the 'great sabbath day' ". ${ }^{117}$ This idea touches on something deeply rooted in Christianity, as we have noted in the context of Medieval iconography; namely the desire to "re-enact" by spatial-temporal means the central mysteries of the Church. Holl's use of seven "bottles", in which a colour field inter-plays with a complementary coloured lens, recalls Grosseteste's integrated model of seven ascending and seven descending hues outlined earlier.

The relation between number and light in Holl's design is initially registered in the monumental - centrally hinged - south entrance door made from Alaskan cedar. This is punctuated by seven large glass discs that are oriented at different angles within the thickness of the door. The discs form lenses through which one can view at oblique angles the spaces beyond. Like the extended light wells in the roof, and surrounding windows, the inward (day-time) effect of light in these discs is reversed at night when they project light outwards. Once inside, the visitor enters the processional corridor alongside the narthex. The space is illuminated by a lofty and narrow light-well (one of the seven bottles) that is oriented on

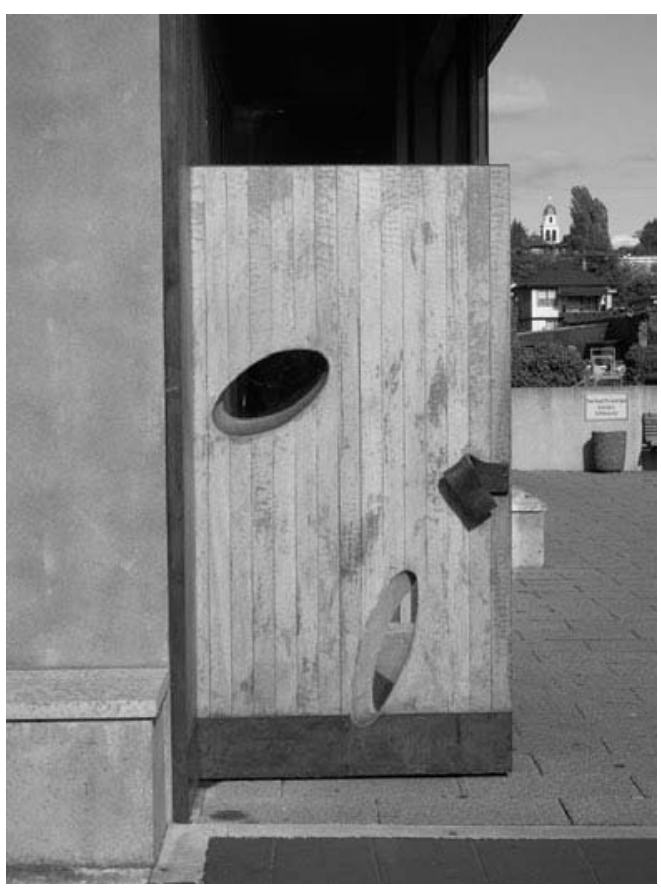

St Ignatius Chapel, Seattle, 1991-97, Steven Holl Architects. View of the entrance door showing oval shaped glazed openings 
3.14

St Ignatius Chapel, Seattle, 1991-97,

Steven Holl

Architects. Interior view of narthex

looking towards the ramp access to the main body of the chapel

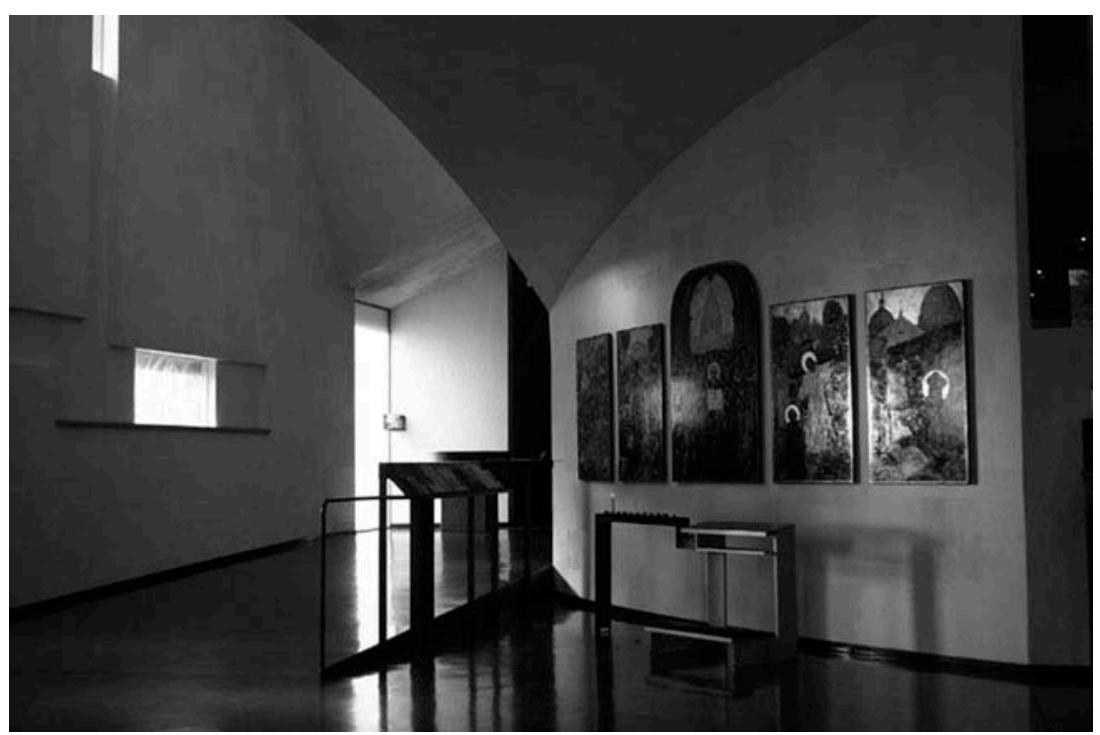

the axis of the procession and projects "white" light deep into the body of the building. The passage of light directs movement into the nave of the body of the Chapel, via the ramp. This contrasts with the bold red interior of the subsidiary Chapel of the Blessed Sacrament beyond (created by a combination of an orange field and a purple lens) that forms the visual focus of the processional route.

At the threshold of the main Chapel is a baptismal font, also carved in Alaskan cedar. Its mirrored surface of still water reflects a bronze shelf above that is cantilevered from the adjacent wall. This holds three bottles of holy oils used in

3.15

St Ignatius Church, Seattle, 1991-97, Steven Holl Architects. View from the baptismal font towards the entrance

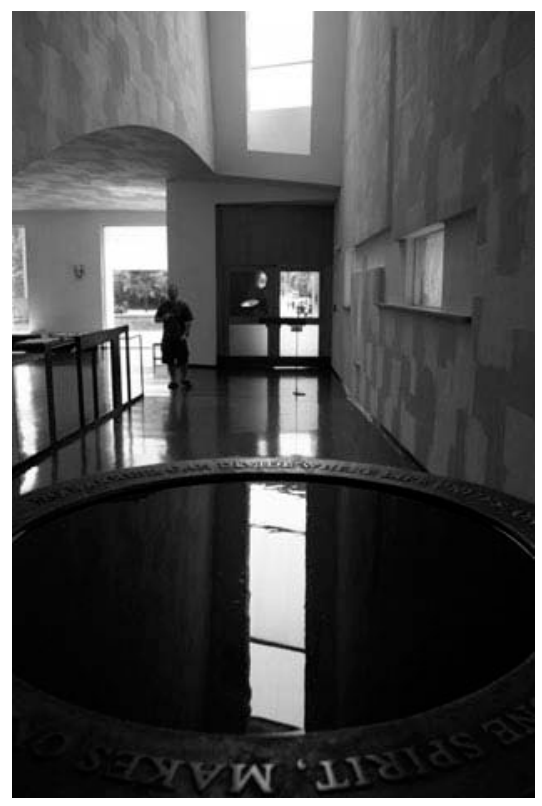




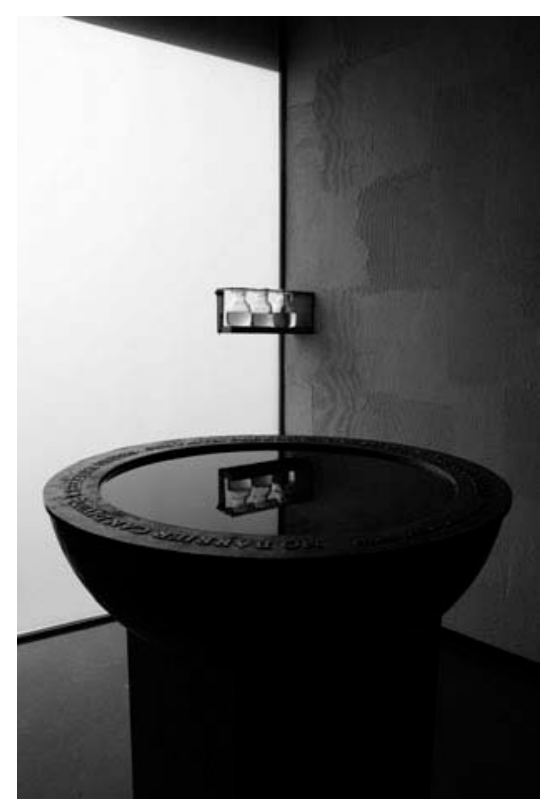

3.16

St Ignatius Church, Seattle, 1991-97, Steven Holl Architects. View of the baptismal font with cantilevered bracket of bottles above containing chrism oils

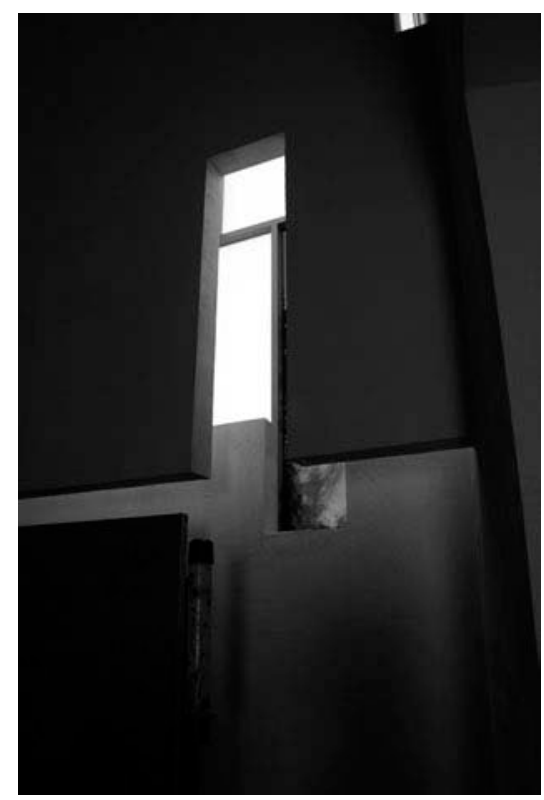

\subsection{7}

St Ignatius Church, Seattle, 1991-97, Steven Holl Architects. View of the east nave baffle

the post-baptismal rite of Confirmation when the Holy Spirit is said to descend upon the neophyte. Silhouetted against a window of clear glass, these assembled bottles of illuminated chrism serve as a microcosm of the building itself. The use of three bottles clearly refers to the triadic symbolism of the baptismal rite in which each immersion signals one of the stages of the Trinity (Father, Son, Holy Spirit). As a symbol of one's entry into the Church, the font provides a visual and spatial "hinge" that allows re-orientation to the altar of the Chapel at the east end. 
Besides forming reflective surfaces for the dissemination of both pure and coloured light, the shape of the ceiling vaulting of the building was also informed by acoustical criteria. Indeed, Holl was very conscious of the effectiveness of the interior for chamber and vocal music given that the focusing of the radial points of the curved roofs are either below the floor level or above the level of the human ear. ${ }^{118}$

3.18

St Ignatius Church, Seattle, 1991-97, Steven Holl Architects. View of ceiling baffle

3.19

St Ignatius Church, Seattle, 1991-97, Steven Holl Architects. View of shaft of light from clerestory glazing
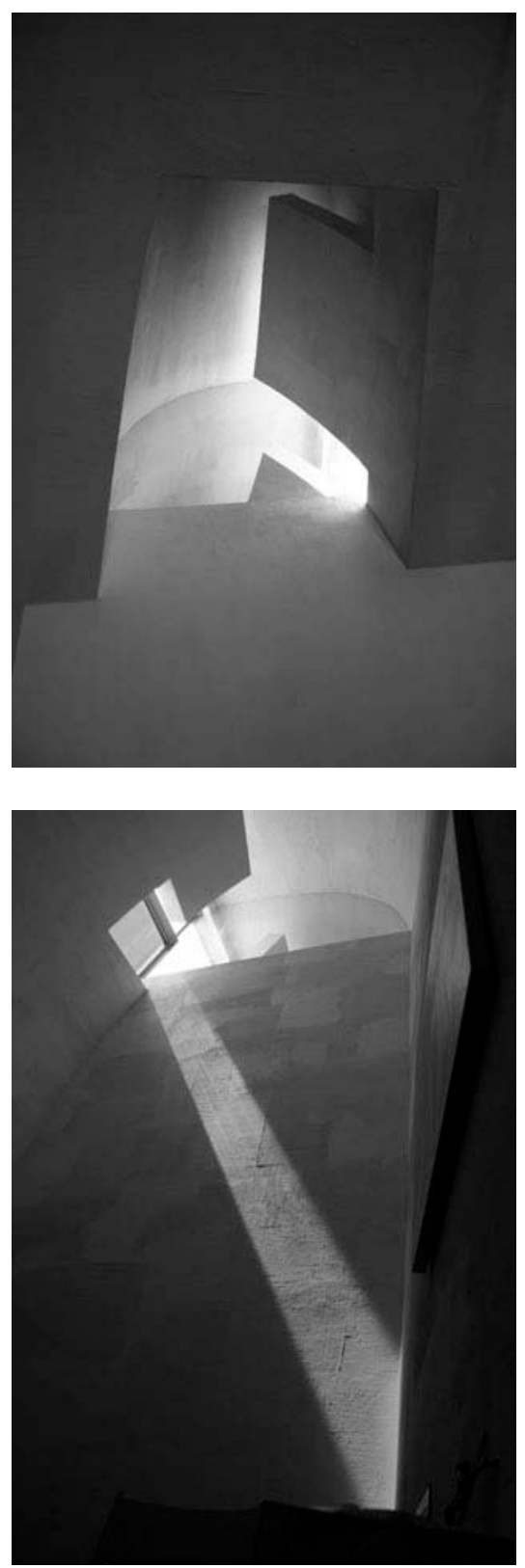
Evident, therefore, throughout the Chapel is an intended interplay between light, sound, materiality and numerology that recalls a deeper Christian tradition rooted in the theology of St Augustine and the Pseudo-Dionysius, and developed in the interiors of Gothic cathedrals. Holl's observance, however, of this tradition was informed by a phenomenological perspective of colour, but one that is not wholly compatible with Walter Benjamin's colour theories. Taken to its extremes, Benjamin sought to recast spatial-temporal notions of order as pure chromatic experience, whereby questions of duration and depth are subsumed within the all-pervasive a-temporal effects of colour. Such an understanding was motivated, as we have seen, by messianic intentions. In the case of St Ignatius Chapel, on the other hand, we sense a desire to create a series of spaces where colour is treated as a mediated field between this world and the next; a field that is not chromatically immersive - in the sense articulated by Benjamin - but rather subject to the diurnal effects of natural (cosmic) light.

This difference brings into sharp focus a problematic tension between traditional "(transcendental) formal inscription and (speculative) chromatic configuration". ${ }^{119}$ We are left asking the question: how might transcendental meaning as it is traditionally understood in the sanctity of word (Logos) - be communicated through the discontinuous and speculative avenues of colour? In the case of Benjamin, as we have seen, colour - in and of itself - is the path to a redeemed self, but one which is brought about by a radically immanent view of redemption. This is in stark contrast to Emmanuel Levinas' commitment, outlined in Chapter 1, to a living transcendence in our relation to the other. What we see in Holl's project is an evident interest in creating situations receptive to religious experience - that initially draws upon the perceptual effects of complementary colour.

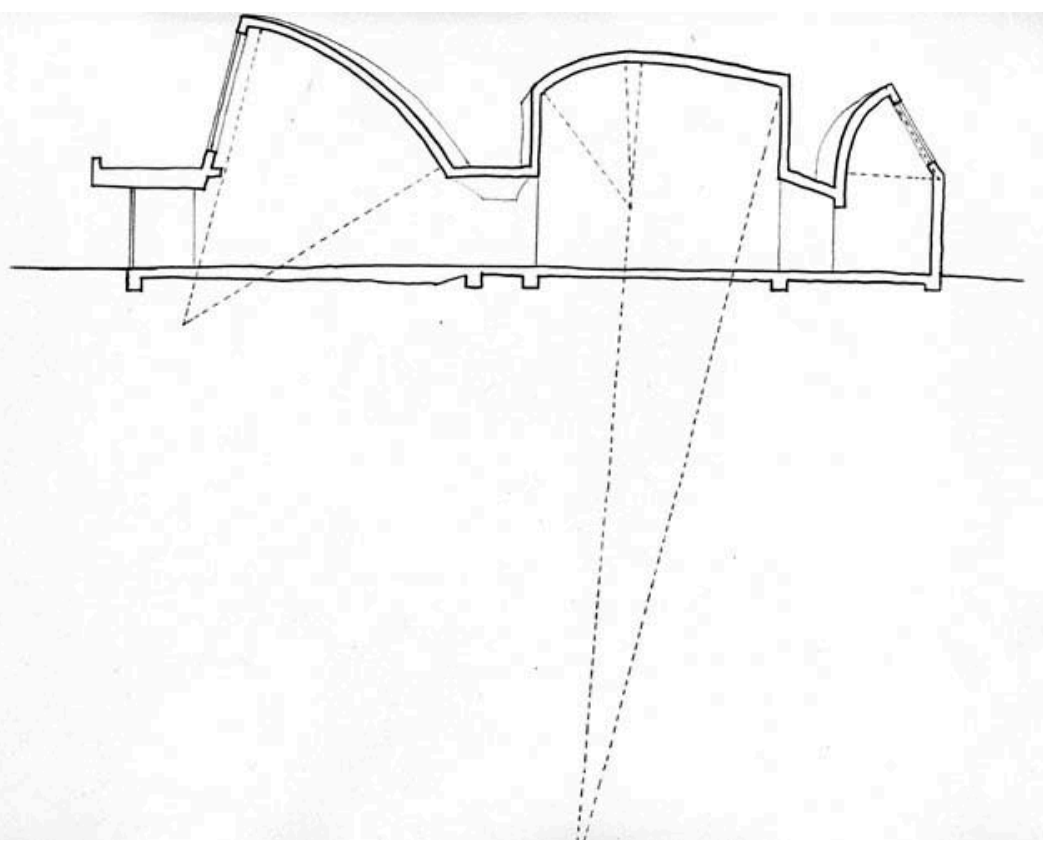


The chromatic theories of Robert Grosseteste are instructive in this regard, given Grosseteste's belief that colour constitutes a "bridge" between the temporal world of darkness and the divine world of infinitesimal light. But it would be naïve to consider the comparison in straightforward terms, given the absence in modernity of an onto-theological world-view that Grosseteste could assume. It would perhaps be more correct to claim that Holl sought to overcome, in the architecture of St Ignatius Chapel, the problematic divide between immanentist and transcendent views of the world, as promulgated in the philosophies of Benjamin and Levinas. This is indicated in the way he treats the palette of colour as if it were building material for constructing spaces that respond to one's yearning for religious progression to salvation, but whose culmination is left largely unarticulated spatially - beyond the trappings of church liturgy. In this progression, we become aware of the way coloured light intercedes in the perspective depth of the spaces that leaves open the possibility of a dialogue with a deeper transcendent tradition. 


\title{
Chapter 4
}

\section{Topography, rhetoric and the vanishing point}

\section{Horizontal and vertical worlds}

In his final work, The Visible and the Invisible, Maurice Merleau-Ponty remarked:

\begin{abstract}
I say that the Renaissance perspective is a cultural fact, that perception itself is polymorphic and that if it becomes Euclidean, this is because it allows itself to be oriented by the system. Whence the question: how can one return from this perception fashioned by culture to the "brute" or "wild" perception? What does the informing consist in? By what act does one undo it (return to the phenomenal, to the "vertical" world, to lived experience)? ${ }^{1}$
\end{abstract}

Merleau-Ponty sees the culturally driven system of perspectivally ordered perception as antithetical to the "vertical" world of lived experience. The assertion assumes that developments in Renaissance perspective were already fashioned by an instrumentally conceived world, a point I challenged in Chapter 2 in the context of Hubert Damisch's interpretation of Edmund Husserl's "Origin of Geometry". In this earlier discussion I argued that implicit in perspectiva artificialis was a deeply embedded onto-theological outlook. This manifested itself, as we saw in the case of Leonardo da Vinci's Last Supper, as a transmission of the eternal verities of Platonic/Christian cosmology (embodied in number and geometry) to the spatial-temporal conditions of ideal pictorial space. In such a transmission, the "vertical" world of lived experience, traditionally communicated as a transcendent realm, was not absent as such but was rather mediated through the "horizontal" world of calibrated space. We get a sense of this in Filippo Lippi's painting, the Annunciation, discussed in Chapter 3. By the eighteenth century, however, this mediation gives way to an emphatically immanent outlook in which perspective is little more than an ordering system deployed for dramatic effect. It is this loss of mediation, and its consequences 
in the modern world-view, that Merleau-Ponty sought to overcome through his phenomenology of perception.

Critically, the mediating role of perspective in the Renaissance involves a complex interplay between topography (both real and ideal) and language. The present chapter examines this relationship in the context of humanist thought, arguing that the increasing importance of historiography in the Renaissance led to an "inscriptive" understanding of topography, as we will see later in the case of Rome.

As we found in Chapter 2, the deployment of proportional systems in perspective reflected a desire to "delimit" what was increasingly considered an unlimited extra-mundane space. The absence of a limit, or telos, in our relationship to an embodied world seemed to contradict the basic Scholastic belief in a closed universe in which a transcendent God could communicate through a hierarchy of material and immaterial states. One of the consequences of this potential conflict was the gradual reduction of measure to quantitative value, an idea that was already considered as early as the fourteenth century by John Buridan: "The space [or distance] between me and you is nothing but the magnitude of the intervening air or of another natural body, if one should intervene." 2

During the fourteenth century the connections between ritual occasion and textual narrative - that earlier emerged in the thirteenth century as we saw in Chapter 3 - become infused with more specific perspective intentions. In this chapter I will explore these intentions by first examining public space in late Medieval Florence, highlighting the way in which these convivial settings for civic and public ceremony were informed by a new symbolic understanding of urban topography.

This initial investigation will be followed by an examination of some of the writings of Leon Battista Alberti and Nicholas Cusanus, both of whom contributed to the establishment of universal principles of perspective that ensured continuity between the situatedness of human thought, language and ideal/sacred space. These principles were conveyed through various modalities of measure where the "vertical" world of lived experience and the "horizontal" world of calibrated (ideal) space were fully entwined. As a "built" example of this dialogue, the Cortile del Belvedere in the Vatican will serve as the focus of this discussion.

The chapter concludes with a case-study of Álvaro Siza's Galician Centre for Contemporary Art in Santiago de Compostela. In this study I will highlight how Siza's attempt to establish relationships between topography, built form and perspective drew upon a deeper tradition that can be traced back to Renaissance perspective. By taking the Cortile del Belvedere as a comparison, I will indicate how Siza's project demonstrates an orientation towards space as a mediating realm between the "situatedness" of the built form and the larger providential city.

\section{Convivial settings}

In Marvin Trachtenberg's recent book, Dominion of the Eye, the author examines the urban spaces in Florence during the fourteenth century, tracing their developments within the fabric of the Medieval city. ${ }^{3}$ From extensive surveys and 
measurements of the Piazza della Signoria and Piazza del Duomo Trachtenberg has discovered that these major public spaces - long considered the by-product of incremental urban development - actually approximate to precise geometric configurations. In the case of the Piazza della Signoria, for example, Trachtenberg has identified an "ideal" plan embedded within the non-rectilinear layout of the piazza. This consists of two distinct squares, one relating to the earlier "Platea Ubertorum" to the east and the other larger square that forms the main part of the piazza fronting onto the west façade of the Palazzo Vecchio. ${ }^{4}$ Significantly, Trachtenberg has observed that the length of the diagonal of the former square is approximately the same as the sides of the latter. In other words, the area of the "Uberti" square is half that of the larger square. This rotational relationship between a larger and a smaller square is reminiscent of the mathematical problem posed by Socrates in Plato's Meno and discussed in Chapter 2. In this dialogue, it will be remembered, a slave boy is asked to determine, by a process of recollection (anamnesis), the length of the side of a square whose area is twice that of a given square of unit length. Prompted by Socrates, the slave boy "discovers" that the diagonal provides the clue to solving the problem. ${ }^{5}$

The geometry of rotation was transmitted to Early Christianity through Neo-Platonic thought, subsequently becoming received knowledge in the practices of Medieval builders and masons. ${ }^{6}$ Evidence of this can be found in the deployment of the "rotational square" in the plans of numerous churches, as we see for example in the east end of the nearby Santa Maria del Fiore in Florence. This rotational effect creates, according to Trachtenberg, a certain "perspectival logic", whereby the generative geometry reveals by its "procreation" a depth within the space of the Cathedral. ${ }^{7}$

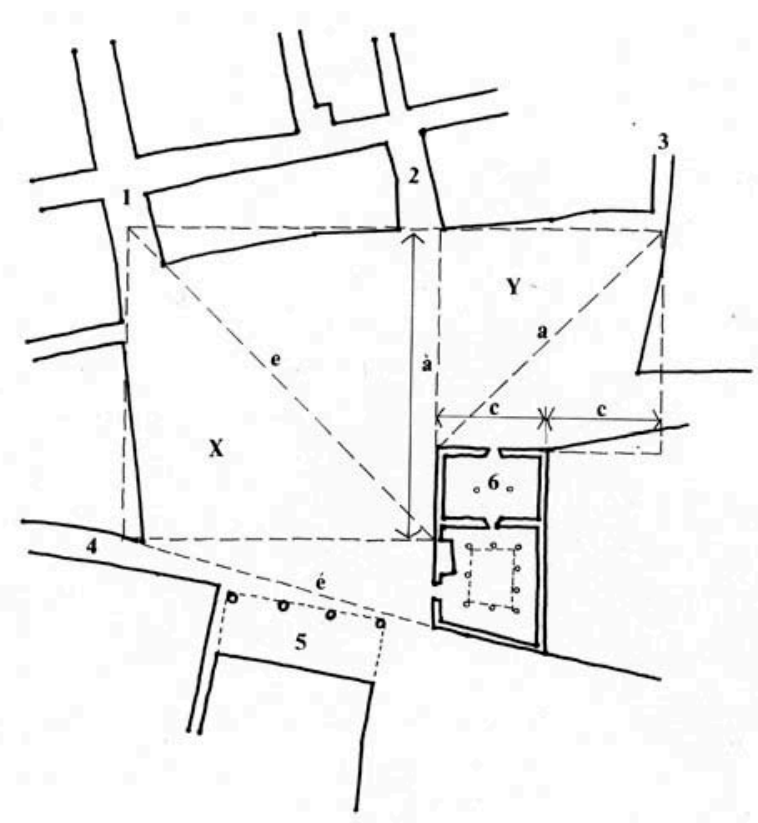

4.1

Plan of Piazza della Signoria, Florence (fourteenth century), showing effect of the rotational square between the two parts of the Piazza. via Calzaiuoli (1); via Farine (2); via Magazzini (3); via Vacchereccia (4); Loggia 1374-82 (5); Palazzo Vecchio (6); Principal Square (X) with diagonal "e"; and "Uberti" Square (Y) with diagonal "a" (approximately equal to à). Drawn by author after Trachtenberg 


\section{Rotational square}

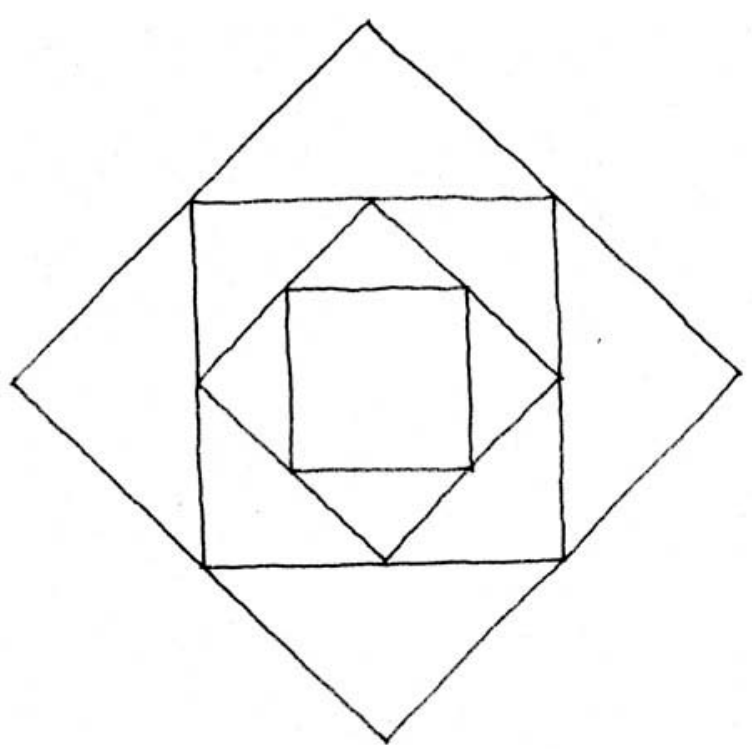

Whilst Trachtenberg argues that the Duomo and Piazza della Signoria share a "common rotational technique" there is an important and critical difference between both spaces that tells us something about the symbolic relation between political and religious institutions in late Medieval Florence. ${ }^{8}$ The experience of the Duomo and Baptistery was conceived around the principle of axial alignment and frontal orientation, underlined by the ceremonial procession between the buildings. The asymmetrical configuration of Palazzo Vecchio, on the other hand, reflects different priorities that could be described as "scenographic" in nature. Hinged at the junction between two interconnected squares, that make up the Piazza della Signoria, the Palazzo Vecchio is experienced by oblique rather than frontal orientation. This orientation, as I will argue later, finds ritual expression in the civic and religious processions of Trecento Florence, in which the Palazzo Vecchio was the principal political focus.

In these late Medieval urban transformations we witness an early attempt to optimise certain visual effects through the articulation of a legible spatial depth. Trachtenberg suggests that the application of certain geometries to Florentine squares was driven in part by the intention to perceive these spaces from particular vantage points. ${ }^{9}$ Coinciding in most cases with important thresholds with ceremonial streets, these vantage points are oriented towards prominent buildings or landmarks such as the belfry of the Palazzo Vecchio, the Baptistery of San Giovanni and the Duomo Campanile. From measurements taken of the Palazzo della Signoria, Trachtenberg has found that the height of the belfry is almost equal to the length of the diagonal of the principal square, highlighted earlier, that extends to the north-west corner of the piazza at the entrance to Via dei Calzaiuoli. ${ }^{10}$

The north-west corner, therefore, serves as the principal vantage point from which the piazza can be seen in all its splendour. The choice of the location 


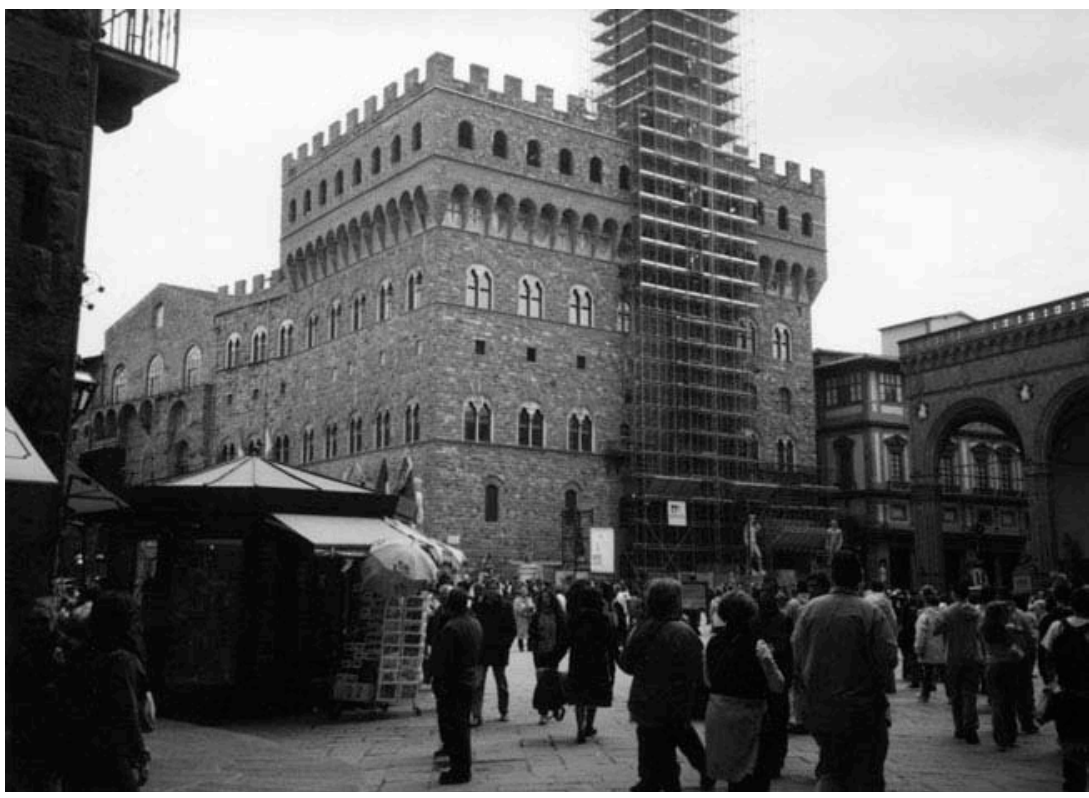

4.3

View of the Piazza della Signoria, with corner of the Palazzo Vecchio, as seen from via dei Calzaiuoli

was not arbitrary given that Via dei Calzaiuoli was developed from the 1340s onwards as the main ceremonial street between the Piazza della Signoria and Piazza del Duomo. It seems likely therefore that the importance attached to this street, as the main entry point into the Piazza della Signoria, was informed by the projecting corner of the Palazzo Vecchio and its lofty belfry that reinforces the oblique view. The resultant "triangulation of vision" (defined by the approximate 90 degree corner of the square and the 45 degree angle subtending from the observer's eye to the apex of the belfry) leads Trachtenberg to call this public space the "Euclidean Piazza". ${ }^{11}$

There is reason to speculate that the visual effect created by the geometry of the piazza was influenced by Medieval optics. In Chapter 3, we saw how the writings of Roger Bacon, notably his theory of the "multiplication of species", probably contributed to a particular "optical" understanding of perspective in the early fifteenth century. In fourteenth-century Florence knowledge of the Medieval "perspectivists" was even more widespread, in particular the writings of John Pecham. ${ }^{12}$ In his Perspectiva communis, Pecham demonstrates, by a drawn diagram, the 90 degree field of vision that could be directly applied to the spatial articulation of the Piazza della Signoria. ${ }^{13}$

But such a straightforward connection may not fully explain the underlying intentions between proportionality and perspectival vision that are implied in the Piazza della Signoria. It has long been assumed that only ecclesiastical buildings were subject to proportional treatments in the Middle Ages, whilst urban squares were by and large residual spaces informed by more pragmatic concerns. The controversy surrounding the building of Milan Cathedral in the fourteenth century, where competing methods of proportionality (between ad quadratum and ad triangulum) were recorded in the annals of the Cathedral, serves as one 
4.4

\section{Elevated} projection of the Piazza della

Signoria and Palazzo Vecchio indicating angle of vision from via dei Calzaiuoli to the apex of the palace belfry. Drawn by author after Trachtenberg

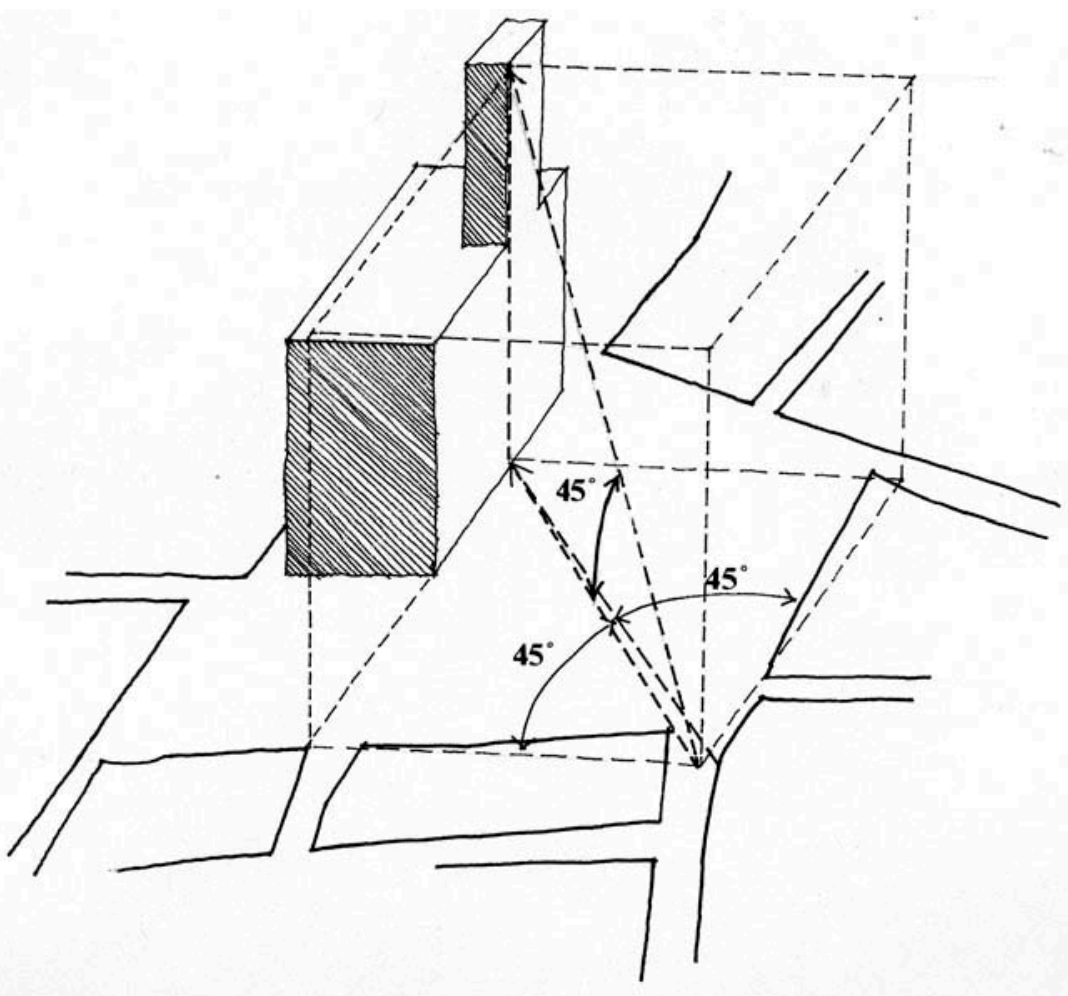

example of this priority. ${ }^{14}$ But to assume a straightforward distinction between sacred and profane space in Medieval urban life, and therefore of their accompanying symbolic meanings, is to overlook an important factor. This concerns the complex interplay between religious, political and economic life in the Middle Ages and how this was manifested in the morphology of the city.

Richard Trexler underlines this point by arguing that public space in Medieval and Renaissance Florence was equally susceptible to sanctification as the interiors of religious establishments. ${ }^{15}$ In the context of the Piazza della Signoria there were attempts, in the early fifteenth century, to objectify government and give it ritual identity. This was undertaken by purifying the space of "mercantile associations". This intention, it could be argued, was already implicit in the geometry of the Piazza in the fourteenth century. ${ }^{16}$ Trachtenberg goes on to suggest:

In employing this technique the planners probably were affected by design currents in the cathedral workshop, which produced a magisterial example of rotational planning for the most ambitious Florentine architectural project of the period. ${ }^{17}$

This leads us to speculate whether the deployment of certain geometric forms to public spaces in Florence was actually informed by the particular ritual and ceremonial practices of these spaces. Understood in the larger context of the city, the 


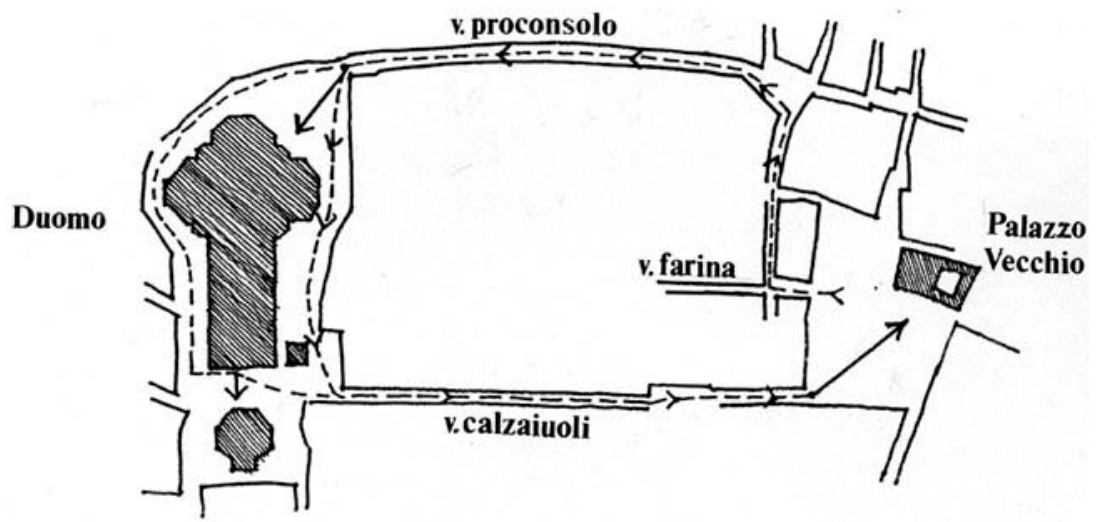

4.5

Plan showing the

"Ringstrasse"

between Piazza

della Signoria and

the Duomo.

Drawn by author

after Trachtenberg

ritual activities of the Piazza della Signoria were symbolically and topographically related to the nearby Piazza del Duomo. During the fourteenth century ritual offerings to St John the Baptist took place during the morning of the feast of the patron saint. Gifts or tributes were initially presented outside the city hall, by "subject communes", before proceeding to the Baptistery. ${ }^{18}$ Furthermore, on the eve of St John's Day dignitaries of the Signoria would process from the Palazzo Vecchio to the Baptistery for evening celebrations, a ceremony that was enlarged by the mid-fifteenth century to include the "whole governmental bureaucracy". ${ }^{19}$ The procession reinforces the inter-relation between political rule and religious devotion.

In all probability, the retinue of officials would have processed along via dei Calzaiuoli on the return journey to the Piazza della Signoria, from where they would have viewed the oblique perspective of the Palazzo Vecchio. The implication here of an intentional relation between ceremony and view suggests that the layout of the piazza was not simply created for purely visual effect. Indeed, similar relationships lie elsewhere in the processional loop - or "Ringstrasse" as Trachtenberg calls it - between the Duomo and the Palazzo Vecchio. ${ }^{20}$ Given these, it seems likely that the Piazza della Signoria was conceived as a coherent ceremonial space. Its underlying geometry was intended to provide an "ideal" backdrop, against which the everyday activities of urban life could be appropriated (and thereby elevated) by the occasioning of sacred and civic ritual. Considering the ease with which Brunelleschi interpreted and reconstructed the "scenographic effect" of the Piazza della Signoria in the early fifteenth century, it seems evident that the "perspectivisation" of urban space was already underway in the late Middle Ages.

Two further aspects of the Palazzo Vecchio give grounds for speculating on such a development. The first is the "Ringhiera", a raised platform that extended around the two main facades of the Palazzo. Introduced in 1323, and demolished in the nineteenth century, this monumental structure functioned as a speaker's podium from where the officials of the Signoria could address the assembled people in the piazza, in much the same way as the Rostra in the Roman Forum. ${ }^{21}$ 
Significantly, the Ringhiera played a key role in the execution of the Dominican reformer, Fra. Girolamo Savonarola in 1498. The corner of the platform served as a "bridgehead" to a raised podium located in the middle of the Piazza. It was here that the Dominican monk was burnt at the stake. The bridge connecting both, along which the monk processed to his execution, was positioned on the

4.6

\section{Execution of Fra}

Savonarola on the Piazza della

Signoria, 1498, Anonymous. Note the diagonal bridge from the Ringhiera to the place of execution and the gridded pavement. Museo di San Marco,

Florence

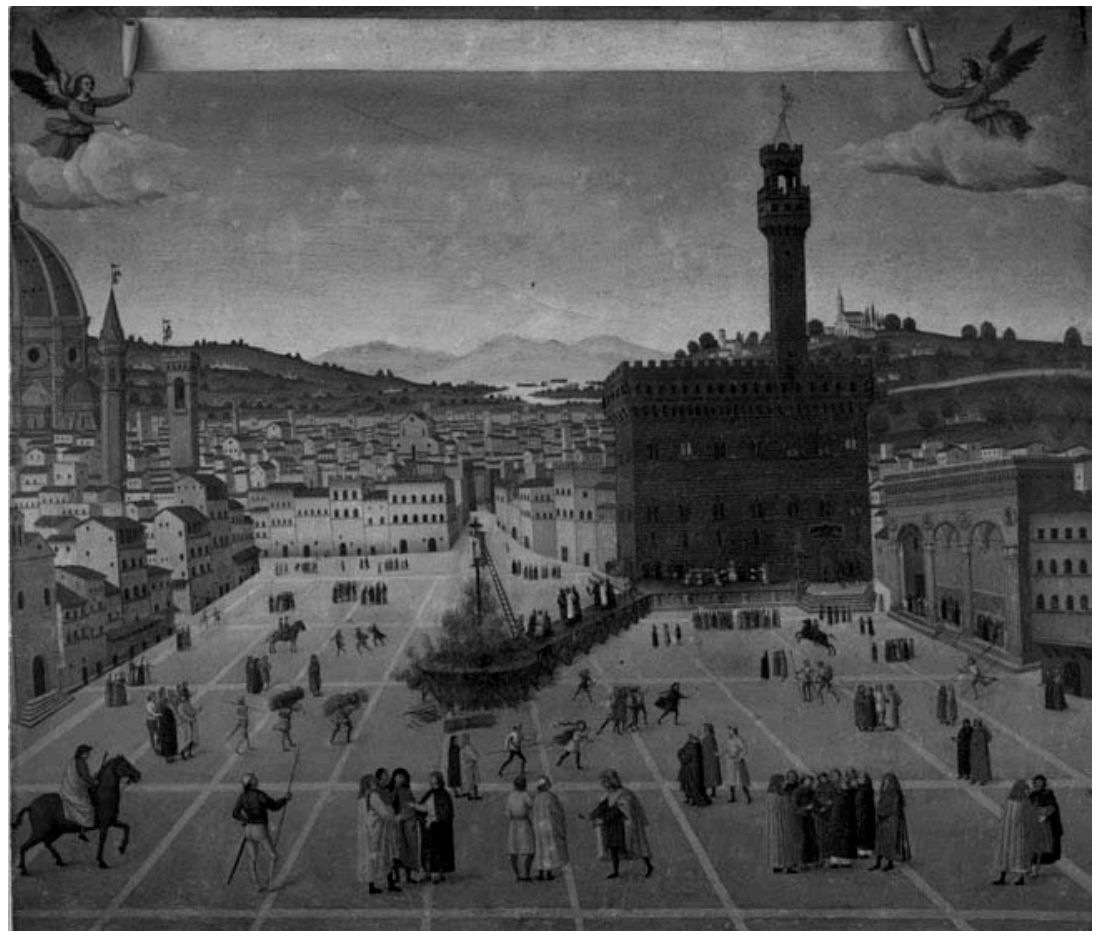

4.7

Plan of the Piazza della Signoria and Palazzo Vecchio (z), indicating approximate position of the connecting bridge from the Ringhiera (y) to Fra

Savonarola's place of execution ( $x$ )

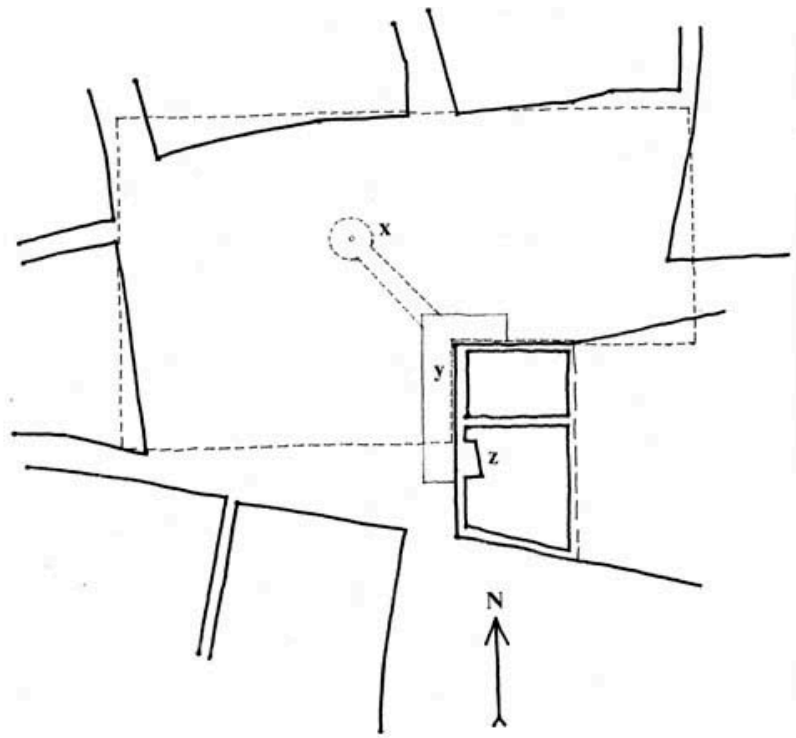


diagonal of the main square. Portrayed in an anonymous painting, the symbolic connotations of the arrangement of platform and connecting bridge, that acknowledges the latent geometry of the piazza, is further echoed by the representation of the piazza as a grid.

Operating as a ceremonial extension to the city hall, the L-shaped "Ringhiera" reiterates the L-shaped space of the Piazza, thereby reinforcing the oblique perspective of the north-west corner of the Palace. In such a resonance, the "pictorial" effect of the Piazza, as experienced from the vantage-point of via dei Calzaiuoli, becomes analogous to the effectiveness of the public sermon being delivered. This relationship between perspective view and sermon is all the more significant in the context of the appropriation of the Piazza for Savonarola's execution, given that the event was the final outcome of the Dominican friar's vitriolic speeches against the "excesses" of Lorenzo de Medici's court. The reciprocity between the occasioning of speech (and therefore of governance) and its urban setting was later to acquire a more coherent expression in Renaissance Humanism, a point I will return to later.

To fully understand the symbolic implications of this analogy will require a more detailed study than can be undertaken here. However, it is important to highlight some underlying principles. In his recent book, Return to Reason, Stephen Toulmin identifies rival methods for judging the merits or defects in our reasoning, between Rhetoric and Logic or the "situational" and the "intellectual" respectively. ${ }^{22}$ Rhetoric refers to a world where speech and language are "more or less situated or embedded in their occasion of use", whilst Logic is de-situated, and therefore self-referential. During the Middle Ages, the rivalry that Toulmin describes becomes a philosophical and theological issue, as found in the heated debates about the nature and role of logic in the quest for truth. ${ }^{23}$ The advent of humanism in the fourteenth century led to the re-assertion of what Toulmin describes as the "reasonableness" of human judgement, where rhetoric and logic constitute not rival camps but a shared domain. ${ }^{24}$

In the Piazza della Signoria we can see how the relation between rhetoric and logic was manifested in urban space; in the inter-relation between the Piazza's underlying geometric order and the appropriation of the space for ceremonial use. The binding of both, through the "perspectivisation" of space, allows the Piazza della Signoria to be understood as both an embodiment of a universal metaphysical order and as an expression of a particular lived (and therefore situated) realm.

The consistency of the perspective effect of the Piazza is further underlined by the layout of the Palazzo Vecchio. As Lise Bek suggests: "the fact that the tower and the portal are set to the right centre of the building enhances the impression of perspective movement towards the furthest, sharp corner of the piazza". ${ }^{25}$ Furthermore, "the projection of the tower to the left of the entrance compels one to look to the right towards the sharp angle of the trapezoid (inner courtyard)". ${ }^{26}$ This movement in depth continues within the enclosed interior courtyard of the Palace where the "theme of the piazza is repeated en miniature". ${ }^{27}$ Combined, both Ringhiera and internal courtyard underline the 
4.8

Plan of the Palazza Vecchio

showing different

interpretations of the

building's geometry: Lis

Bek's continuation of the

diagonal of the principal

square of the piazza to the

south-east corner of the

Palace Cortile (Y), and

Trachtenberg's subdivision

of the building into a grid

of unit length " $a$ "

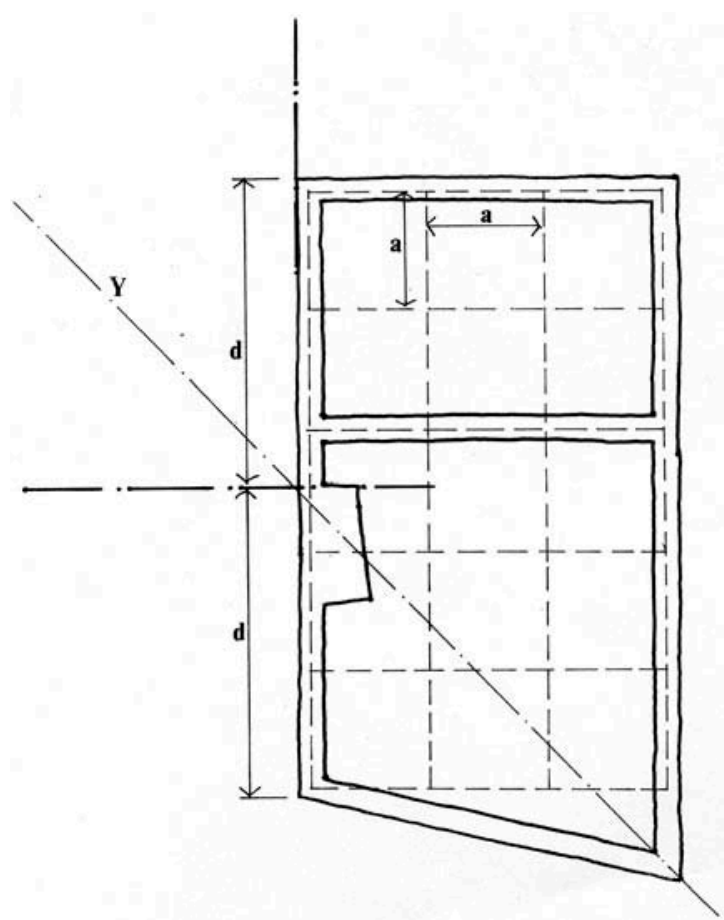

search for continuity between visual experience and spatial (geometric) configuration in fourteenth-century Florence. This perspective outlook is driven by a form of axiality. Both Bek and Trachtenberg consider this to be the space-creating principle or model that is "inherently a part of the theoretical pyramid of vision". ${ }^{28}$

From the arguments of Trachtenberg and Bek one can identify three critical and inter-related features in the Piazza della Signoria:

1. The application of the rotating square in the configuration of the Piazza.

2. The geometric layering of the L-shaped Piazza across the diagonal of the principal square, with its approximate alignment with the Palace tower and internal courtyard beyond.

3. The establishment of the oblique perspective achieved by the combined effects of the first two.

The first characteristic, as we have seen, is revealed in the formation of the duplex Piazza and echoes the "discursive" geometry of the Meno. The second infers a "gnomonic sequence" of L-shaped configurations that leads to a geometry of extension. As though reiterating this perspectively defined gnomic sequence is the effect of the lofty south-east tower of the Palace as a gnomon casting shadows across the north-facing Piazza. ${ }^{29}$ Third, both the first and second characteristics are combined by the "centric ray" of the oblique perspective that is co-linear with the diagonal of the square of the main Piazza. In attempting to confer a homology between these various ways of articulating order in space, the 
layout and perception of Piazza della Signoria brings into question Brian Rotman's assertion of a fundamental irreconcilability between Euclidean geometry and linear perspective. With its absence of an external originating point - and its application of similar triangles - Euclidean geometry is "radically different from a projected, coordinated space; a space in which every position is signifiable in relation to the horizon and centre ray as axes, and the vanishing point as the origin of coordinates". ${ }^{30}$ Whilst Rotman's observations may appear glaringly obvious from a modern rational standpoint, the late Medieval and Renaissance world-views believed in the possibility of a corresponding relationship between an encompassing objective (ideal) world and the situatedness of the human point of view.

\section{Alberti's eye}

What we see emerging in the late Middle Ages is the first sign of a conscious relationship between a perspectivally ordered space and verbal interpretation and formulation. Manifested in the layout and function of the Piazza della Signoria, this relationship anticipates developments in the Quattrocento when text and image become effective instruments for radically redefining the nature and meaning of space.

Of the many figures who contributed to this development Leon Battista Alberti is perhaps the most important. To understand Alberti's ideas about perspective we need first to examine his approach to language. At the heart of Alberti's work as architect and humanist is the idea of a correspondence between text as a metaphor of building and of building as a metaphor of the human body. Underpinning this correspondence is Alberti's fervent belief in the virtues of creativity, in which artistic and literary enterprises serve to underpin humanity's quest for a good and virtuous life. As Cecil Grayson observes, Alberti "may be said to hold and develop a kind of philosophy of life, of which art and architecture are an integral and growing part and ultimately the dominant expression" ${ }^{31}$

The idea of a "philosophy of life" can be traced throughout Alberti's work. His achievements can be divided into two fairly distinct periods: the first as a writer and "theoretician" and the second as a practising architect. Alberti's activities as a humanist and Papal "abbreviator" could be seen, in one sense, as a period of intellectual preparation for his later architectural career. It was during his period in the Papal court in Rome, from 1432, that Alberti embarked on a series of challenging projects, whose range of interests conceal an overarching objective. In short, Alberti sought to establish a common discourse across different forms of enquiry where the symbols of practical life take on "visual as well as verbal embodiment". ${ }^{32}$ Alongside experiments in optics, the "camera obscura" and his ambitious survey of Rome, Alberti also wrote a little treatise (della Famiglia) that examines the virtues of family life. ${ }^{33}$ Written in the vernacular, this work of moral idealism reflects a desire to communicate to the widest possible audience the qualities of domestic life and good citizenship. In his search for order and balance, the realms of human intimacy and urban/architectural space are treated as parts of a single communicative domain.

Alberti's habit of preparing works in both Latin and the vernacular suggests that he sought to address two distinct audiences in his writings: the patron 
(or fellow humanist) and a less well-educated class such as artists and craftsmen. Whilst much of his Latin writings are modelled on ancient texts - many of which emulate the prose of Cicero - Alberti was also acutely aware of the need to standardise the vernacular in order to communicate effectively. Indeed, besides being credited with the writing of the first lexicography of Italian, Alberti also helped develop the foundations of "what would become a standard new genre of Latin writing". ${ }^{34}$

Alberti's concern for the efficacy of language was closely allied to his understanding of architecture and perspective. Whilst initially modelled on Vitruvius' treatise, Alberti's famous De re aedificatoria is nevertheless a unique work that argues for a moral view of building. ${ }^{35}$ Alberti's desire for linguistic clarity led him to criticise Vitruvius' treatise for being almost unintelligible in parts due to the confusion arising from the mixing of Greek and Latin terms. To overcome the disorderly arguments of his predecessor Alberti adopts a firmly Latin bias in his terminology, and indeed in his reading of architecture. This emphasis is supported by an analogy that pervades the whole treatise, namely between the arrangement and style of the text - that gives order and structure to the work - and the processes of designing and making architecture. In this correspondence we are led to the notion that building, like a philosophical tract, is a form of "edification" that instructs and improves society morally. Accordingly, the processes of design and building are allied with the principle of decorum (or propriety), a term that derives from Ciceronian rhetoric. Alberti sees the entwined enterprises of writing and architecture as rooted in a common belief that the creative act of the artist is a mimesis of the creativity of God. ${ }^{36}$

Avoiding illustrative material to support his arguments, Alberti relies instead on the text alone to communicate architectural ideas. His desire for linguistic conciseness sometimes necessitated convoluted descriptions and novel methods, as we see for example in his account of the classical orders:

Alberti ... tries in the De re aedificatoria to emulate through plain alphabetic writing the expressive potential of the images whose use he rejected. This was not without some curious results. Alberti explains how the profile of certain moldings can be obtained by assembling the graphic signs of some alphabetic characters. The capital letters " $\mathrm{C}$ ", " $L$ ", and "S", when combined in different ways, reproduce the profiles of platbands, coronas, ovolos, astragals, channels, waves, and gullets. In this unprecedented way, Alberti might seem to be illustrating his treatise after all; but these are illustrations of a special kind. They are built up of from well-known, elementary, and stereotyped signs: the letters of the alphabet. These were apparently a kind of drawing that most copyists could be counted on to execute reliably. ${ }^{37}$

The adoption of alphabetic characters to convey graphically the profiles of architectural elements highlights a particular use of language that in some ways attempts to overcome the visual and interpretative boundaries that usually distinguish 
textual from graphic narration. Indeed, the nature of the relation between both became a major interest during the age of printing, as we see for example in the complex and interwoven narratives of the Hypnerotomachia Poliphili, first published in 1499. ${ }^{38}$

The relation between textual and graphic narration finds a more sophisticated form of articulation in numismatics. In these commemorative artefacts, emblem and motto are deployed as corresponding symbolic references. Alberti explores this relationship in his writings, as we see for example in the principal manuscript of Della Pittura, the Italian translation of De Pictura dating from around 1436. Before the dedication to Brunelleschi is an emblem of an eagle supported by the motto, Quid Tum ("what next?"). Another example can be seen in the manuscript of Philodoxeos fibula, a little play about the moral qualities of glory that was sent to Lionello d'Este in 1438 as a gift. ${ }^{39}$ In the dialogue is an emblem of a winged eye, the impresa of Alberti. The motif was earlier used in the impressive bronze self-portrait of the artist that dates from around 1435. The winged eye appears on the left of Alberti's head and again on the right, in the form of smaller incidental motifs above and below the abbreviated name of the artist, "L.Bap". Significantly, both winged eye and the motto Quid Tum were later combined along with a ring of laurel - to form an emblem on the reverse of the portrait medallion of Alberti (1446-50) by Matteo de'Pasti. The significance of this emblem has attracted much attention from scholars. Whilst detailed discussion of this medallion is beyond the scope of the present study, it is worth highlighting the most important issues that pertain to its symbolism, as Anthony Grafton outlines:

the eye could represent, as Alberti suggested in his dinner piece, "Rings", the swiftness, glory and universal vigilance of God, or it could claim as much for the godlike creative artist. Or it could evoke both God and the godlike creator at once, as symbols can, offering the onlooker provocation for continued thought rather than a single message that could be put in words. Alberti's motto seems to be a quotation from Virgil, with which he tried to make light of his illegitimate birth. But it could also be a Ciceronian expression of his own defiance of the opposition he had so often met. In any event, the medal fused classical traditions with Florentine fashions, scholarly and aesthetic, to create a modern symbolic language..$^{40}$

Whilst the ring of laurel, which surrounds the winged eye, is the "classical sign of the honor and the distinction won by human deeds", the eye is "more powerful than anything else, swifter, and more worthy. It is the first, chief, king; it is like a god of human parts." 41 The allusion to the eye as both human and godlike reminds one of Grosseteste's assertion, highlighted in Chapter 3, of one's range of vision being guided by one's capacity to love (divinely). In the case of Alberti, however, we witness a more fervently worldly (Humanist), rather than theological (Scholastic), understanding of vision in which judgement is based on a "combination of human pride and reverence before an all-embracing deity". ${ }^{42}$ 
4.9

\section{Winged \\ Human Eye (reverse), \\ Matteo \\ de'Pasti, 1446/1450, bronze}

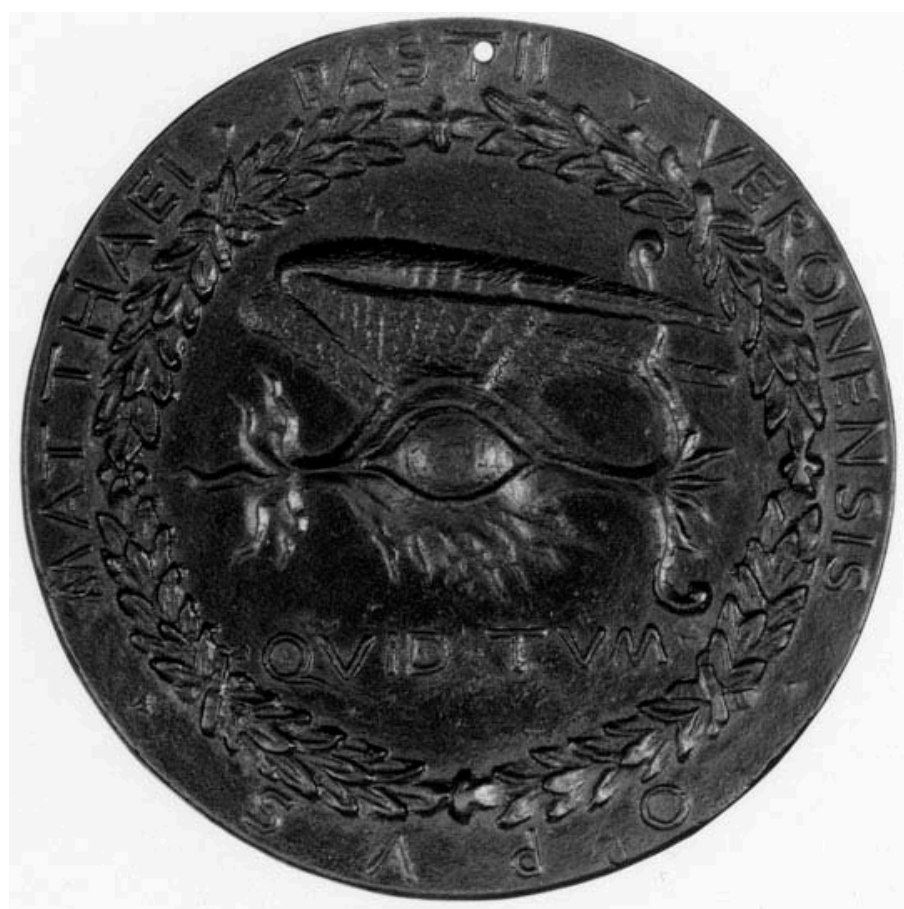

The reference to pride is supported by another important aspect of the motif. This concerns Alberti's first name, Leon. ${ }^{43}$ In many of his writings Alberti makes allegorical references to himself as a lion. Typically, the lion symbolises courage and pride, but Renée Watkins suggests that Alberti may have used the image to emphasise notions of labour and anxious aspiration, traits that embody the enquiring and creative mind striving to achieve noble deeds. ${ }^{44}$ These characteristics give meaning to Alberti's perspective since the pyramid of vision operates like a "drift-net" that captures - and thereby orders - otherwise recondite or inaccessible domains within the calibrated dimensions of pictorial space. The significance of the name Leon in this enterprise is further underlined by the likelihood that Alberti was alluding to a well-known belief that a "lion's eye was of such power that it did not decay with the death of its owner". ${ }^{45}$ Seen in this context, the combination of the portrait of Leon Battista Alberti and "hieroglyph" (on the reverse) evokes in Janus fashion the idea of the "quasi-divine act of 'rational seeing, ' a mode of imaginative vision which came to encompass all [Alberti's] aesthetic ideas of the gaze". ${ }^{46}$

Such emblems operated as memory devices for affirming moral purpose, a purpose that can found elsewhere in Medieval and Renaissance iconography. ${ }^{47}$ But in the case of Alberti, the development of a hieroglyphic view of writing was oriented to what Anthony Grafton describes as "an optical language of philosophy". ${ }^{48}$ In this optical language, the eye is that of the humanist providing moral instruction to his patron or reader. This was a form of language that in one sense departed from Medieval practice where the codex or illuminated 
manuscript traditionally constituted a revelatory body of divine truth that could be called upon to re-affirm received knowledge. ${ }^{49}$

In the more explicit renderings of perspective thought in the Renaissance, language and the visual arts were deemed inter-related through the analogous understanding of the picture plane:

The [intersecting plane] is described [in De pictura] as a surface/veil, which enables a particular visual aspect of the object to be noted. Above all it is characterised by the process of transcription, which allows the form, number, size and disposition of elements to be recorded and disseminated in a universal manner. The operation of this surface is analogous to that of a page ... Alberti's almost unconscious drive for introducing the concept of the intersecting surface must have been indebted to his experience of reading from, and writing on, the page. ${ }^{50}$

Gordana Guisti argues that the projection, through the intersecting plane, of the three-dimensional world onto a flat surface could only have been possible "in a culture deeply rooted in, and conditioned and saturated by, the experiences of reading and writing".$^{51}$ It is likely therefore that the correlation between the single viewing point of Renaissance pictorial space and the stationary viewpoint of reading became axiomatic in Alberti's thinking. ${ }^{52}$

The implicit perspectival nature of Alberti's visual/linguistic world-view, argued by Guisti, contradicts, however, Mario Carpo's argument that Alberti's treatise on architecture demonstrates an understanding of antiquity that is hardly visual; Alberti provides no "ecphrastic reconstruction of any individual building". ${ }^{53}$ He claims, therefore, that "the structure of [Alberti's] discourse, and his methods, are unmistakably those of the medieval Scholastic tradition". ${ }^{54}$ Whilst it seems evident that Alberti's writings are rooted in this tradition, the articulation of a language that calls for typographical characters to communicate the principal features of the classical orders points towards a form of codification anticipatory of modern concepts of vision. ${ }^{55}$ To this extent, the dominance of a visually oriented culture during the Renaissance provided the impetus for new linguistic analogies (like that between the picture-plane and the printed/written page). These departed from the primarily "audio-tactile" culture of the Middle Ages discussed in Chapter $3{ }^{56}$

The language of Alberti, like his understanding of architecture, was inextricably bound to an ideal that was considered a legitimate model for redefining the nature and meaning of decorum in everyday action. This ideal initially centred on the cultivation of individual virtù that provided the impetus for wider social concerns such as architecture. In this pursuit Alberti "was continually concerned to relate his underlying sense of God's order to the actual behaviour of the individual in society" ${ }^{57}$ This understanding acquired a theoretical stamp in Alberti's De Pictura and Descriptio Urbis Romae. Martin Kemp suggests that both texts - along with other related works by Alberti such as the Ludi matematici and Elementa picturae - formed part of a more general endeavour "to endow practical skills with a mathematical base". ${ }^{58}$ 
This was most clearly manifested in the idea of "calibrated" space in perspective. Against issues of order and decorum of actual situations - typically conveyed in the occasions of human dialogue - are "indexed" the paradigmatic scenes exemplified in pictorial representation. Accordingly, perspective constitutes a kind of "example" of how order can be communicated to actual ritual events, a point I discussed earlier in Chapter 2 in the context of Leonardo da Vinci's Last Supper.

Like Alberti's De re aedificatoria, De pictura is similarly deprived of supporting illustrations. Instead, we are given a concise - indeed step-by-step account of pictorial perspective that initially builds upon first principles using basic geometric properties like the point, line, surface (or plane), edge, angle, flatness, convexity and concavity. ${ }^{59} \mathrm{It}$ is as if Alberti was setting out to compile a treatise on Euclidean space. But, as Martin Kemp points out, the reiteration of classical geometric principles is not argued in the context of "immaterial abstractions of pure mathematics". ${ }^{60}$ Rather, Alberti is emphasising the visual (and therefore material) nature of geometry.

Alberti develops this idea of the substantial reality of pictorial space through an understanding of the mediating function of geometry and number; "from our definition a point is a sign because the painter perceives it as if it were rather like something between a mathematical point and a quantity that can be classified by number, as perhaps atoms can be". ${ }^{61}$

The dual meaning of the point, to which Alberti attributes qualitative (mathematical) and quantitative (numerical/visual) value, finds a comparable treatment in Nicholas Cusanus' De Beryllo:

In the indivisibility of a point are enfolded all the foregoing indivisibilities. Therefore, in those indivisibilities there is found nothing except the unfolding of the indivisibility of a point. Therefore, all that is present in a material object is only the point, i.e., is only a likeness of the one. Moreover, a point does not exist as free from a material object - as was evident. From this consideration of a point and a material object elevate yourself unto a likeness of True Being and of the universe; and by means of [this] quite clear symbolism [of a point] make a conjecture about what has been said. ${ }^{62}$

4.10

De Pictura, Leon Battista Alberti

(1404-72).

Perspective

Reconstruction of

the Gridded Floor.

Drawn by author after Gadol

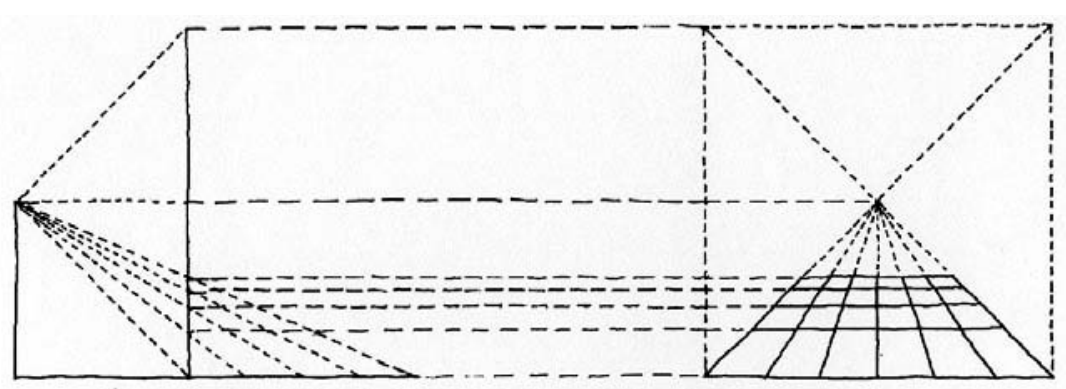


It would be easy to consider Alberti's understanding of the point in rather different terms, given the mathematical and material qualities attributed to it. But such an assumption would only overlook the underlying cosmological nature of his pyramid of vision. We are given a sense of this misunderstanding in Kemp's observation that Alberti "nowhere explains why the properties of the pyramid result in the reciprocal geometry of his pictorial construction". ${ }^{63}$ Kemp's argument that such an explanation is required overlooks the existence of a cosmological tradition of geometric thought in which questions of reciprocity are assumed. This point is succinctly conveyed in the following:

The role of cosmic figures is to represent and initiate the mediating movement between sensible and intelligible phenomena in a simulated transition between point to line, to surface and solid body. The same process of transition is even more explicit in the structure of the luminous or visual pyramid where light moves between body and point via surface and lines. ${ }^{64}$

This parallel relationship between cosmic (eternal) figures and the pyramid of vision could be said to underlie Alberti's desire "to instruct the painter how he can present with his hand what he has understood in his mind" ${ }^{65}$ In other words, the process of constructing pictorial space through the pyramid of vision becomes analogous to the process of "recollecting" the ideal that lies embedded in the timeless realm of geometry. Implicit, therefore, in Alberti's somewhat pragmatic arguments about "perspectival correctness" there pervades a Platonic/Pythagorean view of order.

The extent, and depth, of this influence of geometric thinking on perspective can be traced back to the earliest developments in the "perspectivisation" of space in the thirteenth century outlined in Chapter 3. Of particular importance here is Roger Bacon's belief that the Multiplication of Species depends upon the principle that only in the pyramid can perfect illumination and the action of nature be preserved. The pyramid is the "receptacle" that ensures the even dispersal of rays of light between agent and recipient.

The primacy given to the triangle in the perspective understanding of

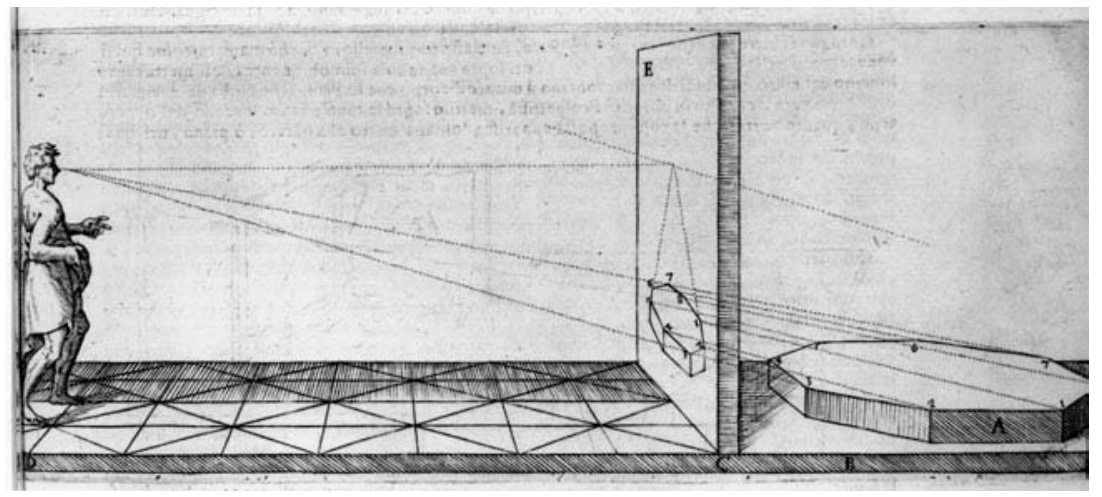

4.11

Perspective construction derived from Leon Battista Alberti's De Pictura. Giacomo Barozzio Vignola (1507-73), Le due regole della prospettiva practica (Rome, 1644), p. 55 
an ideal world provided the metaphysical counterpoint to the "perspectivisation" of actual topography. This can be seen in Alberti's survey of Rome, the Descriptio Urbis Romae, commissioned by Nicholas $V$ in the late 1440s. The survey has long been considered a reworking of Claudius Ptolemy's Geography, or what Carpo describes as a "creative plagiarism, or 'rebirth,' of [Ptolemy's] cartographical methods". ${ }^{66}$ Written in the second century, the Geography became a source of intense interest amongst Renaissance cosmographers in a similar way to the reception of Vitruvius' Ten Books in humanist circles. ${ }^{67}$ A common feature in the interpretations of both works was the emphasis given to methods for calibrating and organising space. As we have seen in the context of Alberti's "reworking" of Vitruvius' treatise, these methods entailed the deployment of "organising lines" (lineamenti) whether at the level of a city, an individual building or an architectural element. I argued in Chapter 2 that these lines, which are registered as proportional relationships of spaces, also conveyed to the beholder a hidden (geometric) order. In the case of the Geography, however:

The idea of a spatial structure governed by geometry but concealed below the level of appearance seemed to offer to both cosmographers and architects a conceptual grid for experience, observation, and technique. For Ptolemy, the use of a graticule, comprising numbered meridians and parallels for "recording the precise location of places on the earth's surface", enabled "a scaled spatial image of terrestrial space to be mapped onto the sphere or, by means of projection, to be transferred onto a planisphere". 68

Parallels and meridians, moreover, are determined "from geocentric observations of the celestial bodies, whose movements are graphically illustrated by the sphere of axes and circles of the sphaera mundi" ${ }^{69}$ This matrix of invisible lines could be compared to Alberti's lineamenti, given that both methods of subdividing spaces lead to some larger arrangement or configuration. Embedded in both, moreover, is the Platonic notion of eternal forms or ideas, only in the case of Alberti, order resides not so much in the human soul but rather in his virtù - in his capacity as an active moral being. This moral well-being, however, requires disegno interno, or "internal design", to sustain what Dalibor Vesely describes as an "imaginary world"; an "ideal image which precedes the realization of such a world". 70 Alberti's lineamenti was later re-interpreted by Serlio in his notion of linee occulte: "a continuous invisible network within which the planes and facades of buildings, and the spaces around them, were defined" ${ }^{71}$

In moving from architecture to cosmology, from Albertian lineamenti to Ptolemaic graticules, we graduate from the particular (practical) world of human virtù - embodied in the individual building and the larger city - to the general or known world of the oikumene. ${ }^{72}$ Developments in cosmography in the Renaissance contributed to an important revision to the Ptolemaic system. Initially, new methods in cartography were inserted into the Geography without fundamentally altering its content and meaning. By the sixteenth century, however, a separation 


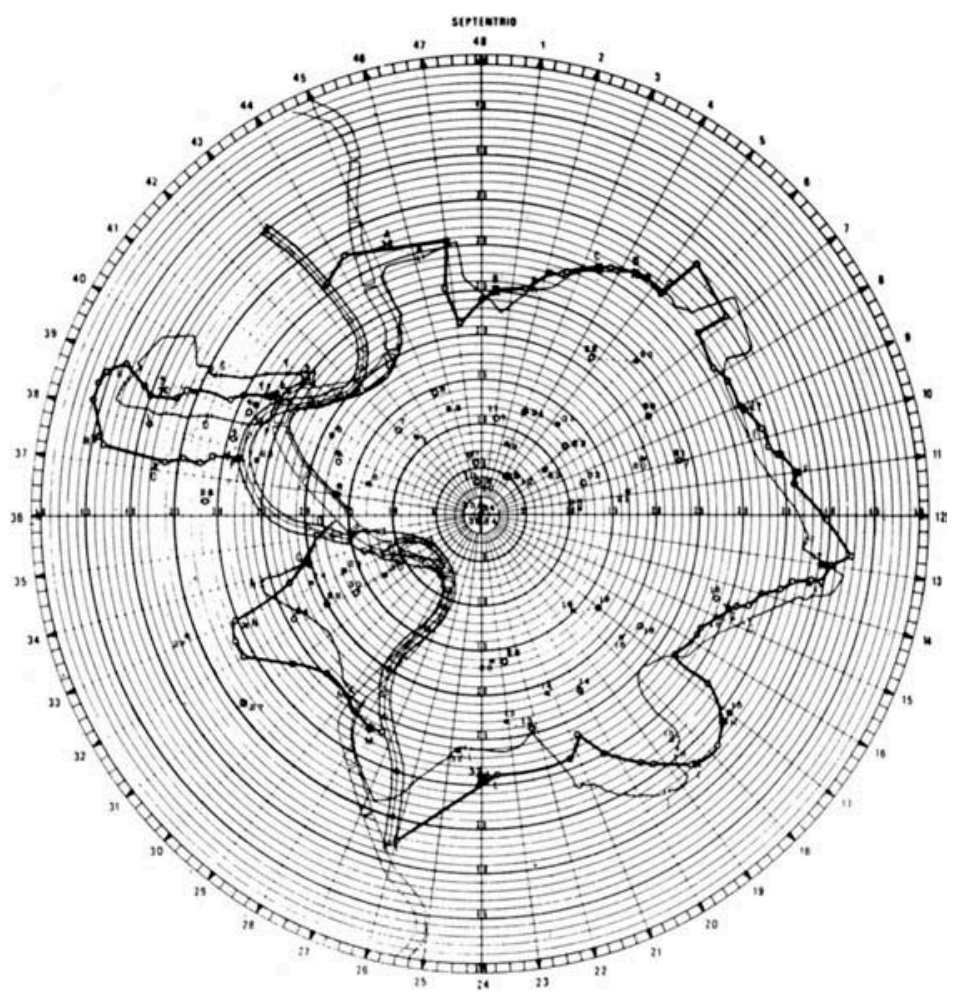

begins to emerge between geographical and astronomical considerations, leading to the belief that "no necessary or harmonious connection between the patterns of celestial and elemental space existed". ${ }^{73}$

It is in the light of this critical separation that we must consider the nature and meaning of perspective in early modern thought. Whilst it would be simplistic to construe the encroaching "emancipation" of topography from its celestial context as symptomatic of modern perspectivism, it seems clear that the change in the terms of reference in mensuration contributed to the eventual notion of the oikumene as a domain located exclusively within the physical earth-bound - world. ${ }^{74}$ In this transformation, "the enclosed room-like space became a place where the traditional vertical relations between celestial and terrestrial, divine and human realities (redolent of Medieval sacred space) could be represented as a horizontal relation between the nearness of the corporeal world and the remoteness of the new quasi-infinite space. " ${ }^{75}$ We will shortly examine this relationship in the context of the Stanza della Segnatura.

This emphasis probably contributed to a misunderstanding about the nature of the Ptolemaic system in the Renaissance that was to have important repercussions in later developments in cartography. The sixteenth-century mathematician Frederigo Commandino claimed that Ptolemy adopted a form of linear perspective for both his method of cartography and in his orthographic projections for sundials. ${ }^{76}$ This claim was to find a modern supporter, Samuel Edgerton, who
4.12

Descriptio Urbis

Romae c.1448-55,

Leon Battista

Alberti (1404-72).

Reconstruction of

Alberti's survey of

Rome by

D. Vagnetti 
4.13

Measuring topographical distances by triangulation.

Giovanni Pomodoro, La geometrica practica di Gio.

Pomodoro Venetiano cauata da gli elementi d'Euclide e d'altri famosi autori ... (Rome, 1667),

p. 46

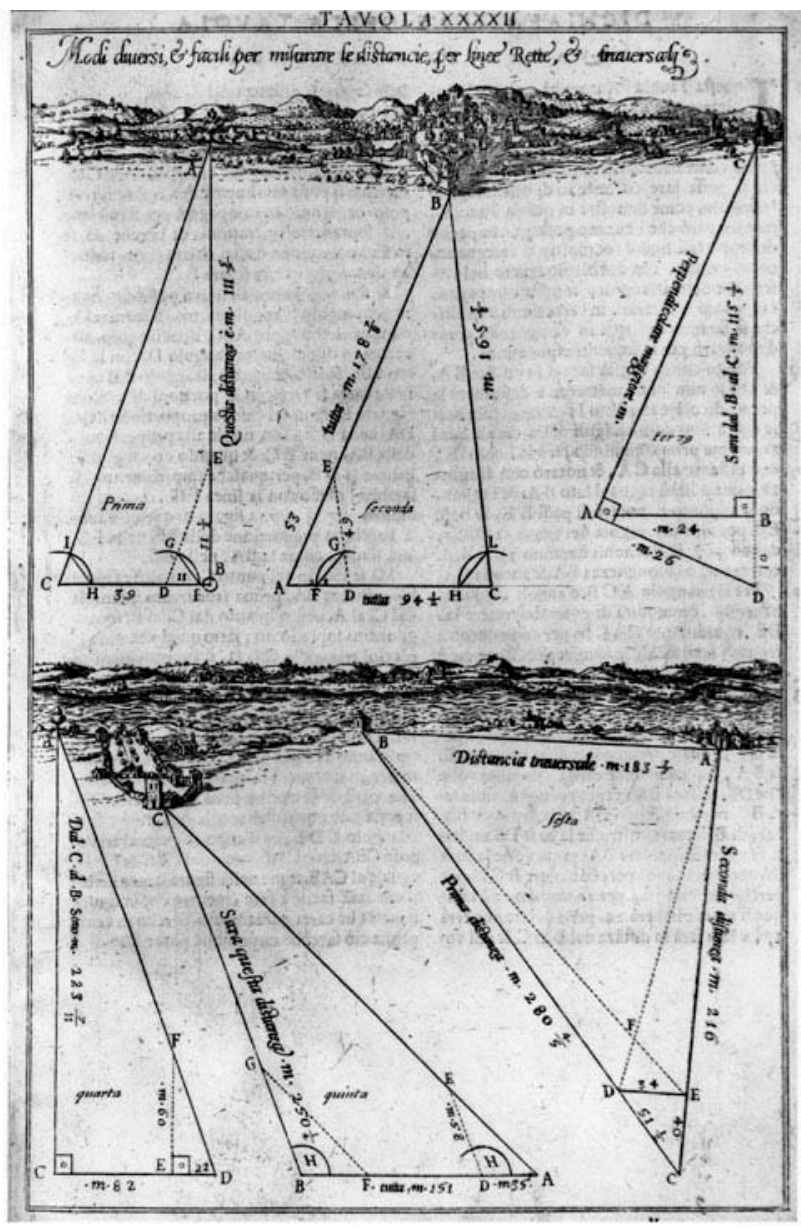

argues that Ptolemy's Geography draws its terms of reference from a "linear perspective system similar to that of [Vitruvian] scenographia". ${ }^{77}$ Alberto PérezGómez discusses the reasons behind this misunderstanding that seem to centre on a misreading of an aspect of Ptolemaic cosmology:

[The observer] looks at a "motionless globe through a point before the eyes in which occurs the intersection of that meridian and that parallel which divided respectively the longitude and the latitude of the known earth into two equal parts" in such a way that they "will exhibit the appearance of a straight line" and one can perceive the curvature of the other meridians and parallels on either side of this intersection. ${ }^{78}$

Edgerton asserts that the description refers to "a form of conic section anticipating perspective". ${ }^{79}$ But as Pérez-Gómez argues, Ptolemy is actually describing an "unfolding of the earth's skin" in which the map lacks a "specific viewer, because 'they are no representations of the world seen, but of the mathematical essence of 
the [cosmos]' ". ${ }^{80}$ A central issue in this misunderstanding is the nature and meaning of distance, as defined by the relation between "the world and its representation". In the case of Ptolemy this is not "the geometrized distance of a perspective construction". Rather, measurement acquires analogical significance, whereby the oikumene is conveyed to the reader as a "mimesis of a reality not seen". ${ }^{81}$

The emphasis on the gridded globe as an object of contemplation rather than a representation of something seen - distinguishes the Ptolemaic world from later developments in Renaissance cartography. It is in the context of this distinction that we must reconsider Carpo's claim, referred to earlier, that Alberti's Descriptio Urbis Romae is a "creative plagiarism, or 'rebirth' of [Ptolemy's] cartographical methods". ${ }^{82}$ Where Alberti's survey of Rome departs from Ptolemy's cosmology is in the latter's assumption that only the sky can be a true reference for understanding the geometry of the earth. Indeed, the shift from an essentially celestially oriented world-view to a predominantly ground-based (terrestrial) one could be said to find demonstrative expression in Alberti's survey of Rome. This, as Joan Gadol notes, centres on Alberti's use of a navigator's astrolabe as an instrument for land mensuration:

Like an astrolabe, [Alberti's] Horizon was divided into four quadrants and its perimeter was graduated. Its radius, like the rule, or alidade, of the astrolabe, was a radial arm that pivoted from the center of the instrument. The navigator (or astronomer) used the radius as a sighting rod for taking vertical angles, or elevation, of the sun and stars. When the instrument was rotated ninety degrees around the horizontal axis, the radius could also be used to mark off horizontal angles, or bearings, on the units of the disk's perimeter. This is the way Alberti ... used the disk; and this very instrument, employed in this fashion, appears in the hands of the surveyors and cartographers of the sixteenth century. ${ }^{83}$

The simple act of adapting the astrolabe from a navigator's or astronomer's tool (in its vertical position) to an instrument for land surveying (by its reorientation to the horizontal position) reflects an understanding of topography as a domain open to systematic calibration and measure. Using the disk of his instrument as the horizon, Alberti constructs lines of sight that radiate out from his point of reference, as David Leatherbarrow explains:

Having raised the plate to the right viewing level, he then aligned its zero meridian with the north-south axis, pointing the zero to the north. This set the stage for the measuring and transcribing procedure. After a landmark in the distance was sighted, the radial arm was rotated until it pointed directly at it, and the degrees from the zero line to the radius were counted, marked and tabulated. Then the distance between the instrument and the landmark was paced off, so that it too could be marked and noted. ${ }^{84}$ 
The nature and meaning of distance - or more specifically the gap separating the architect's eye and an object beyond - becomes a critical factor in this task. As Leatherbarrow points out, the notion of distance before Alberti's survey was less about length and more about time or effort. The time taken to traverse the city by foot for example constituted an acceptable measure of distance, which was expressed not so much in numerical terms as by certain vernacular expressions, such as "a hike" or a "stone's throw away". In Alberti's survey however, this "situational" understanding of distance, judged by a combination of intuition and custom, is overlaid by "metric length pure and simple - length 'in itself' ". ${ }^{85}$

Whilst Alberti's method smacks of an encroaching abstraction it would be inaccurate to consider his survey of Rome as a purely instrumental affair empty of cosmological meaning. As I have already remarked, humanists and antiquarians interpreted urban topography, particularly of Rome, as a domain rich in metaphors that acquire "inscriptive" meanings through time. ${ }^{86}$ This is implied in Alberti's choice of location from which to survey the city. Once the symbolic fulcrum of the ancient city - variously defined as the umbilicus or "centrum Urbis" - the Capitol later became the source of intense antiquarian interest from the fifteenth century onwards.$^{87}$ This is highlighted, for example, in Flavio Biondo's Roma Triumphans in which the author attempts to reconstruct, in Book $X$, the route of the ancient triumphal march, the via triumphalis. ${ }^{88}$ This extended from the Vatican to the Capitol, the latter forming the final destination and culmination of the ancient procession. Biondo's reconstruction, which Alberti knew, relies on ancient textual accounts

4.14

\section{Schematic map of Rome showing route of the via Triumphalis from the Vatican to the Capitol: Circus of Caligula (site of St Peter's Basilica)}

(A); Ponte Triumphalis (B); Theatre of Balbinus (C); Circus of Domitian (Piazza Navona) (D); Hadrian's Mausoleum

(Castel

Sant'Angelo) (E); Theatre of Marcellus (F); Forum Boarium (G); Circus Maximus (H); Roman Forum (I); Capitoline (J)

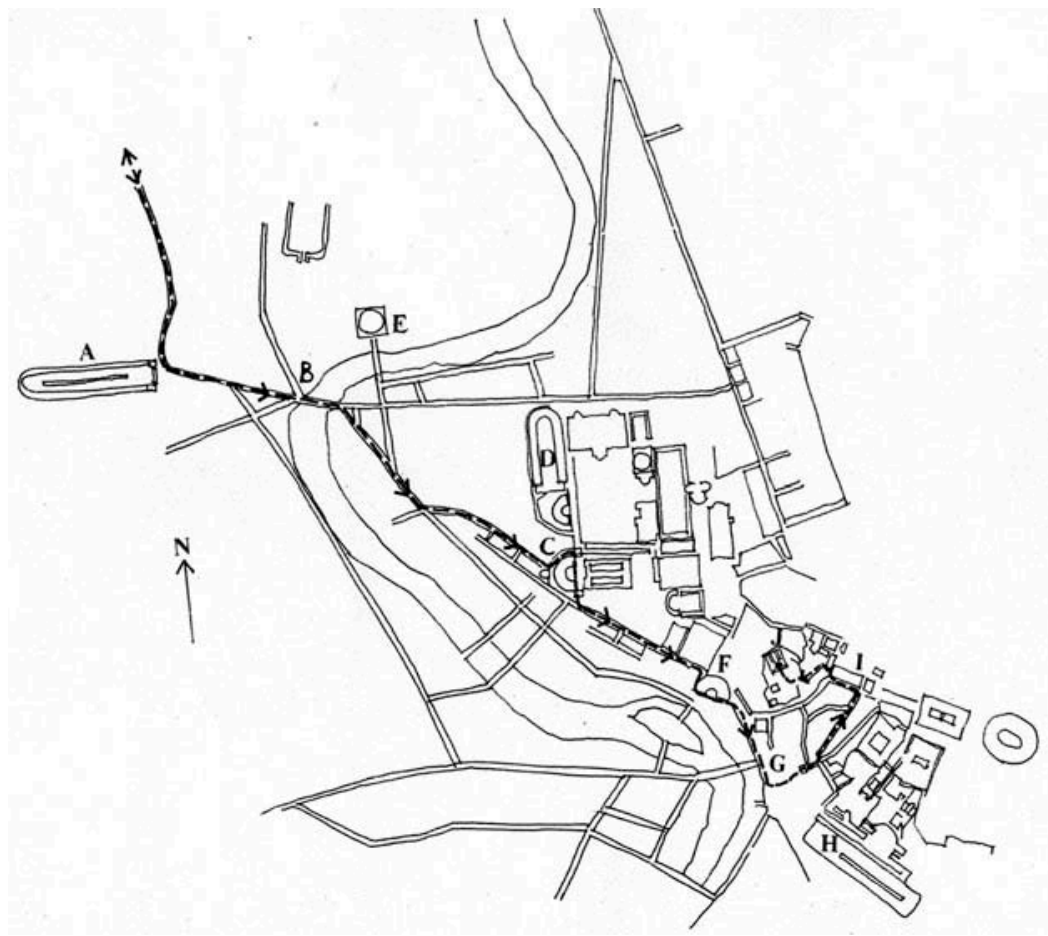


such as the famous description by Suetonius of the triumphal march of Caesar. ${ }^{89}$ From this material Biondo identifies the most important ancient monuments and contemporary buildings that delineate the route of the via triumphalis. These landmarks, that commence with the Vatican obelisk and conclude with the Temple of Jupiter Maximus Capitolinus on the Capitol, served as critical points of reference in the changing palimpsest of the city. ${ }^{90}$

It is in the context of this attention to land-marking in Renaissance cartography and antiquarian thought - a practice incidentally that can be traced to late Medieval pilgrimage maps - that Alberti's city survey should be understood. Indeed, Biondo's allusion to the via triumphalis as an "umbilical chord", that connects the north-western periphery of the city (the Vatican) to the "navel" of Rome (the Capitol), could be said to acquire geometric precision in Alberti's Descriptio Urbis Romae. It could be argued therefore that the choice of the Capitol as the vantage point in Alberti's visual survey of Rome was not simply motivated by practical considerations but also by symbolic intentions. ${ }^{91}$

In one sense, Alberti's choice of vantage point, from which to survey Rome's topography, is a tacit acknowledgement of the venerated status given to the Capitol in antiquity, a status that was being revived through the political, religious and cultural initiatives of the Popes. In doing so, the humanist enterprise of classical renewal achieves a kind of mathematical exactness; quantifiable units were deemed to "measure" qualitative symbolic value that were implicit in the inter-relationships between monuments and landmarks.

This understanding of measure, however, needs to be considered in the light of Leatherbarrow's assertion of a difference between "a geometry of practical situations and one of metrical positions". ${ }^{92}$ The difference is reiterated by Carpo's theory that Alberti's "lost" map of Rome may never have existed since he was seeking to demonstrate that cartographic knowledge could be translated into tabulae, or lists of coordinates. ${ }^{93}$ Hence "Any person with sufficient technical skill could reproduce the map personally from the numbers provided, thus avoiding the inevitable inaccuracies of copying a linear drawing." 94

Accordingly, Carpo is arguing that algorithms substitute ecphrasis. The substitution could be seen as following a similar line of thought to that of Alberti's reliance on language to communicate spatial and architectural ideas in his De pictura and De re aedificatoria. However we consider Carpo's claim, what seems clear is that the "translation" of geometrically determined relations between landmarks into numerical data was not a neutral operation but rather one steeped in symbolic meanings. To understand this symbolism we need to appreciate the influence of Christian/Platonic views of order - as they pertain to geometry and number - on the Descriptio Urbis Romae. This finds expression in the principle of the triangulation of the visual field, as used in land surveying. ${ }^{95}$ We have already examined the symbolic meanings of the triangle in Chapter 3 in the context of Renaissance views of order. The act of tabulating the distance between the eye and a distant object, from within the angle of the visual field, relates analogously to Alberti's pyramid of vision in his perspectiva artificialis. The relationship between both was informed by a deeply felt belief that actual and ideal worlds 
4.15

Outline Map of east and west banks of the Tiber river highlighting triangular relationship between the Meta Romuli to the north (B); the Pyramid of Gaius Cestius Meta Remi to the south (C); and the Tempietto of St Pietro in Montorio on the Janiculum (A).

Also note locations of St Peter's Basilica (D); the Cortile del Belvedere (E); and northern part of the via Triumphalis (F) formed part of the same embodied reality; hence the possibility of graduating from the situated realm of actual topography to the revealed (exemplary) realm of perspective space. Implicated in this transformation, as I will develop later, is a redemptive understanding of perspective and topography.

Alberti's survey of Rome highlights an attempt to conceive the city as a geometrically ordered arrangement of topographical relationships that can be reduced to numerical tabulation. Whilst these systematic methods of land surveying were unique for the period, the underlying assumption of "pre-defined" geometrical relationships was not.

An indication of this idea of a pre-destined order in topography is highlighted in a recorded observation made by a humanist canon, Maffeo Vegio, in the papal curia of Eugenius IV (1431-47). ${ }^{96}$ Standing on the summit of the Gianiculum, on the site traditionally believed to be the place of St Peter's martyrdom, Vegio observed that the two ancient pyramids visible in the distance (the Meta Romuli and the Pyramid of Gaius Cestius) were almost equidistantly placed. The relative

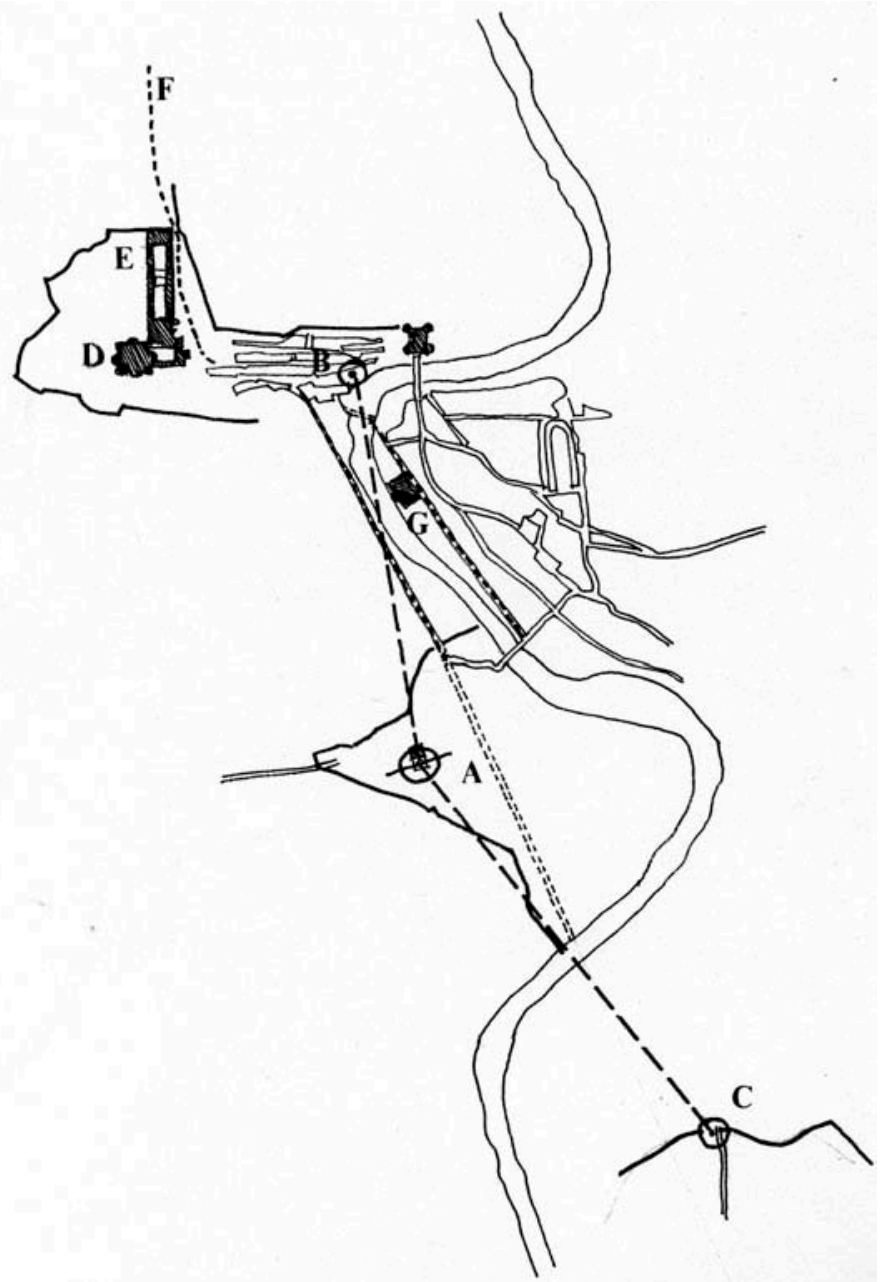




\section{Disclosing Horizons}

accuracy of this observation is confirmed when we mark out on a contemporary map a triangle whose corners coincide with the later Tempietto of San Pietro (built on the supposed site of Peter's martyrdom) and the locations of both pyramids. It would be easy to dismiss Vegio's discovery as merely coincidental. But such an assumption would have been meaningless in a culture steeped in an ontotheological outlook that considered all circumstances to be endowed with providential meanings. In the context of topography, this found expression in the continuity of Rome's mytho-historical past as revealed through textual and archaeological interpretation.

In the particular case of the pyramids, the predestination of Rome's Christianisation, invoked in its topography, was closely bound to the symbolism of these monuments. Throughout the Middle Ages, and for much of the Renaissance, the so-called Meta Romuli - located close to the Castel Sant' Angelo near

4.16

Pyramid of Gaius Cestius, Rome (First century BC). General view

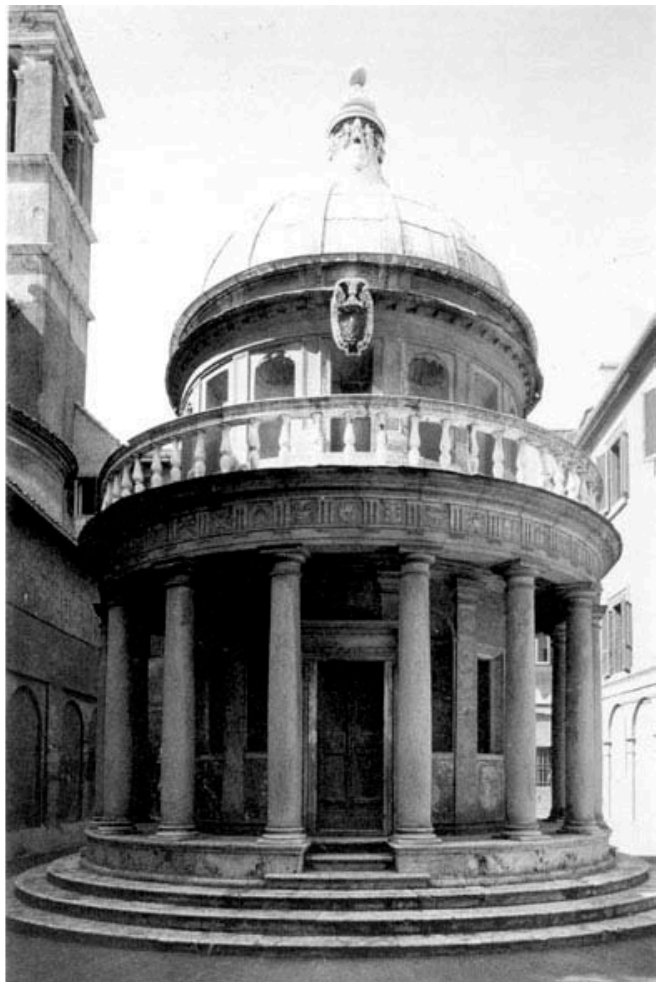

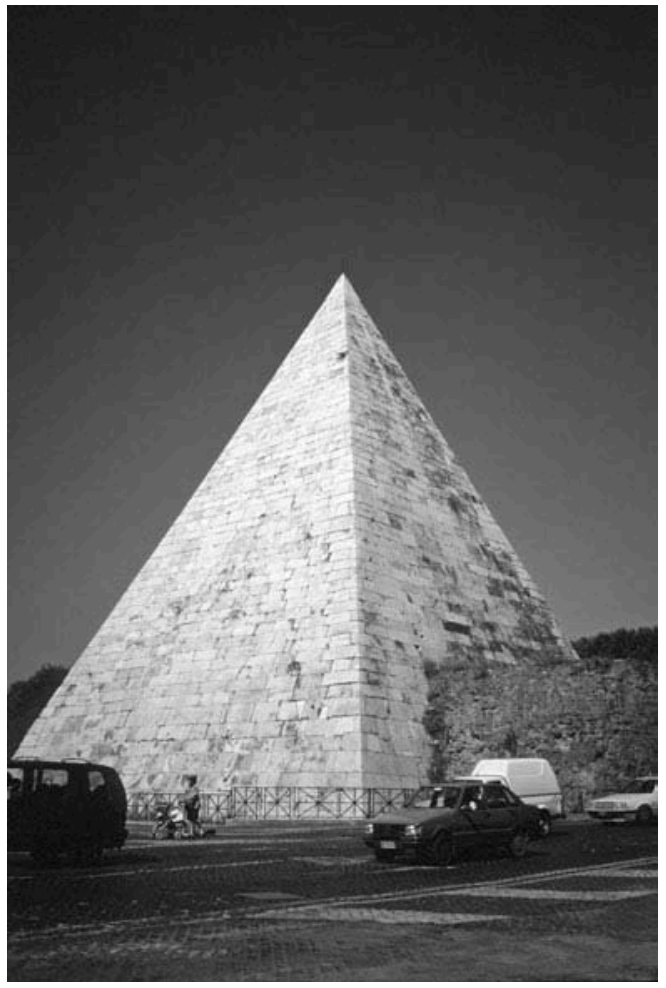

4.17

Donato Bramante (1444-1514),

Tempietto of St Pietro in

Montorio, 1502 
the bend in the Tiber river - served as an important and conspicuous landmark for pilgrims crossing the river to St Peter's Basilica. ${ }^{97}$ Destroyed in the sixteenth century, the pyramid's proportions were unusual and distinctive, suggesting a hybrid form somewhere between an obelisk and an Egyptian pyramid. The still extant Pyramid of Gaius Cestius (nick-named the Meta Remi), on the other hand, was more conventional, located to the south of the city and signalling the gateway to St Paul's Basilica "fuori le mura". ${ }^{98}$ Situated, therefore, at the edges of the walled city, along important pilgrimage routes, both pyramids became closely associated with the burial places of the "Princes of the Church". As a generic term, the metà carried special meanings during the Jubilee celebrations that variously sought to invoke Rome's mythic origins. ${ }^{99}$

The relation between pagan and Christian Rome, conveyed in the symbolism of the Meta Romuli and Meta Remi, was underlined by the pairing of Romulus and Remus (founders of ancient Rome) with Peter and Paul (founders of Christian Rome). The connection was probably motivated by the desire to demonstrate continuity between Rome's ancient origins and its renewal as the "second Jerusalem". ${ }^{100}$

The associations may further explain why the two pyramids are frequently portrayed in representations of St Peter's martyrdom. Two notable examples are worth highlighting briefly here. The first is the famous bronze relief by Filarete on the east door of St Peter's Basilica. This shows the Saint being crucified upside down on the summit of the Gianiculum and flanked by the pyramids, represented at the base of the relief on the left and right hand sides. The second is the fourteenth-century "Stefanschi" Altarpiece, attributed to Giotto, that shows

4.18

Bronze relief of the Martyrdom of St Peter. Bronze door of St Peter's Basilica, Rome (1443), Filarete (Antonio di Piero Averlino) (c.1400-69).

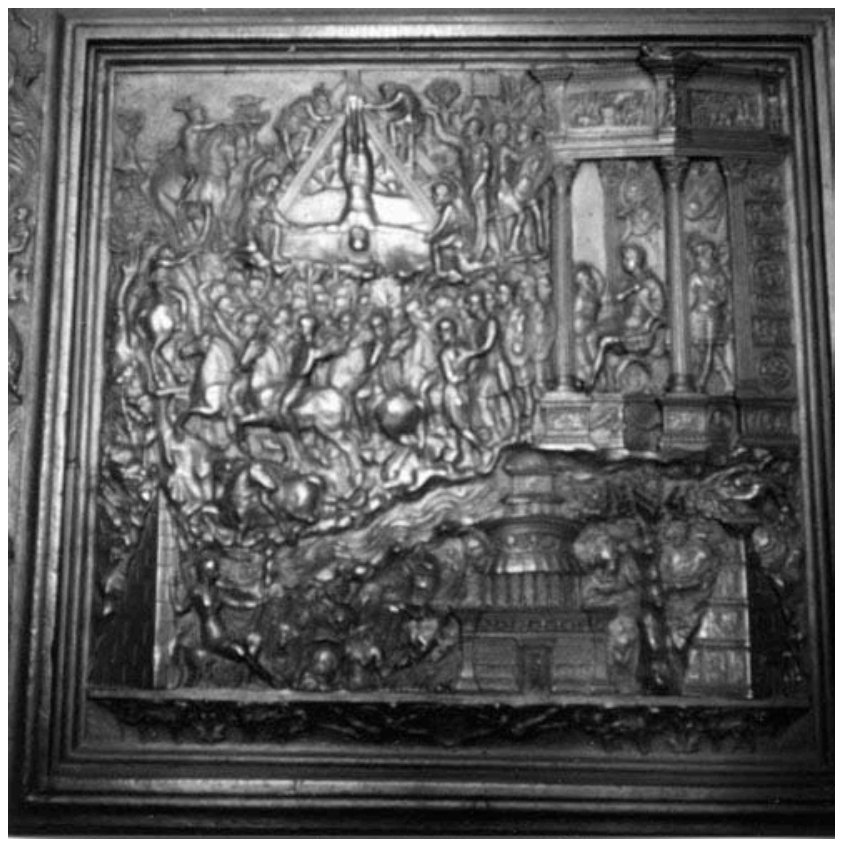


Peter's cross being framed by two slender pyramids. In this example, the two monuments appear like goal-posts, supporting the horizontal member of the cross.

In both examples we see Peter's martyrdom being represented "inter duas metas" (between "metas") in which the topography of Rome is compressed within the sacred drama of the pictorial narrative. ${ }^{101}$ The implication here of a continuity between pagan and Christian traditions is reinforced by the interrelationships of the ancient monuments as observed by Vegio; the place of Peter's martyrdom on the Gianiculum is "pre-ordained" by its topographical relationships (resonated in the symbolism of the triangle) to the locations of the ancient pyramids. $^{102}$

What is "discovered" by direct visual observation of sacred topography (Vegio) is rendered implicitly in the universal terms of triangular vision (Alberti). Accordingly, this reciprocity between the particular and the universal, through the agency of perspective, could be said to be embodied in the geometry of the pyramid. The abiding role of the pyramid of vision as a domain of human redemption is particularised - and concretised - in the mytho-historical meanings of the Meta Romuli and Meta Remi as framing elements of martyrdom. Consequently, the act of (triangular) seeing constitutes a revelatory process of "discovered" geometric relationships that lie embedded in our providential world.

Considered within the broader onto-theological tradition of Medieval and Early Renaissance thought, Alberti's modalities of measure (linguistic/ inscriptive, numerological, geometric, perspectival, etc.) could be considered as an attempt to bring into dialogue different ways of construing order. A similar intention could be said to underlie the frontispiece of Cesare Cesariano's Italian edition of Vitruvius, published in 1521. In referring to Cesariano's particular interest in armillary spheres and "world-system diagrams", Denis Cosgrove describes the illustration in the following terms:

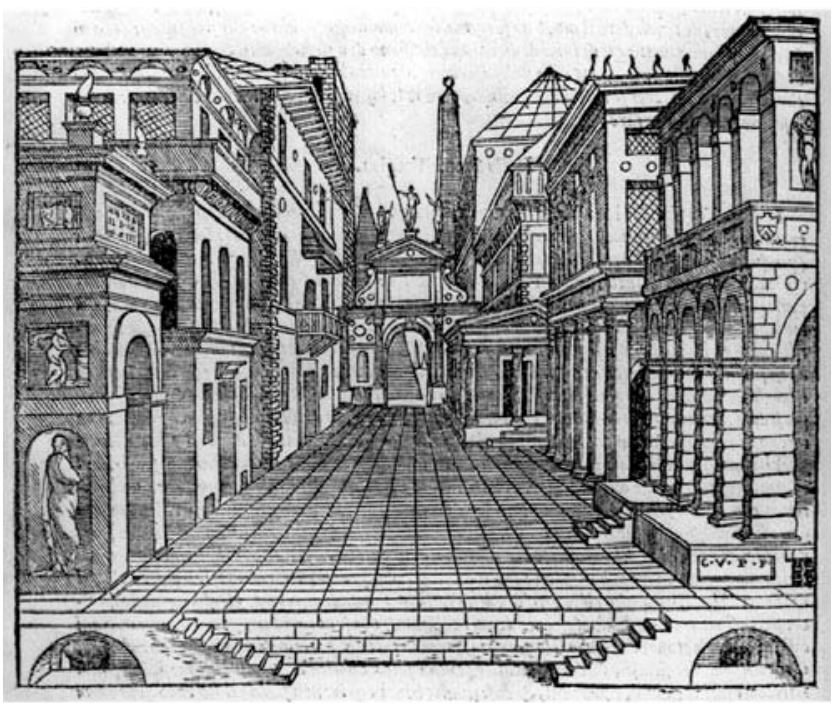

4.19

Allusions to the route of the ancient via triumphalis are discernible in this theatrical scene as we see in the central triumphal arch and the representations of an obelisk (the "agulia" in the Vatican?) and pyramid (Meta Romuli) beyond. Sebastiano Serlio (1475-1554), Tutte l'opere d'architettura (Venice, 1566), bk 2, p. 47v., "Tragic Scene" 
[it] connects the use of the cross-staff in determining the declination of celestial bodies to the visual cone described by Alberti as the basis for constructing linear projection. Cesariano illustrates, too, the use of the gnomon to determine latitude by measuring the sun's meridian shadow at diverse locations. ${ }^{103}$

Whilst Cosgrove's description is helpful in identifying the principal features of the illustration it falls short of explaining adequately the deeper symbolic significance of the image. What is revealed here is an understanding of order itself, whereby the horizontal earth-bound calibrations of real (topographical) and ideal (pictorial) space are brought into a comprehensive and unifying structure by the geometric arrangement of celestial bodies. In this cosmic inter-relationship, Cesariano draws upon Platonic emanation theory; the interaction between intromission and extramission is represented in cosmological terms as an exchange between the orbital motion of the celestial bodies and the spherical vision of the observer. Whilst Alberti's work in land mensuration and perspective reflects a worldly view of order, the presence of a divine celestial hierarchy was never abandoned but was rather refashioned by a humanistic outlook. Cesariano's illustration, in which concentric circles gravitate around the body of the surveyor and his cross-staff, reflects this more immanent emphasis on human experience.

Underlying the varied intellectual and artistic pursuits of Alberti was a belief that all human judgement was essentially perspectival. Alberti's emblem of the winged eye, and its accompanying motto "what next", best exemplifies this belief. The inter-relationship, however, between judgement and perspective is radically different from Nietzsche's perspectivism, outlined in Chapter 1, in which

4.20

Surveyor with cross-staff showing relation between celestial light and perspective. Cesare Cesariano (1475-1543), Di Lucio Vitruvio Pollione de Architectura Libri Dece ... (Como, 1521), p. XI verso

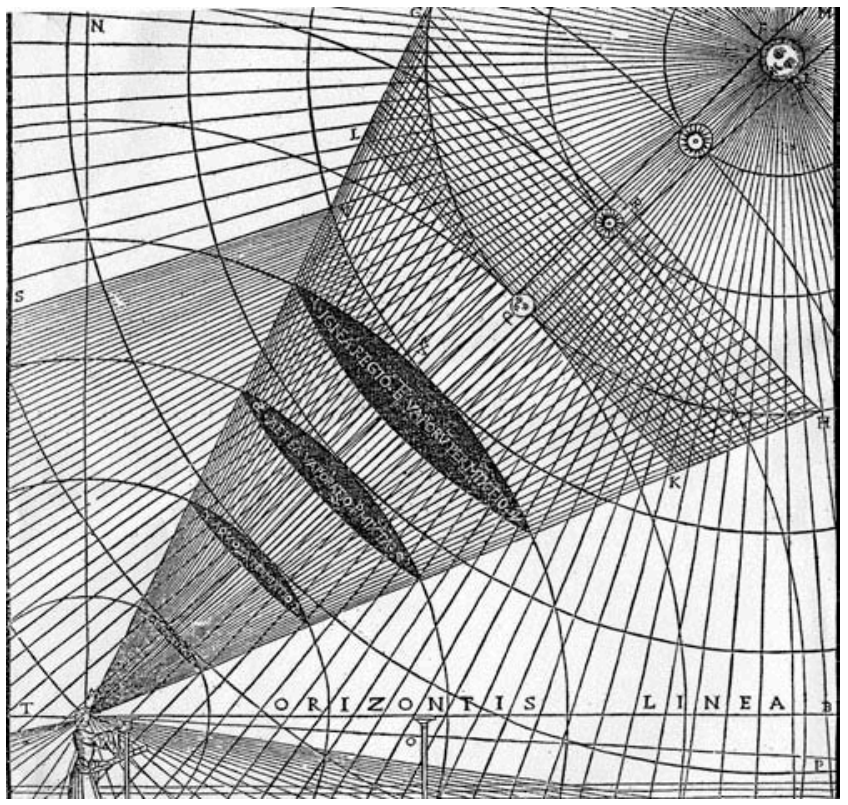


unmediated points of view are seen as the basis upon which perfection can be called upon through individual will. For Alberti, the desire to convey universal truths through the agency of human action was always motivated by the belief that embedded within the multitude of linguistic and pictorial references there resides an all-embracing divine order that both transcends ordinary life and the same time serves as its abiding model.

\section{Nicholas Cusanus}

The German cardinal, Nicholas Cusanus, developed a philosophical/theological approach to perspective that paralleled the more practical and theoretical concerns of his contemporary Leon Battista Alberti. This approach can be seen in a number of works by Cusanus, but in particular in his De Beryllo ("On Intellectual Eyeglasses"), referred to earlier, and De Docta Ignorantia ("On Learned Ignorance"), both of which will be explored briefly here. ${ }^{104}$ Whilst Alberti, the emerging practitioner, maintained the principle of a limit to his perspective, as it is defined within a "mural boundary" (the city walls of Rome or the checkerboard pavement of costruzione legittima), Cusanus articulates a metaphysical stand-point that takes the idea of divine infinitude as a point of departure.

Both perspectives, however, are rooted in the same Christian-Platonic outlook, as Dalibor Vesely emphasises:

Human mind represents in one sense the unity of vision, in another sense a reference to a measure (mensura), which as "the essence of number is the first exemplar of the mind". Because measure is the main characteristic of proportion, the association of human mind and measure speaks also about the proportional structure of mind; and because proportion, as we have seen, is also the essence of perspectivity, the structure of human mind is in Cusanus' understanding perspectival. ${ }^{105}$

For Cusanus the question of measure, between divine infinitude and the finite world of humanity, served as the guiding theme in a number of meditations on geometry and number. Unlike Alberti, however, who generally adhered to the Vitruvian/Pythagorean principle of a "closed" system of proportional relationships, Cusanus construes proportion in terms of "open" geometric relationships. In these relationships the mind abstracts geometrical figures from perceptual experience and then idealises them. Driving this eidetic view of number and geometry is the repentant soul which seeks salvation through the contemplation of divine infinitude:

For just as our mind is to the Infinite, Eternal Mind, so number [that proceeds] from our mind is to number [that proceeds from the Divine Mind]. And we give the name "number" to number from the Divine Mind, even as to the Divine Mind itself we give the name for our mind. ${ }^{106}$ 
Hence, Cusanian cosmology could be said to provide a metaphysical "bridge" between human mind and Divine Mind. Like Alberti, Cusanus relies upon instruments, albeit metaphorical rather than actual, to communicate - and thereby mediate - this relationship. This is most clearly seen in his De Beryllo where Cusanus uses the beryl stone to convey the relation between human and divine (or intellectual) vision:

Beryl stones are bright, white and clear. To them are given both concave and convex forms. And someone who looks out through them apprehends that which previously was invisible. If an intellectual beryl that had both a maximum and a minimum form were fitted to our intellectual eyes then through the intermediateness of this beryl the indivisible Beginning of all things would be attained. ${ }^{107}$

The relation between the absolute maximum and absolute minimum formed a central theme in Cusanus' perspectivism: "the human eye enfolds the absolute maximum and absolute minimum of surfaces within its vision, in the same way as God unfolds the absolute maximum and minimum of being within his person". ${ }^{108}$ Both converge and become indivisible in a process that Cusanus describes paradoxically as the "coincidence of opposites": the "beginnings are minimal and indivisible with respect to quantitative magnitude but are maximal with respect to magnitude-of-power". ${ }^{109}$ As noted in Chapter 3, the theological understanding of the coincidence of opposites can be traced back to the writings of the PseudoDionysius. In his principle of "negative theology" Dionysius believed that the infinitesimal power of the divine was revealed in absolute darkness, a principle that derives from the experience of being blinded by intense light. Hence, absolute brightness and absolute blackness coincide in God's presence. ${ }^{110}$

Cusanian cosmology translated Dionysius' light metaphysics into a series of geometric meditations that focused on the meaning of "unfolding" angles. Cusanus saw all beginnings as triune - or threefold - and therefore endowed with Platonic and Trinitarian symbolism. ${ }^{111}$ In this symbolism Cusanus construes angles as gradations of "cognitive natures", and therefore of human knowledge. These gradations move from Oneness (or unity), through Equality (forming and equalising all things), and finally to Union (from which the indivisibility

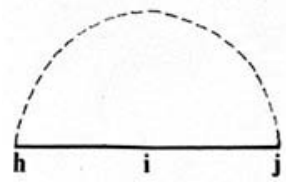

A

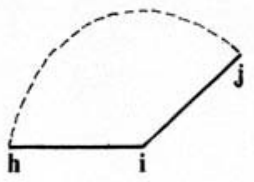

B

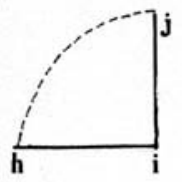

C

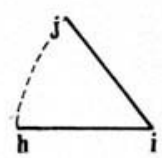

D

4.21

De Beryllo, Nicholas Cusanus (1400-64), "Meditative Angles": straight line (h j) as likeness of true Being (veritas) (A); formation of obtuse angle (at i) as being (B); right angle as living (C); acute angle as understanding (D) 
of Oneness and Equality is conserved). ${ }^{112}$ The degree of acuity or obtusity of the meditative angle constitutes a measure of being, living and understanding. In this movement being is initially "contracted", meaning it is a likeness of itself rather than being in union with God.

The idea of determining human cognition by a moving angle reflects a form of perspective that draws meaning from the intellectual (divine) eye rather than the earth-bound (rational) eye. In this perspective, acuity and obtusity become a measure of human understanding with respect to an infinitesimal divine cosmos. This finds an interesting counterpoint in Alberti's "prince of rays", in his perspectiva artificialis, where one's command of the field of vision (through the convergence of visual rays) is likened analogously to the ruler of a kingdom. ${ }^{113}$ In the case of Cusanus, however, vision is understood as a dialogue between human finitude and divine infinitude. This is highlighted in a remarkable diagram found in his little treatise De coniecturis that shows two intersecting pyramids. The intersection "represents the dialectics of human and divine vision", a form of reciprocated vision that Vesely argues indicates a closeness to contemporary thinking on perspective. ${ }^{114}$ We are reminded, in this diagram, of Emmanuel Levinas' idea of perspective as a "reciprocal alignment" of myself with the other in his notion of alterity, discussed earlier in Chapter 1.

Cusanus further espouses his principle of a "geometry of theology" in De Docta Ignorantia. The work reiterates many of the ideas promulgated in De Beryllo, but develops these into a comprehensive cosmology. Knowledge of God assumes the principle of "Learned Ignorance", an ignorance that renders its possessor wise in the knowledge of his finite - and therefore limited - world. The text of De Docta Ignorantia unfolds as a series of paradoxical arguments about humanity's quest for union with God. These can be summarised as follows:

1. maximum absolutum (God)

2. maximum contractum (Universe)

3. maximum simul contractum et absolutum (Christ)

Mediating between the absolute and contracted maximum, between divine and earthly realms, Christ's mystical incarnation is revealed as a series of

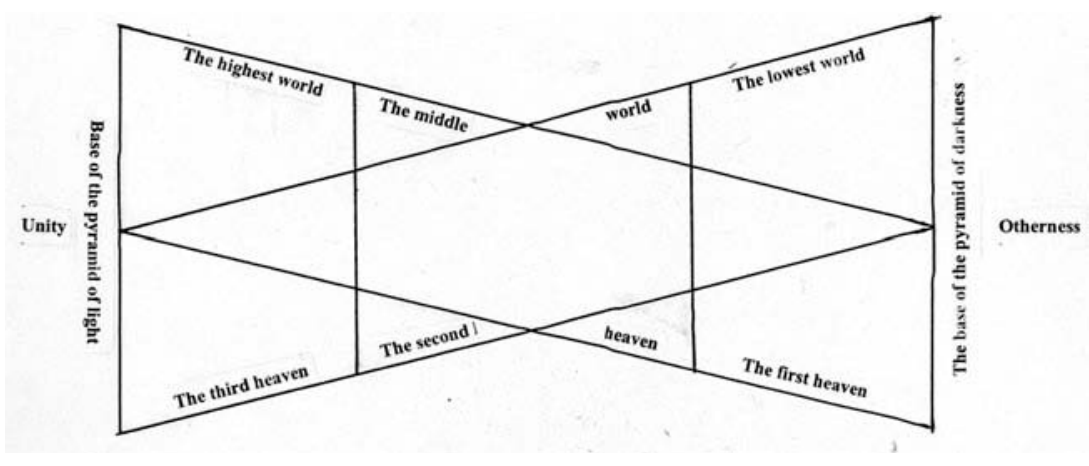


geometrical/numerical paradoxes. These in turn serve as philosophical meditations of the coincidence of opposites:

So if the curved line becomes less curved in proportion to the increased circumference of the circle, then the circumference of the maximum circle, which cannot be greater, is minimally curved and therefore maximally straight. Hence, the minimum coincides with the maximum - to such an extent that we can visually recognise that it is necessary for the maximum line to be minimally and maximally straight. ${ }^{115}$

Cusanus uses the notion of a straight line as the circumference of an infinite circle to demonstrate that God is both centre and circumference of the universe. In this meditation geometry is dynamic and situational, in the sense that it provides an analogous medium to guide one's spiritual journey. In a similar way, therefore, to humanity's yearning for redemption, where reconcilation and union with God is "measured" against the infinitesimal space of his creation, Cusanus' paradoxical geometry furnishes a contemplative realm - but one that never achieves ultimate closure. It is in the context of this open geometry that Cusanian perspective provides the possibility of contemplating the incomprehensible, namely God's infinitude.

\section{The Papal Window}

We have seen in the writings of Alberti how Renaissance proclivities towards synthesis of creative and intellectual endeavours required corresponding relationships between textual, topographical, pictorial and architectural references. This initiative was informed by a new, more intellectually demanding, perspective understanding of the cosmos that Cusanus developed in his geometrical meditations of infinitude.

At the beginning of the sixteenth century, we witness an attempt to represent this synthesis in a more visually sophisticated, and comprehensive, manner than had ever been achieved in the Quattrocento. This was supported by an increasingly historiographic view of perspective that centred on the providential meanings of topography. Centred on papal Rome, these initiatives were inspired by a desire to redeem the city of its iniquitous Medieval past and restore its symbolic role as both "second Jerusalem" and Ancient Rome revived.

At the heart of this "cultural project" was the status of the Pope. Renaissance Rome cultivated a ceremonial and symbolic distance between the Pope and the populace that was influenced by a combination of elements drawn from the cult of the Roman emperor and the symbolism of Apostolic succession. Only by maintaining such an aloofness could the whole redemptive enterprise - of institutional reform and personal salvation - be legitimated and maintained.

Architecture played a critical role in this enterprise as we see for example in Donato Bramante's design for the Cortile del Belvedere. ${ }^{116}$ The Cortile, that links the Vatican Palace to the fifteenth-century Villa Innocentiana to the north, was designed as an elongated courtyard built on three levels. This terminates to the north in a giant "nicchione", or niche, that partly encloses a small open-air theatre. The perspective effect created by the extended triple tiered 


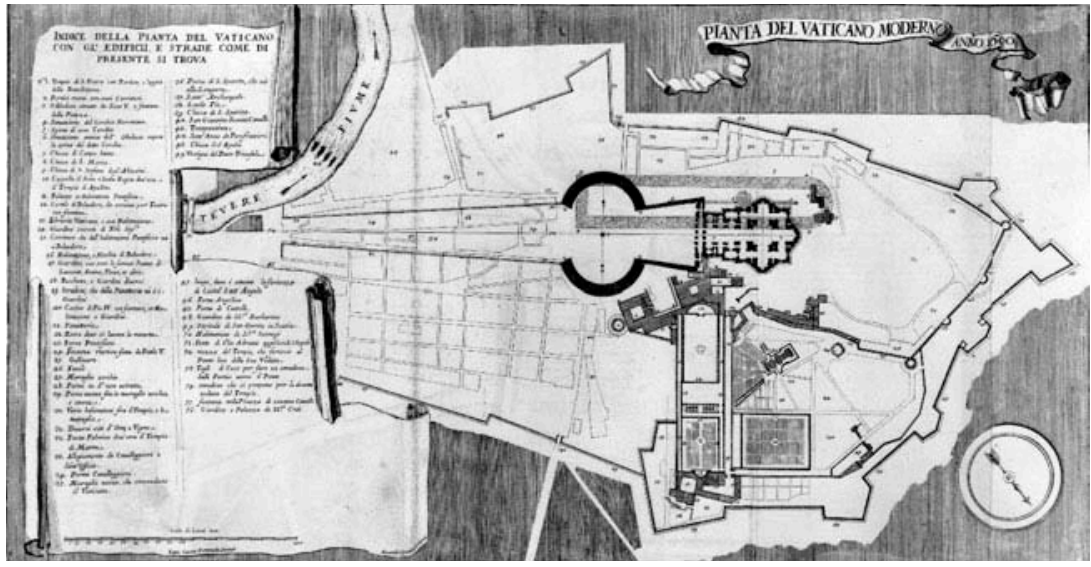

4.23

Map of the Vatican Complex showing St Peter's Basilica, the Vatican Palace, the Cortile del Belvedere and the Villa Innocentiana. Carlo Fontana (1634-1714), II Tempio Vaticano e sua origine, con gl'edifitii piu cospicui antichi ... (Rome, 1694), p. 244

Cortile del Belvedere is articulated as a hierarchical sequence of spaces where ritual participation between Pope, his court and the larger populace of the city is celebrated. Crucially, the nature and meaning of such participation was intimately bound to the relation between otium and negotium; or between "vita contemplativa" and "vita activa". ${ }^{117}$ In this twofold symbolism the active and contemplative aspects of the Pontiff (manifested in the Palace and Villa respectively) are mediated by the colonnades of the Cortile. Flanking the east and west sides of the Cortile, these passageways provided access for the Pope between the Belvedere and his private apartments.

The Stanza della Segnatura, which was originally the private library of Julius II, played a pivotal role in the symbolism of the Cortile del Belvedere. The room is located on the south side of the Cortile, in the Vatican Palace, and roughly on its main axis. Renowned for its famous cycle of frescoes by Raphael, that

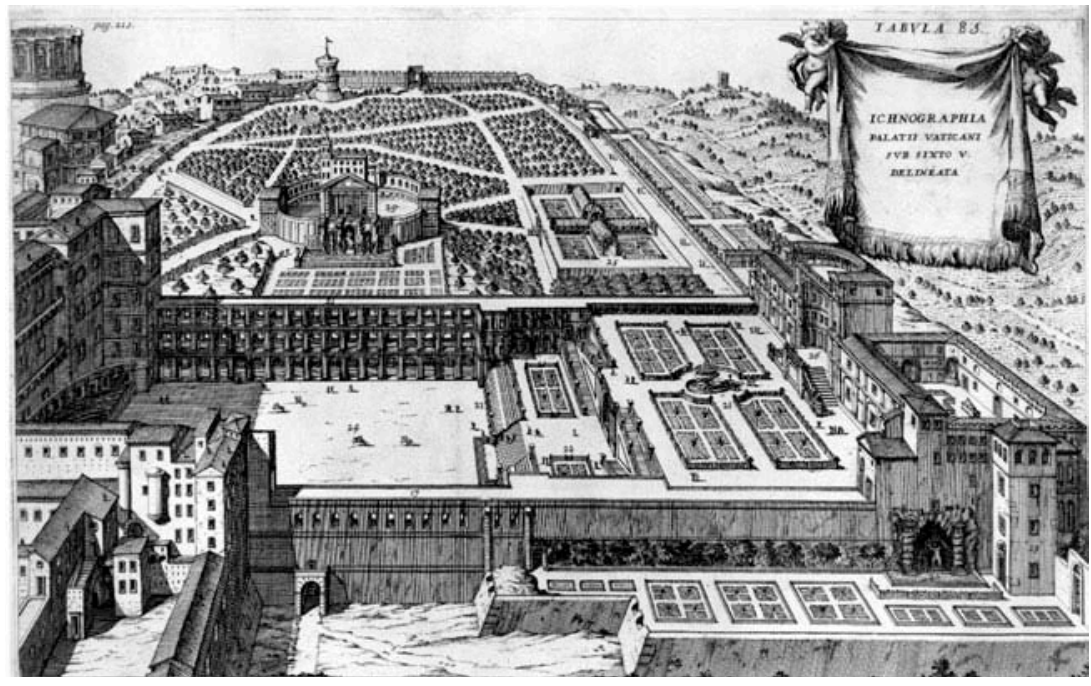

4.24

View of the Cortile del Belvedere. Filippo Buonanni (1638-1725),

Numismata summorum pontificum templi Vaticani fabricam indicantia, chronologia ejusdem fabricate ... (Rome, 1696), p. 215 
4.25

Plan of the Cortile del Belvedere (The room marked "9" is the Stanza della Segnatura). Filippo Buonanni (1638-1725),

Numismata summorum pontificum templi Vaticani fabricam indicantia, chronologia ejusdem fabricate ... (Rome, 1696), p. 225

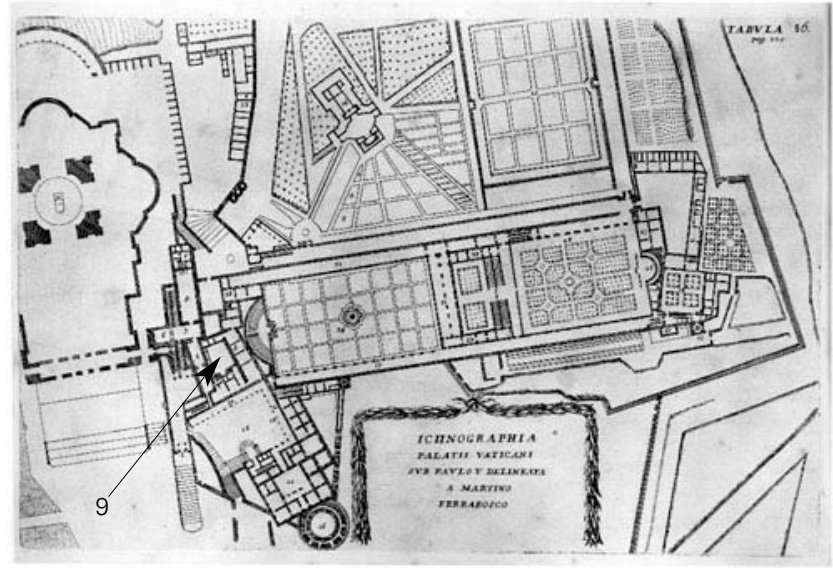

includes the famous School of Athens discussed in Chapter 2, the iconography of the frescos was influenced by Neo-Platonic ideas, in particular the notion of prisca theologia or "ancient theology". ${ }^{118}$ In this theology, ancient sages and thinkers, from Plato to Hermes Trismegistus, were believed to be prophets of Christ.

The north window of the Stanza afforded a privileged view of the extended - perspectival - space of the Cortile. It was from this elevated vantagepoint that the Pope could enjoy the distant views of the prati (countryside) beyond and witness, in closer proximity, the various public spectacles in the lower tier of the Cortile that included jousts and even bull-fights. ${ }^{119}$ Further north, the intermediate level of the Cortile originally contained a monumental nymphaeum in the form of a triumphal arch. Extending further north was an elevated walled garden, terminated by a small horseshoe theatre (set into the nicchione) that was probably intended to serve as a convivial setting for philosophical debates within the papal court.

In the specific context of the "Papal Window", the understanding of view was supported by a complex interplay between a mytho-historic understanding of the past, religious piety and political/military ambitions. Collectively, these terms of reference provided the background to a dialogue between an emerging historical consciousness, characterised by humanist and antiquarian thought, and a still valid onto-theological world-view. Through this complex dialogue, exemplary human achievements (embodied in the actions of the Pope) could be "measured" in perspectival terms against an ideal or divine realm. Without such a dialogue the quest to restore the Golden Age, that was the ultimate aim of the papal court, would have been jeopardised.

The iconography of the fresco cycle in the Stanza della Segnatura most clearly conveys this enterprise. As Manfredo Tafuri asserts, the locations of the frescoes were partly informed by actual spaces or buildings located outside the room. ${ }^{120}$ Indeed, Tafuri even suggests that the frescoes formed a "manifesto" of the architectural projects under Julius II's Pontificate. ${ }^{121}$ To begin with, the School of Athens - which celebrates Greek philosophy - faces east towards the Vatican Library, which contained one of the largest collections of ancient Greek texts in 


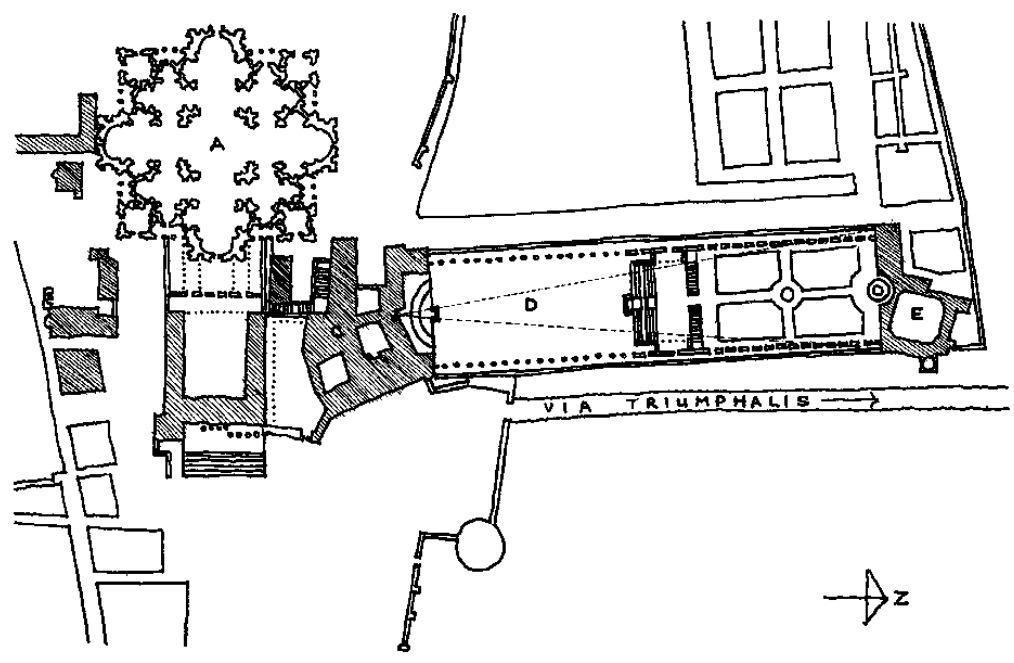

Europe. The fresco of Jurisprudence on the south wall is oriented roughly in the direction of the site of the unfinished Palazzo dei Tribunali, commissioned by Julius II and designed by Bramante. This ambitious project - located across the Tiber river along via Giulia - was planned as the new headquarters of both civil and canon law under the control of the Papacy. The fresco of the Disputa, moreover which celebrates the relation between the Church militant and the heavenly Church - faces west in the direction of the new Basilica of St Peter, also by Bramante. Finally, the north wall of the Stanza is adorned with the fresco of the Parnassus showing Apollo with his entourage of muses and poets. This frames the window, referred to earlier, that overlooks the famous Cortile del Belvedere and papal Villa beyond.

The theme of the Parnassus fresco was probably inspired by the hill on which the papal Villa was built, Mont'Egidio. It is said that a sanctuary dedicated to

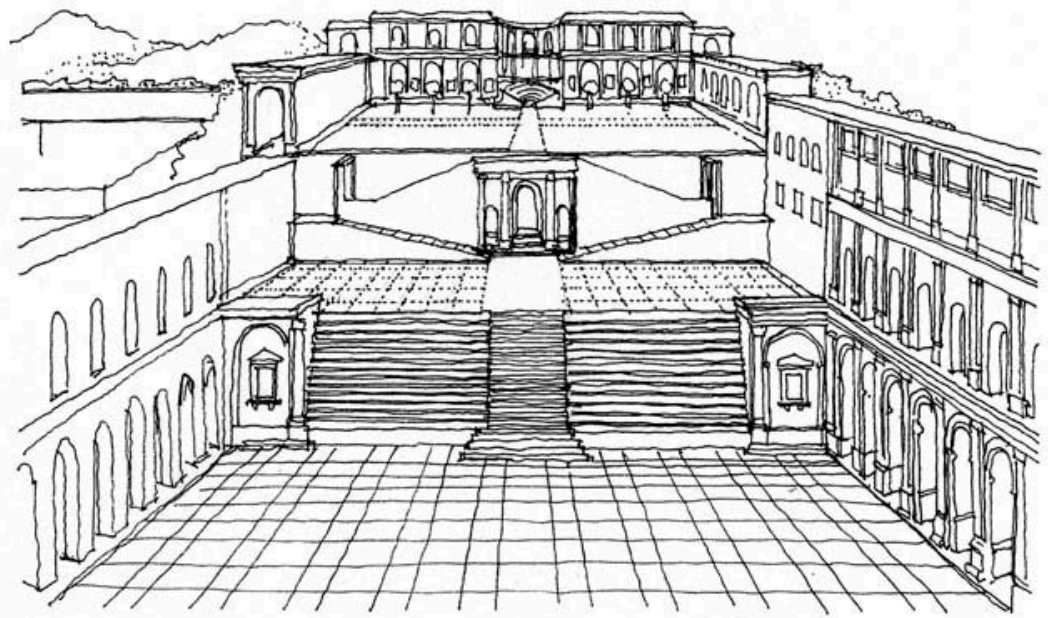

4.26

Hypothetical plan of Bramante's original design for the Vatican

complex - Basilica of St Peter (A);

Vatican Palace (C); Cortile del

Belvedere (D) and Villa Belvedere (E).

Also indicated, the route of the via Triumphalis to the east of the Cortile and the angle of vision from the north window of the Stanza della Segnatura. Drawn by author after Letarouilly

4.27

Reconstructed view from the Vatican Palace towards the Villa Belvedere to the north following

Donato

Bramante's design. Drawn by author after Bernardo della Volpaia and Giovanni Antonio Dosio (16th century) 
Apollo was built here by the Etruscans, who are thought to have brought the cult of Apollo to the Vatican from Veii. Moreover, the famous sculpture of the "Belvedere Apollo" (a Roman copy of an original Greek work) was placed in the Villa courtyard, probably to emulate this historical background. The thematic and topographic connections, therefore, between the Parnassus fresco and the Cortile Belvedere seem almost incontrovertible.

The view through the north window probably provided the primary orientation of the Pope within the room. According to John Shearman, the seat of the Pope would probably have occupied the centre of the room, facing the north window with visual access to the four disciplines (represented in the frescoes) that make up the totality of knowledge, or in facultatibus: Poetry, Theology, Philosophy and Law.

This orientation was intimately bound to the ideas and ambitions of the Pope himself. Described as the warrior Pope, Julius II sought to reunite and expand the papal territories of the Holy See in the Italian peninsula through a combination of political alliance and military conquest. ${ }^{122}$ The Pope was also described in court eulogies as the "second Caesar", on account of his name and his role as a military figure. The orientation of the Cortile del Belvedere was key to this symbolism, given that the longitudinal enclosure runs parallel to the north-south

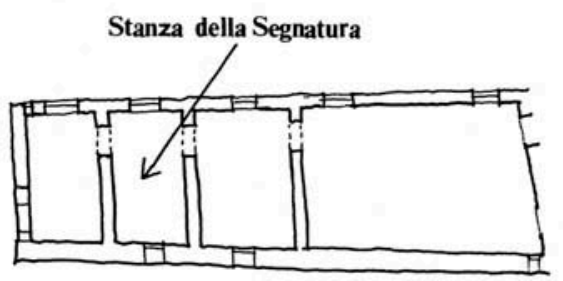

PAPAL APARTMENTS

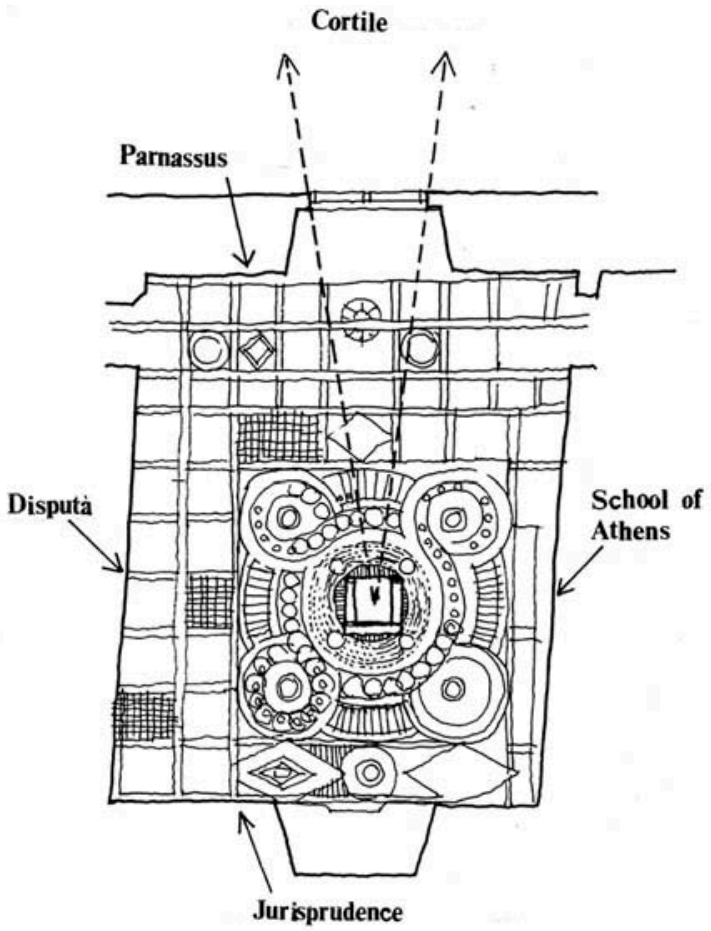




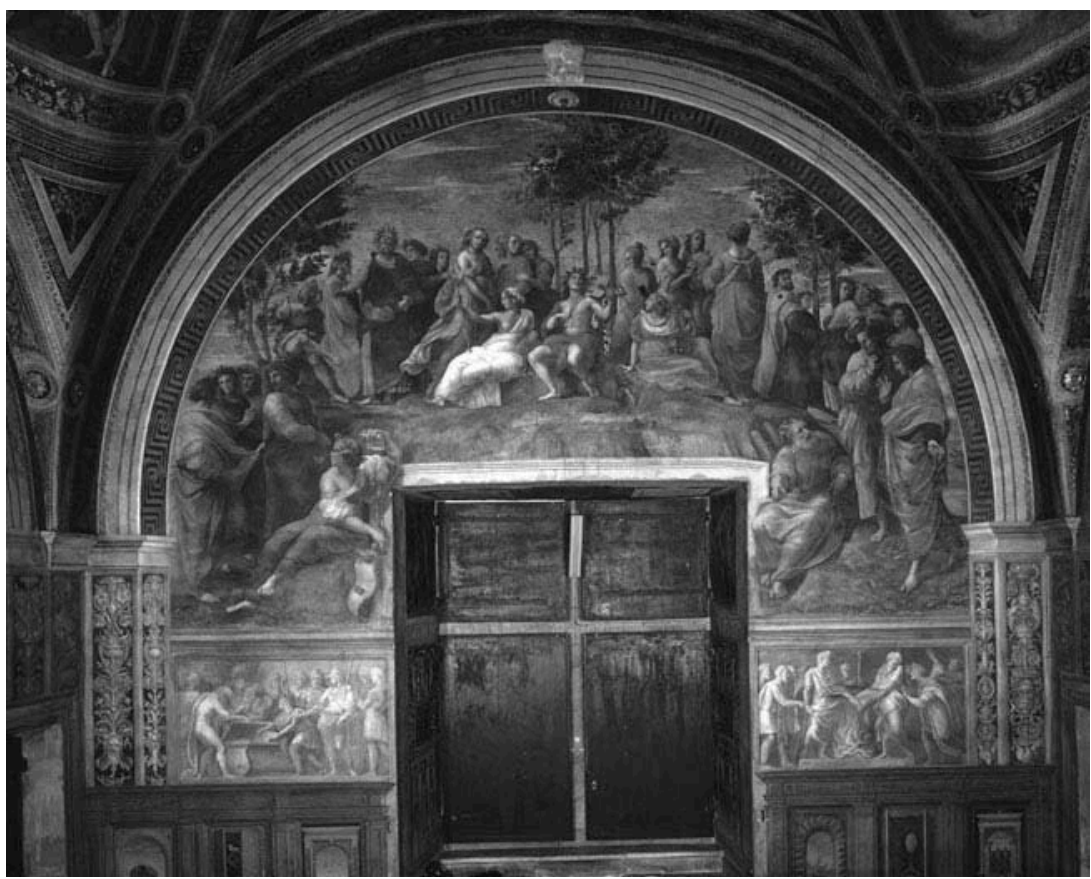

4.29

Parnassus

(1511-12), Raphael

(1483-1520).

Vatican, Stanza

della Segnatura

orientation of the nearby via Triumphalis, the ancient road along which the victorious generals and emperors of antiquity (including Julius Caesar) were thought to have marched triumphantly into the city following military conquests (fig. 4.26). ${ }^{123}$ Remnants of this road, which later became a pilgrimage route, were still visible from the Cortile during the Renaissance. From his Belvedere window the Pope could glimpse the passage of the ancient road extending northwards and the distant hills of the countryside beyond. It would seem plausible therefore that the via Triumphalis provided an important symbolic reference in Julius II's ambitions to rule the whole of Italy.

Amongst the small collection of books that Julius kept in his private library was a map of the peninsula of Italy attributed to Bramante. ${ }^{124}$ The precise contents of this map remain a mystery but it is likely that it contained details of papal territories, including strategic information (roads, etc.) of neighbouring principalities/territories that were earmarked for political alliance or invasion. It has been suggested that this document - now lost - may have been one of the earliest attempts to construct a scaled map of a large land mass, highlighting the principal geographical features, regions and cities. ${ }^{125} \mathrm{An}$ indication of the possible appearance of this map may be gleaned from the "chorographic" map of Italy by Bramante's pupil, Cesare Cesariano, taken from his edition of Vitruvius (1521). ${ }^{126}$ The comparison, however, should not be taken too far given that some of the features of the Cesariano map are inaccurately drawn, which Bramante would almost certainly have corrected. ${ }^{127}$

Armed with this map, and facing the north window, the warrior Pope could contemplate his expanding dominion from the solitary confines of his private 
library. In such a setting, cartography (strategic overview) and perspective (framed view) converge as modalities for measuring and calibrating space; the mere act of seeing constitutes a virtual act of taking possession. ${ }^{128}$ We are reminded here of the famous motto by Julius Caesar, veni, vidi, vici ("I came, I saw, I conquered") which he is said to have uttered in 47 BC following his military campaigns in Egypt, Syria and the Pontus. ${ }^{129}$ In the setting of Julius II's window, however, Caesar's threefold maxim may be said to be subsumed in the single act of seeing.

It should be pointed out that this visual conquest has less in common with Nietzsche's perspectivism (even though it could be said to anticipate it), and has more affinity with Robert Grosseteste's equation of aspectus with affectus, discussed in Chapter 3. In this equation, it will be remembered, one's range of vision is determined by one's capacity to love (divinely). In the case of Julius II, this relationship almost certainly served as the main impetus for implementing the political, religious and cultural initiatives necessary to restore the Golden Age.

The reliance upon the interplay between map, text, fresco, architecture and topography, to define in symbolic terms the strategies of papal rule and conquest, should be considered within a larger geography of power in the sixteenth century. During the Pontificate of Julius II, the "new world" was being discovered and conquered, and the Catholic faith exported by traders and missionaries. ${ }^{130}$ Celebrated in a number of court sermons, these discoveries were framed in a language that considered such territories as part of a new empire of faith, the extent of which not even Julius Caesar could have dreamt of. ${ }^{131}$

From the privileged vantage point of the north window the idea of the Pontiff governing an ever-expanding territory could be said to be "activated" by the agency of Julius II's vision. In this process, the Stanza della Segnatura embodies Julius' personal "world atlas" of the oikumene - the then known world reconstructed perspectivally as the Pope's pyramid of vision.

The Cortile del Belvedere signals an important and decisive transition in the nature and meaning of landscape that was the result of a new perspective outlook. In one sense, the legacy of the hortus conclusus - or walled garden - in the Middle Ages is still discernible in the articulation of the garden on the upper tier. But the priority of the Medieval garden, of shutting off the outside world by an encircling cloister or high wall, only serves as a point of departure in the Cortile for a more complex mediated relationship with the surrounding landscape. The extended configuration of the structure - projecting northwards into the countryside beyond the older fortifications of the Vatican Palace - combined with the openness of the terracing oriented towards the Vatican Palace (with the conspicuously low single storey colonnade framing the upper garden tier) would have pressed upon the visitor an awareness of more distant horizons beyond the enclosure itself. ${ }^{132}$ Unlike the largely static and introverted space of the Medieval cloister, the Cortile functioned as a transitionary - or intermediate - zone that led to a larger encompassing landscape. Indeed, the final "destiny" of the garden could be said to be the prati (countryside) seen from the vantage points of the north window of the Stanza della Segnatura and the Belvedere loggia, the latter being located on the north face of the Villa and accessible from the garden via the giant nicchione. 


\section{Álvaro Siza's Galician Centre for Contemporary Art}

The interplay between view and passage that underlies the Cortile del Belvedere, and its supporting geo-political and religious symbolism, provides an interesting counterpoint to a recent project by Álvaro Siza - the Galician Centre of Contemporary Art in Santiago de Compostela. The comparison, however, does not assume a direct influence of Bramante's Cortile on Siza's Museum, an assertion that would be difficult to sustain given the many changes that have occurred in the former structure since the Renaissance; changes that have largely obscured the original design. Rather, I am arguing that implicit in Siza's project is a perspectival view of landscape that draws upon a deeper tradition whose terms of reference are most clearly articulated in Bramante's design.

Situated on the north-east edge of the old town of Santiago de Compostela, the building is sited in close proximity to the Convent of S. Domingo de Bonaval and its surrounding gardens and abandoned cemetery. Like the Cortile del Belvedere, topography plays a crucial role in Siza's design for the Museum; the

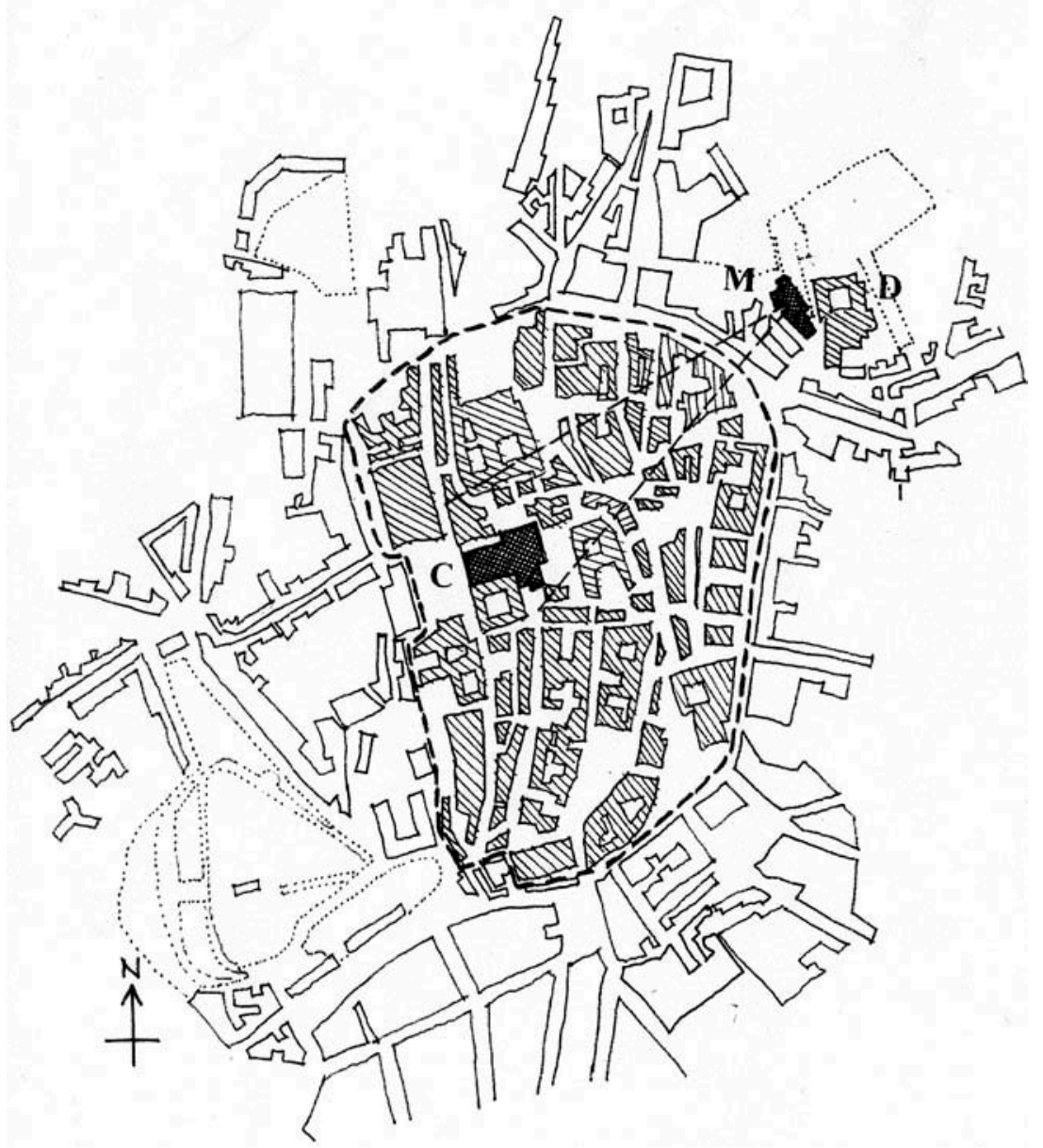

4.30

Galician Centre for Contemporary Art,

Santiago de

Compostela.

Álvaro Siza.

Location Plan (not to scale),

highlighting the boundary of the old fortified Medieval city (dotted line) and the relation between the Museum (M) and Convent of San Domingo de Bonaval (D) to the Cathedral (C). The splayed dotted lines indicate the way in which the Cathedral lies within the ambit of the perspective view from the inverted window of the Museum 
historical context of the Medieval city serves as an underlying narrative in the ordering of spaces and the framing of views.

An initial source of influence in this perceived continuity can be found in the larger urban context of the Galician Centre for Contemporary Art. Historically, the city of Santiago de Compostela is one of the most important and venerated centres of pilgrimage in Europe, renowned for its Cathedral that contains the relics of St James. ${ }^{133}$ The Medieval Christian world knew three major cities of pilgrimage: Rome, Jerusalem and Santiago de Compostela. From the eleventh to the thirteenth centuries, however, Santiago de Compostela was the most visited, highlighted by the extent of the vast network of pilgrimage roads extending across France and northern Spain. These roads commenced in the religious centres of Chartres, St Denis, Vézelay and Le Puy and culminated the shrine of St James. ${ }^{134}$

As found in other cities of the Middle Ages, Santiago de Compostela was surrounded by a fortified wall, built in the eleventh century and delineating the boundary of the present historic district of the city. At the centre of this district is the Cathedral, whose looming Baroque bell-towers and dome are visible at some distance from the pilgrimage roads entering the city - especially from the rising hills to the north. In one sense, Siza's project should be considered as redefining this historical boundary and its inner sanctum - the Cathedral. Located on the north-eastern edge of the old Medieval town, the folded horizontal parapet wall, that defines the distinctive south-east frontage of the museum facing the Cathedral, could be said to echo the fortified wall of the Medieval town that once passed along the nearby Rua as Rodas. This topographical relationship is reinforced by the pairing of the museum building with the Convent of S. Domingo de Bonaval - one of a number of satellite religious communities that surround the Cathedral of Santiago that once served as hospices for visiting pilgrims. As David Dernie notes, the design of the Museum brings into play a number of key topographical features in the town:

The new construction reorders a large area of the town, encompassing the convents of S. Roque and S. Domingo, the Porto do Caminho and the quarter of the city between the streets as Rodas and Valle-Inclan. In addition, the internal ordering of exhibition space, conference hall and museum is, in part, generated by the external requirements to order such a complex topography. ${ }^{135}$

These inter-relationships, as will become clearer later, provide a setting conducive to the experience of art as a form of pilgrimage. The layout of the building required a reconciliation of four different topographical conditions; those of

the convent gardens rising up the hill to the north-east (the redesign of which was an intrinsic part of the commission), the residential grain of the city to the south-east, a large public garden extending due west, and last but not least, the large brooding mass of the Convent of Santo Domingo de Bonaval. ${ }^{136}$ 
Rafael Moneo considers the manner in which Siza cleverly juxtaposes the mass of the Convent with the volumes of the museum:

the impenetrability of the convent's volume, a solid without fissures, contrasts with the epithelial character of the granite of the center, a building one perceives from the start as a play of voids. Convent and center jointly enjoy the green slopes of an abandoned cemetery. The masterful lines of Siza's walls define a subtle geometry that dissolves in the preexisting network of paths and grids. Siza skillfully turned the broad ambit composed of convent, the center, and the new park into a single whole. ${ }^{137}$

Reconciliation of these initially entailed aligning the walls and boundaries of the surrounding landscape with those of the building. Through such alignments the internal arrangement of spaces is partly informed by external topographical features. We are given a sense of this relationship by the subdivision of spaces of the building into three principal zones, each redefining the existing boundary conditions; the first is the ramped entrance that extends along the edge of Valle-Inclan and terminates in the marble foyer. The second consists of the exhibition spaces that lie in a linear block along the edge of the Bonaval cemetery, whilst the third is the auditorium which is located to the north and bridges the other two blocks. The inter-relationships of these elements, as Dernie notes, "mediate between the scales of the convent, the quarter between the streets Valle-Inclan and as Rodas and the college La Salle". ${ }^{138}$

The result of this arrangement is what Kenneth Frampton describes as a "largely windowless wedge, which echoed the zigzag terracing of the
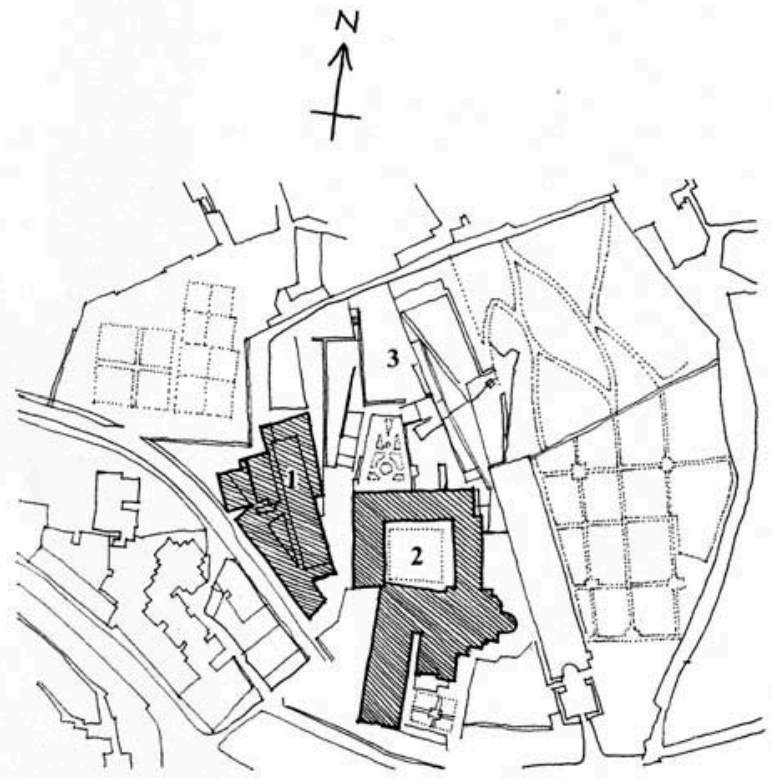

4.31

Galician Centre for Contemporary Art (1988-93),

Santiago de

Compostela,

Álvaro Siza. Site

Plan showing

relation of

Museum (1) to the

Convent of San

Domingo de

Bonaval (2) and

the Convent

gardens (3).

Drawn by author

after Siza 
4.32

Galician Centre for Contemporary Art (1988-93),

Santiago de

Compostela,

Álvaro Siza.

Entrance Level

Plan (not to scale):

Entrance (1);

Hall/Gallery (2);

Access Ramp (3);

Foyer (4);

Conference

Auditorium (5);

Bookshop (6); Bar

(7) and Temporary

Gallery Spaces (8). Drawn by author after Siza

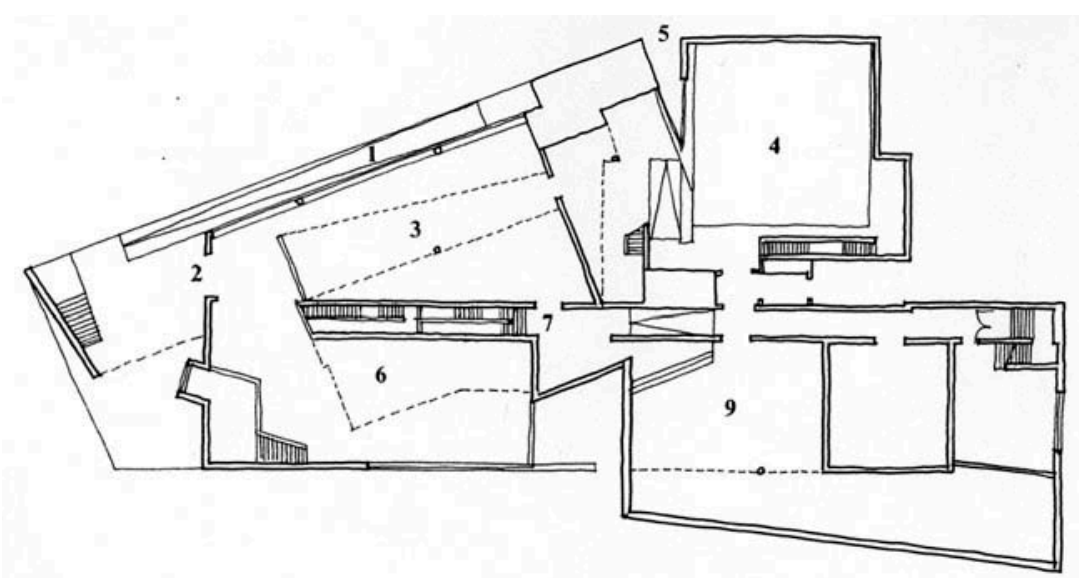

gardens". ${ }^{139}$ This terracing forms part of a larger landscape proposal that entailed the insertion of modest interventions and the opening up of previously hidden layers; these included old granite canals, which form part of an ancient irrigation system, and some previously derelict fountains and stone walls. These alterations and additions both preserve the latent qualities of the gardens and reveal new relationships.

It is along these stratigraphical layers that paths, steps and ramps were formed to traverse the gardens and to orientate movement towards the outer walls of the Museum. The continuity between garden and Museum is underlined by the way Siza cleverly re-articulates these paths within the building, as Frampton notes:

It is one of the ironies of this work that, while it is ostensibly an extension of the topography of the gardens, the circulation spine cuts across the plan in such a way as to interrupt the labyrinthic movement of the space. ${ }^{140}$
4.33

Galician Centre for Contemporary Art (1988-93), Álvaro

Siza. View of a wall fountain in the convent garden. Museum from the garden showing the pedestrian route to the entrance

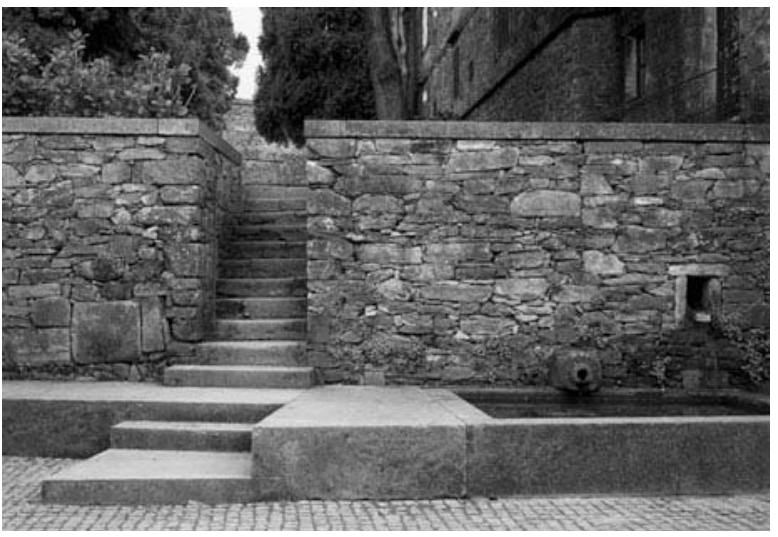


What was conceived externally as a confluence of routes, open to the multifarious aspects of gardens and urban spaces, is transformed internally into a formal axis that directs movement through and "beyond" the building. Given the interstitial nature of the site, located on a wedge of land between the rising landscape of the gardens to the north-east and the dense urban layout of the Medieval city to the south-west, we experience the passage through the building as a shifting - inbetween - zone that mediates the larger landscape beyond through changing levels and framed views.

Embedded between the bookshop, bar and public galleries to the north and the foyer/first floor offices to the south, the ascending passage invokes a perambulatory momentum that culminates in the roof sculpture terrace that provides spectacular views of the city. A hint of this destination is revealed at ground floor

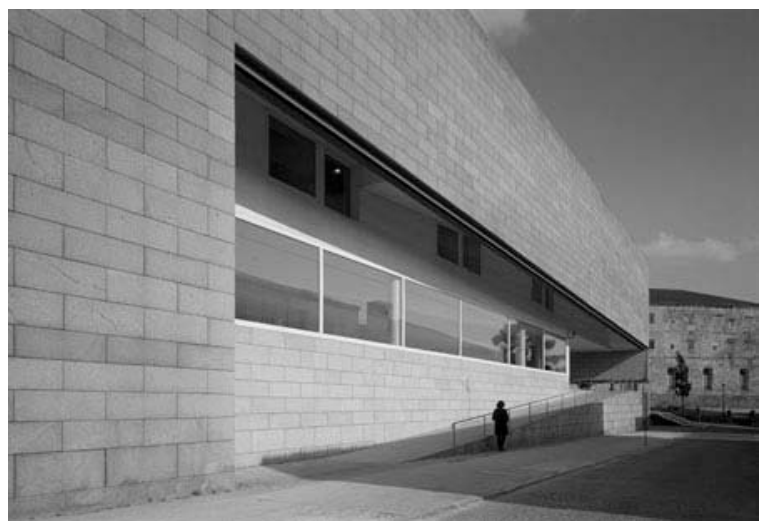

4.34

Galician Centre for

Contemporary Art (1988-93), Álvaro Siza.

View of the main entrance ramp with the Convent of San Domingo de Bonaval beyond

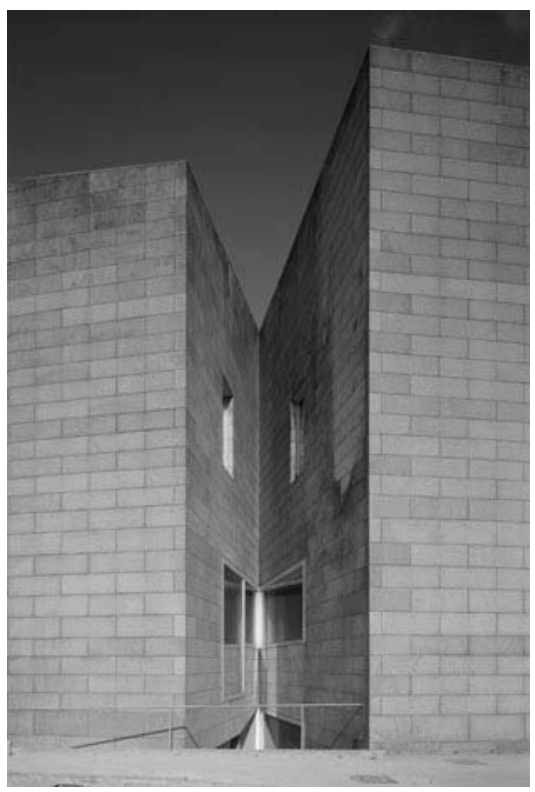

4.35

Galician Centre for Contemporary Art (1988-93), Álvaro Siza. View of the wedged space with inverted window between auditorium and main block of building 
through a high level roof-light that also illuminates part of the main circulation spine. In the course of moving through the building we are given glimpses of Santiago by means of carefully framed openings; most interesting of these is the large inverted window located in the wedged gap between the auditorium and foyer blocks. Sited on the south-west side of the building, this aperture faces towards the Cathedral. Whilst not providing unhindered views of the venerated shrine, on account of the obstruction of nearby buildings, its orientation - and the perspective effect created by the inverted wedged space - seems to draw within its ambit the presence of the Cathedral beyond.

It is the manner in which the perspective articulation of space in the Centre for Contemporary Art and its surrounding topography inter-relate - and ultimately commingle - that comparison with the Cortile del Belvedere is most

4.36

Galician Centre for

Contemporary Art

(1988-93), Álvaro Siza.

View of hall/gallery space with opening to spine stair and roof-light above on the left

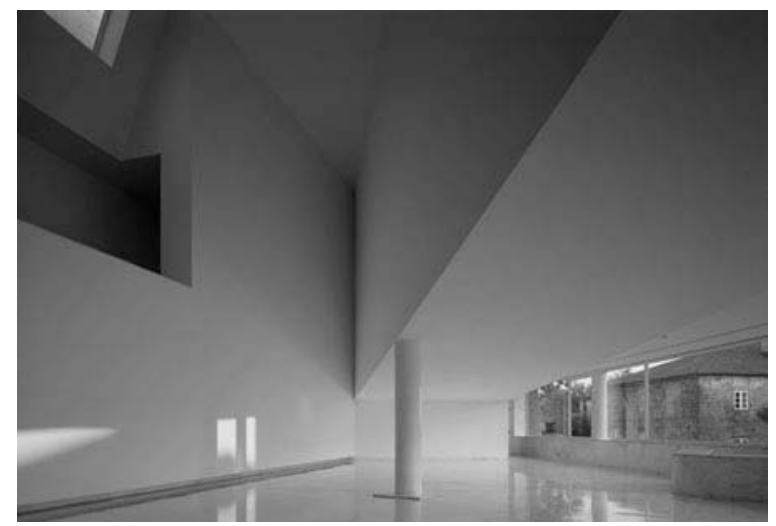

4.37

Galician Centre for Contemporary Art (1988-93), Álvaro Siza. View of the central spine staircase

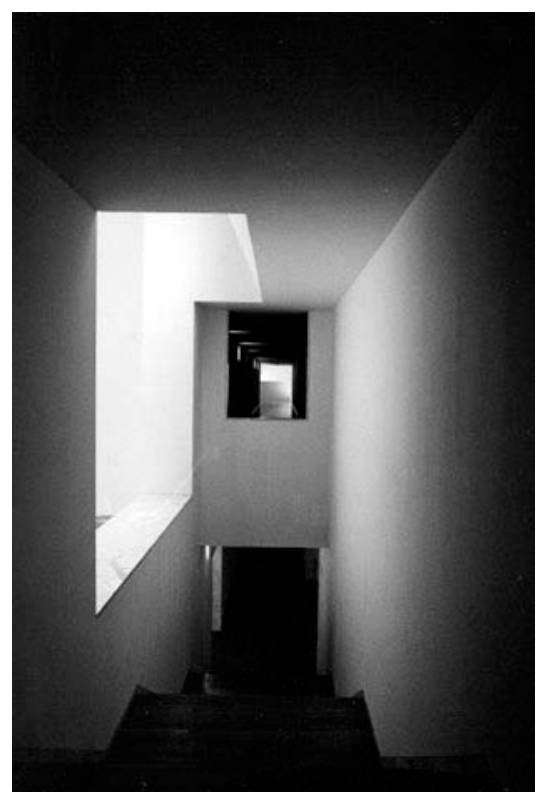


instructive. To fully explain the significance of this comparison it is necessary to delve further into the symbolism of the Cortile. I highlighted earlier how the Cortile was constructed on a north-south axis so that it roughly aligns with the nearby via Triumphalis. The road originally served in antiquity as the triumphal passage for Roman armies returning from conquest. It was later used as one of the principal routes into the city for pilgrims during the Jubilee, hence the later name "via del Pellegrino". The road, incidentally, formed part of a complex network of passages for pilgrims into Rome. Its entrance into the city, highlighted by the bridge crossing at the Tiber river, was also signalled by the pyramidal structure of the Meta Romuli located near the bend in the river.

The symbolic importance of the alignment between Cortile and road is implied in a commemorative medal for the construction of the Cortile; on the reverse of the medal is a representation of the building and a title variously interpreted as "VIA IVLIA TRIUM. ...". ${ }^{141}$ The title suggests a mutuality - or reciprocal relation - between the procession of Julius II to his Villa and the procession of triumphant Roman armies to the Capitol. The connection, however, was never stated explicitly in papal ceremonial, in spite of attempts to cultivate relationships between Julius II and Julius Caesar. Nevertheless, implicit in the symbolism is the idea of a corresponding relationship between the act of seeing from the vantage points of the Vatican and Belvedere - guided by the distant views of the via del Pellegrino - and the physical passage to the Villa extra muros. This relationship is brought to a level of synthesis through the perspective articulation of the Cortile itself that frames the privileged view of the Pontiff.

The ceremonial route to the Villa from the Vatican Palace also provided access to a collection of antiquities, in the form of statues and inscriptions, that were housed in the Villa courtyard. Significantly, this assembly of antiquities was probably one of the first attempts to create a museum collection, whose meanings were deemed to embody the mytho-historic past of ancient Rome. ${ }^{142}$ What we see emerging, therefore, in this complex interplay between view and passage - in which Museum and distant landscape converge as symbolic terms of reference - is a particular sense of place. This conceived topography is a latent narrative endowed with providential meanings.

Given these conditions, it is tempting to consider the Cortile as paradigmatic of a way of articulating order perspectivally; an order that was in one sense specific and unique to the early sixteenth century. At the same time, however, the structure reveals corresponding relationships - between view, passage, terrain, history and so on - that transcend a particular time and place and serve as abiding terms of reference in the experience of architecture. It is in this broader context that we can identify in Siza's scheme a particular resonance that is made apparent by the architect's response to the conditions of the site and to the historical context of Santiago de Compostela. Implicit in this affinity is the notion of experiencing the work of art as a form of pilgrimage, highlighted earlier. In the case of the Cortile this finds expression in the personal procession of the Pope to his collection of antiquities, whose allegorical and symbolic meanings were clearly intended to invoke, within the intimate space of the octagonal cortile, the Pope's quest for a Golden Age. 
This notion of pilgrimage is underlined by the pairing of Siza's and Bramante's museums with religious institutions; the Basilica of St Peter's in the case of the former and the "large brooding mass of the Convent of Santo Domingo de Bonaval" 143 in the latter (that in turn serves as a prelude to the venerated shrine of Santiago visible beyond). It is through this juxtaposition that questions of a precursory journey, in one's encounter with landscape and works of art, take on particular architectural significance.

In the case of the Cortile, as we have seen, perspective is conceived univocally as the exclusive domain of the Pope's pyramid of vision. This ensures an exchange between his ever-expanding dominion (the "Christian empire"), conveyed through the disclosure of distant horizons, and Rome's mytho-historical past, embodied in the Pope's museum of antiquities and in the symbolism of topography. Accordingly, the building and its surrounding landscape seem to be "built" around the Pope's personal ecumene; one that is deemed also to constitute the known world of the Renaissance in general. Accordingly, the actions of the Pope - consummated in his gaze - become "emblematic" of a particular humanist view of redemption. Implicit in this view is a fervent belief in a corresponding relationship between onto-theological and mytho-historical perspectives of the world. The connection is driven home by the approximate alignment of the Cortile with the pilgrimage route (via del Pellegrino), visible from the Villa Belvedere and more distantly from the Stanza della Segnatura.

In the case of Siza's project, however, pilgrimage is expressed more ambivalently as a constellation of perspectives, without a culminating - or privileged - vantage point. Accordingly, the inter-relation between spaces and routes in the Galician Centre for Contemporary Art does not lead to a synthesis, as we see conveyed convincingly in the Cortile - and summarised in the iconography of Stanza della Segnatura; rather it is left open-ended for each visitor to gather and reconstruct.

Hence, unlike the absolute realm of the pontifical office, communicated through the singular perspectival depth of the Pope's pyramid of vision, the multivalent perspectives of Siza's project could be said to invoke a "democratisation" of space through the shifting and fragmentary nature of view. This openness is registered spatially by the experience of art as momentary encounters in a journey without hierarchical definition or a pre-defined destination.

I would like to argue, however, that the difference in the understanding of perspective between Bramante's Cortile and Siza's Museum is not as clearly defined as one would perhaps assume. Embedded in the articulation of spaces in the latter is a way of construing and visualising order that derives from the traditions and practices represented in the former. By this I mean that what is constituted in the privileged view of the Pope (a culture redeemed and reconciled through the agency of the Apostolic succession) serves as an underlying point of reference in the symbolic understanding of the Galician Centre for Contemporary Art. Implicit in Siza's project is a "preparedness" for religious experience, as it is embodied in the Cathedral of Santiago de Compostela. This could be said to draw influence from the Augustinian notion of life as a pilgrimage - or pereginatio - only 
here mediated ambiguously through the contemplation of works of art and landscape. The Cortile provides an abiding example of how this notion of spirtual preparation is articulated perspectivally by drawing the distant horizon of the landscape into the ambit of the providential city. This topographical unity is further underlined, as we have seen, by the passage of the ancient route, the via del Pellegrino; a relationship that could also be said to resonate in the Galician Centre for Contemporary Art in the way the gathering of gardens, paths and works of art culminate in the view of the cathedral. ${ }^{144}$

Perhaps the clearest evocation of this metaphor of pilgrimage in the Galician Centre for Contemporary Art can be found in the experience of the roof-top sculpture terrace. As you ascend to the terrace, views of surrounding buildings - in particular the adjoining Convent and the cityscape beyond - come into view. Sited along the south-west side of the elevated promenade is a large stone pyramid. This partly houses a roof-light that illuminates a corridor below. ${ }^{145}$ The juxtaposition of the pyramid with the stone parapet walls, which encircle and define the building envelope, gives the impression of a fortified city in miniature. It is as if the enclosed roof-terrace becomes a microcosm of Santiago de Compostela, from where views of the roof-tops and bell-towers of the Convent - and other religious buildings - are viewed extra muros in the fashion of the Basilicas of Peter and Paul in Rome. This strange inversion is pressed home when we realise that the pyramid on the roofterrace is positioned on the side of the building facing the Cathedral; it provides a prominent visual marker to the venerated shrine of St James, whose lofty belltowers and dome are clearly visible. This, moreover, could be likened to the metas in Rome that function as sign-posts to the Basilicas outside the walls of the city. ${ }^{146}$ It is of interest to note that the "hybrid" proportions of the roof-top pyramid remind one of the Meta Romuli (referred to earlier in the context of the route of the via del Pellegrino), whilst the pyramid's physical connection to the parapet could be construed as a miniature version of the Pyramid of Gaius Cestius and the Aurelian wall. Such similarities are most probably coincidental but nonetheless further underline the corresponding relationships.

In conclusion, the comparison detailed above between the Galician Centre of Contemporary Art and the Cortile del Belvedere - and by implication

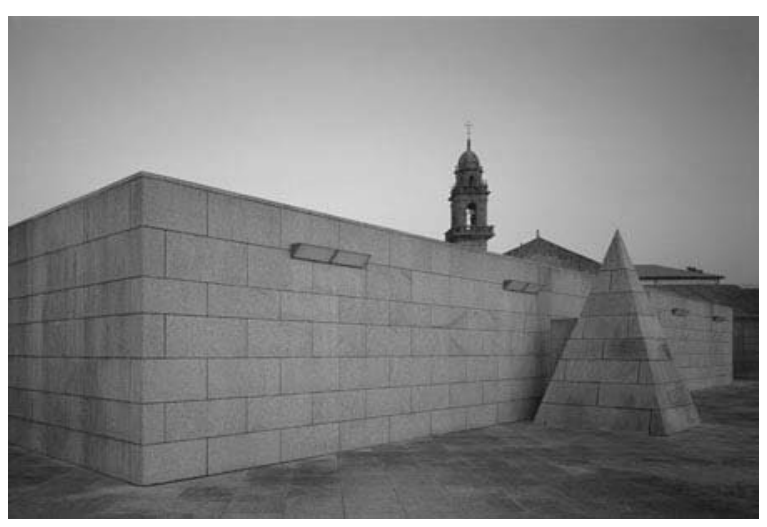


4.39

Galician Centre for Contemporary Art (1988-93), Álvaro Siza. View of the building from an upper level of the convent garden showing horizontal roof parapet and views of the Cathedral beyond

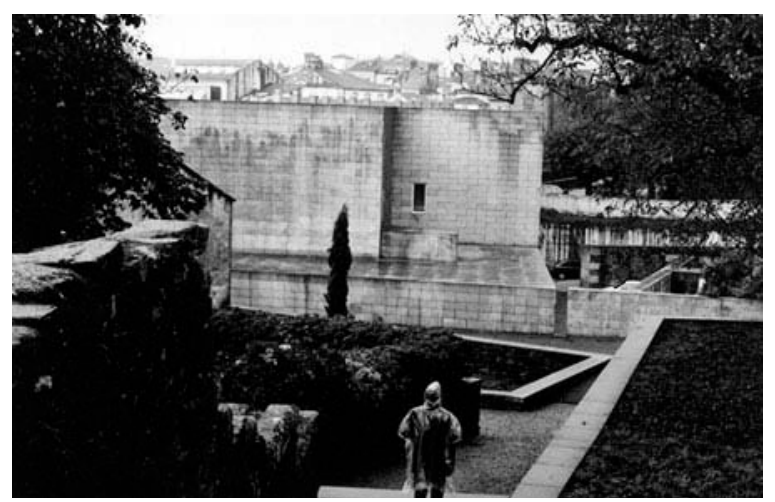

between Santiago de Compostela and Rome - suggests a continuity of themes that reveal the presence of a latent tradition. In this tradition, which can be traced back to the Middle Ages, the perspectivisation of space is underscored by redemptive intentions, namely to bring the actual city within visible (and symbolic) range of sacred space. In the case of the Galician Centre for Contemporary Art, however, such intentions are not stated explicitly, as one would expect in a world no longer informed by a transcendent view of reality. Rather the relationship is conveyed ambiguously through the interplay between local landscape, built form and the larger topography of the pilgrimage city. 


\section{Chapter 5}

\section{Unity in multiplicity}

\section{Baroque and universality}

As arguably the last period in European history when a transcendent understanding of space could be assumed, the Baroque was also a period in which the cosmos was conceived in mechanical terms. In this altered world-view, the traditional closed universe of the Middle Ages - and its subsequent humanist revisions in the Renaissance - were replaced by a more systematic and rational view of order. Expressed in the philosophies of René Descartes and Gottfried Wilhelm Leibniz, this world-view was supported by what was construed as the "selfevident" nature of mental reasoning: the circumspection of inner rational thought (as opposed to the perceived equivocations of outward dialogue redolent of humanism) provided the principal mechanism for distinguishing the mere appearance of things from their innate - and therefore essential - natures.

The discovery - and "mathematisation" - of the hidden mechanical processes of the universe went hand in hand with the growing dominance of the self as a philosophical and theological idea. Both constituted key factors in the development of modern consciousness: the search for objective certainty in science was by necessity accompanied by an equal prevalence of subjective thought. $^{1}$

A seminal figure in the advent of modern science was the late sixteenth-century humanist and occult thinker, Giordano Bruno. ${ }^{2}$ In his world-view, the universe is conceived as an infinite expanse of numberless entities suffused with a "world-soul". This represented a departure from the traditional transcendent view of the cosmos where divine authority is communicated through a preordained hierarchy of heavenly and terrestrial intermediaries.

The idea of the infinite was understood by Bruno as a reality accessible to human involvement, rather than being merely a theoretical or rhetorical idea, as Aristotle argued. Such involvement, however, required a particular hermetic outlook of the world, whose authority was drawn from the received traditions of prisca theologia (ancient theology) discussed in Chapter 4. Expressed in the apocryphal Corpus Hermeticum, the many religious beliefs and philosophical practices 
of antiquity were believed by Bruno to conceal a unified theology. Only by probing the hidden depths of the "natural order" could this world-soul be revealed and ultimately harnessed for the benefit of all humanity.

In one sense Bruno's philosophy could be seen as providing a new rational perspective of Cusanus' idea of the coincidence of opposites. Whilst the latter considered rational argument as a limited human invention, the former saw it as essential to achieving the proper union between human finitude and divine infinitude. Bruno's quest required the reduction of the enquirer to an "instrument" for contemplating - and ultimately revealing - God's purpose. Curiously, this rational emphasis was driven by a "magical" view of the world. Bruno's recasting of traditional theological and philosophical ideas into a universal science, using alchemical and hermetic principles, led to new ways of interpreting the cosmic order.

Bruno's model of the "world-soul" paved the way for the establishment of the principle of "unity in multiplicity" that was to characterise Baroque concepts of order. In this notion, which will serve as the main theme in this chapter, the cosmos comprises inter-connected parts, whose individual natures constitute distinct "horizons of being". The principle of unity in multiplicity provided the background to the establishment of distinct areas of enquiry in the seventeenth century, such as astronomy, geology, cartography, numismatics, archaeology and linguistics. Implicit in these varied fields of study was a common communicative domain, rooted in an all-encompassing divine authority that ensured a rich cross-fertilisation of ideas. It was only in the eighteenth century that such continuity becomes problematic as a result of the advent of independent disciplines, each with their own terms of reference.

The breadth of - and correspondence between - these different areas of enquiry during the Baroque period could be said to find analogous expression in the spatial and symbolic complexities of Baroque architecture. Understood in broad terms, the architecture of the seventeenth and early eighteenth centuries could be characterised as a "constellation" of elements, typically configured as a succession of inter-related spaces, within which the drama of sacred event unfolds and culminates in a unified spectacle for collective involvement. A critical feature of this mode of "transformational" space is the analogical function of geometry. The deployment of successive geometric forms, that we see for example in the work of Guarino Guarini, was informed by analogical thinking that gave qualitative meaning to quantitative value. Through this relationship, human participation could be brought into dialogue with divine/cosmological drama. Significantly, this process of synthesis, as I will seek to demonstrate, is most effectively articulated in the symbolism of the dome during the Baroque.

It is in this context of the Baroque notion of unity in multiplicity that this chapter examines the role of perspective in the understanding of space during the seventeenth and early eighteenth centuries. I propose to explore this topic through the work and ideas of three key figures of the period: Athanasius Kircher, Gottfried Wilhelm Leibniz and Johann Bernhard Fischer von Erlach, all of whom sought to validate a universal order. 
As the great polymath of the Baroque period, the Jesuit priest and German scholar Athanasius Kircher has long been recognised for the versatility of his ideas and the staggering breadth of his knowledge. In particular, his studies in ethnology, geology, geography and linguistics testify to a complex and intertwined view of the natural world. Of comparable stature is the German thinker and scientist Gottfried Wilhelm Leibniz, described by Gilles Deleuze as the philosopher of the Baroque. ${ }^{3}$ Deleuze's assertion is based on the parallels he draws between Leibniz's metaphysics and the metaphorical understanding of the fold. Indeed, the fold could be said to embody Baroque sensibilities, in particular the perceived inter-relationship between corporeality and divine revelation. As the last attempt to formulate a complete cosmology - in the tradition of classical and Medieval/ Renaissance philosophers - Leibniz's metaphysics also played a key role in shaping architectural and cultural ideas in the early eighteenth century.

The extent - and nature - of the influence of both Kircher and Leibniz on architecture is most clearly apparent in the work of Johann Bernhard Fischer von Erlach. Trained in Rome, where he came into contact with Kircher, Fischer later worked as court architect to the Habsburg King Karl (Charles) VI in Vienna, where he came under the influence of Leibniz. It was during his time in Rome that Fischer probably first became aware of the architectural implications of a universal language, as promulgated by Kircher. This was later to materialise as a series of major architectural projects in the Viennese court. Of relevance to this study are the Karlskirche and Hofbibliothek. In each case I will highlight the significance of the dome as a metaphor of a universal order that is articulated at two broadly inter-related levels: the metaphysical (eternal) and the providential (historical).

As a conclusion to this chapter, I will examine a contemporary church Sogn Benedetg (St Benedict) by Peter Zumthor - in the context of Baroque concepts of space. My aim in this study is to demonstrate how Zumthor's essentially phenomenological understanding of space follows similar principles as those of Leibniz's theory of the monad.

\section{Distentio animi and the dome}

During the Baroque period the development of instruments for representing and measuring the movement of heavenly bodies, such as armillary spheres and orreries, presented certain analogous relationships to the cosmological symbolism of the dome. This association was brought about, in part, by the increasingly dominant role played by churches as "instruments" for determining the shifting date of Easter. We saw in Chapter 3 how the understanding of architecture, as a symbolic tool for affirming concordance between the order of Church liturgy and the movement of heavenly bodies, formed part of a much deeper onto-theological tradition. In the Baroque, this symbolism takes on more systematic intentions by the adaptation of churches or cathedrals as makeshift meridian/solar observatories. ${ }^{4}$

Alongside, therefore, the new mechanical view of the universe, which we see in the ideas of Isaac Newton and Gottfried Wilhelm Leibniz, is a corresponding understanding of religious spaces as measuring instruments. Implicit in this correspondence is the ontological meaning of space, in its capacity to 
"shape" humanity's relationship to the divine. We are led to believe, in this spatiality of human redemption, the principle of synchronicity between the movement of celestial bodies and the "movement" of the world-soul.

A guiding influence in this symbolism is St Augustine's notion of distentio animi (distended soul) in which the penitent's search for salvation takes on metaphorical meanings through the "swelling" or "stretching" soul. Outlined in his Confessions, Augustine believed that distentio animi is registered by the mind adjusting itself between three temporal states: expectation, memory and attention. These three states are examined in Paul Ricoeur's commentary on Book 11 of Augustine's Confessions. Ricoeur argues that Augustine's understanding of the present is an experience of the soul, whilst the past is memory in the soul. Finally the future is understood as the expectation in our psyche. ${ }^{5}$ Adjustment between each stage - at any given moment - is achieved through the mind's intention (intentio); in moving between these states the soul, Augustine argues, "distends itself as it engages itself" ${ }^{6}$ In other words, the progressive movement into the depth of the human soul is accompanied by a corresponding ascension towards the heavenly realm. The principle was re-interpreted in Medieval homilies and meditations, as we see for example in St Bonaventure's Itinerarium Mentis in Deum. ${ }^{7}$

What was understood, however, in Augustine's writings as the exclusive prerogative of the individual human soul - unmediated by cosmic events - is transformed in the Baroque into a spatial-temporal paradigm of a world-soul imbued with cosmological meanings. In the resulting entwined relationship between soul and cosmos Gilles Deleuze's metaphor of the fold takes on the deepest significance. ${ }^{8}$ At the heart of this symbolism is the dome, the distended fold par excellence, which is the clearest physical embodiment of a world redeemed. Through the "unfolding" - and subsequent distension - of the dome the two-way movement of the soul (of inwards and upwards) is communicated. Accordingly, as I will argue here, the Baroque dome constitutes the most complete architectural manifestation of distentio animi.

Whilst the spaces of Renaissance centralised churches were conceived around the principle of the concatenation of Platonic forms, whose proportional relationships affirm a state of balance and harmony between God and humanity, the interiors of Baroque churches were motivated by rather different intentions about the notion of a telos. This is highlighted in the deployment of generative - transformative - geometries that reveal the underlying dynamics of redemptive space; a space conceived around the principle of distentio animi. The elliptical form embodies this dynamic; its "deviation" from Platonic geometry attests to the inner mechanisms of the soul.

In a rather different way to the principle of diminishing proportions in Renaissance perspective, Baroque space is the progression of ratios so that they approach infinity "in perpetuity". ${ }^{9}$ In so doing, it shifts "from the human to the divine point of view, and from perspective to projection". ${ }^{10} \mathrm{~A}$ critical aspect of this difference with Renaissance views of space concerns the nature and meaning of opposites: 
The transition from Ptolemy and Copernicus to Kepler implies a shift from thinking in terms of antithesis to thinking in terms of the oxymoron.... Like the substitution of the ellipse for the circle, the substitution of the oxymoron for antithesis also implies a shift from the kinetic to a dynamic conceptualization: "Only the 'conjunction,' that is the 'coincidence' of antonyms in the nucleus of an oxymoron, places antithetical terms both structurally and functionally in a relation of contradictory dynamism, of more or less direct contradiction". ${ }^{11}$

The analogy between the "contradictory dynamism" of the oxymoron and the ellipse assumes that the latter is not generated by two foci, as is often claimed, but rather by species immateriata - of attraction and repulsion. From this principle of form as a function of force, Johannes Kepler

seems to have brought about a complete transformation from the formistic perspective, dominated by faith in final ends and ideal perfection (Renaissance space), to a contextual perspective, where relations are conceived as interactions between phenomena at the same level of reality. ${ }^{12}$

The transformation, reflected in part in Kepler's abandonment of circularity in favour of elliptical orbits of planetary bodies, must be understood not as an "advance" - brought about by the freedom to choose the most perfect model but rather as a constraint imposed by imperfection. Hence, the ellipse "represents a submission to facts far removed from a dreamed of perfection". ${ }^{13}$ Rather than conceiving motion, therefore, as a contemplative realm, Kepler's reluctant submission to the ellipse affirms the status of motion as a reality:

Increase or decrease the proportions: this is what Kepler was forced to do to circular perfection in order to account for the reality of the planetary orbits. "The orbit of a planet is not a circle," he wrote, "but it curves in little by little and then moves back toward the fullness of the circle". ${ }^{14}$

In this deviation from absolutes, the Baroque curve (and its metaphoric articulations in the fold) embody the idea of the "distended" soul seeking union with God; the hidden dimensions of the soul correspond to the latent - imperfect mechanical processes of the universe. One can get a sense of this analogy in the interior of Borromini's S. Ivo della Sapienza in Rome. The plan is formed by two intersecting equilateral triangles that interpenetrate to create a hexagon within a six-pointed star. It is within this configuration that geometry spawns - or "propagates" - sacred space by transforming the immateriality of light into the corporeality of the suspended canopy or awning. In the process the intersecting geometric forms create multiple pleats that invoke the miraculous (supra-worldly) divine order. In this space cosmic drama is brought to the level of human atonement. 
5.1

Plan showing geometric layout of equilateral triangles. S. Ivo della Sapienza, Rome, 1643-48, Francesco Borromini (1599-1667). Drawn by author after Blunt

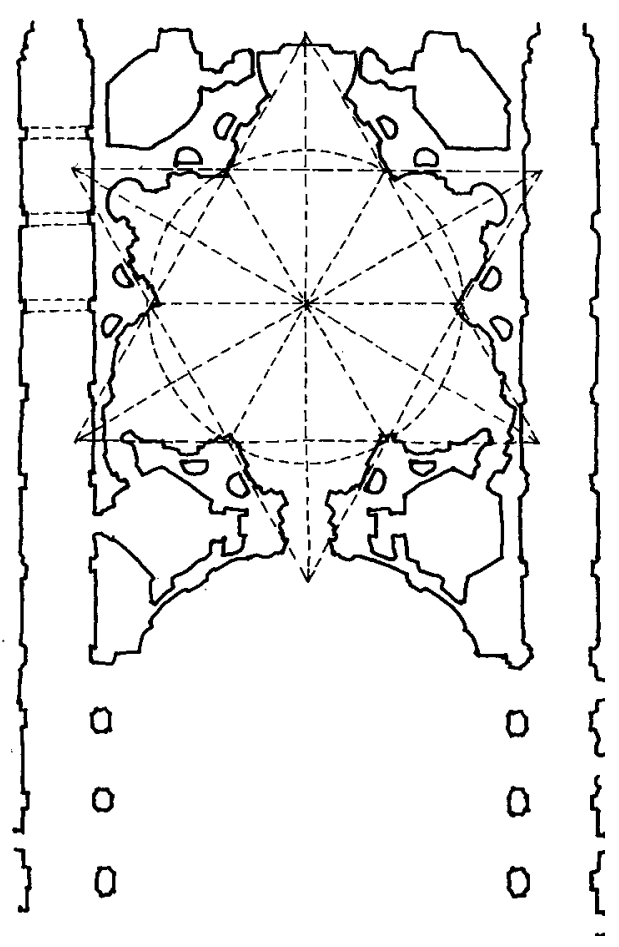

Underlying this idea of geometric propagation is Kepler's principle of the "procreation" of Platonic forms outlined in his Harmonices mundi of 1619: the coupling of one form with another leads to the offspring of new geometries. According to George Hersey, the idea of the sexual reproduction of geometry is key to understanding Kepler's distinction between "effable" and "ineffable" shapes, between the visible (utterable) and the invisible (unutterable) that underpins his whole thinking of geometry. ${ }^{15}$

The development of anamorphic projection in the seventeenth century introduced a new condition to the idea of projected space: by geometrically projecting the position of the observer to infinity, anamorphosis indirectly acknowledges the point of view of the divine. ${ }^{16} \mathrm{~A}$ motivating force behind this correlation is the graduating coincidence between infinite space, God and the human soul that constitutes the telos of divine transcendence. ${ }^{17}$ But this anticipated union is problematised in anamorphosis by the need to go in search of an optimum point of view, whose position is both undeclared and unconditional. In such an "unchartered" world we are led to a situation that anticipates the modern condition of the disengaged subject:

Whereas in the past the picture was already judged towards the maximum of its standpoint, so it is now the case that the world of the picture is only understood as a total dependency from a viewpoint. Only through the understanding of this viewpoint in its punctuality [i.e. 
of a point] and the positioning of oneself on this spot, is it possible to see the picture. This is the phenomenon of anamorphosis in which the idea of the given perspectival situation takes places in an extraordinary radicality. ${ }^{18}$

The shift from the largely static - concatenated - volumes of Renaissance space to the dynamic and layered interiors of Baroque buildings leads to a disjunction between form and content. ${ }^{19}$ The split, which Heinrich Wolfflin describes in psychological terms as a separation of body from spirit, is considered by Alberto Pérez-Gómez as indicating a civilisation being "thrown into history". ${ }^{20}$ Whilst the Renaissance turned itself towards the past in order "to confirm its actions of reconciliation with the cosmological order", the modern view of history (which the seventeenth century heralds) "assumes that human actions truly matter, that they effectively change things ... and that the present is qualitatively different from the past". ${ }^{21}$ What we see in Baroque perspective, therefore, is an analogous operation whereby the visitor seeks "centredness" (and therefore union with God) through physical and emotional involvement.

In one sense, as Karsten Harries argues, seventeenth-century developments in anamorphosis echo René Descartes' distrust in mere appearance. The result of distortion "is inevitable given that we experience the world from a place within the world and thus perspectivally". ${ }^{22}$ This view of the world is driven in part by a misconception that perspective constitutes a geometric entity that can be directly applied to design. The inevitable consequence of the increasing reliance on appearance in the understanding of the world was, as Descartes believed, confusion. ${ }^{23}$ Only by aspiring to an inner spiritual light, revealed through the self-evident truths of mathematics, could this state of confusion be overcome. Accordingly, Descartes inaugurates in his quest for objective truth a shift from a "world we initially perceive as a collection of objects moving in an endless homogeneous space, the perspective-bound form of representation characteristic of painting", to "the transperspectival form of representation characteristic of science". ${ }^{24}$

To some extent, the development of projective geometries in the Baroque, in which the point of view of the divine takes precedence over that of the individual observer, could be said to reflect this "transperspectival" condition. Notwithstanding this important shift, Baroque architecture was still firmly rooted in a transcendent understanding of the world, as I have outlined. Key to this understanding is the manner in which the "inner" human soul and the "outer" cosmos were seen to correspond, a claim that was supported by the combined effects of scientific reason and religious rapture.

\section{Athanasius Kircher}

The breadth of interests in the work of the seventeenth-century Jesuit Athanasius Kircher, and his attempt to draw parallels between diverse areas of thought, attest to some larger unifying principle. At the heart of this principle was Kircher's search for a universal language that can communicate the Gospels to an expanding Christian community. This aim was fostered by a generally optimistic view of human 
redemption that believed in the possibility of overcoming the vanity of humankind that was the legacy of the Tower of Babel. Indeed, God's punishment - in the confusion of tongues - was considered by Kircher as a defining moment in history that continues to obstruct humanity's quest for salvation. ${ }^{25}$

The ambitious task that Kircher set himself led to the publication of approximately forty books on a vast range of subjects, and the implementation of numerous experiments. Of his written works the most pertinent to this chapter are Arca Noe ("Noah's Arc"), Mundus Subterraneus ("Subterranean World"), Obeliscus Pamphilius ("Pamphili Obelisk"), Musurgia Universalis ("Universal Music Making") and Magnes sive de Arte Magnetica ("The Magnet", or "The Magnetic Art"). ${ }^{26}$ As a polymath of international renown, Kircher held the chair of mathematics at the Collegio Romano, the Jesuit College in Rome which was built in the late sixteenth century over the ruins of the ancient Roman Temple of Isis. It was in this imposing complex of buildings that Kircher erected an astronomical observatory, to challenge the claims of Galileo Galilei and thereby reaffirm the authority of the Church in the understanding of the universe. It was also at the Collegio Romano that Kircher brought together a unique collection of artefacts that formed his famous Musaeum Kircherianum. The layout and content of the museum were partly influenced by Kircher's interest in the story of Noah's Ark, as demonstrated in his volume Arca Noe. The idea behind the work was conceived at a mathematicians' convention held during the celebrations of the centenary of the Jesuit Order in 1640. At this event, Kircher embarked on a "technical disquisition" on Noah's Ark that entailed, among other things, the calibrating of the length of the biblical cubit. ${ }^{27}$ It was this interest in the sacred dimensions of the Ark that Kircher sought to apply to his "vessel" of world knowledge. He believed that the museum served a redeeming function by acting as a kind of salvage of recondite fragments and artefacts, many of which were collected by fellow Jesuits from around the world. Significantly, Kircher's collection became the precursor to the more familiar eighteenth-century cabinet of curiosities. ${ }^{28}$

The Musaeum Kircherianum could be said to exemplify Kircher's ambition to define some unitary universal order, an aim that also underlies numerous other initiatives by the German Jesuit. Among these was an observatory that Kircher designed for the Knights Hospitalers in Malta. The observatory is said to have "traced the progress of sun, moon and planets; tallied the dates of movable feasts on the Christian calendar; told time throughout the world ... Inscribed in twelve languages (Hebrew, Chaldaean, Syrian, Arabic, Ethiopian, Coptic, Greek, Latin, Italian, French, Spanish, and German), it also combined three ideal geometric forms: circle, cube, and pyramid". ${ }^{29}$

What becomes apparent in these projects is Kircher's abiding belief in the principles of synchronicity and continuity in the world order that can be tabulated and measured. A guiding theme behind this assumption is the belief in an inter-relation between the eternal patterns of the cosmos - communicated by Platonic Forms or Ideas - and their human and natural counterparts, in the form of languages, histories, geological features and so on. The challenge for Kircher was to find a unifying symbolism that can convey concordance between these parts. 
Whilst this enterprise could be said to anticipate the encyclopaedism of the eighteenth century it is not in any way encyclopaedic in nature. Kircher did not consider the methods for ordering elements as simply an instrumental exercise. Rather, he believed them to be revelatory in nature, disclosing through appropriate arrangement and articulation a pre-ordained cosmological order. Notwithstanding this belief, the idea of an encyclopaedic view of the world, and its supporting epistemological structures, was soon to take on a momentum of its own from the early eighteenth century, as we shall see later in the context of the court of the Habsburgs in Vienna.

Among the many tasks that Kircher set himself was the translation of Egyptian hieroglyphs. This was not merely of intellectual interest but also constituted a central aspect of his quest for a universal language. Kircher believed that the mysterious reliefs that adorn the obelisks in Rome carried with them profound numinous messages that awaited decipherment. The idea is derived in part from Pythagoras' attested veneration of the ancient Egyptians because they believed that true wisdom can never be expressed or experienced directly. Instead, divine knowledge lies "beneath likeness and parables of various sorts" that require translation to reveal their true meanings. ${ }^{30}$ Hence, the hieroglyphics came to be viewed symbolically as an affirmation of a concealed, recondite truth that Kircher sought tirelessly to disclose.

In his attempt to reveal these hidden meanings Kircher inadvertently established, in embryonic form, a symbolic logic. ${ }^{31}$ This finds visual expression in his translations of the so-called Pamphili Obelisk. The obelisk was brought to Rome from Egypt by the Emperor Domitian and positioned in the Sanctuary of Isis, on the site of the Collegio Romano. It was subsequently moved to the Circus of Maxentius along the Appian Way where it lay in pieces until its relocation in the seventeenth century to Piazza Navona, formerly the Stadium of Domitian. The initiative, it seems, was instigated by Kircher himself. The obelisk was incorporated into Gianlorenzo Bernini's celebrated Fountain of the Four Rivers as the crowning piece. Significantly, Bernini acknowledged Kircher's contributions by adding summaries of the Jesuit's translations in the form of four inscribed granite plaques at the base of the obelisk. The results of Kircher's labours were later published in his Obeliscus Pamphilius.

Kircher's involvement in the Fountain of the Four Rivers was, it seems, not just limited to the translation of the obelisk's inscriptions but also probably entailed the design of the fountain itself. As the name suggests, the fountain celebrates the fecundity and plentitude of four rivers - the Nile, Ganges, Danube and Rio della Plata - in the form of four giant sculpted figures. Represented as river deities, these figures were clearly intended to signal the four known continents of the world: Africa, Asia, Europe and the Americas. The layout of the fountain, however, with the crowning obelisk and positioning of the figures at the corners, suggests the idea of the four corners of the globe - a characteristically Jesuit notion that informed Kircher's own interest in the earth's magnetic properties, as we shall see later.

Kircher's contribution to the design of the fountain was also, it seems, motivated by another interest in his vast array of intellectual pursuits, namely 
Fountain of the Four Rivers, 1648-51,

Gianlorenzo

Bernini

(1598-1680).

Piazza Navona,

Rome

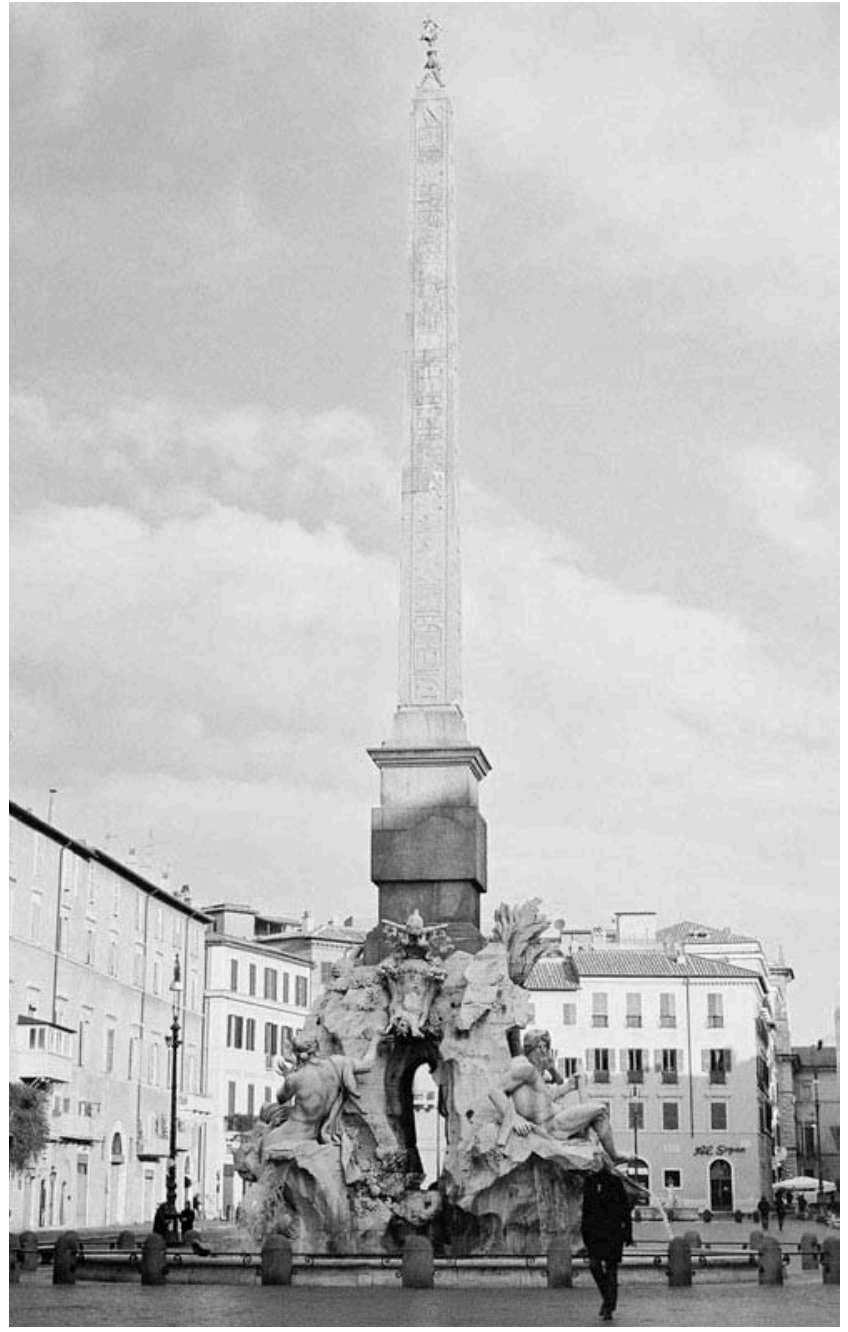

geology. His Mundus subterraneus constitutes one of the earliest attempts to develop a systematic theory of geology. In this work, Kircher argues that mountain ranges conceal huge underground water reservoirs which he called hydrophylacia (meaning "water reservoir" in Greek). ${ }^{32}$ Related to this work was his fascination with the behaviour of volcanoes. Kircher is said to have descended down the smoking crater of Mount Etna during a trip to Sicily and made a sketch of the pouring red lava. Kircher's investigations into geology were informed by a belief that the pressure created by the periodic build-up of subterranean gases, lava and water left behind large subterranean voids.

These cavernous spaces constituted what Kircher believed to be a form of "chthonic architecture" that probably inspired Bernini's design for the Four Fountains. We can see this in the four cascades of the fountain that pour from a central dome-like mound that appears to have been created by the force of 


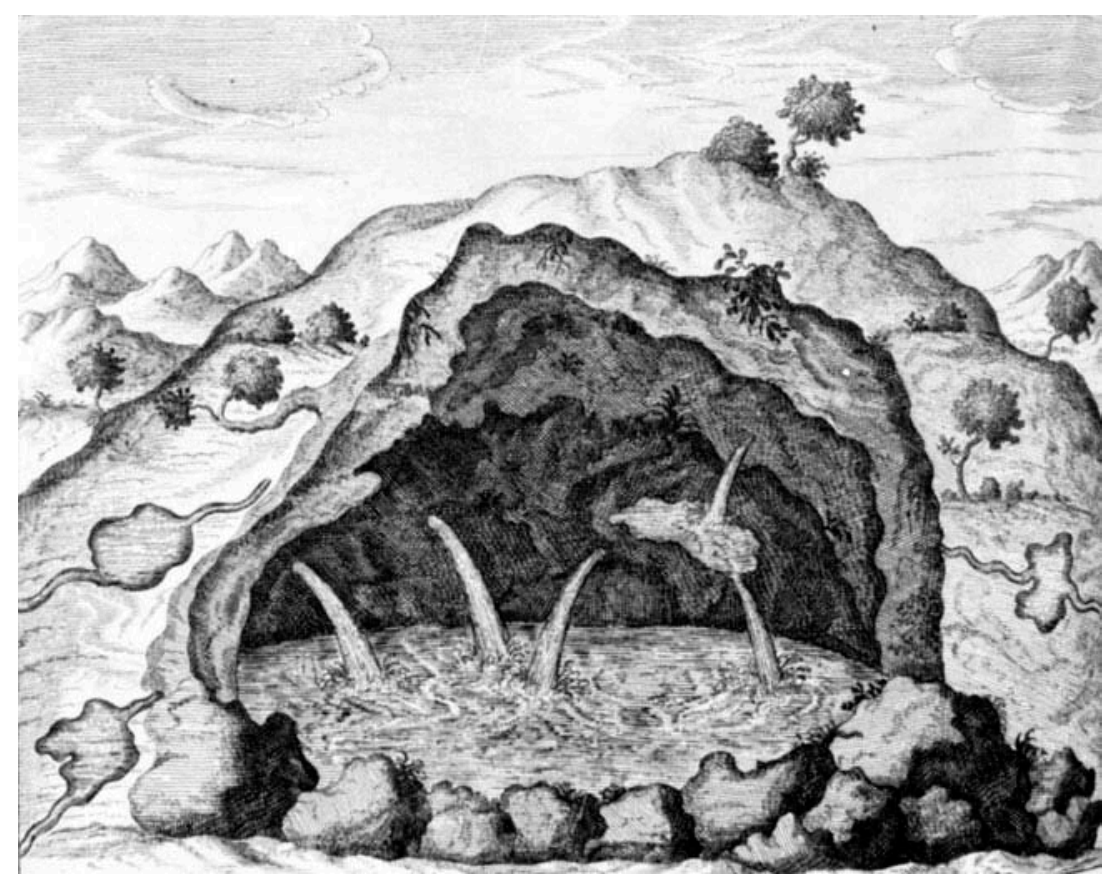

the gushing water. Flanked by the four river deities, the structure could be interpreted as a naturally formed canopy - or "baldacchino" - upon which the Pamphili Obelisk is surmounted.

In the Bernini fountain we encounter a complex iconography that brings into play two themes that could be said to exemplify seventeenth-century views of order. The first theme concerns the quest for a universal language, made explicit by the obelisk and supporting translations of the hieroglyphics. The second concerns the notion of a unified and inter-related cosmic order - signified by the four corners of the globe that converge on the cavernous space beneath the obelisk. This articulation could be construed, in embryonic form, as a dome emerging from the underworld. The idea, as we shall see later, was to acquire philosophical import in the work of Leibniz who also, incidentally, had a keen interest in geology.

The relation between both themes could be understood in iconographic terms as a process of "translation"; from the earthly realm of the chthonic mound, with its "distended" undercroft (evocative of primordial chaos), we progress to the surmounted obelisk - the gnomic "time-piece" of the four corners of the globe and "repository" of a recondite language. Finally, the secrets embedded in the hieroglyphics are revealed in Kircher's translations, inscribed at the base of the fountain and periodically shadowed by the obelisk. By unlocking these secrets, Kircher believed that order could be restored from the chaos inflicted by the confusion of tongues. Only by both re-establishing a universal language and revealing the existence of an inter-related world, could humanity redeem itself
5.3

Representation of an underground spring. Athanasius Kircher (1602-80), Mundus subterraneus (Amsterdam, 1678), p. 234 
5.4

Athanasius Kircher (1602-80), Collegio romano. Museo (Amsterdam, 1678), frontispiece

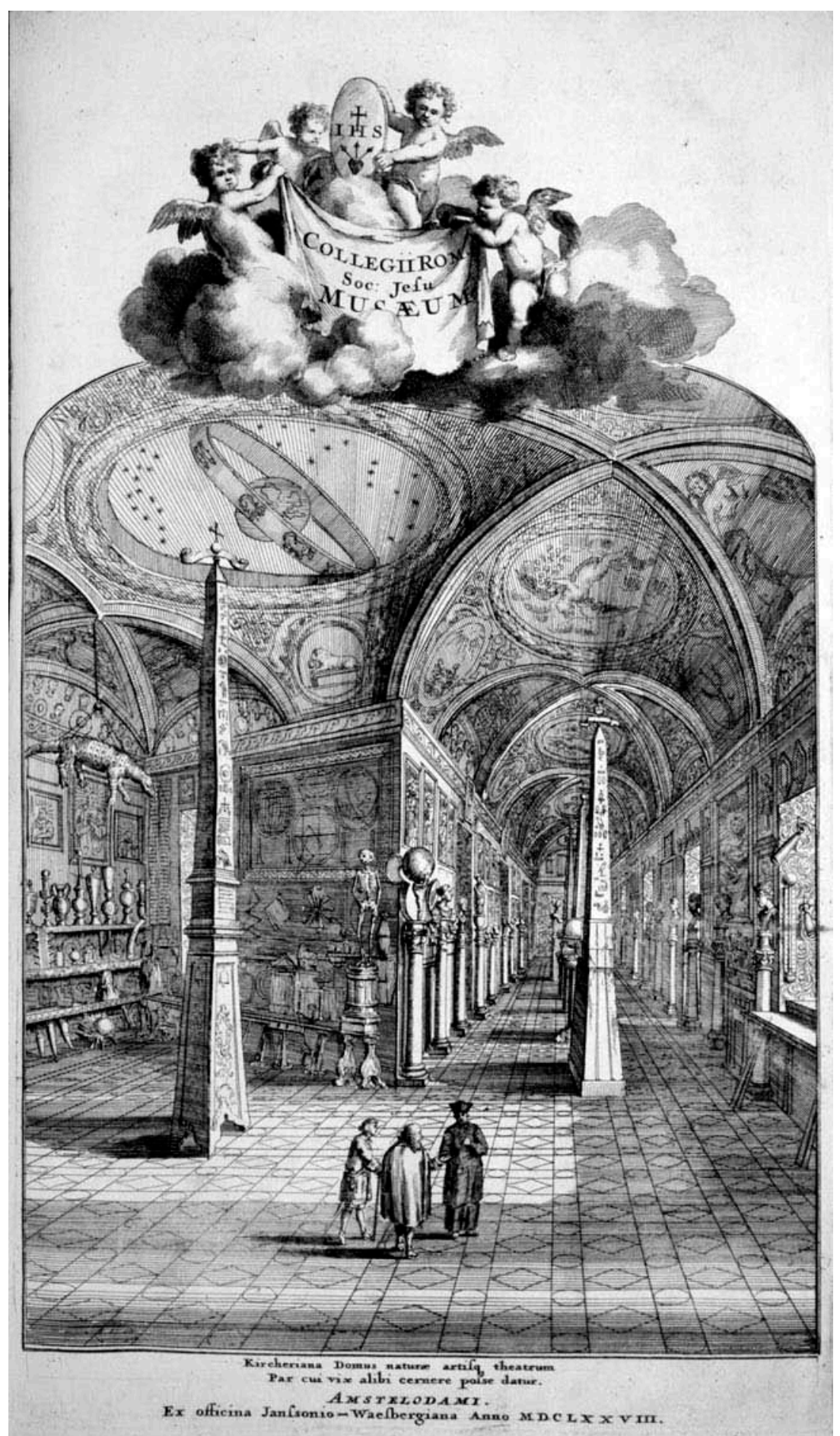


from the sins of Babylon. In this iconography earthly (geological) transformation and human history are interwoven.

The role of the distended dome as a motif of order and universality was also to inform Kircher's theory of music. In his Musurgia Universalis, Kircher considers architectural resonators in the form of elliptical, parabolic and hyperbolic vessels for "universal music-making". ${ }^{33}$ In his treatise Kircher constructs numerous illustrations relating to architectural acoustics which he collectively terms magia phonocamptica, or "the magic [or technique] of sound-bending". 34 In particular, Kircher is "concerned with echoes and reverberations. He writes of caves and classical buildings where strange, elaborated echoes were to be heard, and about how echoes may be bounced onward for long periods of time." 35

His theories and observations were put into practice in his design of a "theatre of echoes" modelled on the Theatre of Marcellus. Consisting of a concave three storey structure formed on one side of an oval orchestral space, the edifice was equipped with various bronze vessels, bells and vases, the latter representing the "musical fundamental of the whole system". ${ }^{36}$ It is interesting to recognise potential correlations between Kircher's study of reverberations in caves, in which the quality of echoes is defined by certain archetypal forms, and his geological interests expressed in the "primordial cave" of Bernini's Fountain of the Four Rivers.

Perhaps the most ambitious of Kircher's collaborative projects was his investigation of the earth's geography. During the 1630s and 1640s Kircher set out to devise a grand geographical map (Consilium geographicum). The global scale of missionary activity during this period presented an opportunity to identify the longitudes and latitudes of all the Jesuit communities in the world. At the same time, fellow Jesuits were instructed by Kircher to provide observational data on tidal changes, local geographical features, the direction of winds, the species of animals and plants, types of minerals and even local customs and languages. ${ }^{37}$ Each Jesuit centre, therefore, constituted a coordinate in the matrix of the earth's surface. In so doing, each signified a microcosm of an ever-expanding Christian

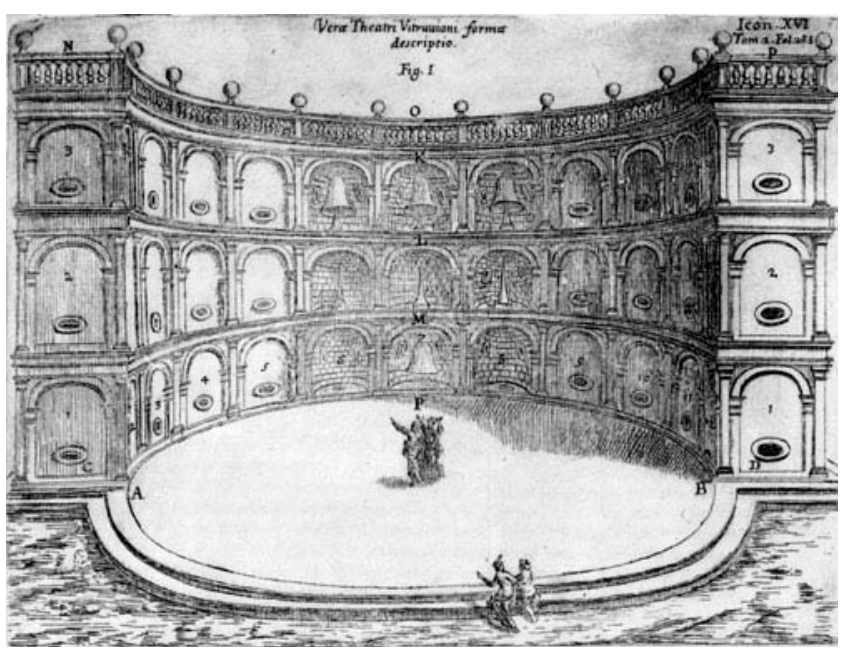

5.5
Athanasius
Kircher (1602-80),
Musurgia
universalis, 1650.
"Theatre of
Echoes" 
empire of faith. By attempting to accurately map the world's geography Kircher and his Jesuit collaborators were also devising a method for recording the nature and extent of Christian conversion.

Ambitious as this project may seem, it only served as a precursor to a more complex mathematical undertaking. Published in 1641 as Magnes sive de arte magnetica ("The Magnet" or "The Magnetic Art"), the work was the product of an intense collaboration, to identify and map magnetic declination of the earth in places as far apart as Goa, Alexandria, Constantinople and Vilnius. ${ }^{38}$ This was undertaken by measuring the deviation of a compass needle from North as defined by the pole star. Kircher solicited mathematicians throughout the international Jesuit community to provide data on the magnetic variation of their respective locations. A table was subsequently published of the data of the declinations, the latitude of the place in which the observation was made and the names of his Jesuit helpers.

The task acquired significant symbolic importance. Magnetism carried a similar meaning for Kircher as gravity did in Newtonian physics; "it is the attractive force that binds the universe together". ${ }^{39}$ If we consider the Jesuit order as a constellation of "sub-centres" of Catholic faith, in which each is deemed a microcosm of papal authority, then it is clear that Kircher's project of magnetic measurement was more than simply a scientific exercise. In the concordance between global observation and absolute authority that Kircher's project advances, we are reminded of Leibniz's notion of multiple perspectives as the basis of a universal divine order. The fine balance between the role of the individual Jesuit observer, as "data collector" of the Catholic faith, and the "centralised global epistolary network" of the Jesuit order required the success of what Michael Gorman aptly describes as a "pious synchronicity". ${ }^{40}$ This is best exemplified in a sundial that Kircher built in his museum at the Collegio Romano:

[This was in] the form of an olive tree representing the different provinces of the Jesuit order ... When a stylus was placed in each Province, and the device was positioned vertically so that the Roman time was given correctly, the clock allowed the time in all the different Jesuit provinces to be read correctly. In this way, the viewer could perceive that the society of Jesus was performing its religious duties masses, confessions, sermons and catechesis - throughout the world, day and night, without interruption and in all languages. ${ }^{41}$

Whilst still rooted in an onto-theological tradition, Kircher's ambitious projects nevertheless foreshadow modern scientific methods, in particular tabulating, analysing and representing the manifold aspects of the cosmos through the agency of human reason.

\section{Leibniz and the monad}

Kircher's ideas of a universal order serve as a precursor to the more systematic metaphysical model of cosmology found in Leibniz's philosophy. In this model the 
theme of distended space, and its perspectival implications, take on more abstract meanings that centre around Leibniz's theory of the soul or monad. What Kircher sought to reveal through the manifold fragments that constitute the body of human knowledge Leibniz develops around the philosophical principle of selfsimilarity. Synthesis and simultaneity underlie Leibniz's cosmology where the universe is reduced to numberless discrete substances. He radicalises Kircher's ethnological model of the world as a series of microcosms by arguing that "each singular substance expresses the whole universe in its own way, and that all its events, together with all their circumstances and the whole sequence of external things, are included in this notion". ${ }^{42}$

Leibniz even suggests that every substance "bears in some way the character of God's infinite wisdom and omnipotence". ${ }^{43}$ In so doing, each substance is a mirror of the universe. This is expressed in the monad whose internal unity ensures a multitude of variations without the need for outside interference. Each monad could therefore be understood as "a little divinity in its own realm" ${ }^{44}$ Charles Taylor calls these subject-like perspectives a form of "proto-self". ${ }^{45}$

Leibniz's cosmology overcomes the pitfalls of relativism by centring the universe at any given monadic point. Significantly, he uses the analogy of the city to convey this understanding of the universe:

Just as the same city viewed from different directions appears entirely different and, as it were, multiplied perspectively, in just the same way it happens that, because of the infinite multitude of simple substances, there are, as it were, just as many different universes, which are, nevertheless, only perspectives on a single one, corresponding to the different points of view of each monad. ${ }^{46}$

In place of Kircher's vision of the universe as a composite of parts or fragments, awaiting reconnection through the agency of human knowledge, Leibniz argues for a universe that is already continuous in all its facets. He develops this argument through his concept of the monad:

to every special point at a given time there corresponds a monad representing the world from its point of view; it is as if the monad were positioned without being really situated at this spatial point viewing the world perspectivally. Conversely, to every monad there corresponds at a given time a unique point of view which can be said to be, among other things, the representational and perspective analogue of a spatial point. $^{47}$

Dionysius Anapolitanos calls this twofold role of the monad a "spatio-temporal plenum", being simultaneously situated within a given time and place and constituting the world in its totality. ${ }^{48}$ Influential in Leibniz's theory of the monad is René Descartes' idea of intellectus, or human reason. Descartes abstracts the representation of an object "from its actuality and from its categorical 
definition". ${ }^{49}$ In other words, the understanding of the world is removed from direct experience and becomes instead an object of self-thought (cogitatio sui). From this argument we witness the beginnings of a "pure reign of consciousness" where nothing is considered before the "mind thinking itself". This idea of an independent thinking subject could be said to underlie Leibniz's monad, departing from St Augustine's embodied notion of self. What Augustine regards as a movement of re-appropriation of the mind to its origin (God) Descartes argues as being subject to the ego alone (a thinking "I" rather than an embodied "self"). 50 Hence, for Descartes God does not reside in the self, but rather transgresses it in a way that correlates to the infinite transgressing the finite.

Leibniz's cosmology could be seen as invoking a spatial analogy of Descartes' thesis of the thinking self:

The concentration of the gaze (intuitus) that assures its object the intense luminosity of rationality, by exposing it in full light, depends on the curve of the mirror. If the objectivity of knowing depends on the object, the object depends on the objectness of its being made evident, which in turn depends on the curve of cognitive thought. Curve of thought, the cogitatio implies a reflecting appropriation, the ultimate implication of which is named ego..$^{51}$

The "registering" of reasoned thought in this process is never a task empty of purpose in Descartes' philosophy. Rather, it seeks to affirm the final cause, the Supreme Being. In this telos, the curve is transgressed by the omniscient being of God in such a way that thought "thinks itself" without the need for mediate reflective action. In a similar way, Leibniz's theories of curvature and point of view cannot be localised or particularised but instead multiply infinitesimally, thereby affirming the Supreme One. Hence, Descartes' idea of God as causa sui was to find in Leibniz its most complete and authentic metaphysical expression. Jean-Luc Marion provides a succinct summary of this development:

By excessively appropriating "God" to itself through proof [reason], thought separates itself from separation, misses distance, and finds itself one morning surrounded by idols, by concepts, and by proofs, but abandoned by the divine.... Hence, in this sense, the radically atheistic pronouncement of metaphysics, that of Leibniz. ${ }^{52}$

In this pronouncement, the traditional transcendent distance separating the human from the divine realm is initially supplemented by a new immanent outlook. This outlook equates sufficient (human) reason with final (divine) reason. The result is that "Metaphysics does not attain and does not conceive the divine, the gods, and still less God, for themselves, but it meets them as if by accident, alone on a detour". ${ }^{53}$ Whilst still operating within a thoroughly theocentric worldview, Leibniz's cosmology nevertheless signals a discernible shift from the traditional hierarchical order that informed the ideas of Kircher and others in the 
seventeenth century. In place of this order, in which God's purpose is deemed a revelatory act, Leibniz conceives a providential design of the universe whose meanings lie immanently within nature itself.

Leibniz's essentially polyvalent view of the universe provides fertile ground in which to consider the nature and meaning of perspective in the Baroque:

If an observer views a certain set of ostensible bodies, their apparent shapes and sizes vary in a systematic way with the ostensible spatial relations between them and the observer's ostensible body. This may be called the "phenomenon of perspective". ${ }^{54}$

In the multiplicity of points of view, the subject is absorbed by the predicate, thereby directly challenging the Cartesian principle of cause and effect. At the same time, in place of Descartes' argument of extensa (extension), as the essence of matter, Leibniz adopts the principle of simultaneity, or the repetitive action upon a plurality of discrete substances. In advancing this principle Leibniz criticises Newton's assertion of the application of a force upon matter, arguing instead for an "ontology of force" in which substance is deemed to be intrinsically active. By adopting Aristotelian teleology as a point of reference, Leibniz asserts that "[to] grasp the nature of beings we have consequently to approach them from the point of view of their last purpose" ${ }^{55}$

The emphasis on divine purpose in the cosmic order pervades Leibniz's studies in logic, chemistry, jurisprudence and geology. It also influenced his understanding of space, in which the theme of the fold figures prominently. In his Studies in a Geometry of Situation (1679) Leibniz sought to establish a descriptive understanding of geometry that provides the basis of a universal science. In the intertwined relationships that Leibniz promulgates - between soul and body, monad and matter - geometry constitutes a metaphysical matrix of numberless points of view.

In contrast to the principle of the vacua, or void, where nature is required to "make leaps", the universe in the Leibnizian world-view is characterised by plenitude and continuity. This is highlighted in Leibniz's understanding of geometric relationships:

a given ellipse approaches a parabola as much as is wished so that the difference between ellipse and parabola becomes less than any given difference... And, as a result, all the geometric theorems which are proved for the ellipse in general can be applied to the parabola by considering it as an ellipse, one of whose foci is infinitely removed from the other, or (to avoid the term infinite) as a figure which differs from some ellipse by less than any given difference. ${ }^{56}$

By considering the world as intrinsically continuous and inter-related in all its aspects, and therefore removed from the hiatuses of practical life, Leibniz is 
opening the way to an aesthetic outlook. A leitmotiv of this outlook can be seen in the pleat "of curves and twisting surfaces". ${ }^{57}$ Arguing for a correspondence between what Deleuze calls the "pleats of matter" and the "folds in the soul", Leibniz was giving formal expression to St Augustine's notion of distentio animi:58

In the Baroque the soul entertains a complex relation with the body. Forever indissociable from the body, it discovers a vertiginous animality that gets it tangled in the pleats of matter, but also an organic or cerebral humanity ... that allows it to rise up, and that will make it ascend over all the other folds..$^{59}$

In Leibniz's cosmology mechanism and geometry were deemed one and the same, given that the purposive actions of the created world are revealed through their geometric relationships. In the curve of the soul the monad has no apertures through which things can enter and leave. Instead, simple substances change from within. Deleuze constructs an allegory of Leibniz's theory of the monad which he calls the "Baroque House":

When we learn that souls cannot be furnished with windows opening onto the outside, we must first, at the very least, include souls upstairs, reasonable ones, who have ascended to the other level ("elevation"). It is the upper floor that has no windows. It is a dark room or chamber decorated only with a stretched canvas "diversified by folds", as if it were a living dermis. Placed on the opaque canvas, these folds, cords, or springs represent an innate form of knowledge, but when solicited by matter they move into action. ${ }^{60}$

In this allegory, the upper floor resonates "as if it were a musical salon translating the visible movements below into sounds up above", an idea that is redolent of Kircher's "theatre of echoes" discussed earlier. ${ }^{61}$ Deleuze's interpretative model also alludes to Leibniz's understanding of the distended soul moving and ascending through its folds and endless pleats. This is evocative of the Baroque dome which, as we shall see in the context of the Karlskirche and Hofbibliothek in Vienna, Leibniz considered a central motif in his cosmology.

The idea of universality as a cultural, theological and political project was given intellectual grounding in the Habsburg court through the initiatives of such figures as Kircher and Leibniz. A highly influential figure in the court of Ferdinand III, Kircher was summoned to replace Johannes Kepler as court mathematician in 1634 only to subsequently accept the appointment at the Collegio Romano in Rome instead. In spite of this, the Hapsburg emperor was a generous patron to Kircher, having paid for sumptuously illustrated publications of the Jesuit's extensive and varied writings. At the same time, Leibniz's attempt to establish an academy of science in Vienna found support at the highest levels of the monarchy, prompted no doubt by the belief that this would further legitimise the status of the imperial city as a world centre of culture and scientific advance. 


\section{J. B. Fischer von Erlach}

What Leibniz promulgated in his universal calculus, and Kircher strove to achieve in his vision of a universal language, acquires architectural significance in the work of J. B. Fischer von Erlach. Whilst Leibniz advanced the principle of the universe as a continuum, whose perspective is different from different points of view, Kircher considered as a vast repository of ethnographic elements or features that reveal a universal order through collective meaning. In a similar way, Fischer regarded architectural styles as distinct - by virtue of their different cultural/ religious traditions and historical backgrounds - yet their symbolic meanings affirm a larger providential plan. By bringing contrasting heterogeneous elements together Fischer sought to create a unified whole through an "idealised synthesis of old and new" ${ }^{62}$ Whilst Alberto Pérez-Gómez is right in asserting that Fischer was probably the first "to have isolated architectural forms that possessed specific horizons of meaning", it is also the case that he was able to articulate convincingly a unified cultural/political order, perhaps the last such example in the history of European architecture. ${ }^{63}$

During his period of study in Rome Fischer came into contact with Kircher, most probably through the informal academy of the exiled Queen Christina of Sweden. It was as a result of this contact that Fischer produced some of the engravings for Kircher's numerous books. Through the Jesuit's influence Fischer developed a lifelong interest in archaeology and numismatics that was to have a profound impact on his architecture. Later, in Vienna, Fischer was to come under the spell of Leibniz, who played an important role in the conception and design of a number of key buildings by the Austrian architect, in particular the Karlskirche and Hofbibliothek.

A common and recurring theme in the ideas of Kircher and Leibniz, as already alluded to, is the cosmological significance of the dome. Whilst Kircher saw, through his geological and sonic investigations, the dome as expressive of the origins and harmony of the earth, Leibniz considered the form as emblematic of a unified and infinite cosmos. In both cases, however, the dome evinces a providential view of order since its geometry reaffirms the relationship between temporal (historical) and eternal domains. We see in Fischer's work an attempt to apply a new imperial/ political dimension to the dome through the initiatives of the Habsburg court.

An early architectural example of this understanding of the dome can be seen in Fischer's Schloss Frain in Vranov. The project entailed the remodelling of an earlier fortified family residence. Fischer designed an imposing domed space, the so-called "ancestral hall", located at the edge of a precipice, that replaced an earlier hall. Designed in the form of an oval, the dome was built without a drum. The resulting configuration could be likened to an inflated canopy that floats miraculously over the space, as if directed by some mysterious otherworldly force. The iconography of the dome, moreover, is supported by a number of key features:

The interior of the [hall] is articulated by ten deep niches containing windows or doors. Above each of these niches is an oval dormer 
window, its clear lines cutting deeply into the mass of the dome. These ten dormer windows, which are interconnected by galleries in the wall, constitute the only architectonic articulation of the dome itself. Each of the wall piers between the windows and the doors below the dome is framed by two pilasters on a high pedestal and between these are ten smaller niches containing statues of the owner of the palace and his ancestors. ${ }^{64}$

The idea of the domical space as an appropriate setting in which to represent ancestral lineage became a central theme in Fischer's last work, the Hofbibliothek, as we shall see later. Like the Schloss Frain, ancestry was given a mythological dimension in the frescoes that adorn the dome space of the Royal Library. In the case of the Schloss Frain, the frescoes portray "the genius of the Althann family appearing as Apollo on his sun chariot, surrounded by symbols of power, peace and plenty". ${ }^{65}$ The insertion of a gallery, moreover, within the thickness of the

5.6

Interior view of "ancestral hall". Schloss Frain in Vranov, Johann Bernard Fischer von Erlach

(1656-1723)

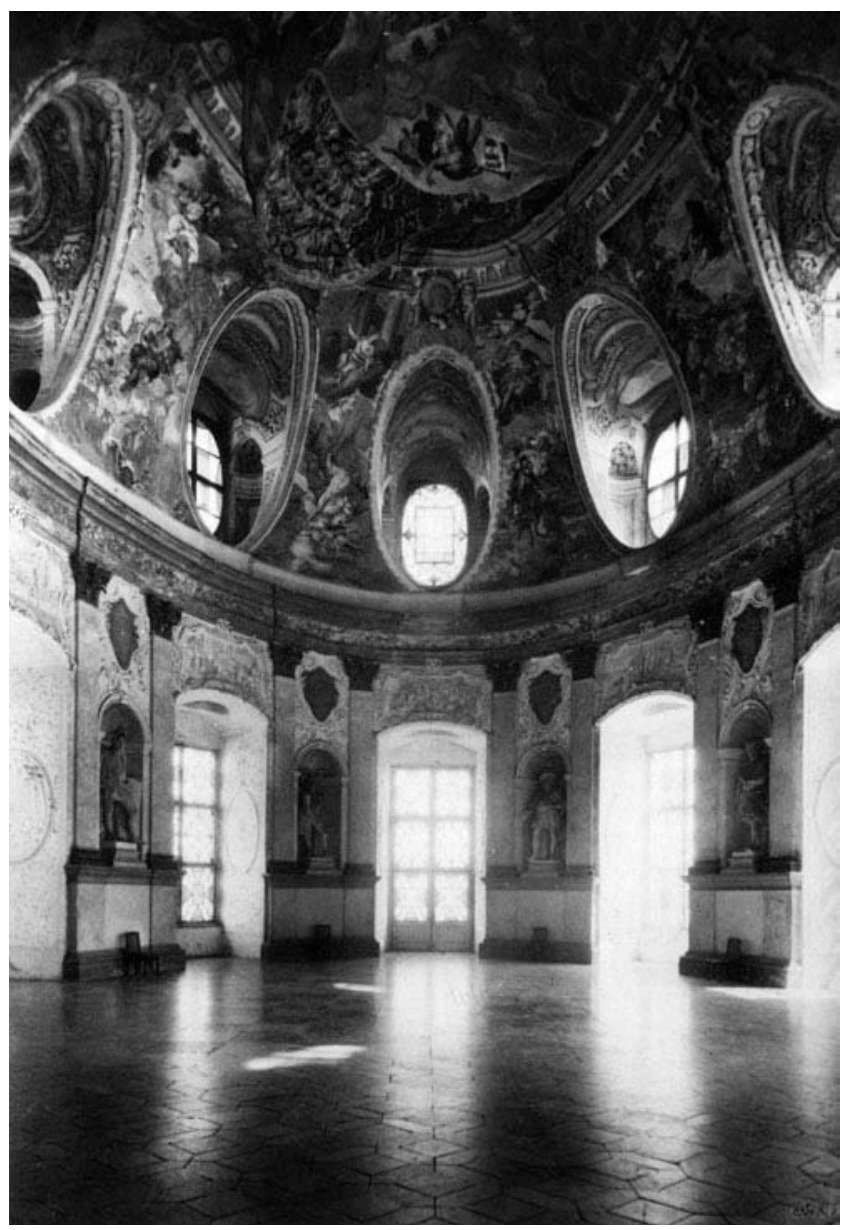


dome and revealed through oval apertures, reminds one of the Leibnizian idea of the fold as an interstitial zone replete with ontological meanings. It is as if the manifold perspectives that permeate this protean space - registered in the painted mythological scenes and ancestral allegories of the Althann family - permeate the hidden voids of the dome. What is disclosed therefore before us, in this apotheosis of the Althann family, is a cosmic order evocative of Leibniz's monad.

In addition to his prodigious architectural output Fischer is also remembered for a remarkable book, the Entwurff Einer Historischen Architectur. ${ }^{66}$ This work demonstrates Fischer's attempt to construct an encyclopaedia of world architecture. Started in 1705, at the height of Fischer's successes in Vienna, the book was not published until just before his death in 1721. Dispensing with the usual formalities of representations and descriptions of the classical orders, a radical departure in itself, Fischer instead wrote five books (chapters) on aspects of world architecture, of which the first was dedicated to the Seven Wonders of the World. Lavishly illustrated with Fischer's fantastical etchings, these architectural wonders served as a kind of kaleidoscope of a world order that the Habsburg Empire (like the Jesuit Order) sought to influence and ultimately dominate. Unusually, Fischer added an eighth wonder to his list of seven that prefaced the others. This was the Temple of Jerusalem whose reconstruction was influenced by earlier reconstructions by the Spanish Jesuit J. B. Villalpanda, friend and correspondent of Kircher. Included in his seven wonders were the Hanging Gardens of Babylon, the Pyramids, the Mausoleum at Halicarnassus and the Temple of Zeus at Olympia. These were also supported by other representations of lesser-known ancient monuments such as Mount Athos in the form of a gigantic statue, as described by Vitruvius in Book II. Fischer's "catalogue" of Western architectural wonders is complemented in Book III by descriptions and representations of the architecture of Asia, from Turkey to China and Japan.

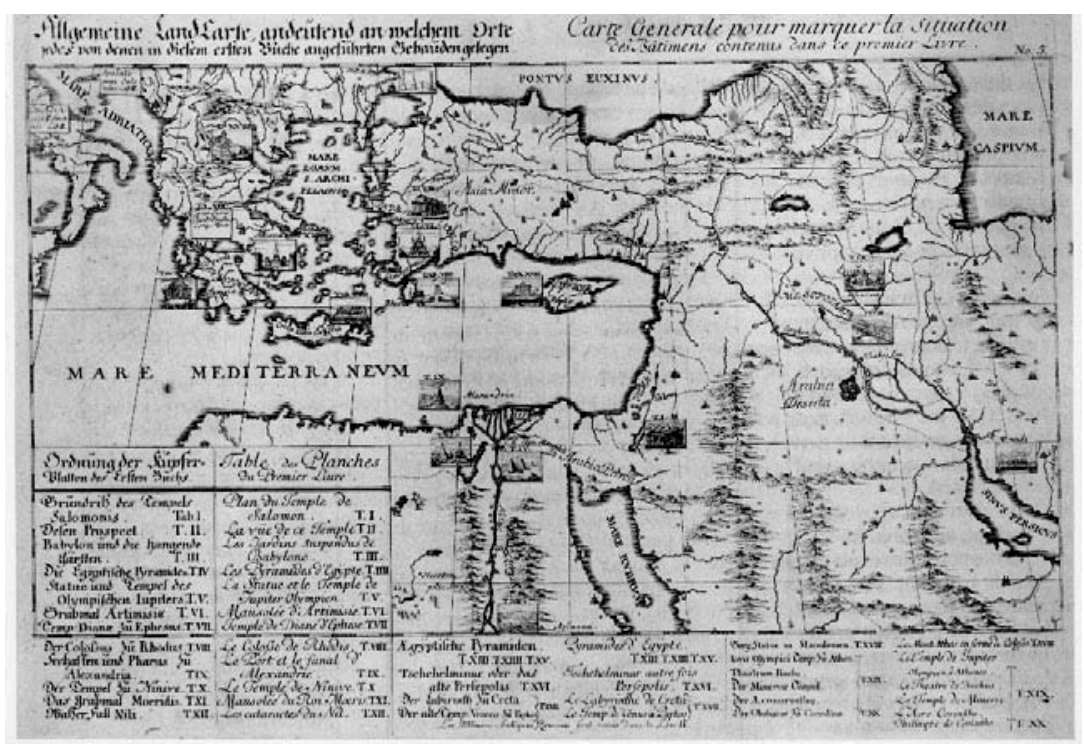

5.7

Map indicating the locations of the "wonders of the world" referred to in Book 1. These are highlighted by small tableaux on the map that refer to the larger prints in the text. Johann Bernard Fischer von Erlach (1656-1723), Entwurff einer Historischen Architectur ... (1725) 
5.8

The Temple of Solomon. Johann Bernard Fischer von Erlach (1656-1723), Entwurff einer Architectur ... (1725) Historischen

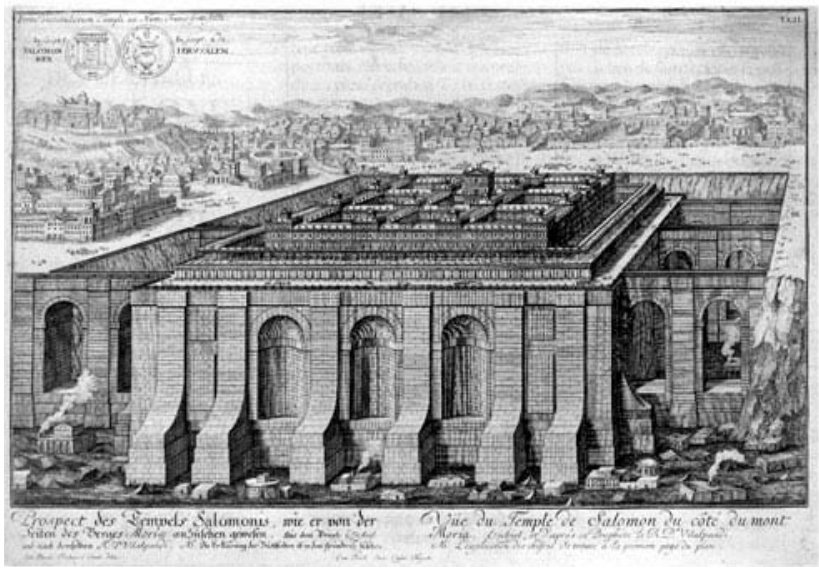

5.9

Palace at

Schönbrun

showing

architect's

deployment of

multiple

architectural

references to

create a

"universal"

architectural style.

Johann Bernard

Fischer von Erlach

(1656-1723),

Entwurff einer

Historischen

Architectur ..

(1725)

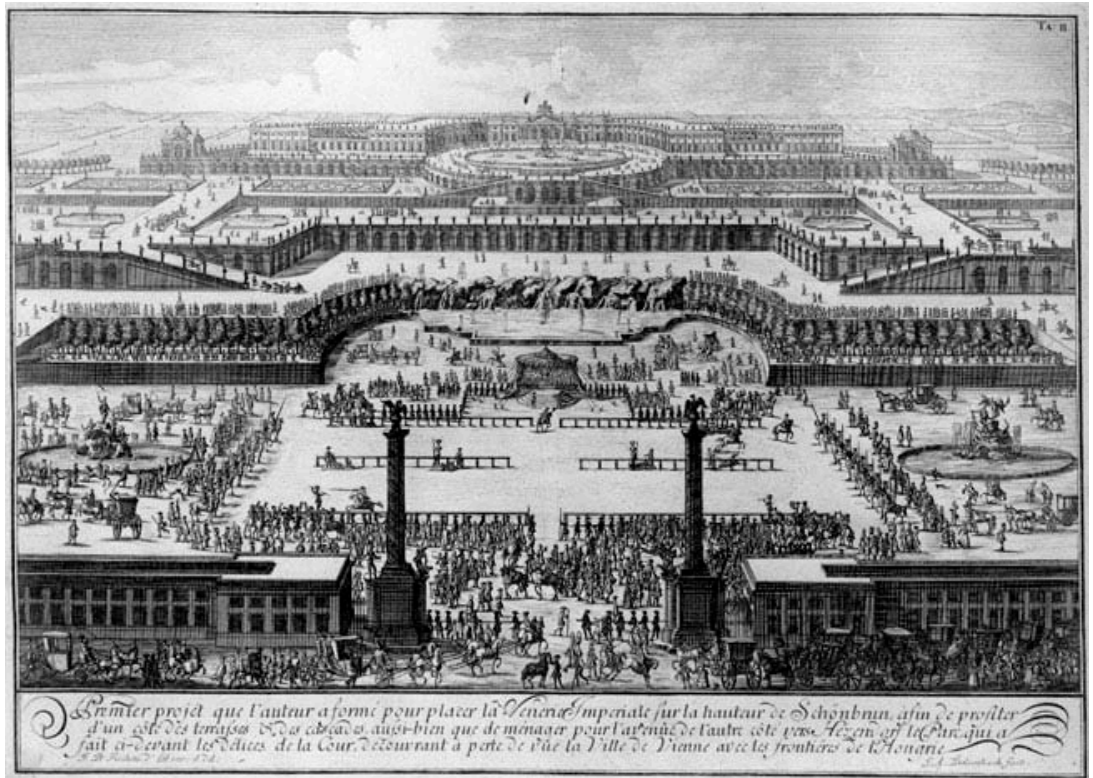

The manner in which Fischer strove to harmonise his project of an encyclopaedic knowledge of architecture, outlined in the Entwurff, with Leibniz's vision of a universal providential order, is most clearly articulated in his Karlskirche in Vienna. Forming a focus of Charles VI's imperial symbolism, the Karlskirche served a twofold function: 1) as a votive church to deliver Vienna from the plague that raged in the city in 1713 , and 2 ) as a dedicatory monument to the greatness of the Habsburg dynasty. Fischer obtained the commission following a competition. We know that Leibniz was very interested in the project, according to a letter written to the German philosopher in 1715 by Carl Gustav Heraeus, imperial antiquarian, numismatist and friend of Fischer. The letter highlights Leibniz's preference for Fischer's design which reflects the emperor's "good taste". ${ }^{67}$ 
From its principal west elevation, the building presents itself as an assembly of architectural and numismatic references that collectively demonstrate Fischer's encyclopaedic knowledge. According to Joseph Rykwert, the west façade was intended to serve as a "frontispiece", or what Hans Sedlmayr more aptly describes as a Schauseite or "display panel". ${ }^{68}$ The elements of this Schauseite can be read as "a sort of compositional, fugal counterbalance of heavily charged formal elements". ${ }^{69}$ The building is dominated by an elliptical dome set high up on a tall drum, whose arrangement of bays of double Corinthian columns and swags reminds one of the drum of St Peter's Basilica in Rome. The association continues with the side pavilions of the Karlskirche that closely follow St Peter's façade by Carlo Maderno. Echoes of other buildings, such as the Collège des Quatre Nations in Paris by le Vau, can also be traced here. ${ }^{70}$ In sharp contrast to these Renaissance/Baroque references is the distinctly antique style of the central hexastyle portico of the building, in all probability an allusion to the Temple of Jupiter and Peace in Rome. The eclectic nature of the juxtaposition of elements reinforces the idea of the building as a carefully assembled amalgam of historical references, each having its own horizon of meaning. This approach becomes most assertive with the incorporation of two tall spiral columns on either side of the central portico. Their superimposition on the west façade contributes to the pyramidal assembly of the elements that make up the elevation, delineated by the flanking pavilions and apex of the central dome. In the case of the colossal columns, the source of influence is fairly self-evident, namely the columns of Trajan and of Marcus Aurelius. But they also probably allude to the second Rome, Constantinople, given the similar addition of minarets to the city's principal church,

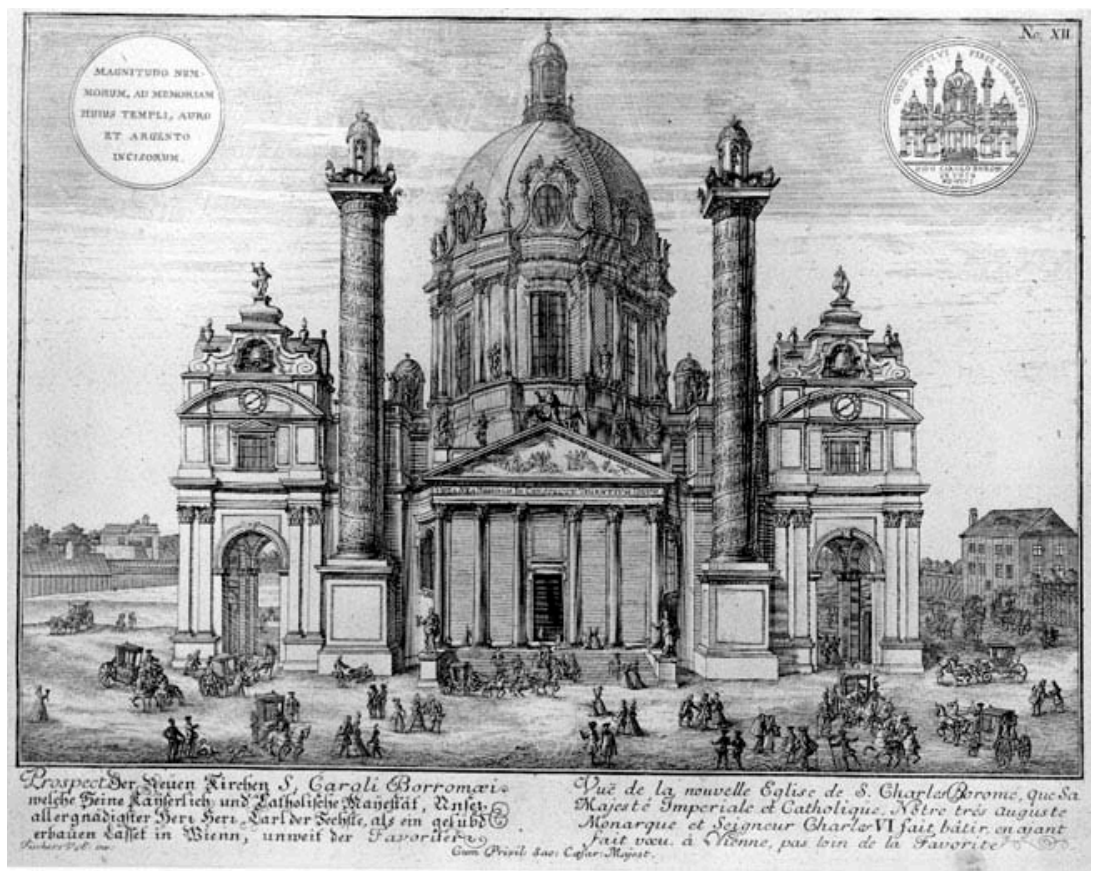

5.10

West façade of the Karlskirche. Johann Bernard Fischer von Erlach (1656-1723), Entwurff einer Historischen Architectur ... (1725) 
St Sophia, by the Ottoman rulers. ${ }^{71}$ Significantly, both the Column of Trajan and St Sophia are represented in Fischer's Entwurff. The combination of references to both Rome and Constantinople in the Karlskirche implies, as Rykwert argues, the idea of Charles VI's Vienna as the "third Rome". ${ }^{72}$

The spiral columns play a key role in the iconography of the Church. Leibniz contributed to the debate about the proposal to crown the columns with statues, as we know from a letter he wrote to Heraeus:

I should be glad to hear your opinion ... and that of Fischer, on the question as to whether it might be appropriate to pay some tribute to Saint Charlemagne and Saint Charles, Count of Flanders, both of whom are predecessors of the Emperor, the one in the Empire, the other in some of the hereditary countries. ${ }^{73}$

In this pairing of the two venerated figures of Charlemagne and the Count of Flanders, the former being Charles VI's predecessor in the imperial title and the latter his predecessor in the heritage of Spain, Leibniz was seeking to bring genealogy and geography into a unified symbolic programme. As it turned out, however, the symbolism of the columns, like the interior frescoes, adhered to the votive status of the Church by celebrating its dedicatory saint, Charles Borromeo. In so doing, the scenes of conquest and triumph of Trajan's campaign in Dacia, represented in the spiral reliefs of the emperor's column, are transcribed into scenes of the life and miracles of the venerated saint.

It is important to recognise that the two columns became the monarch's motto, or insignia, underlining the Herculean and Carolingian associations of Charles VI's rule. The associations extend still further when we consider Fischer's interest in Solomon's Temple; the two columns of the Karlskirche suggest Jachin and Boas, the two columns that stood in front of the Temple in Jerusalem. Rykwert, on the other hand, contends that the link may relate to the two spiral staircases that are concealed behind the portico. ${ }^{74}$

When one attempts to summarise the associations represented on the west façade of the building - of Caesar and Augustus (in their indirect affiliations with the Temple of Peace); Solomon and David (founders of the Temple of Jerusalem); Constantine (founder of St Peter's); and finally of Justinian (founder of St Sophia) - we begin to recognise the extent to which Fischer sought to re-affirm the universal status of Charles VI's rule. What is presented externally as a numismatic exercise, in the juxtaposition of distinct iconic trophies and inscriptive references, is transcribed internally into the synthesising effects of the vast elliptical domed space. The influences of Kircher and Leibniz are clearly felt in this juxtaposition; Kircher in the reading of the façade as a kind of assembly of hieroglyphs awaiting translation, and Leibniz in the unfolding of the main domical interior and adjacent spaces as a perspectival extension that conceals, as well as reveals, their spatial and symbolic qualities.

Unlike the churches in Baroque Rome the articulation of spaces in the Karlskirche, and later Hofbibliothek as we shall see below, were motivated by 
distinct programmatic - one might say ideological - intentions. These need to be seen in the context of the Baroque notion of the concetto, which Vesely describes as "the conceptual content or program of a particular work of art".$^{75}$ In the case of Viennese Baroque, the concetto is formulated around a particular historical perspective of empire, in which the multitude of different motifs and symbolic references are brought to a level of synthesis through the reciprocal relationship between image and text. This synthesis, however, is instigated by a propensity towards an internalised view of power that in some instances could be said to anticipate a nationalist outlook: "The Habsburgs were not a consciously and consequentially Germanizing power . . . but their measures were dictated by an intent of unification and universalism of their empire. Their essential aim was Hausmacht [internal power]" ${ }^{76}$

Hence, by bringing together different horizons of meaning into a single unifying principle, the architecture of Fischer von Erlach reflects a particular ideological outlook that drew meaning from an inward - rather than an outward - view of the world. The ideas of Leibniz clearly played a key role in articulating this interrelationship between universality and autonomy, a point that is especially evident in the Hofbibliothek.

\section{Hofbibliothek}

Perhaps the most important architectural commission, which advanced Leibniz's model of a universal order, is Fischer von Erlach's Hofbibliothek in Vienna. Implicit in the project was the ambition to represent the ideological initiatives of the monarch by cultivating an inter-relation between epistemological and ancestral symbolism. This inter-relation finds expression in the figure of the emperor espousing all knowledge through the multiple perspectives of his empire. Fischer's design for the Royal Library was probably influenced by the Wolfenbuttel Library, designed by Hermann Korb and also influenced by Leibniz's philosophy. In

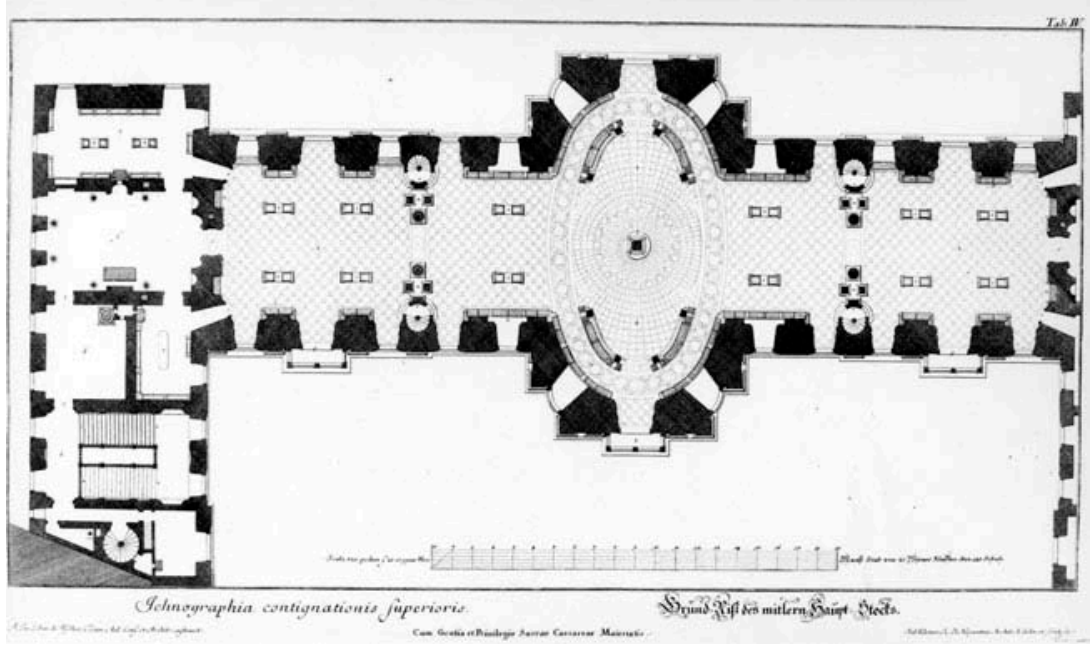

5.11

Salomon Kleiner (eighteenth century), Plan of the Hofbibliothek by J. B. Fischer von Erlach (1733) 
this building, which went through many design changes, the interior is in the form of an oval rotunda with two inner galleries and a lofty roof structure crowned by a heavenly globe. According to Hans Sedlmayr, the globe was an idea of Leibniz that was later to be used at the Hofbibliothek. ${ }^{77}$ Its deployment as an integral part of the embellishments of the façade of the Royal Library attests to the continuing influence of Leibniz's world-view on the architecture of the period.

An important innovation in the design of the Wolfenbuttel Library was the recognition of the potential architectonic qualities of open book-shelves. Traditionally housed in cabinets, the assembly and display of books was a new innovation, that in the case of the Wolfenbuttel Library gives the impression of dense structural walls doubling up as vast repositories of knowledge. This dual function, as we shall see in the context of the Hofbibliothek, was an effective visual metaphor for advancing Leibniz's theory of unity in multiplicity.

Like the Wolfenbuttel, the Hofbibliothek is dominated by a central oval space, only in this case it is flanked on either side by two wings. Seen from the outside, the oval space projects into the cour d'honneur and is contained within a block-like mass. The façade of this central block, which reiterates the flanking wings, comprises battered rusticated walls and an arrangement of pilasters at piano-nobile level. The building finally terminates with a mansard roof that frames the two globes positioned at roof-level. Supported by mythological figures, these globes celebrate the earthly and heavenly realms respectively. Presenting the library to the outside world, this symmetrical arrangement of terrestrial and celestial motifs could be interpreted as demonstrating a mastery of knowledge rather than simply documenting its servility with respect to a higher divine order.

The role of these motifs in the general iconography of the library should be considered in the context of Leibniz's epistemology. He states: "When a truth is necessary, the reason for it can be found through analysis, that is, by resolving it into simple ideas and truths until one comes to primitives. "78 From this point, "primitives", or essential truths, are assigned certain distinct qualities. Like Kircher, Leibniz attempted to devise a syntax of signs that, whilst initially based on the principle of distinct horizons of meaning, could lead to a new universal language. For Leibniz, the library served as the "printed archive of all humanly and worldly occurrences/knowledge".$^{79}$ In other words, it represented the sum of all human knowledge and therefore demanded universal status.

5.12

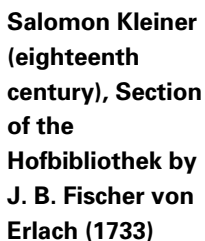

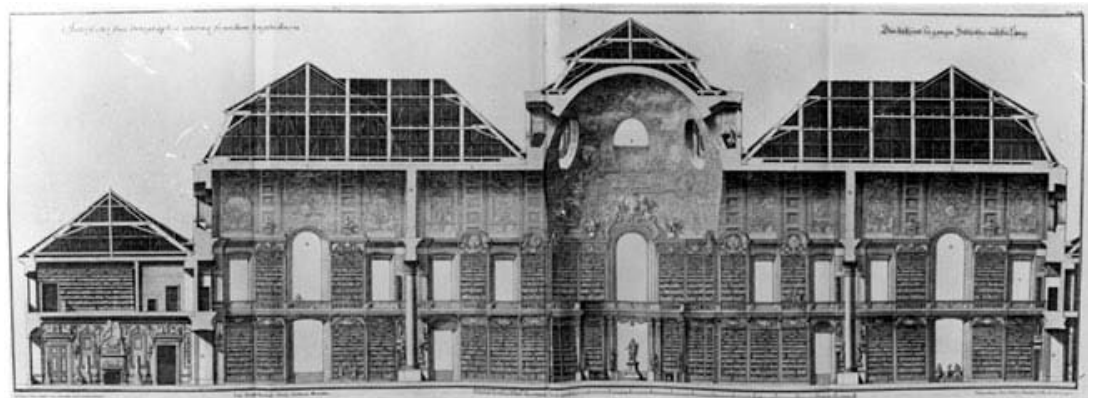




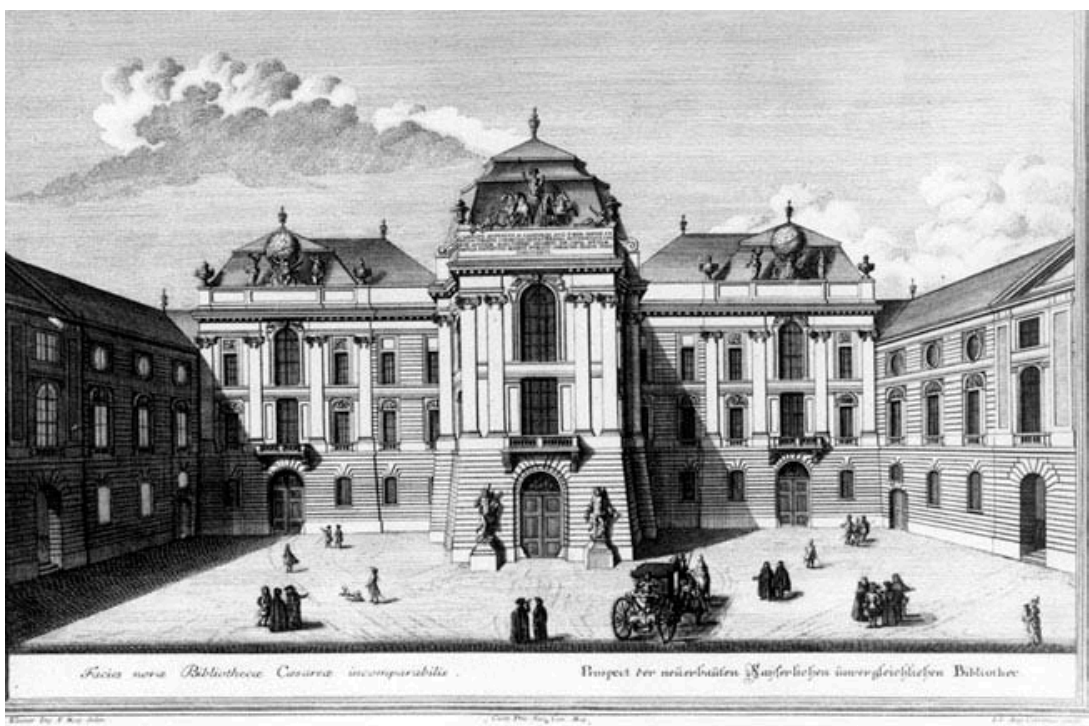

It would seem that Fischer intended to express a bifurcation between the experience of interior space and the appearance of the exterior façade. Fischer deliberately designed the main façade so that it would conceal the internal articulation of spaces. Indeed, the window rhythm of the external fenestration conflicts with the interior arrangement, given that some of the windows are blocked by bookshelves. Likewise, a horizontal moulding extending along the façade, that implies a second floor, is countered by the superimposition of a giant order of pilasters. Hence, the somewhat orderly and conventional tableau of the façade and roof - redolent of early French Classicism - serves merely as a foil to the layering and iconographic richness of the interior.

With these expectations the visitor enters the building via the labyrinthine spaces of the side wing. The way to the main hall is not celebrated as a formal route but is rather structured as a subordinate approach that distracts the viewer's attention. The visitor is finally oriented to the main axis of the library hall where the full effect of the sequence of spaces comes into view. Two features of the library hall inform the experience of this procession. The first is the effect of depth created by the perspective diminution of the walls of books, columns, arches and balustrades. The second concerns the disruption of this unified arrangement by the gradual disclosure of other peripheral spaces not initially perceived at the threshold to the library. In the process of moving through the spaces the full drama of the interior unfolds and culminates in the central oval domed hall. In the experiential shift from the first impressions of unified perspective depth to the perambulatory disclosure of the constellation of spaces that make up the interior of the Hofbibliothek, we are encouraged to experience the library as if it were a microcosm of a world revealed through the acquisition of human knowledge.

The introverted character of the library is underlined by the relatively small window openings that contain deep reveals. Rather than opening up views
5.13

Salomon Kleiner (eighteenth century), Main façade of the Hofbibliothek by J. B. Fischer von Erlach (1733) 
5.14

Hofbibliothek,

Vienna (1722),

Johann Bernard

Fischer von Erlach

(1656-1723). View

of the interior

along main axis of

building towards

the central

domical hall

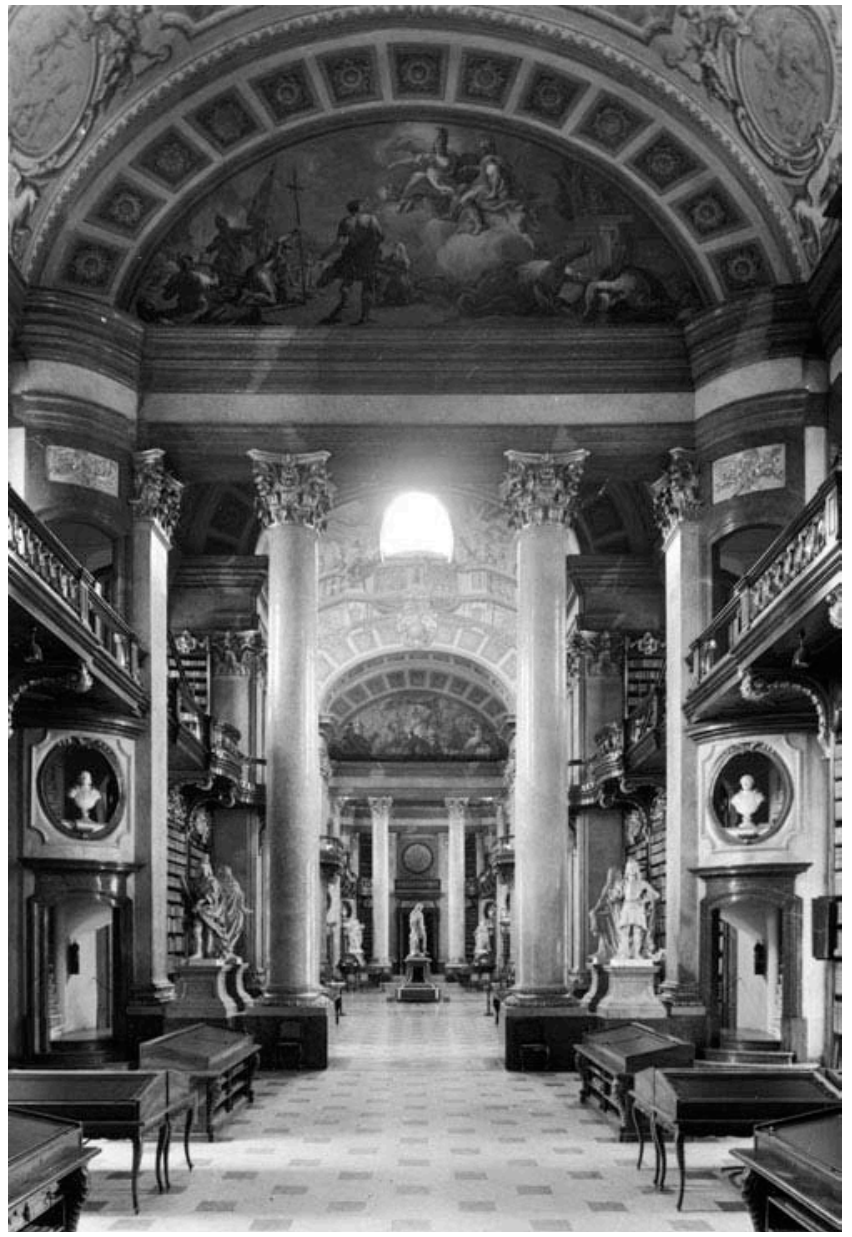

of the outside world these apertures allow incoming light to illuminate the walls of books. Furthermore, the careful positioning of columns, close to concealed windows, ensures they function as effective reflectors of natural light within the space. As Sedlmayr points out, the illusory effect of the column as a source of light seems to take precedence over its function as a structural element. ${ }^{80}$ This is reinforced by the fact that the pairs of monumental columns that frame either side of the main oval space are positioned much closer together than structurally needed. The effect reinforces their emblematic role as the Pillars of Hercules, the motto of Charles VI referred to earlier in the context of the Karlskirche. Supporting both wings of the hall, the paired columns formed a central part of the rhetoric of the space by reinforcing the notion of the monarch bearing the weight of responsibility of imperial rule. At the same time the role of the columns as reflectors of natural light implies the idea of the emperor as the light of knowledge. The imperial symbolism is further underlined by the associations of the two wings of the library; the "Wing of War", through which one enters, and the "Wing of Peace", 
which is attached to the adjoining Imperial Palace. Both are brought into dialogue in the central oval space that becomes a place of mediation. The symbolism of both wings could be said to iterate the representations of earthly and heavenly globes on the façade.

Standing between the paired columns, the visitor encounters for the first time the entire space of the dome. At this point, the complete iconographic programme of the library is revealed. This initially finds expression in the monumental statue of Charles VI as Hercules, located in the centre of the oval space and surrounded by statues of his ancestors. The imperial ancestral lineage, that this arrangement reveals, culminates in the dome fresco in which the emperor is glorified as a god of peace and war. In these scenes of military victories and of the arts and sciences, the imperial iconography performs a metaphorical function by conveying the idea of knowledge as a task requiring both action and intellectual insight. Hence, through the actions of the emperor, all human knowledge is brought together under the patronage of empire. As we have already seen in the

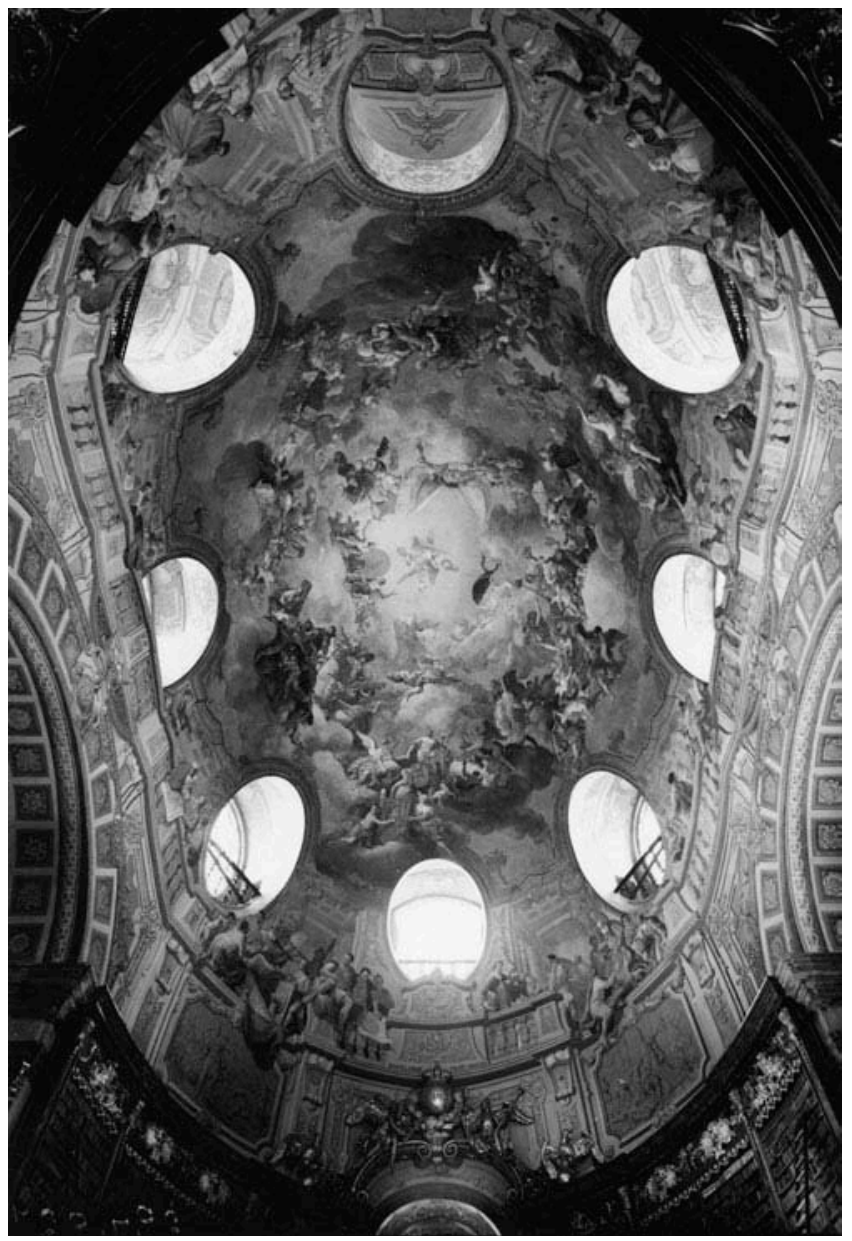

5.15

Hofbibliothek,

Vienna (1722),

Johann Bernard

Fischer von

Erlach

(1656-1723).

View of the

frescoed dome

of the central

hall 
context of the Karlskirche, the significance of the oval in the iconography of the Habsburg Empire was paramount in this context. In serving as a key building in the representation of imperial power, the Hofbibliothek also provided a symbolic framework for communicating a cosmology. Both aspects of the symbolism were of course inter-related given the belief, advanced by Leibniz and others, that cosmic events and human actions were entwined through the "world soul".

As I have already indicated, Leibniz was closely involved in the design of the Hofbibliothek, which he considered an expression of his project of universality. This involvement is most telling in the design of the oval space of the library. The idea of a bifurcation between interior space and exterior façade, between the dynamic and elaborate Baroque interior and the reserved - almost laconic - French classical exterior, reveals more complex symbolic intentions. In particular, the sectional profile of the central domical space of the library reveals the duality of Fischer's architecture as it is defined by exterior block and interior oval. The adjustment of this in-between space is presented as a "zone of action", by which I mean a territory that is not deemed static and fixed but rather one subject to negotiation through its function as a mediating (interstitial) space.

In the design of the dome Fischer conceived the idea of an internal passage around the perimeter of the structure that, like the Schloss Frain before it, could provide access to the domical space. Unfortunately, no drawings or sketches by Fischer remain of the library. The only plans and sections that we have of the building, executed by Salomon Kleiner in 1733, do not fully represent Fischer's ideas or the building as completed. The interplay between actual and illusory space in the dome, in the relation between balconies, book-shelves, windows and frescoes, provokes a constant re-assessment of the content of the enclosing wall. Recessed into the wall are vertical book-shelves, and an adjoining balcony below, that serve in metaphorical terms as the principal supports to the illusory representation in the dome above; the fresco seems to emerge seamlessly from the dense assembly of books below. In this fresco a second gallery is represented as if forming an integral part of the internal arrangement of elements, and thereby creating a direct correspondence to the actual gallery below. The painted balcony, however, is animated by the depiction of figures in the act of discoursing and contemplating.

Those who were privileged to ascend to the dome via the interstitial passageway would not only have a birds-eye view of the oval space below but would also inadvertently participate in the visual drama of the dome's iconography. This is highlighted by the fact that the sunlight from the high level oval windows (through which the passageway passes) would reveal the visitor as a moving silhouette whose juxtaposition with the surrounding frescoes of illustrious personages would further blur distinctions between real and illusory elements. The resulting illusion leads to a delusion in the hollowness of the wall; the fresco is animated by the moving shadows in the openings. Hence, from the perspective of the observer at floor level, the visitor would appear to be absorbed into the surrounding painted scenes. Gottfried Boehm describes this phenomenon in the following terms: 
The possibility of pictorial illusion is achieved through the exchange of natural and artistic worldviews. The natural way of seeing is confronted by a multitude of things which consequently overwhelms it. The original space-in-between [Anschauungsraum] appears to engage with the spectator. Reality and representation are concurrent and therefore can no longer be visually differentiated. ${ }^{81}$

In the context of the Hofbibliothek, the synthesis of the real and the illusory, by which the elevated spectator participates in the scene of the emperor's apotheosis, provides the mechanism for a perceptual passage from earthly matters to the heavenly realm. The position of the balcony/passageway in the dome seems aloof from the places of reading at ground level. To what extent does the inclusion of this vantage-point compromise the setting of learning, in which scholars participate? We know that access to the dome gallery was originally only via one of the side-wings of the library, but from which side is uncertain. ${ }^{82}$ During the mideighteenth century, the library underwent partial reconstruction due to structural problems and it was during this time that a second access point was incorporated. We can only speculate who was allowed to observe the library from this elevated vantage point, and indeed if it was reserved for the emperor alone. If this was the case then the original access to the gallery would probably have been from the Wing of Peace. On the other hand, it may be that the gallery was never intended to be occupied as such but rather served as a symbolic domain in which an imaginary reciprocation between observer and observed takes place; just as light enters the space through the oval windows so the view of the observer takes the same route and is always implicitly understood by the visitor at ground level.

It would be tempting to compare this reciprocity to Michel Foucault's idea of the gaze as a form of visual control. In the Hofbibliothek the visitor imagines her- or himself in the same spot as the privileged observer, thereby reinforcing the experience of power manifested at the moment of the gaze. This comparison, however, seems inappropriate since it assumes a more emphatically instrumental situation than actually existed in the late Baroque. A more helpful source might be Leibniz's notion of multiple perspectives in which each point of view embodies the world as such and consequently takes precedence over all the others. In this cosmology, as we have seen, points of view are deemed "totalisations" of the world, thereby overcoming the difficulties implicit in relativism. Prior to the advent of the panopticon, in the eighteenth century, the notion of a privileged view-point, as we saw in the case of the so-called Papal Window in Chapter 4, was always mediated through a pre-ordained divine authority. The case of the Hofbibliothek could be seen as signalling a critical turning point in this tradition, given that it both acknowledges implicitly a transcendent world-view (through the hierarchy of spaces) and at the same time opens the way to an aesthetic view of representation in the manipulation of the space for the sake of visual effect. ${ }^{83}$

The spaces of the library are arranged and articulated in such a way as to give the impression of endless depth: this begins in the ancestral iconography revealed at ground level and culminates in the cosmic space of Apollo in the 
dome. At the interface between these two conditions is represented the living emperor whose elevated authority provides the socio-political framework for achieving universal knowledge. Hence, the assortment of iconographic motifs and architectural elements which make up the Hofbibliothek is intended to "propagate" the glory and providential power of the Habsburg Empire.

As both an "in-between" and a culminating space, the oval hall attests the synthesising effects of imperial rule, where interior and exterior, temporal and eternal, solid and void and so on are brought into a unified whole through the agency of distended space. To this extent, the dome serves as a metaphorical "instrument" for revealing the latent cosmic order and its universal principles. Given this disclosure, it seems almost irrefutable that Leibniz's idea of the monad played a part in Fischer's design. Just as Fischer's work emphasises a new historicised perspective of the world so Leibniz's cosmology takes the notion of multiple points of view as a generative metaphysical framework for developing a model of a universal perspective horizon.

Drawing upon the ideas of Kircher and Leibniz, Fischer strove to give spatial and temporal definition to the universal claims of imperial ideology; the last time such claims were convincingly demonstrated and represented in Europe before the onset of nationhood.

\section{Peter Zumthor's St Benedict's Church}

In his Thinking Architecture, Peter Zumthor summarises architecture in the following terms:

In architecture, there are two basic possibilities of spatial composition: the closed architectural body which isolates space within itself, and the open body which embraces an area of space that is connected with the endless continuum. The extension of space can be made visible through bodies such as slabs or poles placed freely or in rows in the spatial expanse of a room ... when we, as architects, are concerned with space, we are concerned with but a tiny part of the infinity that surrounds the earth, and yet each and every building marks a unique place in this infinity ... [Buildings] embrace the mysterious void called space in a special way and make it vibrate. ${ }^{84}$

These ideas have an uncanny similarity to Leibniz's model of the universe outlined earlier. Zumthor's notion of the "closed architectural body" which "isolates space within itself" in the "endless continuum", coupled with his assertion that buildings "vibrate" space, finds echoes of Leibniz's theory of the monad. The similarity raises many questions about Zumthor's approach to architecture. In particular, should we consider this affinity with Leibnizian ideas as indicative of a more general interest in Baroque notions of space or does it suggest a particular phenomenological outlook that transcends historical specificity?

We will examine this issue by referring to a small project designed by Zumthor in Switzerland between 1987 and 1988. Called the Caplutta Sogn 
Benedetg (or Church of St Benedict), the building is situated high up on a slope overlooking a hamlet - also called Sogn Benedetg - and a valley beyond. It is accessed by a small windy path that ascends to the entrance. The east end of the church dominates the hamlet below; from this aspect the building appears to emerge out of the ground in the form of a lofty cylindrical tower. Its stern - almost forbidding - appearance, expressed by its imposing height and isolation from the surrounding landscape, gives the impression of a surveillance tower rather than a church. By contrast, the curve of the building tapers along the sloping south and north aspects of the site. This anchors the church to the hillside as if embedding it in the ground.

From the south-west aspect - which is also the entrance side of the building - the church appears to nestle comfortably into the valley, merging with the dramatic panorama of mountains visible to the east. This impression is reinforced by the way in which the shallow pitch of the roof seems to re-iterate the shape of the distant valley beyond, as if drawing the landscape into the ambit of the architectural enclosure. In characteristically Heideggerian fashion, Zumthor seems to have "found" the right place for the church in such a way that its location cannot be altered or disturbed. By articulating a perspectival relationship between local setting and distant horizon, the south-west panoramic aspect of the

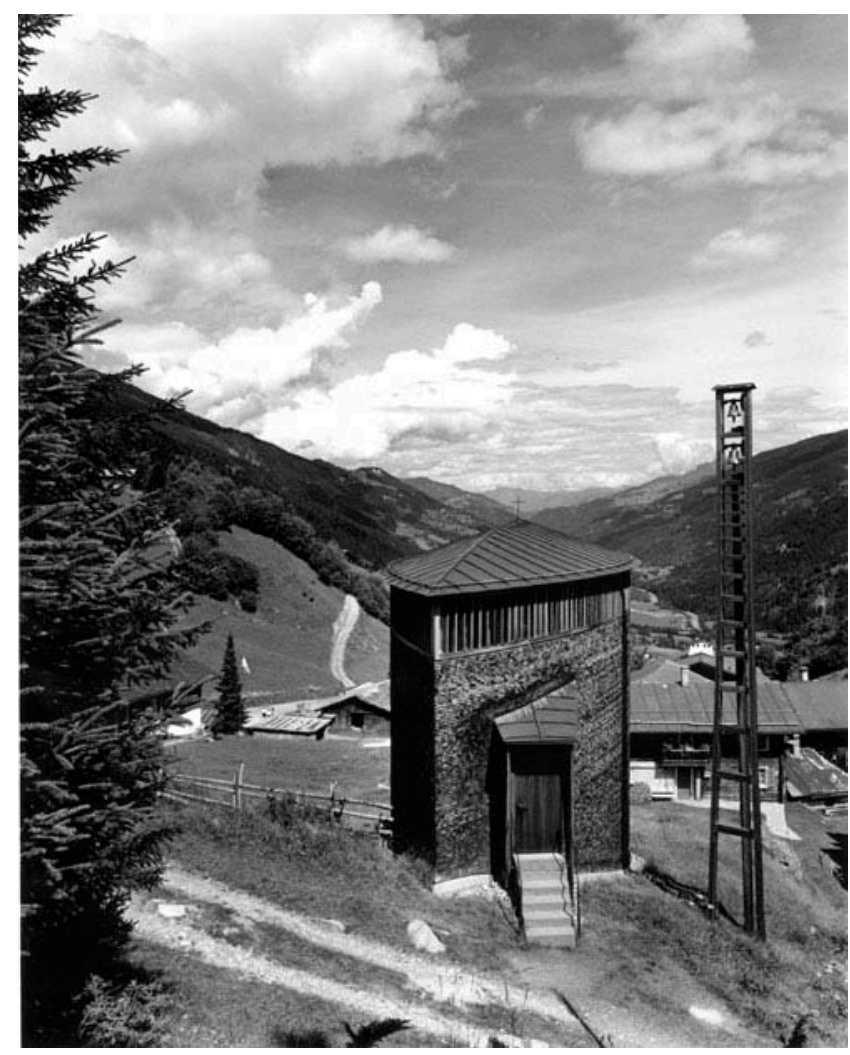

5.16

Caplutta Sogn

Benedetg (St

Benedict's

Church) 1985-88,

Peter Zumthor.

View of church

from the west

showing

panoramic views

of the valley and

mountains

beyond 
5.17

Caplutta Sogn Benedetg (St Benedict's Church) 1985-88, Peter Zumthor. View of church from the east showing its cylindrical appearance

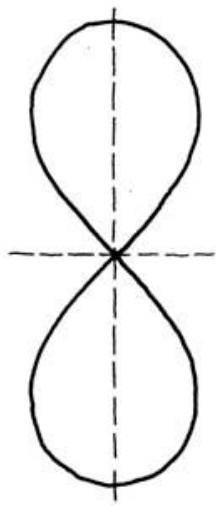

5.18

Geometric form of the Lemniscate indicating lines of symmetry

\subsection{9}

Caplutta Sogn Benedetg (St Benedict's Church) 1985-88. Plan showing relation between entrance (1) and religious icon (2) and altar (3). Drawn by author after Zumthor to a leaf.

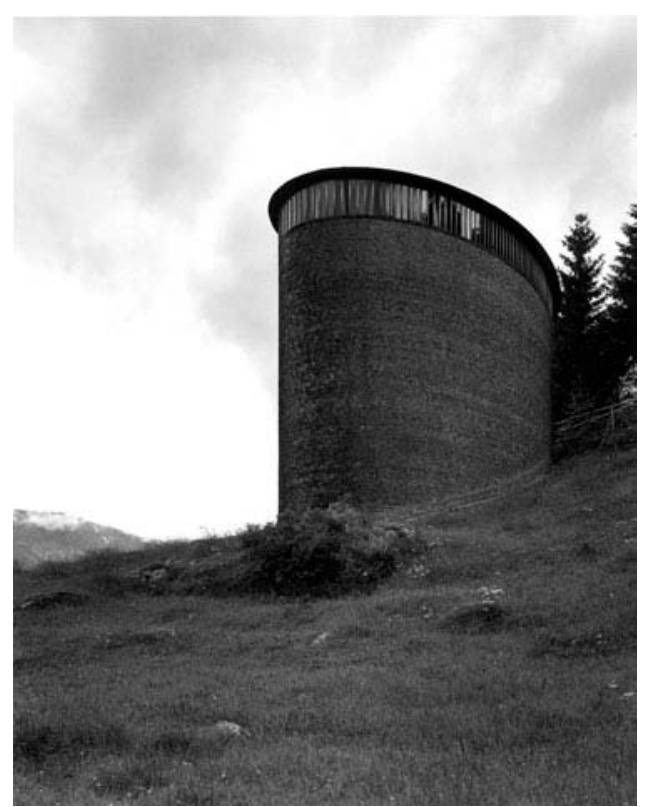

building - along the approaching path - provides a powerful prelude to the intimate and introverted space of the interior.

The very different impressions of the church, as viewed from different aspects, highlight an unorthodox geometrical configuration. Indeed, the form of the building appears to change progressively as one moves around it: from its aloof cylindrical form on the east side, the building takes on the appearance of an oval configuration on the extended north and south sloping sides and finally tapers to a keel-like termination on the west side. A glimpse at the plan of the building, which is in the form of a half lemniscate, explains this strange metamorphosis of geometries. Derived from the Latin lemniscus - meaning "pendant ribbon" - the lemniscate is an algebraic curve configured as an " 8 ", whose subdivision along its horizontal line of symmetry creates a hybrid geometric form that could be likened

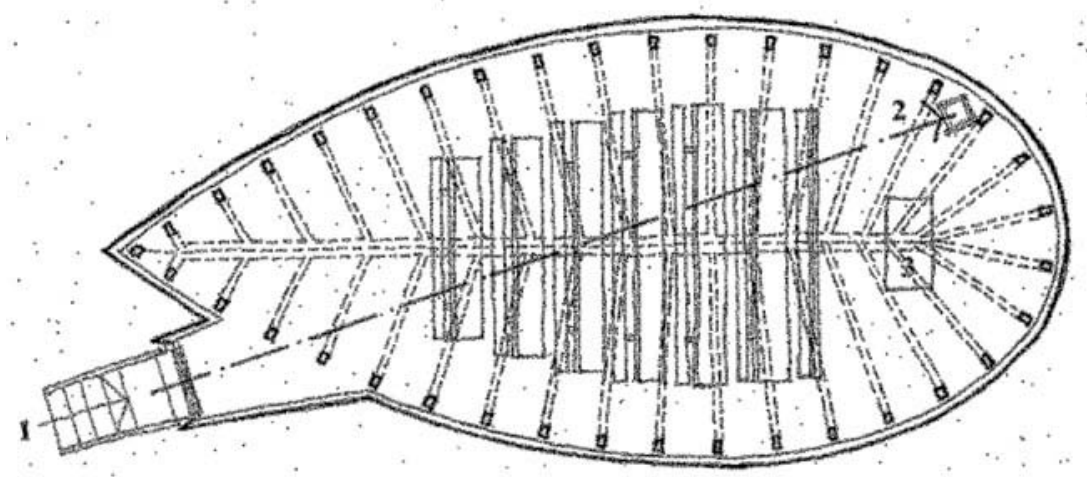


The choice of geometry is revealing since it tells us something about the underlying symbolic intentions of the building, even if these were not perhaps stated explicitly. The term "lemniscate" was first coined by Jakob Bernoulli, a contemporary of - and correspondent with - Leibniz. Published in Acta Eruditorum of 1694, Bernoulli's investigations of the lemniscate, and other complex geometric curves, informed his own work on the infinitesimal calculus. At the time Bernoulli was unaware of the "genealogy" of the lamniscate which had been earlier explored by another contemporary, Giovani Domenico Cassini, in 1680. Essentially, the lemniscate is a polar curve - indeed a special form of oval - that served as an important geometric symbol of the infinitesimal calculus. ${ }^{85}$ In one sense, it could be considered to be an appropriate "emblem" of Leibniz's theory of an interdependent and continuous universe.

Given this historical background, and Zumthor's particular phenomenological understanding of architecture, it would seem reasonable to assume that the decision to adopt a half lemniscate in the design of the Church of St Benedict was motivated by more than simply aesthetic concerns. Its deployment suggests, at least initially, a desire to bring into dialogue the metaphysical and abstract properties of geometry - convergence/divergence, curvature/tangent, inflection/alignment and so on - with the physical conditions of the topography of the site; the latter visually apprehended in the relation between proximate terrain and distant horizon. More critically, the task could be described in phenomenological terms as an attempt to reconcile "reason" with the "path", by which the rational processes that underlie Leibnizian cosmology, and are exemplified in the lemniscate, are brought to the level of direct experience through the given conditions of the ground embodied in the path that leads from the expanse of the landscape to the inner sanctum of the church.

This dialogue between path and reason, between situated experience and the structures of logical argument, forms an underlying theme of a recent book by Renato Cristin that examines the relation between the philosophy of Leibniz and the thought of Heidegger. ${ }^{86}$ What Cristin argues as a disputatious dialogue between Leibniz's defence of being in the unity of monadology and Heidegger's desire to preserve the "sign" of reason through meditative thought, could be said to take on architectural expression in Zumthor's Sogn Benedetg.

We are given a sense of this relationship between the universal and the particular in the construction and material properties of the building, as Zumthor describes:

The main visual characteristic of the many villages in Surselva (the region in which Sogn Benedetg lies) is the particular tension between the architecture of the church and the traditional forms of the secular buildings - the white stone church in a style common the world over, usually basically Baroque, radiates against the dark wooden farm buildings, whose forms are rooted in the regional vernacular. ${ }^{87}$

Zumthor's response to this contrast partly entailed cultivating a dialogue between agrarian architecture and the Baroque churches of the region, the former firmly 
rooted in the local vernacular and the latter derived from a "standard" of religious space. Internally, the Church of St Benedict recalls, as Zumthor affirms, the local churches of Disla or Vattiz. But externally, the building departs from the stone and plaster construction of its forbears, adopting instead a timber frame with wood shingle cladding. ${ }^{88}$ This material gradually darkens in the sunlight, resulting in a black finish on the south side and a silver-grey on the north. The subtle tonal changes to the cladding reinforce the transformative nature of the building's geometry.

The interplay between material, form, geometry and topography creates a rich architectural landscape in the Church of St Benedict. Unlike, however, the more complex - and explicit - articulation of interstitial space in the architecture of Fischer's Hofbibliothek, through the physical and metaphorical interplay between real and illusory space in the central domical space, the combined effects of the elusive form and enigmatic qualities of the construction and materiality in Zumthor's church compel us to seek insight into its hidden meanings by direct experience.

Positioned eccentrically on one side of the line of symmetry of the halflemniscate plan of the church, and protruding from the curved envelope on the south-west aspect, is the entrance porch. In contrast to the earlier ascent to the church, along the path from the hamlet below, the final approach to the entrance threshold entails a gradual descent towards three concrete steps that lead to the door. Projecting from the curved exterior wall the steps and outside landing are covered by a modest porch. Ascending these steps the visitor leaves behind the terra-firma of the surrounding landscape. The bifurcation between exterior space and interior volume is achieved in part by the location of timber columns that partly obstruct the entrance. These form part of a ring of thirty-seven columns, evenly spaced, that reiterate the footprint of the half-lemniscate enclosure. In contrast to the shingle-clad exterior, which responds to the changing conditions of the natural environment through the effects of weathering, the interior reveals a world where time seems to stand still. The separation between both worlds is expressed in the relentless procession of the timber columns. These elements are detached from the surrounding curved wall, whilst at the same time providing structural support to the enclosure; regularly spaced metal ties anchor the exterior wall to the columns. Like an awning stretched over a frame, the columns appear to give shape to the building envelope.

Once beyond the screen of columns at the entrance, a small religious icon comes into view located at the east end of the church, and roughly aligned with the asymmetrical axis of the entrance porch. This small and intricate Byzantine painting is set within a deep wooden frame and supported on a delicate freestanding podium. This initial orientation, however, is disrupted by the rows of pews that cut across the main body of the church and face the east end. The compact arrangement of these elements is reinforced by the way in which the raised pew rails seem to align with the peripheral columns, thereby giving the impression of the curved space as a series of "sliced" zones. This lateral sectioning of interior volume is reinforced by the absence of a central nave or aisle; 


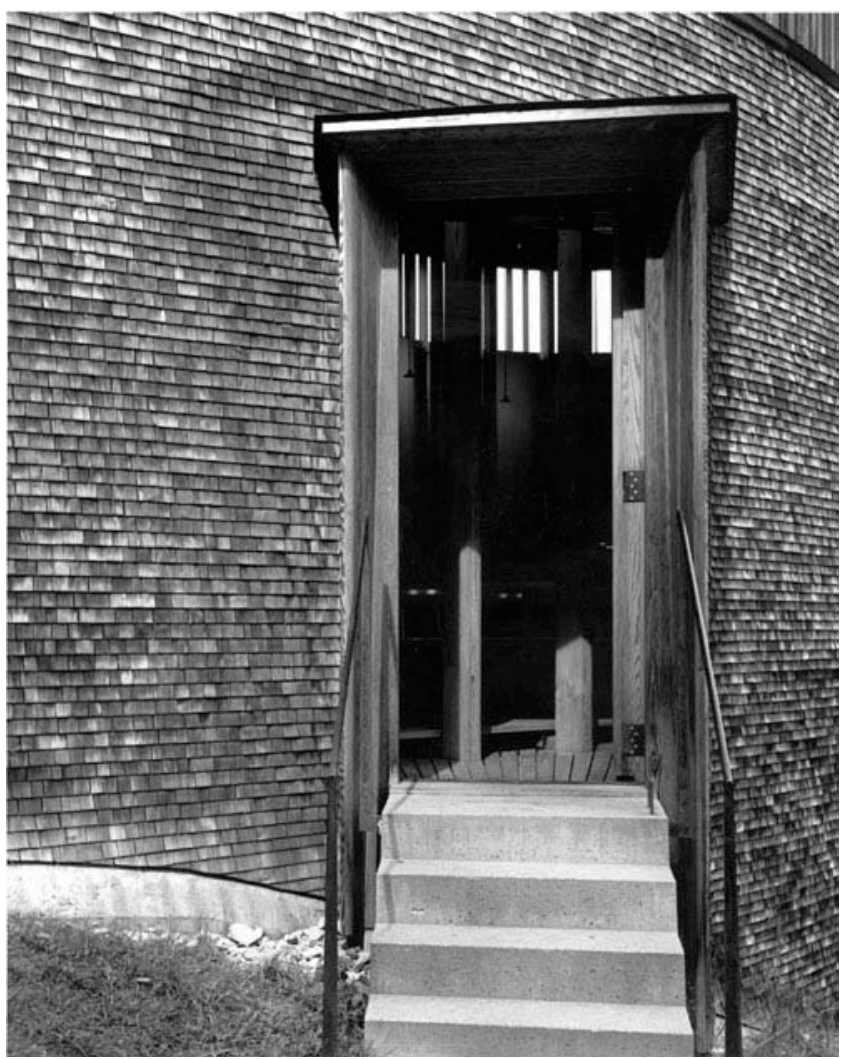

5.20

Caplutta Sogn

Benedetg (St

Benedict's

Church) 1985-88,

Peter Zumthor.

Exterior view of

entrance

showing

perimeter

columns

access to the pews is by way of peripheral aisles that follow the curve of the building enclosure.

The deliberate suppression of a prominent religious focus at the east end means that more sustained attention is given to the enveloping wall and supporting procession of columns. This is further underscored by the absence of a central (axial) processional route to the altar: the visitor, like the attending priest, is compelled to walk along the peripheral aisles that follow the curve of the surrounding "distended" wall. In this eccentric movement, both human body and architectural body are drawn into a common spatial relationship that takes on the role of an imagined interstitial space. This could be compared to the gallery in the central domical hall of Fischer's Hofbibliothek, only in the case of Zumthor's church this mediating space constitutes the principal generator of the interior open to collective human involvement - rather than a distant spectacle for privileged access.

The disengaged columns in the Caplutta Sogn Benedetg also provide support to the roof which, as Zumthor observes, is "a structure of wooden struts, conjuring up the image of the veins of a leaf or the ribs on the inside of a boat" ${ }^{89}$ At its eastern end the radiating effect of the wall and roof structure could be likened to a conch vault, redolent of classical niches; the symbolism of fecundity 
5.21

Caplutta Sogn
Benedetg (St
Benedict's
Church) 1985-88,
Peter Zumthor.
Interior view
looking east
towards altar
and religious
icon

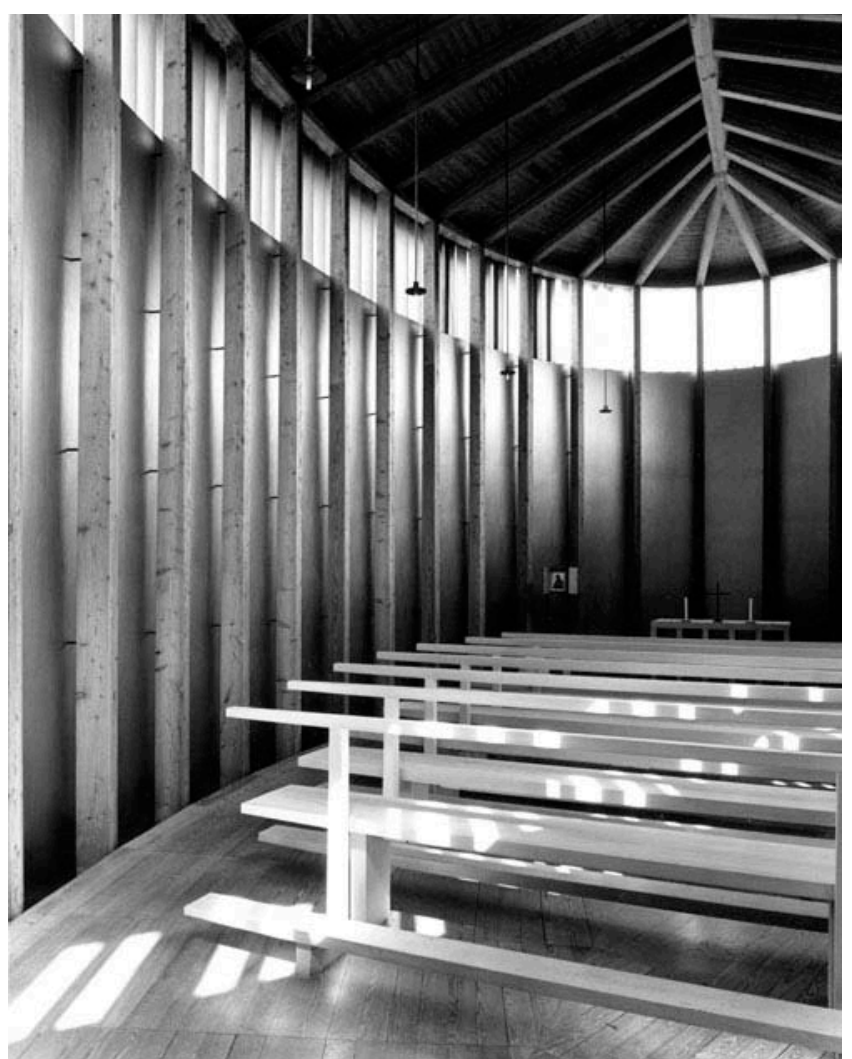

implicit in this ancient motif seems to resonate in the structure of the timber roof. Moreover, the separation of the roof from the enclosing wall of the building, by a continuous ribbon clerestory, makes it appear to hover above the body of the church.

The tension between the inner colonnaded frame and the outer envelope is further emphasised by the design of the floor. From its initial anchorage to the solid concrete threshold of the entrance porch, the timber floor deck seems to "drift" across the voided space beneath the church as if floating precariously above the steeply sloping site. Set back from the building envelope, as far as the inner face of the encircling columns, the finished floor appears disconnected from the vertical structure thereby reinforcing a sense of suspension and detachment. In actuality, the floor is supported on a series of joists that span between the perimeter columns and bear on a central concrete spine beam and wall that extends along the central axis of the building.

Moving to the outer rim of the building, one becomes aware of the presence of the void beneath the floor. This is "registered" by the floor deck that is recessed away from the enclosing wall, revealing the perimeter columns extending down to a lower intermediate level. The overall effect created by the tension between enclosing structure, wall, roof and floor, reminds one of 


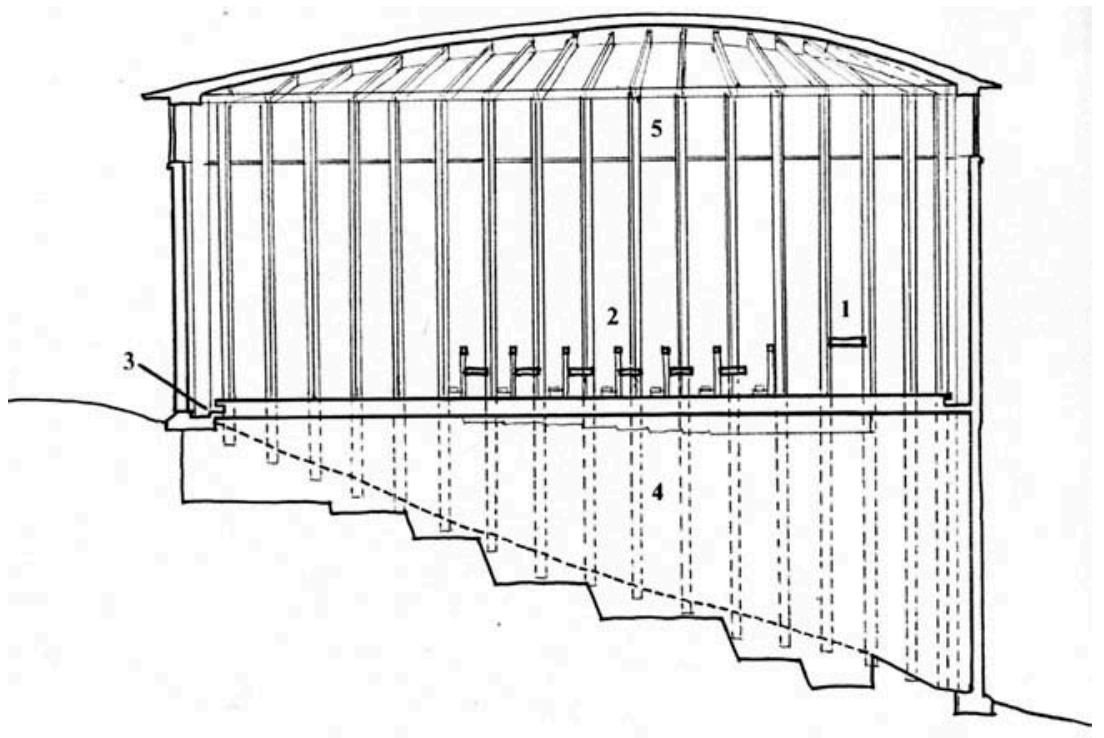

5.22

Caplutta Sogn

Benedetg (St

Benedict's Church)

1985-88.

Longitudinal

section indicating

outline structure

of floor and walls:

Altar (1); Pews (2);

Recessed

perimeter floor (3);

Under-floor void

(4); and Clerestory

glazing (5)

Zumthor's so-called "sound-box", the Swiss Pavilion for the Hanover World Exposition..$^{90}$ In both cases, the body of the building is treated as a resonant vessel whose vibrations invoke some primordial sonority. In the Church of St Benedict, however, this sonority could be said to lie embedded in the enclosing wall of the building, whose bell-like configuration "resonates" the latent rhythms of the valley that surrounds it. This primordial sonority is periodically invoked by the sounding of the actual bells in the nearby wooden bell-tower; the call to prayer is signalled by the oscillating movement of this fragile timber structure. We are reminded, in Zumthor's use of architecture as a sonorous vessel, of Kircher's sound experiments that used different curved geometric forms.

The design of the church both invokes a distancing between the abode of prayer and worship and the outside world, and affirms their potential unity through mutual inter-dependence. This dual meaning is carried through by the absence of window openings at lower level, an omission that is made all the more conspicuous by the spectacular views of the valley beyond. Like Deleuze's allegory of Leibniz's monad as the windowless "Baroque House", the Church of St Benedict could be understood as a unity that draws the multiplicity of perspectives into its (meta)physical web.

What emerges in this study is the way Zumthor's phenomenological response to site and project brief evokes certain affinities with the Leibnizian model of unity in multiplicity and its Baroque manifestations. This affinity, as I have sought to demonstrate, reveals a deeper ontological tradition that in one sense could be likened to St Augustine's meditations on distentio animi. 


\section{Chapter 6}

\section{Nature and immensity}

\section{Transgressing boundaries}

By the mid-eighteenth century Leibniz's model of unity in multiplicity gave way to an understanding of space devoid of "centredness" and therefore of a divine hierarchy. Whilst arguably the last attempt to formulate a complete cosmology, in the tradition of Classical metaphysics, Leibniz's monadic philosophy also laid the foundations for the modern subject. The significance of this change is recognised by Charles Taylor:

Something fundamental changes in the late eighteenth century. The modern subject is no longer defined just by the power of disengaged rational control but by this new power of expressive self-articulation as well - the power which has been ascribed since the Romantic period to the creative imagination. ${ }^{1}$

One indication of this development is the demise of ratio - the idea of corresponding relationships between constituent parts - that in earlier times assured continuity between the particular and the universal, the human and cosmic realms. In its place, as this chapter will explore, emerges an abstract view of space whose understanding relies upon the judgements of an enveloped subject.

This change, however, is perhaps more revealing in landscape than in architecture. In contrast to the systematic "perspectivisation" of landscape that we see in seventeenth-century French gardens (e.g. Versailles and Vau-leVicomte), where nature is subordinated to a pre-ordained geometric order, the eighteenth century viewed landscape as a liberating medium - without geometric constraint - for individual poetic self-expression. ${ }^{2}$ Accordingly, what was earlier underpinned by a still-implicit transcendent order is transformed by the eighteenth century into an intensely inward view of the world. No longer understood as merely an imperfect reflection of divine order, as was the case in the Medieval world-view, nature itself becomes synonymous with God. Direct experience of nature through landscape provided a measure of human self-discovery and 
therefore of our moral well-being. This intense interest in things natural was accompanied by an epistemological quest for human mastery of the perspective field, and therefore of the territories contained within it.

It is for this reason that landscape becomes such a dominant theme in eighteenth-century painting and poetry. From its earlier subservient role in religious and mythical allegory, landscape takes centre stage as an affirmation of the elevated status of nature and of our relationship to it. This essentially immanent understanding of God results in the effective emancipation of the viewing subject from its earlier pre-ordained position; the viewer acquires the freedom to pan the horizon without the apparent "constraints" of the pyramid of vision. Whilst this largely mobile - ambulatory - point of view provided a liberating influence on experience it also brought with it a deep anxiety and uncertainty about one's loss of place in the universe. We are drawn into a constructed world where perspective is no longer the preferred vehicle for appropriating reality - as it once was - but is rather a representation of reality. This perspective, moreover, now surrounds us and directs our very perception of the world.

The resulting loss of distance, however, was perhaps already implicit in earlier post-Renaissance views of perspective that increasingly assumed that: "to think a perspective as a perspective is to be in some sense already beyond its limitations". ${ }^{3}$ This implies that perspective is understood not as a symbolic form of representation, for revealing a divine transcendent realm, but rather as an ordering mechanism whose terms of reference can always be transgressed. Hence, perspective becomes little more than an instrumental device that can be exceeded and therefore objectified.

This understanding could be said to underlie Jean-Jacques Rousseau's complaint of the grand vistas of French formal gardens; in particular the way they open a landscape to new horizons that can be claimed and ultimately possessed: "The taste for perspective and distant views proceeds from the disposition of men who are never satisfied with the place where they are". ${ }^{4}$

Rather than re-affirming continuity between this place and the next, as it once did in the Renaissance, perspective becomes in Rousseau's analysis demonstrative of dissatisfaction with one's place; we seek visual - and by implication psychological - escape through a restless yearning for new horizons. It is precisely this restlessness that is the result of the demise of centredness in the universe. Symptomatic of this sentiment is the desire to explore and redefine unchartered territories; an initiative that could be said to characterise the eighteenth century generally given that it is the age in which excursions to distant lands provided the basis of an encyclopaedic understanding of knowledge.

Related to Rousseau's contempt for the landscaped vista was his criticism of the excessive cultivation and unnaturalness of French formal gardens. He believed, like Abbé Laugier, that the garden should be abandoned in favour of a walk in the country. In The Reveries of a Solitary Walker Rousseau makes clear that "nature is good, that the first movements of nature tend toward the preservation and happiness of human beings". ${ }^{5}$ Withdrawn from external affairs, and 
content with "conversing with my soul", Rousseau sees the solitary walk in the country as a means of animating his thoughts and of removing "from my mind all the troublesome objects". ${ }^{6}$ In reaction to French formal gardens, Rousseau seeks reconciliation with the self by a return to the closed primordial clearing in the forest. In place, therefore, of the privileged position of the viewing subject, characterised by the ruler of a dominion, we see a landscape that is open to collective experience: "The happiest people are groups of peasants who settle their affairs under an oak." 7 The natural setting becomes emblematic of Rousseau's vision of social cohesion, providing the context for his "noble savage" and for his affirmation of the ordinary life. ${ }^{8}$ In one sense, it seems clear that the desire to "break out" of the web of perspective that Rousseau implies, reflects an attempt to overcome its underlying calculating reason. In the intensely subjective realm that Rousseau subscribes to in his Reveries, landscape allows free movement without geometric constraint. Against all existing social mores and restrictions, Rousseau sees landscape as the basis of a new beginning and therefore of a new moral standard.

It is in the light of this search for new beginnings that this chapter examines perspective in the eighteenth century. The combined effects of a wished-for objectified certainty and a divinised nature led to a new sense of wonder at the immensity of the world and therefore at its infinite "presence". This is conveyed through an expanded - all-encompassing - perspective field that extends beyond the traditional geometric limits of the pyramid of vision. Hand in hand, therefore, with a new aesthetic distance, characteristic of the eighteenth century, is the presumption that one exists in perspective space. The drawings of Étienne-Louis Boullée best convey this enveloping condition of perspective. In these works vast landscapes defy conventional terms of reference, such as foreground versus background figure versus ground and so on. In their place we are presented with a "dilation" of the perspective field that is created by a flattening of depth resulting from the lateral expansion of the picture plain. The overall effect could be seen as an attempt to reduce the revealed/concealed articulation of space, redolent of a traditional symbolic understanding of perspective, to a series of simple volumetric and surface relationships. In this horizon, a new emotional response is induced by the dimensionless qualities of nature, now absent of explicit hierarchical or proportional relationships.

It is interesting to compare this idea of the immensity of nature with the Leibnizian notion of interconnectivity between soul, nature and space. What separates, however, the German philosopher's idea of "distended" space - in which simple substances are pregnant with the world soul - from later abstract views of space is most clearly indicated in Edmund Law's An Enquiry into the Ideas of Space, Time, Immensity and Eternity:

Sometimes the Soul dwelling in animal Nature, and under the power of Imagination, mistakes a substantial Being for mere Nothing, and sometimes it mistakes Nothing for a substantial Being: And indeed this is the very first way whereby Men gain the Idea of Space. ${ }^{9}$ 
In suggesting that one could confuse "Nothing" with "substantial Being", Law is laying open the possibility of empty space. Here, we witness the annihilation of the traditional ontological understanding of unity in multiplicity. In its place emerges a world of constructs or human invenzione; connectivity gives way to autonomy and hierarchy to relativity.

A motivating factor behind this shift towards an abstract understanding of space is the development of the idea of an autonomous self, earlier discussed in the context of Rousseau. Anticipated in Leibniz's monad, early modern notions of self-hood take on what Charles Taylor describes as "The Expressivist Turn". ${ }^{10}$ The philosophy of Emmanuel Kant best exemplifies this idea by his assertion that the search for moral imperatives is a subjective or internalised affair. ${ }^{11}$ Rejecting ancient and Medieval traditions, where moral concerns were believed to be rooted in a transcendent order, Kant argues instead that moral laws come from within and require rational judgement for their substantiation. ${ }^{12}$ Whilst nature is considered a means to a more elevated end, pure reason is deemed an end itself that affirms a moral being. Kant believed that "The proximate source of this transformation of the will is not God, but the demands of rational agency itself which lie within me."13 In this radical form of anthropocentrism, the Renaissance idea of man's dignity - embodied in his proportional relationship to the divine world - is replaced by an inward subjective realm without explicit or concrete terms of reference.

The impact of this "expressivist turn" on architecture and landscape was significant. As I will highlight in this chapter, eighteenth-century cultural, scientific and artistic developments set in motion the modern concept of space as a field both open to poetic reverie and subject to rational explanation. Given these very different positions, it is not surprising that attempts to contrive a continuity of relationships in our understanding of the world often involved conflictual terms of reference.

This chapter will examine the perspective implications of these conflicting views of space by focusing on aspects of the Picturesque and the Sublime. Both constituted key modes of representation in eighteenth-century landscape and architecture. I will briefly discuss these relationships by first referring to the writings and ideas of two prominent eighteenth-century figures: the politician and essayist Edmund Burke, and the architect and landscape designer William Chambers.

One consequence of the dominance of immensity in eighteenthcentury perspective, with its enveloping effects upon the viewer, is the growing fear of the void. This fear provided much of the impetus for the growing detachment from the physical world, a detachment that was brought about by a new awareness of the "inner" subjective depths of experience referred to earlier. The imaginary projects by Boullée will serve as examples of how this detachment is articulated in perspective representation. In these works we begin to see a desire to grasp visually the immensity of nature that allows us the illusion of a mastery of totalisation. The symbolic implications of this illusion will be explored in the context of the painted diptych by Casper David Friedrich of the artist's studio. 
Underlying the scene is a complex dialectical relationship between the representation of an "outer" perspective of expanse and light and an "inner" perspective of fragments and shadows.

Finally, the chapter concludes with a case-study of the large urban project of EuraLille, master-planned by Rem Koolhaas. The study examines Koolhaas' claims that density and congestion provide the basis of a new spatialtemporal condition, and questions whether these assertions can draw any parallels with eighteenth-century notions of immensity. Related to this critique will be a brief overview of Koolhaas' intriguing "I'Espace Piranesien" at EuraLille, in particular its associations with the so-called "anti-space" of Piranesi's Carceri etchings.

\section{The picturesque and the sublime}

Whilst, as we saw in Chapter 4, notions of a cosmological world-view underpinned Baroque views of space, the eighteenth century was dominated by a new aesthetic and scientific outlook. Anticipated in the architecture of Fischer von Erlach and in the philosophy of Leibniz, this outlook was driven by a new desire for synthesis. In the visual arts, this is commonly understood as Gesamtkunstwerk; the concept of the total work of art conceived at the level of abstract synthesis rather than one of content. Articulated by the effect of a unified composition of otherwise obscure or recondite elements, Gesamtkunstwerk reflects a greater concern for unity of experience than unity of meaning. ${ }^{14}$ In contrast to Fischer and Leibniz, however, where this process was still informed by a transcendent order, by the mid-eighteenth century unity in multiplicity was largely superseded by a thoroughly immanent outlook.

Initial indications of this change can be seen in the concept of the picturesque, whose influences on English and French landscapes reflect a growing proclivity towards the simplicity of rural life. To fully explain the reasons for this tendency would require a more extensive examination than can be given here. Suffice it to say that interest in rural life reflects a new cultural outlook that was partly precipitated by social and political turmoil during the period. ${ }^{15}$

Whilst it would be wrong to claim that literature was the principal inspiration for this impulse, its role was clearly critical. An example is the pastoral novel Astrée, written in the late fifteenth and early sixteenth centuries and published in the seventeenth century. ${ }^{16}$ A moralising and archaic tale of the life of shepherds in a rural setting, the work became an expression of an idealised life in the eighteenth century, inspiring the paintings of Jean-Antoine Watteau. Like other pastoral romances of the period the form and content of Astrée derive in part from Neo-Platonic thought, in particular the conception of beauty as mediating between idea and experience, the latter manifested in the cultivation of landscape.

Bucolic scenes in literature provided a rich source of inspiration for the conception of actual landscapes as idyllic "set-pieces". An unusual feature of these eighteenth-century settings, and one which was to redefine the meaning of the garden as a place of aesthetic experience, was the simple rusticated dwelling or hermit's retreat. These were inspired by a new interest in the idea of the primitive hut in the eighteenth century, promulgated for example in Marc-Antoine 
Laugier's famous Essai sur l'Architecture (published in 1753)..$^{17}$ It is significant that this preoccupation with origins went hand in hand with an increasing emphasis on artifice in landscape design, a point I will return to later.

The open view in the eighteenth century, in which the distant rural retreat is presented as a picturesque tableau, departs from the predominantly closed vista - protracting to infinity - that was typical of seventeenth-century landscapes. Formed out of "a system of diagonal allées with radial views", the eighteenth-century landscape constitutes a topography for personal discovery and literary musings. ${ }^{18}$ These allées would open up into what A. J. Dézallier d'Argenville describes as "prospects" where "villages, woods, rivers, hills, meadows, and other rural aspects" serve as "beautiful landskips". ${ }^{19}$ In the distant "prospects" of wished-for idyllic settings the wanderer would find inspiration and solace.

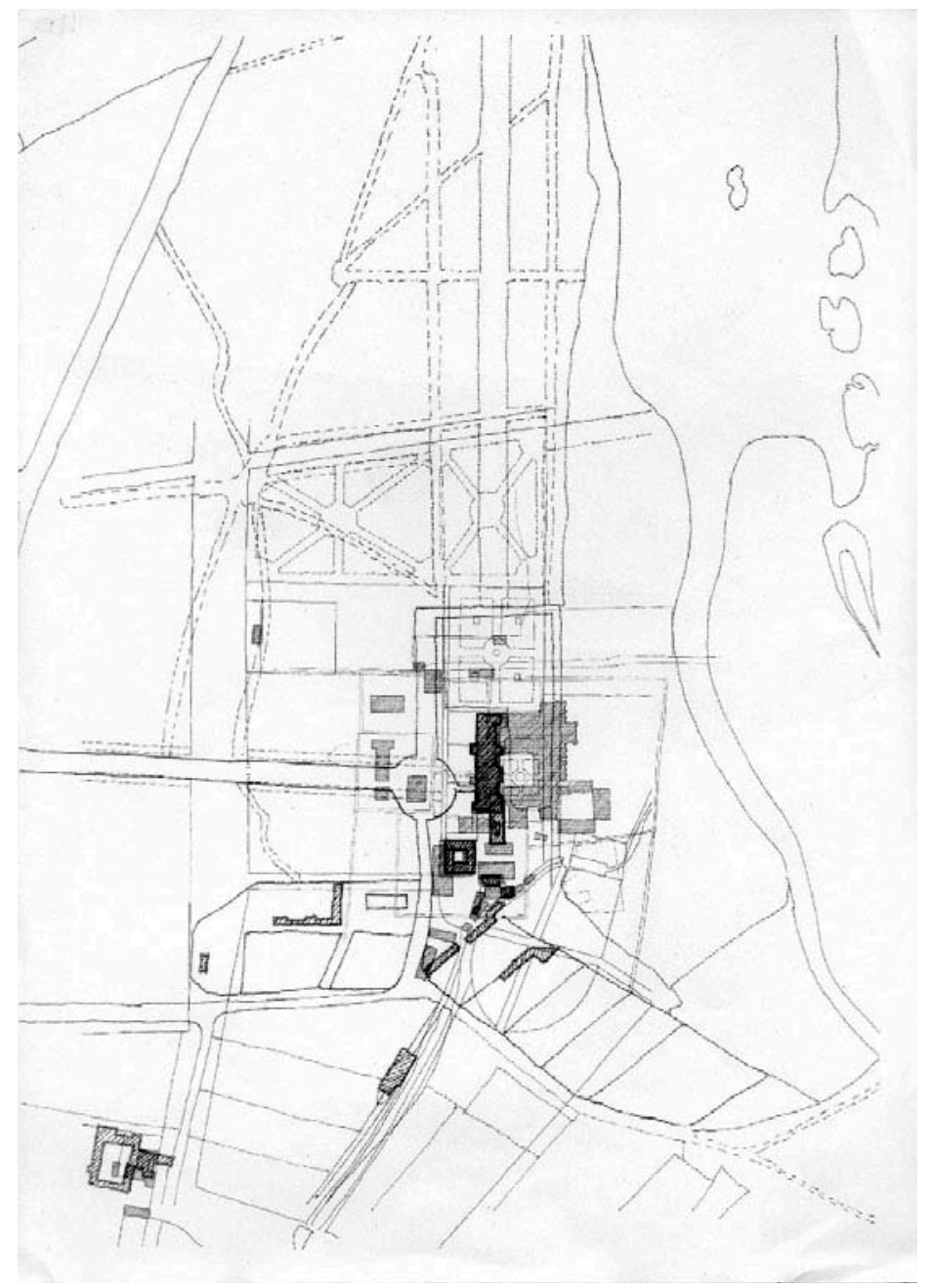

6.1

Rufford Hall,

Nottinghamshire.

Superimposed

plans of estate at

different stages in its history (1250,

1725, 1884 and today), indicating transformations of landscape and buildings from the cloistered spaces of the Medieval priory to the open axial vistas of the estate in the eighteenth and nineteenth centuries. Drawing by Mike Hammock 
A dominant feature therefore of these early eighteenth-century landscapes is their greater openness to the countryside. Techniques such as the "haha" - or boundary ditch - were deployed in France as early as 1709 to control the movement of grazing animals, and at the same time overcome the visible obstacles of fences and boundary walls. Accordingly, the traditional distinction between closed garden and open country becomes blurred, leading to the creation of whole regions as vast cultivated landscapes. This change in understanding of landscape was to inspire William Chambers to declare that England - indeed the whole of the known world - comprises a series of inter-connected gardens. ${ }^{20}$

Apparent throughout these landscapes is the variety and diversity of topographical features, providing a feast of sensual experiences for the wanderer. As J. F. Blondel states in his Maison de Plaisance, the maximum effect of the garden could be gained by "the arrangement and variety of the parts of a garden that cause surprise and amusement", and that "the beauties of a garden should not be perceived at one glance, and that if some of its ornaments are hidden, curiosity will be excited". ${ }^{21}$ Blondel believed, therefore, that the essence of nature cannot be gained from an isolated glance but rather requires more enduring experience of her manifold aspects. This belief, which assumes visual experience as the primary determinant to understanding nature and therefore of God, was radically different from Leibniz's metaphysical model of multiple perspectives. The difference between both characterises the Enlightenment period in general when empiricism and rationalism - sensual experience and a priori argument - constituted rival methods for validating truth. ${ }^{22}$

The correlation, cultivated in eighteenth-century thought, between nature's immensity and her infinitesimal variety provided the backdrop to the idea of the sublime. This is expressed in Burke's seminal work A Philosophical Enquiry into the Sublime and Beautiful, written in 1757. In this essay, Burke attacks the classical/Platonic idea of proportion and harmony as essential ingredients of beauty, asserting instead that "proportion and beauty are not of the same nature". ${ }^{23}$ He suggests that we have wrongly assumed an antithetical relationship between beauty and deformity (or disproportion) since "deformity is opposed, not to beauty, but to the compleat, common form. ... Deformity arises from the want of the common proportions; but the necessary result of their existence in any object is not beauty". ${ }^{24}$ In other words, proportion is equated with the common or unremarkable rather than with the exemplary. Moreover, he says in the context of architecture:

Herein is placed the real power of fitness and proportion; they operate on the understanding considering them, which approves the work and acquiesces in it. The passions, and the imagination which principally raises them, have very little to do. When a room appears in its original nakedness, bare walls and a plain ceiling; let its proportion be ever so excellent, it pleases very little; a cold approbation is the utmost we can reach; a much worse proportioned room, with elegant mouldings and fine festoons, glasses, and other merely ornamental furniture, will 
make the imagination revolt against reason; it will please much more than the naked proportion of the first room. ${ }^{25}$

By taking the example of a woman, Burke asserts that perfection is not the "constituent cause" of beauty. ${ }^{26}$ Rather, qualities that are commonly associated with weakness and imperfection can be considered beautiful. Burke makes the case, therefore, that beauty can be brought about by the effects of distortion that provoke certain emotions and passions. These emotions, moreover, are induced by experiences of disharmony rather than harmony. He concludes with the following succinct summary: "beauty is, for the greater part, some quality in bodies, acting mechanically upon the human mind by the intervention of the senses" ${ }^{27}$ This definition challenges the Platonic view of beauty that is rooted in the eternal and harmonic truths of number and geometry. It assumes that our senses are inadvertently - and unpredictably - arrested by beautiful things whose effects exist prior to any knowledge.

From this initial examination Burke goes on to clarify the meaning of the sublime which he distinguishes from beauty on a number of points; whilst beauty is typically equated with the small, fragile or delicate, the sublime finds expression in the massive or immense. Burke explores the impact of such ideas as vastness, infinity and magnificence on the mind, suggesting that these qualities invoke emotions of "delightful horror" and even pain. ${ }^{28}$

A characteristic feature of an experience of the sublime is the contrasting effects of light and darkness, between blinding light and deep shadows. In reference to Milton's Paradise Lost, Burke makes the following interesting observation:

Extreme light, by overcoming the organs of sight, obliterates all objects, so as in its effect exactly to resemble darkness. After looking for some time at the sun, two black spots, the impression which it leaves, seem to dance before our eyes. Thus are two ideas as opposite as can be imagined reconciled in the extremes of both; and both in spite of their opposite nature brought to concur in producing the sublime. ${ }^{29}$

We could be mistaken, in this exposition on the effects of light, for reading the Pseudo-Dionysius' idea of "negative theology", outlined in Chapter 2; the infinitesimal brightness of divine light corresponds with the experience of its opposite, absolute darkness. For Burke, however, Dionysius' mystical theology would have had little relevance to his essentially aesthetic and sensual experience of nature. What Dionysius describes in mystical terms to convey the ineffable, and ultimately unknowable, God becomes in Burke's Enquiry a descriptive account of how to induce sublime experience by artificial or mechanical means. The following clearly confirms this approach:

Some who allow darkness to be a cause of the sublime, would infer from the dilation of the pupil, that the relaxation, yet in one respect it 
differs from the other sphincters of the body, that it is furnished with antagonistic muscles, which are the radial fibres of the iris; no sooner does the circular muscle begin to relax, than these fibres wanting their counterpoise, are forcibly drawn back, and open the pupil to a considerable wideness. ${ }^{30}$

At the same time as compensating for the dark recesses and shadows associated with the sublime - by the widening of the visual field - the viewer also has to cope with the difficulties of visualising and comprehending the sheer immensity of nature:

Again, if we take it, that one point only of an object is distinguishable at once .... it will make the origin of the sublime from greatness of dimension yet clearer. For if but one point is observed at once, the eye must traverse the vast space of such bodies with great quickness, and consequently the fine nerves and muscles destined to the motion of that part must be very strained. ${ }^{31}$

The combined impact of darkness and immensity on the eye, reflected in the dilation of the pupil, is given perspectival definition in eighteenth-century representations, as I will explain in the context of Boullée's imaginary works. One consequence of this impact is the loss of a clearly defined - and measurable - distance between viewer and viewed, and therefore of an acknowledged point of view. No longer a symbolic form of representation, perspective becomes instead an aesthetic instrument for achieving certain desired sensations. In the safe knowledge of the artificial nature of the sublime landscape, Burke notes:

if the pain is not carried to violence, and the terror is not conversant with the present destruction of the person, as these emotions clear the parts, whether fine, or gross, of dangerous and troublesome incumbrance, they are capable of producing delight; not pleasure, but a sort of delightful horror, a sort of tranquillity tinged with terror; which as it belongs to self-preservation is one of the strongest of all passions. Its object is the sublime. Its highest degree I call astonishment. ${ }^{32}$

Burke's theoretical reading of the sublime was to have an important impact on the design of actual landscapes. In these we see the effects of natural forces - such as lightening and flooding - being "engineered" by various mechanical means to invoke a sense of terror and awe. Burke's description of subliminal experience as a "delightful horror" underlines the role of landscape during this period. The explicitly artificial nature of this operation, by which our sensory, imaginative and judgemental processes define artistic pleasure, run counter to the revelatory views of nature expressed in Romantic thought. Exemplified for example in the poetry of Wordsworth, Romanticism saw landscape as a territory in which God's work can be discovered, through poetic reverie, rather than reconstructed as a theatrical setting. ${ }^{33}$ 
Influential in Burke's understanding of landscape was his attitude towards history. Burke wrote some of his most important works in a climate of vehement opposition to the French Revolution. Highlighted in his Reflections on the Revolution in France, Burke believed that history is a process of continual evolution, rather than a sequence of abrupt revolutionary transformations. ${ }^{34}$ Accordingly, he regarded the French Revolution as an abstract ideological solution, rather than an event reflective of circumstance, whose rational justification bore little resemblance to the reality of everyday existence.

Claiming that equivocations of human action and experience are the only authentic terms of reference for validating historical events, Burke's empirical sensibilities rejected the rational arguments of many of his French contemporaries. In these arguments, Descartes' dismissal of historical enquiry (in particular the study of old texts) was justified on the basis of the need for autonomy of thought in the quest for ultimate truth. In contrast, Burke's perspective of history, in which he demonstrates a broadly liberal and humane view of society, enabled him to consider the past not as a chronology of ideologically driven events - that transcend temporal situations - but rather as a continuum of moments that inform essential ethical principles.

Burke's view of the relation between landscape and history, between a territory open to artifice and the re-invention and largely undifferentiated view of time, represents a defining moment in the erosion of traditional views of order. To get a sense of the extent - and scope - of this transformation we should consider briefly the ideas of Giambattista Vico, expressed in his New Science (1730). By taking Humanist views of history as a point of departure (constituted as the promise of a Golden Age achieved through Church reform and rebirth of JudeoChristian and Etrusco-Roman cultures), and their relation to an inscriptive understanding of topography, Vico re-affirms the idea of providence as a historical fact rather than an onto-theological condition. Accordingly, history becomes the "new science", the "rational civil theology of providence". 35

In spite of his reduction of history to a purely human affair, Vico's New Science is nevertheless steeped in a symbolic understanding of the past. This is implied in his attempt to equate his factual providential history with geometry, a connection that can be traced in the iconography of Raphael's School of Athens, as we saw in Chapter 2: "my Science [of history] proceeds like geometry which, by constructing and contemplating its basic elements, creates its own world of measurable quantities". ${ }^{36}$

As we saw in Chapter 4, in the work of Fischer von Erlach, the relation between geometry and providential history was to find expression in the juxtaposition of domical spaces and numismatic motifs. Significantly, the early eighteenth century would be the last time when such a dialogue could be convincingly represented. This final expression of an older - more assured - transcendent world would be replaced by such views of history as those of Burke, in which the past is nothing more than a continuum of human events without providential or embodied meanings. Denied a larger allegorical narrative - that in pre-eighteenthcentury traditions gave history its purposive (mythic) content - the constructed 
artifices of the sublime landscape become substitute aesthetic instruments for inducing (by sensory stimulation) multivalent experiences. Hence, the impact of these experiences was determined more by duration and intensity than by symbolic meaning.

\section{Chambers and oikoumene}

Burke's view of the sublime was to be especially influential in the work and ideas of William Chambers. Much travelled and knowledgeable about other cultures, Chambers was an unusually worldly figure for his time. Having been born to a Scottish family in Sweden, Chambers received his primary education in England and later travelled to the Far East during his mercantile career in the Swedish East India Company. He received his architectural education in Paris (under Blondel) and in Rome. Chambers was offered a position in the court of Frederick the Great of Prussia which he turned down. These diverse experiences provided Chambers with a unique perspective of the world that was to have an important influence on his work as an architect and landscape architect. The nature of this influence is highlighted in a letter Chambers wrote in 1772 in which he declared that his approach to design sought "to decorate kingdoms, even the world, and far from attending merely to narrow views of selfish individuals, I would diffuse the comforts of cultivation to all mankind". ${ }^{37}$ In this universal vision, Chambers saw landscape extending well beyond the provincial concerns of English private estates and their relation to the countryside. Indeed, he viewed "the whole kingdom" as "one magnificent vast Garden, bounded only by the sea". ${ }^{38}$

Chambers' vision of unhindered landscape, as an expanse shaped by the movement of water, could be said to derive from a much older tradition. This tradition is based on the relation between the ancient Greek terms of oikoumene, meaning "the inhabited earth", and okeanos (from which the word "ocean" derives) denoting the body of water that surrounds the oikoumene:

Oikoumene and okeanos belong together as integral parts of a symbolism which, as a whole, expresses a compact experience of man's existence in the cosmos. The oikoumene, in the literal sense, is man's habitat in the cosmos. The boundary between the two is the horizon, that is toward a border where heaven meets the earth, where this world is bounded by the world beyond. ${ }^{39}$

The meaning of oikoumene changed in the course of history, denoting initially the inhabited land that rose above water in Homeric myth, or more specifically the islands and continents that are surrounded by the sea called the Atlantic. In these early examples oikoumene was not yet a territory to be conquered. Yet, the expansion of geographical knowledge, that underpins the concept of oikoumene, was intimately bound with the idea of empire. From the period of Alexander the Great oikoumene takes on a momentum of its own, whereby the establishment of an imperial outlook inaugurates a process of relentless expansion through the actions of conquerors. 
Following the decline of the Alexandrian and Roman empires, oikoumene was revived and systematised in the early modern age, leading ultimately to the now familiar notion of "globalism":

The concupiscential expansion, which at the same time was an expansion of knowledge, was resumed with the Age of Discoveries, leading ultimately to the circumnavigation of the globe. From the Mediterranean oikoumene bounded by the Homeric okeanos, the boundary was pushed back beyond India, China, and America until the physical shape of the ecumene turned out to be a sphere. The superb irony of the ecumene having the shape of a sphere that brings the concupiscential explorer of reality back home to himself ... since the center of the cosmic horizon is everywhere and nowhere, so that again one is thrown back to the earth as the physical center of meaning. ${ }^{40}$

It is important to recognise, however, that the specifically modern "earth-bound" understanding of the horizon serves as a perceptible limit for encompassing, by perspective means, the immensity of the natural order. This initiative, however, should be considered in the context of a crisis about the nature and meaning of frontier, giving rise to the speculative possibility of abolishing national or geographical boundaries altogether. The crisis was most acute during the period of the eighteenth century and finds expression in such ideas as encyclopaedism and a new sublime view of nature; these ideas were spawned from the perception of the world as a ceaselessly expanding frontier, from whose remotest destinations were retrieved vast quantities of ethnic and natural curiosities for museums and private collections. These provided both aesthetic and scientific compensation characterised by the "cabinet of curiosities" - amid the confusion of rival typologies. Anticipated in Kircher's ambitious enterprises, outlined in Chapter 5, this initiative culminates in the modern - technologically driven - concept of globalisation. ${ }^{41}$

In his journeys to the most distant civilisations of the earth, Chambers had visited the "boundaries" of the okeanos which had, by the eighteenth century, become part of the conceptual oikoumene of the trading kingdoms of Europe, particularly England. Hence, it became possible for Chambers to make a convincing case for the idea of a "global garden" bounded only by the sea.

In Chambers' first major commission upon arriving in England, to design the Kew Gardens for the Dowager Princess Augusta, we see the veteran traveller and encyclopaedic architect putting his enlightened cosmopolitanism into practice. The project entailed the design and layout of an extensive garden, with the addition of a variety of pavilions in the form of temples and shrines in various styles derived from both east and west. A few months before his commission Chambers completed his first book, entitled Designs of Chinese Buildings, Furniture, Dresses, Machines, and Utensils. Published one month after the appearance of Burke's Enquiry, the work includes a short essay on the art of laying gardens. ${ }^{42}$ In this essay Chambers makes a case for supporting the idea of the Chinese 
6.2

\section{Engraving of} garden pavilions based on "temples" visited by Chambers in Canton. William Chambers,

Designs of Chinese Buildings, Furniture, Dresses, Machines and Utensils (London, 1757). PI. VI

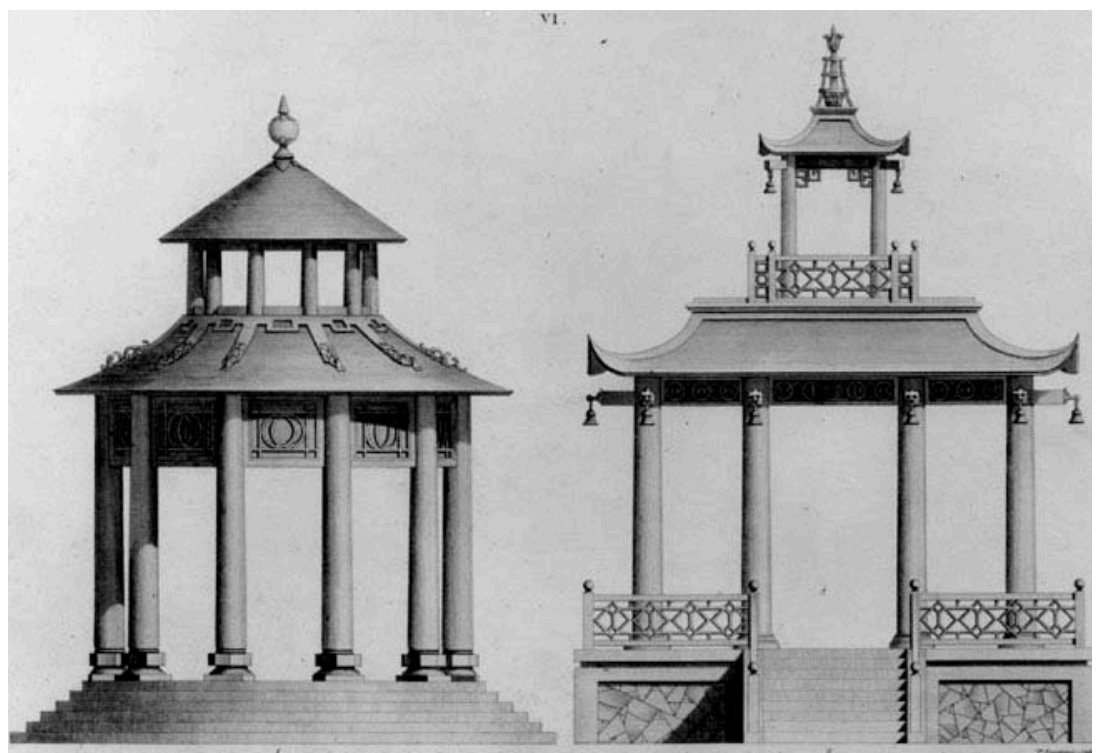

garden as a model for the English landscape, suggesting certain affinities between both. In particular, he admires Chinese methods of imitating nature which he describes as having "beautiful irregularities" which can also be found in English landscapes. ${ }^{43}$ In these examples variety provides a powerful impetus for invoking a sense of wonder and terror, a point that echoes Burke's earlier study of the sublime. But such variety is not without its limits. Indeed Chambers deploys Burke's use of "uniformity" and "succession" that collectively constitute "a continuation of parts causing 'frequent impulses on the senses'". ${ }^{44}$ This gives precedence to continuity of experience over and above any single impression, thereby giving rise to Burke's idea of the "artificial infinite". ${ }^{45}$

Whilst clearly indebted to Burke's study of the sublime, Chambers departs from his ideas in one crucial way: by rescuing proportion from the abyss. Chambers' classical training, and his recognition of parallel proportional systems in Chinese and European architectural traditions, led him to challenge Burke's dismissal of proportion. He undertook this by advancing the notion of "fitness". This attributes proportions not to collective norms, such as classical orders, but to individual forms. ${ }^{46}$

A corollary to this theory is Chambers' appreciation of Chinese buildings as "toys":

as toys are sometimes, on account of their oddity, prettiness, or neatness of workmanship, admitted into the cabinets of the curious, so may Chinese buildings be sometimes allowed a place among compositions of a nobler kind. ${ }^{47}$

Chambers argues that when buildings are reduced to their essential qualities they become toy-like, and in doing so reveal universal norms. He justifies this intriguing 


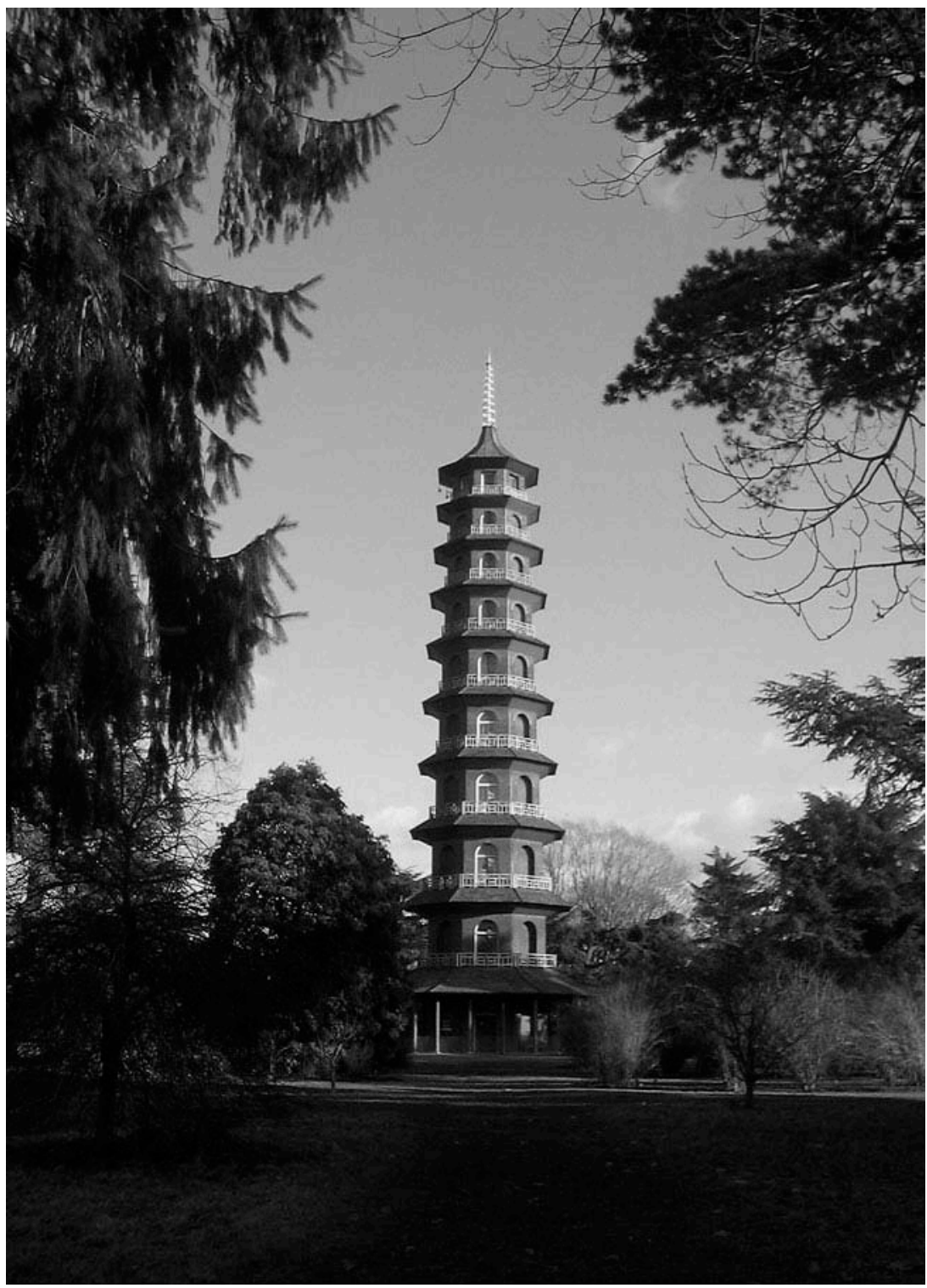

6.3

View of the

Pagoda in Kew

Gardens, 1757-62,

Sir William

Chambers

(1723-96)

claim on the basis of their relation to "compositions of a nobler kind". Each building, therefore, is treated as a microcosm, or entity in itself, immersed in the immensity of nature. In this setting, the cabinet of curiosities is transformed from Kircher's "ark" of saved recondite artefacts - ordered according to a redemptive view of history - to the awesome eighteenth-century landscape of architectural curiosities, composed and assembled for pure aesthetic delight.

Significantly, the choice of examples deployed by Chambers in his study of Chinese gardens provided an available repository of references for his designs for Kew Gardens. The project was motivated in part by his harsh criticism 
of English gardens and the belief that the examples from China would help inject a new understanding of the English landscape. Indeed, Chambers sought to identify a common set of features, or characteristics, that all major architectural styles of the world could share. Hence, classical temples are freely juxtaposed alongside Chinese pavilions at Kew, each indirectly acknowledging the other in this larger "universal" order. Chambers' cosmopolitan perspectivism entailed a process of selecting, collecting and reworking, from which an infinite number of possibilities arise. Rather like botany, Chambers saw the elements of Chinese architecture as specimens that can be extracted and isolated from their original source and adapted in a foreign landscape to arouse wonder.

\section{Boullée's visionary perspectives}

In the late eighteenth century an important relationship emerges in Romanticism that concerns the status of the work of art: "A perfect work of art is a work of the human spirit (genius) and in that sense also a work of nature." According to Johann Wolfgang von Goethe, genius constitutes a key feature in the understanding of nature given that human spirit is an inner expression - poetically conceived - of the outer world of nature. ${ }^{48}$ One consequence of this relationship is that human reason ultimately takes the place of God as the highest form of truth, leading to an equating of human laws with those of Nature.

Goethe's assertion of a correlation between genius and nature is translated pictorially in the visionary drawings of Étienne-Louis Boullée. In these works architecture is reduced to a pictorial effect of solid bodies. Trained as a painter, Boullée describes architecture as if it were a tableau or image with didactic and moral purpose. Overturning the classical principles of proportionality in architecture, Boullée's essentially "mural" approach to architectural representation utilises the idea of caractère. ${ }^{49}$ This denotes the effect of solid bodies on the senses which for Boullée relates to "their analogy with our system". ${ }^{50}$ The Platonic forms that Boullée deploys in his visionary buildings were seen to evoke certain innate sentiments rooted in nature. To achieve this effect architecture must respond to certain principles that Boullée derives from Claude Perrault. These are régularité, symétrie and variété: "régularité produces the beauty of forms; symétrie, 'their order and cohesion'; variété 'the aspects by which they are diversified to our eye'." 51 In the relation between these principles we are led to consider architecture as an assembly of elemental forms whose pictorial effect arouses the senses and induces emotional sentiments. Boullée's emphasis on compositional arrangement - rather than proportion and scale - was driven in part by a firm belief that his visionary architecture can directly influence the viewer's experience of the physical world. Implicit in this belief is the idea that the sensations brought about by the architectural image reflect the "setting to work" of Nature. ${ }^{52}$ In this correlation between nature and architecture we recognise the crucial role played by caractère in Boullée's work as both a poetic and compositional device.

In his imaginary design for a Metropolitan Church, Boullée depicts a vast block-like structure with a Greek cross plan. The uncompromising horizontality of 
the roof parapet is reinforced by the addition of a classical architrave that wraps on all sides of the building. The façades of each arm of the Church are adorned with temple-like porticoes, whilst the sides are lined with colonnades of the same proportion. Redolent of the Parthenon, these superimposed elements are treated like a relief. Amidst the vast vacant spaces and featureless surfaces of the main body of the building, only the superimposed classical motifs give a sense of order, albeit disconnected and largely mute. The blankness of the building is reinforced by the prominent colonnaded dome perched high on a tall drum and located the crossing of the Church. Emerging above the vast expanse of the flat parapet, the dome seems to merge into the surrounding sky, as if an apparition created by the effects of light and shade on the clouds. In contrast, the solidity of the main body of the building is given dramatic effect by sharply contrasting shadows, whose geometric definition gives a sense of permanence rather than temporality. Here the essential character of the setting is conveyed through Boullée's compositional techniques, expressed in the play of light and shadow on the vast blank surfaces of the geometrical solids.

Included in Boullée's treatise, Essai sur l'Art, the representation of the Metropolitan Church tells us much about the artist's understanding of space. ${ }^{53}$ This is initially indicated in the way the perspective is flattened by the emphasis on the horizontality of the parapet and the lateral expanse of the building that extends almost to the edges of the drawing. Consequently, the parapet could be read as a horizon in itself, above which rises the dome - like a celestial body - absorbed in the cosmic ether of the clouds. Just discernible in the vast landscape of the building are crowds of people processing to - or mingling around - the monumental ramped entrance. Flanking the temple-like porticoes are urns that are represented like standard bearers emitting plumes of smoke. These motifs, which Boullée uses elsewhere in his imaginary works, reflect the funerary connotations of late eighteenth-century architecture where history is deemed a reflective medium for mourning a recondite past rather than an experience of assured continuity with a lived tradition. The plumes of smoke provide distant earth-bound counterpoints to the immensity of the clouded sky that fills the upper half of the picture.

Denied any sense of scale - by means of mediating spaces between the human and natural world - the viewer is confronted by his littleness and insignificance in the face of immensity. Accordingly, the viewer's gaze is "incar-

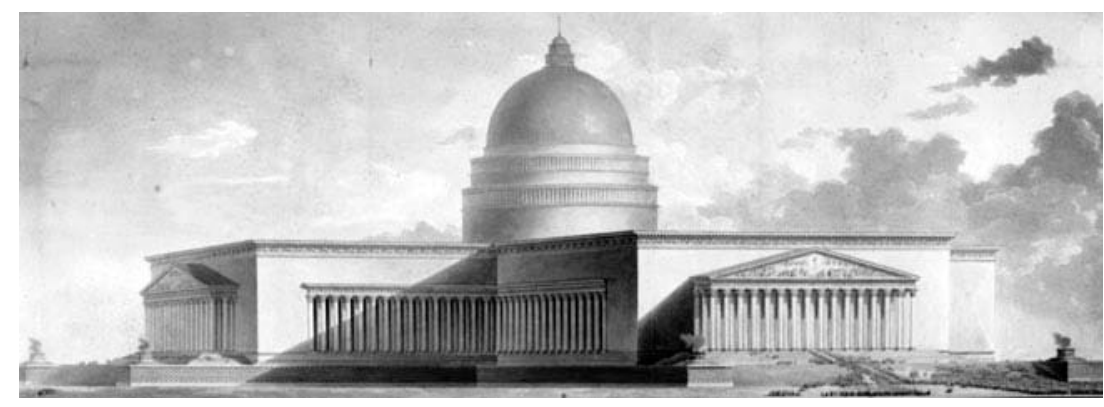


cerated" within the vast spaces of the building, leaving him in a state of bewilderment and even anxiety. What is particularly significant about this drawing is the way in which landscape encroaches on the building, to the point that architecture and the natural order become effectively synonymous.

Implicated in the feeling of anxiety that this scene evokes is the fear of emptiness; of being unable to "locate" - or situate - oneself in the world. This peculiarly modern anxiety, as I have already noted, is countered by an equal desire to control - and ultimately master - the infinite perspective field. One of the consequences of the dialectical tension between both conditions is the growing importance of the panorama in the modern age that ensures a controlled overview of an ever widening field of view, a point I will examine in Chapter 7.

Prophetic of the modern conditions of mental anxiety and scientific control Boullée's scenes could be said to have been anticipated by Blaise Pascal's particular interest in the void during the seventeenth century. Pascal's philosophical and scientific investigations into aspects of the vacuum were informed, it seems, by a personal experience. This was later to become a casebook for early nineteenth-century psychological investigations of "la peur des espaces", or agoraphobia. ${ }^{54}$ The episode, which was described in an account by the nineteenth-century critic George Saintsbury, served as "a dramatic example of the relations between spatial experience and psychological-philosophical enquiry" in Romantic thought:

It seems that Pascal in driving to Neuilly was run away with by the horses, and would have been plunged in the river but that the traces fortunately broke. To this, which seems authentic, is usually added the tradition ... that afterwards he used at times to see an imaginary precipice by his bedside, or at the foot of the chair on which he was sitting. ${ }^{55}$

It is interesting to note that the story actually originated in a letter written by the abbé Boileau in the early eighteenth century, seventy-five years after Pascal's death. In this letter Boileau uses the anecdote to warn his penitents of the consequences of excessive "abstract and metaphysical studies" ${ }^{56}$ Pascal's horror vacui may have led to his conversion, suggesting the belief - or perhaps the hope - that religious devotion can somehow allay the (modern) fear of the void. Significantly, as Anthony Vidler points out, "Pascal remained a powerful source for reflecting on the void and especially for late eighteenth-century architects like Etienne-Louis Boullée and Nicolas Ledoux, who were increasingly led to reformulate the progressive ideal of Enlightenment space under the influence of Boileau, Burke and Rousseau." ${ }^{57}$

Perhaps the most celebrated evocation of unfathomable space in the eighteenth century, and one which also invokes succinctly Goethe's premise of an affinity between genius and nature, is illustrated in Boullée's celebrated design for the "Cenotaph to Newton". In this work, Boullée seeks to represent the universal science that Newton had advanced by conceiving his tomb as a universe in itself: 


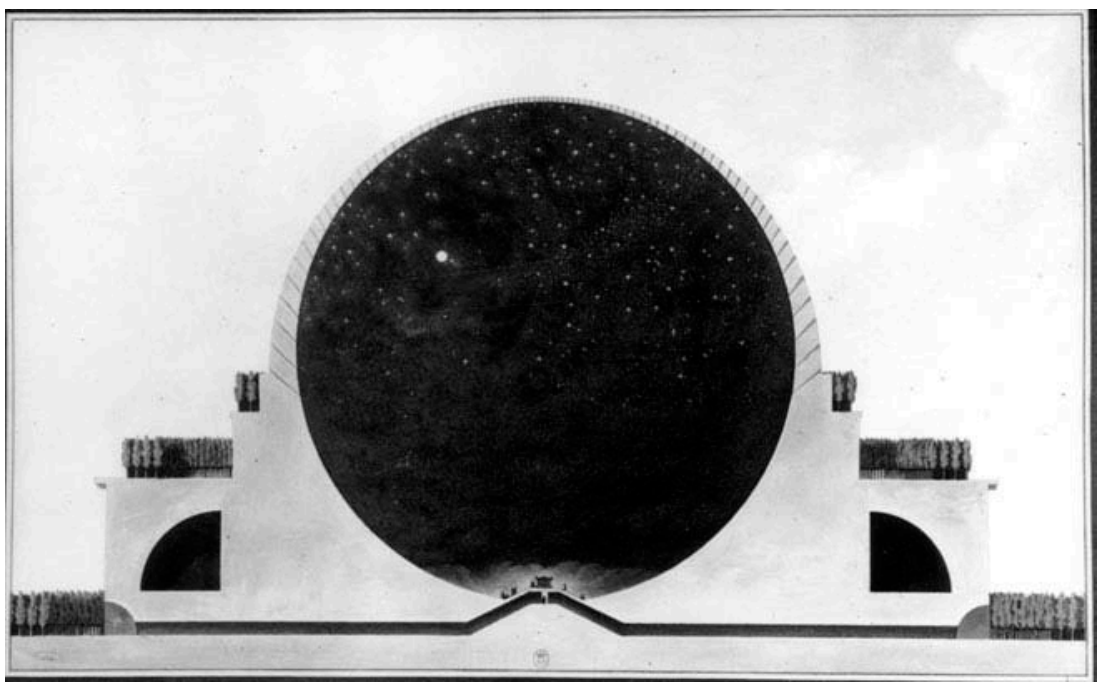

6.5

Design for a

cenotaph to

Newton, c.1780-90,

Étienne-Louis

Boullée (1728-99).

Section through

building during

daytime

"Sublime spirit! Vast and profound genius! Newton ... you ascertained the shape of the earth, and I have conceived the idea of enveloping your discovery." ${ }^{58}$ The Cenotaph seeks to equate the infinitude of the universe with the infinitesimal scope of Newton's genius. Comprising a giant perforated sphere built into a threetiered plinth, each crowned with rows of cypress trees, the Cenotaph could be considered as a combination of sphere and tumulus. Both elements derive from well-known pagan monuments: the Pantheon and Caesar's Mausoleum respectively. However, the overwhelming scale of the Cenotaph to Newton, and the absence of any indicative tectonic or material references, gives the monument a strangely ethereal quality.

Boullée's decision, moreover, to represent the monument in elevation and section, rather than in perspective, was probably intended to emphasise the sheer immensity of the building. By seeming to approximate orthographic projection to a "flattened" perspective the elevation becomes in effect the perspective of infinitesimal vanishing points on a two-dimensional surface; the immensity of deified nature is revealed through - and equated with - the mastery of totalisation, constituted in human genius. Hence, reason and nature become one.

This effect is further emphasised by Boullée's representation of the monument during the day and night. Echoing Burke's argument of the sublime as an equal play of opposites, Boullée uses the effects of light and shadow to dramatise the inter-relationship between human genius and divine nature. The use of the section to represent the two diurnal states of the monument (as starry cave and radiant sphere) renders the scene as cosmic rather than earth-bound event.

\section{Casper David Friedrich's studio}

This chapter has outlined the nature and meaning of the transformations in perspective during the eighteenth century, charting the role of landscape as the principal domain in which our relationship to the world was redefined. The 
emphasis on immensity, and its visual manifestation in the opening up of the perspective field, was intimately bound to the elevation of nature to the status of the divine. Closely associated with this change, as already indicated, is the redefinition of the modern self. The combination of these developments provided a moral framework for discerning the world in two complementary ways: either circumspectly through rational judgement or poetically through imagination. The division between them could be said to form the basis of the modern subjective/objective dichotomy.

Symptomatic of this split is the inability to redefine a mediating realm between proximity and distance, conveyed in the relation between the localised setting of a domestic interior and the larger city. Although this bifurcation doesn't become fully established until the mid-nineteenth century, traces of this change are already apparent at the beginning of the century.

Evidence of this can be seen in Casper David Friedrich's diptych of his studio in Dresden, executed in 1806, which will be discussed here. Both paintings of the diptych are dominated by a large window, each providing views of the river Elbe. Carla Gottlieb argues that the work highlights an important innovation in the representation and iconography of the window, namely the close-up. ${ }^{59}$ This is indicated by the overwhelming size of the window openings, in relation to the other elements in the room, and by the distant scenographic landscape beyond. The scenes of both paintings provoke a certain melancholia and uneasiness created by dissonant relationships between foreground and background. The resulting juxtaposition of disparate elements, each affording its own terms of reference, gives the impression of a disjunction between intimacy and monumentality. The latter is emphasised by the effect of light and shadow on the bare internal walls, whilst the former finds expression in the sparse display of personal paraphernalia of the artist: an envelope addressed to the artist lies on the window sill; a small mirror hangs on the wall between the windows, showing a ghostly reflection of the artist's head; and a pair of scissors and a key both hang precariously on the wall. The combination of the "cavernous spaces" of the window reveals and the relatively flat scenographic landscape in the background gives the impression of a theatrical set awaiting the arrival of the principal actor (the artist), who in the end never appears. In his place we are left with fragments that ambiguously register his absence.

Gottlieb suggests that the twin openings allude to the Christian symbolism of windows as eyes, only here the eyes are those of the artist which are "filled with divine light". ${ }^{60}$ This direct allusion to Christian symbolism should, however, be treated with some caution given the prevailing cultural conditions of the period, discussed earlier, that would have made such references difficult to sustain.

To understand the significance of the windows in this work we need first to examine the perspective of the paintings. It would seem that both windows were painted from the same vantage point in the studio. This, however, does not result in homogeneity of spaces between both paintings, as one would perhaps expect. Rather, something more disquieting is invoked in their 


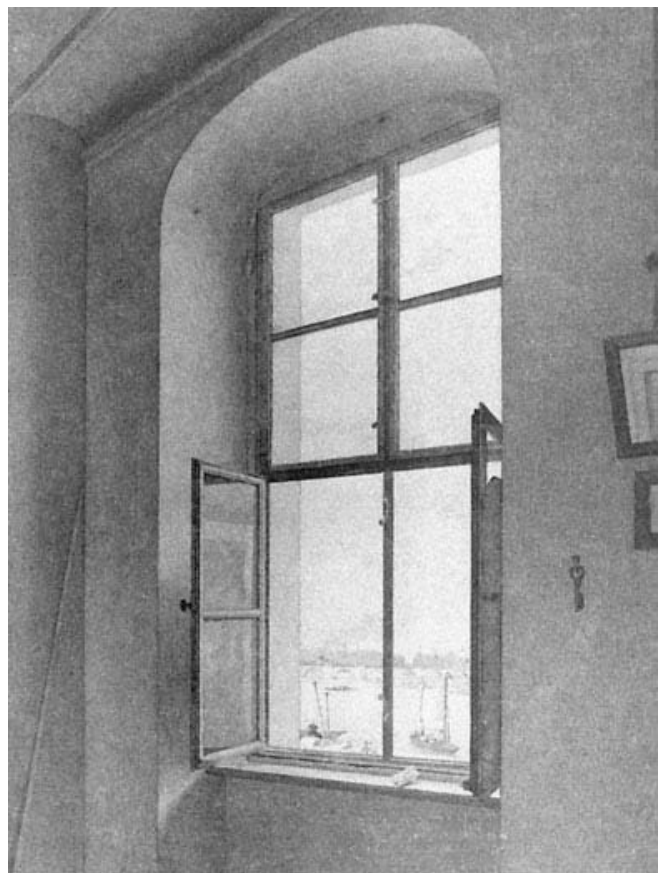

6.6

Blick aus dem Atelier des Kunstlers, 1806, Casper David Friedrich (1774-1840). Left window

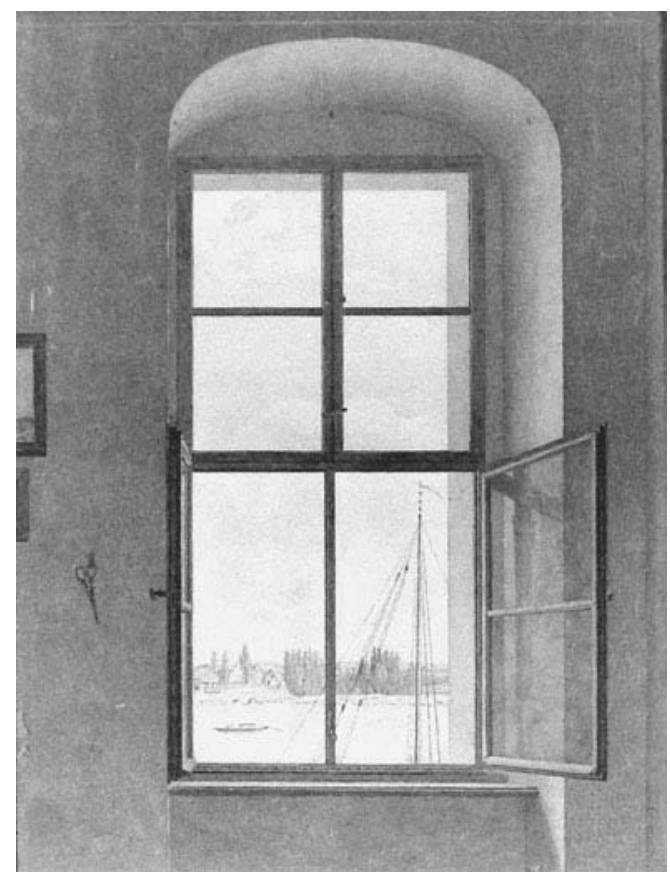

6.7

Blick aus dem Atelier des Kunstlers, 1806, Casper David Friedrich (1774-1840). Right window 
juxtaposition. Considered in perspective terms, we are presented here with a contrast between the almost frontal view of the right window, in which spatial depth is communicated through the proximity between window opening and picture plain, and the oblique projection of the left window defined by the sharp converging lines of the open casements and ceiling above. In the latter case, the effects of light and shadow on the oblique view draws one's attention to the distant landscape beyond the window frame.

The contrast between both windows is further underlined by the different ways in which the river Elbe is represented in each. In the right-hand panel the river is conveyed as a largely static and two-dimensional feature, resulting from the appropriation of the background landscape by the geometrical configuration of the window; the intersecting axes of the horizontal river bank and the tall mast of a moored vessel are framed within the lower right-hand window pane. The lefthand perspective panel, on the other hand, portrays the winding course of the river extending into the depth of the distant landscape. Against this depth, however, are represented river vessels in the middle ground of the painting that appear to pass along the edge of the window sill - as if mooring along its ledge. This ambiguity creates a tension between proximity and depth; a tension that could be said to permeate the diptych.

Implicit in the composition of the work is a disjunction between presence and absence; between the emptiness of the studio, where fragments, shadows and miscellany invoke a ghostly presence, and the brooding sense of imminent departure - of wanting to be elsewhere - articulated in the representation of a moored river vessel in the right panel. These sublime emotions evoke a sense of introspection and melancholia. Hence, the interior of the studio becomes a place of distraction where views of distant horizons provide solace from the memories induced by the scattered remnants of the artist's studio.

The tension between the "mournful" space of the studio and the active life of the working river, visible beyond, reminds one of Friedrich Hölderlin's later period in Tübingen. In Chapter 1, we saw how Hölderlin's itinerant life provided an essential context for sustaining a mythical view of the world; the experiences of the wanderer constitute a poetic narrative of a dream-like landscape where German history and Greek myth become entwined. In 1802 (around the same time that Friedrich painted his diptych) Hölderlin returned to his homeland after a short period as a tutor in Bordeaux, ending his itinerant life. In an advanced stage of schizophrenia, he spent the next four years in a carpenter's house in Tübingen on the banks of the Neckar River. It was here that he lived in a tower (Hölderlinturm) that still exists today and which has become synonymous with the poet's life. ${ }^{61}$ From the elevated vantage point of his window Hölderlin could view the river and surrounding landscape.

It was in this tower that Hölderlin wrote his last fragments of poetry that provide a testimony to his declining mental health. His abandonment of the wanderer's life, in which the poet sought engagement with divine nature through a mytho-historic perspective, and his subsequent withdrawal to the tower, reveals something decisive about the nature and meaning of the modern self. Like the 
over-scaled windows in Friedrich's diptych, where the eyes of the artist seem to be reflected by - and projected into - the artist's studio, Holderlin's retreat to the elevated view is similarly prophetic of Martin Heidegger's idea of modern "enframing"; the world is reduced to a series of "set-pieces" - or tableaux without larger constitutive meanings. ${ }^{62}$

In the case of Friedrich's diptych, this inference of enframing is underlined by an absence of a "measured" relationship between the monumentality and vacancy of the interior space and the open views beyond. The disjunction is further reiterated in the relation between two panels of the diptych. This is suggested by Helmut Borsch-Supan who attaches particular iconographic meanings to the artist's paraphernalia: the left-hand panel represents the "active life" of youthfulness, signified by the hanging key and the flowing river, whilst the right-hand panel, with its hanging scissors - a reference to the cutting of the thread of life evokes imminent death. ${ }^{63}$ In the right-hand scene, moreover, that shows the bank of the river - in the form of an agrarian landscape of rustic houses - we are reminded of some pagan and Early Christian representations of Arcadia/Paradise. ${ }^{64}$

The duality, implicit in the diptych, between youthfulness and death is evocative of the alpha-omega symbolism (of beginning and end) found in Early Christian iconography. ${ }^{65}$ Allusions to passage between one and the other can be found in the images shown reflected in a mirror, located between the windows and therefore represented in both paintings. On the left panel, the mirror reflects the corner of the door into the studio - the "obverse" of the paradise scene shown beyond through the window - whilst on the right panel the mirror reflects part of the artist's head. This second image reinforces the ambiguous anthropomorphism of the painting in the way the flanking windows parade as eyes. Whilst the mirror gives a glimpse of the otherwise hidden recesses behind the viewing subject, the windows in front give us more direct visual access to distant horizons. The resulting tension is never fully reconciled but is rather maintained as a tenuous dialogue.

The ambiguous relationship between religious (eschatological) symbolism and sublime experience evident in Casper David Friedrich's diptych, tells us much about the Romantic age. The once unifying order of seeing and believing, implicit in the Papal Window described in Chapter 4, is here bifurcated into fragments of conflicting spatial-temporal settings. In spite of this duality, however, we get a sense of the artist searching for ways of "bridging" the divide between the distant and the proximate within the horizon of the contemplative subject. Without, however, the kind of mediating symbols, and supporting onto-theological world-view, that gave the Papal Window its meaning we are left relying upon the genius of the artist as the sole unifying agent. In distancing himself from traditional iconography, Friedrich is seeking to let "the forms of nature speak directly, their power released by their ordering within the work of art" ${ }^{66}$ Unlike the disengaged - and dispassionate - reason that prevailed in instrumental thinking in the eighteenth century, Friedrich's work reveals an understanding of order that is wholly enigmatic. ${ }^{67}$ Whilst, however, some Romantic artists believed optimistically in the possibility of restoring one's proper relationship with the world through the 
agency of poetic reverie, the examples of Friedrich's diptych and Hölderlin's Tower seem to suggest a self that is intensely introspective. Notwithstanding this aspect of both "horizons" it is evident that the modern window becomes the final recourse to wished-for unity, but one that has little to do with the aesthetic concerns of Gesamtkunstwerk. Given this context, it could be argued that Friedrich's diptych both reflects upon the embodied world of pre-modern traditions and at the same time anticipates the disembodied world of the late nineteenth century. ${ }^{68}$

\section{Rem Koolhaas' EuraLille and "I'Espace Piranesien"}

Eighteenth-century views of immensity could, in one sense, be said to anticipate the age of late Capitalism; in the increasingly globalised culture of the late twentieth and early twenty-first centuries, whose largely unquestioned adherence to the principle of a conquest of space - chiefly characterised by an abstract and horizontal expanse - can be traced back to the crisis of representation in the eighteenth century. The idea of a "geography" of power, manifested in the modern predilection towards a mastery of space, was already established by the eighteenth century, as we saw earlier in regard to the idea of a "dilated" perspective field.

To what degree, however, this pre-established world-view informed the new global understanding of architecture will serve as the general theme of this case-study. This examines the master-plan of EuraLille by Rem Koolhaas and OMA, and the design of the so-called "Espace Piranesien". The study aims to show how the associations that Koolhaas promotes, between his particular global perspective of architecture and earlier ideological models, are not as straightforward as he implies. In essence, Koolhaas' notions of bigness and congestion could be said to relate only tangentially to the early modern understanding of immensity.

In Koolhaas' extensive writings and publications, in particular his Delirious New York (1979) and more recently $S, M, L, X L$ (1995) he advocates an architectural position that construes space as largely undifferentiated and open to ideological "exploitation". ${ }^{69}$ Whilst in the former work Koolhaas formulates his ideas of the narcissistic city, in which bigness and congestion are key, in the latter he stretches the programmatic possibilities of architecture to their extremes by presenting his own architectural output as an almost unabated visual narrative without specificity. To support this initiative Koolhaas freely juxtaposes images of his built and un-built projects with those of past ideologues. Besides his fascination with the "paper" architecture of Boullée, Koolhaas has also had a long interest in Constructivism and some aspects of the totalitarian architecture of Stalinist Moscow - such as the entries for the Palace of the Soviets. By the sheer bulk and visual overload - of its contents, $S, M, L, X L$ could be seen as intentionally metonymic of Koolhaas' buildings; the reflective silver cover of the book "camouflages" - one might say deflects attention from - the bewildering array of images that comprise its content.

Of all the themes that inform his projects, that of bigness seems the most prominent and persistant. Influenced by Koolhaas' enduring interest in the architectural implications of Capitalism and Communist ideology, bigness serves 
as an effective rhetorical device in his design process. Its deployment provides a critical context in which Koolhaas re-evaluates the socio-economic and cultural power-structures that define the contemporary city.

Challenging the established Modernist precept of a dependency of form on function Koolhaas construes architecture as a facilitator of new spatial and socio-cultural relationships. Initially drawing inspiration from Robert Venturi's decorated shed, Koolhaas sees the production of architecture as a bifurcated operation; the formlessness of undifferentiated space, characteristic of contemporary commercial/corporate activity, provides the ingredients for reinvention. At the same time, the enclosure is treated as it if is disconnected from the multiple activities of interior space, and at the same time is liberated from the "obligation" to respond to the prevailing conditions of the urban context:

In bigness, the distance between core and envelope increases to the point where the façade can no longer reveal what happens inside. Bigness transforms the city from a summation of mysteries. What you see is no longer what you get. ${ }^{70}$

Hence, exteriors and interiors belong to "two different kinds of architectures": the former based on the effects of appearance and the latter open to maximum flexibility and driven by "themes, programs, iconographies - with which the volatile metropolitan citizens, with their overstimulated nervous systems, combat the perpetual threat of ennui". ${ }^{71}$ In place, therefore, of an architecture that seeks continuity between the different levels of form and programme, and therefore mediates the local with the larger whole, Koolhaas' design philosophy remains firmly committed to the "big picture". Hence, there is no differentiation between architecture and urbanism; city and building become effectively coterminous.

Koolhaas' master-planning of EuraLille, an 8.5 million square foot development, provides an interesting case-study of how this vision of the city is manifested architecturally. Located on the edge of the city of Lille in the north of

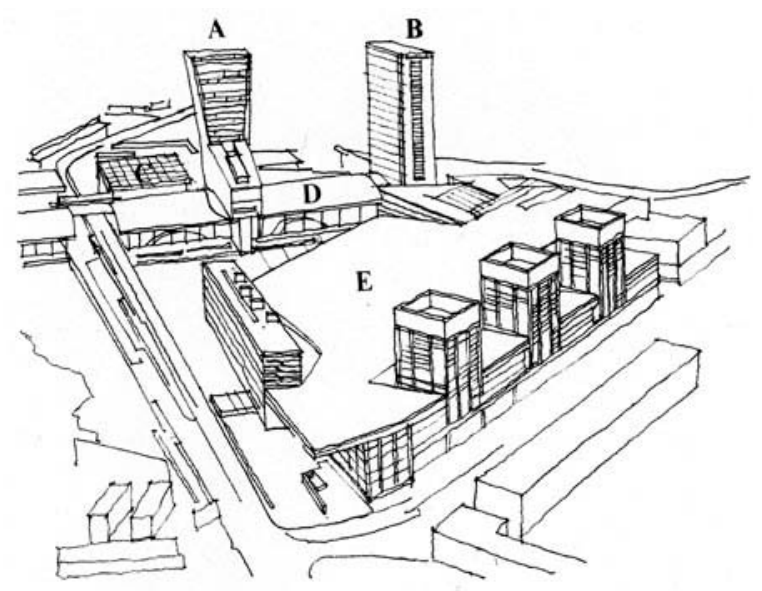

6.8

Outline drawing of the EuraLille complex (excluding Lille Grand Palais), indicating the principal buildings: offices of the Crédit Lyonnais (A); World Trade Centre (B), LilleEurope Railway Station (D) and Shopping Mall (E) 
France - close to the existing railway station - EuraLille stands alone as a synthetic new city, inserted into a complicated urban condition. The project involved the collaboration of a large number of architects, including Jean Nouvel, Claude Vasconi and Christian de Portzamparc. Conceived at the end of Francois Mitterrand's presidency, EuraLille was seen in one sense as a culmination of the "Grands Projets" in Paris, given that it functions at one level as a satellite to the capital city thanks to the development of the high-speed TGV rail link.

It would be a mistake, however, to consider the project only in terms of its regional location. Indeed, from the earliest sketches, it is clear that Koolhaas saw the development as having a potentially European - even international dimension. This is made possible by the principal function of the complex, an inter-European railway station, that serves as a major interchange for trains travelling between Paris, London (via the Euro-Tunnel) and Brussels. By inscribing a circle - whose centre lies at the location of Lille and whose circumference is $200 \mathrm{~km}$ (considered the critical commutable distance for high-speed train travel) Koolhaas "discovered" that the encircled space encompasses all the cities named above. Hence the TGV minimises the hindrance of distance and gives Lille a strategic European location. As Koolhaas points out:

It will become the center of gravity for the virtual community of 50 million Western Europeans who will live within one and half hours travelling distance. If you are English, you can set up office in northern France and be "closer" to the city of London than you would be to some parts of greater London itself. You can organize a concert in Lille where anyone from London, Paris or Brussels can attend. ${ }^{72}$

6.9

Rhetorical map of

Europe showing concentric rings emanating from Lille, Rem

Koolhaas. Taken from Rem

Koolhaas and

Bruce Mau,

$S, M, L, X L$ (New

York: Monticelli

Press, 1995),

p. 1158

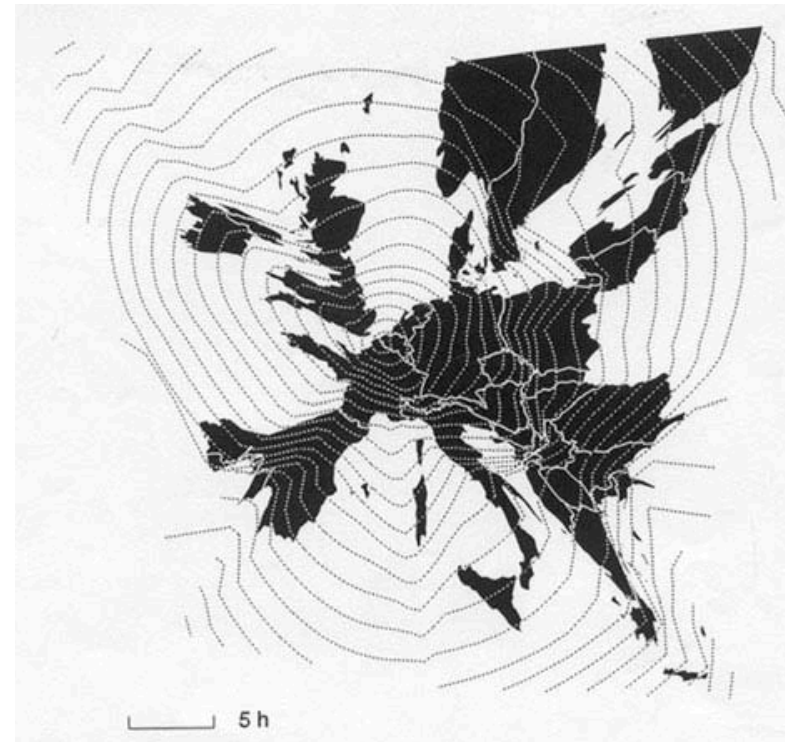




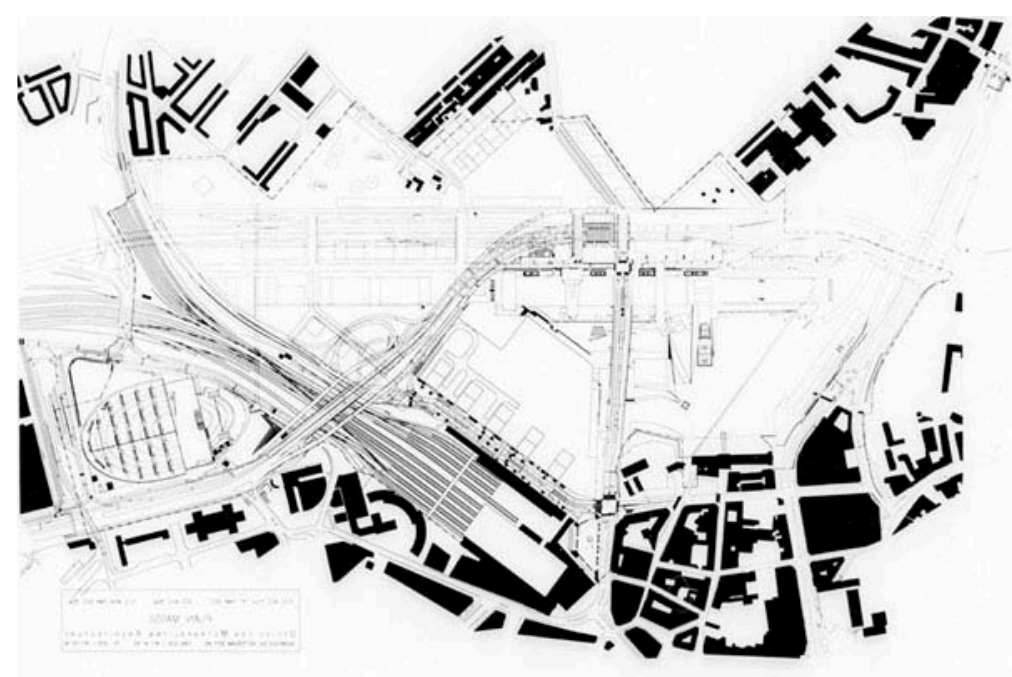

6.10

Master plan for EuraLille, 1989-95,

Rem Koolhaas and OMA. General plan

By conceiving the project in terms of transportation links between major capital cities (and therefore countries) Koolhaas transgresses the local and urban conditions of the site and the surrounding city; "It has not been spawned by Lille: it has landed there."73 Hence, the project could be described as "self-contained", forming a node in the network of transportation interchanges across Europe and beyond. It is as a result of this placelessness that Koolhaas gives due priority to the infrastructural concerns of the complex and its overall aesthetic appearance, over and above contextual relationships. To achieve this, OMA had to alter - or realign - an extraordinary amount of existing structure.

Koolhaas seeks to change the "psychological space of northern Europe" by creating an urbanism that is governed by macro temporal concerns (as defined by duration between cities), instead of the more local spatial relationships between buildings and the existing fabric of the city. ${ }^{74}$ "What is important about this place is not where it is but where it leads to and how quickly - in other words, to what extent it belongs to the rest of the world."75

The project comprises four main parts: the TGV station (with supporting offices and hotel), a huge shopping mall, the Congrexpo or Lille Grand Palais (a vast oval building accommodating exhibition centre, convention centre and concert hall) and finally a green park. Each part of the development is characterised by distinct formal attributes. The development is laid out within a complex network of railways and roads. One of the requirements of the design was to ensure a clear visual and communication link between the new and existing railway stations. At the same time, Koolhaas had to deal with the existing topographical relationships between the main highway, which passes adjacent to the site, and the TGV railway lines. Added to this was the introduction of a major underground regional railway station at the intersection of these routes; accessed via the so-called "Espace Piranesien" to be discussed later. Considering the inherent difficulties of the site (or sites), resulting from the existing infrastructure, the 
6.11

Master plan for EuraLille, 1989-95, Rem Koolhaas and OMA. View of main entrance to shopping mall

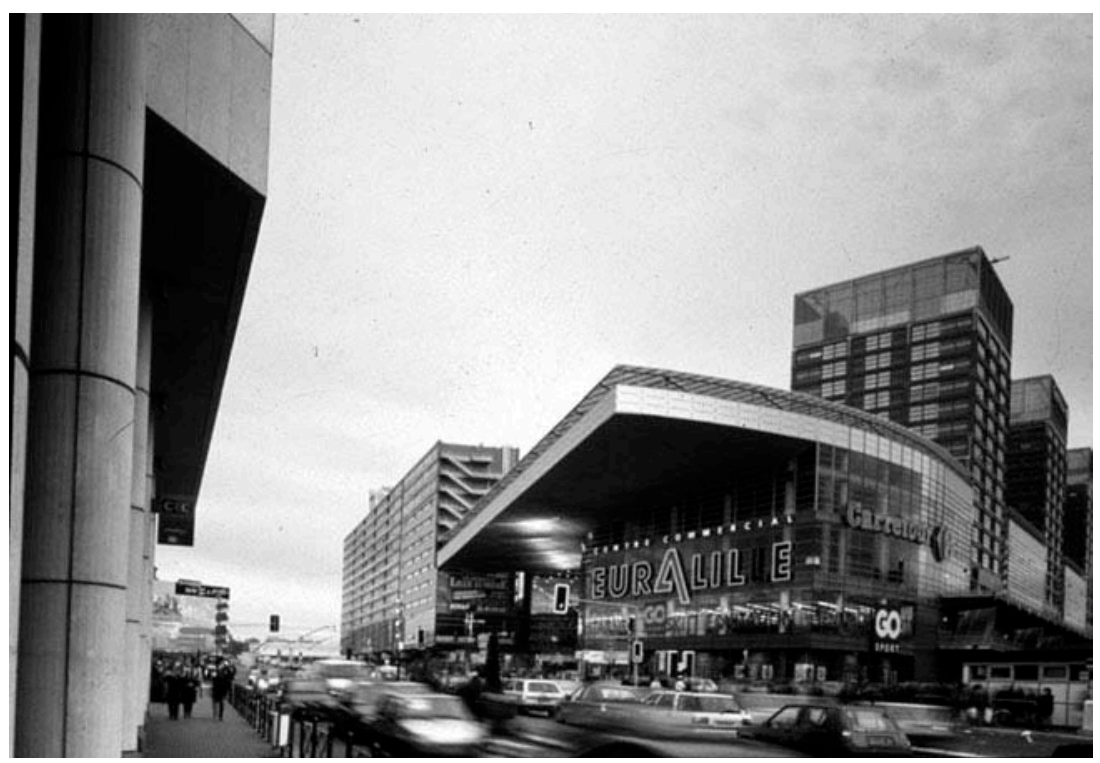

whole master-plan could, in one sense, be described as an exercise in "plumbing" on a regional scale.

Each part, or subsidiary element, of the site was allocated to one of the chosen architects whilst Koolhaas maintained overall control of the master-plan. These individual projects were developed on the basis of distinct programmes and functions. Whilst Jean Nouvel received the project for the huge shopping complex, Koolhaas designed the conspicuous oval-shaped Congrexpo, a huge congress centre with supporting exhibition space and auditorium located on an isolated site. Supporting the vast complex of buildings of EuraLille is a 10,000 space car-park, reputedly the largest in Europe.

From this brief outline of the EuraLille we begin to get a picture of an amalgam of monolithic structures, the forms and scales of which seem incongruous with the morphology of the old city of Lille. Among these is the location and layout of the new railway station. Signalling the extended axis of the station is a series of high-rise office buildings located above - or adjacent to - the track of the TGV. These include the rather bland World Trade Centre by Claude Vasconi and the more distinctive "boot tower" (offices of the Crédit Lyonnais) by Christian de Portzamparc. Parading as iconic objects, these towers seem alien to the surrounding urbanscape, evoking more an imagined - placeless - metropolis delineated by the trajectory of the TGV between Paris and Brussels.

Sited between the old railway station of Lille and the new railway station of EuraLille is the huge triangular block of the shopping complex designed by Jean Nouvel. The vast expanse of flat roof that dominates this building is interrupted by a series of office blocks that punctuate its perimeter. Like an airport shopping mall, this retail complex is intended to serve "international" consumers travelling en-route to other destinations. In the wedge formed between the TGV 
terminal, shopping complex and elevated road is a large out-door space intended as a formal garden. One can only ponder over the purpose of this space as a gathering area, given that the functions of the buildings that surround it seem to preclude any obvious out-door activity - even as a means of access.

It is as if, in the absence of any considered relationship to the city of Lille, the principal objective of EuraLille is containment to ensure maximum profit within the limited period of transit for the travelling consumer. Upon arriving at the station one gets a passing glimpse of the old city from the insulated comfort of the TGV. This physical and psychological separation is maintained within the building complex in such a way that it amplifies Koolhaas' abiding principle of bifurcation between interior space and external envelope. We could construe this perennial - universal - state of transit, which the complex of EuraLille exemplifies, as constituting the antithesis of the urban and regional specificity of Lille.

Considered in the context of eighteenth-century notions of immensity, something interesting is revealed in the EuraLille model. As I have already intimated, the articulation of a "dilated" perspective field in the subliminal landscape of the eighteenth century was informed by what was generally understood as a synonymous relationship between divine infinitude and the immensity of nature. In the quest for objective certainty that underlies eighteenth-century scientism, space becomes "flattened". Consequently, depth is subsumed within the infinitesimal expanse of an unmediated middle ground. From this permanence of an abstract middle ground distance can no longer be "measured" by perspectival means. We get a sense of this crisis in Casper David Friedrich's diptych discussed earlier. It could be argued that the spatial conditions prevalent in EuraLille derive in part from late eighteenth-century sensibilities. The maintenance of a disengaged relationship with the "external" world is echoed at the local level by the absence of any tangible references (such as tectonic or material qualities) that differentiate one space from another. Instead we are presented with generalities of surface that undermine any sense of particularity or definition. In attempting to construe space as an exclusively temporal domain, without measurable references to place or locale, Koolhaas has resorted to a homogenised middle ground redolent of eighteenth-century views of space; the disconnection from both distant (general) and proximate (local) domains results in an ambivalent and measureless field.

In one sense we can discern in EuraLille an attempt to redefine the eighteenth-century idea of the architectural object transgressing its traditional specificity of place by usurping its surrounding landscape. However, in the case of EuraLille, this claim to a larger constituting order takes on a particular rhetorical note in the manner in which the complex is presented iconographically as part of a larger European geography.

In spite of the variety of architectural forms prevalent in EuraLille the resulting effect is strangely ambivalent. Rafael Moneo's use of the term "cocktail architecture" - to convey Koolhaas' work in general - could equally be applied to this collaborative project. ${ }^{76}$ We are confronted, in the midst of formal variety, with largely undifferentiated space; sameness pervades the mega-structures of the complex since the absence of any means of comparability - through scale or 
material specificity - leads to a homogeneity of sorts. To this extent, Koolhaas could be seen as the very antithesis of Álvaro Siza, as Moneo asserts: "in the name of contemporaneity, Koolhaas wants his architecture to be global, universal, unlinked to specific conditions of place. This is diametrically opposed to Siza's attention to accident, the specific." 77

In this respect, Koolhaas, and his collaborators, have taken the scenario of the airport terminal to its ultimate conclusion; the creation of mass transitionary space results in a suspension of a "grounded" reality and in its place we are left "killing time" - or what Koolhaas describes (and referred to earlier) as a combating "of the perpetual threat of ennui". ${ }^{78}$

This suspension of a grounded reality is, however, rather different from the emotionally charged experiences of eighteenth-century landscapes, as we saw earlier in regard to the sublime. It would seem that underlying the methods and techniques of "inducing" sublime experience in these landscapes was an attempt to salvage some residue of revelatory experience. In other words, notwithstanding the artificial methods deployed in this enterprise, eighteenthcentury landscapes were still regarded as an expression of divine creation. Like the "arresting language" of Hölderlin, the sublime landscape could also be seen as an attempt to awake us from the slumber of seemingly unremitting scientific progress. It is only when the belief in a divine otherness is finally - and irretrievably - removed from the experience of landscape that such technologically driven projects as EuraLille become possible and ultimately convincing.

Allied to the eighteenth-century idea of landscape as ultimately "God's work", is the issue of "character" that defines the order/regularity of volumes and their perception. The term could be seen to establish the "foundation for a selfreferential architectural order". But such an order still assumed, at least in some form, a symbolic culture. ${ }^{79}$ Indeed, character provided a semblance of continuity with a background tradition, in the face of undifferentiated and limitless space. Accordingly, character could be said to "rescue" architecture from the abyss of the infinitesimal. It is in this context of undifferentiated space that we could consider Koolhaas' "cocktail architecture", in particular its attempt to parade a sense of internal cohesion (through juxtaposition and variety) in the midst of an abstracted and limitless space devoid of larger constituting order.

Perhaps the clearest exposition of the differences, and similarities, between eighteenth-century views of order and those reflected in the EuraLille project are highlighted in the so-called "Espace Piranesien". As the name implies, Koolhaas construed an affinity between the vast network of transportation routes at EuraLille and Piranesi's imaginary scenes in his famous Carceri etchings. Taking the idea of the latter as polemical of a subtraction of building and therefore of a "negative" architecture - Koolhaas creates a subterranean void that is flooded at its base and "open" to the sky via a glazed space frame roof structure. Like a Gordian knot, the "Espace Piranesien" attempts to give monumental significance to the confluence of transportation routes that comprise the EuraLille complex. This finds expression in the web of pedestrian bridges, lifts and stairs that criss-cross the cavernous space. These provide 


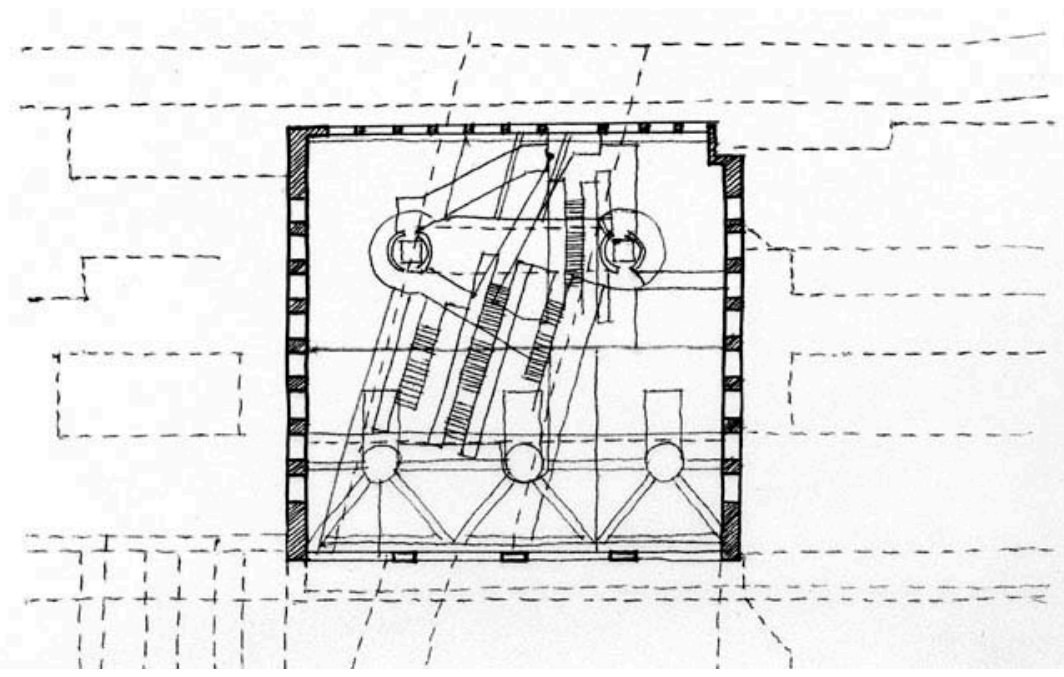

6.12

Master plan for EuraLille, 1989-95, Rem Koolhaas and OMA. General plan of "I'Espace Piranesien".

Drawn by author after OMA

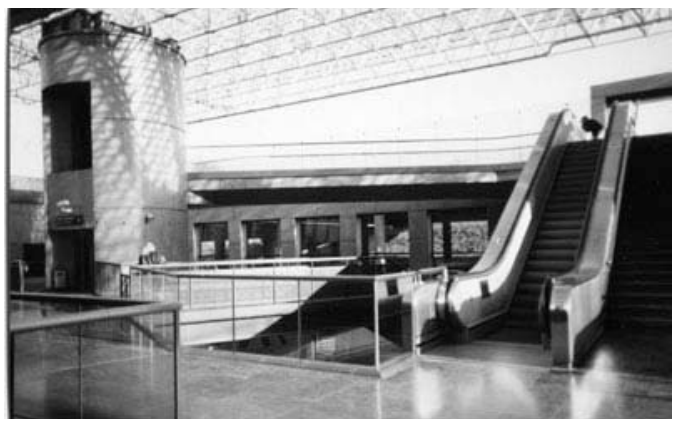

6.13

Master plan for EuraLille, 1989-95, Rem Koolhaas and OMA. View of upper level of "I’Espace Piranesien" showing glazed roof

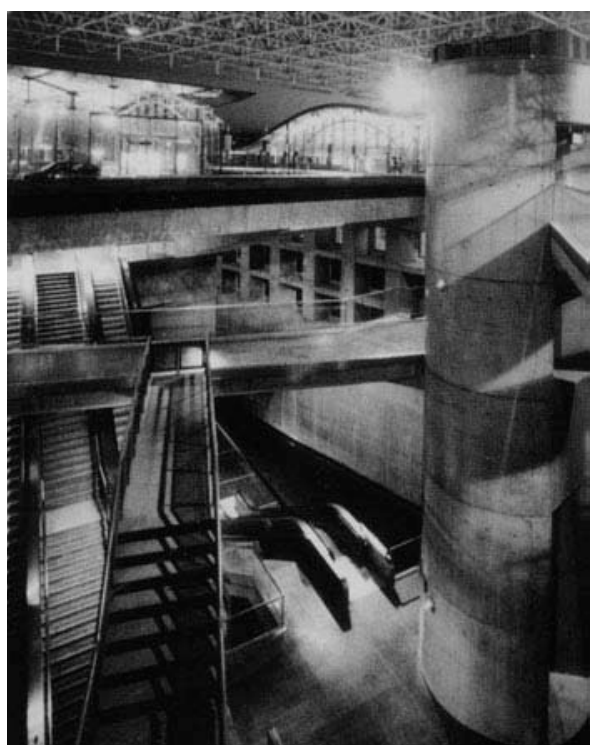

6.14

Master plan for EuraLille, 1989-95, Rem Koolhaas and OMA. View of "I'Espace Piranesien" looking down towards the flooded base 
access to the highway, railway, three levels of car-parking and finally a regional metro at the lowest level.

The association, however, of "I'Espace Piranesien" with Piranesi's etchings requires further examination. At one level the association would seem to be flawed given that Piranesi's imaginary scenes are untranslatable as legible spaces. ${ }^{80}$ The very impossibility of their construction, and the manner in which the representations are denied a stable centre, reveal a culture in crisis. Indeed, the general disintegration of traditional order, prevalent in the eighteenth century, finds perhaps its clearest expression in the "disarticulation" of structure in the Carceri. Such disarticulation, as Tafuri argues, "induces the spectator to recompose laboriously the spatial distortions, to reconnect the fragments of a puzzle that proves to be, in the end, unsolvable". ${ }^{81}$

The very impossibility of translating these scenes into actual physical spaces is echoed by the equal impossibility of translating them into discursive eidetic constructs, in the manner of Platonic thought. This, perhaps more than anything, signals the demise of a "preestablished harmony" and therefore of a symbolic understanding of perspective. ${ }^{82}$ Significantly, Tafuri describes the perpetual irreconcilability of elements in the Carceri as a kind of metaphorical voyage; a labyrinthine journey without end and replete with painful encounters. ${ }^{83}$ Enmeshed in the tentacles of heterotopia the voyager is enslaved by the conquest of a mechanically conceived universe.

It is in the light of this idea of a perpetual journey - a journey that spawns a myriad of alternative routes - that one recognises a certain affinity with "I'Espace Piranesien", albeit one that is less polemical and ultimately more prosaic. What is revealed in this space is essentially an "aestheticisation" of disorientation and anxiety, presented, however, in the guise of utility and efficiency. Transient space is monumentalised and presented as a chthonic world of water, concrete and light. To this extent, it is the very reverse of Koolhaas' strategic map of Europe with its much vaunted conquest of geographical distance through high speed travel. The seemingly effortless journey of the TGV is interrupted abruptly in "I'Espace Piranesien" by the transformation of pedestrian passage into a bewildering network of routes. Its impact upon the passenger has the effect of transforming the appearance of efficiency and assured technological determinacy into little more than a problem of plumbing. The result of this transformation of the generalities of congestion and bigness is a spatial phobia - a personal horror vacui.

By leaving the transit passenger disoriented and running breathlessly for the next train, "I'Espace Piranesien" affirms the distopic nature of modern technology and globalisation, a condition that in some ways was foreseen in Piranesi's etchings. 


\section{Chapter 7}

\section{Disjointed views}

\section{Attention and perspective}

As we saw in Chapter 6, in the context of Casper David Friedrich's diptych, the window takes on metaphorical significance of the modern self; its demarcation of physical and visual boundaries evokes a tension between one's thoughts and emotions and the world "out there". This bifurcation was heralded in Descartes' introspective stance. Motivated by a desire for epistemological certainty - in the face of equivocations of everyday encounter - Descartes saw the window as an appropriate motif for redefining our circumspect relationship to the world:

If by any chance I look out of the window and see men crossing the square, I normally say that I see the men themselves ... And yet, what do I see from the window if not hats and coats (that) could conceal spectres and automata? But I judge that they are real men. Thus something which I thought I was seeing with my eyes is in fact grasped solely by the faculty of judgement which is in my mind. ${ }^{1}$

Essential to Descartes' philosophical outlook is the need to reside at a safe distance from the city, both psychologically and geographically; to be able on the one hand to retain solitude in the crowd and on the other to seek refuge from the city by inhabiting its periphery. In attempting to avoid, where possible, the deleterious effects of outside disturbance on his cogito Descartes uses reason as a mental filter through which the act of seeing can be distinguished from the clarity of a priori judgement, between mere appearance and authentic reality. By demarcating a mental distance through the processes of rational argument - between the physical window (from which we apprehend the visible world) and the mental framework of our thoughts - Descartes attempts to distinguish fact from construed reality.

Questioning Descartes' mental window, Hubert Damisch argues that "Had Descartes indeed considered agitation in the street 'by chance', without premeditations as opposed to going to his window merely in thought; he would not 
have hesitated even for an instant, to see men there." 2 Damisch is alluding here to the experience of the nineteenth-century city where Descartes' appeal to abstract systems of judgement is irrevocably disturbed by relentless commotion and distraction. It is in the context of the social, industrial and cultural transformations of the nineteenth century, in which the city emerges as both a place of intense production and as a centre for mass consumption, that the window becomes a critical device for articulating one's perspective as private space. Christopher Prendergast argues this point in the context of the poems of Charles Baudelaire: "The window may invite a fertile transaction between the poet and the city, but more often it serves to open up a gap between subject and object to bring about cleavage rather than communication." ${ }^{3}$

What differentiates, however, the nineteenth-century window from the meaning advanced in Descartes' philosophy is that, in the case of the former, the view no longer serves circumspectly as a critical framework for reflective thought, revealed as little more than a phantasm against which the epistemological certainties of metaphysics are re-affirmed. Instead, the observer's gaze glides over multiple points of reference without prolonged focus, only to pause "momentarily on contingent particulars, and then move on as in the shift of attention". ${ }^{4}$

This chapter examines the nature and meaning of the view in the nineteenth century by initially examining Charles Baudelaire's prose poem "Les yeux des pauvres" ("The eyes of the poor") and Emile Zola's novel La Curée ("The Kill"). The disjointed experience of seeing, that was most acutely felt in the perception of the nineteenth-century city, reflects a largely disembodied self. One of the characteristic features of modern disjointed experience is a profoundly antioptical approach to vision; the priority given to scenographic effect challenges the epistemological assumptions underpinning the Classical model of a geometry of vision. Anticipated in the eighteenth-century idea of dilated perspective outlined in Chapter 5, with its principles of immensity and infinity, the shift of attention is brought about by a mobility of vision structured around a fragmentary understanding of the world. One of the consequences of this disjointed outlook is the reduction of perceptions of the city to two dialectically related terms of reference: the panorama and the magnified view. Both modalities of seeing could be said to "collide" at the elevated street window, the interface between interior space and exterior expanse, creating visceral disturbance that galvanises social discord and unease. Denied a mediating realm, the modern window constitutes a bifurcated zone that separates the intensely introverted world of domestic space from the amorphous - almost dream-like - scenography of the city beyond. Combined, both illustrate the essentially dual nature of perceptions of the nineteenth-century city. The duality, moreover, could be more succinctly defined as a conflict between the street, with its associations of unruly mobs and civil disturbance, and the overwrought and claustrophobic interiors of the urban/suburban dweller.

The present chapter explores aspects of the urban panorama and the magnified view, in particular their impact on a perspective understanding of the city. At a time when initiatives to encapsulate visual experience were critical to distilling the complexities of modern urban life, we see emerging in the nineteenth 
century carefully choreographed - or simulated - impressions of the city. These are typically expressed in photography and painting where urban space is represented as a series of captured moments - or impressions - that seek to arrest, and thereby suspend, rapid cultural, social, political and technological change. The resulting effect, as we shall see in the case of Paris, is the appearance of visual homogeneity in an otherwise heterogeneous and fragmented urban experience. In such initiatives the framed spectacle emerges as the dominant overview where the particular and the general - the city as personal experience and as collective celebration - become effectively disconnected. Significantly, as I will argue later, only at the scale of the domestic can such a disjunction be brought to a level of comprehensibility. We see this most poignantly in the way the city is abbreviated as an assembly of personal memorabilia that clutter the mantel-pieces and glass cabinets of urban and suburban dwellings. ${ }^{5}$ One of the consequences of this disjunction is that urban space is perceived increasingly as a territory for disinterested observation - as the realm of the flâneur. ${ }^{6}$

In the context of the panorama, distance is constituted around geographic remoteness, whereby the elevated viewer seeks to absorb the city as a totality. Hence, the panorama provides a visual framework for encapsulating - and thereby mastering - the horizon and its supporting geo-political, cultural and technological associations. I will examine the notion of encapuslation in the specific context of nineteenth-century Paris, highlighting through Honoré Balzac's The Girl with the Golden Eyes the idea of the city as a dreamlike - fossilised - landscape without physical qualities or even obvious signs of life.

The magnified view, on the other hand, draws meaning from the distortions inflicted by excessive magnification of desirable objects or settings. Expressed in Marcel Proust's Remembrance of Things Past the observed detail (whether in the form of a napkin, a woman's cheek or the corner of a mirror) becomes a fragment of erotic obsession divorced from any larger constituting reality. The emphasis on magnification will inform a more general discussion of domestic life in the nineteenth-century city.

In both the panorama and magnified view the utility of the middle ground, as a mediated realm between proximity and depth, is effectively abandoned in favour of the extremities of the visual field. To these must be attributed a belief - or perhaps a hope - in a "mastering totalisation" where both detail and generalisation can, in themselves, encompass the totality of human experience. ${ }^{7}$ The reality, however, reveals a rather different situation, one of potentially conflicting spatial conditions; between the paraphernalia and material attributes of the nineteenth-century urban dwelling and the more rationalised realm of the cityscape (the latter exemplified in Baron Haussmann's transformations of Paris and later world expositions). The themes pertaining to both forms of visual encapsulation will be explored further in the context of the house of the symbolist painter, Gustave Moreau, outlining relationships between the artist's work and his studio.

Finally, the chapter concludes with an examination of Eric Parry's project for the studios of Tom Philips and Antony Gormley in Camberwell, London. 
By interpreting the project through Parry's enduring interest in the architecture of fin-de-siècle Europe (in particular the work of Victor Horta) I will argue that his attempt to create an architecture conducive to artistic exploration was fostered in part by a critique of modern urban life, of which the nineteenth-century city was key.

\section{Attention and distraction}

A pervading theme in the nineteenth-century perceptions of reality, particularly during the last decades, is the priority given to the search for attentiveness. Explored in Jonathan Crary's recent book Suspensions of Perception, the emergence of the modern condition of distraction in the nineteenth century can best be understood by examining its reciprocal relation to the "rise of attentive norms and practices". ${ }^{8}$ In this relationship nineteenth-century notions of perception departed from the privileging of vision found in the geometrical constructs of optical science. Characterised by such notions as synaesthesia, the emphasis on the interplay between the senses was, according to Crary, an attempt to recover embodied experience and thereby overcome the excessively scientific outlook of the period. He describes this modality of perception as "physiological optics" that is informed by instantaneous, or atemporal, perception. ${ }^{9}$

In this new emphasis on extempore experience, as opposed to preemptive judgement, attention becomes a critical factor in determining engagement in an otherwise detached environment. The problem of attention arises during the nineteenth century as a result of what Crary describes as "the historical obliteration of the possibility of thinking the idea of presence in perception". ${ }^{10}$ In other words, the scientific emphasis on the instrumental role of perception undermines the ontological foundations of human experience. As a reaction to this, attention serves as both "a simulation of presence and a makeshift, programmatic substitute in the face of its impossibility". ${ }^{11}$

In the apparent freedom of the modern observer - unconstrained by traditional belief-structures and practices - perception is predicated on the contradictory principles of absorption and deferral. ${ }^{12}$ The emphasis on attention assumes the need for psychological effort on the part of the perceiving subject, when confronted by the distractions of a culture in precipitous change. Accordingly, attentiveness could be considered as the modern psychological equivalent to the embodied notion of attunement. In the latter, as we saw in Chapter 2 in the context of Lincoln Cathedral, reception to divine otherness requires a revelatory experience of the penitent observer. Significantly, in the late nineteenth century we witness an interest in the psychological impliciations of such experience, albeit one that does not assume the authority of divine transcendence but rather constituted in thoroughly immanent terms. Here, experience is partly self-induced, brought on by the cultivation and re-sensitising of the senses. Expressed in the artistic and literary endeavours of the Decadent and Symbolist movements, and in the architectural innovations of Art Nouveau, the attempt to re-establish the richness and diversity of human experience was underpinned by a growing belief in the decline of the human race. Influenced by Darwinian theories, the completion 
of humanity's evolutionary process was considered by some as signalling a future of terminal decline and ultimate extinction. ${ }^{13} \mathrm{~A}$ contributory factor in this process was the physical and mental exhaustion inflicted by the demands of a culture dominated by production and commerce. Not surprisingly, the nineteenth century witnessed an intense interest in maladies and mental illness which it saw as symptomatic of social and cultural vitiation. ${ }^{14}$

The shift from an attuned to an attentive understanding of space is registered in the transformation from an encroaching perspectivisation of cosmological traditions - witnessed in the Middle Ages - to a psychological understanding of perspective characteristic of nineteenth-century culture. A critical turning point in this gradual transformation, as I pointed out in Chapter 1, can be found in Emmanuel Kant's transcendental philosophy. For Kant, "all possible perception could occur only in terms of an original synthetic unification principle, a self-cause, that stood over and above any empirical sense experiences such as vision". ${ }^{15}$ This assured pre-ordained order underwent what Crary describes as a "steady demolition" in the nineteenth century. ${ }^{16}$ In place of Kant's transcendental unity is Arthur Schopenhauer's notion of will that was central to nineteenth-century views of attention. According to Schopenhauer, attention is linked to perceptual disintegration. ${ }^{17}$ The window becomes in this instance a potent metaphor for evoking the observer's much-needed frame of reference in the face of uncertainty and dissonance. Accordingly, it "opens onto the cognitive chaos of modernity against which attention will be conjured up to do battle". ${ }^{18}$

It is through the ideas of Frederick Nietzsche, however, that the concept of will is given spatial-temporal significance. No longer considered a path to some culminating truth, the quest for synthesis entails instead a "shifting alignment of forces that was endlessly creative and metamorphic". ${ }^{19}$ As I outlined in Chapter 1, Nietzsche gave new emphasis to the experiential - as opposed to the optical - nature of the perspective field. Overturning Leibniz's theological metaphysics, Nietzsche replaces the idea of an all-perceiving Being (monad) with the idea that all sensuous being is perspectivally oriented to the world. ${ }^{20}$

In this perspectivism, attention becomes a psychological vehicle for resisting change by functioning as a mechanism for capturing the moment, as Nietzsche argues: "I do not posit 'semblance' in opposition to 'reality', but on the contrary take semblance to be reality which resists transformation into an imaginative 'world of truth'. A particular name for that reality would be 'will to power' ". ${ }^{21}$

This relation between semblance and reality underpins Nietzsche's perspectivism which he considered the expression of will to power par excellence. In this process "any given fixed apparition ... allows life to rest firmly on a particular perspective and to preserve itself". ${ }^{22}$ Paradoxically, the attention underlying Nietzsche's perspectivism is a means of forgetting, whereby the flux of human existence is given an atemporal dimension. ${ }^{23}$ Accordingly, one's perspective of the world would "attain instants of eternity" which can overcome the destruction of a contemplative realm wrought by modernity's emphasis on production.

The significance of the window in nineteenth-century culture, as a motif of wished-for stability, takes on a particular meaning when we consider it in 
the context of the "atemporal dimension" of Nietzsche's perspectivism. In reference to Baudelaire's poem "Les Fenetres", "The window is fertile in that it opens a space for the productivity of the imagination, supplies a passage from vision into reverie and a release from self into otherness". ${ }^{24}$ However, as Prendergast makes clear, the relation between the poet's gaze and the window "proves potentially deceptive", given the inability to "connect the inward imperatives of the imagination with the outward forms of the real" ${ }^{25}$ The result is that the once communicative domain, ensured by the interplay between seeing and believing (discussed in Chapter 3 in the context of the Papal Window), is replaced by an irresolvable dissonance. Damisch describes this relationship in the following terms:

For the drift to which the air, moreover, and even the noises of the city expose the modern subject is not, or is no longer, an affair of either perspective or point of view, nor of judgement. Even if he remains in his lodging, the mere opening of the window can provoke in him an overflow that literally flings him outside of himself. ${ }^{26}$

The cleavage invoked by the modern window, between one's lodgings (whether it be a domestic interior or other private space) and the mechanised city of the

7.1

Jeune homme à sa fenêtre, 1875 , Gustave Caillebotte (1848-94)

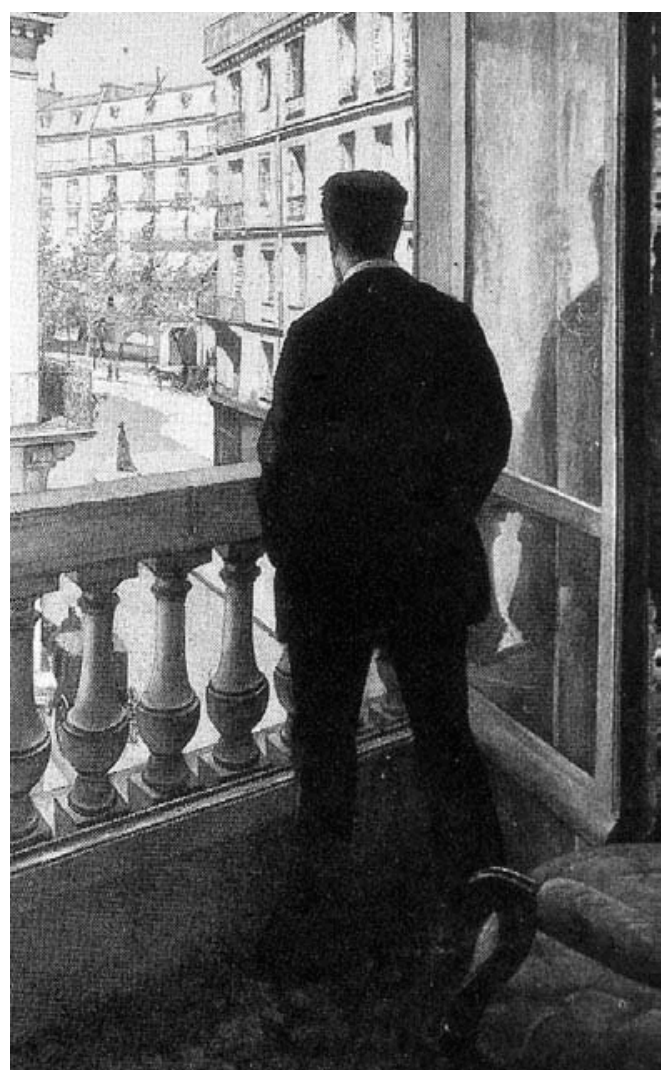


outcast or mob, finds expression in two literary works of the nineteenth century: Baudelaire's poem "Les Yeux des pauvres" and Zola's novel La Curée. The first describes a scene in a café along one of Baron Haussmann's boulevards. There are two main characters in the poem, the narrator and his lover, both sitting alongside a window on the paved terrace. The narrator describes an enchanted scene created by the "dazzling lights and decorations of the café's interior" ${ }^{27}$ The illusion of luxury and gratification conveyed in this scene is brought to an abrupt halt by unexpected intruders. The lovers notice a poor family - a father and his two children - looking with curiosity through the café window. What was earlier a scene of unbridled tranquillity, in which the spectacles of the outside world and the interior space conflate at their intersection along the privileged vantage point of the paved terrace, is disturbed by the intrusion of unwanted outcasts. They disrupt the tranquil setting by invading the private space - and insulated lives - of the lovers:

For the lovers the window initially frames a scene of urban pastoral; for the poor it is a barrier. From the clash of those two meanings of the window, the relations of looking and seeing issue in a splintering of the images the narrator-lover wishes to find and have confirmed. ${ }^{28}$

From this moment the scene of reciprocated affection is transformed into one of resentment and agitation brought about by the different reactions of the lovers. Faith in the principle of democratised space, heralded by the building of the boulevards and in the attendant notion of a multivalent perspective field, is undone by the reality of unbridgeable difference. The "dream-machine" of the café becomes an instance of only short-lived - ephemeral - delight, whose destruction is ironically inflicted by the very mechanism (the window) that sustained its earlier harmonious identity.

A somewhat different situation is portrayed in Zola's novel where lovers are described occupying a first-floor dining room in the Café Riche. Unlike the street scene evoked in Baudelaire's poem, Zola deliberately locates the lovers at an elevated position, removed from the bustle of the boulevard and yet in its visible range. Here, the window of the private dining room redefines within its frame of reference a shared perspective view of the boulevard. But such a view is emptied of involvement - of emotional engagement. In attempting to achieve a "perspective of mastery on the city", by the elevated location of the view of the boulevard, the reality of "bright and mobile forms" leads to a "blur, in the consciousness of the observer", that in turn merges "into the condition of the indistinct and the undifferentiated". ${ }^{29}$ Prendergast argues that such disconnected observations prefigure "the alienated perspective of modernism, the existentially estranged viewpoint on the city characteristic of a great deal of twentieth century literature" ${ }^{30}$

In both examples, of the street scene in Baudelaire's poem and the elevated view in Zola's novel, we are left with a loss of meaning in the perspective field. This is the very condition that Nietzsche seeks to transcend by his notion of 
human will as the motivating force behind one's point of view. Denied, however, the kind of attentiveness advocated by Nietzsche - in which the moment is surcharged with atemporal significance - the observer is compelled to dwell aimlessly in the gap separating the introspective self and the flux of the city. Prendergast argues this point in relation to the scene in Zola's La Curee:

the removal of the perspective of sense and the principle of differentiation is accomplished at a price. If the construction of an intelligible, discriminating image confers an "identity" on the city by shutting out the anomalies which threaten the coherence of that image, then not making sense involves a shutting out; the view of the city as unintelligible, as having no distinct identity, conveniently overlooks what Zola's text does not forget: that, behind the abstract faces in the deceptively uniform crowd ... there are important distinctions, and that to represent the city as a blur is to lose sight of real social structures of difference and division. ${ }^{31}$

The existence of these structures of difference and division becomes the catalyst for Nietzsche's perspectivism where observation is not merely a discriminating act to determine the relation between beings. ${ }^{32}$

\section{Illusion of a "mastering totalisation"}

Characteristic of nineteenth century-views of attention is the manner in which they lead to a "narrowing and focusing of conscious awareness" and thereby to a "shrinkage of the visual field". ${ }^{33}$ This is echoed in Nietzsche's contention that in modern culture a "narrowed attentiveness" is central to perspectivism. ${ }^{34}$ It is interesting to consider this condition in the light of the development, and popularisation, of the panorama in the nineteenth century. The emergence of a "worldpicture" during this period - advanced in part by unprecedented international trade and industrial development - doubtlessly contributed to the establishment of the panorama as one of the principal organising mechanisms for visualising an expanded horizon. The notion of horizon is especially critical here, given that it served as the visual armature around which modern constructs of universal space were articulated. ${ }^{35}$

Historically, the horizon, as both a mental construct and a visual reference, has played a central role in the understanding of perspective. In both practical and psychological terms, horizon defines a relationship between the known and the unknown worlds. It became a mental reference for the recorded voyages of Nicholas Cusanus and Johann Wolfgang von Goethe. ${ }^{36}$ As I indicated in Chapter 6 , the prominence given to the horizon in the vast architectural landscapes of Boullée in the late eighteenth century reinforced the sense of nature's overwhelming immensity and therefore divinity. In the nineteenth-century panorama, however, the horizon served a different purpose. Emptied of associations with nature's divinity, it functioned as a purely instrumental device to underline a hoped-for mastery of totalisation, whereby the particular and the local are 
subsumed within an all-encompassing overview. The absence, however, of a discernible frame of reference in the panorama created anxieties about absorbing or "taking in" - the view:

This new and overwhelming impression of an apparently limitless horizon defeated the attempts of the unpracticed eye to take it in, just as the mind struggled to take in and express in words the experience of being completely surrounded by water. ${ }^{37}$

One consequence of the difficulty in taking in the view is the shift in the understanding of the panorama from a stance of pure mastery - with its associations of visual control and surveillance - to one of a more ambiguous dreamlike experience. Roland Barthes implies such a shift in his poetic account of the view from the Eiffel Tower:

to perceive Paris from above is infallibly to imagine a history; from the top of the Tower, the mind finds itself dreaming of a mutation of the landscape which it has before its eyes; through the astonishment of space, it plunges into the mystery of time, lets itself be affected by a

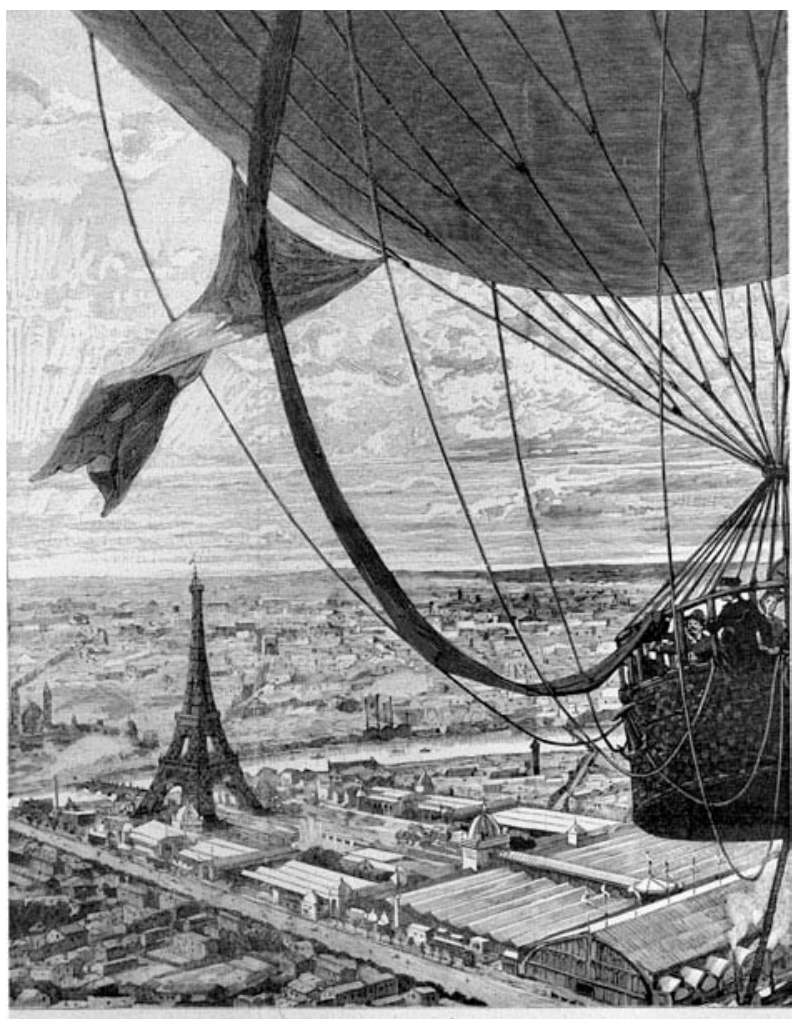

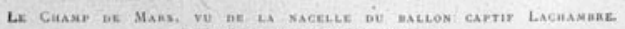

7.2

View of the Eiffel

Tower from the

balloon "Captif

Lachambre". From

L'Exposition de Paris

(1889) Avec la

Collaboration

d'Ecrivains Speciaux

(Paris: Libraire

Illustrée, 1889),

p. 289 
kind of spontaneous anamnesis: it is duration itself which becomes panoramic. $^{38}$

This sense of forgetfulness - redolent of Nietzsche's perspectivism, where forgetting allows us to "attain instants of eternity", takes on more negative connotations in Odilon Redon's lithograph, The Eye Like a Strange Balloon Mounts Toward Infinity. Here, we are drawn into a supra-human experience where the eye of the observer becomes the all-seeing eye of God. In this scene there is an almost palpable sense of wanting to depart from the earth-bound horizon, of remaining in a permanent state of elevation above a barren and alienating landscape. ${ }^{39}$ It is interesting to consider the nineteenth-century panorama in these terms, as a form of escapism where our involvement in everyday temporal matters can be momentarily suspended. Not surprisingly, therefore, the panorama formed a central theme in the pastimes of the middle-classes, whether in the form of artificial constructs such as the Leicester Square Rotunda and Colosseum in London - or as towers and natural promontories exemplified in the Eiffel Tower and Montmartre in Paris. In these settings, the city is both reconstructed and fantasised.

Like Haussmann's transformations of Paris, the panorama was similarly identified in democratic terms as "affording a view in which theoretically all

7.3
The Eye Like a
Strange Balloon
Mounts Toward Infinity, 1882, Odilon
Redon (1840-1916)

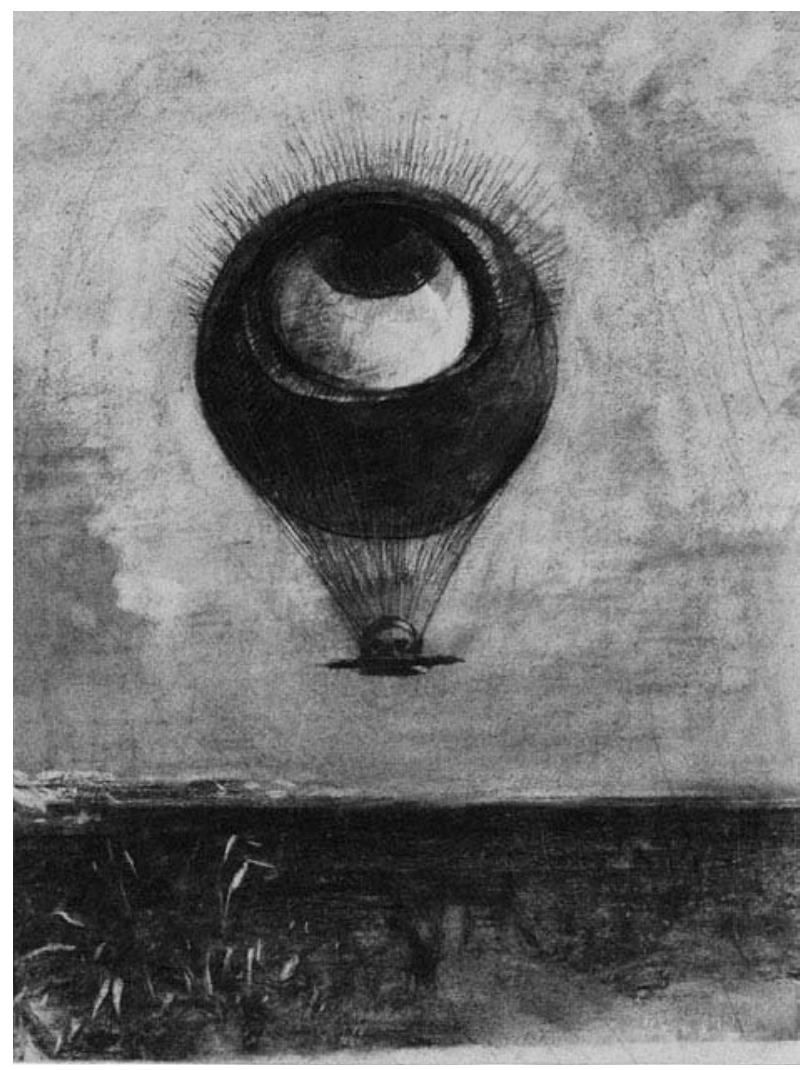


citizens might participate".$^{40}$ Allied to the ostensible democratisation of the view is the perception of the city as largely unintelligible. Removed from the realms of inhabitation and everyday circumstance, we encounter the city as if frozen in time, whose abstracted patterns can be admired and revered at a distance. This is most eloquently expressed by Roland Barthes, again in reference to the Eiffel Tower:

What, in fact, is a panorama? An image we attempt to decipher, in which we try to recognize known sites, to identify landmarks. Take some view of Paris taken from the Eiffel Tower; here you make out the hill sloping down from Chaillot, there the Bois de Boulogne; but where is the Arc de Triomphe? You don't see it, and this absence compels you to inspect the panorama once again, to look for this point which is missing in your structure; your knowledge (the knowledge you may have of Parisian topography) struggles with your perception, and in a sense, that is what intelligence is: to reconstitute, to make a simulacrum of Paris, of which the elements are in front of you, real, ancestral, but nonetheless disoriented by the total space in which they are given to you.... Hence we approach the complex, dialectical nature of all panoramic vision; on the one hand, it is a euphoric vision, for it can slide slowly, lightly the entire length of a continuous image of Paris, and initially no "accident" manages to interrupt this great layer of mineral and vegetal strata, perceived in the distance in the bliss of altitude; but, on the other hand, this very continuity engages the mind in a certain struggle, it seeks to be deciphered, we must find signs within it, a familiarity proceeding from history and from myth. ${ }^{41}$

In the observer's absorption of the city from an elevated vantage-point we become aware of a shift in emphasis from eighteenth-century views of perspective. Whilst it could be argued that Leibniz's monadic theology, and the later developments in concepts of immensity and infinity, served as historical precedents to the panorama, the understanding and structuring of the latter was quite different. In the dilated perspectives of Boullée, as we have seen, the sense of awe invoked by scenes of enormity is amplified by the manner in which an architecturally constructed horizon elevates building to a landscape and ultimately to a world. Denied any measured perspectival depth we are confronted by an expanse without intermediate points of reference. By abolishing perspectival distance, between landscape and observer, architectural representation is reduced to "mural" representation. In the panorama, on the other hand, the abstractions of immensity are replaced by the totalising effects of the elevated outlook that give the illusion of the viewer as absolute centre; it "evokes the idea of positioning the observing subject at a point sufficiently distant from its object for it to be taken in as a whole, at a "single view" ".42

When understood in the context of nineteenth-century nationalism and the emerging world-picture, the viewing subject is centred on a vision of the city that is itself presented politically, economically and culturally as the fulcrum of modern industrial civilisation. Evidently, this understanding of centre is far 
removed from notions of "centreness" that prevailed in the Renaissance and Baroque periods. Similarities, nevertheless, could be drawn between the polyvalent perspectivism found in Leibniz's theology, in which each monad constitutes at any one time the centre of the cosmos, and the nineteenth-century gaze in which the universe is "seen from the point of view of the universe". ${ }^{43}$ But such comparisons should be considered in the light of the demise - in the late eighteenth century - of a cosmological and onto-theological tradition that underpinned Leibniz's monadic model of the universe. In its place emerges a psychological perspective of the world.

From the elevated position, the city is presented both as a miraculous construct of interwoven events, whose overall impression has an almost mesmerising effect upon the viewer, and at other times as a carnage of disorder and decrepitude prompting calls for its radical transformation. ${ }^{44}$ In Balzac's The Girl with the Golden Eyes, this conflict is developed by drawing themes from Dante's Divine Comedy. As an analogy to the cosmological system of circles found in Dante's work, Balzac presents Paris as a complex system of networks. This operates at many levels, from the layout of the city to the class structure of its inhabitants. The subterranean world of Paris becomes emblematic of hell whilst the elevated position - redolent of Dante's ascent through Purgatory - enables the observer to subjugate the material world through the agency of the field of vision. In place of the Medieval hierarchical cosmos Balzac deploys a system of taxonomies, whose inter-relationships nevertheless recall Dante's model of spheres and circles. ${ }^{45}$ In this translation, the city is presented in perpetual motion, but not one based on the "rhythms of nature, the cycle of the seasons or any other 'pastoral' motif". ${ }^{46}$ Instead, Balzac portrays the city productively and metaphorically as a field awaiting harvest. Accordingly, the primordial world of cyclic renewal is translated into a world of consumption that evokes a condition - antithetical to the natural order - of incremental exhaustion and fatigue. Within this internalised structure of decline - and ultimate extinction - Balzac posits the notion of "selfconsumption", by which the systems of production and consumption implicate an "instrumentalising" of the self. What emerges, therefore, in The Girl with the Golden Eyes is a world on the brink of constructing its own reality through the elevated perspective, from where mastery and ultimate control over the changing circumstances are sought through sheer exposure. ${ }^{47}$

\section{Magnification and distortion}

At the other end of the perceptual spectrum in the nineteenth century is the magnified view. Emblematic of nineteenth-century bourgeois domestic life, the magnified view played a key role in the recovery of intimacy. This is evoked in Marcel Proust's epic work Remembrance of Things Past. In a scene where Marcel bestows a kiss on Albertine the relation between perspectival view and intimacy is described in almost mechanical terms:

At first, as my mouth began to approach the cheeks which my eyes had recommended it to kiss, my eyes, in changing position, saw a 
different pair of cheeks; the neck, observed at closer range and as though through a magnifying glass, showed in its coarser grain a robustness which modified the character of the face. ${ }^{48}$

Here, the detail acquires almost photographic quality in the way the moment of personal contact is magnified, and thereby isolated from its context. The analogy of the photographic lens or magnifying glass reinforces the estranged - even alienating - quality of what was intended to be an intimate experience. Mieke Bal reinforces this analogy:

The fundamental character of photography is that the bond between subjectivity and vision is broken. This break is primarily temporal, but it is also the "coarse grain" that cannot be seen by the naked eye. It casts an uncanny gloom over what we know to be inescapable reality; the close-up, like the photograph, separates the subject from the object. $^{49}$

The separation, expressed in Proust's analogy of the photograph, implicates a more radical distance which Bal argues "separates the subject from himself", or, to use the terms of Serge Doubrovsky, the "subject of existence ('hero') from [the] subject of discourse ('narrator')". ${ }^{50}$ Therefore, "At stake here is not a temporal disjunction but an ontological break." ${ }^{51}$

Proust's almost obsessive interest in the particular and the gestural is underscored by a reflexive relation between character and magnification:

And I wondered by what strange accident, in the impartial telescope through which Mne de Villeparisis considered, from a safe distance, the minuscule, perfunctory, vague agitation of the host of people whom she knew, there had come to be inserted at the spot through which she observed my father a fragment of glass of prodigious magnifying power which made her see in such high relief and in the fullest detail everything that was pleasant about him ... and altering the scale of her vision, showed her this one man, so large among all the rest so small, like that Jupiter to whom Gustave Moreau, when he portrayed him by the side of a weak mortal, gave a superhuman stature. ${ }^{52}$

A brief comparison between Proust's description of the magnifying power of a shard of glass and Nicholas Cusanus' De Beryllo - discussed in Chapter 4 - highlights the transformation in ways of seeing that occurred from the Renaissance to Modernity. Whilst Proust alludes to an almost mythic view of Modernity, by substantiating the aesthetic effects of the magnified image, Cusanus considers the act of looking through a beryl stone as analogous to the higher form of "intellectual vision" redolent of the Platonic Idea. The shift from one to the other - which reflects a critical change in perspective - entailed a shift from a connectedness between temporal (visual) and eternal (intellectual/divine) worlds to the propensity 
to reinforce the indubitable and inescapable reality of the visual. Accordingly, the world that Proust evokes is one that realigns the traditional perspective field to a radically fragmented horizon, whose terms of reference are guided by largely disconnected points of view.

The magnifying glass does not merely facilitate the close-up, like some mechanical instrument, but also proceeds - through its union with the eye - to modify the object. In a similar way to the plunging perspective that Damisch invokes in the experience of the window, the magnifying instrument provides a means of penetrating into otherwise unchartered depths. Denied, however, the kind of communicative framework that existed in the embodied (mediated) worlds of pre-modern times the modern perceiver is compelled to consider the fragment either as a pure aesthetic entity, without any larger constituting reality, or as a metaphor for a wished-for restorative world..$^{53}$ On the latter point, that calls for creative input on the part of the observer, the search for continuity has to compete with the proclivity of the magnified image to affirm a splitting of vision into mutually exclusive elements.

This conflict underlies the perception of the city in the nineteenth century that influenced the social, political and cultural contexts of urban life. Comparison with earlier historical examples is revealing. To take the example of the Renaissance, the inter-relation - and inter-dependence - between social, political and religious units (the individual, the family, the confraternity/guild, religious/ political bodies - Cardinalate, Signoria, etc. - and city/state) were sustained by cultivating symbolic relationships between the various forms of ritual participation (civic, festive, religious) and their corresponding representative structures (architecture, urban planning, painting, etc.). As we saw in Chapter 4, this inter-relationship and inter-dependency provided the foundations for cultural renewal (renovatio) and religious reform. No such continuity existed in the age of industrialisation, at least not in any explicit sense. In its place we see an unprecedented emphasis on the social and moral functions of family life - and, by implication, of domestic space. Significantly, these were often perceived in opposition to the city of commerce and production. In his or her participation in urban life, the dweller is compelled to negotiate through a complex system of instrumental or coded references largely divorced from the intimacy of personal/family existence. Henri Lefebvre explores the consequences of this dichotomy:

Shattered by the host of separations and segregations, social unity is able to reconstitute itself at the level of the family unit, for the purpose of, and by means of, generalized reproduction. The reproduction of production relations continues apace amid (and on the basis of) the destruction of social bonds to the extent that the symbolic space of "familiarity" (family life, everyday life), the only such space to be "appropriated" continues to hold sway. What makes this possible is the way in which "familiar" everyday practice is constantly referring from representations of space (maps and plans, transport and communication systems, information conveyed by images and signs) to 
representational space (nature, fertility). Reference from one to the other, and back again, constitutes an oscillation which plays an ideological role.... In this sense space is a trap - and all the more so in that it flees immediate consciousness. ${ }^{54}$

Once forming an indelible part of urban life, the dialogue between the "representation of space" and "representational space" becomes an ideological quest in modernity. A key factor in this quest, as earlier indicated, is the relation between the house and the city; between private and public life. Rather than forming an integral - and by implication mediating - part of urban space, the house is presented as its very antithesis; as a domain from which refuge from urban life can be sought. In the ferment of industrial and commercial development, that characterised nineteenth-century urban life, John Ruskin makes a plea for the house to serve as a substitute for those spaces traditionally reserved for public communion - like the café and the church. By attempting to bring these public activities into the fold of private domestic life, Ruskin is effectively arguing that the house can provide the context in which a more ethically grounded understanding of the city can be conceived. ${ }^{55}$

Critical to the establishment of domestic spaces, which are both congenial to the family and conducive to a cultured way of life, is the role of taste. Highlighted in the proliferation of handbooks during the period that seek to educate "by example" through the design and furnishing of dwellings, domestic interiors become expressions of the personal character of the owner or occupant. ${ }^{56}$ But such issues were not simply intended to aid aesthetic judgement but also to arouse certain feelings or emotions. These sentiments were, however, not just expressed in the articulation of interiors and their contents but also in the nature of the views from the house. The suburban dwelling was especially significant in this regard, in the way it gives the illusion of remoteness from the bustle of urban life, through the cultivation of a quasi-rural setting, and at the same time benefiting from accessibility to - and visibility of - the city.

An interesting example is the suburban house of Edmond and Jules Goncourt - famous novelists and dramatists - located in Auteuil on the outskirts of Paris. What was originally a semi-rural retreat, Auteuil became subsumed by the everexpanding suburban periphery during the late nineteenth century. The brothers moved to the house after living together in the centre of the city for eighteen years. The house and its setting were conceived as a work of art - an aesthetic refuge from the commotion of the city beyond. From their earlier experiences as socialites and public literary figures in Paris, the suburban retreat offered a very different environment. It is as if the physical separation of the house from the cultural life of the city was more than compensated by the extraordinary array of precious and exuberant artefacts that populate the cabinets and so-called "boudoir l'Orient" of the dwelling. Allied with this accumulation of the exotic was the articulation of views:

Edmond mentions that from his bedroom window at the back of the house he could see the fort at Issy, to the south of Paris. From the 
windows of the grenier, on the rare occasions when the blinds were opened, it must have been possible to take in the view Horace Walpole saw from the terrace of the gardens that had previously constituted part of the Domain of Montmorency, this "glorious prospect ... over which is extended all Paris with the horizon broken by the towers and domes of Notre Dame, St. Sulpice, the Invalides, the Val de Grâce, etc.". 57

This visual accessibility to the Parisian skyline was, however, conditioned by a certain contentment of separation, as implied in the closing lines of Edmond's $L a$ maison d'un artiste, an itinerary and description of the house and its contents published in 1881: "I experience a sort of enjoyment to feel myself so close to Paris and yet so far away." 58

There is a striking difference between this modern search for new foundations of domestic life and the classical view of the city, best exemplified in the relation between villa and palace. Cultivated during the Renaissance and Mannerist periods, these exemplary models of dwelling were never conceived as antithetical but rather as constitutive parts of the same embodied reality in which the ideal and the real were indelibly entwined. This inter-relationship was maintained in spite of intermittent political or religious turmoil, such as the Sack of Rome and its aftermath. ${ }^{59}$ It provided a context in which a balance between otium and negotium - between the cultivation of the soul in the countryside and the enhancement of worldly skills in the city - could be conveyed iconographically. Even during the social, political and religious crises of the seventeenth and early eighteenth centuries, this dialectical relationship was never completely lost.

In the case, however, of Ruskin's attempt to restore religious devotion and moral well-being, the nineteenth-century house becomes the last bastion of a hoped-for social and religious cohesion. Hence, what makes Ruskin's plea all the more significant is the urgency of the project and the manner in which the periodic retreat to the country was no longer considered an adequate and meaningful response to the kaleidoscopic changes taking place in the city during the nineteenth century.

\section{Gustave Moreau's house}

The reality of the nineteenth-century middle-class urban dwelling was rather different from Ruskin's ideal recuperative model. In these interiors, the accumulation and assembly of memorabilia and artefacts provided the principal mechanism for redefining one's relationship to the city. An evocation of this relationship is described by Alan Balfour in the context of Berlin in the late nineteenth and early twentieth centuries:

On the surface of this fortunate part of the city [Leipziger Platz], nothing is enhanced save a complacent consumption of the products of industry. Underneath, however, in the interiors of the apartments, a profound change is taking place. These newly affluent citizens - freed 
for the first time in their history from the burden of mere survival, confident and self-aware and married to all the many new products of industry - construct in their private rooms a personal universe. In it they gather scenes and objects from remote places and pasts. Drawing rooms, dining rooms, and bedrooms all have become boxes in a world theatre. Behind the image of the photograph personal realities are being constructed to ease repression and externalize desire, to stimulate erotic or exotic dreams, and to provide safe passage to the comforts of a dream world. Within the limits of things manufactured, domestic reality has become the property of individual consciousness, composed of objects freed from singular notions of virtue or progress, and no longer dependent on faith or the dictates of an aristocracy. ${ }^{60}$

The organisation of these fragments or elements was no longer guided by the allegorical principles of the seventeenth-century cabinet of curiosities, outlined in Chapter 5 in the context of Athanasius Kircher. Instead, the process was a purely sentimental and private affair, motivated by personal associations and nostalgias. In constructing a private world, the nineteenth-century urban dwelling was also a

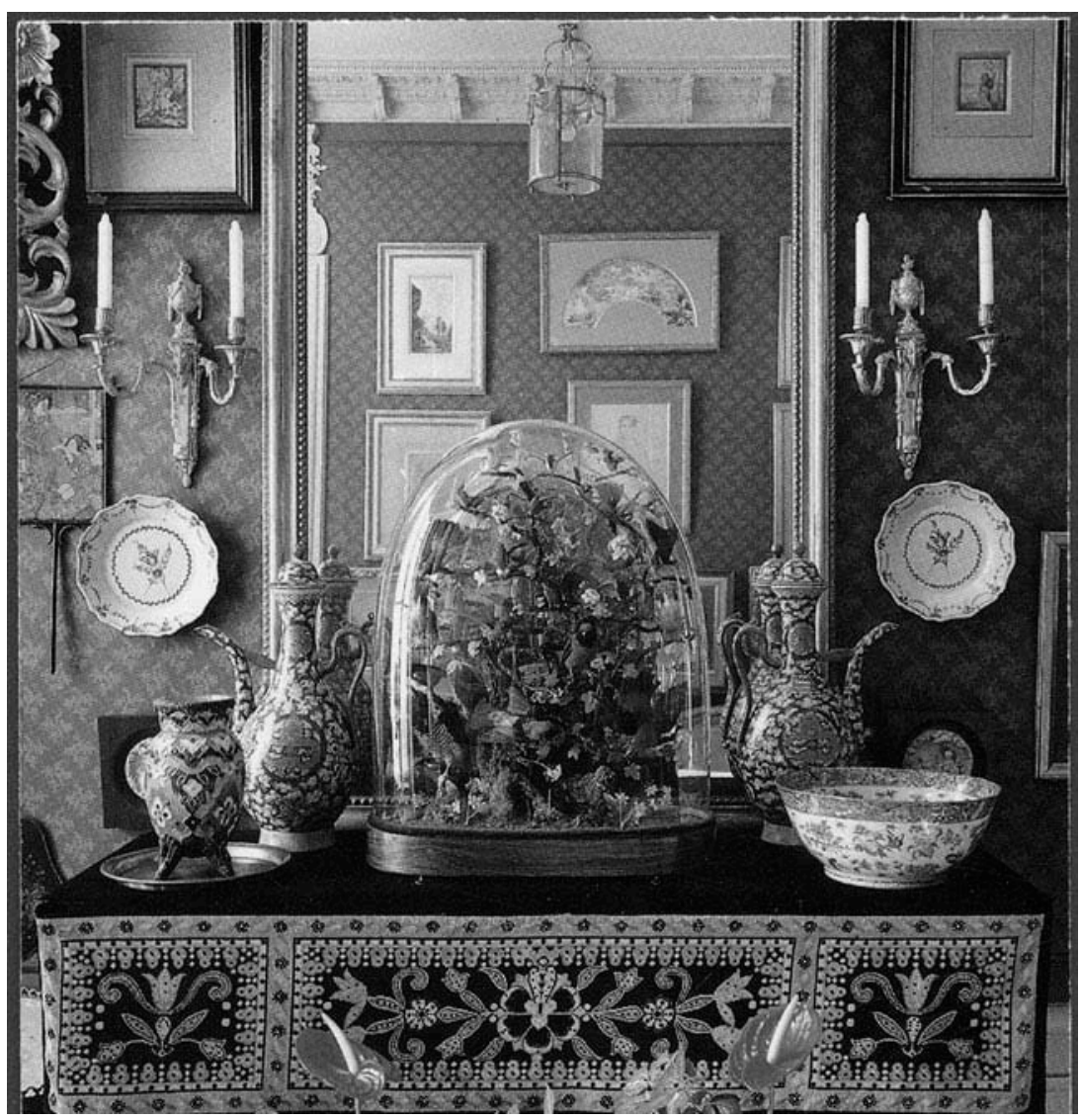

7.4

House of Gustave

Moreau

(nineteenth

century). Artist's

private apartment.

View of the

mantelpiece

showing assembly

of artefacts 
place where one's sensations could be given free reign. Of particular interest is the influence of the Decadent aesthetic on domestic space, highlighted for example in the interiors of the house of the Symbolist painter Gustave Moreau.

Before examining aspects of Moreau's house and his paintings it is important to put into historical and cultural contexts the Decadent movement. The foundations of the movement could arguably be traced back as early as Mannerism and later in Romanticism, providing the basis of a renewal of symbolic thinking in fin-de-siècle France and Belgium. ${ }^{61}$ At the heart of the movement was a pessimistic outlook of human existence in which nature is presented as empty of ontological significance, indeed as little more than a neutral mechanism defined by scientific laws. In the face of the abyss of embodied meaning, and the resulting banality of everyday life, the Decadent movement advances the belief that the imagination is the only means of experiencing a higher form of reality redolent of the transcendent realm of earlier traditions. ${ }^{62}$ Denied a shared communicative domain, the subject (in this instance the artist) seeks solace through intense sensual experience without moral or intellectual preconditions. This finds expression in Joris-Karl Huysmans' strange novel Against Nature (A rebors), the story of an aristocratic aesthete, Des Esseintes, who indulges in very personal and sometimes bizarre pleasures through art and literature. ${ }^{63}$ Repelled by the vulgarity of Parisian life, he retreats to his private abode of high taste, from where he constructs an intense world of synthaesthetic experience: "the production of a mental sense-impression relating to one sense by the stimulation of another sense". ${ }^{64}$ Moving between states of day-dream and morbidity, Des Esseintes measures reality against a background of olfactory and saporific hallucinations.

In the novel the author refers to the work of Gustave Moreau, which he much admired, and to which he evidently saw an affinity with Des Esseintes' narcissism and obsession with precious objects and decaying matter ${ }^{65}$ It is in the context of this affinity that Moreau's house becomes most revealing. As Jean Pierrot asserts, the "most important constellations of images emerging during the decadent period" incorporated "water, the mirror, precious stones, minerals and vegetations". ${ }^{66}$ Supplementing this constellation is the fascination with the spiral, arabesque or whiplash; the last of these commonly considered a leitmotiv of Art Nouveau. These elements converge in the architectural and painterly experience of Moreau's house, manifested in both illusory and real space. Gustave's paintings are dominated by splendid and sometimes bizarre jewels, whose faceted forms and reflective properties induce an almost hallucinatory response. To these are also attributed the contemplative effects of infinitude - a pre-occupation of nineteenth-century aesthetic experience - where the projection of splintered light and colour invokes a multitude of fragmentary experiences. The dress of Salome, depicted in Moreau's celebrated painting Salome Dancing Before Herod of 1876 and described in detail in Huysman's Against Nature, best conveys these qualities. An intriguing feature of the painting is the manner in which Moreau portrays the jewels with patina-like surfaces, alluding to a state of metamorphosis where the gem becomes a semi-organic material susceptible to decay. Implied here is an inter-relation between the eternal and ineffable light of the gem - symbolic of pure 
intellect - and the mortification and detritus of organic matter. The conjoining of both is most eloquently summarised in Moreau's observation that "I believe neither in what I touch nor what I see. I only believe in what I do not see, and solely in what I feel."

Moreau's house was conceived as both a place of work and as a museum where his paintings and drawings could be displayed. Clearly, the enigmatic retreat of Des Esseintes - with its clutter of precious objects and ordered collections of volumes - could be compared to the interiors of Moreau's house; only Des Esseintes' fascination with gems and crystalline forms is translated into mythical narratives in Moreau's richly coloured canvases that adorn the walls.

Given this difference, the artist's "studiolo" - which combines the "cabinet de réception" and private apartment - reveals a series of spaces that could easily have been lifted from the pages of Against Nature. In the studiolo are assembled the artist's collection of rare books and precious or unusual objects that Moreau collected until his death in 1898. The private apartment, moreover, where the painter's mother and father lived, contains souvenirs that were more intimately associated with Moreau's parents and friends. Of particular interest here is the assembly of artefacts on the mantel-piece, especially the bizarre glass dome that contains fossilised plants and stuffed birds beautifully composed like an ornamental menagerie. Emptied of life, nature is metamorphosed into an artificial construct. The almost obsessive treatment of these natural forms gives Moreau's house an intensely introspective character that is very different from the cosmological meanings cultivated in Kircher's Jesuit Museum, discussed earlier.

The neurosis underlying Decadent thought, particularly in regard to its radical form of solipsism, became a source of much interest to early psychologists. ${ }^{67}$ Often considered as emblematic of this condition the whiplash was interpreted by some as evocative of physical and nervous exhaustion. ${ }^{68}$ Found in paintings and architecture, the motif became a signature of everything that was unsettling about late-nineteenth century culture. Significantly, the main staircase of Moreau's house, which connects the second and third floors, could be said to evoke this condition. Whilst not strictly speaking a whiplash, the unconventional form of the stair - which twists in a spiral form, yet interrupts this geometry by the insertion of intermediate landings - serves to prolong and elevate the experience of ascent. As if suspended miraculously from the floor above, the staircase appears to be cut out of the plastered ceiling, thereby giving the impression of a fragile and unstable structure. Echoing the dream-like landscapes and mythical scenes that surround it, the staircase draws us into an ascending spiral movement that anticipates some as-yet-undetermined or mysterious destination, perhaps the vantage point of the panorama of Paris synonymous with the dreamstate in the later nineteenth century. Implicit in this provocative and ingenious staircase is a sense of wanting to go beyond mere physical ascent by the empathic qualities of the structure.

The interiors of Gustave Moreau's house exemplify the nature and meaning of perspective in the late nineteenth century. Whilst not directly informed by traditional belief-structures and cosmologies, there is sense in which Moreau 
7.5

House of Gustave Moreau

(nineteenth century). View of spiral staircase in artist's studio

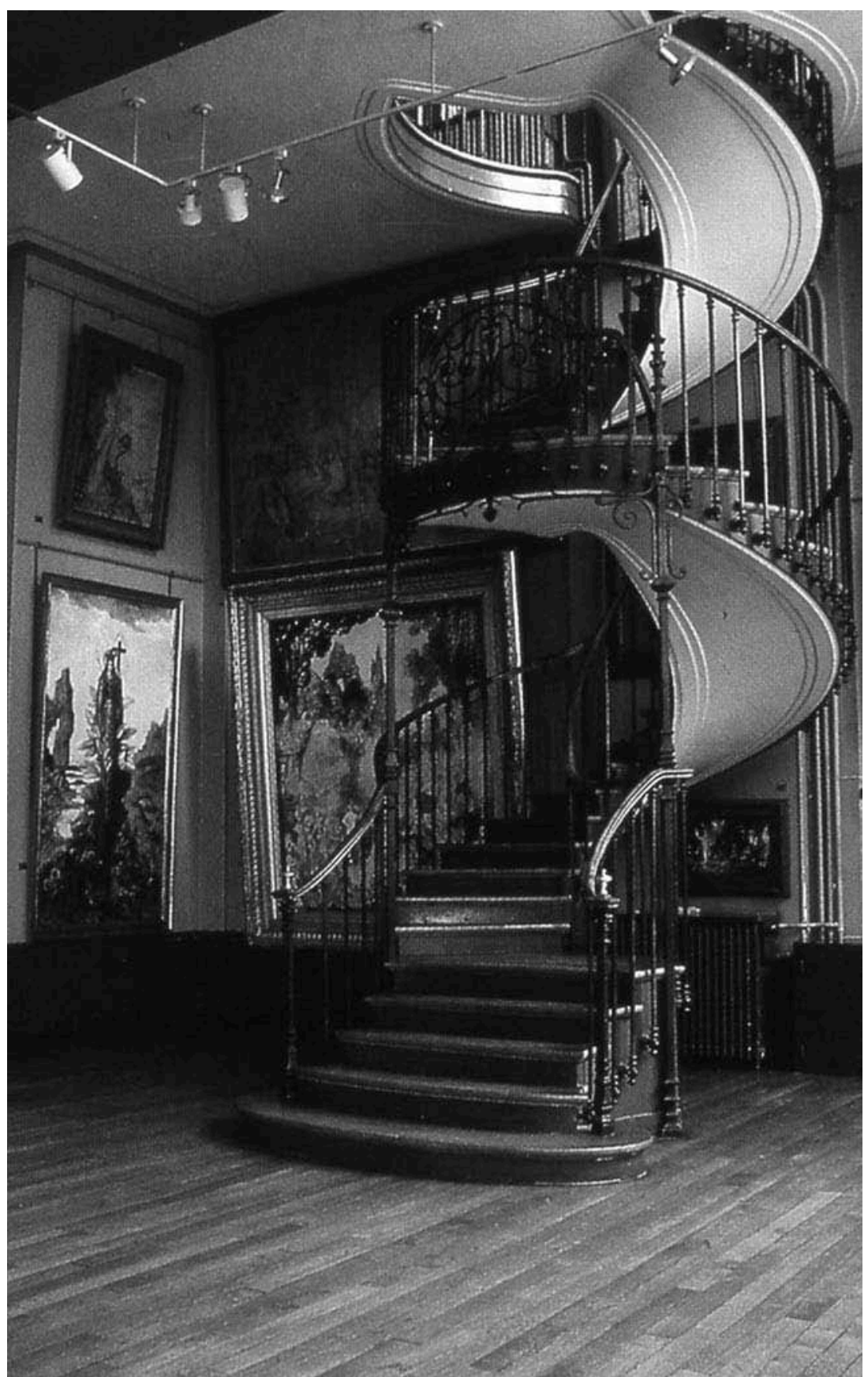

was seeking to "reground", in his private dwelling, a transcendent ideal that could overcome the coarse reality of modern industrial life. In this enterprise, fragment is not construed as an end in itself, as an isolated realm that sustains its own identity at the expense of some larger reality, but rather becomes the vehicle of trans- 
cendence to a mythically constituted order. Accordingly, by channelling the outpouring of his imagination, Moreau's perspective differs from that put forward by Damisch in his examination of the nineteenth-century street window. The latter, it will be remembered, identifies a fundamental dichotomy between street and interior space, where the mere act of opening a window provokes in the observer "an overflow that literally flings him outside of himself". For Moreau, on the other hand, the dwelling provides a creative context in which one's relationship to the city can be restored through the agency of human imagination. It is perhaps for this reason, more than any other, that Moreau's house held such a fascination for André Breton, founder of the Surrealist movement. ${ }^{69}$

\section{Eric Parry's artists' studios, London}

Eric Parry's design for some artists' studios in Camberwell, London, completed in 1989, was informed by a deeply felt belief in the problematic relationship between individual creativity and the modern/contemporary city. Influential in Parry's approach to the project was his interest in aspects of the nineteenth-century city, in particular Brussels during the fin-de-siècle period. ${ }^{70}$ Like Horta's idea of architecture as a form of portraiture, in the way interior space responds to the moods and emotions of its occupant, Parry was similarly concerned with how architecture might reflect the particular and unique conditions of individual artistic activity. For this reason, a brief overview of the background of the artists/clients in the project is necessary to fully understand the project. The artists in question, Tom Philips and Antony Gormley, are established figures in the British art scene, albeit very different in their respective fields and approaches: Philips is primarily a painter and writer whilst Gormley is a sculptor.

Notwithstanding these differences, a prevailing concern that unites their work - and one which served as a prevailing theme in Parry's project - is the sense in which creativity in contemporary culture is often undermined by the proclivities towards a disengaged or disinterested view of the world. Primarily a painter and academician, Tom Philip's work also extends into other related fields, having been an exhibition curator, art critic and film maker. Evident throughout his output is a desire to search for corresponding relations or links; in particular between visual and textual narratives. This has drawn Philips to the analytic and linguistic philosophy of Ludwig Wittgenstein in which propositions (and their interrelationships) arise not by following pre-established logical systems but rather by reflecting on what one is doing in developing a new system. ${ }^{71}$ This "philosophy of logic" could be said to serve as a background to much of Philips' creative output, in particular two works to be examined here. Significantly, both are textual narratives rather than paintings. The first is Philip's famous book A Humument: $A$ Treated Victorian Novel. ${ }^{72}$ Here, the artist took a relatively obscure nineteenthcentury novel by W. H. Mallocks, entitled A Human Document, and proceeded to quarry its contents, transforming or stripping out parts of the text and replacing them with images that yield new narratives. The result is not a superimposed story but rather a series of palimpsests; visual narratives grafted onto erased segments of a pre-existing textual narrative. The work could be compared to James 
Joyce's Ulysses, albeit in this case created by a combination of background text and foreground image.

The second work by Tom Philips to be examined here is a lecture he delivered in 2002 to the Architecture Forum at the Royal Academy of Arts. Entitled "The Nature of Ornament: A Summary Treatise", the lecture comprises a series of succinct statements, each numbered and following an evolving argument or theme, that attempt to summarise the multiple meanings of ornament. In "No.143", for example, Philips states: "Opulence has its climactic assertion by total coverage; the golden dome, the jade princess. Thus at the point of highest opulence we find the greatest simplicity." Further on, in "No.151", he goes on to assert: "Its solipsism is innocent. We cannot via ornament praise ourselves without at the same time reverencing nature and celebrating whatever intimation of a divine order our varied cultures possess."73 Juxtaposed, Philips' "reconstituted" novel and lecture reveal something significant about the author's understanding of authenticity and historicity that has a certain bearing on Parry's design of Philips' studio, as I will explain later.

Like Tom Philips, Antony Gormley's educational background is academic in nature, having studied archaeology and anthropology at Cambridge before embarking on a career in sculpture. It was probably due to this academic background that Gormley was early drawn to the human body and its changing spatial-temporal conditions. Moving beyond the classically inspired compositions of Henry Moore, Gormley's sculptures evince a primordial engagement with the world, whereby matter and space are constitutive of the same unifying phenomenal world. Antithetical to Enlightenment views of rational space, Gormley's work is rooted in a phenomenological perspective. The modern prioritising of abstract space over corporeal experience is reversed by conceiving the human body as a register of "adimensional" space which we enter into in order to become its effective "custodian". ${ }^{74}$ As will become clearer later, this phenomenological understanding of space was not to go unnoticed in Parry's design of Gormley's studio.

Located off Bellenden Road in Camberwell, London, the site of the project comprised two existing buildings divided by a yard. Both structures were retained whilst a series of existing lean-to buildings were demolished. The two buildings were adapted to provide accommodation for both studios. The only major additional building is a large open plan sculpture studio for Gormley that links the two existing buildings and closes off the yard on the east side. As David Turnbull points out, this insertion has important spatial implications since its west elevation - comprising a rusticated brick wall with large double doors - serves as the principal focus from the entrance to the courtyard, with Philips' studio on the right and Gormley's ancillary accommodation on the left-hand side.

The layout and detailing of Gormley's studio is simple. Adjoining the large sculpture studio on the ground floor - and fronting onto Philips' studio - is a lead-working studio/workshop with connecting clean area and toilet/dark-room. Access to the first floor accommodation - comprising painting/print studio and office - is via an outside steel and in-situ concrete staircase, located above the 


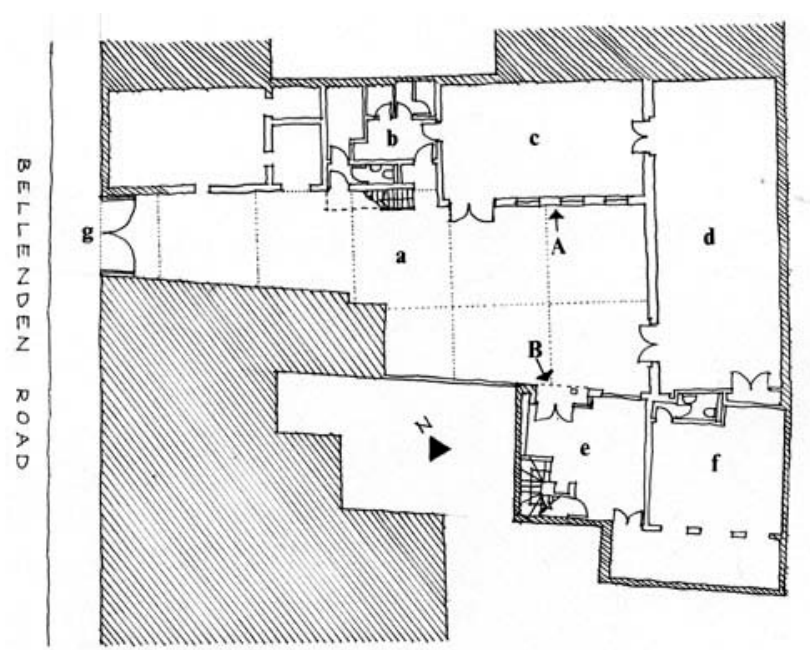

7.6

Artists' Studios for Antony Gormley and Tom Philips, London, 1989, Eric Parry Architects. Ground floor plan: Gormley's Studio (A) showing sculpture studio (d); lead working studio (c); and clean area with external staircase (b); Philips' Studio (B) showing entrance/exhibition space (e); and etching studio (f). Also communal courtyard (a); and entrance gate from Bellenden Road (g). Drawn by author after Parry

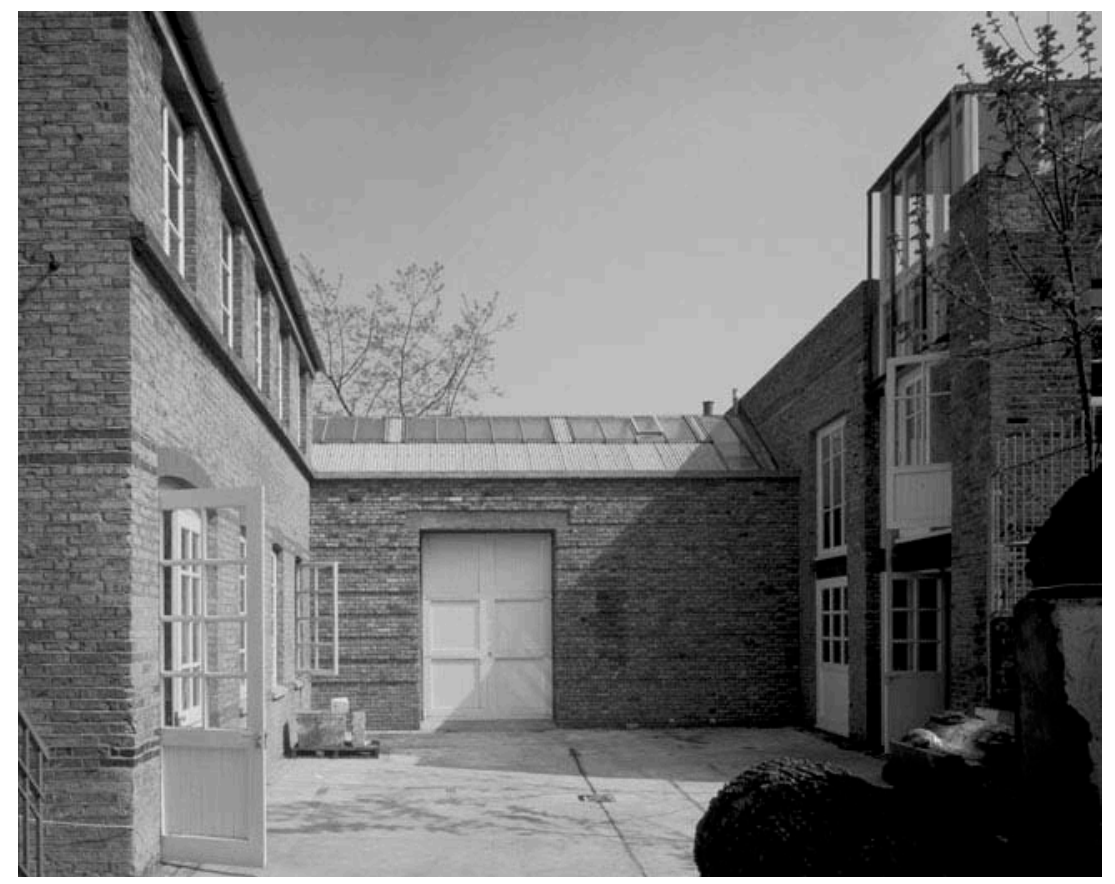

7.7

Artists' Studios for Antony Gormley and Tom Philips, London, 1989, Eric Parry Architects. General view of the communal courtyard with Philips' studio on the right and Gormley's studio on the left

ground floor toilet and passing through a loggia with intermediate landing to the office. Gormley made clear, at the outset of the project, that the interior should contain no elaboration of details such as architraves or cover mouldings. Hence, all the doors in the main studio are designed to close flush with walls and the floors appear to merge with the walls without the interruption of skirtings. Furthermore, under-floor heating was installed to avoid the addition of conspicuous radiators. 
The result of this suppression of applied elements is most telling in the sculpture studio where, in spite of the relatively limited height of the ridge, the space seems almost scaleless. This bare, roof-lit space contrasts with the smaller adjoining workshop and first-floor painting studio where the artist's creative processes are registered in the accumulation and layering of surface marks and sculpted fragments. By reducing the space to a simple illuminated vessel, without clear subdivisions, the main studio provides a setting in which the artist can manipulate perceptions of scale through the sculpting and assembling of contrasting figures. ${ }^{75}$

Rather than considering, however, the spaces of his studio as merely neutral or utilitarian, Gormley treats them as visceral receptacles within which he probes the situational relationships between his own body and those of his

7.8

Artists' Studios for Antony Gormley and Tom Philips, London, 1989, Eric Parry Architects. Interior view of main studio of Antony Gormley

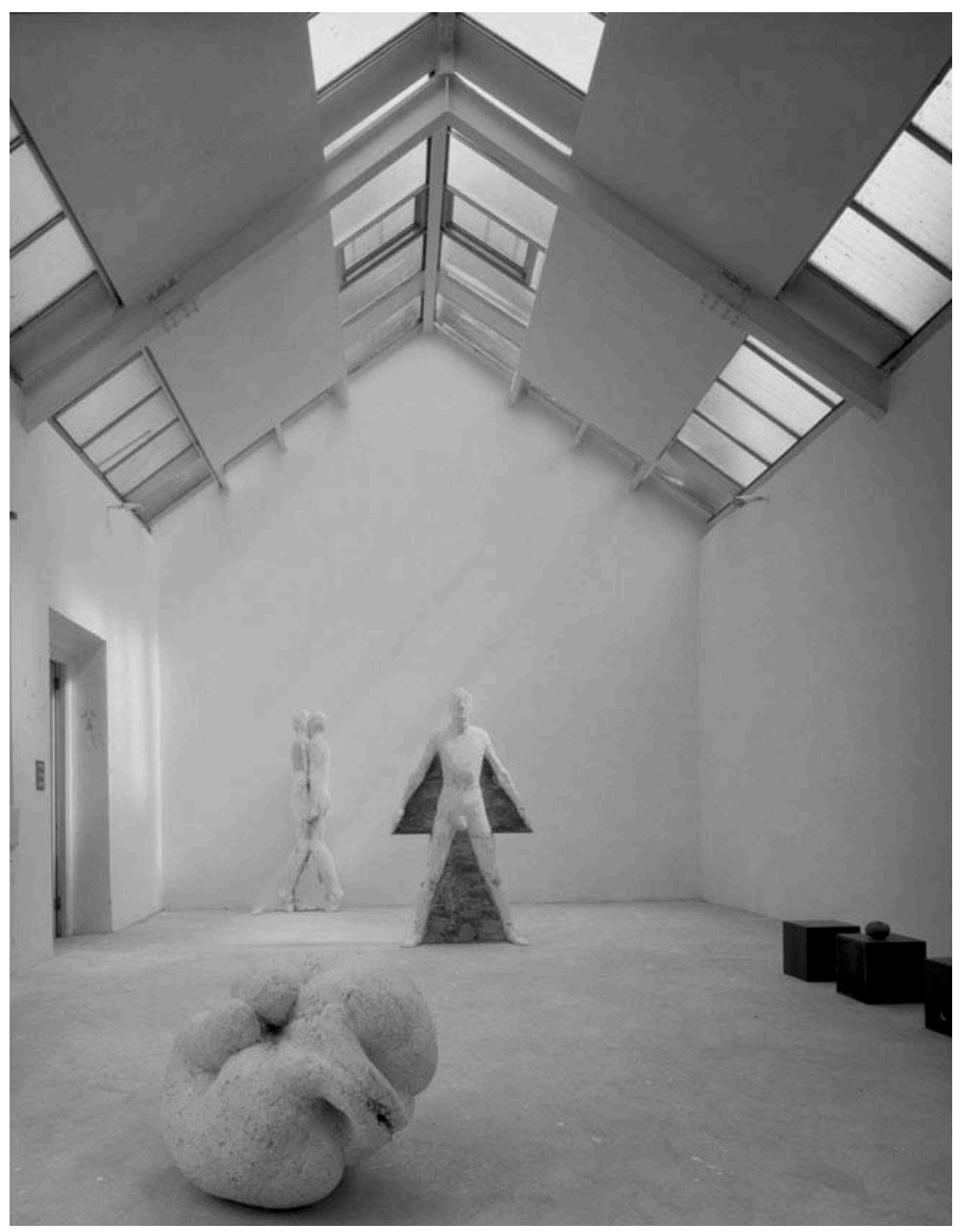


figures. To this extent, Gormley's studio is treated as an intensely internalised space - albeit configured so as to operate periodically as a public gallery - where the artist can create new spatial relationships through the synergy between his sculpted figures and their momentary (architectural) settings.

Parry's design for Philips' studio reflects a very different set of priorities. In contrast to the relatively open planned and extended spaces of its neighbour, Philips' studio was conceived as a "stacking studio": "From the courtyard, [the] studio is established as a tower inserted into the existing wall ..., providing a densely planned vertically organised sequence of spaces. "76

This verticality is initially expressed externally by the way the inclusion of glazed double doors at ground and first floor, and a large extended dormer

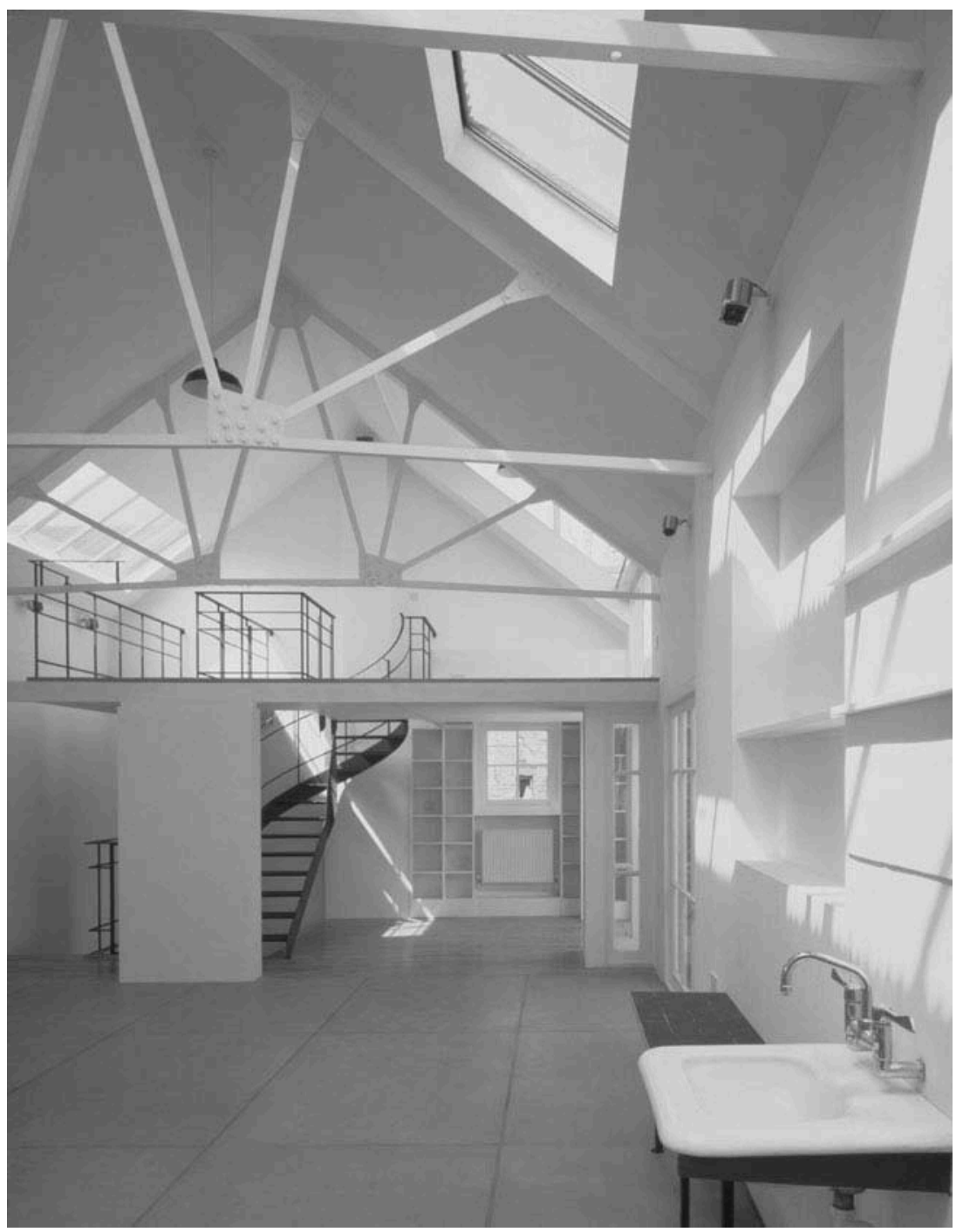

Artists' Studios for Antony Gormley and Tom Philips, London, 1989, Eric Parry Architects. View of Tom Philips' first floor studio looking towards the studio balcony 
window above, give the impression of the studio as a tall glass cabinet inserted into the brick façade. The emphasis on verticality is echoed at the entrance of the building where the ground floor doors are recessed into the building in order to accommodate an access hatch through the exposed soffit of the first floor. Through this opening large canvases can be transported to and from the first floor studio; Philips recalls seeing a similar feature in Cezanne's studio many years earlier. ${ }^{77}$

Upon entering the building at the ground floor, which opens onto an exhibition space and adjoining etching studio, the visitor is confronted by an epitaph of Van Gogh inscribed in Portland stone - "TIME IS A GREAT DEALER". This was installed by Philips as a kind of "frontispiece" to the the staircase and

\subsection{0}

Artists' Studios for Antony Gormley and Tom Philips, London, 1989, Eric Parry Architects.

View of the epitaph to Van Gogh at entrance in front of staircase

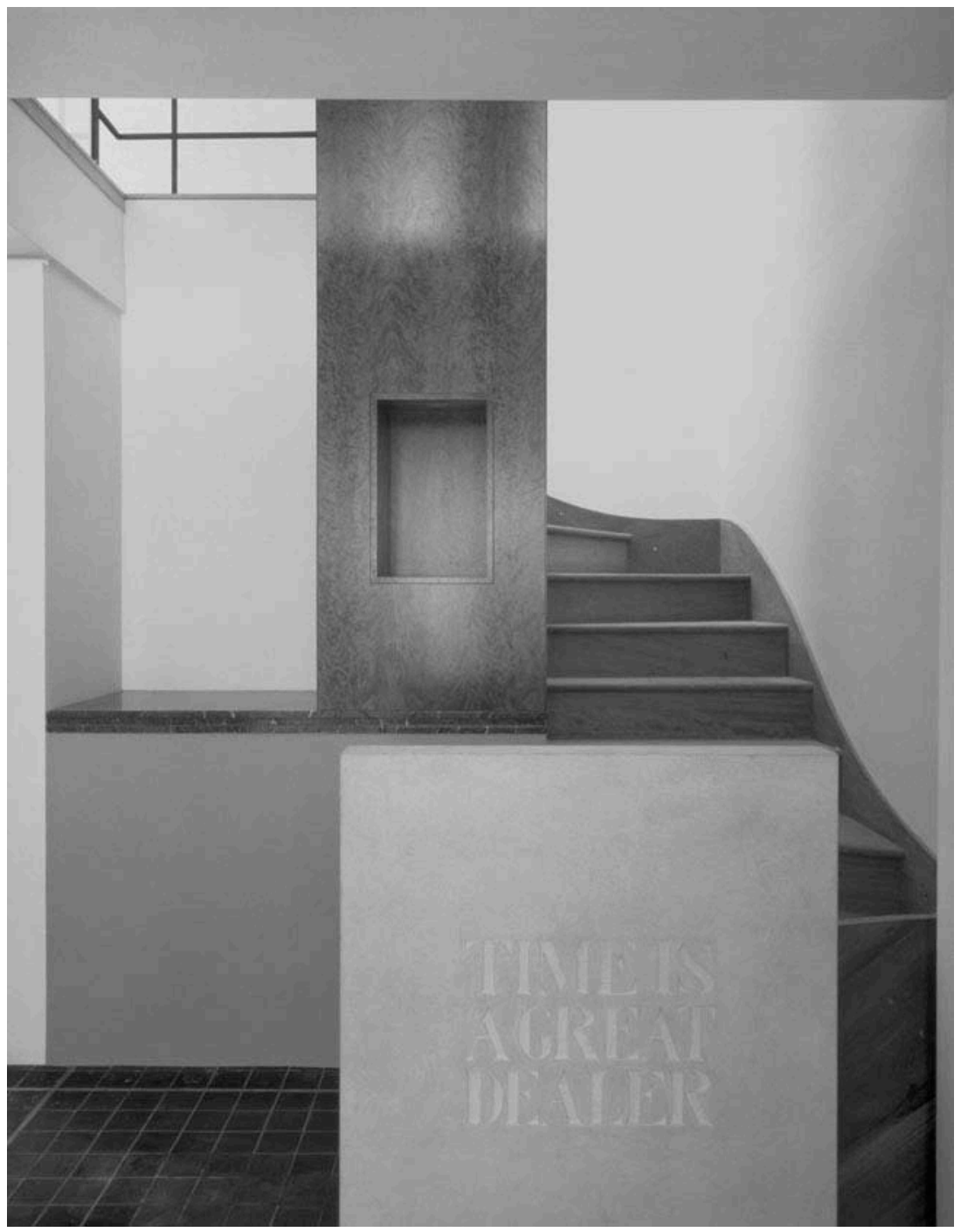


square column visible behind..$^{78}$ The juxtaposition of the epitaph with the collage of surfaces (tile, brass, yew veneer, marble, stone, plaster, steel), that comprise the internal finishes, reminds one of Philips' method of superimposing image on text highlighted in his A Humument. In the case of the studio, however, the message of the epigraph, and its prominence, invites a particular response to the interior spaces and their surfaces through the idea of the durational nature of creativity. Hence, the inscription "inaugurates" a linguistic reading of the architecture, a point I shall return to later.

Inserted into the yew-veneered column, around which the staircase ascends between ground and first floor, are a series of openings or recesses. These provide display areas for Philips' varied collection of books and precious

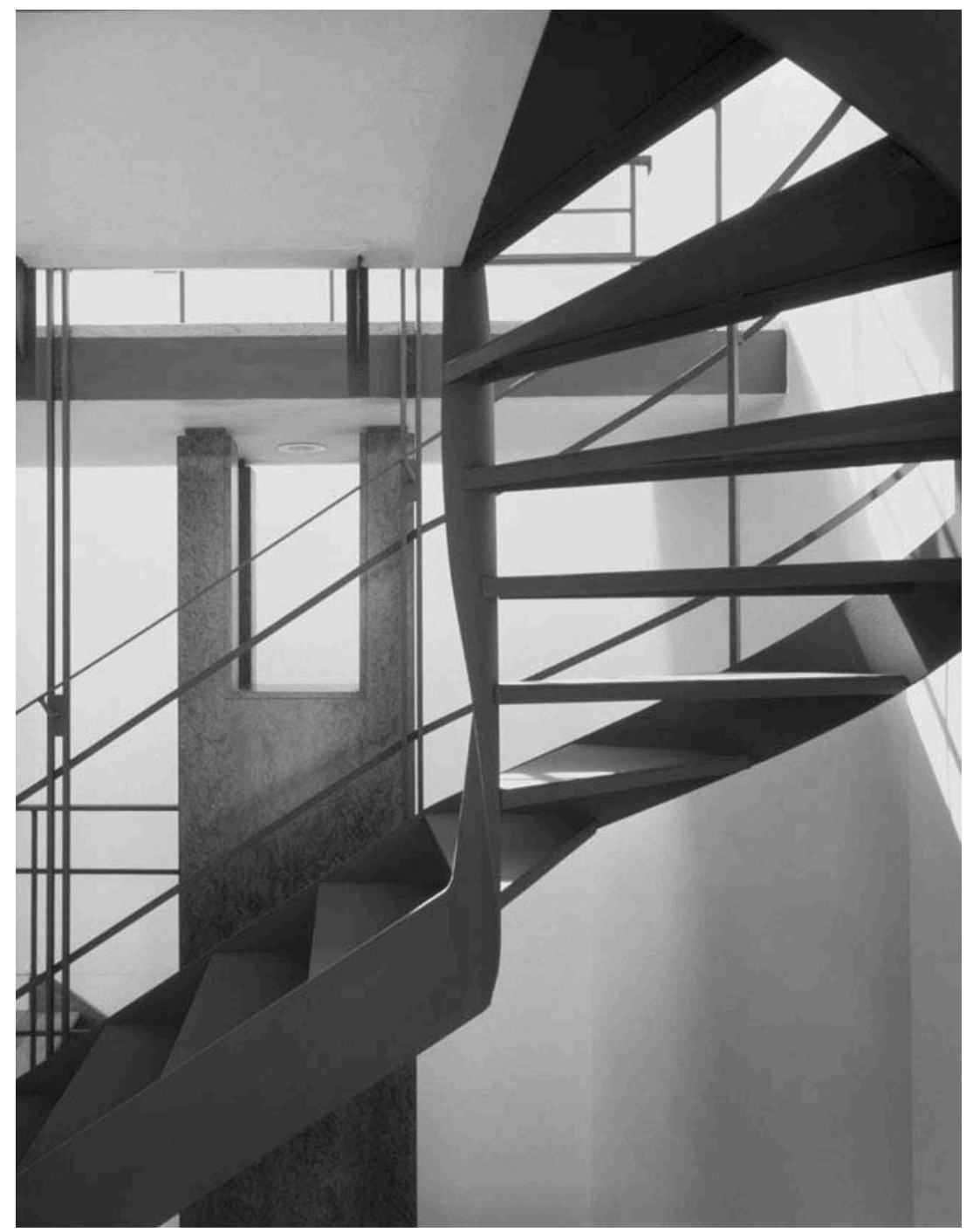

7.11

Artists' Studios for Antony Gormley and Tom Philips, London, 1989, Eric Parry Architects.

View of steel spiral staircase to balcony level in Tom Philips' studio 
artefacts, including primitive sculptures. Conceived as a cabinet of curiosities, echoing the "glass cabinet" of the studio tower that encloses it, the column takes on the role of a "columna memorialis" that evokes the rich and varied influences on Philips' work. ${ }^{79}$

From the ground floor the staircase gives access to the first floor library and painting studio and at second floor (mezzanine) level to a still-life/ portrait studio overlooking the painting studio below and the courtyard. The designated function of this mezzanine is indicated by the incorporation of a raised rectangular podium - for the artist's reclining model - that extends from the staircase to the window of the tower.

7.12

Artists' Studios for Antony Gormley and Tom Philips, London, 1989, Eric Parry Architects. View of the steel spiral staircase and adjacent yewveneered column at first floor level in Tom Philips' studio

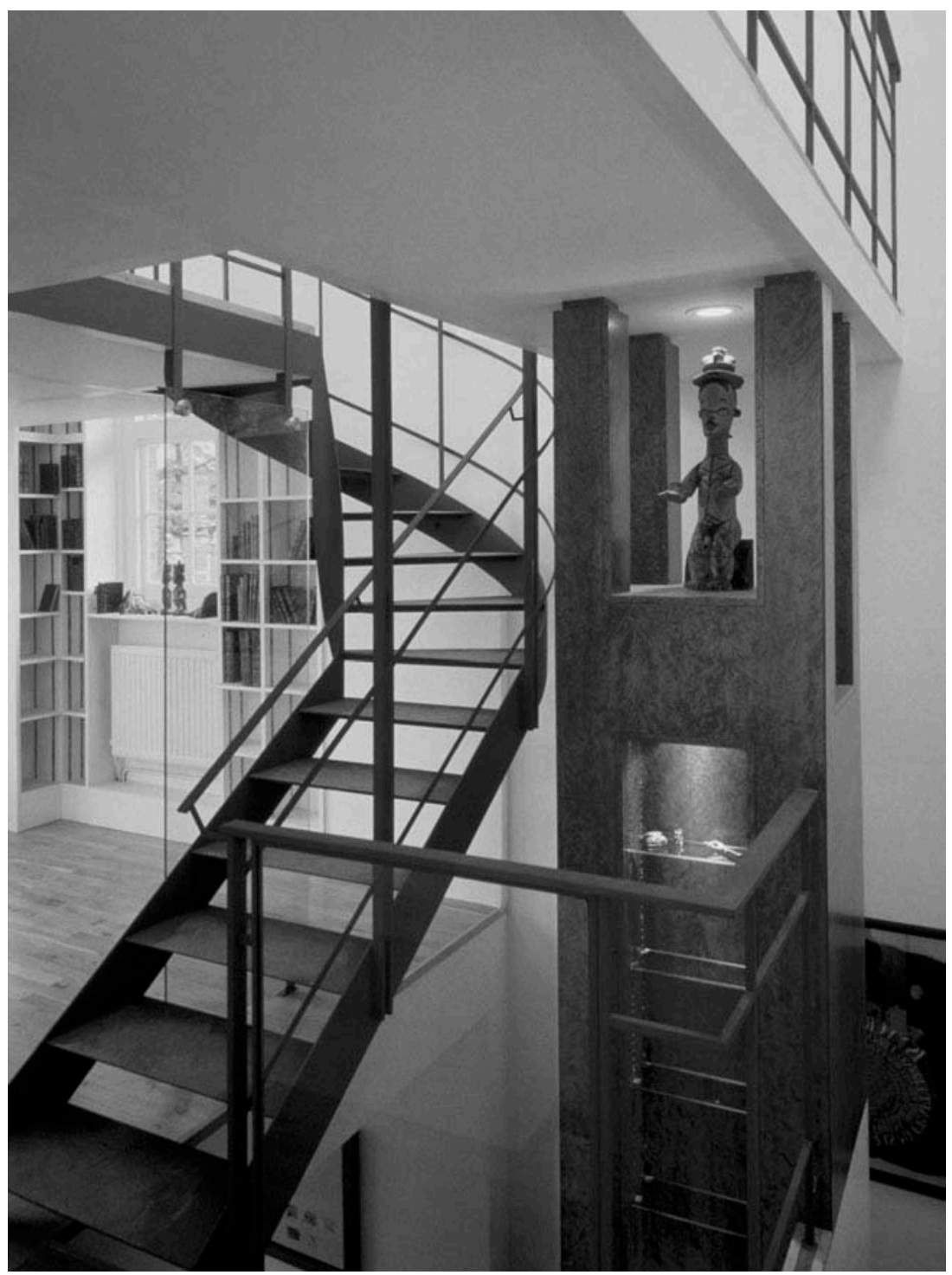


What becomes clear in the design of Philips' studio is the way in which all the spaces of the interior seem to disseminate from the inserted tower - or more specifically from the spiralling movement of the staircase and its more static enclosed column. The relationship between the various functions of each floor level, and the juxtaposition of different materials, clearly characterises the design of the studio.

Philips' studio contrasts with the ascetic nature of the spaces of its neighbour where the range of materials is limited, and the spatial distinction between functions - evident in the design of Philips' studio - is conspicuously

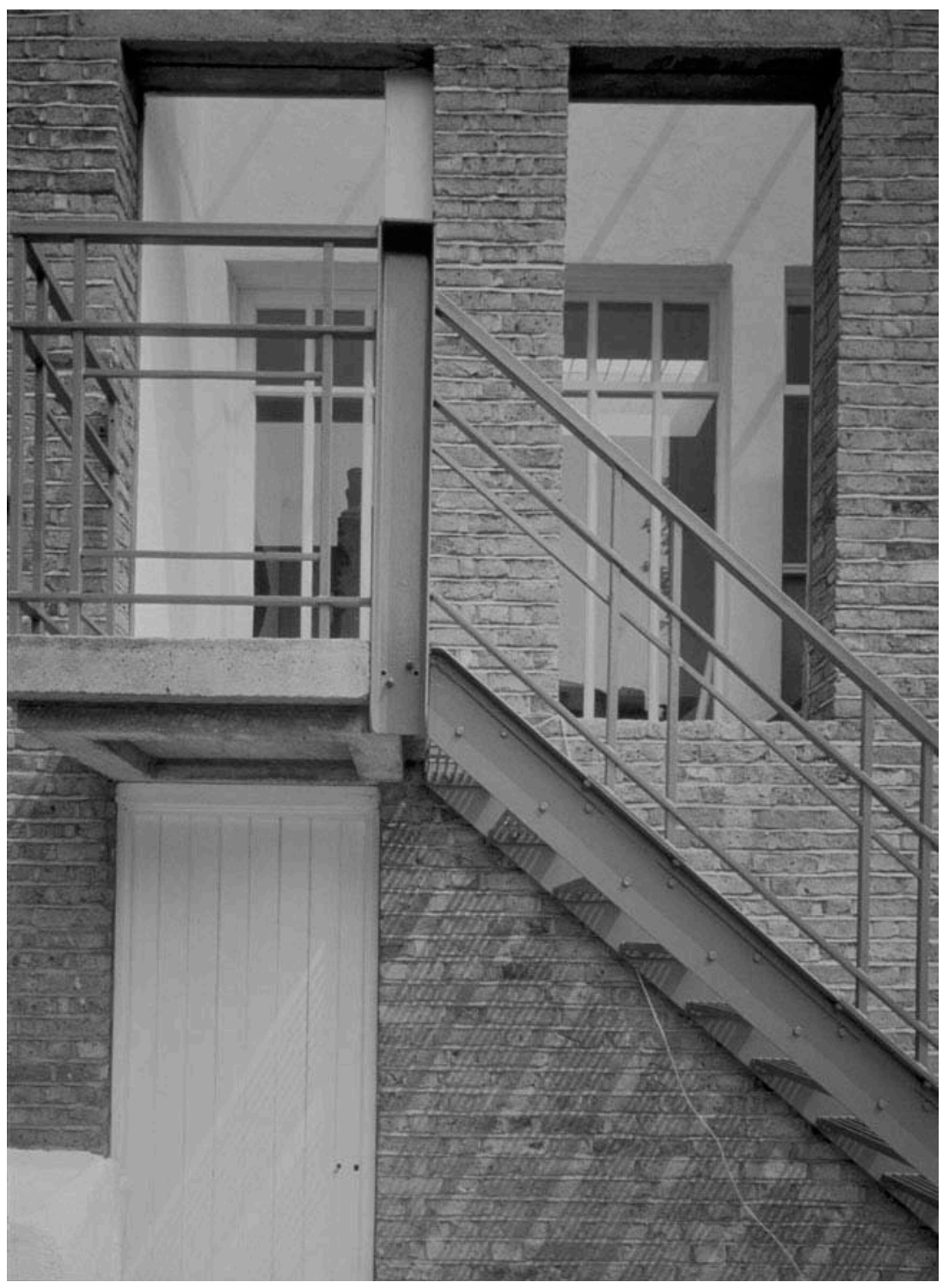

7.13

Artists' Studios for Antony Gormley and Tom Philips, London, 1989, Eric Parry Architects. View of the outside steel and concrete staircase for Antony Gormley's studio 
absent. This difference is further underlined in the design and location of the staircases for each studio. In the case of Gormley's studio, the staircase to the first floor is constructed using a combination of standard steel sections and in-situ concrete designed as two simple straight flights with intermediate landing to the office. It is treated moreover as an appendage to the building, accessible only from the outside - a feature that further underlines the ascetic nature of Gormley's environment and perhaps his working practices. The staircase in Philips' studio, by contrast, is highly wrought and spatially complex, serving - as we have seen - as the focus of the interior spaces around which the levels seem to unfold. This leads Turnbull to describe the latter as "the blossoming or unfolding outward of the interior of the tower toward the roof". ${ }^{80}$ From its initially solid wood construction between ground and first floor - with closed risers - the spiralling movement of the staircase is unleashed above in the form of a delicate open tread steel structure fabricated using an assortment of steel sections and flat steel plates.

To understand Parry's intentions behind the sophisticated design of the staircase in Philips' studio we should briefly examine a survey drawing he undertook with David Dernie of the interior of the Hôtel Tassel by Victor Horta. ${ }^{81}$ In this exquisitely detailed longitudinal section, Parry demonstrates the way the main staircase seems to emerge from its surrounding spaces by the play of light and shadow on surfaces and by the appropriation of varied materials to a unified architectural vocabulary; these comprise arabesque and foliated forms characteristic of late nineteenth-century Art Nouveau interiors. Evocative of the whiplash motif, the form of the staircase conveys the way architecture of this period was seen as a material expression of the tensions and fragile nature of modern existence; the subservience of materials to the restless movement - implicit in Horta's distinctive style - becomes analogous to the power of dream and imagination to transcend the banalities of everyday reality. At one level, the analogy takes on linguistic significance by the manner in which architectural form acquires a certain calligraphic quality - as if invoking the "signature" of its inhabitant. Like the development of a character in a novel or the portrait of a sitter, the architect similarly probes the idiosyncrasies of his client in order to conceive the dwelling as the very embodiment of its occupant. In the case of the Hôtel Tassel, the client was a professor of Descriptive Geometry at the Université Libre de Brussels. As one of the most remarkable interiors of the late nineteenth century, the Hôtel Tassel was conceived around the implicitly geometrical nature of architectural ornament; embedded within the abundant variety of forms there lies a latent geometric order. From its universal and abstract principles geometry is transformed, by the situations implicit in the spaces, into a richly tactile ornamental structure.

We could be forgiven for thinking on similar lines in the case of Parry's design of Philips' studio, given that the dialogue between staircase, inner column and inscriptive frontispiece becomes almost totemic of the artist's own creative processes. A useful reference in this regard, which Parry would almost certainly have identified with, is Philips' understanding of ornament outlined earlier. His assertion that the "solipsism" of ornament is "innocent" is based on the premise 


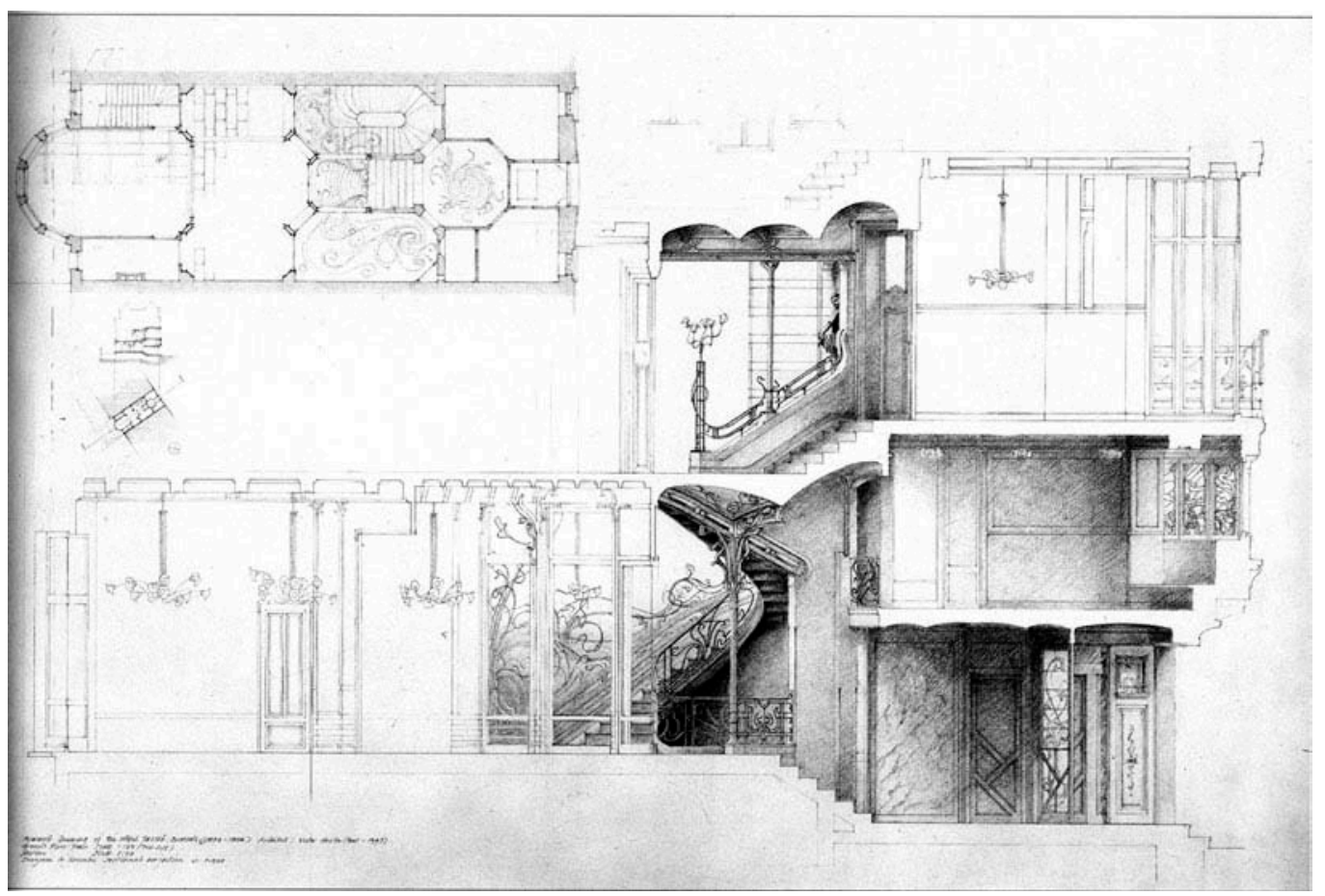

that ornament cannot affirm self-praise without - at the same time - affirming our reverence towards nature. In other words, by virtue of the richness and ambiguity of ornament - being simultaneously geometric and organic, body and surface - it celebrates the vitality of everyday temporal existence, and at the same time, affirms a deeper primordial/symbolic relationship to the world. This dual meaning is palpably present in both Philips' work and in the design of his studio.

Perhaps a closer affinity, however, can be identified between Parry's 7.14

Eric Parry and David Dernie, Section and plan survey drawings of the Hôtel Tassel by Victor Horta (1893-97) design and Gustave Moreau's house referred to earlier. In particular, the hybrid nature of the staircase in the latter, with its shifts, re-alignments and its seemingly "umbilical" connection between the lower studio/exhibition space and the upper more private - attic studio, could be compared to the staircase in Philips' studio. In each case, ascending movement between intermediate levels becomes metaphorical of the creative impulse of the artist.

Underlying this analogous relationship, however, there pervades a more troubling aspect. This centres on the idea of the artist's house as tower implicit in both Philips' and Moreau's studios - that is redolent of Friedrich Hölderlin's retreat in Tübingen outlined in Chapter 6 . In this commanding vantage point the retreat par excellence - the search for creative freedom in the modern world is by necessity correlated with solitude, introspection and even insanity.

The contrast evident in Parry's designs of the studios of Antony Gormley and Tom Philips indicates not just different ways of creating spaces conducive to artistic activity - each equally legitimate - but also reveals a deeper 
dilemma about the role of architecture as a positive vehicle for facilitating broadly consensual situations that can sustain the internal conflicts of contemporary life. The dilemma is best summarised by Parry himself when he says that: "The artist's studio is a place of reverie, of intimate immensity, and yet it often resembles an uncomfortable workshop." 82 The expression "intimate immensity" conveys that strange interplay between the infinitesimal possibilities of creative thought and the intimacy of the situations necessary for their cultivation. In the case of Gormley, the underlying dialectical meanings of intimate immensity are played out in the inter-relation between the visceral spaces of his studio and the "silent" encounters of his sculpted pieces. For Philips, on the other hand, meaning is sought in part through the synergy between the supporting textual and iconographic material, which forms an indelible part of his academic and working environment, and the tactile/material qualities of his studio. As Turnbull notes, it is somewhere between the two realms of pure imagination and the mundane world of the workshop that the architect must create spaces that can mediate the intensely private environment demanded of creative activity and the public face of the artist's work. $^{83}$

This modern search for a mediating realm reached a point of intense creative and intellectual activity during the fin-de-siècle in Europe, as we see for example in the architecture of Art Nouveau and in the emergence of phenomenological thought. Parry's design for the studios demonstrates a certain affinity with this thinking, finding in its internal conflicts a suitable backdrop against which to redefine new avenues of thought - or ways of seeing the world. But such perspectives, as we see characterised in Moreau's studio, invariably draw meaning from the cultivated environment of the artist's studio, beyond which exists uncertainty and even chaos.

We are given a sense of this separation in Parry's design for the entrance to the courtyard from the street. This consists of a sub-division of openings, each registered anonymously by an explicit display of security measures in the form of locks, from the large double gates used periodically for vehicular access to the smaller entrance door and adjacent letter-box. What is open to the possibilities of dialogue internally is deemed problematic in the hostile environment outside. Whilst this ostensibly utilitarian statement may appear at first to be an expression of protection of artistic freedom, it could conversely be construed as a demonstration of creative emasculation in the public domain. 


\title{
Conclusion
}

\author{
Architecture that looks back at us
}

The beginnings of a perspective view of the world, as this investigation has sought to highlight, signalled a shift in the nature and meaning of order. It heralded a new representational paradigm that, on the one hand, drew meaning from the deeply rooted onto-theological tradition of Christian-Platonic cosmology and, on the other, provided the necessary spatial parameters for articulating the emergent modern self. As Erwin Panofsky notes:

the history of perspective may be understood ... as a triumph of the distancing and objectifying sense of the real, and as a triumph of the distance-denying human struggle for control; it is as much a consolidation and systematization of the external world, as an extension of the domain of the self. ${ }^{1}$

By transforming an embodied - transcendent - reality into a visually accessible realm, perspective becomes increasingly a mechanism for appropriating the experience of "otherness" to the level of intimacy in individual human consciousness. This change, as we have seen, could be defined in architectural terms as a shift from the hierarchical spaces of Baroque churches - the last convincing examples of a transcendent view of order - to a largely immanent and introspective outlook prevalent in nineteenth-century domestic interiors.

The transformation that began even before the "invention" of perspectiva artificialis, as we saw in Chapter 3, was characterised by a series of critical developments in the understanding and representation of space. These "stages", each teleological in nature, subsequently became, in the course of history, paradigmatic of particular cultural world-views.

In this study I have traced the underlying motivating forces - philosophical, theological, political, scientific, artistic and so on - that have shaped these different modalities of perspective. I have further highlighted, through supporting case-studies of modern and contemporary buildings, how these paradigms continue to influence architectural thought and practice. But such influences require, as I have tried to demonstrate, a particular orientation towards the given perspective outlook. Typically, this is revealed through the design process by an interpretative response to the conditions of the site and the "thematics" of the project. 
Understood, therefore, in hermeneutical terms, orientation allows a creative dialogue between the given historical perspective and our own. In so doing, questions of tradition and innovation are never considered as antithetical but rather as constitutive of the same historical reality, of which we are always a part.

The openness to such orientation, however, and its creative possibilities, are constantly challenged and undermined in architectural practice by the lack of ratio in contemporary culture; the inability to identify - and act upon - correlative ideas across disciplines or modes of thought. ${ }^{2}$ A symptom of this hindrance to analogical thought, and one that is most apparent in the modern condition of "enframing", is the emancipation of image from its source of origin. Bernard Cache considers this problem:

As long as we think of images in the mode of representation, we are caught in the sack of a logic that reduces the world to the cerebral images that we form of it ... We have gotten into the habit of classifying images in our inside while leaving things outside ourselves. ${ }^{3}$

One of the consequences of this emancipation is the mistaken identification of mere appearance for reality (in its manifold layers of meaning), or the misguided belief that reality as ground - or referent - is merely a chimera that can be constantly re-invented through the agency of technology. Only by leaving, as Cache remarks, images where we see them, "in things themselves" - by resituating them in their originating spatial-temporal contexts - can we begin to engage with the phenomenal world. ${ }^{4}$ This is perhaps the most critical challenge facing architects today in a culture that conceives images as the principal vehicle for communicating - and ultimately manifesting - design ideas. ${ }^{5}$

I wish to make a distinction here between image (as synchronic "set piece") and representation (as a diachronic field of relationships) to highlight an important and arguably unique aspect of virtual reality. This concerns the belief that the domain can stand on its own terms of reference without mediation with the physical world, except at the point when computer generated form is deemed sufficiently "realisable" that it can be fabricated digitally. ${ }^{6}$ We are given a sense of this autonomy in the priority given to the image as a metonym of architectural experience. From the perspective of contemporary architectural design, we are increasingly susceptible to the photogenic qualities of space (the "set-pieces") to the point that these circumvent design development.

This strategy is very different from, for example, Le Corbusier's practice of photographing his completed buildings. In this instance, the photograph serves as part of an ongoing interpretative framework that reveals certain "embedded" geometric relationships in the perspective, through the play of light and shadow, surface and depth and so on. ${ }^{7}$ Here, the photograph becomes a mediating - reflective - medium that opens up possibilities of dialogue between the largely abstract and "universal" rationale of proportioned space, that constitutes the principal generating device of Le Corbusier's architecture (typically conveyed through the deployment of "regulating lines" in plan and section), and the 
perceived relationships of elements in space revealed and recorded from particular vantage points. ${ }^{8}$ Implicit in the dialogue between both modes of architectural representation is a belief in the potential unity of architectural order.

This mediating function of the photograph is conspicuously absent in the imagistic tendencies of contemporary architecture. The unwillingness to interpret photographs, in the way understood by Le Corbusier, is symptomatic of the demise of the traditional practice of translation between modes of representation and built form. The expectations of clients today for high resolution digital images that parade projects as already built (often derived, ironically, from images of other built examples), only reinforces the hermetic nature of the design process - its internalised and self-perpetuating operations - thereby further contributing to a "short-circuiting" of the process itself. By blurring the distinction between constructed digital images of the un-built and photographs of the built, architectural design is increasingly perceived by the general public, and indeed by many architects, as a perennial exercise in the fabrication of image, rather than a practice of translating drawings into buildings, as it should be.

As exists elsewhere in our consumerist culture, architecture is being presented in a permanent state of completion (as a noun rather than as a verb as Alberto Pérez-Gómez would describe it). An obvious consequence of this pervasive impression of completeness is the absence, in either an explicit or implicit sense, of the unfinished. Driven in part by the tendency to deploy digital technology in architecture to homogenise - and thereby mask - process, by making it seem seamless rather than messy, architectural creativity is motivated less by a desire to open up new avenues of dialogue in our experience of the world (topographical, historical, cultural, social, symbolic, etc.) and more about pursuing the illusory quest for synchronic freedom in the production of space. It is worth remembering, in this context, that the age that witnessed the flowering of perspective - the Renaissance - was also a period that was dominated by the unfinished. ${ }^{9}$ This coincidence was probably due to the fact that perspective in the fifteenth and sixteenth centuries served as a symbolic form of representation that ensured dialogue between this world and the next, the past and present, the ideal/sacred and ritual/ceremonial occasion and so on. Accordingly, the "unfinished", whether it be in the form of incomplete projects - such as Michelangelo's Rondanini Pietà or Bramante's Palazzo dei Tribunali - or as drawings of ancient ruins, affirmed continuity in the perspective view of a world bent on redeeming itself. Accordingly, the unfinished represents an attempt to measure - and thereby fathom - the relationship between a transcendent otherness and the reality that is "readily accessible".

The absence today of this ability to measure in the light of an allencompassing seer (God) has led to the apparent need for a substitute - or "auxiliary" - reality that can convey a sense of uniformity and homogeneity in the face of a discordant world. As I outlined in Chapters 3 and 4, against the traditional onto-theological outlook (of which perspective constituted one of the principal spatial paradigms) all lesser human initiatives could be judged. In contemporary culture this communicative - dialectical - function of perspective, and its support- 
ing ideality, has been overshadowed by the monologue of image. We are left with the self-referential systems of virtual reality, albeit ones that are presented as different from previous modes of encapsulation by their apparent experiential "openness" to infinitesimal possibilities. We could be forgiven for mistaking these possibilities as sufficient grounds for treating virtual reality as a site for unhindered exploration that can run alongside concrete experience. ${ }^{10}$ But such assumptions only confuse the immersive mechanisms of the medium with the world of our subjective existence.

This confusion has its origins in the modern illusion of a "mastering totalisation", discussed in Chapter 7, where a wished-for totality of the world can be encapsulated in the form of a commanding vision (panorama). Jacques Lacan, however, argues that there exists another form of overview, more comprehensive than the last, which he highlights in the context of Raymond Ruyer's Neo-finalisme:

in order to situate perception in a teleological perspective, [Ruyer] is forced to situate the subject in an absolute overview. There is no need, except in the most abstract way, to posit the subject in absolute overview.... Yet there is a phenomenal domain - infinitely more extended than the privileged points at which it appears - that enables us to apprehend, in its true nature, the subject in absolute overview. There are facts that can be articulated only in the phenomenal dimension of the overview by which I situate myself in the picture as stain. ${ }^{11}$

Lacan deploys the term "stain" in the context of anamorphic projection to explain the discovery of an "ideal" point of view that the subject is "supposed to know" by interpreting the anamorphic content of ordinary visible things. Outside this punctum, or invisible point in space, all other locations - and therefore other points of view - are required by the presumed all-encompassing nature of the other.

The question of the nature and meaning of the other underlies Lacan's theory of vision that serves as a useful model for examining the nature and meaning of perspective today. His theory centres on the problematic intersection between the optical apprehension of the subject and the ubiquitous gaze: Lacan's correlative of the traditional notion of an all-seeing divine Being. Drawing inspiration from Merleau-Ponty's Visible and Invisible, Lacan makes a clear distinction between the gaze and the eye, by which the former affirms the pre-given overview of our presence - and visibility - in the world, whilst the latter defines our visual relationship to it:

[The] eye is only the metaphor of something that I would prefer to call the seer's "shoot" (pousse) - something prior to his eye. What we have to circumscribe .... is the pre-existence of a gaze - I see only from a point, but in my existence I am looked at from all sides. ${ }^{12}$

To aid his exposition of vision Lacan produces a diagram that consists of two intersecting pyramids: 
the first is that which, in the geometric field, puts in our place the subject of representation, and the second is that which turns me into a picture. On the right-hand line is situated ... the apex of the first triangle, the point of the geometrical subject, and it is on that line that I, too, turn myself into a picture under the gaze, which is inscribed at the apex of the second triangle. The triangles are here superimposed, as in fact they are in the function of the scopic register. ${ }^{13}$

The idea of a "picture" looking back at the viewer challenges the primacy - and self-sufficiency - attributed to the thinking self in Cartesian thought. The resulting two-way perspective relationship could be compared to Nicholas Cusanus' diagram of intersecting triangles, examined in Chapter 4, which Dalibor Vesely argues is indicative of the closeness of Cusanus' "interpretation of sight to contemporary thinking of perspective".${ }^{14}$ Here, one of the triangles culminates in the light and unity of being (unitas), whilst the other in the shadow (tenebrae) and the diversity of the human world (alteritas)..$^{15}$

Notwithstanding Cusanus' closeness to contemporary thinking, the apparent similarities between both diagrams conceal an important difference in their underlying structures; a difference that highlights the gap separating premodern from modern perspective views of the world. Cusanus' intersection of unity of being and diversity of the human world is reduced in Lacan's model to an immanent intersection of the gaze with the subject of representation. Whilst in the former, the relation between both realms is conveyed in geometric terms as a communicative domain between human finitude and divine infinitude (reflected in the separation of the two intersecting "picture-planes"), the latter reduces the relationship between eye and gaze to the coincidence - and therefore conflation of the two planes. This difference tells us something about the meaning of the "other" in Lacanian thought (communicated by the "outstripping" of twodimensional images by the encompassing overview of three-dimensional objects) in contrast to the notion of "divine otherness" in Cusanian cosmology. The gaze that is returned to the subject by the object, is in Lacanian terms conditioned by

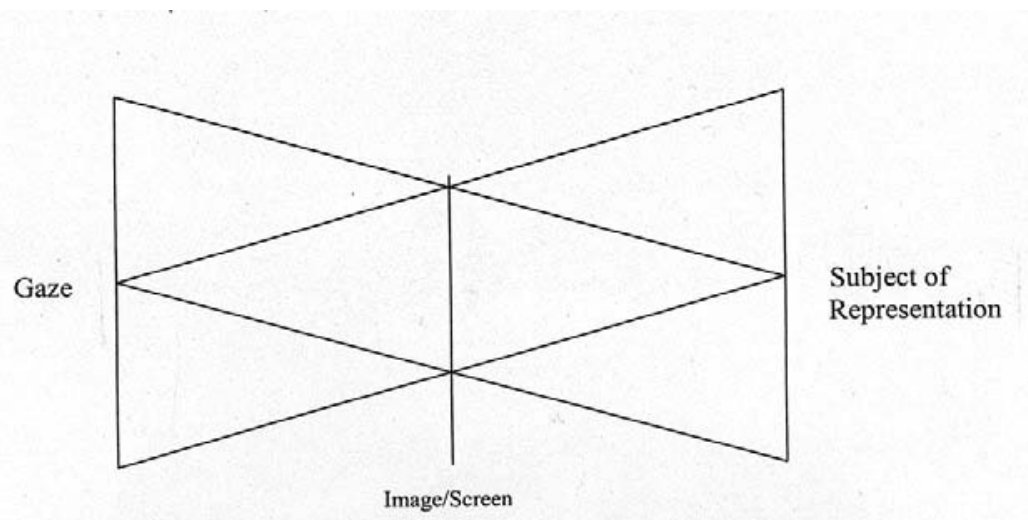

C.1

The inter-relation between the Gaze and the Subject of Representation. From Jacques Lacan, The Four Fundamental Concepts of Psycho-Analysis (New York: SUNY Press, 1995), p. 106 
the lack of the other, or more specifically the inability of the subject to properly apprehend the other. This leads to a slippage - or permanent "misalignment" between viewer and viewed and the subsequent creation of a surplus void in the centre of the other. Only by a process of interpolation (through the establishment of interjections, insertions, interventions, etc.) can this surplus be managed and given expression. ${ }^{16}$

The differences between the diagrams of Cusanus and Lacan indicate the critical shift from a predominantly transcendent to a thoroughly immanent view of the world. In Lacan's notion of the viewer as picture, which receives the effects of the gaze, we are given a dialectical model that has important architectural implications; spaces serve as ontological receptacles in which our perception of them implicitly acknowledges their effects on us as circumscribing volumes. As beings who are looked at in the spectacle of the world, our presence is also inscribed by the spaces we occupy. Thus, our relationship to space is a reciprocal one that assumes that architecture looks back at us. In this reciprocity, "situatedness" - the context in which we dwell - is always informed by a presiding historical background, of which architecture is its constitutive realm. This background order, however, is never fixed in any archetypal sense but is rather informed by cultural, political, social and technological developments. Hence, as historical beings we participate, through our everyday experiences, in the creation of new spatial conditions that both acknowledge past paradigms and anticipate future ones.

What I have tried to map out in this study is a model of perspective that considers the Lacanian diagram of vision not as an abstract construct but rather as a metaphorical motif that alludes to a deeper tradition redolent of Cusanian cosmology. In this re-interpretation, embedded in the synchronic nature of Lacanian dialectic - evinced in the back and forth movement between subject and gaze - is a diachronic (historical) ground. I have sought to illuminate this point by posing the premise that architecture not only provides the setting for the "here and the now" but also bears witness to the history of human situations. In each case architecture becomes the witness of human events. This largely unrecognised dialogue underlies our perspective outlook today and serves as an abiding reference in our understanding of the nature and meaning of architectural representation.

Throughout this investigation I have used the window as a metaphorical framework to convey the changes that have taken place in the nature and meaning of perspective; from the Papal Window of Julius II's Cortile del Belvedere (Chapter 4) to the nineteenth-century window (Chapter 7). I would like to conclude this study with a brief examination of a contemporary example, designed and described by Cache, to highlight how this historical ground in perspective continues to influence our relationship to the world. Located in an apartment in Montreux, the window overlooks Lake Léman. Placed within the frame of the opening is a glass coffee table that is configured so that it echoes the landscape beyond. In so doing the furniture "reproduces the landscape, not as a reflection but as a miniature". ${ }^{17}$ The articulation of the window frame initially sets up the "laws of 
perspective", from which the visible topographical features are registered as a landscape on the surface of the table:

The mountain becomes a sculpture in the round; what is big becomes small ... beyond relativizing the point of view, perspective is that art that allows us to hold a mountain between our fingers. It is a strange optic that threatens purely mechanical relations: the big can be contained in the small, the outside in the inside.... The window frames the landscape as much as the landscape encompasses the frame. ${ }^{18}$

Cache manipulates the ambiguity of scale in the perspective view by bringing the landscape into the interior space as a construct. The strategy raises interesting questions about how we perceive and represent the relation between inside and outside. The reduction of landscape to an assembly of small pieces on a coffee table could be likened to William Chamber's labelling of oriental architecture as "toy-like", whose components can be reconstructed as aesthetic objects in an English landscape. This example, as I inferred in Chapter 7, serves as an interesting precursor to the reliance in the modern age on domestic artifacts to stand in the place, so to speak, of actual experiences of places or events. In this metonymic role the increasingly private vision of the world in the nineteenth century is brought to the level of intimacy and intense introspection by the assembly and display of personal memorabilia. Cache's point that "Our entire subjectivity lies in the perspective of a miniaturized world" could, in one sense, be applied to the private interiors of the nineteenth century. Here, the displaced fragments of subjective experience provided the means of reconnecting with the world, through the archaeology of personal - tactile - possessions. ${ }^{19}$

In the case of Cache's interior, however, the miniaturised world is directly juxtaposed with its originating source - the real landscape beyond - rather than being withdrawn to some sheltered or concealed place. Moreover, instead of presenting the surface of the coffee table as an illusory extension of the actual
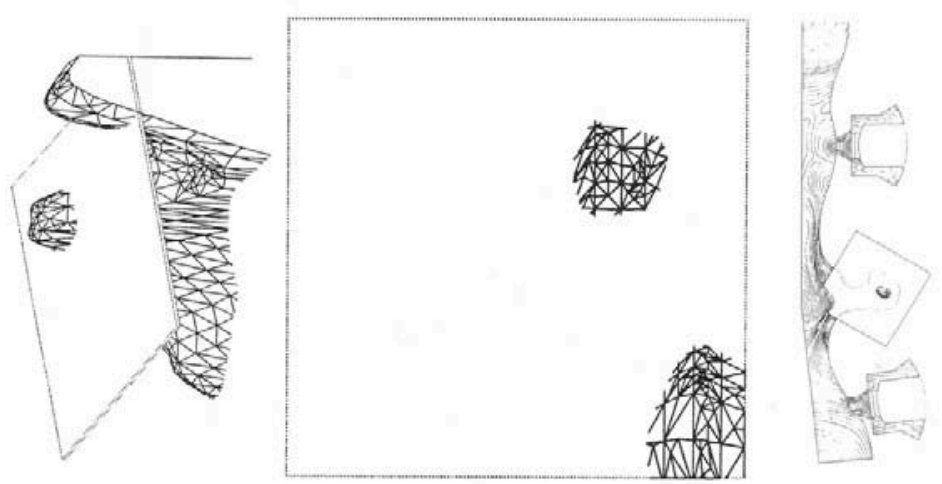

C. 2

Design for a

"topographical

table". Bernard

Cache, Michael

Speaks (ed.) and

Anne Boyman

(trans.), Earth

Moves: The

Furnishing of

Territories (MIT

Press, 1995) p. 141 
landscape - in the fashion deployed for example in some Baroque gardens Cache constructs it as its double. ${ }^{20}$ What was formerly apprehended in perspective terms as "a mountain between our fingers", is reconstructed here as tactile elements that serve both as conversation pieces - within the setting of the coffee table - and as "markers" of the landscape beyond. In this mediation, Cache seems to be searching for the kind of metaphorical relationships that underpinned the Papal Window; namely the homology between seeing and believing communicated through the symbolic/analogical relationships of view, map, text and so on.

Whilst Cache's modest intervention does not deal with the same level of complexity in iconography found in its Renaissance predecessor, it raises important issues about how contemporary architecture can create situations that cultivate analogical relationships.

Only by seeking to establish meaningful and memorable places, that are conducive to interpretation and which reaffirm our relationship to the world as historical beings, can we begin to overcome the endemic insularity of disciplinary thought - and its accompanying modes of visualisation - that have become the bane of creativity in our age. ${ }^{21}$ This investigation of perspective, in which I have argued for the existence of a latent tradition of perceiving and representing space, gives us, I believe, a framework for such an undertaking that can be communicated to a wider audience. 


\section{Notes}

\section{Introduction}

1 K. Harries, Infinity and Perspective (Cambridge, MA: MIT Press, 2001), p. 69.

\section{Order and chaos, or "What to leave out?"}

1 D. M. Kleinberg-Levin, Gestures of Ethical Life: Reading Hölderlin's Question of Measure After Heidegger (Stanford: Stanford University Press, 2005), p. xxviii. Hölderlin's notion of measure is examined in M. Heidegger, ". . Poetically Man Dwells ...", in M. Heidegger, Poetry, Language, Thought, translated by A. Hofstadter (New York: Harper \& Row, 1971), pp. 213-29. See also W. Marx, Is There a Measure on Earth? Foundations for a Nonmetaphysical Ethics (Chicago: The University of Chicago Press, 1987), p. 31.

2 lbid., p. xix.

3 D. J. Constantine, The Significance of Locality in the Poetry of Friedrich Hölderlin (London: The Modern Humanities Research Association, 1979), p. 4.

4 Quoted in Kleinberg-Levin, Gestures of Ethical Life, p. 33.

5 P. Fenves, Arresting Language: From Leibniz to Benjamin (Stanford: Stanford University Press, 2001), p. 6.

6 D. Vesely, Architecture in the Age of Divided Representation: The Question of Creativity in the Shadow of Production (Cambridge, MA: MIT Press, 2004), p. 251

7 W. Leibniz, "Monadology", in Philosophical Writings, edited by G. H. R. Parkinson, translated by M. Morris and G. H. R. Parkinson (London: Dent, 1973), p. 193, para. 83.

8 Vesely, Architecture in the Age of Divided Representation, p. 251.

9 I. Kant, Critique of Pure Reason, translated by J. M. Meiklejohn (Dutton, New York: Everyman's Library, 1979), pp. 54-61.

10 On this see P. Ricoeur, Time and Narrative, 3 vols (Chicago: University of Chicago Press, 1990), vol. 1, pp. 3-90; vol. 3, pp. 11-22.

11 Fenves, Arresting Language, p. 6.

12 Kleinberg-Levin, Gestures of Ethical Life, p. xvii.

13 Fenves, Arresting Language, p. 5.

14 Heidegger, “. . . Poetically Man Dwells ...', p. 228.

15 Hölderlin likens the wanderer to eagles and Alpine dwellers: Constantine, The Significance of Locality, p. 85.

16 Ibid., p. 84.

17 In its "becoming-in-the-midst-of-flux", the river "bears 'place' within itself". G. Pattison, The Late Heidegger (London: Routledge, 2000), pp. 178-9.

18 Ibid.

19 Constantine, The Significance of Locality, p. 108 
20 Ibid., pp. 85-6.

21 M. Heidegger, "Die Zeit des Weltbildes", Holzwege, in Gesamtausgabe (Frankfurt am Main: Klostermann, 1977), bk 5, pp. 75-113; Pattison, The Late Heidegger, p. 56.

22 M. Heidegger, Holzwege, quoted in J. L Marion, The Idol and Distance: Five Studies (New York: Fordham University Press, 2001), p. 27.

23 For an introduction to this see P. Emad, "The Place of the Presocratics in Heidegger's Beiträge zur Philosophie", in D. C. Jacobs (ed.), The Presocratics after Heidegger (Albany: State University of New York, 1999), pp. 55-71.

24 G. Simmel, "The Metropolis and Mental Life", in D. Levine (ed.), On Individuality and Social Forms (Chicago: University of Chicago Press, 1971), pp. 324-39.

25 This is explored in C. Taylor, Sources of the Self: The Making of the Modern Identity (Cambridge: Cambridge University Press, 1998), esp. pp. 143-76.

26 A. Koyré, Newtonian Studies (London: Chapman \& Hall, 1965), p. 24, quoted in Vesely, Architecture in the Age of Divided Representation, p. 231.

27 For a good examination of this see J. Crary, Suspensions of Perception: Attention, Spectacle, and Modern Culture (Cambridge, MA: MIT Press, 2001), pp. 11-79.

28 E. S. Casey, The Fate of Place: A Philosophical History (Berkeley: University of California Press, 1989), pp. 252-3.

29 Vesely, Architecture in the Age of Divided Representation, p. 207.

30 Ibid., pp. 94-5. Vesely points out that the use of the term Gesamtkunstwerk for the earlier period of the Baroque is misleading given that the "visual unity of [Baroque] space is only a secondary manifestation of a deeper unity that cannot be grasped through aesthetic experience", p. 218.

31 Marx, Is There a Measure on Earth?, p. 31.

32 Marion, The Idol and Distance, p. 93.

33 Ibid., p. 89.

34 Ibid., p. 23.

35 Heidegger, ". . Poetically Man Dwells ....", pp. 228-9.

36 Marion, The Idol and Distance, p. 88.

37 For discussion of the idea of a "mastering totalization" see C. Prendergast, Paris and the Nineteenth Century (Oxford: Blackwell, 1992), pp. 210-14.

38 See N. Temple, "The Bishop's Eye: Robert Grosseteste and the Architecture of Light", in Architectural Theory Review, vol. 9, no. 1 (2004), pp. 1-18.

39 Fenves, Arresting Language, p. 2.

40 Ibid.

41 S. D. Hales and R. Welshon, Nietzsche's Perspectivism (Urbana: University of Illinois Press, 2000), p. 12.

42 Ibid., p. 59.

43 Ibid., p. 18

44 Ibid., pp. 20-1.

45 lbid.

46 M. Heidegger, Nietzsche Vol. 1: The Will to Power as Art, translated by David Farrell Krell (London: Routledge \& Kegan Paul, 1981), p. 212.

47 lbid., p. 215.

48 See M. Heidegger, What is a Thing?, translated by W. B. Barton, Jr., and V. Deutsch (Chicago: Henry Regnery Company, 1967).

49 Heidegger, Nietzsche Vol. 1, p. 214.

50 D. Vesely, "On the Relevance of Phenomenology", in Form; Being; Absence: Pratt Journal of Architecture, vol. 2 (1988), p. 61.

51 Heidegger, Nietzsche Vol. 1, p. 216.

52 Vesely, Architecture in the Age of Divided Representation, p. 287. 


\section{Disclosing Horizons}

53 Marx, Is There a Measure on Earth?, pp. 2, 4.

54 Pattison, The Late Heidegger, p. 165.

55 M. Heidegger, Being and Time, translated by J. Macquarrie and E. Robinson (Oxford: Blackwell), pp. 275-8.

56 Hans-Georg Gadamer, Truth and Method (London: Sheed \& Ward, 1981), pp. 268-9.

57 Heidegger, Being and Time, p. 275.

58 Ibid.

59 P. Carl, "Architectural Design and Situational History", in A. Hardy and N. Teymur, Architectural History and the Studio (London: ?uestion Press, 1996), p. 78. In opposition to this is the notion of "de-situated space" which "proposes to encompass everything in general and nothing in particular", p. 88.

60 Vesely, Architecture in the Age of Divided Representation, p. 369.

61 Ibid., p. 370.

62 See also N. Temple, "Renovatio Urbis: Architecture and Topography in Rome During the Pontificate of Julius II", unpublished PhD thesis, Leeds Metropolitan University (2000), pp. 330-82.

63 On this important point I am grateful to Dalibor Vesely for his invaluable insight into the symbolism of eighteenth-century landscapes, following discussions at the Philadelphia Museum of Art in November 2001.

64 E. Husserl, The Crisis of European Sciences and Transcendental Phenomenology (Evanston: Northwestern University Press, 1970), p. 28.

65 Ibid., p. 119.

66 T. Kisiel, The Genesis of Heidegger's Being \& Time (Berkeley: University of California Press, 1995), p. 370

67 Ibid., p. 371.

68 For a discussion of the notion of "facticity" in Heidegger's thought see ibid., pp. 23-8.

69 Ibid., p. 372.

70 Ibid.

71 Ibid., p. 373.

72 C. Michalson, "Theology as Ontology and as History", in J. M. Robinson and J. B. Cobb Jr (eds), The Later Heidegger and Theology (New York: Harper \& Row Publishers, 1963), pp. 136-56.

73 Kisiel, The Genesis of Heidegger's Being \& Time, pp. 200-3.

74 Heidegger, Being and Time, pp. 122-34.

75 Ibid., p. 123.

76 lbid., p. 124.

77 Ibid., p. 125.

78 Casey, The Fate of Place, p. 153.

79 J. L. Marion, On Descartes' Metaphysical Prism: The Constitution and the Limits of Onto-TheoLogy in Cartesian Thought (Chicago: The University of Chicago Press, 1999), p. 73.

80 Ibid., p. 123.

81 Heidegger, "... Poetically Man Dwells ...", p. 223.

82 M. Gelvin, A Commentary on Heidegger's Being and Time (DeKalb: Northern Illinois University Press, 1989), p. 66.

83 Kisiel, The Genesis of Heidegger's Being \& Time, p. 374.

$84 \mathrm{Ibid}$.

85 Heidegger, Being and Time, p. 141.

86 Ibid., pp. 134-8.

87 Marx, Is There a Measure on Earth?, p. 75.

88 Ibid.

89 lbid., p. 81. 
90 Ibid.

91 G. Boehm, "Die Krisis der Perspekivität in Heidegger's 'Sein und Zeit' ", in G. Boehm, Studien zur Perspektivität, translated by Alexander Eisenschmidt (Heidelberg: Carl Winter Universitätsverlag, 1969), p. 188.

92 lbid., p. 115.

93 Ibid., p. 116.

94 lbid., p. 121.

95 Heidegger, Being and Time, p. 172.

96 M. Heidegger, An Introduction to Metaphysics, translated by R. Manheim (New Haven: Yale University Press, 1959), p. 205, quoted in Casey, The Fate of Place, p. 260.

97 Boehm, “Die Krisis der Perspekivität in Heidegger's 'Sein und Zeit' ”, p. 122.

98 Ibid.

99 E. Levinas, Alterity and Transcendence (New York: Columbia University Press, 1999), p. 126.

100 lbid., p. xiii.

101 Ibid., p. 28.

102 lbid., p. 30.

103 Ibid., p. 127.

104 Ibid., p. 97.

105 H.Gatty, Giordano Bruno and Renaissance Science (Ithaca: Cornell University Press, 1999), pp. 99-127.

106 E. Levinas, Totality and Infinity: An Essay on Exteriority, translated by Alphonso Lingis (Pittsburgh, PA: Duquesne University Press, 2000), p. 19.

107 Ibid., p. 196.

108 lbid., p. 61.

109 Ibid., p. 62.

110 M. Merleau-Ponty, The Visible and the Invisible, translated by Alphonso Lingi (Evanston: Northwestern University Press, 1968), p. lii.

111 D. Low, Merleau-Ponty's Last Vision: A Proposal for the Completion of The Visible and the Invisible (Evanston: Northwestern University Press, 2000), p. 17.

112 lbid.

113 Merleau-Ponty, Visible and Invisible, p. 9.

114 Ibid., pp. 248-51.

115 Ibid.

116 Low, Merleau-Ponty's Last Vision, p. 6.

117 Merleau-Ponty, Visible and Invisible, p. 202.

118 Ibid., p. 230.

\section{Number, geometry and dialectic}

1 E. Husserl, "The Origin of Geometry", in The Crisis of European Sciences and Transcendental Phenomenology (Evanston: Northwestern University Press, 1970), pp. 353-78.

2 lbid., p. 360.

3 I use Dalibor Vesely's meaning of the term: "Tradition is neither pure experience nor is it given by nature. It is an experience sedimented and embodied in culture in the same way as our soul is embodied in our body. If it is possible to describe historicism as a monologue then tradition is a dialogue with the past and an anticipation of the future." Architecture and Continuity: Themes 1 (London: Architectural Association, 1982), p. 8.

4 R. Evans, The Projective Cast, Architecture and its Three Geometries (Cambridge, MA: MIT Press, 1995), p. 38. 
5 J. Hankins, Plato in the Italian Renaissance (Leiden: E. J. Brill, 1991), p. 6.

6 Husserl, "The Origin of Geometry", p. 366.

7 J. Derrida, Edmund Husserl's Origin of Geometry: An Introduction, translated by J. P. Leavey Jr (New York, Stony Brook: Nicolas Hays Ltd., 1978), p. 35, n. 20.

8 H. Damisch, The Origin of Perspective (Cambridge, MA: MIT Press, 1995), p. 86.

9 Ibid.

10 lbid., p. 83.

11 M. Gazalé, Number: From Ahmes to Cantor (Princeton: Princeton University Press, 2000), p. 161.

12 "Eurytus, a disciple of Philolaus, in the last generation of the ancient Pythagoreans, tried to express the nature of man 'by means of pebbles which he arranged in a figure ... having the shape of a man'". J. E. Boodin, "The Discovery of Form", in P. P. Weiner and A. Noland (eds), Roots of Scientific Thought (New York: Basic Books Publishers, 1985), p. 57.

13 C. H. Buttimer, Hugonis de Sancto Victore Didascalicon, De Studio Legendi: A Critical Text (Washington, D.C.: The Catholic University Press, 1939), VI, 3, pp. 114-15, quoted in I. Illich, In the Vineyard of the Text: QA Commentary to Hugh's Didascalicon (Chicago: The University of Chicago Press, 1996), p. 30.

14 R. Padovan, Proportion: Science, Philosophy, Architecture (London: Spon Press, 1999), p. 48.

15 D. Furley, The Greek Cosmologists Vol. 1: The Formation of the Atomic Theory and its Earliest Critics (Cambridge: Cambridge University Press, 1987), p. 52.

16 M. Gazalé, Gnomon: From Pharaohs to Fractals (Princeton: Princeton University Press, 1999), p. 11.

17 Ibid., p. 7.

18 Ibid., p. 6.

19 Ibid., p. 7. Indra McEwen infers, in reference to Vitruvius' threefold rubric of architecture, the gnomon as indicative of a process of "squaring" the universe; I. K. McEwen, Vitruvius: Writing the Body of Architecture (Cambridge, MA: MIT Press, 2003), pp. 229-37.

20 For discussion of this see ibid., pp. 15-24.

21 D. Vesely, Architecture in the Age of Divided Representation: The Question of Creativity in the Shadow of Production (Cambridge, MA: MIT Press, 2004), p. 208.

22 Gazalé, Gnomon, pp. 198-249.

23 On the ideas of Hugh of St Victor see G. A. Zinn, Jr, "Historia fundamentum est: The Role of History in the Contemplative Life According to Hugh of St. Victor", in G. H. Shriver (ed.), Contemporary Reflections on the Medieval Christian Tradition. Essays in Honor of Ray C. Petry (Durham, N.C.: Duke University Press, 1974), pp. 135-58.

24 Ilich, In the Vineyard of the Text, p. 36.

25 The Theology of Arithmetic: On the Mystical, Mathematical and Cosmological Symbolism of the First Ten Numbers, Attributed to lamblichus, translated by R. Waterfield (Grand Rapids, Michigan: Phanes Press, 1988).

26 McEwen, Vitruvius: Writing the Body of Architecture, p. 42.

27 lbid., p. 43.

28 Ibid., p. 41. For an account of the method of storing scrolls in antiquity see, J. W. Clark, The Care of Books (Cambridge: Cambridge University Press, 1909), pp. 31-8.

29 lbid., p. 61.

30 Ibid., pp. 60-1.

31 lbid.

32 The transition from geometric forms to mathematical proportions enables the sensible to participate in the intelligible. See J. Hendrix, Platonic Architectonics: Platonic Philosophies \& the Visual Arts (New York: Peter Lang, 2004), pp. 5-22.

33 Aristotle makes the distinction between the reality of occupied place and the abstract notion of empty infinity. Aristotle: Physics, translated by R. Waterfield (Oxford: Oxford University Press, 1999), bk IV, pp. 78-117. 
34 A. Koyré, From the Closed World to the Infinite Universe (Baltimore: Johns Hopkins University Press, 1957).

35 Furley, The Greek Cosmologists, p. 136.

36 W. K. C. Guthrie, A History of Greek Philosophy (Cambridge: Cambridge University Press, 1962), p. 247.

37 B. Rotman, Signifying Nothing: The Semiotics of Zero (Stanford: Stanford University Press, 1993), p. 1.

38 This formed the basis of Nicholas Cusanus' principle of "learned ignorance". See K. Harries, Infinity and Perspective (Cambridge, MA: MIT Press, 2001), pp. 42-63.

39 K. Popper, "The nature of philosophical problems and their roots in science", in Conjectures and Refutations (London: Routledge \& Kegan Paul, 1965), pp. 143-4.

40 Plato, Republic, translated by D. Lee (Harmondsworth: Penguin Books, 1980), bk V, 432c.

41 F. M. Cornford, "Anamnesis", in K. C. Guthrie (ed.), Plato's Meno: with essays edited by Malcolm Brown (Indianapolis: The Bobbs-Merrill Company, 1971), pp. 116-17.

42 G. Vlastos, "Anamnesis in the Meno", in J. M. Day (ed.), Plato's Meno in Focus (New York: Routledge, 1994), p. 95.

43 Popper, "The nature of philosophical problems", p. 161. Guthrie, however, translates it as: "If you don't want to count it up, just show us on the diagram." Plato, Protagoras and Meno, translated by W. K. C. Guthrie (Harmondsworth, Middlesex: Penguin Books, 1970), 84E.

44 Popper, "The nature of philosophical problems', p. 161. For a more detailed discussion of this see I. Toth, Lo schiavo di Menone (Milan: Vita e Pensiero, 1998).

45 Hendrix, Platonic Architectonics, p. 14.

46 Popper, "The nature of philosophical problems", p. 163.

47 lbid., p. 164.

48 lbid., p. 159.

49 G. F. Hemens, Proceedings of the Xth International Congress of Philosophy (Amsterdam, 1949), Fasc. 2, p. 847, quoted in Popper, "The nature of philosophical problems", p. 166.

50 Vlastos, "Anamnesis in the Meno", p. 95.

51 Husserl, "The Origin of Geometry", p. 359.

52 lbid., p. 360.

53 Ilich, In the Vineyard of the Text, p. 41.

54 Ibid., p. 40.

55 Ibid.

56 A. E. Taylor, Plato: The Man and his Work (London: Methuen, 1978), p. 130.

57 Ibid.

58 Husserl, "The Origin of Geometry", p. 360.

59 Ibid., p. 361.

60 J. Hankins, Plato in the Italian Renaissance (Leiden: E. J. Brill, 1991), p. 4.

61 Plato, Phaedrus, translated by H. N. Fowler (Cambridge, MA: Loeb Edition, Harvard University Press, 1960), 274C-275B, quoted in F. A. Yates, The Art of Memory (Chicago: University of Chicago Press, 1984), p. 38.

62 M. R. Wright, Cosmology in Antiquity (London: 1995), p. 48.

63 The principle of monotheism in Platonic thought became a particularly contentious issue in the Renaissance, as we see for example in the philosophy of Marsilio Ficino. Hankins, Plato in the Italian Renaissance, pp. 267-359.

64 F. M. Cornford, Plato's Cosmology: The Timaeus of Plato (Indianapolis: Hackett Publishing Company, 1997), p. 177.

65 For discussion of the philosophy of Parmenides and Heraclitus see E. Burnet, Early Greek Philosophy (London: A\&C Black, 1930).

66 J. Sallis, Chorology: On Beginning in Plato's Timaeus (Bloomington: Indiana University Press, 1999), p. 60. 


\section{Disclosing Horizons}

67 Ibid., p. 60.

68 Cornford, Plato's Cosmology, p. 187.

69 lbid., p. 195.

70 Ibid., p. 194.

71 Ibid., p. 196.

72 Sallis, Chorology, p. 66.

73 "Taking these three beings, [the Demiurge] blended them, mixing the nature of the same (the nature that is selfsame, the first kind) and the nature of the different (the second) with the being yielded by the previous blending (the third kind, in the middle). Thus he made one out of three. As counting, 1,2,3, one gathers the three ones into the counting number, into 3." Ibid., p. 69.

74 On prisca theologia, see F. A. Yates, Giordano Bruno and the Hermetic Tradition (Chicago: University of Chicago Press, 1964). The notion of "ancient theology" forms the theme of a commentary by the Renaissance humanist Giles of Viterbo. H. Pfeiffer, "Le Sententiae ad mentem Platonis e due prediche di Egidio da Viterbo ...", in M. Fagiolo (ed.), Roma e l'Antico nell'arte e nella cultura del Cinquecento (Rome: Istituto della Enciclopedia Italiana, 1985), pp. 33-40.

75 Cornford, Plato's Cosmology, p. 211.

76 Plato's Timaeus, translated by F. M. Cornford (Indianapolis: The Bobbs-Merrill Company, 1959), 53c.

77 Cornford, Plato's Cosmology, p. 216.

78 Plato's Timaeus, p. 138.

79 lbid., pp. 136-7.

80 Cornford, Plato's Cosmology, p. 69.

81 Hence, Cornford argues that the "harmony of the world-soul has nothing to do with the music of the spheres". Ibid., p. 79.

82 Sallis, Chorology, p. 72.

83 On Cicero's part translation see N. Lambardi, I/ "Timaeus" ciceroniano (Florence, 1982). On lamblichus' commentary see J. M. Dillon, lamblichi Chalcidensis, In Platonis dialogos commentariorum fragmenta (Leiden: E. J. Brill, 1973).

84 According to C. L. Joost-Gaugier, this translation "came to be regarded as a symbol of Platonic cosmology and the Greek appreciation of the rational beauty of the universe". "Plato and Aristotle and their Retinue: Meaning in Raphael's School of Athens", Gazette des Beaux Arts, vol. 143 (2001), p. 152.

85 M. Sbacchi, "Euclidism and Theory of Architecture", Nexus Network Journal: Architecture and Mathematics Online (www.nexusjournal.com/Sbacchi.html), p. 3.

86 Ibid.

87 Ibid. p. 4. Wittkower partly bases his argument on the probability that neither "Palladio nor any Renaissance architect ever in practice used irrational proportions". R. Wittkower, Architectural Principles in the Age of Humanism, Vol. 19, Studies of the Warburg Institute, 1949 (London: Alec Tiranti, 1952), p. 95.

88 R. Wittkower, Idea and Image (London: Thames \& Hudson, 1978), p. 116. Wittkower's argument should not assume that Pythagorean number was not applied to architecture in the Middle Ages, as we see for example at Milan Cathedral. See J. Roosval, "Ad Triangulum Ad Quadratum", Gazette des Beaux-Arts, vol. XXVI (1944), pp. 149-62.

89 Padovan, Proportion, p. 183.

90 L. B. Alberti, On the Art of Building in Ten Books, translated by Joseph Rykwert, Neil Leach and Robert Tavernor (Cambridge, MA: MIT Press, 1996), p. 307.

91 Sbacchi, "Euclidism and Theory of Architecture", p. 4.

92 L. Steinberg, Leonardo's Incessant Last Supper (New York: Zone Books, 2001), pp. 56-7. I expand Steinberg's assertion that duplexity "lies at the heart of Renaissance painting and its love of perspective" by suggesting a broader influence on all aspects of representation. 
93 L. March, Architectonics of Humanism: Essays on Number in Architecture (Chichester: Academy Editions, 1998), p. 200.

94 Ibid., pp. 200-1.

95 Ibid.

96 Wittkower, Idea and Image, p. 126, quoted in Padovan, Proportion, p. 214.

97 Ibid.

98 A good example is Leonardo's Last Supper. See Steinberg, Leonardo's Last Supper, p. 183.

99 Ibid., p. 56.

100 lbid.

101 Ibid., p. 57.

102 Ibid.

103 lbid.

104 lbid., p. 183.

105 M. Kemp, Leonardo (Oxford: Oxford University Press, 2004), pp. 4-5.

106 Ibid., p. 59.

107 Steinberg, Leonardo's Last Supper, p. 77.

108 I assume here the meaning given to the term by Emmanuel Levinas. Alterity \& Transcendence (New York: Columbia University Press, 1999).

109 Steinberg, Leonardo's Last Supper, p. 181.

110 Ibid., p. 121. This description finds remarkable similarities to the following description of the fresco: "In the stunning variety of poses, the subtlety of the grouping and the breathtaking translation into gesture of an emotional shock wave that spreads out from Christ to the edges of the group and turns back toward the centre like ripples from a pebble dropped into a bucket of water." R. E. Lieberman, "The Architectural Background", in M. Hall (ed.), Raphael's School of Athens (Cambridge: Cambridge University Press, 1997), p. 68.

111 lbid., p. 147.

112 For discussion of the symbolism of the angle in Cusanian cosmology see Chapter 4.

113 J. Gadol, Leon Battista Alberti: Universal Man of the Early Renaissance (Chicago: University of Chicago Press, 1973), p. 42.

114 L. B. Alberti: On Painting, translated by Cecil Grayson, introduction by Martin Kemp (London: Penguin Books, 1991), bk 1: pp. 50-1.

115 Ibid., p. 13.

116 J. Dubreuil, La perspectiva practique: necessaire a tons peintres graveurs ... (Paris: 1647-51), p. 122.

117 Evans, The Projective Cast, p. 38.

118 In this concept, the absolute maximum and absolute minimum (that which is maximally large and maximally small) coincide as aspects of the same infinitesimal cosmos. Humankind occupies a limited contractual relationship within this inter-connected world. Nicholas of Cusa on Learned Ignorance: A Translation and an Appraisal of De Docta Ignorantia, translated by J. Hopkins (Minneapolis: Banning Press, 1985).

119 Steinberg, Leonardo's Last Supper, p. 134. He explores this more specifically in the context of Pico della Mirandola's assertion that "the mind can compose all contradictions". Ibid.

120 We are given a sense of this spatial-temporal condition of perspective in Velasquez' Las Meninas where the spatial relationship between the figures (from background to foreground) registers the hierarchy of the royal family and its court with respect to age and status; this moves from the artist's sitters (King Philip and his wife Mariana), reflected in the mirror in the background, and concludes in the foreground with representations of a youthful court jester and a dwarf. Bernard Cache cleverly identifies in this last, prominent, figure an intentional ambiguity between "proximity and distance, youth and age". This is played out in the surfaces of the painting by the texture of the skin; "the dwarf's skin was not the same as the adult's or the child's, and some Spanish artists excelled at reproducing this texture against the backdrop 


\section{Disclosing Horizons}

of curtains". B. Cache, Earth Moves: The Furnishing of Territories (Cambridge, MA: MIT Press, 1995), p. 148.

121 On the three wisdom traditions see I. D. Rowland, "The Intellectual Background of the School of Athens: Tracking Divine Wisdom in the Rome of Julius II", in Hall, Raphael's School of Athens, pp. 131-70. On Renaissance views of history see W. von Leyden, "Antiquity and Authority, A Paradox in the Renaissance Theory of History", Journal of the History of Ideas, 19 (1958), pp. 473-92.

122 This idea of the present is based on the principle of the "decline theory" of history, whereby the further one is historically from original creation the more decrepit is the age in question. See V. De Caprio, "Il mito delle origini nelle 'Antiquitates' di Annio da Viberbo", in Cultura Umanistica a Viterbo - Atti della Giornata di Studio per il V Centenario della Stampa a Viterbo, 1988 (Viterbo: Associazione Roma nel Rinascimento, 1991), pp. 87-110. On Giles of Viterbo's view of history see J. W. O'Malley, "Man's Dignity, God's Love and the Destiny of Rome: A Text by Giles of Viterbo", Viator: Medieval \& Renaissance Studies, vol. 3 (1972), pp. 389-416.

123 Joost-Gaugier, "Plato and Aristotle and their Retinue", pp. 149-64.

124 lbid., p. 152.

125 Ibid., p. 154

126 See Hall, Raphael's School of Athens, p. 34.

127 lbid.

128 I am grateful to J. Field for confirming the exceptional nature of vanishing points in paintings coinciding with important symbolic elements in the Renaissance. The School of Athens and the Disputa are however clearly exceptions.

129 This is examined in N. Temple, "Renovatio Urbis: Architecture and Topography during the Pontificate of Julius II", unpublished doctoral dissertation (Leeds Metropolitan University, 2000), pp. 330-82.

130 On St Augustine's peregrinatio, see N. Temple, "Conversion and Political Expedience: Imperial Themes in the Early Christian Baptistery", in Anales Del Instituto De Investigaciones Esteticas, no. 80 (2002), pp. 5-45.

131 T. Verdon, "Pagans in the Church: The School of Athens in Religious Context", in Hall, Raphael's School of Athens, p. 117.

132 Rowland, "The Intellectual Background of the School of Athens", p. 145.

133 K. Harries, Perspective and Infinity (Cambridge, MA: MIT Press, 2001), p. 63.

134 This assumption is underlined by M. Kemp's assertion that "[Leonardo] exhorted himself to 'return to the study of natural things', rather than falling back upon traditional wisdom". Leonardo, p. 154.

135 I. Rowland, The Culture of the High Renaissance: Ancients and Moderns in Sixteenth-Century Rome (Cambridge, Cambridge University Press, 1998), pp. 105-8.

136 Ibid., p. 108.

137 Ibid., p. 107. The image derives from the Medieval tradition of representing God as geometer of the universe, a representation that gave credence to the principle of a concordance between revelation and reason. For an example see P. Whitfield, Landmarks in Western Science: From prehistory to the atomic age (London: The British Library, 1999), p. 81.

138 Rowland, The Culture of the High Renaissance, p. 108.

139 Kemp, Leonardo, p. 29.

140 Whitfield, Landmarks in Western Science, p. 94.

141 Padovan, Proportion, p. 304.

142 G. Vasari, Lives of the Painters, Sculptors and Architects, translated by A. B. Hinds (New York: Dutton, 1963), bk 2, p. 187. Significantly, Vasari only mentions this in the life of Bramante and not in the life of Raphael.

143 K. Oberhuber, Raffaello (Milan: Mondadori, 1982). A version of this diagram was published by A. Bruschi, Bramante architetto (Bari: Laterza, 1969), figs. 485-7. See also S. Valtieri, “La 
Scuola di Athene", in Mitteilungen des Konsthistorischen Institutes in Florence, XVI (Florence, 1972), pp. 63-72.

144 For a discussion of tabulation and the abacus in the Renaissance see Rowland, The Culture of the High Renaissance, pp. 109-40.

145 A. W. Crosby, The Measure of Reality: Quantification and Western Society, 1250-1600 (Cambridge: Cambridge University Press, 1999).

146 Ibid., p. 45.

147 The coat of arms is the same as the seal of Giles' beloved monastery at Lecceto. For an interpretation see Temple, Renovatio Urbis, p. 43.

148 Rowland, "The Intellectual Background", p. 157.

149 Vasari, Lives of the Artists, translated by G. Bull (Harmondsworth, Middlesex, 1965), p. 292. The late seventeenth-century art historian, Giovan Pietro Bellori, made the first recorded identification of the figure as Pythagoras. "The Image of the Ancient Gymnasium of Athens, or, Philosophy", translated by A. Sedgwick Wohl, in Hall, Raphael's School of Athens, pp. 48-56.

150 This is highlighted for example in Bramante's daring proposal to construct a hieroglyph of the pontifical title of Julius II (Iulio II.Pont.Max). G.Vasari, le Vite: De Piu Eccellenti Pittori, Scultori e Architettori, edited by R. Bettarini (Florence: Studio per Edizioni Scelte, 1976), vol. IV, pp. 79-80.

151 Ilich, In the Vineyard of the Text, p. 12.

152 For an account of this history of the Magan David, see G. Scholem, Kabbalah (New York: Dorset Press, 1974), pp. 362-8. For a discussion of its numerological and geometrical meanings see March, Architectonic of Humanism, pp. 119-20.

153 Padovan, Proportion, pp. 140-1.

154 D. Fowler, The Mathematics of Plato's Academy: A New Reconstruction (Oxford: Clarendon Press, 1999), pp. 30-5.

155 Ibid., pp. 32-4.

156 Sallis, Chorology, p. 55.

157 D. F. Krell, "A Malady of Chains: Husserl and Derrida on the Origins and Ends of Geometry, with a Note to the Archeticts of the Future", in Archeticture: Ecstasies of Space, Time and the Human Body (Albany: State University of New York Press, 1995), pp. 175-88.

158 Ibid., pp. 175-6.

159 lbid.

160 lbid., p. 187.

161 D. De Long and D. Brownlee, Kahn (London: Thames \& Hudson, 1997), p. 204.

162 S. W. Goldhagen, Louis Kahn's Situated Modernism (New Haven: Yale University Press, 2001), p. 5.

163 Ibid., p. 29.

164 Ibid., p. 47.

165 See note 143.

166 Ibid., p. 48.

167 lbid., p. 47.

168 Ibid., p. 52.

169 The way in which the shadows cast by the pyramids are informed by the relative points of view of the images is redolent of the legend of Thales of Miletus who is credited by Plutarch with having discovered a method for calculating the height of the pyramid of Giza. It is said that he calculated the length of the shadow of the pyramid at the same time as the shadow cast by his own body, when it coincides with his height. By applying the properties of similar triangles Thales was able to calculate the height of the pyramid.

170 Goldhagen, Louis Kahn's Situated Modernism, p. 58.

171 lbid., p. 44.

172 De Long and Brownlee, Kahn, p. 60. 
173 Ibid., p. 60. See also A. Latour (ed.), Louis I. Kahn: L'uomo, il maestro (Rome: Edizioni Kappa, 1986), p. 147.

174 J. W. Cook and H. Klotz, Conversations with Architects (London: Lund Humphries, 1973), p. 179.

175 R. Bauval and A. Gilbert, The Orion Mystery: Unlocking the Secrets of the Pyramids (New York: Three Rivers Press, 1995).

176 Harries, Infinity and Perspective, pp. 145, 174a.

177 Goldhagen, Louis Kahn's Situated Modernism, pp. 60-2.

178 Ibid. On authenticity in Heidegger's philosophy see K. Harries, "Authenticity, Poetry, God", in B. E. Babich (ed.), From Phenomenology to Thought, Errancy and Desire: Essays in Honor of William J. Richardson, S.J. (Dordrecht: Kluwer Academic, 1995).

179 Cook and Klotz, Conversations, p. 179.

180 M. Heidegger, Being \& Time (Oxford: Blackwell, 1997), p. 441.

181 Goldhagen, Louis Kahn's Situated Modernism, p. 209.

\section{Light, memory and colour}

1 D. Vesely, Architecture in the Age of Divided Representation: The Question of Creativity in the Shadow of Production (Cambridge, MA: MIT Press, 2004), p. 110.

2 lbid.

3 lbid.

4 J. Gassner, Medieval and Tudor Drama (London: Applause Theatre and Cinema Book Publishers, 1987), pp. 44-187.

5 O. von Simson, The Gothic Cathedral: Origins of Gothic Architecture and the Medieval Concept of Order, Bollingen Series XLVIII (Princeton: Princeton University Press, 1974), pp. 227-8.

6 M. Heidegger, Being and Time (Oxford: Blackwell, 1997), p. 176.

7 W. Watts and Robert J. O'Connell (trans.), St. Augustine's Confessions, Loeb Classical Library (Cambridge, MA: Harvard University Press, 1912). See also R. H. Nash, The Light of the Mind: St. Augustine's Theory of Knowledge (Academic Renewal Press, 2003).

8 M. T. Clanchy, From Memory to Written Record: England 1066-1307 (Oxford: Blackwell Publishing, 2002), p. 3.

9 Ibid., p. 115.

10 lbid.

11 lbid., p. 134.

12 I. Illich, In the Vineyard of the Text: A Commentary to Hugh's Didascalicon (Chicago: The University of Chicago Press, 1993), p. 58. This probably explains the origin of the Latin verb to read (legere), that relates to certain physical activities such as "picking", bundling, harvesting or collecting.

13 lbid., p. 81.

14 lbid., p. 82.

15 Clanchy, From Memory to Written Record, pp. 119-20.

16 Ibid., pp. 177-8.

17 F. A. Yates, The Art of Memory (Chicago: The University of Chicago Press, 1984), pp. 1-17.

18 Ibid., p. 5.

19 Clanchy, From Memory to Written Record, p. 175.

20 lbid.

21 Illich, In the Vineyard of the Text, p. 25.

22 Clanchy, From Memory to Written Record, p. 181.

23 Clanchy describes this change as follows: "when indexing schemes make their way from the 
hearts and minds of their creators, their arche in Hugh of St Victor's terms, on to the pages of books and documents". Ibid., p. 179.

24 Illich, In the Vineyard of the Text, p. 43.

25 Ibid., p. 63.

26 Clanchy, From Memory to Written Record, p. 179.

27 lbid.

28 For a brief discussion of this see A. Zajonc, Catching the Light: The Entwined History of Light and Mind (New York: Oxford University Press, 1993), ch. 1.

29 A striking example is the eleventh-twelfth-century mosaic of the Last Judgement in the Cathedral at Torcello.

30 Plato, Republic (Harmondsworth: Penguin Books, 1980), pp. 316-24.

31 For a succinct account of this see Frederick S. J. Copleston, A History of Philosophy, Volume 2, Mediaeval Philosophy, Part 1: Augustine to Bonaventure (New York: Image Books, 1962), pp. 106-15.

32 The Pseudo Dionysius, "The Mystical Theology," in C. Luibheid (trans.), Pseudo-Dionysius: The Complete Works (New York: Paulist Press, 1987), p. 136.

33 The significance of Dionysian cosmology declined and went into obscurity by the end of the Middle Ages. This was due in large measure to the accusations of pantheism levelled at the ninth-century Irish translator of the Dionysian Corpus, John Scotus Eriugena. His De Divisione Naturae was criticised by many in the Church as advocating a form of "pantheistic monism". Dionysius' idea of negative theology was revived during the Renaissance, principally through Nicholas Cusanus' development of the concept of the "coincidence of opposites". For discussion of De Divisione Naturae see Copleston, A History of Philosophy, Volume 2, pp. 133-55.

34 The Pseudo-Dionysius, "The Celestial Hierarchy" and "The Ecclesiastical Hierarchy", in Luibheid (trans.), Pseudo-Dionysius, pp. 143-260.

35 Luibheid, The Pseudo-Dionysius, p. 27.

$36 \mathrm{He}$ is likely to have been an anonymous follower of the later Neo-Platonist, Proclus. See Erwin Panofsky, "Note on a Controversial Passage in Suger's 'De Consecratione Ecclesiae Sancti Dionysii' ", Gazette des Beaux-Arts, sixth series, XXVI (1944), p. 110.

37 Ibid., p. 111. For John Scotus Eriugena see note 33.

38 Panofsky, "Note on a Controversial Passage", p. 109.

39 Ibid.

40 For discussion of this see J. McEvoy, The Philosophy of Robert Grosseteste (Oxford: Oxford University Press, 1986), pp. 74-90.

41 J. Gage, Colour and Culture: Practice and Meaning from Antiquity to Abstraction (London: Thames and Hudson, 1999), p. 55, ill. 33.

42 Ibid., p. 288, n. 56.

43 For discussion of this see D. C. Lindberg, Studies in the History of Medieval Optics (London: Variorum Reprints, 1983).

44 H. Damisch, The Origin of Perspective (Cambridge, MA: MIT Press, 1995), p. 68.

45 For discussion of this see A. Pérez-Gómez and L. Pelletier, Architectural Representation and the Perspective Hinge (Cambridge, MA: MIT Press, 1997), pp. 177-279.

46 C. Grayson, Studi su Leon Battista Alberti (Citta di Castello: Ingenium, Leo S. Olschki, 1998), p. 139.

47 For discussion of Medieval Aristotelian thought see D. Westberg, Right Practical Reason: Aristotle, Action and Prudence in Aquinas, Oxford Theological Monographs (Oxford: Clarendon Press, 1994).

48 Lindberg, Studies in the History of Medieval Optics, p. 15.

49 For discussion of this dispute see D. Park, The Fire within the Eye: A Historical Essay on the Nature and Meaning of Vision (Princeton: Princeton University Press, 1997), pp. 39-61. 
50 Zajonc, Catching the Light, p. 26.

51 Zajonc describes the impact of Euclidean optics in the following terms: "Everything needed for the study of geometrical optics was developed, but in the process one can detect an important distancing from the subjective human experience of seeing. Euclid's meticulous mathematical style of argumentation has replaced the more poetic treatment of Empedocles or Plato. As every physicist knows, the elegant forms of mathematics can easily outshine the dull stirrings of experience, and eventually come to replace the phenomenon they originally were intended to describe. Euclid's handling of light foreshadows the growing separation of sight as lived experience from sight as a formal object of investigation." Catching the Light, p. 26.

52 For a brief overview of this influence see P. Whitfield, Landmarks in Western Science: From Prehistory to the Modern Age (London: The British Library, 1999), pp. 60-2.

53 Park, The Fire within the Eye, pp. 99-101.

54 Ibid., p. 100.

55 Lindberg, Studies in the History of Medieval Optics, p. 12.

56 C. C. Riedl (trans.), Robert Grosseteste's On Light (Milwaukee: Marquette University Press, 1983).

57 Copleston, A History of Philosophy, Volume 2, p. 259.

58 De Luce, translated by Clare C. Riedl (British Library), p. 1. See www.colorado.edu/StudentGroups/lcm/lunch/deluce.html.

59 lbid.

60 "Hexaëmeron", in C. F. J. Martin (trans.), Robert Grosseteste: On the Six Days of Creation: A Translation of the Hexaëmeron (Oxford: Oxford University Press, 1996), part II, ch. IX, 2.

61 Sir R. W. Southern, "Richard Dales; the Editing of Robert Grosseteste", in Aspectus et Affectus: Essays and Editions on Grosseteste and Medieval Intellectual Life in Honour of Richard C. Dales (New York: AMS Press, 1993), p. 5.

62 McEvoy, Grosseteste, p. 90.

63 I am grateful to the Librarian of Lincoln Cathedral Library, Dr Nicholas Bennett, for this information.

64 Park, The Fire Within the Eye, p. 99.

65 The Rev. J. H. Strawley, The Story of Lincoln Minster (London: Raphael Tuck \& Sons, 1947), pp. 23-33.

66 Strawley, The Story of Lincoln Minster, p. 33.

$$
\begin{aligned}
& \text { Prebentes gemine iubar orbiculare fenestre } \\
& \text { Ecclesie duo sunt oculi: recteque videtur } \\
& \text { Maior in hijs esse presul, minorque decanus. } \\
& \text { Est aquilo Zabulus, est Santus Spiritus auster: } \\
& \text { Quos oculi duo respiciunt. Nam respicit austrum } \\
& \text { Presul, ut inuitet: aquilonem vero Decanus, } \\
& \text { Vt uitet: uidet hic ut salvetur, uidet ille } \\
& \text { Ne pereat. Frons ecclesie candelabra celi } \\
& \text { Et tenebras lethes oculis circumspicit istis. }
\end{aligned}
$$

Quoted in and translated by Chr. Wordsworth, Notes on Medieval Services in England: With an Index of Lincoln Ceremonials (London: Thomas Baker Publishers, 1898), p. 143.

68 For much of the Middle Ages, it was not uncommon for the bishop to be resident outside Lincoln, in view of the demands of running the largest diocese in England that stretched from the Humber to the Thames. We know, however, that Grosseteste spent much of his time in the Bishop's Palace where he added a porch to the west hall.

69 Wordsworh, Notes on Medieval Services, pp. 146-7.

70 A. F. Kendrick, The Cathedral Church of Lincoln: A History and Description of its Fabric and a List of Bishops (London: G. Bell \& Sons, 1928), p. 66. 
71 This topographical relationship might also explain the location of the so-called Dean's Aisle: "By analogy to the 'Chanters Aisle' [on the south of the Choir], this should be the north choir aisle, parallel to the choir; but apparently Peck, in his addition to Sanderson (Desid. Curiosa, p304), applies it to the great north transept, or 'cross isle', by which the Dean passes to the Deanery. However, the context shows that this is a mere blunder." Wordsworth, Notes on Medieval Services, p. 142. Whatever the confusion, it seems clear that the term was used to denote the aisle, or a part thereof, on the north face of the Cathedral in relation to the Dean's Eye and Deanery.

72 Whilst there is no clear evidence in the preserved liturgy at Lincoln that topography was used ritually, in the way that operated for example in Carolingian ceremonial, it is worth speculating that the procession from the Bishop's Palace to the Cathedral would have been considered as a ritualising of spiritual ascendancy. For contemporaneous accounts of ceremonies at Lincoln see H. Bradshaw, Statutes of Lincoln Cathedral (Cambridge: Cambridge University Press, 1897), in particular "The Installation, or Enthronement, of a Bishop and the Reception of Royal Persons at Lincoln", pp. 553-8.

73 Kendrick, The Cathedral Church of Lincoln, p. 25.

74 Refer to Pseudo-Dionysius, "The Celestial Hierarchy" and "The Ecclesiastical Hierarchy", in Luibheid (trans.), Pseudo-Dionysius, pp. 143-260.

75 "A Pamphlet, Sent to the Dean and Chapter of Lincoln, on the Bishop's Right to Visit his Chapter", in H. R. Luard (ed.), Roberti Grosseteste: Episcopi Quodam Lincolniensis Epistolae (London: Longman and Roberts, 1861), p. cxiv, CXXVII.

76 See note 67 for the original Latin.

77 "firmament ... also called the heavens since it was to be adorned and engraved with stars". Martin, Robert Grosseteste: On the Six Days of Creation, p. 105. According to Martin, the association of "caelum" with "caelatum" probably refers to Bede's "De orthographia s.v. caelo".

78 Gage, Colour and Culture, p. 74.

79 D. E. Duncan, The Calendar: The 5000-Year Struggle to Align the Clock and the Heavens - and What Happened to the Missing Ten Days (London: Fourth Estate, 1999), p. 63.

80 J. L.Heilbron, The Sun in the Church: Cathedrals as Solar Observatories (Cambridge, MA: Harvard University Press, 1999).

81 Vesely, Architecture in the Age of Divided Representation, p. 162.

82 Ibid., p. 160.

83 Ibid.

84 lbid., p. 161.

85 Ibid., p. 160, n. 154. Vesely refers to Martin Kemp's claim that there is no direct relation between Medieval optics and Renaissance perspective and therefore Ghiberti's third Commentary is "entirely retrospective". M. Kemp, "Science, Non-Science and Nonsense", in Art History, vol. I, no. 2 (1978).

86 lbid., p. 163.

87 Ibid., pp. 163-4.

88 S. Y. Edgerton, Jr, "'How Shall This Be?' Part II", in artibus et historiae: an art anthology, IRSA, no. 16 (VIII), Florence-Vienna (1987), p. 46.

89 lbid., p. 48, n. 18.

90 Ibid.

91 Ibid.

92 L. Steinberg, "'How Shall This Be?' Part I", in artibus et historiae: an art anthology, IRSA, no. 16 (VIII), Florence-Vienna (1987), p. 25.

93 lbid.

94 Ibid., p. 39.

95 Ibid. 
96 Ibid., p. 39, n. 37.

97 Vesely, Architecture in the Age of Divided Representation, p. 130.

98 Steinberg, "'How Shall This Be?' Part I", p. 35.

99 A. Zajonc, Catching the Light, p. 7.

100 Ibid., p. 9.

101 lbid., p. 54.

102 Ibid., pp. 110-11.

103 B. Stroud, The Quest for Reality: Subjectivism and the Metaphysics of Colour (New York: Oxford University Press, 2000), p. 9.

104 Ibid., pp. 61-4.

105 P. Fenves, Arresting Language: From Leibniz to Benjamin (Stanford: Stanford University Press, 2001), p. 174.

106 Ibid.

107 H. Caygill, Walter Benjamin: The Colour of Experience (London: Routledge, 1998), p. 1.

108 Ibid., p. 9.

109 Ibid.

110 Fenves, Arresting Language, p. 175.

111 S. Holl, J. Pallasmaa and A. Pérez-Gómez, Questions of Perception: Phenomenology of Architecture (Tokyo: A+U Publishing, 1998), p. 61.

112 The Spiritual Exercises of Saint Ignatius of Loyola, translated by W. H. Longridge (London: Robert Scott, 1922), p. 6.

113 S. Holl, The Chapel of St. Ignatius (New York: Princeton Architectural Press, 1999), p. 9.

114 Held in 1963, the Council declared: "The general plan of the sacred edifice should be such that in some way it conveys the image of the gathered assembly." Ibid., p. 11.

115 lbid., p. 16.

116 lbid., p. 82.

117 F. X. Durrell, The Resurrection: A Biblical Study (London: Sheed \& Ward, 1986), p. 20.

118 Holl, The Chapel of St. Ignatius, p. 37.

119 Stroud, The Quest for Reality, p. 10.

\section{Topography, rhetoric and the vanishing point}

1 M. Merleau-Ponty, The Visible and the Invisible (Evanston: Northwestern University Press, 1968), p. 212.

2 E. Grant, "Place and Space in Medieval Thought", in P. K. Machamer and R. G. Turnbill (eds), Motion and Time, Space and Matter: Interrelations in the History of Philosophy and Science (Columbus: Ohio State University Press, 1976), p. 151.

3 Marvin Trachtenberg, Dominion of the Eye: Urbanism, Art, and Power in Early Modern Florence (Cambridge: Cambridge University Press, 1997).

4 lbid., pp. 114-17.

5 Plato, Protagoras and Meno, translated by W. K. C. Guthrie (Harmondsworth: Penguin Books, 1970), pp. 130-40.

6 Often called the "quadrature" method, it is thought to date back to at least Vitruvius. For discussion of its Medieval history see K. J. Conant, "The After-life of Vitruvius in the Middle Ages", in Journal of the Society of Architectural Historians 27 (1968), pp. 33-8.

7 Trachtenberg, Dominion of the Eye, p. 120. The idea of generating geometry as a form of procreation is examined in G. L. Hersey, Architecture and Geometry in the Age of the Baroque (Chicago: Chicago University Press, 2000), pp. 80-2.

8 Trachtenberg, Dominion of the Eye, p. 120-4. 
9 Ibid., pp. 42-62; pp. 81-5; pp. 97-105.

10 lbid., pp. 236-7. The diagonal also approximately coincides with the so-called "centric ray" of perspective. Ibid.

11 lbid., p. 232.

12 D. Lindberg, Theories of Vision from Alkindi to Kepler (Chicago: Chicago University Press, 1976), chs 5-7.

13 Tratchenberg, Dominion of the Eye, p. 234.

14 J. S. Ackerman, "Ars Sine Scientia Nihil Est: Gothic Theory of Architecture at the Cathedral of Milan", in Distance Points: Essays in Theory and Renaissance Art and Architecture (Cambridge, MA: MIT Press, 1994), pp. 211-68.

15 R. C. Trexler, Public Life in Renaissance Florence (Ithaca: Cornell University Press, 1996), pp. 256-62.

16 lbid., p. 259.

17 Tratchenberg, Dominion of the Eye, p. 118.

18 Trexler, Public Life in Renaissance Florence, p. 257.

19 Ibid., p. 260.

20 Tratchenberg, Dominion of the Eye, p. 238.

21 On the Roman Rostra see E. Nash, Pictorial Dictionary of Ancient Rome (Oxford: Oxford Classical Texts, 1961), Rome 2: p. 272.

22 S. Toulmin, Return to Reason (Cambridge, MA: Harvard University Press, 2001), p. 21.

23 A. Broadie, Introduction to Medieval Logic (Oxford: Oxford University Press, 1993).

24 Toulmin, Return to Reason, p. 21.

25 L. Bek, Towards Paradise on Earth: Modern Space Conception in Architecture - A Creation of Renaissance Humanism (Odense University Press, Analecta Romana Instituti Danici IX, 1980), p. 30 .

26 lbid.

27 Ibid. Trachtenberg contradicts this observation by emphasising a clear distinction between the "rotational method" deployed in the two main areas of the Piazza and the regular grid of the Palace plan. Dominion of the Eye, pp. 118-19.

28 Ibid., p. 240.

29 Comparison could be made between the Florentine piazza and the effect created by the campanile of the Palazzo Pubblico on the fan-shaped Piazza del Campo in Siena, a model that the Florentine authorities sought to emulate and even surpass.

30 B. Rotman, Signifying Nothing: The Semiotics of Zero (Stanford: Stanford University Press, 1993), p. 17.

31 C. Grayson, Studi su Leon Battista Alberti (Città di Castello: Leo S. Olschki, 1998), p. 104.

32 Ibid.

33 L. B. Alberti, The Family in Renaissance Florence, translated by R. N. Watkins (Columbia, S.C., 1969).

34 Grayson, Studi su Leon Battista Alberti, p. 103.

35 Leon Battista Alberti, On the Art of Building in Ten Books, translated by J. Rykwert, Neil Leach and Robert Tavernor (Cambridge, MA: MIT Press, 1996).

36 For discussion of the mimetic nature of architecture see D. Vesely, Architecture in the Age of Divided Representation: The Question of Creativity in the Shadow of Production (Cambridge, MA: MIT Press, 2004), pp. 366-72.

37 M. Carpo, Architecture in the Age of Printing: Orality, Writing, Typography, and Printed Images in the History of Architectural Theory (Cambridge, MA: MIT Press, 2001), p. 124.

38 Hypnerotomachia Poliphili (Venice: Aldus Manutius, 1499). For studies of the various narratives of the text see in particular R. Stewering, "The relationship between world, landscape and Polia in the Hypnerotomachia Poliphili"; G. Polizzi, "Le Poliphile ou I' Idee du jardin: pour une analyse littéraire de l'esthétique colonnienne"; N. Temple, "The Hypnerotomachia Poliphili as a 


\section{Disclosing Horizons}

possible model for topographical interpretations of Rome in the early sixteenth century", in Word \& Image: A Journal of VerbalNisual Enquiry, vol. 14, no. 1/2 (1998), pp. 2-10; pp. 61-81; pp. 145-55.

39 A youthful work, the play was long thought to be a genuine work of antiquity. The manuscript is in the Biblioteca Nazionale di Firenze (II. IV.38). For a brief description of the play see A. Grafton, Leon Battista Alberti: Master Builder of the Italian Renaissance (New York: Hill \& Wang, 2000), pp. 4-6. On the emblem, see R. Watkins, "L. B. Alberti's Emblem, the Winged Eye, and his Name, Leo", in Mitteilungen des Kunsthistorischen Instituts in Florenz, IX, H III-IV (1960), pp. 256-8.

40 Grafton, Leon Battista Alberti, pp. 105-6.

41 Watkins, “L. B. Alberti's Emblem”, p. 257.

42 Ibid. Also, J. Gadol, Leon Battista Alberti: Universal Man of the Early Renaissance (Chicago: University of Chicago Press, 1969), p. 70.

43 The association of Alberti with a lion is underlined by the medallion portrait of the artist in which his hair is treated like the mane of a lion. Watkins, "L. B. Alberti's Emblem", p. 257.

44 lbid.

45 Leon Battista Alberti: On Painting, introduction by M. Kemp (London: Penguin Books, 1991), p. 11.

46 Gadol, Leon Battista Alberti, p. 69.

47 F. A. Yates, The Art of Memory (Chicago: University of Chicago Press, 1974).

48 Grafton, Leon Battista Alberti, p. 105. On Renaissance hieroglyphics see K. Giehlow, “Die Hieroglyphenkunde des Humanismus in der Allegorie der Renaissance ..." in Jb. d. Kunsthist. Sammlungen d. Allerh. Kaisersh XXXII (1915), esp. pp. 36-7.

49 I. Illich, In the Vineyard of the Text: A Commentary to Hugh's Didascalicon (Chicago: Chicago University Press, 1996), p. 19.

50 G. K. F. Giusti, “The Cutting Surface: On Perspective as a Section, Its Relationship to Writing, and Its Role in Understanding Space", in AA Files, 40 (2004), p. 59.

51 Ibid., p. 60.

52 lbid., pp. 60-61.

53 Carpo, Architecture in the Age of Printing, p. 120.

54 Ibid., p. 119.

55 W. Benjamin, "The Work of Art in the Age of Mechanical Reproduction", translated by H. Zohn, in H. Arendt (ed.), Walter Benjamin: Illuminations (London: Fontana/Collins, 1970), pp. 219-53.

56 The term is used by Samuel Edgerton, Jr, to describe the period before the "invention" of perspectiva artificialis and the printing press. "Alberti's Optics", unpublished doctoral dissertation of the University of Pennsylvania (1965), p. 44.

57 Kemp, Introduction, On Painting, p. 4.

58 Ibid., p. 6.

$59 \mathrm{lbid}$., p. 12. Drawings were added to an early Italian translation of De Pictura by a relatively unknown Ferrarese friar, Battista Panetti. Numbering ten in all, these were intended to "clarify Alberti's verbal explanation of 'pyramidal' and 'triangular' vision". Grayson, Studi su Leon Battista Alberti, pp. 225-9.

60 Kemp, Introduction, On Painting, p. 12.

61 De Punctis et lineis apud pictores, in G. Mancini (ed.), Opera inedita (Florence, 1890), p. 228, quoted in Kemp, Introduction, On Painting, p. 12.

62 Nicholas of Cusa, "De Beryllo (On [Intellectual] Eyeglasses)", Nicholas of Cusa: Metaphysical Speculations, translated by J. Hopkins (Minneapolis: The Arthur J. Banning Press, 1998), p. 45, para. 23-4.

63 Kemp, Introduction, On Painting, p. 13.

64 Vesely, Architecture in the Age of Divided Representation, p. 9. 
65 On Painting, p. 24, quoted in Introduction, p. 14.

66 Carpo, Architecture in the Age of Printing, p. 123.

67 D. Cosgrove, "Ptolemy and Vitruvius: Spatial Representation in the Sixteenth Century Texts and Commentaries", in A. Picon and A. Ponte (eds), Architecture and the Sciences: Exchanging Metaphors (New York: Princeton Architectural Press, 2003), p. 21.

68 Ibid., p. 30.

69 Ibid.

70 Vesely, Architecture in the Age of Divided Representation, p. 134.

71 Cosgrove, "Ptolemy and Vitruvius", p. 38.

72 E. Voegelin, Order \& History, Vol. 4: The Ecumenic Age (University of Missouri Press, 2000), pp. 45-273.

73 Cosgrove, "Ptolemy and Vitruvius", p. 35.

74 A. Pérez-Gómez and L. Pelletier, Architectural Representation and the Perspective Hinge (Cambridge, MA: MIT Press, 1997), p. 96.

75 D. Vesely, "The Perspectival Transformation of the Medieval World", unpublished manuscript, 2002 , p. 35.

76 Pérez-Gómez and Pelletier, Architectural Representation, p. 94.

77 S. Y. Edgerton, The Renaissance Rediscovery of Linear Perspective (New York: Harper \& Row, 1975), pp. 70-1.

78 Pérez-Gómez and Pelletier, Architectural Representation, p. 95.

79 Quoted in ibid., p. 94.

80 Ibid., pp. 95-6.

81 L. Nuti, "The Perspective Plan in the Sixteenth Century: The Invention of a Representational Language", Art Bulletin 76 (1994), p. 126, quoted in Pérez-Gömez and Pelletier, Architectural Representation, p. 96.

82 Carpo, Architecture in the Age of Printing, p. 123.

83 Gadol, Leon Battista Alberti, p. 172.

84 D. Leatherbarrow, Uncommon Ground: Architecture, Technology, and Topography (Cambridge, MA: MIT Press, 2000), p. 3.

85 Ibid., p. 6.

86 Charles Burroughs describes the inscriptive nature of the stations of the cross, as they are commemorated and "re-enacted" in the pilgrimage routes through Rome. From Signs to Designs: Environmental Process and Reform in Early Renaissance Rome (Cambridge, MA: MIT Press, 1990), pp. 4-10 and p. 232; On antiquarian aspects of inscription see P. Jacks, The Antiquarian and the Myth of Antiquity: The Origins of Rome in Renaissance Thought (Cambridge: Cambridge University Press, 1993), ch. 3.

87 lbid., p. 160.

88 This is discussed in M. Martindale, The Triumphs of Caesar by Andrea Mantegna (London: Harvey Miller Publishers, 1979), p. 61.

89 Suetonius, Lives of the Caesars: Oxford World Classics, translated by C. Edwards (Oxford: Oxford University Press, 2001), pp. 3-42.

90 Biondo's account probably influenced the celebrated map of Rome by Alessandro Strozzi (1474) in which ancient monuments are selectively represented to highlight the principal routes through the city. The map is in the Biblioteca Laurenziana (Cod. Red. 77, fols. 7v-8r). See G. Scaglia, "The Origin of an Archaeological Plan of Rome by Alessandro Strozzi", Journal of the Warburg and Courtauld Institutes (1964), pp. 137-59.

91 In the fifteenth century, the Capitol was located at the periphery, rather than the centre, of the inhabited part of the city. This was due both to the decline in the population of Rome during the Middle Ages and the shift of political and religious activity to the Vatican and Borgo districts in the early fifteenth century. This led to the areas on the east and west banks of the Tiber becoming the most densely populated districts in the Renaissance. 
92 Leatherbarrow, Uncommon Ground, p. 5.

93 M. Carpo, "Descriptio Urbis Romae: Ekphrasis geografica e cultura visuale all'alba della rivoluzione tipografica", Albertiana 1 (1998), pp. 111-32.

94 Cosgrove, "Ptolemy and Vituvius", p. 49, n. 14.

95 The use of triangulation in surveying also formed part of a little treatise by Alberti on mathematical games: "Ludi matematici", in Anicco Bonucci (ed.), Opere volgari (Florence: 1843), vol. 4, pp. 405-40.

96 F. Pacifici, Dissertazioni sul Martirio Di San Pietro nel Gianicolo ... (Rome: 1814), ch. II.

97 B. M. Peebles, "La 'Meta Romuli' e una Letera di Michele Ferno", Atti della Pontificia Accademia Romana di Archeologia Rendiconti, XII, Vatican (1936), pp. 21-63.

98 For an account of the use of the name Meta Remi for the Pyramid of Cestius see S. B. Platner and T. Ashby, A Topographical Dictionary of Ancient Rome (Oxford, 1929), p. 478 ("Sept.C.Cesti").

99 Jacks, The Antiquarian and the Myth of Antiquity, p. 240.

100 The concordance between Rome's mythic origins and its "re-foundation" as the Christian city is underlined by the adoption of 29 July as the day on which both the Princes of the Church (Peter and Paul) and Romulus and Remus are celebrated. This was commemorated in a sermon by Pope Leo I on the feast day of 441. For discussions of this see ibid., p. 27.

101 M. Fagiolo, "La basilica Vaticana come tempio-mausoleo 'Inter duas metas': le idee e i projetti di Alberti, Filarete, Bramante, Peruzzi, Sangallo, Michelangelo", in Storia dell'Architettura XXII (1986); J. Huskinson, "The Crucifixion of St. Peter: a Fifteenth-Century Topographical Problem", in Journal of the Warburg and Courtauld Institutes 32 (1969), $139 f$.

102 This symbolism probably influenced the iconography of a scene from the famous fifteenthcentury fresco cycle by Benozzo Gozzoli of the life of St Augustine. The fresco is located in the Church of St Agostino in San Gimignano. Augustine is shown standing in front of the walled city of Rome, probably leaving the city for Ostia (via San Paolo fuori le mura), with the Pyramid of Cestius visible in the background framing the saint's head like a halo. The significance of the scene should be considered in the context of St Augustine's City of God, a theological account of the fall of pagan Rome, following the invasion by the Goths in the early fifth century, and its much anticipated "resurrection" as the Christian city par excellence. The pyramid invokes the symbolism of redemption, in its association with St Paul's martyrdom, and therefore with Rome's providential history.

103 Cosgrove, "Ptolemy and Vitruvius", p. 44.

104 "On [Intellectual] Eyeglasses (De Beryllo)", in J. Hopkins (trans.), Nicholas of Cusa: Metaphysical Speculations, pp. 35-73; J. Hopkins (trans.), Nicholas of Cusa, On Learned Ignorance: A Translation and an Appraisal of De Docta Ignorantia (Minneapolis, Minnesota: Arthur J. Banning Press, 1985).

105 Vesely, Architecture in the Age of Divided Representation, p. 51. The mutual interests of Cusanus and Alberti are likely to have been partly the result of direct contact. We know that during the period of Alberti's residency in Rome in the 1450s Cusanus' home served as an important gathering place for eminent thinkers in science and philosophy such as Peurbach, Regiomontanus and Toscanelli. Gadol, Leon Battista Alberti, p. 186. See also E. Hempel, "Nicolaus von Cues in Seinen Betziehungen zur Bildenden Kunst", in Berichte der Sachs. Akad. D. Wiss. Zu Leipzig Bd. 100 H.3, Berlin (1953).

106 From "Idiota de Mente", translated by J. Hopkins, Nicholas of Cusa on Wisdom and Knowledge (Minneapolis, Minnesota: Arthur J. Banning Press, 1988), pp. 103-4.

107 Nicholas of Cusa, "On [Intellectual] Eyeglasses", p. 36.

108 Vesely, Architecture in the Age of Divided Representation, p. 161.

109 Nicholas of Cusa, "On [Intellectual] Eyeglasses", p. 55.

110 In the Renaissance the Dionysian corpus played a key role in the development of hermetic thought, as we see for example in Marsilio Ficino's Theologia Platonica. This was following a 
period of decline and obscurity during the late Middle Ages. F. A. Yates, Giordano Bruno and the Hermetic Tradition (Chicago: University of Chicago Press, 1991), pp. 117-29.

111 Nicholas of Cusa, "On [Intellectual] Eyeglasses", pp. 51-4.

112 lbid., pp. 42-51.

113 Leon Battista Alberti, On Painting ("De Pictura"), bk 1, 8 (pp. 43-4).

114 Vesely, Architecture in the Age of Divided Representation, pp. 157-8.

115 J. Hopkins (trans.), Nicholas of Cusa on Learned Ignorance: A Translation and Appraisal of De Docta Ignorantia (Minneapolis: Arthur J. Banning Press, 1985), bk 1, p. 60.

116 For a historical survey of the building see J. Ackerman, The Cortile del Belvedere (Vatican City: Biblioteca Apostolica, 1954).

117 The literature on the frescoes is extensive. The following are the most relevant to this study: H. Pfeiffer, "La Stanza della Segnatura sullo sfondo delle idee di Egidio da Viterbo", Colloqui del Sodalizio tra Studiosi dell'Arte, 1970-1972 (Rome: De Luca Editore, 1973), pp. 31-43; H. Pfeiffer, "Le Sententiae ad mentem Platonis e due prediche di Egidio da Viterbo in referimento agli affreschi della Segnatura e della Cappella Sistina", in M. Fagiolo (ed.), Roma e I'Antico nell'arte e nella cultura del Cinquecento (Rome: Istituto della Enciclopedia Italiana, 1985), pp. 33-40; J. Shearman, The Vatican Stanze: Functions and Decoration, Proceedings of the British Academy, vol. LVII (London: Oxford University Press, 1972); E. Gombrich, "Raphael's Stanza della Segnatura and the Nature of its Symbolism", R. Woodfield (ed.), The Essential Gombrich (London: Phaidon Press, 1996), pp. 485-514.

118 The theme of prisca theologia figured prominently in the writings of Giles of Viterbo, papal spokesman to Julius II and head of the Augustinian Order. See Giles of Viterbo, Sententiae ad mentem Platonis, Cod. Vat.Lat. 6325, fol. 34r.

119 J. Ackerman, "The Belvedere as a Classical Villa", in Ackerman, Distance Points, pp. 325-61.

120 M. Tafuri, "Roma instaurata", in M. Tafuri et al., Raffaello architetto, catalogo mostra (Milan: Electa Editrice, 1984), p. 63.

$121 \mathrm{lbid}$.

122 For discussion on this see C. Shaw, Julius II: The Warrior Pope (Oxford: Blackwell, 1996), pp. 209-316.

123 N. Temple, "renovatio urbis: Architecture and Topography in Rome during the Pontificate of Julius II", unpublished PhD thesis (Leeds Metropolitan University, 2000), ch. 7.

124 V. Bellio, "Un disegno geografico di Donato d'Angelo detto il Bramante", in Bollettino della società geografica italiana, XL (1903), pp. 499-503.

$125 \mathrm{lbid}$.

126 For a brief description of the map see Cosgrove, "Ptolemy and Vitruvius", pp. 36-7.

127 lbid.

128 This interpretation could be likened to Empedocles' understanding of vision, in which the extramission of light from the eye is likened to a finger extending out to "touch" the incoming rays (intromission) from the observed object. D. Park, The Fire within the Eye: A Historical Essay on the Nature and Meaning of Light (Princeton: Princeton University Press, 1997), p. 35.

129 For a detailed historical account of these military campaigns and the significance of Caesar's maxim see T. A. Dodge, Caesar: A History of the Art of War Among the Romans Down to the End of the Roman Empire, with a Detailed Account of Caius Julius Caesar (New York, Da Capo Press, 1997), ch. 27.

130 J. W. O'Malley, "The Discovery of America and Reform Thought at the Papal Court in the Early Cinquecento", in First Images of America: Impact of the New World on the Old (Los Angeles: 1976), pp. 185-200; J. H. Parry, The Establishment of the European Hegemony, 1415-1715 (New York: HarperCollins, 1966); S. A. Bedini (ed.), Christopher Columbus and the Age of Exploration: An Encyclopedia (New York: Da Capo Press, 1998), esp. pp. 138-49.

131 On the symbolism of Caesar in Giles' writings, see his sermon "Maximus Caesar et Pontifex Maximus", translated by M. Boulding, in F. X. Martin, Friar, Reformer, and Renaissance 


\section{Disclosing Horizons}

Scholar: Life and Work of Giles of Viterbo 1469-1532 (Villanova, PA: Augustinian Press, 1992), pp. 297-308.

132 The perspective effect of the Cortile was radically altered in the late sixteenth century by the construction of the Sistine Hall and the later Braccio Nuovo (New Wing) in the early nineteenth century. Both cut across the Cortile, at either side of the intermediate tier, creating a new courtyard (Cortile della Biblioteca).

133 W. Melezer, The Pilgrimage Guide to Santiago de Compostela (New York: Italica Press, 1993).

134 C. Rudolph, Pilgrimage to the End of the World: The Road to Santiago de Compostela (Chicago: Chicago University Press, 2004); D. M. Gitlitz and L. K. Davidson, The Pilgrimage Road to Santiago: The Complete Cultural Handbook (New York St. Martin's Griffin, 2000).

135 D. Dernie, New Stone Architecture (London: Laurence King Publishing, 2003), p. 154.

136 K. Frampton, Álvaro Siza: Complete Works (London: Phaidon, 1999), p. 42.

137 R. Moneo, Theoretical Anxiety and Design Strategies: The Work of Eight Contemporary Architects (Cambridge, MA: MIT Press, 2004), p. 247.

138 Dernie, New Stone Architecture, p. 154.

139 Frampton, Álvaro Siza, p. 42.

140 lbid.

141 R. Weiss, "The Medals of Pope Julius II (1503-1513)", in Journal of the Warburg \& Courtauld Institutes, XXVIII (1965), p. 181.

142 For discussions of the collection see H. H. Brummer, The Statue Court in the Vatican Belvedere (Stockholm: Almquist \& Wiksell, 1970).

143 Frampton, Álvaro Siza, p. 42.

144 This is given added significance when we examine the meaning of the word "Pontiff" (derived from the ancient terms for priest - Pontifex or Pontifice - and rooted in the Latin words for bridge, pons or pontis), which suggests the idea of the pontifical office as a form of "bridging".

145 The inclined walls of the pyramid partly iterate another sloping wall of the larger roof-light, located on the east side of the triangular void and illuminating the foyer and spine corridor below. This wall provides the first visual marker upon entering the terrace, on account of its visible deviation from the perspective effect of the narrow passage.

146 Siza's deployment of the pyramid as both a metaphorical and topographical device is redolent of Josef Plecnick's use of the motif in his projects in Prague and Ljubljana. See F. Burkhardt, Joze Plecnik, 1872-1957 (Cambridge, MA: MIT Press, 1989).

\section{Unity in multiplicity}

1 This development is examined in C. Taylor, Sources of the Self (Cambridge: Cambridge University Press, 1992), esp. pp. 368-90.

2 On his philosophy see F. A. Yates, Giordano Bruno and the Hermetic Tradition (Chicago: University of Chicago Press, 1991), pp. 190-397.

3 G. Deleuze, The Fold: Leibniz and the Baroque (London: The Athlone Press, 1993), p. xi.

4 J. L. Heilbron, The Sun in the Church: Cathedrals as Solar Observatories (Cambridge, MA: Harvard University Press, 2001).

5 P. Ricoeur, Time and Narrative, vol. 1 (Chicago: University of Chicago Press, 1984), pp. 5-30.

6 Ibid.

7 A. Nemetz, "Itinerarium Mentis in Deum: The Human Condition", in S. Bonaventura 1274-1974, vol. III (Rome: Collegio S. Bonaventura Grottaferrata, 1973), pp. 345-59.

8 Deleuze, The Fold, pp. 3-26.

9 D. Vesely, Architecture in the Age of Divided Representation: The Question of Creativity in the Shadow of Production (Cambridge, MA: MIT Press, 2004), p. 208. 
10 Ibid.

11 F. Hallyn, The Poetic Structure of the World: Copernicus and Kepler (New York: Zone Books, 1993), p. 215.

12 Ibid., p. 209.

13 Ibid., p. 207.

14 Ibid., p. 208.

15 G. Hersey, Architecture and Geometry in the Age of the Baroque (Chicago: Chicago University Press, 2000), pp. 89-93.

16 We see this most clearly in Girard Desargues' Manière universelle of 1636. See A. PérezGómez and L. Pelletier, Architectural Representation and the Perspective Hinge (Cambridge, MA: MIT Press, 1997), pp. 69-75.

17 Taylor, Sources of the Self, pp. 143-207.

18 G. Boehm, Studien zur Perspektivität, translated by Alexander Eisenschmidt (Heidelberg: Heidelberg Universitätsverlag, 1969), p. 55.

19 Pérez-Gómez and Pelletier, Architectural Representation and the Perspective Hinge, p. 295.

20 Ibid.

21 Ibid., pp. 295-6.

22 K. Harries, Infinity and Perspective (Cambridge, MA: MIT Press, 2001), pp. 105-6.

23 In his Third Meditation Descartes remarks on such things as light, colours, sounds, scents etc., that "they are thought by me with so much obscurity and confusion that I do not even know if they are true or false", quoted in Harries, Infinity and Perspective, p. 107.

24 Ibid., p. 118.

25 This is explained in his Turris Babel, Amsterdam: Ex officina Janssonio-Waesbergiana (1679).

26 For a summary of these works see I. D. Rowland, The Ecstatic Journey: Athanasius Kircher in Baroque Rome (Chicago: University of Chicago Library, 2000). pp. 1-29.

27 Ibid., p. 6.

28 For an account of the background to the early museum see P. Findlen, Possessing Nature: Museums, Collecting, and Scientific Culture in Early Modern Italy (Berkeley: University of California Press, 1996), pp. 97-128.

29 Rowland, The Ecstatic Journey, p. 10.

30 Ibid., p. 16.

31 In this "symbolic logic" Kircher was the first to correctly establish that the Coptic language derives from ancient Egyptian. This is highlighted in his Coptic Forerunner (Prodromus Coptus) of 1636. Rowland, The Ecstatic Journey, p. 8.

32 Athanasius Kircher, Mundus subterraneus, in XII libros digestus, vol. 1. Amsterdam: Apud Joannem Janssonium \& Elizeum Weyerstraten (1665).

33 Hersey, Architecture and Geometry in the Age of the Baroque, p. 33.

34 Ibid., p. 32.

35 Ibid.

36 lbid., p. 33.

37 M. J. Gorman, "The Angel and the Compass: Athanasius Kircher's Geographical Project" (http://www.stanford.edu/group/shl/Eyes/angel/), draft of publication in P. Findlen (ed.), Baroque Imaginary: The World of Athanasius Kircher, S.J. (1602-80) (London: Routledge, 2002).

38 Ibid.

39 Rowland, The Ecstatic Journey, p. 74. In the Magnes, Kircher also refuted Kepler's elliptical orbits.

40 Gorman, "The Angel and the Compass", p. 10.

41 Ibid.

42 G. W. Leibniz, Discourse on Metaphysics and other Essays, translated by D. Garber and R. Ariew (Indianapolis: Hackett Publishing Company, 1991), p. 9.

43 Ibid. 


\section{Disclosing Horizons}

44 Ibid., p. 83.

45 Taylor, Sources of the Self, p. 375.

46 Ibid., p. 57.

47 D. A. Anapolitanos, Leibniz: Representation, Continuity and the Spatio-temporal (London: Kluwer Academic Publishers, 1999), pp. 60-1.

48 Ibid

49 J.-L. Marion, On Descartes' Metaphysical Prism (Chicago: University of Chicago Press, 1999), p. 78.

50 Pérez-Gómez and Pelletier, Architectural Representation and the Perspective Hinge, p. 56.

51 Marion, Descartes' Metaphysical Prism, p. 94.

52 J.-L. Marion, The Idol and Distance (New York: Fordham University Press, 2001), p. 12.

53 Pérez-Gómez and Pelletier, Architectural Representation and the Perspective Hinge, p. 295.

54 C. D. Broad, Leibniz: An Introduction (Cambridge: Cambridge University Press, 1975), p. 99.

55 A. T. Tymieniecka, Leibniz' Cosmological Synthesis (Assen: Van Gorcum, 1964), p. 11.

56 Quoted in Anapolitanos, Leibniz, p. 64.

57 Deleuze, The Fold, p. xi.

58 Ibid., p. 4.

59 Ibid., p. 11.

60 Ibid., p. 4.

61 Ibid., p. 4, n. 5.

62 H. Aurenhammer, J.B. Fischer von Erlach (London: Allen Lane, 1973), p. 161.

63 A. Pérez-Gómez, Architecture and the Crisis of Modern Science (Cambridge, MA: MIT Press, 1984), p. 313.

64 Aurenhammer, J.B. Fischer von Erlach, pp. 42-3.

65 Ibid., p. 44.

66 Published in 1721, the work was the first attempt to write a history of architecture. The German text was reprinted with an English translation by $T$. Lediard in 1730, later republished: A Plan of Civil and Historical Architecture (Ridgewood, N.J.: Gregg Press, 1964).

67 M. Krapf, "The Architectural Model in the Sphere of Influence of the Imperial Court in Vienna", in H. A. Millon (ed.), The Triumph of the Baroque: Architecture in Europe 1600-1750 (New York: Rizzoli, 1999), p. 397.

68 J. Rykwert, The First Moderns: The Architecture of the Eighteenth Century (Cambridge, MA: MIT Press, 1980), p. 74.

69 lbid., p. 70.

70 lbid.

71 lbid., p. 73.

72 Ibid., p. 74.

73 Krapf, "The Architectural Model", p. 401.

74 Rykwert, The First Moderns, p. 74.

75 Vesely, Architecture in the Age of Divided Representation, p. 221.

76 B. Anderson, Imagined Community (London: Verso, 1991), p. 84.

77 See C. P. Warncke, Ikonographie der Bibliotheken (Herzog August, Bibliothek Wolfenbuttel, 1992), pp. 188-9.

78 Gottfried Wilhelm von Leibniz, Monadology and Other Essays, translated by P. Schrecker and A. M. Schrecker (Indianapolis: Bobbs-Merrill Educational Publications, 1977), p. 153.

79 Gottfried Wilhelm von Leibniz, Deutsche Schriften, translated by Alexander Eisenschmidt (Berlin, 1840), p. 470.

80 H. Sedlmayr, Johann Bernhard Fischer von Erlach (Vienna: Verlag Herold, 1976), p. 142.

81 Boehm, Studien zur Perspektivität, p. 86, translated by Alexander Eisenschmidt.

82 This was confirmed by the head librarian at the Nationalbibliothek in Vienna. I am grateful to Alexander Eisenschmidt for this information. 
83 On the significance of the panopticon see J. Semple, Bentham's Prison: A Study of the Panopticon Penitentiary (Oxford: Oxford University Press, 1993).

84 P. Zumthor, Thinking Architecture (Basel: Birkhäuser, 1998), p. 21.

85 The most common form of lemniscate comprises a locus of points, the product of whose distances from two fixed points (the foci) at a distance $2 a$ away is a constant $a^{2}$. D. M. Burton, The History of Mathematics: An Introduction (New York: McGraw-Hill Publishers, 1985), pp. 446-8; E. Maor, e: The Story of a Number (Princeton: Princeton University Press, 1994), pp. 114-18.

86 R. Cristin, Heidegger and Leibniz: Reason and the Path (Dordrecht: Kluwer Academic Publishers, 1998), pp. 109-30.

87 H. Binet and P. Zumthor, Peter Zumthor, Works: Buildings and Projects, 1979-1997 (Baden: Lars Muller, 1999), p. 56.

88 Ibid.

89 Ibid.

90 P. Zumthor, Corps Sonore Suisse (Swiss Sound Box) (Boston: Birkhauser, 2000).

\section{Nature and immensity}

1 C. Taylor, Sources of the Self: The Making of the Modern Identity (Cambridge: Cambridge University Press, 1998), p. 390.

2 For an excellent interpretation of seventeenth century gardens see A. S. Weiss, Mirrors of Infinity: The French Formal Garden and 17th Century Metaphysics (New York: Princeton Architectural Press, 1995).

3 K. Harries, Infinity and Perspective (Cambridge, MA: MIT Press, 2002), p. 123.

4 J.-J. Rousseau, "Eloisa, III", in Eloisa: or, a Series of Original Letters (Dublin: Peter Wilson, 1767), p. 116.

5 Jean-Jacques Rousseau: The Reveries of the Solitary Walker, translated by C. E. Butterworth (Indianapolis: Hackett Publishing Company, 1992), p. 153.

6 Ibid., p. 5.

7 Taylor, Sources of the Self, p. 360.

8 Ibid., pp. 278-81.

9 E. Law, An Enquiry into the Ideas of Space, Time, Immensity and Eternity (Cambridge: W. Fenner and R. Beresford, 1734); republished in The Collected Works of Edmund Law, edited by V. Nuovo (Bristol: Thoemmes Press, 1997), ch. 1, p. 75.

10 Taylor, Sources of the Self, pp. 368-90.

11 At the heart of this assertion is Kant's supreme principle of morality, known as the "Categorical Imperative". See S. Korner, Kant (Harmondsworth: Penguin, 1955).

12 Taylor, Sources of the Self, p. 364.

13 Ibid., p. 366.

14 Dalibor Vesely, however, makes the point that the term is misleading in the context of Baroque architecture given that the aesthetic unity sought in these spaces was rather a "secondary manifestation of a deeper unity". Architecture in the Age of Divided Representation: The Question of Creativity in the Shadow of Production (Cambridge, MA: MIT Press, 2004), p. 218.

15 For discussion of the English literary background to this idea see M. Røstvig, The Happy Man: Studies in the Metamorphosis of a Classical Ideal. I:1600-1700 (Oslo: 1954).

16 D. Wiebenson, The Picturesque Garden in France (Princeton: Princeton University Press, 1978), p. 6.

17 M.-A. Laugier, Essai sur l'Architecture. First edition anon. (Paris: 1753). For discussion of this treatise see W. Hermann, Laugier and Eighteenth Century French Theory - Studies in Architecture, No. VI (London: Zwemmer, 1986). 


\section{Disclosing Horizons}

18 Wiebenson, The Picturesque Garden in France, pp. 6-7.

19 Ibid., p. 7.

20 J. Harris, Sir William Chambers (Pennsylvania State University, 1970), pp. 192-3.

21 Wiebenson, The Picturesque Garden in France, p. 7.

22 For discussion of the dispute see L. BonJour et al. (eds), In Defence of Pure Reason: A Rationalist Account of A Priori Justification (Cambridge: Cambridge University Press, 1997); L. BonJour, The Structure of Empirical Knowledge (Cambridge, MA: Harvard University Press, 1987).

23 E. Burke, A Philosophical Enquiry into the Sublime and Beautiful And Other Pre-Revolutionary Writings, edited by D. Womersley (London: Penguin Books, 1998), p. 139.

24 Ibid., pp. 137-8.

25 Ibid., p. 143.

26 Ibid., p. 144.

27 Ibid., p. 146.

28 Ibid., p. 165.

29 Ibid., p. 121.

30 Ibid., p. 174.

31 Ibid., pp. 166-7.

32 Ibid., p. 165.

33 D. Wesling, Wordsworth and the Adequacy of Landscape (London: Routledge and Kegan Paul, 1970).

34 E. Burke, Reflections on the Revolution in France: Rethinking the Western Tradition, edited by F. Turner (New Haven, Conn: Yale University Press, 2003).

35 G. B. Vico, New Science, translated by D. Marsh (London: Penguin Books, 1999), p. 150.

36 Ibid., p. 129.

37 Harris, Sir William Chambers, pp. 192-3.

38 W. Chambers, A Dissertation on Oriental Gardening (second edition). Reprinted and edited by J. Harris (London: Gregg International Publishers, 1972), pp. 133-4.

39 E. Voegelin, Order and History, Vol. 4: The Ecumenic Age (Indianapolis: Louisiana State University Press, 1974), p. 202. The modern term "ecumene", used in Christian doctrine to celebrate a unified church, derives from the Greek oikumene.

40 Ibid., pp. 210-11.

41 A. D. King (ed.), Culture, Globalization and the World System: Contemporary Conditions for the Representation of Identity (Minneapolis: University of Minnesosta Press, 1997).

42 Sir W. Chambers, Designs of Chinese Buildings, Furniture, Dresses, Machines, and Utensils ... (London: 1757). Facsimile reprinted (New York: Arno Press, 1980), pp. 14-19.

43 E. Harris, "Burke and Chambers on the Sublime and Beautiful", in Essays in the History of Architecture Presented to Rudolf Wittkower, edited by D. Fraser et al. (London: Phaidon Press, 1967), p. 207.

44 Ibid., p. 209.

45 Ibid.

46 Chambers argues this point by taking the example of a horse. Ibid., p. 212.

47 Chambers, Designs of Chinese Buildings, p. ii (Preface).

48 Goethe's point is that human nature, exemplified in genius, is a manifestation of "outside nature". J. W. Goethe, Conversations of Goethe, translated by J. Oxenford (Da Capo Press, 1998), pp. 246-52.

49 E.-L. Boullée, Architecture. Essai sur l'art (Paris: Hermann, 1968), edited by J. M. Pérouse de Montclos, pp. 47-8.

50 lbid., p. 40.

51 H. W. Kruft, A History of Architectural Theory from Vitruvius to the Present (New York: Princeton Architectural Press, 1994), p. 159. 
52 Ibid., p. 160.

53 For the English translation of the Essai, see H. Rosenau, Boullée's Treatise on Architecture (London: Tiranti, 1953).

54 A. Vidler, Warped Space: Art, Architecture, and Anxiety in Modern Culture (Cambridge, MA: MIT Press, 2000), p. 18.

55 Quoted in Vidler, Warped Space, p. 19.

56 lbid., p. 21.

57 Ibid. For a survey of horror vacui see J. P. Fanton d'Andon. L'horreur du vide (Paris: Editions du Centre National de recherche scientifique, 1978).

58 Boullée, Essai, p. 137.

59 C. Gottlieb, The Window in Art: From the Window of God to the Vanity of Man (New York: Abaris Books, 1981), p. 293.

60 Ibid., p. 296.

61 In 1806 Hölderlin was committed to the local asylum and died in 1843. For an account of Hölderlin's life and poetry see F. Hölderlin, Selected Poems and Fragments, translated by M. Hamburger (London: Penguin Books Ltd., 1998), Introduction.

62 On Heidegger's notion of enframing see G. Pattison, The Late Heidegger (London: Routledge, 2000), p. 56.

63 H. Borsch-Supan, Casper David Friedrich (London: Thames \& Hudson, 1974), pp. 26-7.

64 Ibid. Taken literally Borsch-Supan's funerary symbolism alludes to the idea of the moored vessel as Charon's ferry awaiting departure to the ancestral abode on the opposite bank of the river. Such a symbolic reading, however, tends to obscure the specifically Romantic view of landscape as outlined in this chapter.

65 On alpha-omega symbolism see A. Watts, Myth and Ritual in Christianity (London: Thames \& Hudson, 1983), pp. 149, 232.

66 Taylor, Sources of the Self, p. 381.

67 Taylor uses the word "enigmatic" to describe the Romantic view of order in general. Ibid., p. 380.

68 This disembodied world is most clearly expressed in the nineteenth century in the tendency to conceive the world as both panoramic (constituted in the city as entity) and focalised (the domestic fragment). See Chapter 7.

69 More recent editions are: R. Koolhaas, Delirious New York: A Retroactive Manifesto for Manhattan (New York: Monacelli Press, 1997); R. Koolhaas and B. Mau, S, M, L,XL (New York: Monacelli Press, 2002).

70 Ibid., pp. 500-1.

71 R. Koolhaas, "Life in the Metropolis, or, The Culture of Congestion", in Architectural Design 5 (1977), p. 320, quoted in R. Moneo, Theoretical Anxiety and Design Strategies in the Work of Eight Contemporary Architects (Cambridge, MA: MIT Press, 2004), p. 313.

72 Koolhaas, $S, M, L, X L$, p. 1158.

73 Ibid., p. 1160

74 B. Tschumi, Columbia Document No. 3 (New York: Columbia University Press, Distributed Art Publishers 1993), pp. 37-8.

75 lbid., p. 40.

76 Moneo, Theoretical Anxiety and Design Strategies, p. 314

77 Ibid., p. 316.

78 Ibid., p. 313.

79 Vesely, Architecture in the Age of Divided Representation, pp. 259-60.

80 Manfredo Tafuri highlights this in his perspective rendering and plans of plate VII of Piranesi's Carceri. The Sphere and the Labyrinth (Cambridge, MA: MIT Press, 1990), illustration 10.

81 Ibid., p. 26

82 lbid., p. 40.

83 Ibid., p. 41. 


\section{Disjointed views}

1 From R. Descartes, Meditations on First Philosophy, in J. Cottingham (ed.), Philosophical Writings of Descartes (Cambridge: Cambridge University Press, 1985), bk 2, p. 12, quoted in H. Damisch, Skyline: The Narcissistic City (Stanford: Stanford University Press, 2001), p. 4.

2 Ibid., p. 5.

3 C. Prendergast, Paris and the Nineteenth Century (Oxford: Blackwell, 1992), p. 37.

4 lbid., p. 42.

5 The idea of buildings as objects of curiosity that evoke exotic associations or serve as aidememoirs of forgotten situations, was already articulated as an idea in the eighteenth century in William Chambers' notion of oriental buildings as "toy-like". W. Chambers, Designs of Chinese Buildings, Furniture, Dresses, Utensils ... (London, 1757). Facsimile reprinted (New York: Arno Press, 1980), p. ii (Preface).

6 On the flâneur see W. Benjamin, Charles Baudelaire: A Lyric Poet in the Era of High Capitalism (London: New Left Books, 1973), pp. 35-66. S. Buck-Morss, The Dialectics of Seeing (Cambridge, MA: MIT Press, 1989), pp. 185-7 and 304-7.

7 Prendergast, Paris and the Nineteenth Century, pp. 212-14.

8 J. Crary, Suspensions of Perception: Attention, Spectacle, and Modern Culture (Cambridge, MA: MIT Press, 2001), p. 1.

9 Ibid., p. 4.

10 Ibid.

11 Ibid.

12 Ibid., p. 10.

13 This state is explored in Paul Bourget's seminal essay Essai de Psychologie Contemporaine (Paris: Alphonse Lemerre, 1936). Also examined in J. Pierrot, The Decadent Imagination, 1880-1900 (Chicago: University of Chicago Press, 1981), pp. 10-23.

14 A leading figure in the study of hysteria in the nineteenth century, and its relationship to art, was the French neurologist Jean-Martin Charcot (1825-93) who worked at the famous Salpêtrière hospital in Paris. W. Bannour, Jean-Martin Charcot et I'hystérie (Paris: Diffusion, 1992). See also the excellent study on the relation between psychology and art in the nineteenth century: D. L. Silverman, Art Nouveau in Fin-de-Siecle France: Politics, Psychology, and Style (Berkeley: University of California Press, 1992), pp. 75-107. Ibid.

17 Ibid., p. 55. A. Schopenhauer, The World as Will and Representation, 2 vols, translated by E. F. J. Payne (New York: Dover, 1966), vol. 2, p. 138 Crary, Suspensions of Perception, p. 56.

19 Ibid., p. 15.

20 M. Heidegger, Nietzsche, Vol. 1: The Will to Power, translated by D. F. Krell (London: Routledge \& Kegan Paul, 1981), p. 213.

21 Ibid., p. 215.

22 Ibid., p. 216.

23 S. D. Hales and R. Welshon, Nietzsche's Perspectivism (Urbana: University of Illinois Press, 2000), pp. 15-36.

24 Prendergast, Paris and the Nineteenth Century, p. 36.

25 Ibid.

26 Damisch, Skyline: The Narcissistic City, p. 15.

27 Prendergast, Paris and the Nineteenth Century, p. 37.

28 Ibid., p. 38.

29 Ibid., p. 42.

30 Ibid. 
31 Ibid., p. 44.

32 Heidegger, Nietzsche, Vol. 1: The Will to Power, p. 213.

33 Crary, Suspensions of Perception, p. 24 and p. 39.

34 Ibid., p. 52.

35 This development can be traced back to the new quantitative understanding of geography in the Renaissance when topography was systematically calibrated and mapped. Closely allied to this, as we saw in Chapter 3, was the development of the ideal city and its representation in the exemplary settings of perspectiva artificialis. For a philosophical discussion on the notion of horizon see H.-G. Gadamer, Truth and Method (London: Sheed and Ward, 1981) pp. 269-74.

36 On Cusanus, see K. Harries, Infinity and Perspective (Cambridge, MA: MIT Press, 2001), p. 45; on Goethe see his Italian Journey: 1786-1788, translated by W. H. Auden and E. Mayer (London: Collins, 1962), p. 220.

37 S. Oettermann, The Panorama: History of a Mass Medium (New York: Zone Books, 1997), p. 11.

38 R. Barthes, "The Eiffel Tower", in Barthes: Selected Writings, edited by S. Sontag (London: Fontana Press, 1989), p. 244.

39 Oettermann, The Panorama, pp. 18-19.

40 Prendergast, Paris and the Nineteenth Century, p. 48.

41 Barthes, "The Eiffel Tower", pp. 243-4.

42 Prendergast, Paris and the Nineteenth Century, p. 53.

43 Ibid., p. 53.

44 The contradiction derives in part from the Augustinian notion of Rome as both the city of salvation (Jerusalem) and of sin (Babylon). The twofold theme underlies St Augustine's The City of God and served as a model for the millenarian notion of the "fullness of time" invoked in Medieval mysticism and Renaissance humanism. See N. Cohn, The Pursuit of the Millennium: Revolutionary Millenarians and Mystical Anarchists of the Middle Ages (Oxford: Oxford University Press, 1990); J. W. O'Malley, "Man's Dignity, God's Love and the Destiny of Rome: A Text of Giles of Viterbo", in Viator: Medieval \& Renaissance Studies, vol. 3 (1972), pp. 389-416.

45 Prendergrast, Paris and the Nineteenth Century, p. 54.

46 Ibid., p. 55.

47 Ibid., p. 59.

48 M. Bal, The Mottled Screen: Reading Proust Visually (Stanford: Stanford University Press, 1997), p. 202.

49 Ibid., p. 203.

50 Ibid.

51 Ibid.

52 M. Proust, Remembrance of Things Past, translated by C. K. Scott-Moncrieff and T. Kilmartin (London: Penguin Books, 1981), vol. 1, p. 754, quoted in Bal, The Mottled Screen, p. 79.

53 For discussion of the fragment see D. Vesely, Architecture in the Age of Divided Representation: The Question of Creativity in the Shadow of Production (Cambridge, MA: MIT Press, 2004), pp. 325-6, p. 335.

54 H. Lefebvre, The Production of Space (Oxford: Blackwell, 1998), pp. 232-3.

55 J. D. Rosenberg (ed.), The Genius of John Ruskin: Selections from his Writings (Charlottesville: University Press of Virginia, 1998), pp. 315-98.

56 The idea of the house as a "portrait" of its occupant is a characteristically Symbolist/Decadent idea that influenced Art Nouveau architecture. Victor Horta, for example, sought to create a portrait of his client in his design of the Tassel house in Brussels. D. Dernie, Victor Horta (London: Wiley-Academy, 1995), pp. 24-60.

57 D. Periton, "The interior as aesthetic refuge: Edmond de Goncourt's La maison d'un artiste", in M. Hvattum and C. Hermansen (eds), Tracing Modernity: Manifestations of the Modern in Architecture and the City (London: Routledge, 2004), p. 150. 
58 E. de Goncourt, La maison d'un artiste (Paris: Charpentier, 1881), vol. II, p. 382, quoted in Periton, "The interior as aesthetic refuge", p. 150.

59 For discussion of the relation see E. Bernert, "Otium", Würzburger Jahrbücher für die Altertumswissenschaft, IV, 1949-50, pp. 89-99.

60 A. Balfour, Berlin: Politics of Order 1737-1989 (New York: Rizzoli, 1990), p. 48.

61 Implicit in these different cultural and artistic movements, each occurring during periods of crisis, is a latent tradition that parallels developments in modern instrumental thinking and serves as its "symbolic" counterpart. For discussion of this see D. Vesely, "Introduction", Architecture and Continuity: Themes 1 (London: Architectural Association, 1982), pp. 7-12.

62 This idea was championed by Oscar Wilde. Pierrot, The Decadent Imagination, 1880-1900, pp. 23-5.

63 J.-K. Huysmans, Against Nature (A rebours), translated by M. Mauldon (Oxford: Oxford University Press, 1998).

64 The Concise Oxford Dictionary, edited by D. Thompson (Oxford: Clarendon Press, 1995), p. 1412.

65 Huysmans, Against Nature, p. 108.

66 Pierrot, The Decadent Imagination, ch. 8, p. 220.

67 Silverman, Art Nouveau in Fin-de-Siècle France, pp. 75-107.

68 Psychological interest in the whiplash was closely associated with the notion of the "pathological curve" found in the posture of some of Charcot's patients at the Salpêtrière hospital in Paris. Ibid.

69 F. Rosement, André Breton and the First Principles of Surrealism (London: Pluto Press, 1978), p. 10. References to Moreau's ideas can be seen in A. Breton, What is Surrealism?, edited by F. Rosemont (London: Pluto Press, 1978), p. 161, p. 370.

70 This interest was highlighted in an informal way in a brief essay by Parry on the subject of his favourite city, Brussels, published under the title "My Kind of Town" in the journal Architecture Today, vol. 16 (March, 1991), back page.

71 H. O. Mounce, Wittgenstein's Tractatus: An Introduction (Chicago: University of Chicago Press, 1989), p. 3. Philips' interest in Wittgenstein's philosophy is highlighted in two recent sculptures by the artist in his "cube" series, entitled "Wittgenstein's Trap" and "Wittgenstein's Dilemma".

72 T. Philips, A Humument: A Treated Victorian Novel (London: The Tetrad Press, 1970).

73 Published on www.tomphilips.co.uk/essaysan/ornament/index.html.

74 The term "adimensional" is quoted from an interview with Gormley that took place on 4 June 1996 in the artist's studio with F. David Peat. www.fdavidpeat.com/interviews/gormley.htm.

75 D. Turnbull, "Artists' Studios, Camberwell, London SE15: Appraisal", in The Architects' Journal (June 1989), p. 51

76 lbid., p. 48.

77 Ibid., pp. 49-51.

78 Shown in ibid., p. 21 (fig. 20).

79 Ibid., p. 51.

80 lbid., p. 61.

81 The drawing was published in Dernie, Victor Horta, p. 89.

82 Quoted in ibid., p. 53.

83 Ibid.

\section{Conclusion}

1 E. Panofsky, Perspective as Symbolic Form (New York: Zone Books, 1997), pp. 67-8.

2 I use the term ratio in the broadest sense as articulated by I. K. McEwen, Vitruvius: Writing the Body of Architecture (Cambridge, MA: MIT Press, 2003), p. 60. 
3 B. Cache, Earth Moves: The Furnishing of Territories (Cambridge, MA: MIT Press, 1995), pp. 140-2.

4 Ibid., p. 140.

5 The problematic relation between image and architectural production formed the central theme of an international conference held in Las Palmas in 1997 and called "Architectural Education and the Magazine". It was organised by the EAAE (European Association for Architectural Education) and hosted by the Escuela Técnica Superior de Arquitectura de Las Palmas. Unfortunately, the conference proceedings were not published.

6 On digital fabrication and its impact on architecture see B. Kolarevic (ed.), Architecture in the Digital Age: Design and Manufacturing (London: Spon Press, 2004).

7 An example, Le Corbusier's painting studio at 24 rue Nungesser et Coli, is examined by P. Carl, "Le Corbusier's Painting Studio", Scroope: Cambridge Architecture Journal, Issue 5 (1993-94), pp. 36-7. See also B. Colomina, Privacy and Publicity: Modern Architecture as Mass Media (Cambridge, MA: MIT Press, 1996), p. 323-35.

8 The manner in which Le Corbusier searches out corresponding relationships between elements in the perspective of the photograph has interesting parallels to the composition and iconography of Raphael's fresco, the School of Athens described in Chapter 4.

9 The unfinished in the sixteenth century was intimately bound to perpetual motion; human creativity, and its implications as an image and likeness of God, were palpably felt as emerging and transforming in the modalities of representation. M. Jeanneret, Perpetual Motion: Transforming Shapes in the Renaissance from da Vinci to Montaigne, translated by N. Poller (Baltimore: Johns Hopkins University Press, 2001).

10 The confusion arising from direct comparisons between the endless possibilities of virtual reality and the "infinitesimal" realm of transcendent reality is most apparent in M. Wertheim, The Pearly Gates of Cyberspace: A History of Space from Dante to the Internet (New York: W. W. Norton \& Company, 1999).

11 J. Lacan, The Fundamental Concepts of Psychoanalysis, translated by A. Sheridan (London: Penguin Books, 1994), p. 98; R. Ruyer, Neo-finalisme (Paris: Presses Univ. de France, 1952), pp. 98-9.

12 Ibid., p. 72.

13 Ibid., pp. 105-6.

14 D. Vesely, Architecture in the Age of Divided Representation: The Question of Creativity in the Shadow of Production (Cambridge, MA: MIT Press, 2004), p. 157.

15 Ibid., pp. 157-8.

16 I am grateful to Donald Kunze for helping me understand the structure of Lacan's diagram. Kunze also enlightened me on the essential nature of interpolation in architecture as a form of harmonics or ratio; the cultivation of hollows and voids, edges with no possible resolution because of the incommensurability of what lies on either side.

17 Cache, Earth Moves, p. 140.

18 Ibid.

19 Ibid.

20 The effect of the surface of the glass coffee table, in its reflection of the landscape outside, could be likened in miniature to the ingenious "mirrored" landscape at Chantilly in France. A. Weiss, Mirrors of Infinity: The French Formal Garden and 17th Century Metaphysics (New York: Princeton Architectural Press, 1995), p. 78-93.

21 For one interpretation of the inter-relation between modern disciplines and their different modes of representation see B. M. Stafford, Good Looking: Essays on the Virtue of Images (Cambridge, MA: MIT Press, 1998). 


\section{Index}

abacus 28,61

Albers, Josef 66-7, 69, 71, 73

Alberti, Leon Battista 42-3, 49, 58, 85,

$98,113,122-40,141$

Alexander the Great 209-10

Alhazen 98-9

Al-Kindi (Alkindi) 86

anamnesis 36

anamorphosis 165-6, 265

Anapolitanos, Dionysius 174

Aristotle (Aristotelianism) 32, 53, 56,

76-7, 85-6, 160, 176; Ethics 55,88

Art Nouveau 233, 247, 259, 161

Atomists 32

attunement (Gestimmtheit) 77, 88

Augusta, Dowager Princess 210

Augustine, St 5, 52, 56, 82, 110, 157 , $163,175,177,198$

Avicenna 98

Bacon, Roger 85, 98-100, 116, 128

Bal, Mieke 242

Balfour, Alan 245

Balzac, Honoré 232, 241

Baroque 151, 160-91, 198, 262, 269

Barthes, Roland 238

Baudelaire, Charles 231, 235-6

Baumgarten, Alexander 5

Bek, Lise 120-1

Benjamin, Walter 78, 102, 110-11

Bernini, Gianlorenzo 168-72

Bernoulli, Jakob 194

Biondo, Flavio 133-4

Blondel, J. F. 205
Boehm, Gottfried 18-19, 22, 189

Boethius, Anicius Manlius Severinus

30

Bonaventure, St 163

Borromeo, Charles 183

Borromini, Francesco 164

Borsch-Supan, Helmut 220

Boullée, Étienne-Louis 2, 201, 213-16, $221,237,240$

Bourdieu, Pierre 66

Bramante, Donato 60, 63, 143, 146, $148,150,157,264$

Breton, André 250

Brownlee, David 66, 69, 71

Brunelleschi, Filippo 43, 98, 118

Bruni, Leonardo 42

Bruno, Giordano 21, 160

Buridan, John 113

Burke, Edmund 202, 205-11, 216

Cache, Bernard 263, 267-9

Caesar, Julius 134, 148-9, 156

Carl, Peter 14

Carpo, Mario 126, 132, 134

Casey, Edward 9-10, 17

Cassini, Giovani Domenico 194

Caygill, Howard 102

Cesariano, Cesare 138-9, 148

Cezanne, Paul 26, 255

Chambers, William 202, 205, 209-13, 268

character (caractère) 213, 227

Charlemagne 183

Charles VI 162, 181, 183, 187, 188

Chastel, André 54

Christina, Queen of Sweden 178 
Cicero, Marcus Tullius 42, 123, 124

Clanchy, M. T. 78

Colocci, Angelo 62

colour 78, 84, 101-11; phenomenology 78, 102; symbolism 78, 95, $102,103-11$; theories of 84 , $101-2$

Commandino, Frederigo 130

concetto 184

Copernicus, Nicolaus 164

Cornford, F. M. 34, 40-1

Cosgrove, Denis 138-9

Crary, Jonathan 233-4

Cristin, Renato 194

Crosby, Alfred 61

Cusanus, Nicholas 19, 37, 48, 50, 53, $58,98,113,127,140-3$, $161,237,242,266$

Damisch, Hubert 1, 26, 84, 112, 230-1, $235,243,250$

Dante Alighieri 5, 241

Deconstructivism 65

Deleuze, Gilles 162-3, 177, 198

De Long, David 66, 69, 71

Dernie, David 151-2, 259

Derrida, Jacques 26, 65

Descartes, René (Cartesian philosophy) 6, 15-19, 21, 37, 88, 101, $160,166,174-6,208$, 230-1, 266

Dézallier d'Argenville, A. J. 204

Dionysius, the Pseudo-Areopagite 77, $82,93,110,141,206$

Doubrovsky, Serge 242

Dubreuil, Jean 50

Edgerton, Samuel 78, 130-1

Empedocles 41

Enlightenment 3, 205, 215

Eriugena, John Scotus 83

Euclid 35, 51, 54, 59-60, 63-5, 66-7, 77, 116; Elements 35, 42, 51, 61; Optics 60, 86

Eugenius IV 135
Euler, Leonhard 101

Evans, Robin 25

Fenves, Peter 5-6, 102

Ficino, Marsilio 54, 62

Filarete (Antonio Averlino) 137

Fischer von Erlach, Johann Bernhard 161-2, 178-91, 195, 196, 203, 208

Florence 113-17, 121; Baptistery 115; Cathedral of Santa Maria del Fiore 96-7, Palazzo Vecchio 114-18, 120; Piazza del Duomo 96-7, 114-15; Piazza della Signoria, 114-22; 114-15, 118; via dei Calzaiuoli 115-16, 120

Foucault, Michel 190

Fowler, David 64

Frampton, Kenneth 152-3

Frederick the Great, of Prussia 209

Friedrich, Casper David 3, 8, 202, $216-21,226,230$

Fuller, Buckminster 69, 71, 74

Furley, David 28, 32

Gadol, Joan 132

Gage, John 83, 95

Galileo Galilei 26, 167

geometry $1,9,38-44,46,57,59,61-4$, $66,69,73,75,88,98,117$, $122,127-9,132,135$, 138-40, 142, 165, 193-5, 201, 206, 233, 259; anthyphairetic 64; Euclidean 42, 51, 64, 66-7, 122; lemniscate 193-5

Gesamtkunstwerk 10, 203, 221

Ghiberti, Lorenzo 78, 96-8

Giles of Viterbo 52, 62

Giotto di Bondone 137

gnomon 28-9, 121, 170; gnomic sequence $47,81,121$

Goethe, Johann Wolfgang von 213, 215, 237 
Goldhagen, Sarah 66, 68-70

Goncourt, Edmond and Jules 244-5

Gorman, Michael 173

Gormley, Antony 232, 250-4, 259-61

Gothic 88; Lincoln Cathedral 78, 88-96,

97, 233; Milan Cathedral 116-17

Gottlieb, Carla 217

Grafton, Anthony 124-5

Grayson, Cecil 85, 122

Grosseteste, Robert 78-81, 83-96, $102,106,111,124,149$

Guarini, Guarino 161

Guisti, Gordana 126

Hankins, James 25

Harries, Karsten 1-2, 166

Haussmann, Baron 232, 236, 239

Heidegger, Martin 8, 10, 12, 20, 74, 192, 194; being-in-theworld (Dasein) 14-17, 19-20, 23; "enframing" 8, 19, 220; the open (das offene) 18; region (Gegend) 18

Henry of Avranches 88-9

Heraclitus 38

Heraeus, Carl Gustav 181, 183

Hermeneutics 10, 14, 19, 23

Hermes Trismegistus 145

hermetic thought 63, 161

Hersey, George 165

Hölderlin, Friedrich 4-11, 16, 219, 221, 227, 260

Holl, Steven 78, 102-11

Horta, Victor 233, 250, 259

Hugh, St, of Avalon 88-9

Hugh of St Victor 28, 30, 80

Humanism 33, 37, 61, 85, 96, 113, 123-4, 125, 133, 139, 208

Husserl, Edmund 15-17; on geometry 24-7, 35, 36, 54, 57, 64-5, 75,112

Huygens, Christiaan 101

Huysmans, Joris-Karl 247 lamblichus 30, 42

Ignatius, St, of Loyola 103-4

Ilich, Ivan 36, 80

indexing 79-81

infinity (infinitesimal) 6, 20-1, 32-3, 50, $82,130,140,174,175$, 205-6, 211, 215-16, 231, 265-6

International Style 69

Jesuits 103-4, 167, 172-3, 180 Joost-Gaugier, Christiane 53-4, 56 Joyce, James 65, 250-1 Julius II 52, 60-1, 144-5, 147-9, 156, 267

Kahn, Louis 25, 65-75, 101

Kant, Immanuel 15, 23, 102, 202, 234

Kemp, Martin 46, 50, 127-8

Kepler, Johannes 164, 177

Kircher, Athanasius 161-2, 166-73, 174-5, 177, 185, 191, 198, $210,212,246,248$

Kisiel, Theodore 15, 18

Kleiner, Salomon 189

Koolhaas, Rem 3, 203, 221-9

Korb, Hermann 184

Koyré, Alexandre 9

Krell, David Farrell 65, 75

Lacan, Jacques 265-7

Late Capitalism 3

Laugier, Marc-Antoine 200, 203-4

Law, Edmund 201-2

Leatherbarrow, David 132-4

Le Corbusier 263-4

Ledoux, Nicolas 215

Lefebvre, Henri 243

Leibniz, Gottfried Wilhelm 5, 160, 161-2, 170, 173-8, 180-1, 184-5, 189-91, 194, 198, 199, 201-2, 203, 205, 234, 240

Leonardo da Vinci 60-1, 63, 98; Last Supper 18, 22, 37, 43, 
44-50, 51, 52, 61, 67, 112, Neo-Platonism 30, 37, 40, 54, 81, 114, 127

Levinas, Emmanuel 20-1, 22, 110-11, 142

Liberal Arts 54

light 1, 7-8, 76-8, 81-8, 96-101, 203, 214, 216, 247; analogical meanings $81-5,94-5$, 100-1; corporeality 85-7; cosmological significance 81, 84, 86, 88, 101; phenomenology 101 ; theories of $98,100-1,139$ lineamenti 43, 129

Lippi, Fra Filippo 78, 100, 112 Lombard, Peter 82

London 239; Artists' Studios, Camberwell (Eric Parry) 250-61; Colosseum 239; Leicester Square Rotunda 239

Luther, Martin 61

McEwen, Indra 30

Maderno, Carlo 182

Mallocks, W. H. 250

March, Lionel 43

Marion, Jean-Luc 10, 17, 175

Marx, Werner 10, 13, 18

mathematics 33, 85, 160

measure 1, 4-6, 9-12, 17, 33, 50, 134, $138,142,199,220,226,264$

Medici, Cosimo de 99

Medici, Lorenzo de 120

Merleau-Ponty, Maurice 2, 20, 21-3, 50, 112-13, 265

Michelangelo Buonaroti 264

Milton, John 206

Mitterrand, Francois 223

Moneo, Rafael 226-7

Moore, Henry 251

Moreau, Gustave 232, 246-50

negotium 144

Neo-Kantianism 23 203

Newton, Sir Isaac 17, 101, 162, 173, 176

Nicholas $\vee 129$

Nietzsche, Frederick 1, 12-14, 16, 139, $149,234,237$

Nouvel, Jean 223, 225

number $1,24,25,27-33,34,35,37$, $38,39,40,46,47,48,49$, $50,61,63,206$

oikumene 129-30, 209

optics 47, 77, 81, 84-6, 94, 98-9, 100-1, 231, 233; perspectiva naturalis 84 ; species $86,99,100,166$, 128

otium 144

Pacioli, Luca 61

Padovan, Richard 42, 43

Palladio, Andrea 42

Panofsky, Erwin 83, 262

panorama 13, 232, 237-8, 240, 248, 265

Paris 238, 240-1, 244-5, 247-8;

182; Eiffel Tower 238-40;

House of Gustave Moreau

245-50; Notre Dame 245;

St Sulpice 245; Val de Grâce 245

Parmenides 38

Parry, Eric 232-3, 250-61

Pascal, Blaise 215

Pattison, George 14

Peckham, John 86, 116

Pérez-Gómez, Alberto 1, 131, 166, 178, 264

Perrault, Claude 213

perspective 4, 6-7, 12-14, 25-6, 44, $45,54,58,60,65-6,76-7$, 80, 99-100, 113, 118-22, $139,140,150,183,200-2$, 216, 231, 236, 248, 262-4,
Collège des Quatre-Nations 
perspective continued

266-9; "awkward" (linkisch)

6, 11; "dilated" 201;

elevated 241; multiple 190;

perspectiva artificialis 13 ,

$26,44,49,51,60,84,112$,

134

Petrarch, Francesco 7

phenomenology 14-23, 26, 74, 77,

113,194

Philips, Tom 232, 250-1, 254-9

Pico della Mirandola 53

Picturesque 203-5

Pierozzi, Antonino 98

Pierrot, Jean 247

Piranesi, Giovanni Battista 3, 203, 227

Plato 24, 32, 34-42, 53, 56-60, 62, 64,

67, 81, 86, 101, 145; Meno

$34-8,42,48,65,73,78$,

114, 121; Timaeus 35,

38-42, 55-9, 64-5, 71

Platonic solids/forms 25, 39-40, 50-1,

$57,85,134,139,140,163$,

$167,205,206,213,229$,

242

poiēsis 13

Popper, Karl 34, 35

Portzamparc, Christian de 223, 225

Prendergast, Christopher 231, 235

prisca theologia 52

Proust, Marcel 232, 241-3

psychology 9, 200, 215, 231, 233, 248

Ptolemy, Claudius 54, 129-32, 164

Pythagoras 27-40, 42, 46, 54, 58-9,

$61-3,64-5,128,140,168$

Pythagorean/Platonic cosmology 2 ,

$44,57-8,64-5,73,81,86$,

112

Ralf de Diceto 80

ratio $31,42,50,58,199$

Redon, Odilon 239

Renaissance 2, 9, 13, 18, 25, 32-3, 37, 42-65, 96-100, 112,

118-20, 122-49, 156-8,
$160,166,200,243,264$,

269

Ricoeur, Paul 163

Romanticism 14, 207, 213, 215, 220,

247

Rome 122, 129, 132-3, 135-8, 140,

143; Aurelian Wall 158;

Capitol (Capitoline Hill)

133-4; Castel Sant'Angelo

136; Circus of Maxentius

168; Collegio Romano

(Musaeum Kircherianum)

167-8, 248; Column of

Marcus Aurelius 182-3;

Column of Trajan 182-3;

Fountain of the Four Rivers

168-72; Gianiculum 135,

137-8; Meta Romuli 135-8,

158; Piazza Navona

(Stadium of Domitian) 168;

Pyramid of Gaius Cestius

("Meta Remi") 135, 137-8,

158; Roman Forum 118;

Sanctuary of Isis 168; Sant'

Ivo della Sapienza 164-5; St

Paul's Basilica 137, 158;

Tempietto of San Pietro in

Montorio 136; Temple of

Jupiter and Peace 182;

Temple of Jupiter Maximus

Capitolinus 134; Theatre of

Marcellus 172; Tiber River

137; via Giulia 146; via del

Pellegrino 157; via

Triumphalis 133-4, 156

Rotman, Brian 33, 122

Rousseau, Jean-Jacques 200-1, 202

Rowland, Ingrid 60

Ruskin, John 244-5

Ruyer, Raymond 265

Rykwert, Joseph 182-3

Saintsbury, George 215

Sallis, John 38, 41, 65

Santiago de Compostela 113, 150-1, 
156, 158; Convent of S.

Domingo de Bonaval 150-2,

157; Galician Centre for

Contemporary Art 113,

150-9; St James' Cathedral

151,155

Sanzio, Raphael 61; School of Athens

24, 42, 44, 50-65, 66, 208

Sartre, Jean-Paul 74

Savonarola, Fra Girolamo 52, 119-20

Sbacchi, Michele 42

Scholasticism 80, 113

Schopenhauer, Arthur 234

Scully, Vincent 71

Sedlmayr, Hans 182, 185, 187

Serlio, Sebastiano 129

Sforza, Ludovico 60

Shearman, John 147

Simmel, Georg 9

situation 14, 16, 120, 135, 142-3, 215

Siza, Álvaro 113, 150-9, 227

Socrates 34-5, 48, 114

Sophism 34

Southern, Richard 88

space $3,102,106,111,117,121,178$, $179,180,186,189,191$, $195,199,215,250,264$, 267; calibrated/proportioned 112, 127, 263; distended 163, 177, 191, 198, 201; homogeneous 166; immensity of 202, 214-17, 226, 231, 237; "perspectivisation" of 76 , 120; pictorial 126, 128;

Platonic Receptacle 38-9; sacred 130

Springer, Anton 54

Steinberg, Leo 43, 44-50, 55, 78, 100

sublime 203-9

Suetonius 134

Surrealism 250

Tafuri, Manfredo 145, 229

Taylor, A. E. 36
Taylor, Charles 174, 199, 202

technē 13

Tetractys 30, 39, 41

Thales 74

Toulmin, Stephen 120

Trachtenberg, Marvin 113-18

Trexler, Richard 117

Turnbull, D. 259, 261

Uccello, Paolo 96-7

Van Gogh, Vincent 255

Vasari, Giorgio 61, 63

Vasconi, Claude 223, 225

Vatican 134, 147, 156; Belvedere Villa 143-4; Cortile del Belvedere 144, 149, 155-8, 267; Papal Palace 143-4; Stanza della Segnatura (Papal Window) 130, 143-9, 155, 267, 269; St Peter's Basilica 146, 157-8, 182; Vatican Library 145

Vegio, Maffeo 135-6, 138

Venturi, Robert 222

Verdon, Timothy 56

Vesely, Dalibor 1, 13-14, 76, 78, 97, $98,100,129,140-2,184$, 266

Vico, Giambattista 208

Vidler, Anthony 215

Vienna 162, 168, 178; Hofbibliothek $162,177,178,179,183$, 184-91, 195, 196;

Karlskirche 162, 177, 178, 181-3, 187

Villalpanda, J. B. 180 virtù 129

Vitruvius Pollio, Marcus 30, 42, 129, 138,148

Vlastos, Gregory 34, 35

Watkins, Renée 125

Watteau, Jean-Antoine 203

Witelo 86 
Wittgenstein, Ludwig 250

Wittkower, Rudolf 42

Wofflin, Heinrich 166

Wordsworth, William 207

Young, Thomas 101
Zajonc, Arthur 101

zero 33,132

Zola, Emile 231, 236-7

Zoroaster 54

Zumthor, Peter 162, 191-8 
eBooks - at www.eBookstore.tandf.co.uk

\section{A library at your fingertips!}

eBooks are electronic versions of printed books. You can store them on your PC/laptop or browse them online.

They have advantages for anyone needing rapid access to a wide variety of published, copyright information.

eBooks can help your research by enabling you to bookmark chapters, annotate text and use instant searches to find specific words or phrases. Several eBook files would fit on even a small laptop or PDA.

NEW: Save money by eSubscribing: cheap, online access to any eBook for as long as you need it.

\section{Annual subscription packages}

We now offer special low-cost bulk subscriptions to packages of eBooks in certain subject areas. These are available to libraries or to individuals.

For more information please contact webmaster.ebooks@tandf.co.uk

We're continually developing the eBook concept, so keep up to date by visiting the website. 